Ricardo Carrazedo

\title{
MECANISMOS DE CONFINAMENTO EM PILARES DE CONCRETO ENCAMISADOS COM POLÍMEROS REFORÇADOS COM FIBRAS SUBMETIDOS À FLEXO- COMPRESSÃO
}

\begin{abstract}
Tese apresentada à Escola de Engenharia de São Carlos da Universidade de São Paulo, como parte dos requisitos para a obtenção do Título de Doutor em Engenharia de Estruturas.
\end{abstract}

Orientador: Prof. Titular João Bento de Hanai

São Carlos, 2005 
Ficha catalográfica preparada pela Seção de Tratamento da Informação do Serviço de Biblioteca - EESC/USP

Carrazedo, Ricardo

Mecanismos de confinamento em pilares de concreto encamisados com polímeros reforçados com fibras submetidos à flexo-compressão / Ricardo Carrazedo. -- São Carlos, 2005 .

Tese (Doutorado) -- Escola de Engenharia de São Carlos-Universidade de São Paulo, 2005.

Área: Engenharia de Estruturas.

Orientador: Prof. Dr. João Bento de Hanai.

1. Concreto. 2. Pilares. 3. Polímero reforçado com fibras de carbono. 4. Confinamento. 5. Plasticidade. 6. Reforço. I. Título. 
Dedico este trabalho à minha família, a Maria Fernanda de Oliveira e a todos os amigos que me apoiaram nesta caminhada. 


\section{Agradecimentos}

Deixo aqui meus agradecimentos:

- A Maria Fernanda de Oliveira, pelo apoio, amor e paciência durante estes anos;

- Aos meus familiares, em especial, meus pais, minha irmã e minha avó, pelo incentivo nos momentos difíceis;

- Ao Prof. João Bento de Hanai pela orientação, incentivo e compreensão durante esses anos;

- Aos demais professores do Departamento de Estruturas da EESC/USP, em especial ao Prof. José Samuel Giongo, pela atenção e amizade; ao Prof. Sérgio Baroncini Proença pelas contribuições à minha formação e ao presente trabalho; ao Prof. Toshiaki Takeya pela grande disposição e atenção;

- Ao Adilson Roberto Takeuti, pela amizade, conselhos e colaborações sempre bem-vindas;

- Aos amigos do departamento de estruturas, em especial Alex e Silvana, Alexandre Sudano, Andrei, Claudius, Clayton, Daniela L. David, Fernando Menezes, Gustavo Chodraui, Gustavo Tristão, Josafá, Petrus e Selma, Rodrigo Neves e Raissa, Rodrigo Delalibera, Tatiane B. Dumet, Walter e Suzana, Yuri e Patrícia, e muitos outros, que contribuíram com sugestões, críticas ou simplesmente pela sua amizade;

- Aos funcionários da secretaria do Departamento de Estruturas, em especial à Rosi, à Nadir e ao Toninho, pelo ótimo atendimento;

- Ao Massaki, pela sua grande disposição e eficiência;

- Aos funcionários do Laboratório de Estruturas, em especial a Luiz V. Vareda e Amauri;

- Ao Prof. Antonio Alves Dias, por possibilitar a utilização da infra-estrutura do LaMem, sempre que necessário;

- À SIKA e à TEXIGLASS pelo fornecimento de materiais do sistema de reforço com PRF;

- Ao Departamento de Engenharia de Estruturas da Escola de Engenharia de São Carlos / Universidade de São Paulo, cuja seriedade e organização contribuíram muito para o correto direcionamento das atividades deste trabalho;

- À Florida International University, em especial ao Prof. Amir Mirmiran, por possibilitarem o desenvolvimento do estágio de quatro meses nessa instituição, tempo muito bem aproveitado para este trabalho e para meu crescimento pessoal;

- À FAPESP - Fundação de Amparo à Pesquisa do Estado de São Paulo, pela bolsa de estudos e pelo suporte financeiro, essenciais para o desenvolvimento desta pesquisa. 


\section{Sumário}

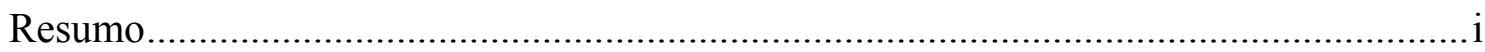

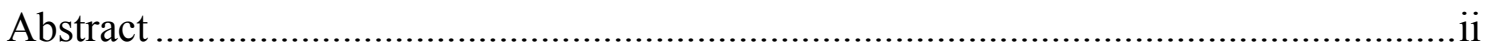

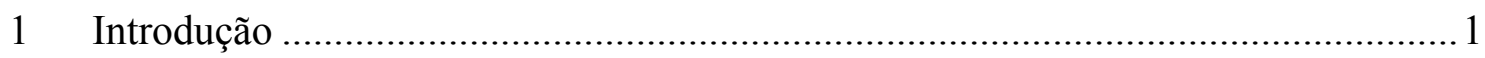

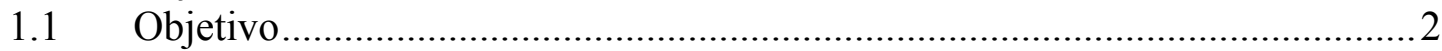

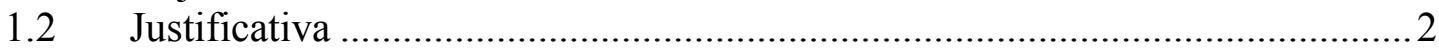

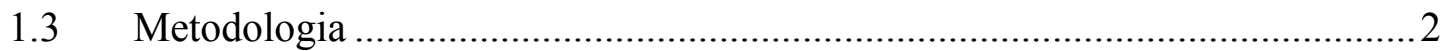

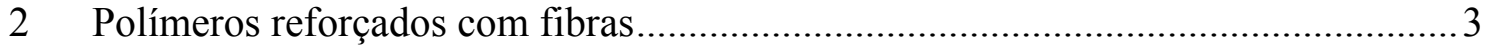

2.1 Polímeros reforçados com fibras colados externamente ..................................3

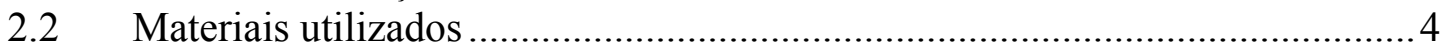

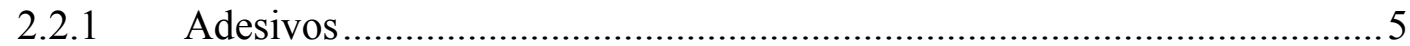

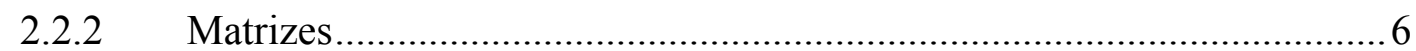

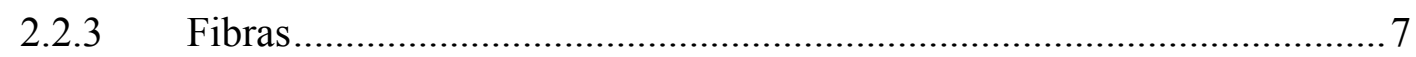

2.2.4 Polímeros reforçados com fibras utilizados para reforço......................... 7

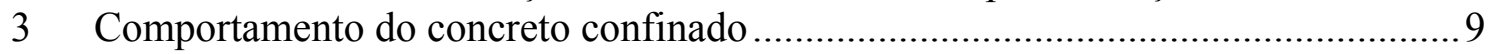

3.1.1 Influência do tipo de confinamento ................................................... 10

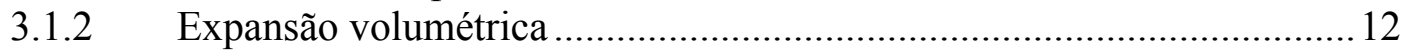

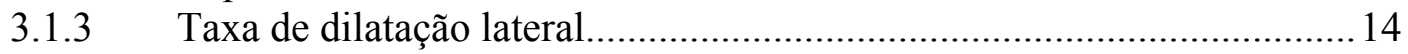

3.1.4 Influência da rigidez da camisa............................................................. 15

3.1.5 Dependência da história de carregamento................................................. 16

3.1.6 Classe de resistência à compressão axial do concreto ............................. 17

3.1.7 Influência das propriedades do concreto.................................................. 17

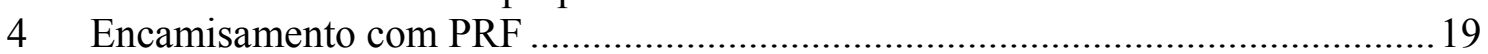

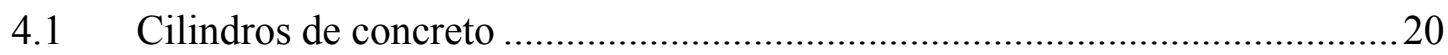

4.1.1 Comportamento tensão x deformação em pilares circulares...................20

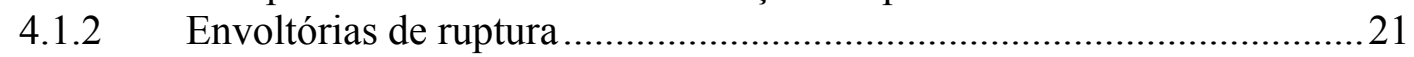

4.1.3 Variabilidade das envoltórias de ruptura............................................22

4.1.4 Deformação última do concreto confinado ..............................................22

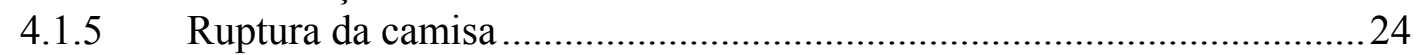

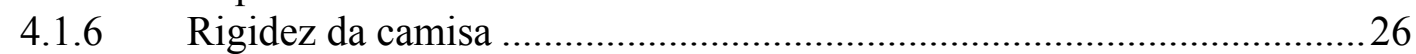

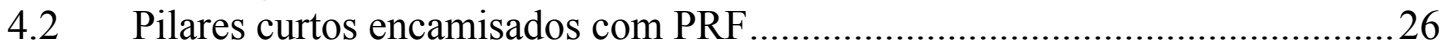

4.2.1 Influência da taxa de armadura transversal pré-existente ........................26

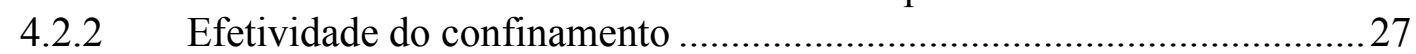

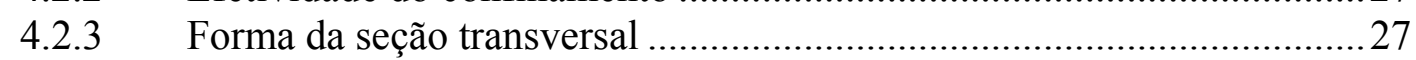

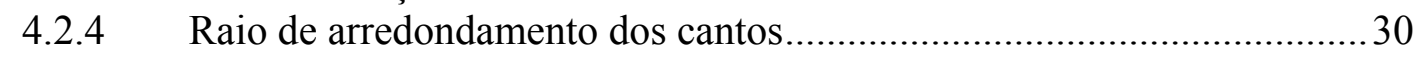

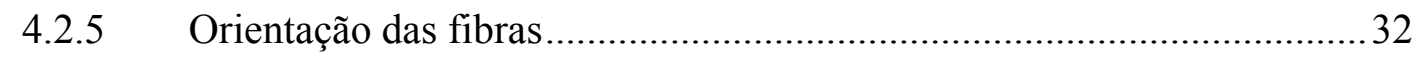

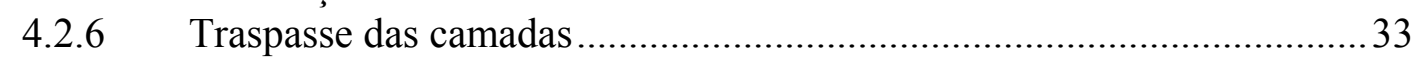

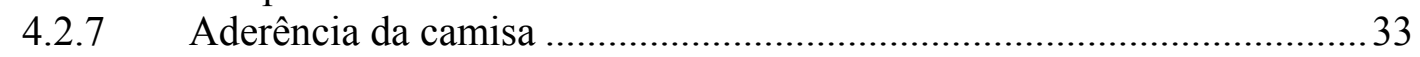

4.2.8 Conceito das áreas efetivas de confinamento........................................... 34

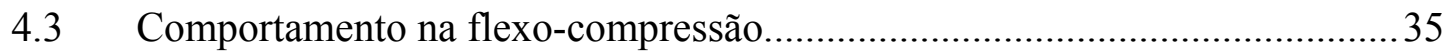

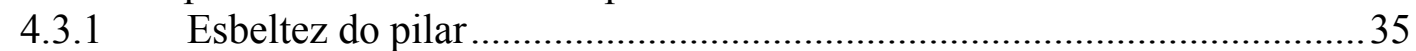

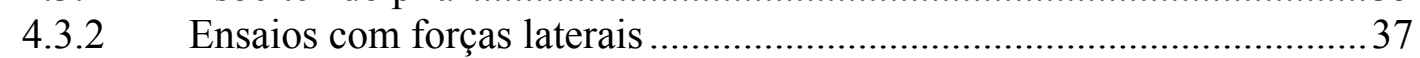

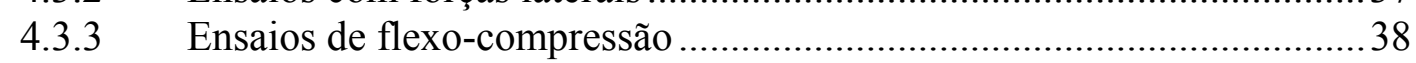

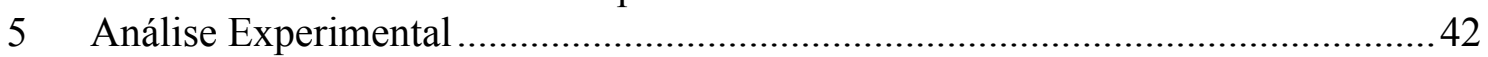

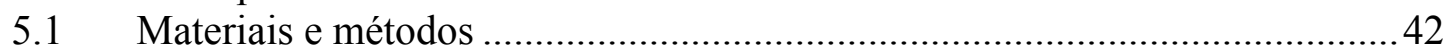

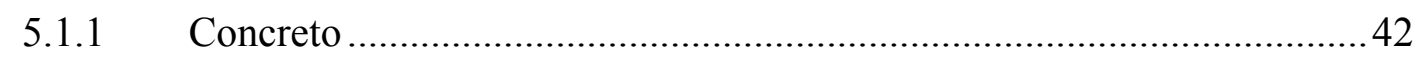

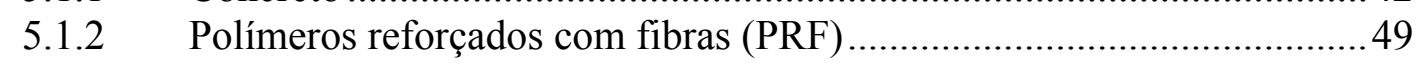

5.1.3 Corpos-de-prova encamisados com PRFC ............................................52

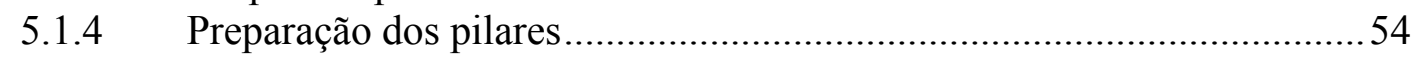


5.2 Pilares submetidos à compressão centrada sem o sistema de rótulas .............55

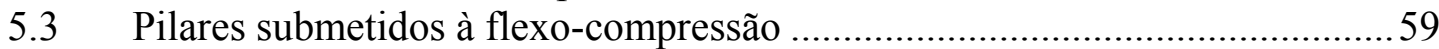

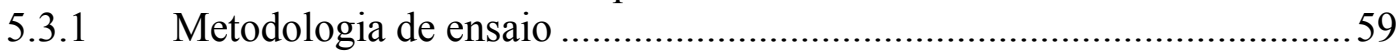

5.3.2 Ensaios de verificação do comportamento da rótula...............................60

5.3.3 Descrição das séries definitivas .............................................................66

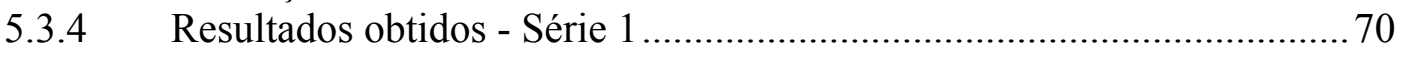

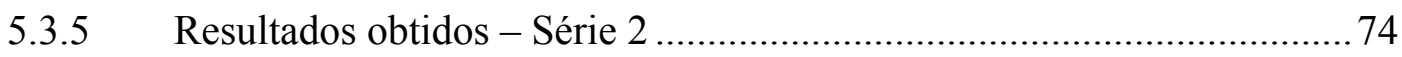

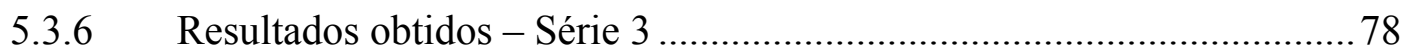

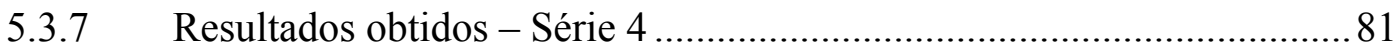

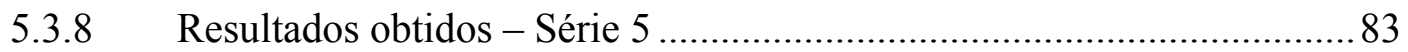

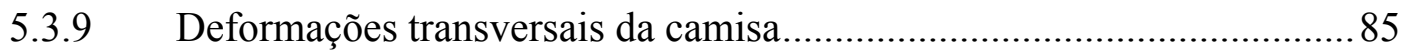

5.3.10 Comparações de resistência axial ....................................................... 107

5.3.11 Análise da deformabilidade ............................................................ 120

5.3.12 Rotações e efeitos de segunda ordem ............................................... 123

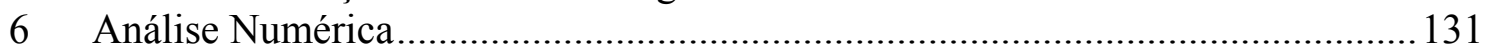

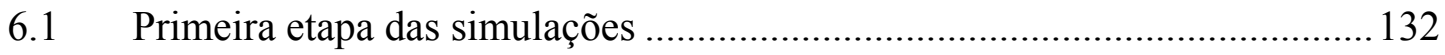

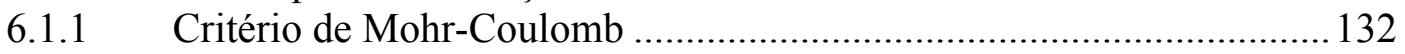

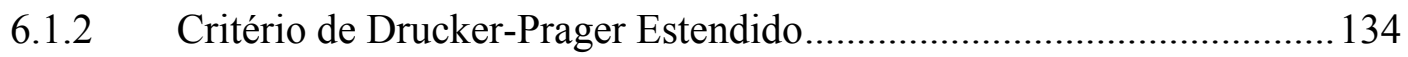

6.1.3 Modelo constitutivo para a camisa de PRF ....................................... 135

6.1.4 Estudos sobre a forma da seção transversal ......................................... 136

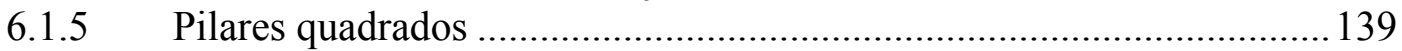

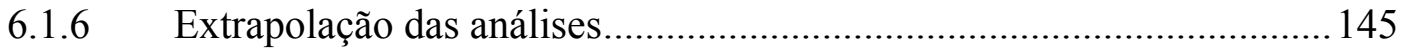

6.1.7 Simulação dos ensaios piloto ............................................................... 149

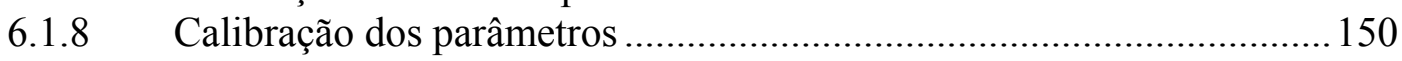

6.1.9 Comparação resultados numéricos $\mathrm{x}$ experimentais .............................. 153

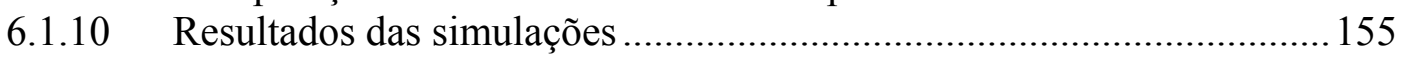

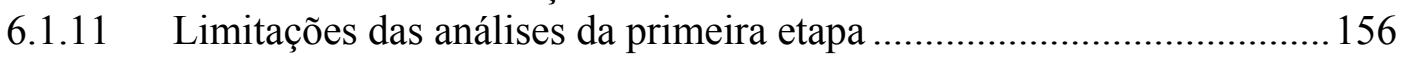

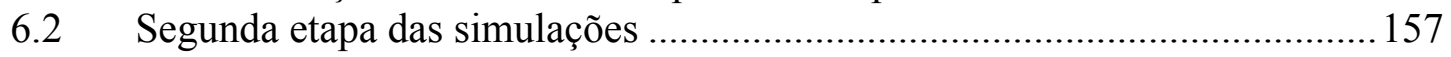

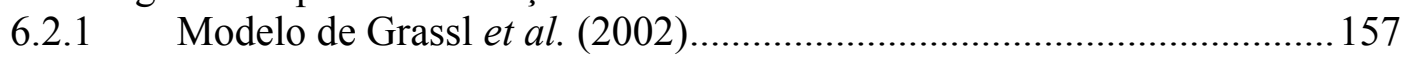

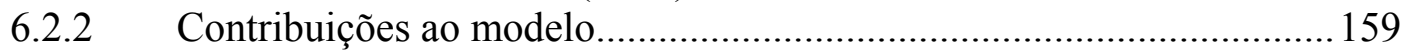

6.2.3 Escolha dos parâmetros da sub-rotina................................................. 160

6.2.4 Validação da sub-rotina ..................................................................... 161

6.2.5 Comparação com resultados experimentais ........................................... 161

6.2.6 Escolha dos parâmetros do potencial plástico........................................ 164

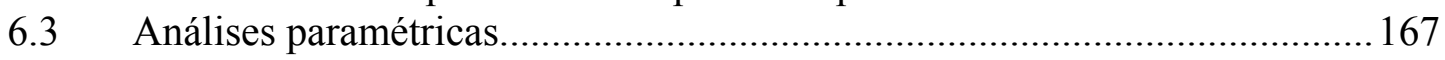

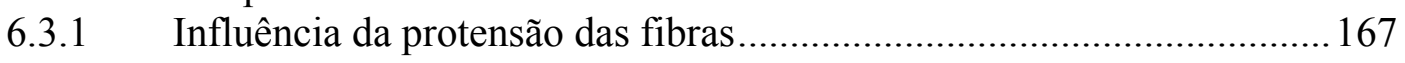

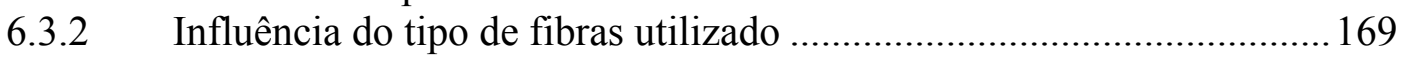

6.3.3 Calibração dos parâmetros para confinamento não uniforme................ 171

6.3.4 Análise paramétrica da influência do raio de arredondamento ............... 176

6.3.5 Análise da influência da relação entre lados.......................................... 183

6.3.6 Influência da excentricidade da força de compressão............................ 189

6.3.7 Estudo das tensões principais.................................................................. 195

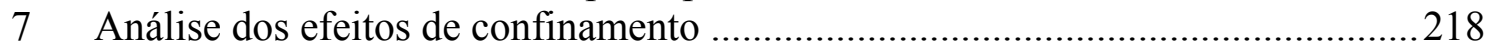

7.1 Pilares de seção circular encamisados com PRF.........................................2218

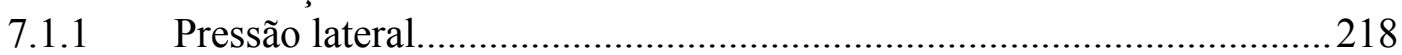

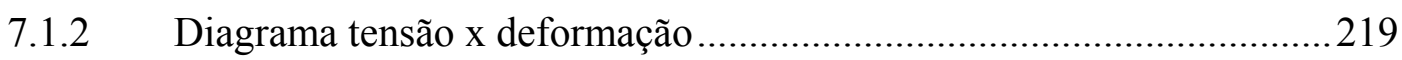

7.1.3 Ganho de resistência do concreto confinado........................................220

7.1.4 Ganho de resistência inicial do concreto confinado..............................221

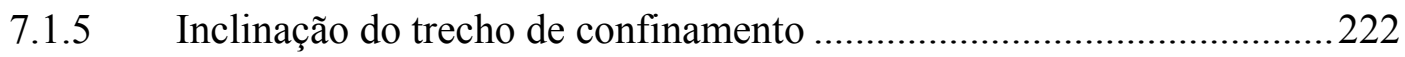

7.1.6 Deformação última do concreto confinado ..........................................224 
7.2 Pilares submetidos a confinamento com pressão não uniforme.....................228

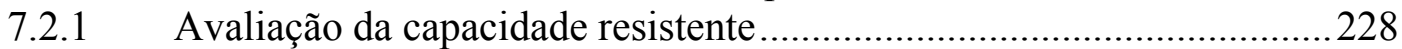

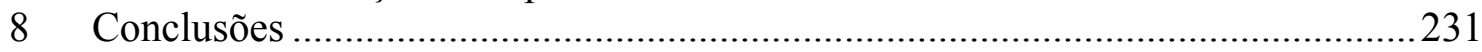

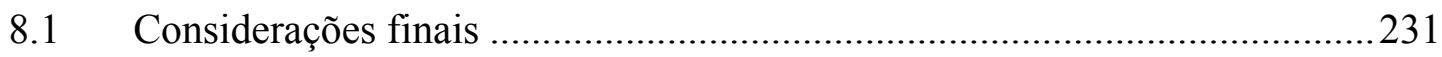

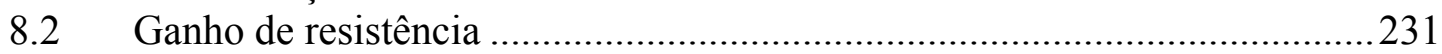

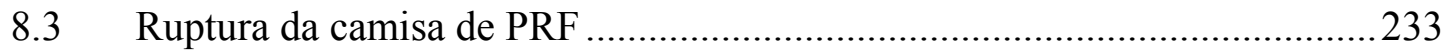

8.4 Forma do diagrama tensão $\mathrm{x}$ deformação do concreto confinado.................. 233

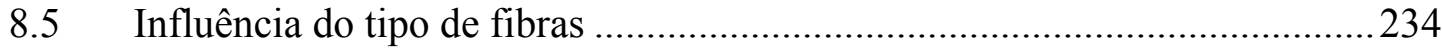

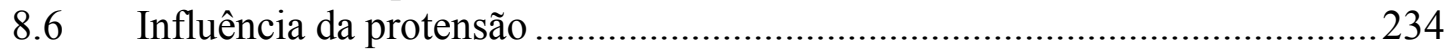

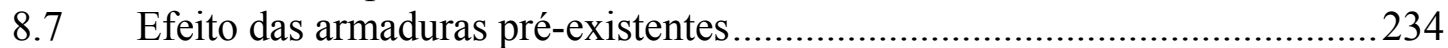

8.8 Desempenho dos ensaios de flexo-compressão ..........................................235

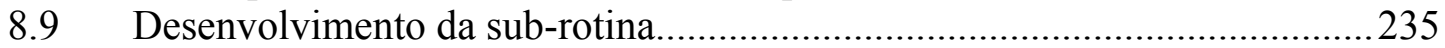

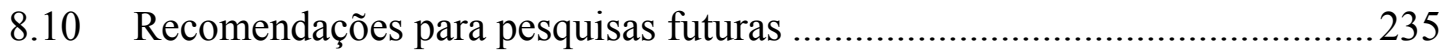

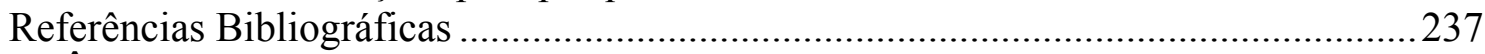

APÊNDICE I - Sub-rotina Umat implementada .................................................. 243 


\section{Resumo}

CARRAZEDO, R. (2005). Mecanismos de confinamento em pilares de concreto encamisados com polímeros reforçados com fibras submetidos à flexo-compressão. Tese (Doutorado) - Escola de Engenharia de São Carlos, Universidade de São Paulo, São Carlos, 2005.

Neste trabalho avaliou-se a influência da forma da seção transversal e da excentricidade do carregamento sobre o efeito de confinamento em pilares de concreto encamisados com polímeros reforçados com fibras (PRF). Para estas avaliações foi utilizada a análise experimental, por meio de ensaios de pilares sob flexo-compressão, e a análise numérica com o método dos elementos finitos.

Observou-se que ocorreram reduções significativas dos efeitos de confinamento em pilares de seção quadrada e retangular quando a relação entre o raio de arredondamento dos cantos e o maior lado da seção transversal diminuiu.

A influência da relação entre o lado maior e menor, no caso de pilares de seção retangular, não foi tão significativa se comparada ao efeito redutor do raio de arredondamento mencionado anteriormente.

Ocorreram ganhos de resistência em todos os pilares ensaiados, indicando que o encamisamento com PRF pode ser utilizado mesmo em situações em que a força de compressão seja aplicada com pequenas excentricidades. $\mathrm{O}$ efeito da excentricidade sobre o confinamento dependeu da forma da seção transversal considerada. Em pilares de seção circular a excentricidade reduziu levemente os efeitos de confinamento. Nos pilares de seção quadrada a excentricidade não reduziu significativamente os efeitos de confinamento, sendo que para os menores raios de arredondamento o efeito de confinamento foi até maior na presença da excentricidade. Nos pilares de seção retangular observou-se que aplicando a excentricidade na direção da menor inércia o comportamento foi semelhante ao dos pilares de seção quadrada. Porém, aplicando a excentricidade na direção da maior inércia observou-se um grande efeito de confinamento, maior inclusive que no pilar centrado.

Palavras-chave: concreto, pilares, polímero reforçado com fibras de carbono, confinamento, plasticidade, reforço; 


\section{Abstract}

CARRAZEDO, R. (2005). Confinement mechanisms in concrete columns wrapped by carbon fiber reinforced polymers subjected to flexural compression. Ph. D. Thesis Escola de Engenharia de São Carlos, Universidade de São Paulo, São Carlos, 2005.

In this work the influence of the cross section shape and eccentricity of the compressive load on the confinement of concrete columns wrapped by fiber reinforced polymer (FRP) was evaluated. Experimental analysis, through flexural compression tests of columns, and numerical analysis developed through the finite element method were used to study these effects.

Significant reductions of confinement effects were noticed in square and rectangular cross sections when the ratio of the round off radius to the major side of the column was reduced.

The ratio between the major and minor side in rectangular columns was not so important to define the effectiveness of confinement as was the fore mentioned factor.

Increases of strength were noticed in all columns tested, showing that FRP wrapping can be successfully used even with small eccentricities of loading. The effect of the eccentricity on the confinement showed to be dependent on the cross section shape. In circular columns the eccentricity of loading reduced the confinement effects. For the square cross section columns tested the confinement was not significantly affected by the eccentricity. In fact, for square columns with low round off radius, the eccentricity increased the confinement effects. Rectangular columns subjected to eccentric loading in the direction of the minor inertia showed a behavior similar to square columns. On the other hand, with the eccentricity applied in the direction of the major inertia, an important confinement effect was observed, more important than in the case of concentric loading.

Keywords: concrete, columns, carbon fiber reinforced polymer, confinement, plasticity, strengthening; 


\section{Introdução}

Os Polímeros Reforçados com Fibras (PRF) são materiais normalmente ortotrópicos que possuem elevada resistência mecânica na direção das fibras, módulo de elasticidade variável de acordo com o tipo de fibras utilizado e baixa massa específica. Alguns PRF possuem resistência e módulo de elasticidade da ordem do aço, com uma massa específica aproximadamente 5 vezes menor. Além disso, a combinação de fibras com diferentes orientações em cada camada e diferentes tipos de fibras, permite produzir estruturas com comportamento otimizado de acordo com carregamento a que são submetidas.

Estas propriedades especiais tornaram os PRF atrativos em aplicações na indústria aeronáutica há muitos anos e mais recentemente no reforço de estruturas da construção civil.

Os benefícios do encamisamento em pilares são os ganhos de resistência e ductilidade do concreto, por meio do confinamento, e a contenção das armaduras longitudinais, evitando sua flambagem. Além disso, sabe-se que é possível utilizar fibras orientadas na direção longitudinal do pilar e melhorar seu desempenho na flexão (FIB, 2001).

Apesar do considerável número de pesquisas realizadas a respeito do confinamento com PRF, a grande maioria destas abordou pilares submetidos à força de compressão centrada, havendo apenas indicativos dos benefícios do efeito de confinamento na flexo-compressão. Além disso, os estudos do efeito da forma da seção indicam uma redução do efeito de confinamento em pilares de seção quadrada e retangular. Logo, julga-se que para uma correta avaliação dos efeitos de confinamento em pilares encamisados com PRF seja necessária a avaliação do efeito da excentricidade do carregamento e da forma da seção transversal. 


\subsection{Objetivo}

A presente pesquisa pretendeu investigar o efeito de confinamento em pilares de concreto armado encamisados com polímeros reforçados com fibras de carbono. $\mathrm{O}$ principal objetivo foi avaliar, qualitativa e quantitativamente, como o confinamento do concreto obtido com esta técnica poderia contribuir no reforço de pilares de concreto armado de diferentes seções transversais, quando estes fossem submetidos a forças de compressão com excentricidade variável. Procurou-se investigar a distribuição interna de pressões laterais nestas situações, as tensões nas camisas, os acréscimos de resistência e deformação última no concreto confinado.

\subsection{Justificativa}

A grande maioria dos ensaios de pilares encamisados com PRFC encontrados na literatura até os dias atuais foi de seções transversais circulares. Sabe-se, no entanto, que a forma da seção transversal é uma variável de grande importância na eficiência do reforço por encamisamento, e sua influência não é adequadamente conhecida. A falta de parâmetros para dimensionamento do reforço com confinamento em seções diferentes da circular desencoraja sua aplicação em muitos casos. Além disso, há poucos relatos de ensaios de pilares encamisados com PRFC submetidos à compressão excêntrica. Logo, não é possível quantificar adequadamente o efeito de confinamento desenvolvido nestas situações nem estimar os acréscimos de capacidade resistente.

\subsection{Metodologia}

Os principais procedimentos utilizados na avaliação dos problemas foram a análise experimental, numérica e teórica, fundamentadas num adequado conhecimento da bibliografia existente. As simulações numéricas e a análise experimental foram utilizadas conjuntamente, sendo mutuamente complementadas.

As simulações numéricas serviram para balizar aspectos importantes dos ensaios realizados e possibilitaram aumentar o campo observável de resultados dos ensaios. A utilização de modelos numéricos representativos do comportamento experimental foi essencial para a confiança nos resultados obtidos.

Os problemas foram avaliados a partir de casos mais simples, aumentando a complexidade dos ensaios em função do conhecimento adquirido e de análises dos resultados obtidos. 


\section{Polímeros reforçados com fibras}

Os polímeros reforçados com fibras (PRF) são compósitos constituídos de resinas poliméricas e fibras de alta resistência à tração. Estes materiais têm apresentado uma crescente utilização no setor da construção civil, principalmente com respeito ao reforço de estruturas de concreto armado.

\subsection{Polímeros reforçados com fibras colados externamente}

Segundo a FIB (2001), as principais vantagens da utilização dos PRF no reforço de estruturas de concreto são a imunidade à corrosão, baixo peso próprio, facilidade de aplicação em lugares de difícil acesso, redução dos custos de mão-de-obra, resistência à tração consideravelmente alta, rigidez adaptável às necessidades de projeto, grande capacidade de deformação e grande disponibilidade em tamanhos e geometrias.

No entanto, como desvantagem pode ser considerada o comportamento elásticolinear até a ruptura, que resulta em reduzida ductilidade do material. Além disso, o custo destes materiais é muitas vezes maior que o do aço. Porém, deve-se considerar em conjunto com o custo a maior resistência, o que pode tornar este tipo de reforço viável economicamente. Outro problema é o coeficiente de dilatação térmica incompatível entre o concreto e os compósitos de fibras de carbono e aramida. A exposição a altas temperaturas (como em incêndios) pode causar a degradação prematura e o colapso (algumas camisas de PRF perdem a rigidez em virtude do aumento de temperatura entre $45^{\circ} \mathrm{C}$ e $70^{\circ} \mathrm{C}$ ). Assim, para optar pela utilização de PRF no reforço de estruturas de concreto, deve-se considerar não apenas a resistência mecânica, mas também a construtibilidade e o comportamento ao longo do tempo (FIB, 2001).

Os compósitos utilizados para reforço de estruturas de concreto são normalmente encontrados na forma de tecidos e lâminas pré-fabricadas (ver Figura 2.1). As lâminas possuem espessura da ordem de $1 \mathrm{~mm}$ e são produzidas por pultrusão ou por laminação. São utilizados apenas adesivos para sua fixação ao concreto. Os tecidos podem ser unidirecionais, bidirecionais ou com mais orientações de fibras, podendo ser 
ainda pré-impregnados. A moldagem e a cura dos tecidos são feitas no local de aplicação.
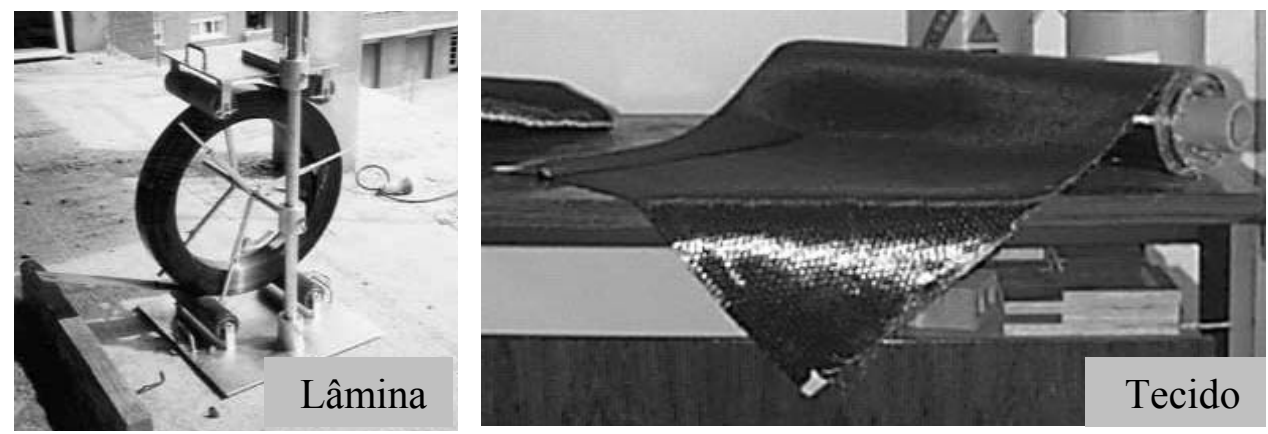

Figura 2.1- Lâmina pré-fabricada de PRFC e tecido de fibras de carbono (GETTU, 2002)

A utilização dos PRF encontrou aplicações em diversas situações de reforços em elementos estruturais como vigas, lajes, pilares e outros. A técnica de reforço antecessora aos PRF colados externamente foi a de lâminas de aço coladas com epóxi. As desvantagens desta técnica eram a perda de aderência com a corrosão das lâminas de aço, dificuldade no manuseio das lâminas em locais estreitos e limitação no comprimento das lâminas, criando a necessidade de juntas em alguns casos. A substituição das lâminas de aço por PRF eliminou estes problemas (FIB, 2001).

$\mathrm{O}$ encamisamento de pilares com aço apresenta também inconvenientes por causa da corrosão. O encamisamento com concreto armado é uma técnica ainda bastante utilizada. Porém necessita de intensa mão-de-obra para execução e muitas vezes causa interrupção da ocupação do edifício. Além disso, os elementos reforçados apresentam indesejados acréscimos de peso próprio e rigidez. O encamisamento com tecidos de PRF se tornou então uma atrativa solução para o reforço de estruturas de concreto, possibilitando importantes acréscimos de resistência e ductilidade sem afetar tanto a rigidez dos elementos reforçados (FIB, 2001).

\subsection{Materiais utilizados}

Os sistemas de PRF são constituídos de fibras de alta resistência à tração, matrizes e adesivos. As matrizes e adesivos são normalmente resinas poliméricas. A resina utilizada na matriz deve assegurar que a matriz e as fibras trabalhem solidariamente. $\mathrm{O}$ adesivo é necessário para uma boa aderência entre o reforço e o concreto. Em alguns sistemas a mesma resina é utilizada como adesivo e como a matriz do compósito. Os sistemas de reforço utilizados podem ser divididos atualmente em três grandes tipos: 
- Sistemas curados no local (geralmente com tecidos);

- Sistemas com elementos pré-fabricados;

- Sistemas especiais.

\subsubsection{Adesivos}

Sua função é proporcionar um caminho de transferência das tensões de cisalhamento entre o concreto e o compósito, com o objetivo de desenvolver a total ação do compósito (FIB, 2001).

Os adesivos mais comuns são as epóxis. Ao utilizar uma epóxi, dois conceitos importantes devem ser lembrados: tempo em aberto e "pot life". "Pot life" é o tempo durante o qual se pode trabalhar com a epóxi a partir da mistura com o endurecedor. Tempo em aberto é o tempo disponível depois que o adesivo foi aplicado até que este esteja unido ao substrato.

Outra propriedade importante é a temperatura de transição vítrea ("glass transition" ou $\mathrm{T}_{\mathrm{g}}$ ). Para temperaturas abaixo de $\mathrm{T}_{\mathrm{g}}$ os polímeros se encontram num estado relativamente duro, elástico, e frágil como o vidro. Para temperaturas acima de $\mathrm{T}_{\mathrm{g}}$ o comportamento é semelhante ao da borracha, e pode ocorrer uma grande redução de desempenho.

As epóxis apresentam algumas vantagens sobre os outros polímeros para aplicação como adesivos na engenharia civil (FIB, 2001):

- alta atividade superficial e boas propriedades de molhagem de diferentes substratos;

- $\quad$ podem ser formuladas para um longo tempo em aberto;

- alta resistência coesiva;

- podem ter sua ductilidade aumentada com uma fase dispersa de borracha;

- possui reduzida retração e permite a adesão de grandes áreas de reforço apenas com pressão de contato;

- baixa fluência e grande retenção de carregamento ao longo do tempo;

- podem ser tixo-trópicas para aplicação em superfícies verticais;

- podem acomodar irregularidades com espessuras consideráveis.

Na Tabela 2.1 são apresentadas as propriedades típicas de adesivos epóxi curados a frio. 
Tabela 2.1 - Propriedades típicas de adesivos epóxi curados a frio (FIB, 2001)

\begin{tabular}{cc}
\hline Propriedade a 20 \\
\hline Densidade $\left(\mathrm{kg} / \mathrm{m}^{3}\right)$ & $1100-1700$ \\
Módulo de elasticidade $(\mathrm{GPa})$ & $0,5-20$ \\
Módulo ao cisalhamento (GPa) & $0,2-8$ \\
Coeficiente de Poisson & $0,3-0,4$ \\
Resistência à tração $(\mathrm{MPa})$ & $9-30$ \\
Resistência ao cisalhamento $(\mathrm{MPa})$ & $10-30$ \\
Resistência à compressão $(\mathrm{MPa})$ & $50-110$ \\
Deformação ultima de tração $(\%)$ & $0,5-5$ \\
Energia de fraturamento $\left(\mathrm{J} / \mathrm{m}^{2}\right)$ & $200-1000$ \\
Coeficiente de dilatação térmica $\left(10^{-6} /{ }^{\circ} \mathrm{C}\right)$ & $25-100$ \\
Absorção de água aos 7 dias $-25^{\circ} \mathrm{C}$ & $0,1-3$ \\
(\%w/w) & $45-80$ \\
Temperatura de transição vítrea $\left({ }^{\circ} \mathrm{C}\right)$ & \\
\hline
\end{tabular}

\subsubsection{Matrizes}

As funções das matrizes são proteger as fibras, mantê-las na posição e distribuir o carregamento. A matriz tem grande influência sobre algumas propriedades mecânicas do compósito, como a resistência e o módulo de elasticidade transversal, ao cisalhamento e à compressão. Resinas termo-fixas como as epóxis, poliésteres e vinilésteres são as mais utilizadas. Possuem boa trabalhabilidade e resistência química. As epóxis normalmente possuem melhores propriedades mecânicas e durabilidade, entretanto são as mais caras. A temperatura de fusão e cura, viscosidade e reatividade com as fibras são muito importantes para definição do processo de fabricação do compósito (FIB, 2001).

$\mathrm{Na}$ Tabela 2.2 são apresentadas as propriedades típicas de algumas resinas termo-fixas utilizadas como matrizes.

Tabela 2.2 - Propriedades típicas de algumas resinas termo fixas (HYER, 1998)

\begin{tabular}{cccc}
\hline Propriedade a $\mathbf{2 0}^{\circ} \mathbf{C}$ & Poliéster & $\begin{array}{c}\text { Vinil- } \\
\text { éster }\end{array}$ & Epóxi \\
\hline Densidade $\left(\mathrm{kg} / \mathrm{m}^{3}\right)$ & $1100-1500$ & 1150 & $1100-1400$ \\
Módulo de elasticidade $(\mathrm{GPa})$ & $1,2-4,5$ & $3-4$ & $2-6$ \\
Módulo ao cisalhamento (GPa) & $0,7-1,2$ & - & $1,1-2,2$ \\
Resistência à tração (MPa) & $40-90$ & $65-90$ & $35-130$ \\
Resistência à compressão (MPa) & $90-250$ & 127 & $100-200$ \\
Deformação ultima de tração $(\%)$ & $2-5$ & $1-5$ & $1-8,5$ \\
Coeficiente de dilatação térmica $\left(10^{-6} /{ }^{\circ} \mathrm{C}\right)$ & $60-200$ & 53 & $45-70$ \\
Absorção de água a 1 dia - $20^{\circ} \mathrm{C}(\%)$ & $0,1-0,3$ & - & $0,1-0,4$ \\
Temperatura de transição vítrea $\left({ }^{\circ} \mathrm{C}\right)$ & $50-110$ & $100-150$ & $50-250$ \\
\hline
\end{tabular}




\subsubsection{Fibras}

As fibras contínuas são as mais utilizadas, sendo preferidas as fibras de carbono, aramida e vidro. As fibras de vidro têm como atrativo o baixo custo. Dentre as fibras de vidro existentes são preferidas as resistentes a álcalis, podendo resistir melhor ao meio alcalino do concreto. As fibras de aramida foram introduzidas no mercado no início da década de 70. São anisotrópicas, com alto módulo de elasticidade e resistência na direção longitudinal. Apresentam um comportamento não-linear e dúctil na compressão. As fibras de carbono são normalmente produzidas a partir do piche ou PAN. Além de alta resistência à tração possuem um elevado módulo de elasticidade (FIB, 2001). Na Tabela 2.3 são apresentadas as propriedades típicas das fibras de alta resistência:

Tabela 2.3 - Propriedades típicas das fibras (FIB, 2001)

\begin{tabular}{lccc}
\hline \multicolumn{1}{c}{ Material } & $\begin{array}{c}\text { Módulo de } \\
\text { elasticidade (GPa) }\end{array}$ & $\begin{array}{c}\text { Resistência à } \\
\text { tração }(\mathbf{M P a})\end{array}$ & $\begin{array}{c}\text { Deformação } \\
\text { última de tração } \\
(\%)\end{array}$ \\
\hline $\begin{array}{l}\text { Carbono } \\
\text { Alta resistência }\end{array}$ & $215-235$ & $3500-4800$ & $1,4-2,0$ \\
$\quad \begin{array}{l}\text { Ultra-alta } \\
\text { resistência }\end{array}$ & $215-235$ & $3500-6000$ & $1,5-2,3$ \\
$\quad \begin{array}{l}\text { Alto módulo } \\
\text { Ultra-alto módulo }\end{array}$ & $350-500$ & $2500-3100$ & $0,5-0,9$ \\
\hline $\begin{array}{l}\text { Vidro } \\
\text { E }\end{array}$ & $500-700$ & $2100-2400$ & $0,2-0,4$ \\
$\quad$ S & 70 & $1900-3000$ & $3,0-4,5$ \\
\hline Aramida & $85-90$ & $3500-4800$ & $4,5-5,5$ \\
$\quad$ Baixo módulo & $70-80$ & $3500-4100$ & \\
$\quad$ Alto módulo & $115-130$ & $3500-4000$ & $4,3-5,0$ \\
\hline
\end{tabular}

\subsubsection{Polímeros reforçados com fibras utilizados para reforço}

As frações volumétricas das fibras dos PRF tipicamente utilizados para reforço de estruturas de concreto são da ordem de $50 \%$ a 70 \% nos sistemas com lâminas e $25 \%$ a 35\% nos sistemas com tecidos. Pode-se utilizar a lei das misturas para uma aproximação das propriedades mecânicas do compósito a partir das propriedades dos materiais componentes e das frações volumétricas. No entanto, recomenda-se realizar os ensaios de caracterização para melhor confiabilidade e precisão (FIB, 2001).

No caso de lâminas basta realizar o ensaio de corpos-de-prova e obter as propriedades mecânicas utilizando as dimensões da amostra. Para o caso de tecidos aplicados manualmente ocorre uma grande variação da espessura da camada aplicada e conseqüentemente das frações volumétricas das fibras. Além disso, para uma quantidade constante de fibras, a força e a deformação de ruptura são muito pouco 
afetadas pelo acréscimo da quantidade de resina. Por este motivo FIB (2001) recomenda associar as propriedades mecânicas obtidas nos ensaios de caracterização somente às fibras e utilizar a espessura das fibras para o dimensionamento.

No entanto, recomenda-se que sejam utilizadas as propriedades mecânicas do compósito caracterizadas experimentalmente e sua espessura na avaliação do reforço, para evitar erros na adoção das propriedades mecânicas do material. Procura-se assim evitar que, por desconhecimento, o projetista do reforço utilize as propriedades mecânicas das fibras fornecidas pelo fabricante, que normalmente são bem superiores às obtidas nos compósitos produzidos com elas. 


\section{Comportamento do concreto confinado}

O efeito da pressão lateral sobre a resistência axial e ductilidade de corpos-deprova de concreto pode ser facilmente observado com resultados de ensaios triaxiais de AIRE UNTIVEROS (2002) apresentados na Figura 3.1. Foram utilizados concretos com resistência à compressão de 34,7 $\mathrm{MPa}$ e 68,2 $\mathrm{MPa}$. Podem-se observar importantes acréscimos de resistência e deformação última com o aumento da pressão lateral.
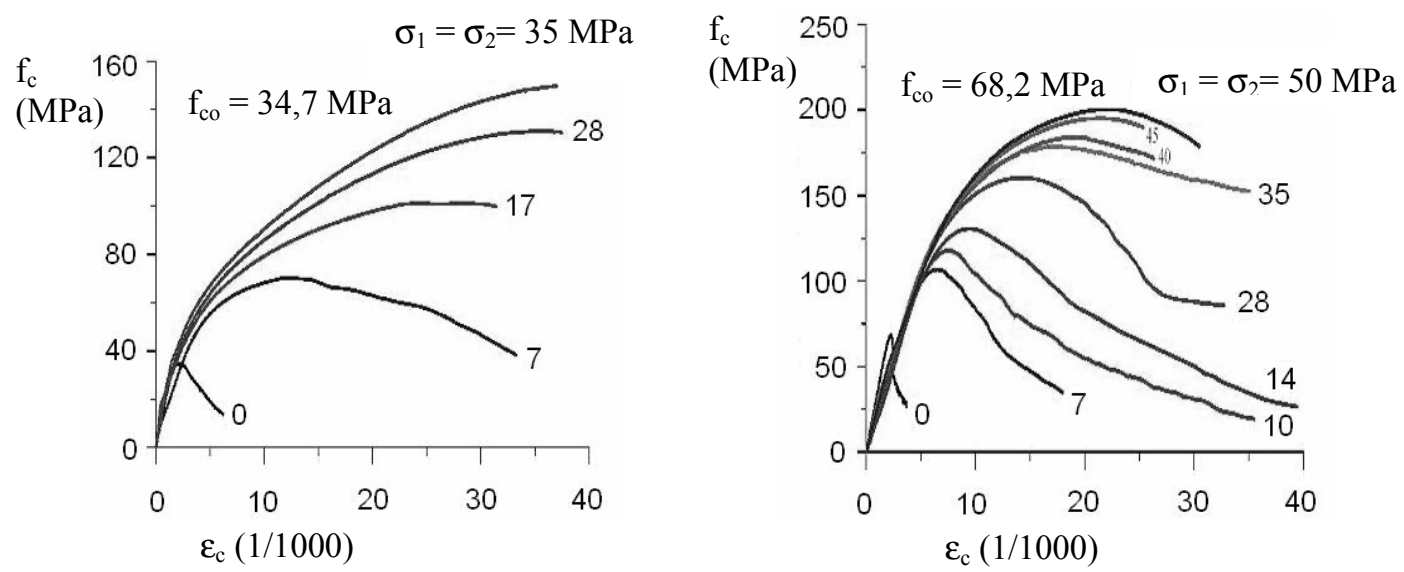

Figura 3.1 - Diagramas tensão $\mathrm{x}$ deformação do concreto confinado em ensaios triaxiais (AIRE UNTIVEROS, 2002)

É necessário neste ponto um esclarecimento com relação à nomenclatura empregada. É comum a utilização dos termos resistência do concreto confinado $\left(f_{c c}\right)$ e deformação última do concreto confinado $\left(\varepsilon_{\mathrm{cc}}\right)$ na literatura sobre confinamento em pilares de concreto. No entanto, em pilares confinados o que ocorre realmente é um acréscimo da tensão longitudinal $\left(\sigma_{3}\right)$ que pode ser aplicada a este pilar por causa da pressão lateral $\left(f_{1}\right)$. Ou seja, existe um estado triaxial de tensões em que é possível que esta componente de tensão $\left(\sigma_{3}\right)$ atinja maiores valores. $\mathrm{O}$ mesmo pode-se dizer com relação à deformabilidade destes pilares, que num estado triaxial de confinamento podem sofrer deslocamentos axiais bastante significativos até a ruptura. 
Mas por facilidade de discussão, prefere-se manter a utilização dos termos resistência do concreto confinado e deformação última do concreto confinado, que são bem aceitos e utilizados nas publicações internacionais sobre o assunto.

\subsubsection{Influência do tipo de confinamento}

Diversos pesquisadores observaram comportamentos distintos de pilares de concreto confinados em ensaios triaxiais, por tubos de aço ou camisas de PRF. Uma diferença entre estes tipos de confinamento está na história de carregamento a que o concreto é submetido. Nos ensaios triaxiais a pressão lateral é geralmente aplicada no início e mantida constante ao longo do restante do ensaio, durante o qual a tensão axial é acrescida continuamente.

No confinamento passivo, em geral, aplica-se a tensão de compressão axial e então, dependendo da deformabilidade do concreto e das propriedades da camisa, após um certo carregamento, as pressões laterais se tornam significativas e o efeito de confinamento importante.

Estes aspectos podem ser observados na Figura 3.2, construída a partir de resultados de AIRE UNTIVEROS (2002). Foram comparados ensaios de corpos-deprova de concretos de mesma classe de resistência (30 MPa), produzidos com os mesmos materiais, e com uma pressão lateral máxima da mesma ordem (8 MPa). Esta foi aplicada de três maneiras distintas: em ensaio em câmara triaxial, passivamente com tubo de aço de 1,8 mm e com 3 camadas de tecido de fibras de carbono (PRFC).

A primeira diferença observada foi em relação ao diagrama tensão $\mathrm{x}$ deformação. No concreto confinado ativamente a pressão lateral atuante logo no início do ensaio aparentemente inibe de maneira mais eficiente a formação das primeiras micro-fissuras, prolongando o trecho inicial linear do diagrama tensão x deformação axial. A inclinação da curva se reduz gradualmente até o pico e segue-se então um diagrama descendente.

No tubo de aço, por sua elevada rigidez transversal, observou-se um comportamento semelhante àquele com confinamento ativo, já que elevadas pressões laterais foram atingidas rapidamente. No entanto, pode-se observar que o seu comportamento neste caso foi mais dúctil que o do confinamento ativo, talvez por um acréscimo da pressão lateral após o escoamento do aço em função de seu encruamento.

$\mathrm{O}$ diagrama tensão $\mathrm{x}$ deformação do concreto confinado com PRF foi bem distinto dos dois anteriores. Observou-se que a pressão lateral cresceu linearmente até o 
final do ensaio, e esta somente atingiu valores consideráveis após certa micro-fissuração do concreto.

Nos concretos submetidos ao confinamento passivo, grande parte da diferença entre o comportamento do concreto confinado com aço ou com PRFC pode ser atribuída à diferença de rigidez das camisas. Apenas para comparação, foram calculados os módulos laterais (ver definição na Tabela 4.1) da camisa de PRF e do tubo de aço cujos diagramas tensão x deformação são apresentados na Figura 3.2. Apesar de ambas as camisas possibilitarem a obtenção de uma pressão lateral final da ordem de $8 \mathrm{MPa}$, o módulo lateral da camisa de aço (no regime elástico) é cerca de 5 vezes maior que o da de PRF, o que explica a grande diferença inicial no diagrama tensão x deformação. Isto quer dizer que no regime elástico a camisa de aço é mais rígida que a de PRF, mobilizando um maior efeito de confinamento. No entanto, a partir do escoamento do tubo de aço sua rigidez reduz-se consideravelmente, de modo que o ganho de resistência do concreto confinado praticamente se estabiliza. Na verdade, deve-se observar que na situação em questão ocorreram diferentes histórias de carregamento comparando-se a camisa de PRFC e a de aço. 


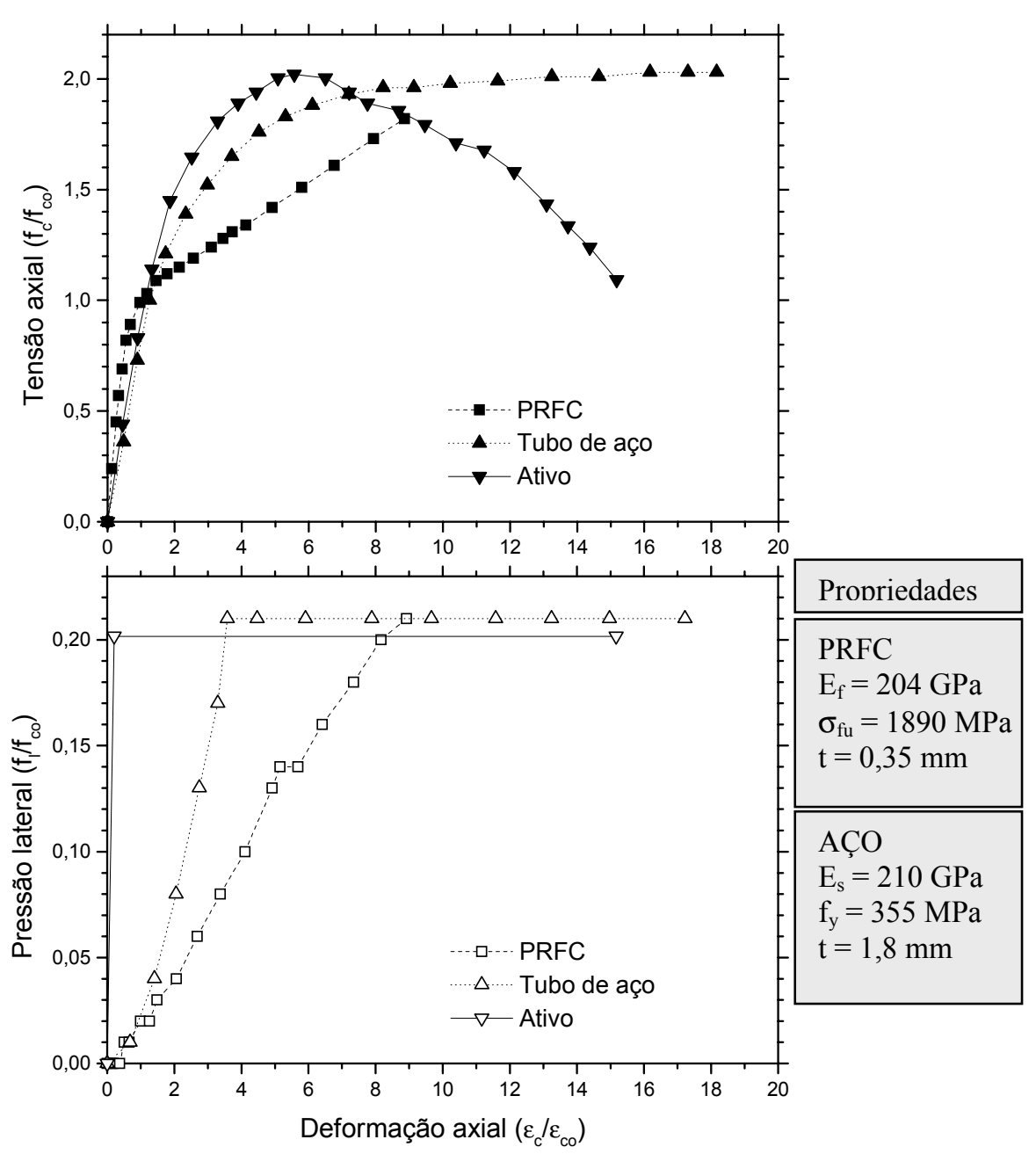

Figura 3.2 - Influência do tipo de confinamento no diagrama tensão x deformação do concreto confinado (construído a partir de resultados de AIRE UNTIVEROS, 2002)

\subsubsection{Expansão volumétrica}

PANTAZOPOULOU (1995) sugere que a utilização de envoltórias triaxiais de resistência não é suficiente para analisar as rupturas em diferentes estados de tensão do concreto e que a deformação volumétrica deve ser utilizada como um índice para avaliação do estado interno do material.

IMRAN \& PANTAZOPOULOU (1996) observaram em ensaios triaxiais de concreto uma relação entre a evolução da deformação volumétrica e o diagrama tensão x deformação axial. Como se pode observar na Figura 3.3, o crescimento da deformação volumétrica $\left(\varepsilon_{\mathrm{v}}\right)$ inicia-se no sentido da contração, e é praticamente linear, tanto para o concreto confinado quanto para o concreto não confinado. No entanto, a partir de determinada deformação axial esta linearidade se perde e o comportamento passa a se desenvolver no sentido de uma expansão volumétrica. 
Segundo IMRAN \& PANTAZOPOULOU (1996), o início do trecho descendente do diagrama tensão x deformação axial $\left(\sigma_{3} \times \varepsilon_{3}\right)$ se dá com o crescimento da expansão volumétrica $\left(\varepsilon_{\mathrm{v}}\right)$. O ponto $\varepsilon_{3}{ }^{0}$ representa a separação entre contração e expansão volumétrica e, segundo os autores, define a deformação axial a partir da qual a resistência axial começa a cair. Pode-se observar ainda que na presença de pressões confinantes o trecho de contração volumétrica é maior e então a expansão volumétrica se dá a uma taxa de crescimento bem menor.

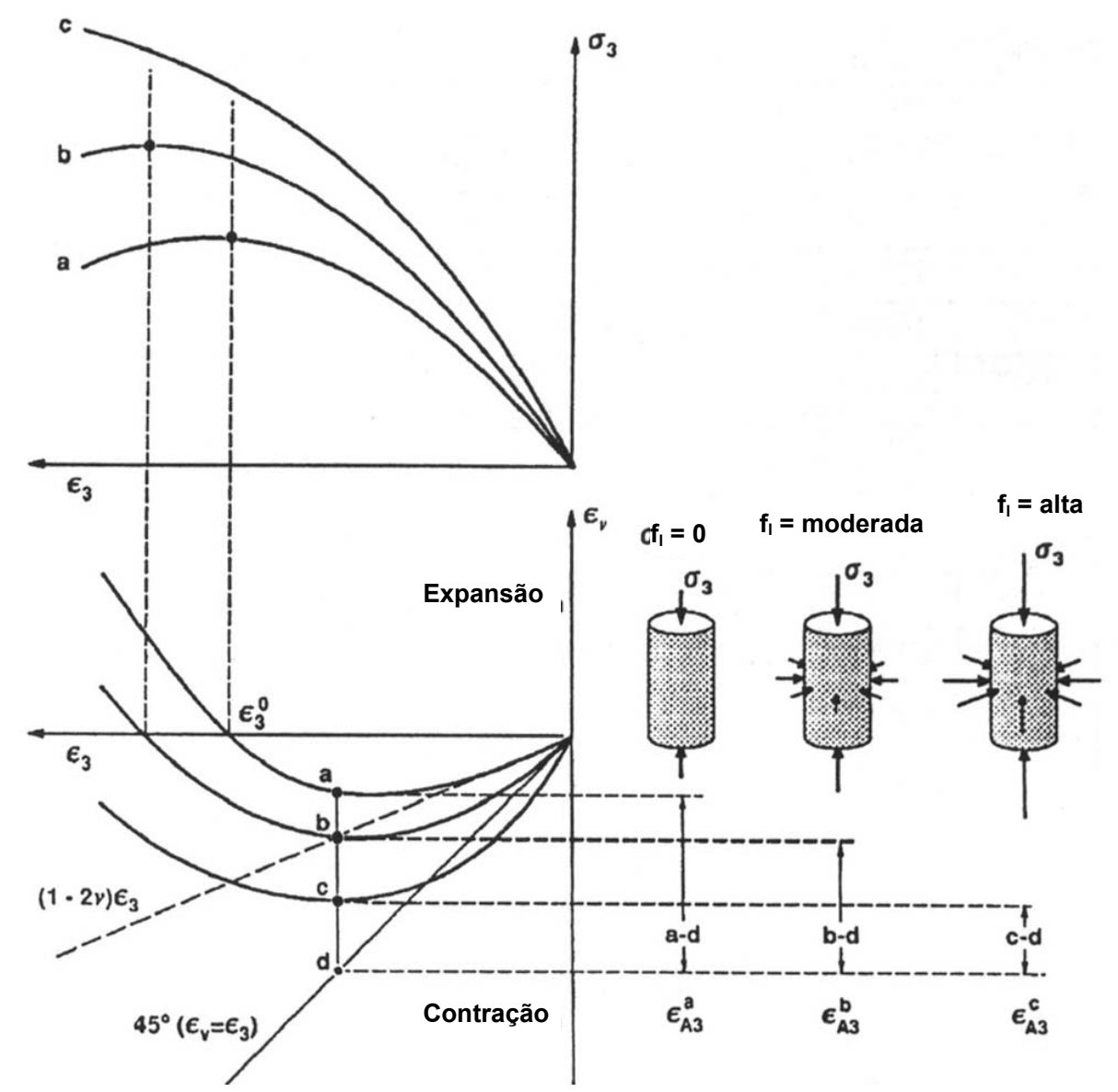

Figura 3.3 - Deformações axiais e volumétricas do concreto confinado em ensaios triaxiais (IMRAN \& PANTAZOPOULOU, 1996)

A expansão volumétrica do concreto, no caso do confinamento com PRF, iniciase de maneira semelhante, com compactação volumétrica (ver Figura 3.4). Porém, em torno de $80 \%$ de $\mathrm{f}_{\mathrm{co}}$, a tendência de deformação volumétrica se inverte para expansão. Esta tensão, correspondente ao valor mínimo da deformação volumétrica, é denominada tensão crítica (CHEN, 1982). Dependendo da rigidez da camisa, o concreto experimenta a partir deste ponto um crescimento da expansão volumétrica (camisas com pequena rigidez) ou mesmo uma reversão da deformação volumétrica no sentido da compactação 
(camisas com grande rigidez). Nos pilares com camisas mais rígidas e resistentes esta compactação final é considerável. A ruptura do pilar ocorre com a ruptura da camisa (MIRMIRAN \& SHAHAWI, 1997).

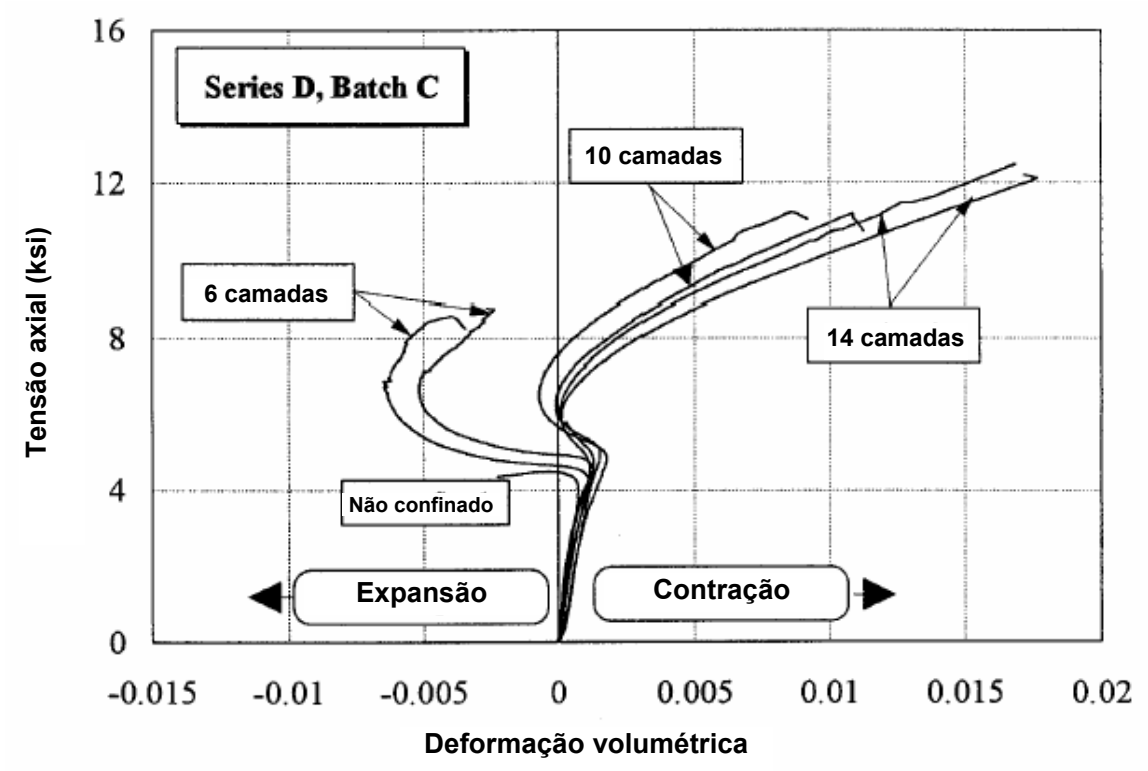

Figura 3.4 - Deformabilidade volumétrica do concreto confinado com PRFV (SAMAAN, 1997)

\subsubsection{Taxa de dilatação lateral}

Segundo SAMAAN et al. (1998) a taxa de dilatação lateral $(\mu)$, definida como a taxa de variação da deformação lateral em relação à deformação axial $\left(\delta \varepsilon_{1} / \delta \varepsilon_{3}\right)$ tem grande importância sobre o confinamento.

No concreto não confinado, $\mu$ cresce indefinidamente com o início da microfissuração. No confinamento com aço, o crescimento de $\mu$ é pequeno até que o aço escoe, a partir de onde o comportamento é similar ao do concreto não confinado. No confinamento com PRF a resposta é bem distinta. Inicialmente a taxa de dilatação lateral cresce rapidamente (semelhante ao concreto não confinado) até que a camisa seja efetivamente mobilizada. Então ocorre uma restrição da dilatação lateral e $\mu$ se reduz a um valor assintótico (SAMAAN et al., 1998).

Em pilares circulares confinados com PRF, aumentando a espessura da camisa ocorre uma redução do valor final de $\mu$ (MIRMIRAN \& SHAHAWI, 1997 - b).

PESSIKI et al. (2001) observaram que $\mu>0,5$ representa expansão volumétrica do material e que menores valores de $\mu$ resultaram em um diagrama tensão $\mathrm{x}$ 
deformação do concreto confinado bi-linear, com aumento da capacidade resistente no segundo trecho linear. Valores altos de $\mu$ resultaram em uma menor pressão lateral, e praticamente sem ganho de resistência no segundo trecho linear.

\subsubsection{Influência da rigidez da camisa}

PANTAZOPOULOU (1995) sugere que a rigidez lateral e não a pressão lateral é a causa do acréscimo de resistência do concreto. Uma evidência apontada pela autora no comportamento do concreto é a diferença dos acréscimos de resistência observados em diferentes tipos de ensaios triaxiais. Quando câmaras triaxiais são utilizadas para aplicar a pressão lateral, os acréscimos de resistência são semelhantes aos propostos por RICHART et al. (1929), dados pela equação (3.1).

$$
f_{c c}=f_{c o}+k_{1} \cdot f_{l}
$$

onde:

- $\mathrm{f}_{\mathrm{co}}$ é a resistência à compressão uniaxial do concreto;

- $\mathrm{f}_{\mathrm{cc}}$ é a resistência à compressão do concreto confinado;

- $\mathrm{f}_{1}$ é a pressão lateral;

- $\mathrm{k}_{1}$ é o coeficiente de ganho de resistência axial pela pressão lateral.

No entanto, ensaios realizados por KOSAKA et al. ${ }^{1}$ (1984) apud PANTAZOPOULOU (1995), onde o confinamento foi aplicado travando o concreto entre placas de aço, o acréscimo de resistência foi de 10 a 25 vezes o valor da pressão lateral. Segundo a autora, esta grande diferença no desempenho para intensidades similares de pressão lateral e tipos similares de concreto indica que a pressão lateral é uma inadequada referência do efeito de confinamento.

A partir desta discussão PANTAZOPOULOU (1995) afirma que o concreto é um material mais sensível à restrição do que à pressão. Segundo a autora, utilizando a deformação volumétrica como uma medida do estado interno do material a modelagem triaxial é facilitada. Sugere assumir que o estado interno de fissuração do material é unicamente suficiente para determinar a capacidade residual do material e que o confinamento, ativo ou passivo, é apenas uma manifestação de condições de contorno laterais cinemáticas presentes.

\footnotetext{
${ }^{1}$ Kosaka, Y.; Tanigawa, Y.; Hatanaka, S. (1984). "Inelastic deformational behaviour of axially loaded concrete under low lateral confining stresses". Trans. Japan Concrete Inst., 6(III-5-B), 263-270.
} 
SAMAAN et al. (1998) concorda que o concreto é um material mais sensível à restrição lateral do que à pressão. Segundo o pesquisador isto explica as diferenças encontradas entre confinamento passivo e ativo, e a grande diferença no confinamento com PRF e com aço.

\subsubsection{Dependência da história de carregamento}

Há pontos de vista divergentes na literatura sobre a influência da história de carregamento no ganho de resistência do concreto confinado. Alguns autores sugerem que o acréscimo de resistência do concreto confinado é independente da história de carregamento ("path-independent”) a que este é submetido. Segundo esta hipótese, se o mesmo concreto é submetido à mesma pressão lateral na ruína, porém com diferentes histórias de carregamento, a resistência à compressão do concreto confinado é a mesma.

Os ensaios de RICHART et al. (1928) mostraram acréscimos de resistência semelhantes em função da pressão lateral no confinamento ativo e passivo com barras de aço na forma de espirais, de modo que o autor sugeriu que o coeficiente $\mathrm{k}_{1}$ de 4,1 é adequado a ambos os casos. Segundo DE LORENZIS \& TEPFERS (2001), IMRAN \& PANTAZOPOULOU (1996) realizaram ensaios triaxiais com quatro histórias de carregamento diferentes, observando o mesmo acréscimo de resistência, porém diferentes comportamentos quanto à deformabilidade. Porém, trabalhos como o de AIRE UNTIVEROS (2002) mostraram diferentes envoltórias de resistência para o concreto em diferentes formas de confinamento.

Ensaios triaxiais realizados por BAZANT \& TSUBAKI (1980) mostraram que quando a pressão lateral é aplicada logo no início do carregamento o concreto sofre uma menor micro-fissuração, e com isto a resposta é mais rígida. Observaram que com a aplicação prévia da pressão hidrostática preveniu-se o crescimento de micro-fissuras de cisalhamento (DE LORENZIS \& TEPFERS, 2001).

De fato, pode-se concluir que a história de carregamento afeta significativamente o diagrama tensão x deformação do concreto confinado, bem como sua deformação última. Além disso, não há evidências significativas para concluir que o ganho de resistência em função do confinamento seja independente da história de carregamento, já que o estado de fissuração interna do material pode ser diferente em histórias de carregamento distintas para o mesmo valor de pressão lateral. 


\subsubsection{Classe de resistência à compressão axial do concreto}

ANSARI \& LI (1998) e AIRE UNTIVEROS (2002) observaram que o efeito do confinamento é maior no concreto de resistência usual ( $f_{c o}=34,7$ MPa) comparativamente ao de alta resistência $\left(\mathrm{f}_{\mathrm{co}}=68,2 \mathrm{MPa}\right)$.

No caso do confinamento ativo, AIRE UNTIVEROS (2002) observou maiores ganhos relativos de resistência pelo efeito confinamento no concreto de resistência usual. Porém, mais nítido foi o maior ganho de deformação última do concreto de resistência usual.

Um interessante aspecto observado nos ensaios de AIRE UNTIVEROS (2002) foi que corpos-de-prova de concreto de alta resistência encamisados com PRF podem apresentar maiores efeitos de confinamento para pequenas intensidades de deformação axial do que o concreto de resistência usual. Ou seja, ocorre certo prolongamento do comportamento inicial do diagrama tensão x deformação. Esta observação pode ser feita na Figura 3.5. Acredita-se que esta diferença se deve à distinta deformabilidade do concreto de alta resistência em comparação ao concreto de resistência usual.

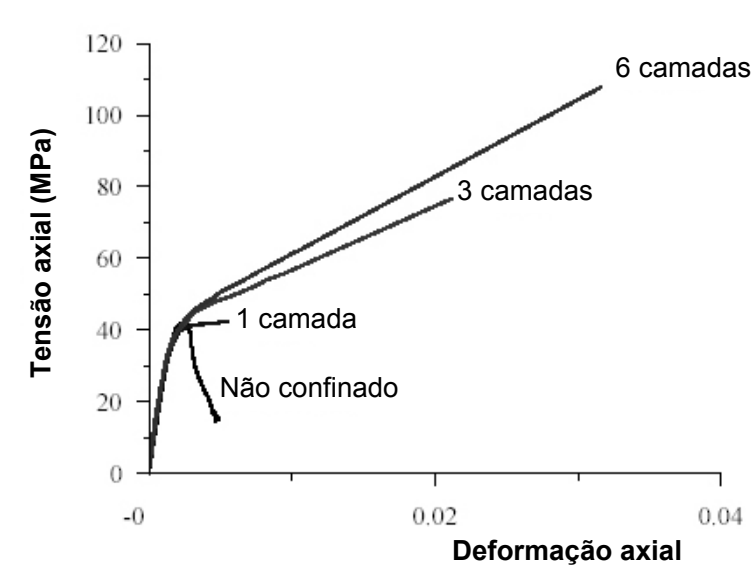

(a)

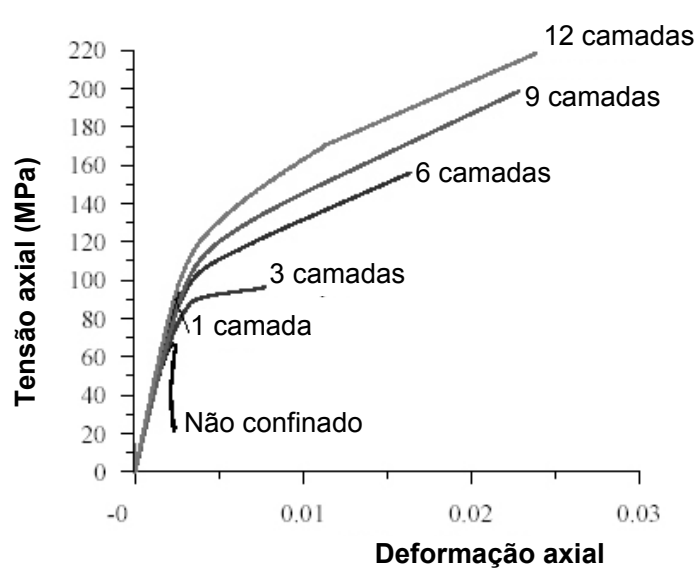

(b)

Figura 3.5 - Diagramas tensão x deformação do concreto confinado com PRFC

(a) concreto de resistência usual (b) concreto de alta resistência (AIRE UNTIVEROS, 2002)

\subsubsection{Influência das propriedades do concreto}

Há outras características do concreto além de sua resistência à compressão, que podem influenciar sua deformabilidade e eventualmente a resistência do concreto confinado. Entre outros se pode citar as propriedades mecânicas dos agregados e da 
pasta de cimento e as proporções da mistura. No entanto, não foram encontrados estudos avaliando quantitativamente o efeito destes parâmetros.

RICHART et al. (1928) realizaram ensaios com 3 dosagens de concreto diferentes e afirmaram que $\mathrm{k}_{1}$ provavelmente seja mais afetado pelo tipo de materiais utilizados do que pelas proporções da mistura de concreto. 


\section{Encamisamento com PRF}

Antecedendo os estudos de confinamento do concreto com PRF, KURT (1978) realizou um estudo do confinamento com tubos de PVC e ABS preenchidos com concreto. Obteve coeficientes $\mathrm{k}_{1}$ entre 2,93 e 3,68, obtendo uma média de 3,25. Observou ainda um considerável aumento da deformabilidade nos tubos preenchidos com concreto.

No entanto, FARDIS \& KHALILI (1981) observaram que os ganhos obtidos por KURT (1978) em função do confinamento foram pequenos (da ordem de 1,4 MPa), já que os plásticos não são muito rígidos nem resistentes.

FARDIS \& KHALILI (1981) observaram que os PRF podem ser utilizados com as fibras orientadas na direção transversal para promover o confinamento passivo do concreto e na direção longitudinal para a absorção de esforços de flexão e aumentar a rigidez à flexão do pilar. Segundo os autores, com o aumento da rigidez à flexão, melhora ainda o comportamento com relação à instabilidade. O principal objetivo dos autores era desenvolver elementos híbridos de PRF preenchidos com concreto que, segundo os autores, possibilitavam economias com fôrmas e com automatização da construção.

O primeiro trabalho publicado no Brasil sobre encamisamento de concreto com PRF foi o de HOWIE et al. (1996), onde os autores observaram a importância da arquitetura da camisa no desempenho do reforço de pilares com PRF.

A partir de então se seguiram diversas pesquisas em todo o mundo sobre o assunto. A maior parte dos ensaios observados na literatura foi realizada com cilindros de concreto - usualmente corpos-de-prova - encamisados com PRF e submetidos à compressão axial centrada.

Em menor número, porém, foram realizados ensaios de pilares, armados ou não, com diferentes formas de seção transversal. Há, ainda, alguns relatos de ensaios de pilares de concreto confinados submetidos à flexo-compressão. 


\subsection{Cilindros de concreto}

O termo "cilindros de concreto" foi definido por DE LOREZINS \& TEPFERS (2001) como elementos cilíndricos de concreto de pequenas dimensões sem armaduras. Segundo os autores a maior parte dos ensaios foi realizada com corpos-de-prova cilíndricos de concreto de $10 \mathrm{~cm}$ x $20 \mathrm{~cm}$ e $15 \mathrm{~cm}$ x $30 \mathrm{~cm}$.

\subsubsection{Comportamento tensão $x$ deformação em pilares circulares}

$\mathrm{O}$ comportamento tensão $\mathrm{x}$ deformação axial do concreto confinado com PRF em pilares circulares é predominantemente bi-linear, como indica a Figura 4.1. O diagrama tensão x deformação segue basicamente o comportamento de corpos-de-prova de concreto não confinado até um valor próximo de $\mathrm{f}_{\mathrm{co}}$. Após uma fase de transição, a rigidez axial praticamente se estabiliza num segundo trecho linear, sendo função basicamente da rigidez lateral da camisa $\left(\mathrm{E}_{\mathrm{l}}\right)$ e das propriedades do concreto.

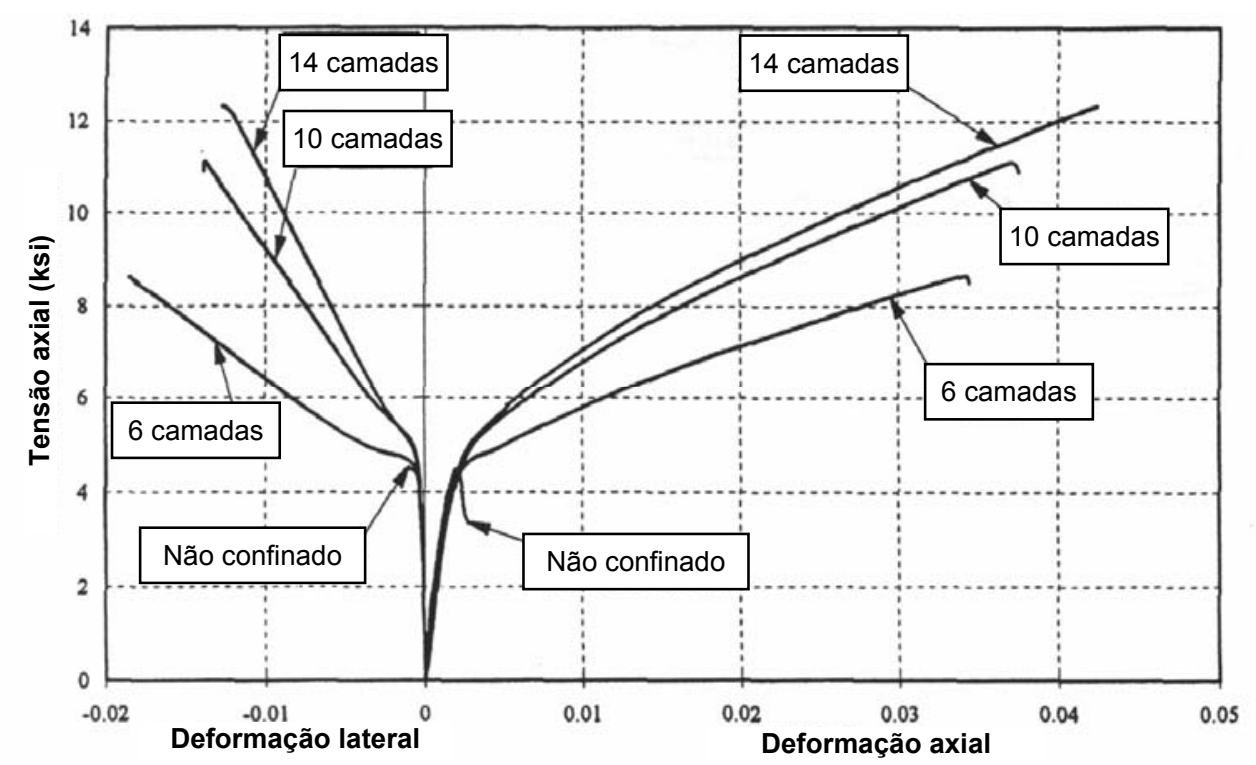

Figura 4.1 - Deformabilidade do concreto confinado (MIRMIRAN \& SHAHAWI, 1997)

Algumas diferenças com relação a estes diagramas podem ser observadas nos casos de camisas de espessura muito pequena ou muito pouco rígidas, que, por apresentar baixo grau de restrição lateral, não possibilitam a ocorrência de um segundo trecho linear ascendente, ocorrendo uma curva descendente logo após ser atingida uma resistência igual ou ligeiramente superior à do concreto não confinado.

Deve-se observar ainda que, no caso de serem utilizadas camisas bastante rígidas, pode ocorrer um prolongamento do primeiro trecho linear, ou um trecho de 
transição entre os dois trechos lineares (Figura 4.1) mais prolongado, no entanto, com características semelhantes às explicadas anteriormente.

\subsubsection{Envoltórias de ruptura}

As primeiras tentativas de análise teórica do efeito de confinamento com PRF foram realizadas com modelos teóricos modificados, desenvolvidos originalmente para confinamento com armaduras transversais de aço. No entanto, alguns pesquisadores como SAMAAN et al. (1998) e SAAFI et al. (1999) observaram que o aumento de resistência do concreto confinado com PRF era estimado para mais com os modelos teóricos desenvolvidos para camisas de aço.

Surgiu, a partir daí, um número significativo de modelos teóricos de confinamento para cilindros de concreto com PRF, normalmente empíricos e calibrados em função de alguns poucos resultados de ensaios. Na Tabela 4.1 são apresentadas as equações propostas por diversos autores para a avaliação da resistência do concreto confinado. Pode-se notar que estas são normalmente funções da variável $\mathrm{f}_{1} / \mathrm{f}_{\mathrm{co}}$, que é a pressão lateral normalizada com relação à resistência do concreto.

A pressão lateral $\left(f_{1}\right)$ em pilares circulares encamisados com PRF pode ser calculada por meio da equação:

$$
f_{l}=\frac{2 \cdot n \cdot t_{f} \cdot E_{f}}{D} \cdot \varepsilon_{f}
$$

onde:

- $\mathrm{n}$ é o número de camadas de PRF aplicadas;

- $t_{\mathrm{f}}$ é a espessura de cada camada de PRF aplicada;

- $\mathrm{E}_{\mathrm{f}}$ é o módulo de elasticidade do PRF na direção de confinamento;

- D é o diâmetro do pilar circular;

- $\varepsilon_{\mathrm{f}}$ é a deformação de ruptura do PRF. 
Tabela 4.1 - Equações para avaliação da resistência do concreto confinado com PRF

\begin{tabular}{|c|c|c|c|c|c|}
\hline $\begin{array}{l}\text { Modelo } \\
\text { teórico }\end{array}$ & $\mathrm{N}^{\mathrm{o}}$ & $\mathrm{f}_{\mathrm{cc}}$ & $\begin{array}{l}\text { Modelo } \\
\text { teórico }\end{array}$ & $\mathrm{N}^{\mathrm{o}}$ & $\mathrm{f}_{\mathrm{cc}}$ \\
\hline $\begin{array}{c}\text { FARDIS \& } \\
\text { KHALILI (1981) }\end{array}$ & 1 & $\begin{array}{l}\frac{f_{c c}}{f_{c o}}=1+4,1 \cdot \frac{f_{\mathrm{l}}}{f_{c o}}\left(f_{c o}=30 \mathrm{MPa}\right) \\
\frac{f_{c c}}{f_{c o}}=1+3,7 \cdot\left(\frac{f_{\mathrm{I}}}{f_{c o}}\right)^{0,86}\left(f_{c o}=50 \mathrm{MPa}\right)\end{array}$ & $\begin{array}{l}\text { TOUTANJI } \\
\text { (1999) }\end{array}$ & 5 & $\frac{f_{c c}}{f_{c o}}=1+3,5 \cdot\left(\frac{f_{l}}{f_{c o}}\right)^{0,85}$ \\
\hline $\begin{array}{l}\text { MIYAUCHI et al., } \\
\text { (1997) }\end{array}$ & 2 & $\frac{f_{c c}}{f_{c o}}=1+3,485 \cdot \frac{f_{l}}{f_{c o}}$ & $\begin{array}{l}\text { SAAFI et al., } \\
\text { (1999) }\end{array}$ & 6 & $\frac{f_{c c}}{f_{c o}}=1+2,2 \cdot\left(\frac{f_{I}}{f_{c o}}\right)^{0,84}$ \\
\hline $\begin{array}{l}\text { KONO et al. }{ }^{2}, \\
\quad(1998)^{*}\end{array}$ & 3 & $\frac{f_{c c}}{f_{c o}}=1+0,0572 \cdot f_{l}$ & $\begin{array}{c}\text { SPOELSTRA } \\
\& \\
\text { MONTI (1999) }\end{array}$ & 7 & $\frac{f_{c c}}{f_{c o}}=0,2+3\left(\frac{f_{1}}{f_{c o}}\right)^{0,5}$ \\
\hline $\begin{array}{l}\text { SAAMAN et al., } \\
\text { (1998) }\end{array}$ & 4 & $\frac{f_{c c}}{f_{c o}}=1+6,0 \cdot \frac{f_{1}^{0,7}}{f_{c o}}$ & $\begin{array}{l}\text { MANDER } e t \\
\text { al. } \\
(1988)\end{array}$ & 8 & $\frac{f_{c c}}{f_{c o}}=-1,254+2,254\left(1+7,94 \frac{f_{1}}{f_{c o}}\right)^{0,5}-2 \frac{f_{1}}{f_{c o}}$ \\
\hline \multicolumn{3}{|c|}{ Equações adicionais } & \multicolumn{2}{|c|}{$E_{1}=\frac{2 \cdot t_{f} \cdot E_{f}}{D}$} & Pressão lateral: \\
\hline \multicolumn{3}{|c|}{ Demais variáveis: } & \multicolumn{3}{|c|}{$\mathrm{f}_{\mathrm{co}}=$ resistência do concreto não confinado } \\
\hline \multicolumn{3}{|c|}{$t_{\mathrm{f}}=$ espessura da camisa de PRF } & \multicolumn{3}{|c|}{$\varepsilon_{\mathrm{f}}=$ deformação transversal no PRF } \\
\hline \multicolumn{3}{|c|}{$\mathrm{E}_{\mathrm{f}}=$ módulo de elasticidade do PRF } & \multicolumn{3}{|c|}{$\mathrm{D}=$ diâmetro do pilar circular } \\
\hline
\end{tabular}

\subsubsection{Variabilidade das envoltórias de ruptura}

Existem grandes diferenças nas envoltórias de ruptura do concreto confinado com PRF propostas por diversos autores. Na Figura 4.2 são mostradas as envoltórias dos modelos teóricos apresentados na Tabela 4.1 para fins de comparação. Estas foram obtidas considerando uma resistência do concreto de $25 \mathrm{MPa}$.

\footnotetext{
${ }^{2}$ Kono, S.; Inazumi, M.; Kaku T. (1998). Evaluation of Confining Effects of CFRP Sheets on Reinforced Concrete Members. Proceedings of the 2nd International Conference on Composites in Infrastructure ICCI'98, 5-7 January 1998. Tucson, Arizona. pp.343-355.
} 


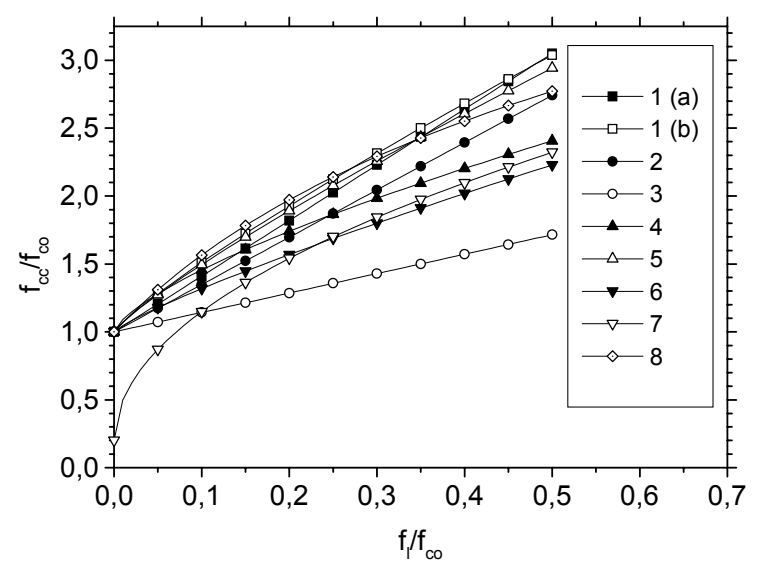

Figura 4.2 - Envoltórias de ruptura do concreto confinado (Referente à Tabela 4.1)

Como grande parte dos modelos teóricos apresentados anteriormente foi obtida utilizando resultados experimentais, algumas prováveis fontes desta variabilidade entre os modelos são as diferentes propriedades dos concretos utilizados, sendo incluídos os diferentes tipos de agregados, dosagens e classes de resistência e diferenças em dimensões de corpos-de-prova. Além disso, pela inadequada caracterização do PRF ou por falta de instrumentação da camisa nos ensaios com corpos-de-prova, ocorreram muitas vezes imprecisões na avaliação da pressão lateral. A incerteza na avaliação da pressão lateral é provavelmente a principal fonte de variabilidade nos modelos teóricos anteriormente apresentados, já que os resultados foram calibrados em função da resistência do concreto confinado $\left(\mathrm{f}_{\mathrm{cc}}\right)$ e da pressão lateral $\left(\mathrm{f}_{\mathrm{l}}\right)$.

\subsubsection{Deformação última do concreto confinado}

Segundo DE LOREZINS \& TEPFERS (2001) a deformabilidade do concreto confinado depende da história de carregamento. Parâmetros como a rigidez da camisa, tipo de agregado, tamanho, proporções da mistura e relação água/cimento são importantes e difíceis de incluir nos modelos teóricos. Os modelos teóricos analisados pelos autores não obtiveram boas estimativas para a deformação última do concreto confinado $\left(\varepsilon_{\mathrm{cc}}\right)$. 
Tabela 4.2 - Previsões dos modelos teóricos para a deformação última do concreto confinado

\begin{tabular}{|c|c|}
\hline Modelo teórico & $\varepsilon_{\mathrm{cc}}$ \\
\hline \multirow{2}{*}{ Miyauchi et al. (1997) } & $\frac{\varepsilon_{c c}}{\varepsilon_{c o}}=1+10,6 \cdot\left(\frac{f_{l}}{f_{c o}}\right)^{0,373}$ \\
\hline & $\frac{\varepsilon_{c c}}{\varepsilon_{c o}}=1+10,5 \cdot\left(\frac{f_{l}}{f_{c o}}\right)^{0,525}$ \\
\hline Kono et al. (1998) ${ }^{*}$ & $\frac{\varepsilon_{c c}}{\varepsilon_{c o}}=1+0,280 \cdot f_{l}$ \\
\hline \multirow{3}{*}{ Saaman et al. (1998) } & $\varepsilon_{c c}=\frac{f_{c c}-f_{o}}{E_{2}}$ \\
\hline & $f_{o}=0,872 \cdot f_{c o}+0,371 \cdot f_{l}+6,258$ \\
\hline & $E_{2}=245,61 \cdot f_{c o}^{0,2}+0,6728 \cdot E_{l}$ \\
\hline Toutanji (1999) & $\frac{\varepsilon_{c c}}{\varepsilon_{c o}}=1+\left(310,57 \cdot \varepsilon_{f u}+1,90\right) \cdot\left(\frac{f_{c c}}{f_{c o}}-1\right)$ \\
\hline Saafi et al. (1999) & $\frac{\varepsilon_{c c}}{\varepsilon_{c o}}=1+\left(537 \cdot \varepsilon_{f u}+2,6\right) \cdot\left(\frac{f_{c c}}{f_{c o}}-1\right)$ \\
\hline Spoelstra \& Monti (1999) & $\frac{\varepsilon_{c c}}{\varepsilon_{c o}}=2+1,25 \cdot \frac{E_{c o}}{f_{c o}} \cdot \varepsilon_{f u} \cdot \sqrt{\frac{f_{l}}{f_{c o}}}$ \\
\hline \multicolumn{2}{|c|}{ Variáveis envolvidas } \\
\hline $\begin{array}{l}\mathrm{f}_{\mathrm{cc}}=\text { resistência do concreto confinado } \\
\varepsilon_{\mathrm{cc}}=\text { deformação ultima do concreto confinado } \\
\mathrm{f}_{\mathrm{l}}=\text { pressão lateral } \\
\mathrm{E}_{1}=\text { módulo lateral ou de confinamento }\end{array}$ & \begin{tabular}{|l}
$\mathrm{f}_{\mathrm{co}}=$ resistência do concreto não confinado \\
$\varepsilon_{\mathrm{co}}=$ deformação última do concreto não confinado \\
$\varepsilon_{\mathrm{fu}}=$ deformação de ruptura da camisa \\
$\mathrm{E}_{\mathrm{co}}=$ módulo de elasticidade secante do concreto
\end{tabular} \\
\hline & *apud de LORENZIS \& TEPFERS (2001) \\
\hline
\end{tabular}

\subsubsection{Ruptura da camisa}

CARRAZEDO (2002), entre outros, observou que a ruptura da camisa de PRF à tração circunferencial normalmente se dá a uma tensão diferente da resistência à tração obtida nos ensaios de amostras do compósito segundo a ASTM D 3039 (1995). Segundo SHAHAWY et al. (2000), valores de resistência à tração mais próximos dos observados nos ensaios de pilares encamisados com PRF podem ser obtidos com ensaios de tração de anéis, conforme a ASTM D 2290 (1992).

A tensão na camisa de PRF pode ser avaliada nos ensaios de pilares circulares utilizando extensômetros orientados na direção circunferencial, desde que seja conhecido o módulo de elasticidade do compósito a partir de ensaios de caracterização. No entanto, um número limitado de ensaios utilizando esta instrumentação na camisa foi encontrado na literatura, sendo que, na maioria dos ensaios a pressão lateral foi calculada com base na resistência à tração do compósito obtida em ensaios de 
caracterização realizados conforme a ASTM D 3039 (1995) ou, de maneira menos precisa, utilizando as propriedades das fibras fornecidas pelo fabricante. Os dados fornecidos pelo fabricante normalmente se baseiam em ensaios de filamentos, que apresentam resultados bem superiores aos do compósito, pois não há influência dos vazios e da não uniformidade de tensões existente no compósito em virtude da sua micro-mecânica.

DE LOREZINS \& TEPFERS (2001) identificaram algumas variáveis responsáveis pela redução da resistência à tração da camisa de PRF em relação ao ensaio de caracterização:

- o estado triaxial de tensão em que se encontra a camisa, levando em conta o efeito da compressão no sentido longitudinal do pilar;

- o processo de fissuração do concreto e a heterogeneidade das deformações podem causar concentrações de tensões no PRF;

- a curvatura da camisa, especialmente em cantos com pequeno raio;

- a má qualidade de execução do encamisamento, que inclui o desalinhamento das fibras e a preparação inadequada da superfície;

- na aplicação de numerosas camadas de PRF as deformações medidas na face externa são menores que as observadas nas camadas interiores, levando a subestimar o valor da tensão na camisa;

- no caso de aplicação manual, com a sobreposição de numerosas camadas de PRF, a quantidade de defeitos cresce significativamente, pois defeitos ocorridos nas camadas anteriores, como a ondulação da superfície, interferem nas camadas exteriores.

Provavelmente o fator redutor dependa também do material constituinte da fibra. DE LOREZINS \& TEPFERS (2001) comentam, por exemplo, que em compósitos de fibras de aramida o fator redutor é menos severo, em função da maior tenacidade destas fibras.

A arquitetura dos tecidos empregados também tem influência na forma de ruptura da camisa. KARBHARI e GAO (1997) comentam que, por causa da presença de fibras a $45^{\circ}$ em alguns de seus ensaios, o modo de ruptura não ocorreu pela ruptura à tração das fibras, mas sim com um considerável cisalhamento e rotação dos tecidos, levando à abertura de fissuras inclinadas nos tecidos e separação entre fibras de camadas adjacentes. 
Logo, acredita-se que uma avaliação mais precisa da ruptura da camisa provavelmente seja realizada com a utilização de critérios de ruptura específicos para PRF, levando em consideração a interação de tensões e a arquitetura dos tecidos utilizados.

\subsubsection{Rigidez da camisa}

A rigidez da camisa, quantificada pela variável $\mathrm{E}_{1}$ (apresentada na Tabela 4.1) é considerada de maior importância no confinamento, já que a pressão lateral é função desta variável. Esta variável é diretamente proporcional ao módulo de elasticidade do compósito, que, por sua vez, depende do tipo de fibra. Deste modo, são necessárias mais camadas de fibras de vidro ou aramida para obter a mesma rigidez lateral de uma camisa de fibras de carbono. $\mathrm{O}$ acréscimo de muitas camadas de tecido pode se tornar anti-econômico, e até mesmo afetar negativamente as propriedades da camisa. Por este motivo a FIB (2001) recomenda que, para o ganho de resistência pelo confinamento, seja utilizada a fibra de carbono, sendo as demais indicadas para o aumento da ductilidade.

Uma outra opção mais eficiente para o aumento da capacidade resistente por meio do confinamento pode ser a utilização de fibras de carbono de alto módulo ou ultra alto módulo, que permitem significativa rigidez lateral da camisa com pequenas espessuras. WANATABE et al. (1997) recomendam a utilização de fibras de carbono de alto módulo para obter significativos ganhos de resistência pelo confinamento.

\subsection{Pilares curtos encamisados com PRF}

\subsubsection{Influência da taxa de armadura transversal pré-existente}

CARRAZEDO (2002) observou que em pilares de seção circular com diferentes taxas de armadura transversal ocorreu uma soma dos efeitos de confinamento considerando as armaduras internas (pré-existentes) e a camisa. Observou uma pequena interação das variáveis número de camadas de compósito (n) e taxa de armadura transversal $\left(\rho_{\mathrm{s}}\right)$, e que a importância relativa de $\mathrm{n}$ foi maior que a de $\rho_{\mathrm{s}} \mathrm{n}$ a resistência dos pilares. Observou ainda que para valores fixos de $\rho_{\mathrm{s}}$ ocorreram importantes ganhos de resistência normalizada com o acréscimo de $n$, para todos valores de $\rho_{\mathrm{s}}$ utilizados. Nesse trabalho foi denominada resistência normalizada o valor obtido com a tensão última na área bruta de concreto do pilar dividida pela resistência do concreto. 
Com relação à deformação última do concreto, CARRAZEDO (2002) observou uma grande interação das variáveis $\mathrm{n}$ e $\rho_{\mathrm{s}}$. Com as menores taxas de armadura transversal ( 0 e $1 \%)$ o aumento de $n$ causou um grande acréscimo de deformação última. Porém no modelo com $\rho_{\mathrm{s}}=2 \%$ o aumento de $\mathrm{n}$ praticamente não alterou a deformação última. Concluiu que apenas uma das duas variáveis com um valor elevado é suficiente para garantir uma elevada deformação última.

CARRAZEDO (2002) observou que aparentemente não houve influência de $n$ na deformação de ruptura da camisa. No entanto, com o aumento de $\rho_{\mathrm{s}}$, a deformação de ruptura da camisa diminuiu. Porém não foram realizados ensaios suficientes para afirmar com certeza que a redução da deformação de ruptura da camisa estava fortemente associada ao aumento de $\rho_{\mathrm{s}}$.

\subsubsection{Efetividade do confinamento}

Há diversos fatores que podem influenciar a efetividade do confinamento com PRF em pilares curtos de concreto armado. Entre estes se pode citar a forma da seção transversal, o raio de arredondamento dos cantos e a excentricidade do carregamento.

COLE \& BELARBI (2001) observaram que se o concreto é bem confinado, a inclinação no trecho regido pelo efeito de confinamento (segundo trecho linear) é positiva, indicando que a pressão lateral é suficiente para combater a deterioração do concreto. Se o concreto não é bem confinado, a pressão lateral não é suficiente para superar a degradação do concreto e o diagrama pode ser descendente.

\subsubsection{Forma da seção transversal}

Um dos principais fatores redutores da eficiência do confinamento é a forma da seção transversal. Em seções diferentes da circular, a pequena rigidez à flexão da camisa de PRF permite grandes reduções da pressão lateral em trechos retos. Isto é compreensível, pois ao se considerar apenas a rigidez de membrana da camisa é necessária uma curvatura da camisa para que esta contraponha carregamentos transversais a seu plano médio. Logo, nos trechos retos, as camisas usualmente empregadas praticamente não aplicam pressão lateral sobre o concreto, por causa da pequena espessura.

TENG \& LAN (2003) realizaram ensaios com pilares de seção transversal circular e elíptica. Para os pilares de seção elíptica foram utilizadas diferentes relações $\mathrm{a} / \mathrm{b}$, sendo a o maior raio da elipse e b o menor raio da elipse. Os autores observaram importantes ganhos de resistência e ductilidade mesmo em seções elípticas mais 
alongadas, como no caso de $\mathrm{a} / \mathrm{b}=5 / 2$, em que ocorreu um ganho de $38 \%$ de resistência do pilar encamisado em relação ao pilar de referência.

TENG \& LAN (2003) observaram que as deformações de tração da camisa medidas nos eixos maiores (ponto 1 da Figura 4.3) mostraram-se sempre inferiores às medidas nos eixos menores (ponto 2 da Figura 4.3), porém a ruptura ocorreu nos eixos maiores. A explicação dada pelos autores é que nos eixos maiores, a maior curvatura faz com que a resistência da camisa seja reduzida e que, já que a instrumentação foi utilizada apenas na face exterior da camisa, o efeito de flexão da camisa estava sobreposto nesta leitura. Este efeito de flexão causou a redução da deformação na face externa da camisa nos eixos maiores (ponto 1) e o aumento desta deformação nos eixos menores (ponto 2).

Para os pilares com altas relações a/b e com pequenas quantidades de PRF, o diagrama tensão x deformação apresentou um segundo trecho descendente, que indica o reduzido efeito de confinamento.

Os autores sugerem a utilização de um fator redutor da pressão lateral dependente da relação a/b, como mostra a Figura 4.3.

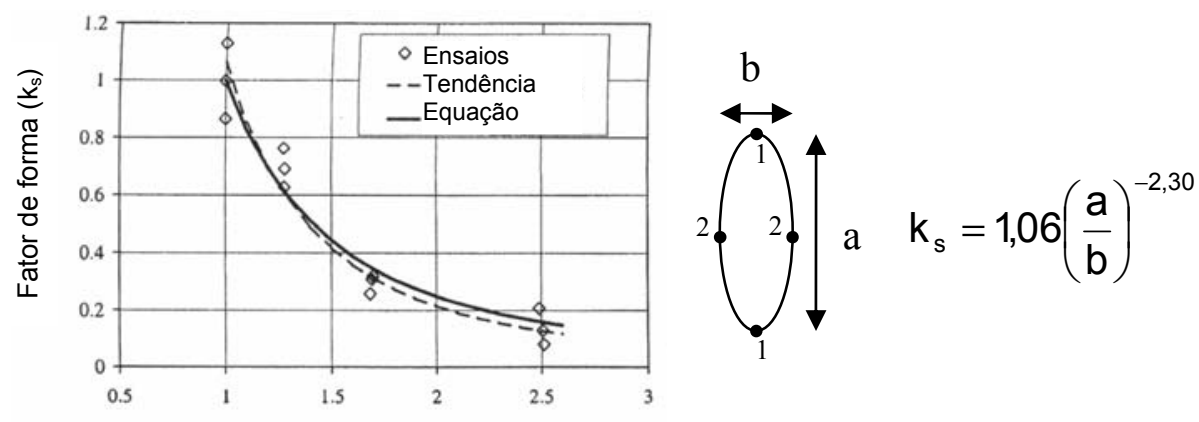

Figura 4.3 - Variação de $k_{\mathrm{s}} \operatorname{com} \mathbf{a} / \mathbf{b}$

A deformação axial de pico do concreto confinado foi relacionada por TENG \& LAN (2003) a uma variável que denominam de taxa efetiva de confinamento $\left(\mathrm{k}_{\mathrm{s}} \mathrm{f}_{\mathrm{l}} / \mathrm{f}_{\mathrm{co}}\right)$. Entre os pilares ensaiados, aqueles com $\mathrm{k}_{\mathrm{s}} \mathrm{f}_{1} / \mathrm{f}_{\mathrm{co}} \leq 0,11$ apresentaram diagrama tensão $\mathrm{x}$ deformação com o segundo trecho descendente. Nos demais pilares a deformação axial de pico do concreto foi também a última, e aumentou com a taxa efetiva de confinamento.

Nos ensaios de SHEHATA et al. (2001) foi possível observar a redução da efetividade do confinamento em função da forma da seção transversal, comparando pilares de seções transversais circulares, quadradas e retangulares. Todos os pilares 
tinham $300 \mathrm{~mm}$ de comprimento. Os pilares circulares possuíam $150 \mathrm{~mm}$ de diâmetro, os quadrados $150 \mathrm{~mm}$ de lado e o retangulares 188 x $100 \mathrm{~mm}$ de lado, e o raio de arredondamento empregado nos cantos foi de $1 \mathrm{~cm}$.

A efetividade do confinamento foi máxima para pilares circulares e mínima para os retangulares. Os diagramas tensão x deformação são apresentados na Figura 4.4. A nomenclatura apresentada indica inicialmente a direção da deformação (longitudinal ou lateral) seguida do número de camadas de PRFC (após a letra w).
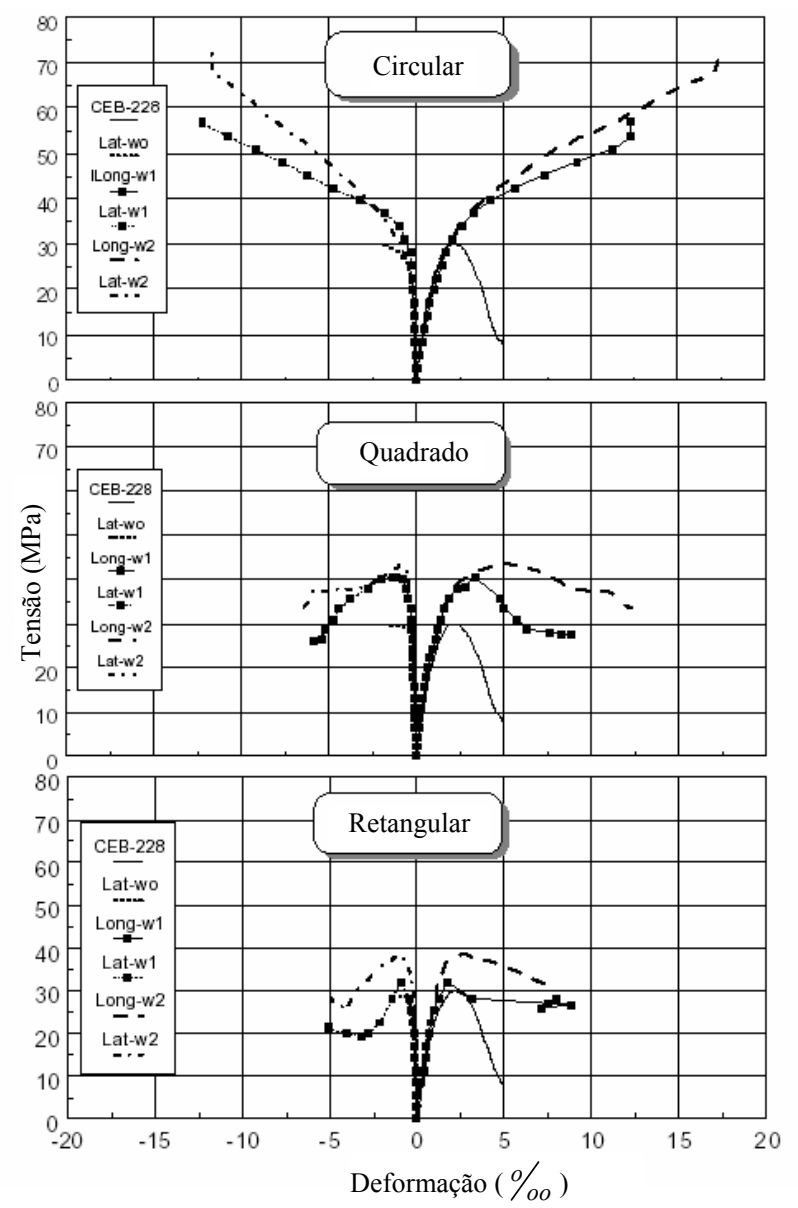

Figura 4.4 - Diagramas tensão x deformação do concreto confinado em pilares com diferentes seções transversais (SHEHATA et al., 2001)

SHEHATA et al. (2001) isolaram um coeficiente de efetividade do confinamento em função da forma da seção transversal. Para isto inicialmente obtiveram o coeficiente $\mathrm{k}_{1}$ a partir dos resultados dos pilares circulares. Estimaram então a pressão lateral dos pilares quadrados e retangulares utilizando equacionamento semelhante ao dos pilares circulares. Assim obtiveram: 


$$
k_{1} \cdot k_{e}=\frac{\left(f_{c c}-f_{c o}\right)}{f_{1}}
$$

Como o valor de $\mathrm{k}_{1}$ já era conhecido e atribuído a uma propriedade do material, os autores puderam estimar coeficientes de efetividade de 0,33 para pilares de seção quadrada e de 0,16 e 0,30 para pilares de seção retangular com 1 e 2 camadas de PRF, respectivamente.

\subsubsection{Raio de arredondamento dos cantos}

CARRAZEDO (2002) observou diferentes coeficientes de efetividade em pilares de mesmas dimensões, mas com diferentes raio de arredondamento. Com um procedimento semelhante ao de SHEHATA et al. (2001) obteve um coeficiente de 0,63 para pilares de seção quadrada. A principal diferença entre os pilares ensaiados por SHEHATA et al. (2001) e CARRAZEDO (2002) era o raio de arredondamento dos cantos, de 1 e $3 \mathrm{~cm}$ respectivamente. Além disso, a diferença nos raios empregados também causou diferentes formas de ruptura. SHEHATA et al. (2001) relatou que a ruptura ocorreu nos cantos, enquanto CARRAZEDO (2002) descreveu a ruptura nas faces laterais.

MIRMIRAN et al. (1998) ensaiaram pilares de seção transversal quadrada com as mesmas dimensões de seção transversal de CARRAZEDO (2002) e SHEHATA et al. (2001), porém com um raio de arredondamento de 6,35 $\mathrm{mm}$. Nos seus ensaios houve um trecho descendente pós-pico que se estabilizou em $70 \%$ da resistência do concreto não confinado, independentemente da espessura da camisa (MIRMIRAN et al., 1998).

ROCHETTE \& LABOSSIÉRE (2000) observaram que para um número constante de camadas de tecido, o aumento do raio de arredondamento proporcionou significativos aumentos de capacidade resistente. As deformações registradas pelos extensômetros próximos aos cantos mostraram-se menores no caso de menores raios de arredondamento, indicando que os cantos com pequenos raios de curvatura são mais suscetíveis de sofrer ruptura prematura (ROCHETTE \& LABOSSIÉRE, 2000). 
Segundo MIRMIRAN et al. (1998), ROCHETTE (1996) ${ }^{3}$ considerou o raio de arredondamento como uma variável importante para definir a efetividade do confinamento. MIRMIRAN et al. (1998) então propuseram uma nova variável para medir a efetividade do confinamento, denominada relação modificada de confinamento (MCR).

$\operatorname{MCR}=\left(\frac{2 r}{D}\right) \frac{f_{1}}{f_{c o}}$

onde r é o raio de arredondamento dos cantos e $\mathrm{D}$ é o lado do pilar.

Segundo MIRMIRAN et al. (1998), a variável MCR prevê se há um trecho descendente pós-pico. Para MCR $<15 \%$ os autores sugerem que não há ganho de resistência, já que a camisa é pouco efetiva no confinamento. Esta intensidade de MCR é esperada em camisas de pequena espessura e em pilares com raios de arredondamento bem reduzidos (MIRMIRAN et al., 1998).

YANG et al. (2001) realizaram um estudo para verificar o efeito do raio de arredondamento dos cantos com relação à resistência à tração do compósito. Elaboraram um sistema de ensaio de tração do PRF que permitiu a variação do raio de arredondamento dos cantos. Observaram que a resistência à tração no PRF aumentou com o aumento do raio de arredondamento, como indica a Figura 4.5.

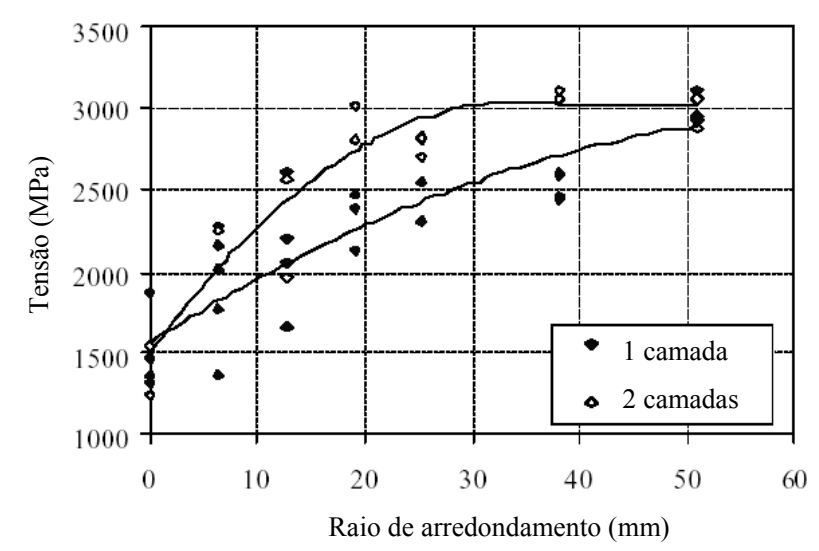

Figura 4.5 - Efeito do raio de arredondamento sobre a resistência à tração do PRFC (YANG et al., 2001)

Para o caso de menores raios de arredondamento, as maiores deformações ocorreram nos cantos, onde também ocorreu a ruptura, indicando a concentração de

${ }^{3}$ Rochette, P. (1996). Confinement of short square and rectangular columns with composite materials, MS thesis, Univ. of Sherbrooke, Quebec, Canada. 
tensões. Com o aumento do raio de arredondamento as maiores deformações passaram a ser observadas na região reta da amostra, onde ocorreu a ruptura da amostra. Além disso, a diferença nas deformações em diferentes posições foi menor para os maiores raios (YANG et al., 2001). YANG et al. (2001) observaram ainda que a utilização de múltiplas camadas pode aumentar levemente a resistência dos laminados à flexão e aumentar a performance global do encamisamento.

\subsubsection{Orientação das fibras}

ROCHETTE \& LABOSSIÉRE (2000) observaram que, em pilares encamisados com compósito bidirecional de fibras de aramida, as tensões máximas de compressão axial sempre superaram $f_{\text {co }}$. Esses pilares possuíam seção quadrada com lados de 152 $\mathrm{mm}$ e raio de arredondamento dos cantos de $25 \mathrm{~mm}$. Observaram também uma queda da tensão axial logo depois de atingida uma deformação axial de $0,3 \%$, seguida de uma retomada do crescimento a uma deformação de 0,5 a $0,7 \%$. O valor máximo local da tensão no início do carregamento aumentou com acréscimo do número de camadas, e mesmo nas situações de reforço mais leve o ganho de capacidade resistente foi da ordem de $20 \%$. Os autores atribuíram este acréscimo à contribuição das fibras orientadas na direção longitudinal (ver Figura 4.6).

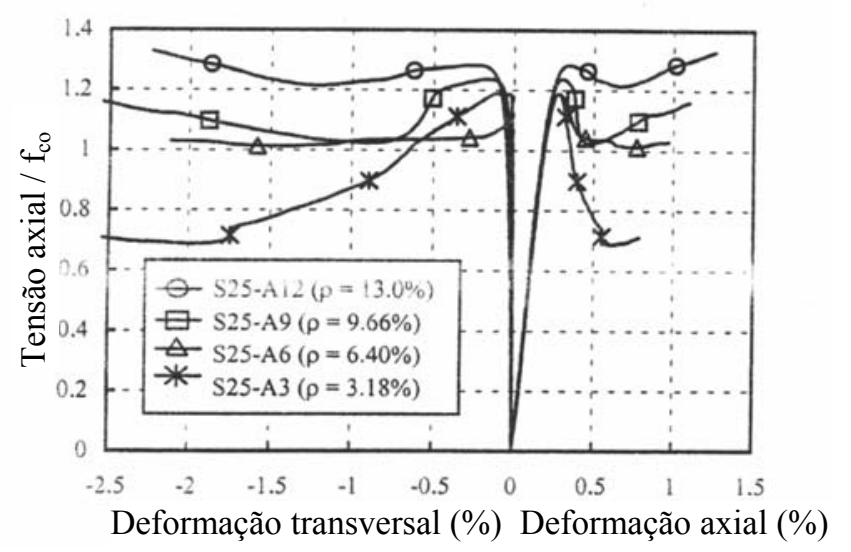

Figura 4.6 - Efeito da variação do número de camadas de tecidos

bidirecionais de aramida (ROCHETTE e LABOSSIÉRE, 2000)

Segundo CHAALLAL \& SHAHAWY (2000), a utilização de ângulos específicos para a direção das fibras na camisa, em função das tensões a que esta é submetida, levaria a uma otimização do desempenho. Porém esta alternativa não é prática para implementação. Por isto sugerem a utilização de tecidos bidirecionais em pilares com tensões multiaxiais. 
TAN (2002) sugeriram a utilização de um sistema de reforço com fibras transversais para confinamento e fibras longitudinais para absorver diretamente forças axiais. Observaram que em pilares retangulares bastante alongados (com lados de 115 mm x $420 \mathrm{~mm}$ ), aumentando a quantidade de fibras longitudinais, ocorreram aumentos de capacidade resistente e ductilidade. Entretanto, com o aumento da quantidade de fibras transversais ocorreu apenas aumento da ductilidade.

Além disso, TAN (2002) afirma que as fibras longitudinais somente foram efetivas quando envolvidas por fibras transversais. Os autores sugeriram que é possível uma otimização entre fibras longitudinais e transversais que leva a melhores resultados. MAALEJ et al. (2003) também sugerem que para pilares com alta relação entre lados o esquema de reforço esteja focado em introduzir mais fibras no sentido longitudinal do que pressão lateral.

\subsubsection{Traspasse das camadas}

Quanto à moldagem da camisa, MIRMIRAN et al. (1998) utilizou duas formas distintas para o encamisamento: envolvendo os pilares com um tecido contínuo até atingir o número de camadas necessárias, sem emendas; envolvendo os pilares com camadas individuais chegando ao mesmo número total de camadas de tecidos. Observaram que estas diferenças de moldagem praticamente não interferiram nos diagramas tensão x deformação axial e lateral dos pilares ensaiados.

\subsubsection{Aderência da camisa}

MIRMIRAN et al. (1998) construíram dois tipos de pilares, sendo no primeiro a camisa moldada inicialmente, curada e depois preenchida com concreto. No segundo tipo, foram moldados os cilindros de concreto, que, após 28 dias de cura, foram encamisados com PRF. Os autores verificaram praticamente não existir diferença no comportamento tensão $\mathrm{x}$ deformação destes pilares.

As mesmas conclusões foram obtidas por CARRAZEDO (2002), porém este comparou os diagramas de corpos-de-prova de concreto encamisados com PRF de maneira convencional (com aderência) e corpos-de-prova de concreto encamisados com isolamento entre o adesivo e o concreto por meio de um filme plástico (para eliminar a aderência). 


\subsubsection{Conceito das áreas efetivas de confinamento}

É intuitivo imaginar que pilares de seção transversal quadrada ou retangular sejam menos eficientes no confinamento passivo com PRF que os pilares circulares. Em função da baixa rigidez à flexão das camisas de PRF, as faces retas oferecem pouca restrição lateral. Com isso a distribuição de pressões laterais é muito diferente da uniforme existente nos pilares circulares, sendo maior nos cantos e menor nas faces laterais. Com base nestes aspectos alguns autores sugeriram a existência de áreas efetivas de confinamento nos pilares encamisados com PRF.

A FIB (2001) utilizou um procedimento semelhante ao modelo de confinamento de MANDER et al. (1988), para descontar as áreas inefetivas de confinamento. As áreas efetivas (hachuradas) são delimitadas por parábolas com inclinação inicial de $45^{\circ}$, incluindo as regiões dos cantos arredondados, como indica a Figura 4.7.

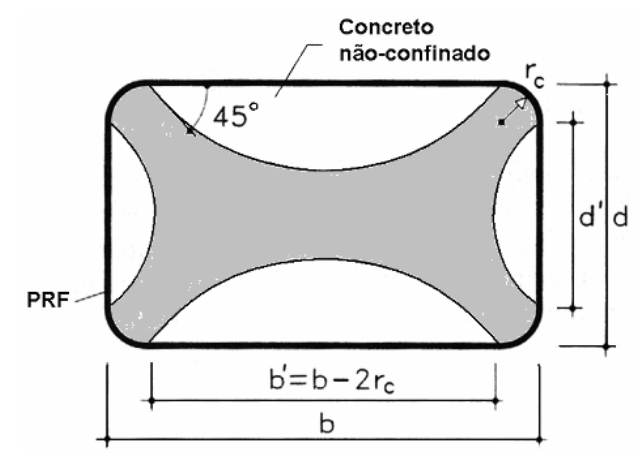

Figura 4.7 - Áreas de confinamento inefetivo (FIB, 2001)

As áreas efetivas são levadas em consideração com um coeficiente $k_{\mathrm{e}}$ que multiplica a pressão lateral, obtendo-se assim uma pressão lateral reduzida ou efetiva, dada pela equação (4.5). Este coeficiente é a relação entre a área efetivamente confinada (hachurada) e a área total da seção transversal do pilar.

$$
f_{l e}=k_{e} \cdot f_{l}
$$

Usualmente, nos pilares de seção transversal quadrada, uma pressão lateral uniforme é calculada utilizando a formulação de cálculo da pressão lateral dos pilares de seção transversal circular, apenas substituindo o diâmetro (D) pela largura da seção quadrada (h). Isto é possível porque a resultante pressão lateral é a mesma nos dois casos. 
No caso de pilares retangulares, a FIB (2001) sugere o cálculo de duas pressões laterais uniformes nas duas direções paralelas às faces, sendo estas pressões proporcionais às taxas volumétricas das fibras nestas direções.

HARRIES et al. (2003), no entanto, afirmaram que a equação das áreas efetivamente confinadas não pode ser utilizada para comparação de pilares com diferentes raios de arredondamento e não considera a rigidez à flexão do PRF, o que provocou diferenças entre as áreas efetivamente confinadas em pilares ensaiados pelos autores com 3 e 9 camadas de PRFV. Além disso, em comparações entre pilares circulares e quadrados que deveriam possuir o mesmo efeito de confinamento com a formulação anteriormente citada, esta se mostrou muito conservativa para os pilares quadrados. Por isso recomendam que estes fatores devem ser melhor investigados.

CAMPIONE e MIRAGLIA (2003) sugerem que a resistência à tração da camisa em pilares de seção quadrada deve ser dada por:

$$
f_{r}=f_{u} \cdot\left[\left(1-\frac{\sqrt{2}}{2} k_{i}\right) \frac{2 r}{b_{d}}+k_{i} \frac{\sqrt{2}}{2}\right]
$$

Onde:

- $f_{u}$ é a tensão de ruptura do PRF;

- $\mathrm{k}_{\mathrm{i}}$ é um fator redutor obtido experimentalmente para considerar a concentração de tensões, para o qual os autores sugeriram um valor de 0,2121;

Para determinar o valor da deformação última do concreto, CAMPIONE e MIRAGLIA (2003) adaptaram o balanço energético de MANDER et al. (1988), considerando o efeito do PRF. Porém os próprios autores comentaram que a deformação última calculada desta maneira mostrou-se conservativa em relação aos resultados experimentais observados na literatura.

\subsection{Comportamento na flexo-compressão}

\subsubsection{Esbeltez do pilar}

MIRMIRAN et al. (2001) observaram uma redução de $71 \%$ da capacidade resistente em pilares com índice de esbeltez de 36 em comparação a pilares curtos. As deformações axiais e laterais foram ainda mais reduzidas (redução de 85 e 87\%, respectivamente). Estes pilares foram encamisados com PRFV com fibras a $\pm 75^{\circ}$, com uma espessura total da camisa de 3,68 $\mathrm{mm}$. 
Os autores observaram ainda que a esbeltez dos pilares não influenciou significativamente a rigidez do sistema híbrido. Entretanto, reduziu consideravelmente a resistência e a deformação última dos pilares. Aumentando a esbeltez de 11 a 36 a capacidade resistente caiu de $75 \%$ para menos de $30 \%$ da capacidade resistente obtida com o pilar curto. As deformações axiais foram reduzidas de $69 \%$ para $15 \%$ e as transversais de $84 \%$ para $13 \%$ das registradas no pilar curto. Estas reduções resultaram em uma sub-utilização da resistência do concreto confinado.

MIRMIRAN et al. (2001) utilizaram uma técnica incremental para comparar as forças de flambagem de Euler com a capacidade resistente da seção transversal. Foi utilizado o modelo teórico de confinamento de SAMAAN et al. (1998) para representar o diagrama tensão $\mathrm{x}$ deformação do concreto confinado e foi considerada a contribuição das fibras na direção longitudinal. Na Figura 4.8 são apresentadas as curvas de estabilidade dos pilares com diferentes índices de esbeltez e a curva de resistência da seção transversal. Note que onde a curva de estabilidade encontrou a curva de resistência da seção transversal se obteve o limite de instabilidade.

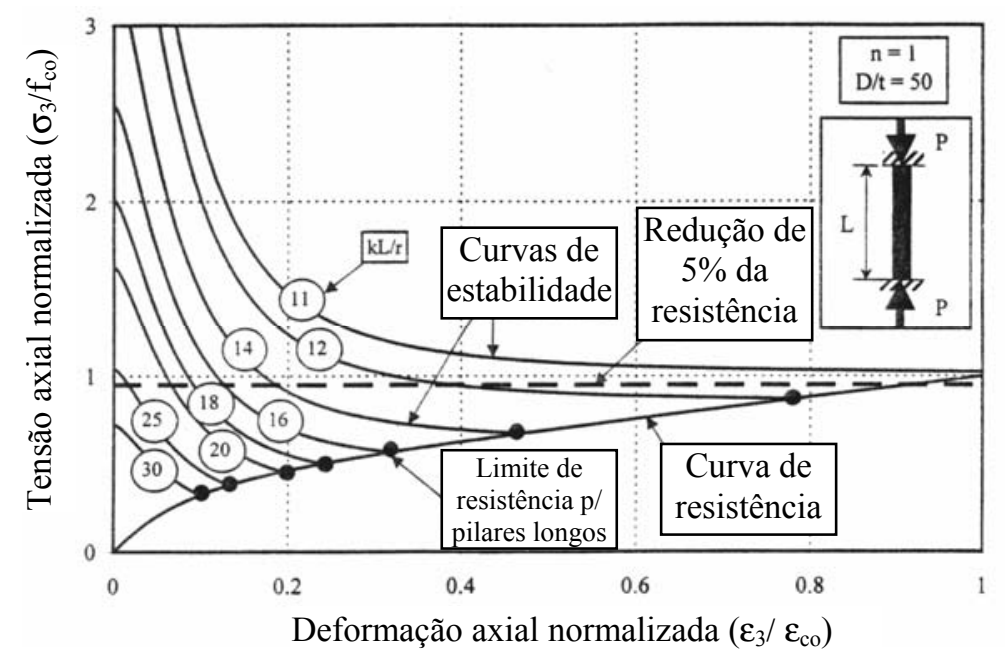

Figura 4.8 - Curvas tensão x deformação para pilares curtos e longos (MIRMIRAN et al., 2001)

MIRMIRAN et al. (2001) observaram que com o aumento do módulo de elasticidade do PRF, o limite de esbeltez e a resistência da seção aumentaram significativamente. Já o parâmetro D/t (diâmetro / espessura do tubo) não afetou tão significativamente o limite de esbeltez.

THÉRIAULT \& NEALE (2000) demonstraram também a preocupação com a instabilidade dos elementos encamisados, pois, segundo os autores, pilares classificados como curtos antes do encamisamento podem não mais o serem após o encamisamento. 
Além disso, THÉRIAULT \& NEALE (2000) sugerem que a capacidade resistente do elemento reforçado seja limitada ao dobro do elemento de referência, também para evitar problemas de instabilidade.

\subsubsection{Ensaios com forças laterais}

BOUSIAS et al. (2002) realizaram ensaios de pilares engastados em uma das extremidades e submetidos a uma força axial na extremidade livre sobreposta a ciclos de flexão por meio de uma força lateral na extremidade livre. A capacidade resistente lateral dos pilares encamisados foi aproximadamente a mesma dos modelos de referência. A força axial pôde ser mantida até o final do ensaio, após diversos ciclos, indicando o sucesso da intervenção em manter a capacidade resistente axial do pilar.

Observaram resultados semelhantes em pilares com camisas de PRFV e PRFC de igual rigidez. O acréscimo de 2 a 5 camadas de PRFC, no entanto, não trouxe muitos benefícios (BOUSIAS et al., 2002).

$\mathrm{O}$ confinamento foi muito menos efetivo nos pilares ensaiados à flexão na menor inércia. Ocorreram aumentos da deformação última nestes pilares quando encamisados, porém não houve acréscimo de capacidade resistente. A ruptura ocorreu por tração das fibras. Os autores concluíram que a técnica possibilita um pequeno acréscimo na capacidade lateral do elemento sem afetar a rigidez, o que significa poucos efeitos colaterais (BOUSIAS et al., 2002).

MIRMIRAN et al. (2000) ensaiaram pilares inicialmente carregados até o valor final da força axial e então submetidos a forças laterais, com a força axial mantida constante. Diferentes valores de força axial foram utilizados. Dois tipos de pilares foram construídos, sendo os do tipo1 produzidos com "spin-cast" de fibras a $\pm 45^{\circ}$, que em função da alta taxa volumétrica de reforço foram considerados super-armados e as do tipo 2 com "filament winding" a $\pm 55^{\circ}$ considerados sub-armados.

No pilar T1S3 (tipo 1) os momentos de segunda ordem corresponderam a 15\% do momento total. Por outro lado, no pilar T2S2 (tipo 2) o momento de segunda ordem correspondeu a $34 \%$ do momento total sob ação da força lateral máxima e a $52 \%$ do total sob ação do momento total máximo.

O momento resistente dos pilares tipo 1 foi praticamente o dobro do tipo 2 . Além disso, nos pilares do tipo 1 foram gerados menores momentos de segunda ordem. Os deslocamentos laterais foram maiores nos pilares tipo 2, em que se formaram rótulas plásticas. 
MIRMIRAN et al. (2000) observaram que a força lateral resistida pelos pilares diminuiu com o aumento da força axial. Os diagramas momento x deslocamento no meio do vão apresentaram curvas bi-lineares, sendo que o primeiro trecho dependeu basicamente das propriedades do concreto e o segundo das propriedades do tubo. A transição entre os trechos lineares representou a fissuração do concreto. A inclinação do segundo trecho foi bem maior no pilar do tipo 1 em função da maior rigidez. Segundo MIRMIRAN et al. (2000), é melhor projetar os tubos com elevadas taxas volumétricas porque as seções sofrem menores deflexões, e rompem a forças mais elevadas. Além disso, os efeitos de segunda ordem são menores nestes casos.

\subsubsection{Ensaios de flexo-compressão}

PARVIN \& WANG (2001) realizaram ensaios de pilares de seção quadrada de $108 \mathrm{~mm}$ de lado e $305 \mathrm{~mm}$ de comprimento encamisados com 0,1 e 2 camadas de PRFC e submetidos à flexo-compressão reta com excentricidades dentro do núcleo central de inércia $(0,7,6$ e 15,2 mm). Utilizaram concreto de 21,4 $\mathrm{MPa}$ de resistência à compressão. Os cantos foram arredondados com raio de 8,26 mm. Na base dos pilares foi utilizada uma placa de aço e um bloco em $\mathrm{V}$ para possibilitar a aplicação da excentricidade e vinculação de rótula nesta extremidade.

A Figura 4.9 apresenta os diagramas força $\mathrm{x}$ deslocamento axial dos pilares ensaiados. Mesmo na presença de força excêntrica foram observados importantes acréscimos de capacidade resistente e ductilidade.

Os autores implementaram uma simulação numérica utilizando o critério de plastificação de MOHR-COULOMB com encruamento isótropo para representar o concreto confinado e modelaram a camisa de PRF com elementos de casca tridimensionais, com as propriedades elásticas obtidas nos ensaios de caracterização. A interação entre o concreto e a camisa foi simulada utilizando elementos de contato assumindo-se perfeita aderência entre os dois materiais, com grande valor de força de separação entre estes. Os resultados obtidos são apresentados na Figura 4.9. 


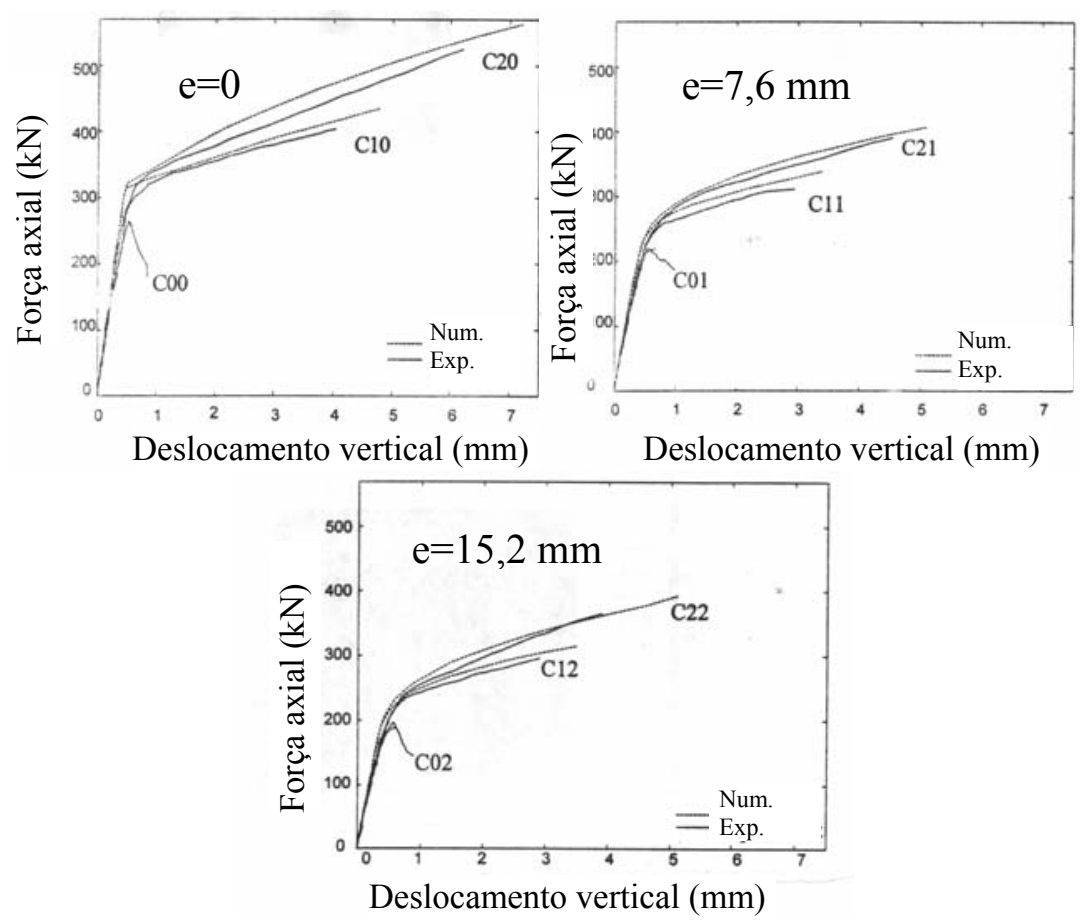

Figura 4.9 - Diagramas força x deslocamento (PARVIN \& WANG, 2001)

As simulações numéricas de PARVIN \& WANG (2001) mostraram as distribuições de tensões axiais nos modelos com compressão centrada e excêntrica. Nos pilares sob compressão centrada a área efetivamente confinada concentrou-se no núcleo e nos cantos da seção transversal. Nos pilares com compressão excêntrica a área efetivamente confinada deslocou-se para o lado de maior compressão por causa do gradiente de deformações, como indica ilustrativamente a Figura 4.10.

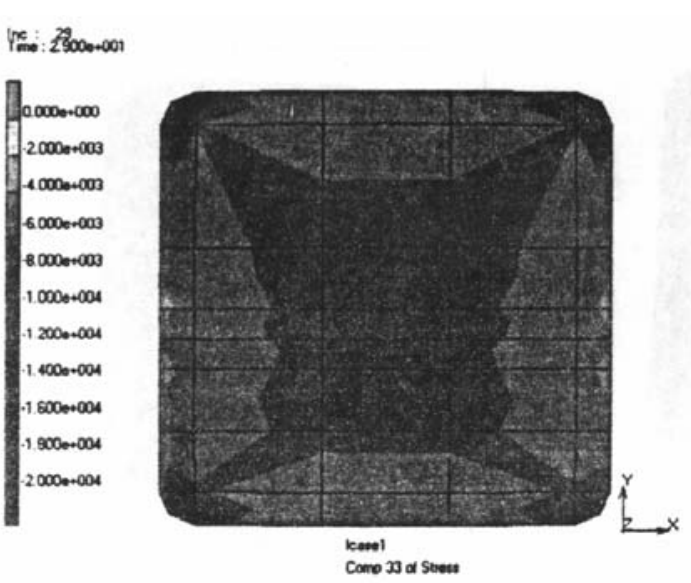

(a)

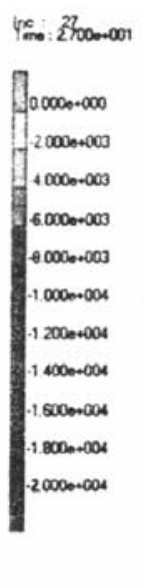

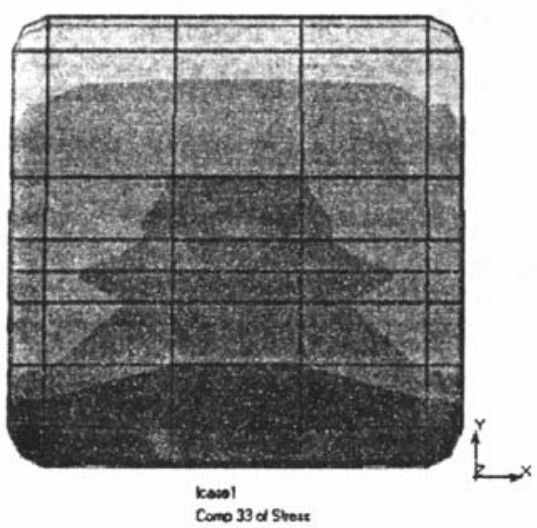

(b)

Figura 4.10 - Distribuição de tensões axiais em pilares encamisados com a camada de PRFC

(a) compressão centrada (C10) (b) compressão excêntrica (C11) (PARVIN \& WANG, 2001) 
Os autores concluíram que a camisa de PRFC pode aumentar significativamente a capacidade resistente e a ductilidade de pilares sob compressão excêntrica. O gradiente das deformações reduziu a eficiência do confinamento, de modo que um menor ganho de resistência deve ser considerado. A rigidez da camisa é um parâmetro importante para a eficiência do reforço. Uma camisa mais rígida controla melhor as deformações transversais e resulta em maior deformabilidade.

PARVIN \& WANG (2001) recomendam pesquisas futuras semelhantes a essa, porém com dimensões mais próximas da escala real. Segundo os autores, os efeitos da excentricidade em diferentes seções transversal, de diferentes tipos de PRF e de pilares de concretos de alta resistência também merecem ser investigados (PARVIN \& WANG, 2001).

CHAALLAL \& SHAHAWY (2000) ensaiaram pilares de seção retangular (203 x $356 \mathrm{~mm}$ ) de concreto armado com 3,6 m de comprimento encamisados com 2 camadas de tecidos bidirecionais de PRFC. A resistência do concreto foi de $21 \mathrm{MPa}$ e os pilares tiveram os cantos arredondados com $25,4 \mathrm{~mm}$ de raio. A força foi aplicada com excentricidade na maior inércia dos pilares, por meio de consolos. O ganho máximo de capacidade resistente foi de $30 \%$ na compressão pura e de $54 \%$ na flexão pura. Em solicitações combinadas de compressão e flexão o acréscimo de capacidade resistente atingiu $70 \%$. O aumento da deformação de compressão em função do confinamento foi entre 49 e $166 \%$.

Para a previsão da capacidade resistente dos pilares foram elaborados diagramas de iteração com diferentes distribuições de deformações, calculando os respectivos valores de força axial (P) e momento (M). 


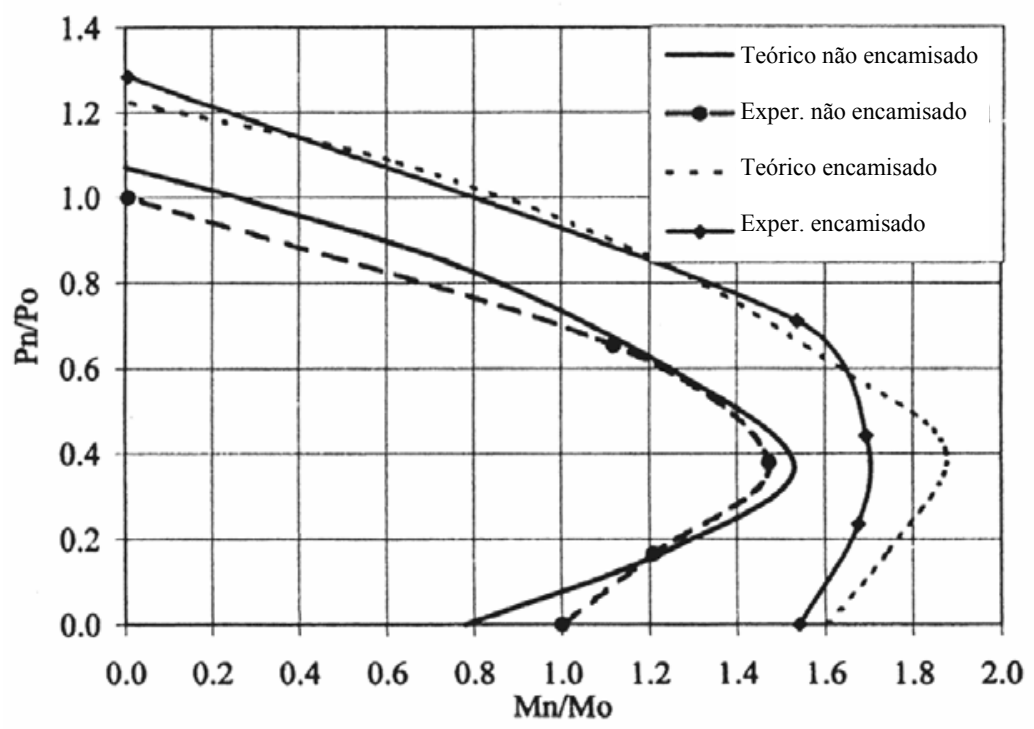

Figura 4.11 - Diagramas de interação dos pilares com e sem encamisamento (CHAALLAL \& SHAHAWY, 2000)

Nos pilares encamisados submetidos à flexo-compressão, a ruína ocorreu por esmagamento do concreto nos cantos das faces comprimidas e por ruptura à tração dos tecidos nas faces tracionadas. No pilar sob flexão pura ocorreu apenas a ruptura da camisa na face tracionada (CHAALLAL \& SHAHAWY, 2000).

Foram também observadas as deformações transversais da camisa nas regiões comprimidas. Nos diagramas momento total $\mathrm{x}$ deformação transversal observou-se deformações transversais logo no início do carregamento. Nos pilares com menor excentricidade as deformações transversais foram maiores no início do ensaio, em função da maior área confinada. Como a linha neutra estava mais profunda os pilares apresentaram maior força axial para o momento aplicado. A face mais comprimida apresentou as maiores deformações transversais, enquanto na face tracionada não foram observadas deformações transversais. Nos extensômetros transversais colados nas maiores faces as deformações foram de compressão ou tração, dependendo da posição da linha neutra. Dos ensaios observou-se que o concreto nas regiões comprimidas foi efetivamente confinado, a julgar pelas grandes deformações longitudinais e transversais na face comprimida (CHAALLAL \& SHAHAWY, 2000). 


\section{Análise Experimental}

A análise experimental envolveu ensaios de caracterização mecânica do concreto e dos polímeros reforçados com fibras de carbono (PRFC), ensaios de modelos de pilares de concreto sob compressão centrada e principalmente ensaios de modelos de pilares sob flexo-compressão.

\subsection{Materiais e métodos}

\subsubsection{Concreto}

Utilizou-se areia quartzosa natural como agregado miúdo e pedra britada $n^{\circ} 1$ de origem basáltica como agregado graúdo. Os traços unitários em massa dos concretos utilizados estão indicados na Tabela 5.1. A mistura foi realizada em uma betoneira de eixo vertical com capacidade de 200 litros. A cura foi realizada em câmara úmida por 7 dias.

Tabela 5.1 - Traços unitários em massa dos concretos utilizados

\begin{tabular}{ccc}
\hline Material & $\begin{array}{c}\text { Traço unitário em massa (kg) } \\
\text { Séries 1 a 4 }\end{array}$ & $\begin{array}{c}\text { Traço unitário em massa (kg) } \\
\text { Série 5 }\end{array}$ \\
\hline Cimento CP V - ARI - Ciminas & 1,000 & 1,000 \\
Areia natural & 2,947 & 4,3 \\
Pedra britada $n^{\circ} 1$ & 3,5 & 4,7 \\
Água & 0,70 & 0,85 \\
\hline
\end{tabular}

Os ensaios de compressão axial e diametral de corpos-de-prova de concreto para controle de resistência e os ensaios para avaliação do módulo de elasticidade foram realizados com controle de força em uma máquina hidráulica eletrônica da marca ELE, modelo AUTOTEST 2000, com capacidade de $2000 \mathrm{kN}$. Foram utilizados extensômetros removíveis à base de extensômetros elétricos de resistência da marca MSI, com curso de $15 \mathrm{~mm}$ e base de leitura de $100 \mathrm{~mm}$ nos ensaios de compressão axial, como mostra a Figura 5.1 - a. Os extensômetros foram instalados diametralmente opostos e retirados a aproximadamente $70 \%$ da resistência do concreto no trecho ascendente do diagrama tensão $\mathrm{x}$ deformação para evitar danos. Nos ensaios de 
compressão axial foi utilizado controle de força com uma taxa de carregamento de 2,4 $\mathrm{kN} / \mathrm{s}$.

Para obter o diagrama tensão $\mathrm{x}$ deformação axial completo do concreto, foram ensaiados alguns corpos-de-prova de cada série com controle de deslocamento na máquina universal INSTRON modelo 8506, utilizando uma taxa de deformação de $5.10^{-5} / \mathrm{s}$. Nestes ensaios obteve-se a curva tensão x deformação completa com leituras de dois extensômetros removíveis (semelhantes aos anteriores) e dois transdutores de deslocamento posicionados entre os pratos da máquina de ensaio, diametralmente opostos, como indica a Figura 5.1 - b.

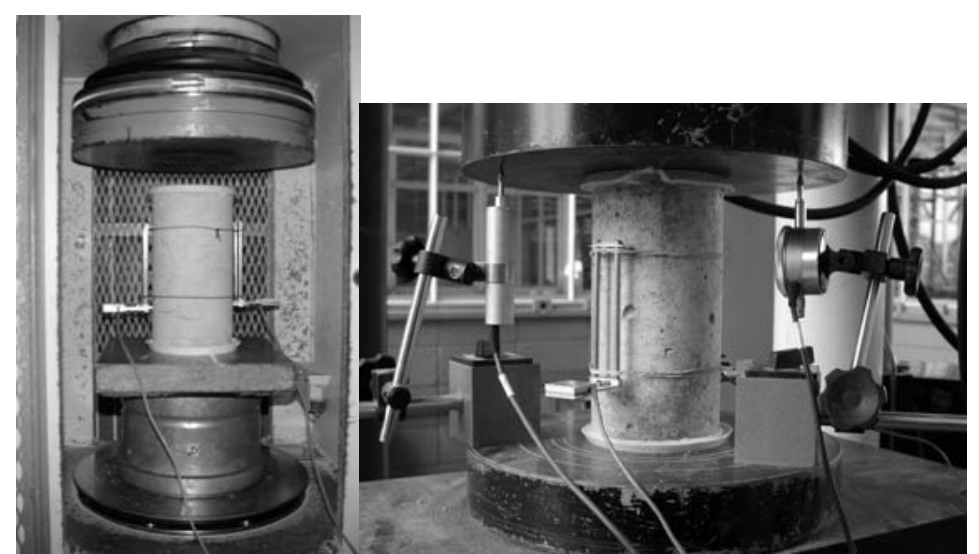

(a)

(b)

Figura 5.1 - Instrumentação utilizada nos ensaios de corpos-de-prova de concreto

A evolução da resistência à compressão axial dos corpos-de-prova cilíndricos (de $10 \times 20 \mathrm{~cm}$ ) em função da idade é apresentada na Tabela 5.2. Como se pode observar, ocorreu uma boa correspondência da resistência à compressão entre as séries 1 a 4, que utilizaram a mesma dosagem de concreto. A série 5 apresentou uma resistência inferior às demais séries justamente para verificar a influência da resistência do concreto. 
Tabela 5.2 - Resistência à compressão axial obtida com corpos-de-prova cilíndricos de 10 x $20 \mathrm{~cm}$

\begin{tabular}{|c|c|c|c|c|c|c|c|c|c|c|c|}
\hline \multicolumn{6}{|c|}{ Série } & \multicolumn{6}{|c|}{ Série } \\
\hline Idade(dias) & S1 & S2 & S3 & S4 & S5 & Idade(dias) & S1 & S2 & S3 & S4 & S5 \\
\hline 7 & 34,65 & 34,88 & 32,65 & 35,00 & 22,82 & 34 & & 42,25 & & & \\
\hline 7 & 33,06 & 33,00 & 34,91 & 33,14 & 24,37 & 34 & & 43,10 & & & \\
\hline 7 & 33,50 & 32,82 & 34,64 & 36,32 & & 34 & & & & 39,90 & \\
\hline 14 & 40,44 & 42,77 & 41,76 & & & 34 & & & & 37,40 & \\
\hline 14 & 41,56 & 40,68 & 41,43 & & & 36 & 43,77 & & & & \\
\hline 14 & 41,95 & 40,19 & 39,39 & & & 36 & 43,70 & & & & \\
\hline 23 & & & & 40,51 & & 38 & & & & & 30,50 \\
\hline 23 & & & & 39,36 & & 38 & & & & & 32,70 \\
\hline 23 & & & & 45,70 & & 39 & & & & & 29,60 \\
\hline 30 & & & 46,66 & & & 39 & & & & & 32,00 \\
\hline 30 & & & 45,99 & & & 41 & & & 43,58 & & \\
\hline 31 & 44,02 & & & & & 41 & & & 45,38 & & \\
\hline 31 & 44,84 & & & & & 48 & & & 43,40 & & \\
\hline 31 & 43,52 & & & & & 52 & & 40,20 & & & \\
\hline 32 & & & & 39,76 & & 52 & & 44,40 & & & \\
\hline 32 & & & & 40,25 & & 54 & 40,90 & & & & \\
\hline 32 & & & & 40,45 & & 54 & 41,20 & & & & \\
\hline
\end{tabular}

$\mathrm{Na}$ Figura 5.2 são apresentadas as resistências dos concretos obtidas nas diferentes séries. Pode-se verificar uma boa correspondência entre as séries 1 a 4 .

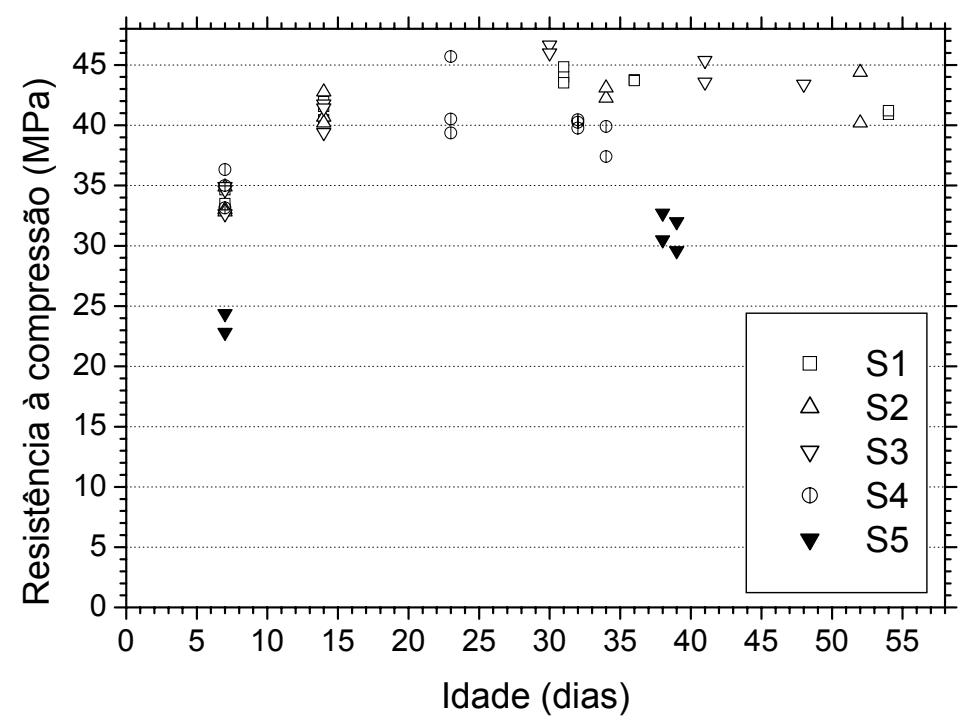

Figura 5.2 - Crescimento da resistência com a idade para as diferentes séries

Os ensaios dos pilares foram realizados em idades próximas aos 28 dias como indicado na Tabela 5.3 e esquematicamente na Figura 5.3. 
Tabela 5.3 - Idade de ensaio das diferentes séries

\begin{tabular}{|c|c|c|c|c|}
\hline \multicolumn{5}{|l|}{ Série 1} \\
\hline Idade (dias) & 28 & 29 & 30 & 33 \\
\hline Pilar & So0r1 & S10r1 & S20r1 & $\begin{array}{l}\text { S20r1; S20r1; S20r1; } \\
\text { S20r1; S20r1; S20r1; }\end{array}$ \\
\hline \multicolumn{5}{|l|}{ Série 2} \\
\hline Idade (dias) & 32 & 33 & 34 & \\
\hline Pilar & $\begin{array}{l}\text { S11r3; S11r3b; } \\
\text { S01r3 }\end{array}$ & S02r3; S21r3 & $\begin{array}{l}\text { s00r3; S20r3; } \\
\text { S10r3; S22r3; }\end{array}$ & \\
\hline \multicolumn{5}{|l|}{ Série 3} \\
\hline Idade (dias) & \multirow{2}{*}{\multicolumn{2}{|c|}{$\begin{array}{c}38 \\
\text { C00; C02; C10; } \\
\text { C12; C20; C22; }\end{array}$}} & & \\
\hline Pilar & & & & \\
\hline \multicolumn{5}{|l|}{ Série 4} \\
\hline Idade (dias) & \multicolumn{2}{|c|}{35} & \multicolumn{2}{|c|}{37} \\
\hline Pilar & \multicolumn{2}{|c|}{ R00; ROX3; ROY2; } & \multicolumn{2}{|c|}{ R20; R2X3; R2Y2; } \\
\hline \multicolumn{5}{|l|}{ Série 5} \\
\hline Idade (dias) & 34 & \multirow{2}{*}{\multicolumn{2}{|c|}{$\begin{array}{c}35 \\
\text { X12r1; X12r3; X00; } \\
\text { X10r1; X10r3; }\end{array}$}} & \\
\hline Pilar & $\mathrm{x} 02$ & & & \\
\hline
\end{tabular}

Para avaliar o crescimento da resistência (y) com a idade (x) e analisar alguns dos resultados das diferentes séries ( 1 a 4) com os mesmos parâmetros utilizou-se uma equação exponencial dada em (5.1), ajustada pelo método dos mínimos quadrados com os dados das séries 1 a 4, como indica a Figura 5.3.

$$
y(x)=a \cdot e^{\frac{b \cdot x}{c+x}}
$$

Baseando-se no ganho de resistência à compressão com a idade (eq. (5.1)) e na pequena variabilidade da resistência à compressão entre as diferentes séries adotou-se o valor de $\mathrm{f}_{\mathrm{co}}=42,5 \mathrm{MPa}$ como representativo da resistência dos corpos-de-prova de concreto das séries 1 a 4 . Este valor foi o obtido com a equação ajustada para a idade de 34 dias, o qual acredita-se ser preciso o suficiente para estas análises. 


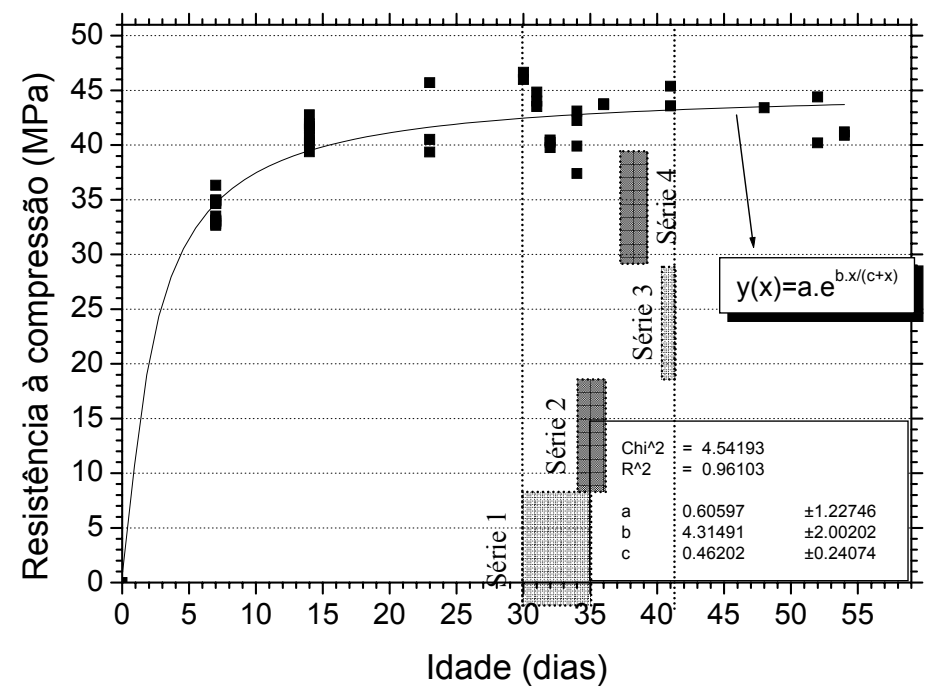

Figura 5.3 - Crescimento da resistência com a idade

Para os corpos-de-prova de concreto da série 5 adotou-se $\mathrm{f}_{\mathrm{co}}=31,06 \mathrm{MPa}$, referente a uma idade de 35 dias, já que os ensaios foram realizados aos 34 e 35 dias. O valor médio de resistência à compressão aos 38 dias, por exemplo, foi de $31,2 \mathrm{MPa}$.

O módulo de elasticidade do concreto foi determinado nos ensaios de corpos-deprova realizados na máquina hidráulica eletrônica da marca ELE, modelo Autotest 2000, conforme Figura 5.1 (a). As deformações axiais foram medidas nos $10 \mathrm{~cm}$ centrais com extensômetros removíveis. Foram então utilizados os pontos do diagrama tensão x deformação até $25 \%$ da resistência à compressão para o ajuste da reta. Foram utilizadas duas amostras para cada ensaio. Os resultados obtidos são apresentados na Tabela 5.4.

Tabela 5.4 - Determinação do módulo de elasticidade

\begin{tabular}{|c|c|c|c|c|}
\hline \multirow{2}{*}{ Série } & \multicolumn{3}{|c|}{ Módulo de elasticidade (GPa) } & \multirow{2}{*}{ Idade do ensaio (dias) } \\
\hline & Valores individuais & Valor & médios & \\
\hline S1 & 28,$0 ; 28,9$ & 28,5 & \multirow{4}{*}{28,55} & 36 \\
\hline $\mathrm{S} 2$ & 27,$2 ; 28,2$ & 27,7 & & 34 \\
\hline S3 & 30,$9 ; 28,9$ & 29,9 & & 30 \\
\hline S4 & 27,$4 ; 28,9$ & 28,1 & & 23 \\
\hline S5 & 24,$7 ; 27,3$ & \multicolumn{2}{|c|}{26,0} & 39 \\
\hline
\end{tabular}

Os diagramas tensão x deformação foram obtidos com ensaios de corpos-deprova de 10 x $20 \mathrm{~cm}$ na máquina universal de ensaios INSTRON, com controle de deslocamento. Para obter estes diagramas, apresentados na Figura 5.5, foram utilizados transdutores entre pratos da máquina de ensaio. Apenas nos ensaios dos corpos-de- 
prova da série 5 foram utilizados extensômetros removíveis nos $10 \mathrm{~cm}$ centrais dos corpos-de-prova. Os diagramas tensão x deformação dos corpos-de-prova da série 5 são apresentados na Figura 5.4.

Pode-se observar uma diferença entre as deformações últimas obtidas com os transdutores e com os extensômetros removíveis. A deformação última obtida com os extensômetros $\left(2,81.10^{-3}\right.$ e $\left.2,80.10^{-3}\right)$ foi $78,7 \%$ da obtida com os transdutores $\left(3,57.10^{-3}\right.$ e $3,56.10^{-3}$ ). Além disso, devem ser observadas algumas diferenças importantes entre as leituras de deformação obtidas das duas maneiras distintas. O extensômetro removível registrou as deformações na região central do corpo-de-prova enquanto o transdutor de deslocamento registrou as deformações no comprimento total do corpo-de-prova. Nas leituras feitas com os transdutores existiu a influência da camada de enxofre utilizada no capeamento do corpo-de-prova, que reduziu consideravelmente o módulo de elasticidade e provocou o aparecimento de uma acomodação no início do diagrama. Por outro lado, após a tensão máxima ser atingida, as deformações se concentraram na região central do corpo-de-prova, pois o confinamento oferecido pelo atrito com a máquina de ensaio manteve o concreto das extremidades mais íntegro.

Já no caso da utilização do extensômetro removível, a inclinação inicial foi significativamente maior, por não ter sofrido influência do capeamento e acomodações. Contudo, como a fissuração se concentrou na região central do corpo-de-prova, quando a tensão se aproximou da resistência à compressão do concreto as deformações registradas por estes extensômetros foram maiores que as registradas pelos transdutores entre pratos da máquina.

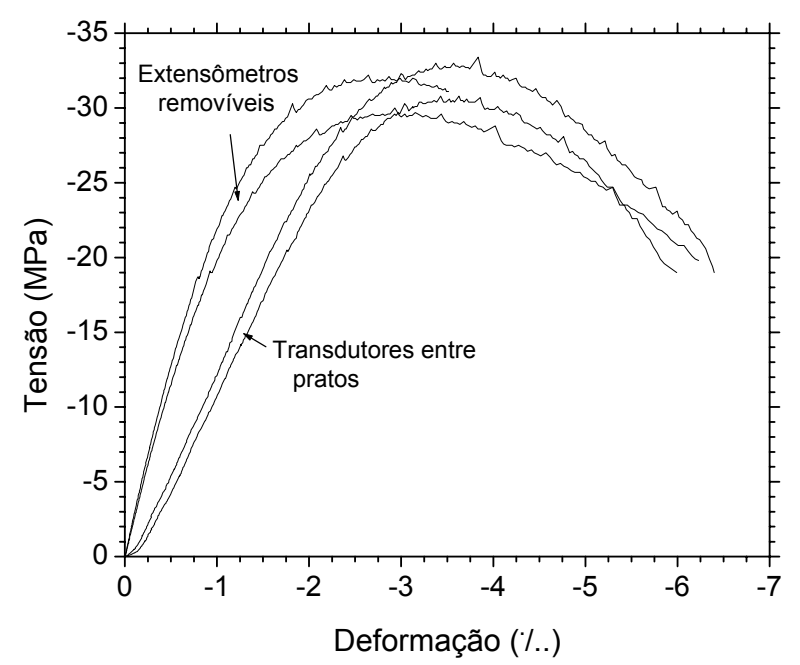

Figura 5.4 - Diagramas tensão x deformação obtidos com as leituras dos transdutores e dos extensômetros removíveis 
Na Figura 5.5 são apresentados os diagramas tensão x deformação dos corposde-prova instrumentados somente com transdutores de deslocamento. Pode-ser observar que houve um aumento da deformação última com o aumento da resistência do concreto. A deformação última do concreto foi então correlacionada com a resistência por meio de uma regressão linear.
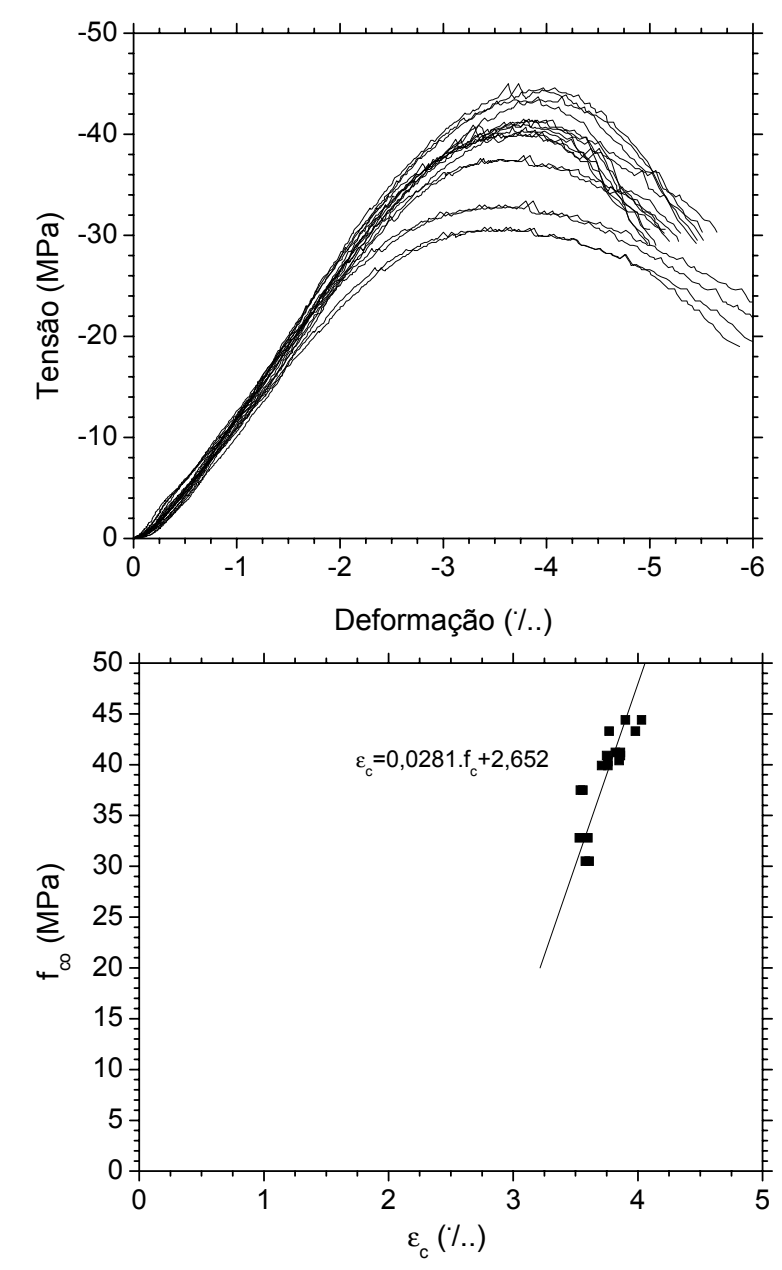

Figura 5.5 - Diagramas tensão x deformação axial

(a) curva completa (b) valores de pico

Esta linha de tendência foi então utilizada para obter as deformações últimas do concreto para os ensaios dos corpos-de-prova das séries 1 a 4 , conforme indica a expressão (5.2).

$$
\frac{\varepsilon_{c}^{\text {ext }, A}}{\mathcal{E}_{c}^{\text {trans }, A}}=\frac{\mathcal{\varepsilon}_{c}^{\text {ext }, B}}{\mathcal{\varepsilon}_{c}^{\text {trans }, B}}
$$

onde: 
- $\varepsilon_{c}^{e x t, A}=2,805 \cdot 10^{-3}$ é a deformação última do concreto da série 5 medida com extensômetros removíveis;

- $\varepsilon_{c}^{\text {trans }, A}=3,565 \cdot 10^{-3}$ é a deformação última do concreto da série 5 medida com transdutores entre pratos;

- $\quad \varepsilon_{c}^{\text {trans }, B}=3,846.10^{-3}$ é a deformação última do concreto das demais séries medida com transdutores entre pratos;

- $\varepsilon_{c}^{e x t, B}=3,03 \cdot 10^{-3}$ é a deformação última do concreto das demais séries referente aos extensômetros removíveis, estimada com a equação (5.2).

Foram realizados ensaios de determinação da resistência à tração por compressão diametral (tração indireta) com corpos-de-prova de $10 \mathrm{~cm}$ de diâmetro x 20 cm de comprimento. Os resultados são apresentados na Tabela 5.5 em conjunto com a resistência à tração direta estimada por meio da NBR 6118 (2003).

Tabela 5.5 - Ensaios de resistência à tração por compressão diametral

\begin{tabular}{ccccc}
\hline \multirow{2}{*}{ Série } & \multicolumn{2}{c}{ Resistência à tração indireta } & Resistência à tração direta \\
$\mathrm{f}_{\mathrm{ct} \text { sp }}(\mathrm{MPa})$ & & $\mathrm{f}_{\mathrm{ct}}=0,9 \mathrm{f}_{\mathrm{ct}, \mathrm{sp}}(\mathrm{MPa})$ & Idade do ensaio (dias) \\
\cline { 2 - 5 } & Valores individuais & Média & Média & \\
\hline 3 & 3,$57 ; 3,84$ & 3,70 & 3,33 & 41 \\
4 & 3,$03 ; 3,38 ; 3,32$ & 3,24 & 2,92 & 34 \\
\hline
\end{tabular}

Com base nos resultados acima apresentados foi adotada a resistência à tração do concreto de 3,33 MPa para as séries 1 a 4. Para a série 5 a resistência à tração foi de 2,92 MPa.

\subsubsection{Polímeros reforçados com fibras (PRF)}

O encamisamento dos pilares foi efetuado com resina epóxi (SIKADUR-330) fornecida pela SIKA S.A. e tecidos de fibras de carbono CVU 334HM - 0,3 fornecidas pela TEXIGLASS. Foram realizados ensaios de tração com as fibras a 0,45 e $90^{\circ}$. Os ensaios foram realizados em uma máquina de ensaios da marca DARTEC, modelo M1000 RK, com capacidade de 100 kN, do Laboratório de Madeiras e Estruturas de Madeira (LAMEM). As amostras foram preparadas conforme recomendações da ASTM D3039 (1995). As dimensões das amostras, a força e a tensão de ruptura são apresentadas na Tabela 5.6. Infelizmente nem todos os ensaios de caracterização foram realizados satisfatoriamente, de modo que apenas alguns puderam ser aproveitados para 
análise dos resultados. Os resultados descartados estão indicados com um traço na Tabela 5.6.

Tabela 5.6 - Dimensões das amostras, força e resistência de ruptura do compósito

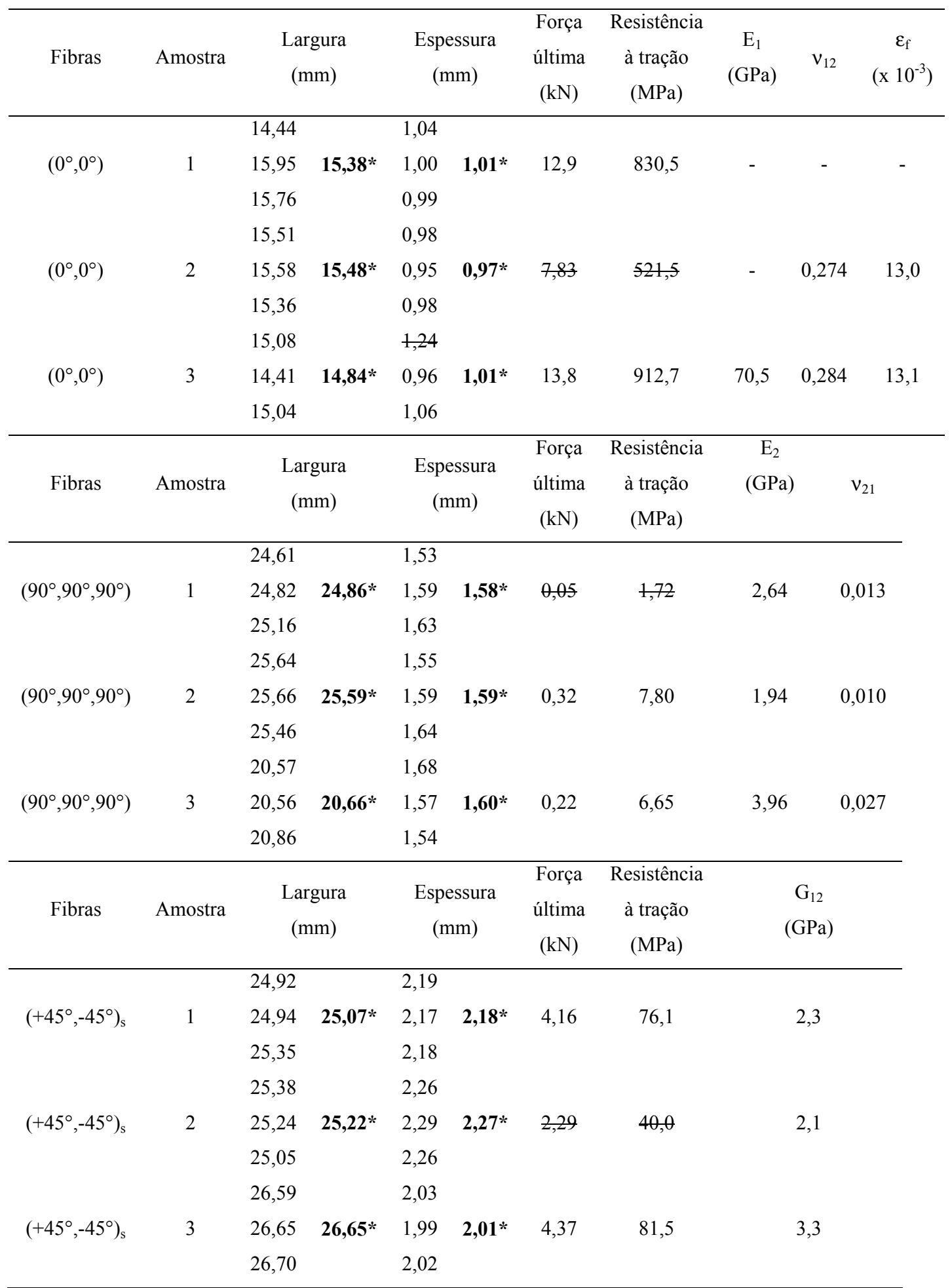

*valores médios 
O módulo de elasticidade na direção das fibras $\left(E_{1}\right)$ foi determinado nos ensaios com as fibras a $0^{\circ}$, com as leituras das deformações longitudinais e a tensão axial na amostra. Obteve-se em média 70,5 GPa para o compósito.

O coeficiente de Poisson $\left(v_{12}\right)$ foi determinado também no ensaio com as fibras a $0^{\circ}$, porém com o auxílio das leituras dos extensômetros a $90^{\circ}$. Obteve-se o valor médio de 0,28 .

O módulo de elasticidade na direção perpendicular às fibras $\left(E_{2}\right)$ foi determinado com as amostras a $90^{\circ}$ e os extensômetros longitudinais. Obteve-se em média 2,85 GPa.

O coeficiente de Poisson $v_{21}$ foi determinado com as fibras a $90^{\circ}$ e os extensômetros transversais. Obteve-se o valor médio de 0,017 , da mesma ordem de grandeza do obtido com a equação (5.3):

$$
v_{21}=v_{12} \cdot \frac{E_{2}}{E_{1}}=0,011
$$

O módulo de cisalhamento foi determinado a partir do ensaio de amostras com as fibras a $[+45,-45]_{\mathrm{s}}$ instrumentadas com extensômetros longitudinais e transversais. Foi possível avaliar as tensões e deformações de cisalhamento com o auxílio das equações:

$$
\begin{aligned}
& \left|\tau_{12}\right|=\left|\frac{\sigma_{x}}{2}\right| \\
& \mathrm{e} \\
& \left|\gamma_{12}\right|=\left|\varepsilon_{x}-\varepsilon_{y}\right|
\end{aligned}
$$

A partir dos ensaios e das equações acima apresentadas obteve-se o valor de 2,57 GPa (média de 2,3, 2,1 e 3,3) para o módulo de cisalhamento $\left(\mathrm{G}_{12}\right)$.

Conforme discutido em CARRAZEDO (2002), a espessura do compósito tem uma variabilidade considerável na aplicação manual dos tecidos de fibras de carbono. Além disso, observou-se que aumentando a espessura da camada com a utilização de uma quantidade maior de resina, não ocorre aumento da força de ruptura no ensaio de tração de uma amostra. Por isso é comum a associação das propriedades destes compósitos apenas às fibras, desprezando-se a contribuição da resina. Os resultados destes ensaios foram então transformados em propriedades das fibras e apresentados na Tabela 5.8. Para isto admitiu-se a espessura da camada de fibras de carbono igual a 0,17 $\mathrm{mm}$. Esta espessura foi obtida dividindo-se a gramatura do tecido $\left(300 \mathrm{~g} / \mathrm{m}^{2}\right)$, conforme Tabela 5.7, pela massa específica das fibras de carbono $\left(1,77 \mathrm{~g} / \mathrm{cm}^{3}\right)$, adotada 
considerando-se as fibras do tipo T-300 (Amoco) com os valores obtidos em GIBSON (1994).

Tabela 5.7 - Determinação da espessura efetiva das fibras de carbono

\begin{tabular}{|c|c|c|c|c|c|c|c|}
\hline Amostra & Camadas & $\begin{array}{c}\text { Largura } \\
(\mathrm{mm})\end{array}$ & $\begin{array}{c}\text { Comprimento } \\
(\mathrm{mm})\end{array}$ & $\begin{array}{l}\text { Área da amostra } \\
\qquad\left(\mathrm{m}^{2}\right)\end{array}$ & $\begin{array}{c}\text { Massa } \\
(\mathrm{g})\end{array}$ & $\begin{array}{c}\text { Gramatura } \\
\left(\mathrm{g} / \mathrm{m}^{2}\right)\end{array}$ & $\begin{array}{l}\text { Espessura efetiva } \\
\text { (mm) }\end{array}$ \\
\hline 1 & 2 & 60 & 250 & 0,015 & 9,4 & \multirow{2}{*}{301,5} & 0,177 \\
\hline 2 & 2 & 85 & 170 & 0,0145 & 8,4 & & 0,164 \\
\hline
\end{tabular}

Analisando a Tabela 5.8, onde são apresentados os resultados da caracterização realizada na presente pesquisa, pode-se observar uma grande semelhança com os resultados obtidos por CARRAZEDO (2002). CARRAZEDO (2002) ensaiou 5 amostras de outro tecido de fibras de carbono, obtendo em média $2758 \mathrm{MPa}$ de resistência à tração, $12,5 \cdot 10^{-3}$ de deformação de ruptura e $219 \mathrm{GPa}$ de módulo de elasticidade à tração. Pode-se dizer então que as propriedades das fibras utilizadas em ambas pesquisas são bastante semelhantes sendo a principal diferença entre os tecidos a gramatura empregada.

Tabela 5.8 - Propriedades das fibras a partir do ensaio de tração

\begin{tabular}{ccccccc}
\hline Fibras & Amostra & $\begin{array}{c}\text { Área da seção } \\
\text { transversal das fibras } \\
\left(\mathrm{mm}^{2}\right)\end{array}$ & $\begin{array}{c}\text { Força } \\
\text { última } \\
(\mathrm{kN})\end{array}$ & $\begin{array}{c}\text { Resistência } \\
\text { à tração } \\
(\mathrm{MPa})\end{array}$ & $\begin{array}{c}\text { Deformação } \\
\text { Última } \\
\%\end{array}$ & $\begin{array}{c}\text { Módulo de } \\
\text { Elasticidade } \\
\mathrm{E}_{1}(\mathrm{GPa})\end{array}$ \\
\hline$\left(0^{\circ}, 0^{\circ}\right)$ & 1 & 5,23 & 12,9 & 2467 & - & - \\
\hline$\left(0^{\circ}, 0^{\circ}\right)$ & 2 & 5,26 & 7,83 & 1489 & 13,0 & - \\
\hline$\left(0^{\circ}, 0^{\circ}\right)$ & 3 & 5,04 & 13,8 & 2738 & 13,1 & 209 \\
\hline \multicolumn{7}{r}{ Valores a considerar } \\
\hline
\end{tabular}

\subsubsection{Corpos-de-prova encamisados com PRFC}

Foram ensaiados corpos-de-prova $(10 \times 20 \mathrm{~cm})$ encamisados com 1 e 2 camadas de PRFC para avaliar o efeito de confinamento com pressão lateral uniforme e obter com isso algumas propriedades do concreto como ângulo de atrito e coesão. Foram utilizados extensômetros elétricos de resistência para obter as deformações transversais e axiais da camisa. Além disso, foram utilizados transdutores de deslocamento entre pratos da máquina de maneira semelhante aos utilizados nos demais corpos-de-prova.

Foram ensaiados dois corpos-de-prova para cada intensidade de resistência à compressão axial do concreto (série 5 e demais séries), sendo utilizadas uma e duas camadas de fibras de carbono, com nomenclatura conforme Tabela 5.9: 
Tabela 5.9 - Nomenclatura e resultados obtidos com os corpos-de-prova encamisados

\begin{tabular}{|c|c|c|c|c|c|c|c|c|c|c|}
\hline \multirow[b]{2}{*}{$\begin{array}{l}\text { Corpo- } \\
\text { de- } \\
\text { prova }\end{array}$} & \multirow[b]{2}{*}{$\begin{array}{c}\mathrm{f}_{\mathrm{co}} \\
(\mathrm{MPa})\end{array}$} & \multirow{2}{*}{$\begin{array}{l}\text { Número } \\
\text { de } \\
\text { camadas } \\
\text { (n) }\end{array}$} & \multirow[b]{2}{*}{$\begin{array}{c}\mathrm{f}_{\mathrm{cc}} \\
(\mathrm{MPa})\end{array}$} & \multirow[b]{2}{*}{$\frac{f_{c c}}{f_{c o}}$} & \multirow[b]{2}{*}{$\begin{array}{l}\varepsilon_{\mathrm{fu}} \\
\% o\end{array}$} & \multirow[b]{2}{*}{$\begin{array}{c}f_{l}=\frac{2 \cdot t \cdot n \cdot \varepsilon_{f u} \cdot E_{f}}{D} \\
(\mathrm{MPa})\end{array}$} & \multirow{2}{*}{$\frac{f_{l}}{f_{c o}}$} & \multirow[b]{2}{*}{$\mathrm{k}_{1}$} & \multirow{2}{*}{$\begin{array}{l}\varepsilon_{\mathrm{cc}} \\
\% o\end{array}$} & \multirow[b]{2}{*}{$\frac{\mathcal{E}_{c c}}{\mathcal{E}_{c o}}$} \\
\hline & & & & & & & & & & \\
\hline C30n1 & 31,1 & 1 & 65,5 & 2,11 & 10,6 & 7,53 & 0,242 & 4,57 & 20,0 & 7,14 \\
\hline C30n2 & 31,1 & 2 & 88,0 & 2,83 & 10,0 & 14,2 & 0,457 & 4,00 & 27,6 & 9,84 \\
\hline $\mathrm{C} 40 \mathrm{n} 1 *$ & 42,5 & 1 & 64,4 & 1,52 & $5,5^{*}$ & 3,91 & 0,092 & 5,60 & 13,0 & 4,29 \\
\hline $\mathrm{C} 40 \mathrm{n} 2$ & 42,5 & 2 & 108,4 & 2,55 & 11,3 & 16,0 & 0,452 & 4,11 & 28,3 & 9,34 \\
\hline
\end{tabular}

* nesta amostra ocorreu uma ruptura prematura das fibras, de modo que se adotou a deformação lateral na face oposta à ruptura para os cálculos

Com base nos resultados apresentados na Tabela 5.9 pode-se observar que o ganho de resistência pôde ser estimado com a equação de RICHART et al. (1928) e com $\mathrm{k}_{1}=4,1$.

$$
\mathrm{f}_{\mathrm{cc}}=\mathrm{f}_{\mathrm{co}}+\mathrm{k}_{1} \cdot \mathrm{f}_{\mathrm{l}}
$$

Além disso, foi possível estimar os parâmetros do critério de Mohr-Coulomb. O ângulo de atrito do concreto foi de $37,4^{\circ}$. A coesão foi de 7,68 e 10,5 MPa para os concretos com $\mathrm{f}_{\mathrm{co}}=31,2$ e 42,5 $\mathrm{MPa}$, respectivamente.

De maneira mais precisa, pode-se considerar que o valor de $\mathrm{k}_{1}$ depende de $\mathrm{f}_{1} /$ $\mathrm{f}_{\mathrm{co}}$, com uma relação não linear entre estas variáveis, conforme Figura 5.6.

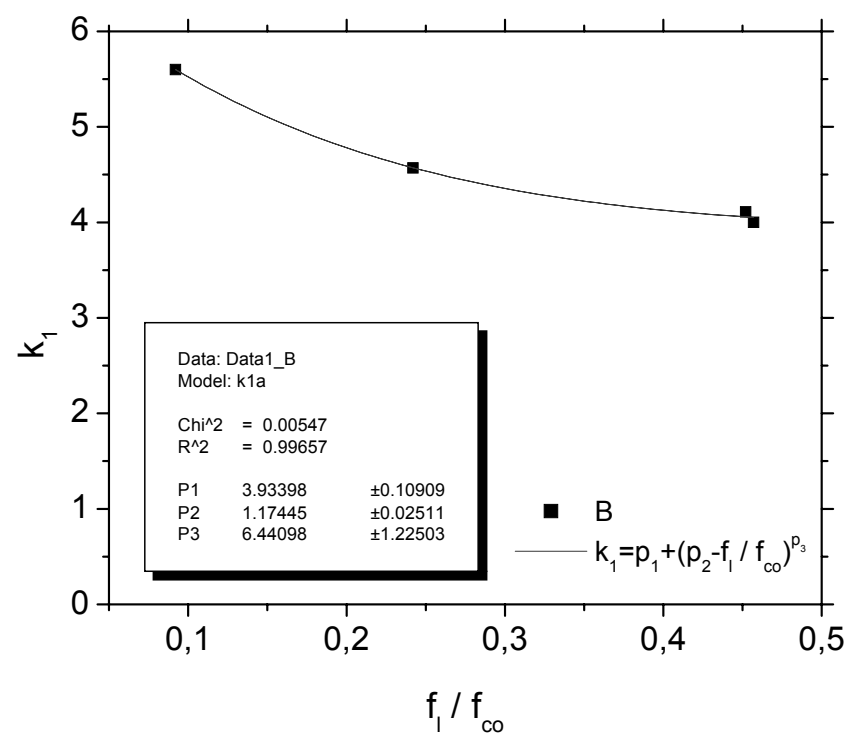

Figura 5.6 - Determinação de $k_{1}$ em função de $f_{l} / f_{\text {co }}$ para os corpos-de-prova ensaiados 


\subsubsection{Preparação dos pilares}

Os pilares foram concretados em fôrmas de madeira. Na Figura 5.7 são apresentadas fotografias das fôrmas utilizadas, em que se pode notar os cantos arredondados. As peças utilizadas nos cantos foram moldadas com massa plástica, com o auxílio de tubo nos diâmetros adequados e cantoneiras. As peças foram então serradas e coladas nos cantos das fôrmas.
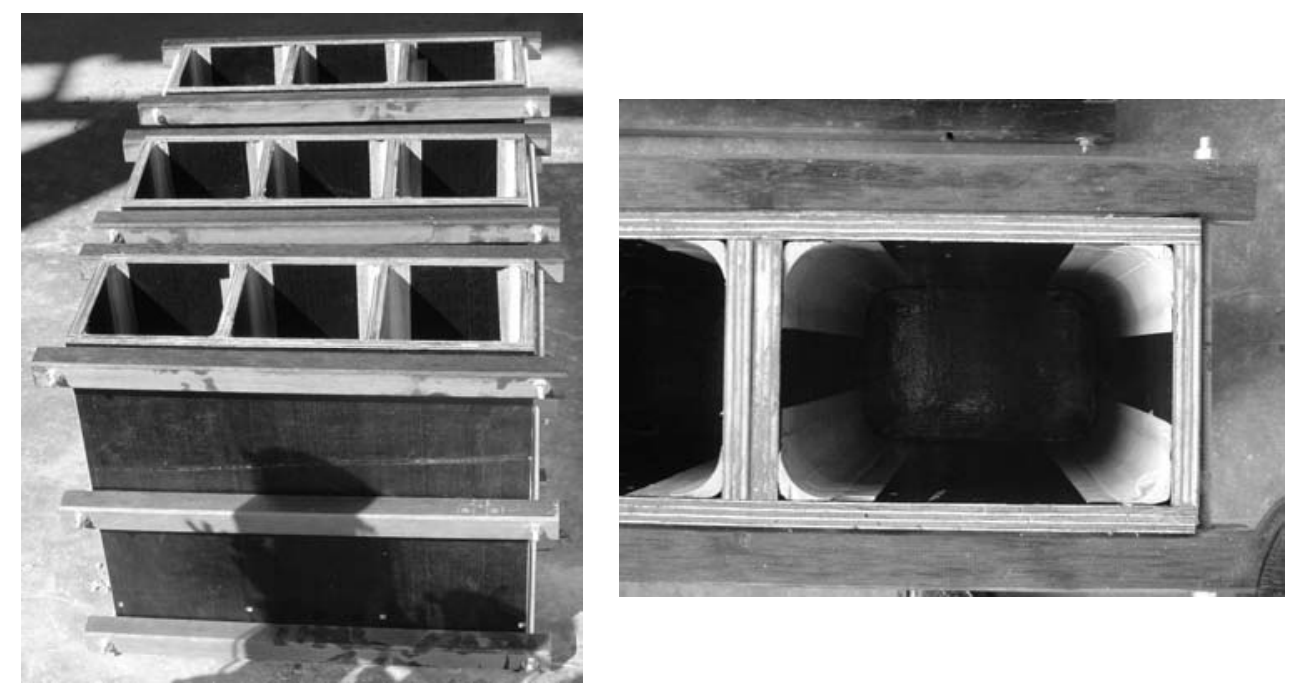

Figura 5.7 - Fotos das fôrmas utilizadas

A concretagem dos pilares foi realizada em uma betoneira de eixo vertical com capacidade de 200 litros, como a da Figura 5.8.

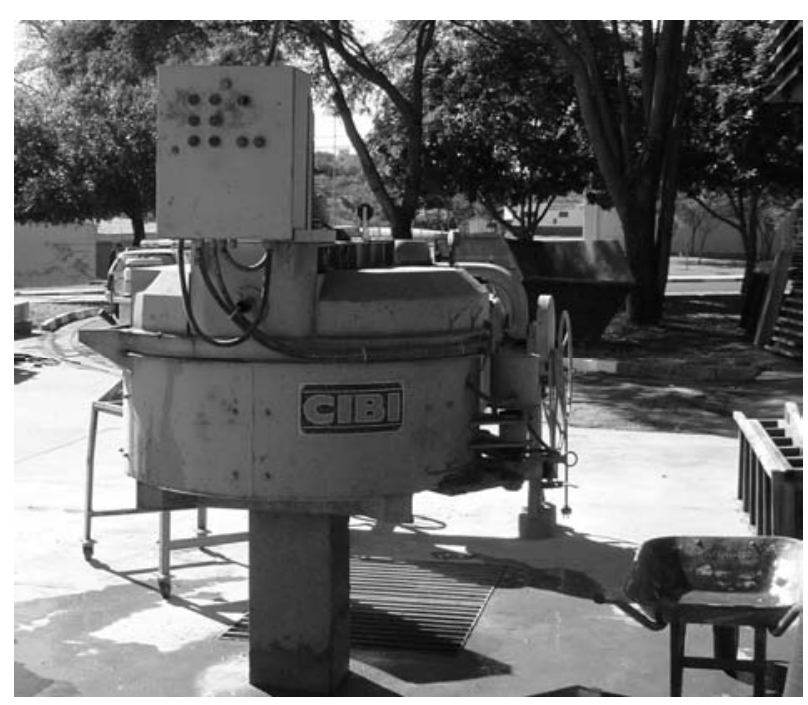

Figura 5.8 - Betoneira de eixo vertical utilizada 
A cura foi realizada em câmara úmida por 1 semana. Após a cura, os pilares secaram ao ar e foram então encamisados com o compósito de fibras de carbono e resina epóxi. Na Figura 5.9 é apresentada uma ilustração da aplicação do encamisamento com fibras de carbono e resina epóxi. A resina epóxi foi misturada com um misturador elétrico durante o tempo necessário para se obter um material homogêneo e de coloração uniforme. Após a mistura aplicou-se a resina sobre as superfícies a serem encamisadas. O consumo de epóxi foi de $1,0 \mathrm{~kg} / \mathrm{m}^{2}$ para as superfícies de concreto e de $0,75 \mathrm{~kg} / \mathrm{m}^{2}$ para as superfícies já cobertas com fibras de carbono ( $2^{\mathrm{a}}$ ou $3^{\mathrm{a}}$ camadas). Após a impregnação da superfície com a resina epóxi foram aplicados os tecidos unidirecionais, expulsando o ar com um pequeno rolo plástico. Utilizou-se traspasse dos tecidos na direção das fibras de $10 \mathrm{~cm}$. Na direção transversal às fibras não foi necessário traspasse.

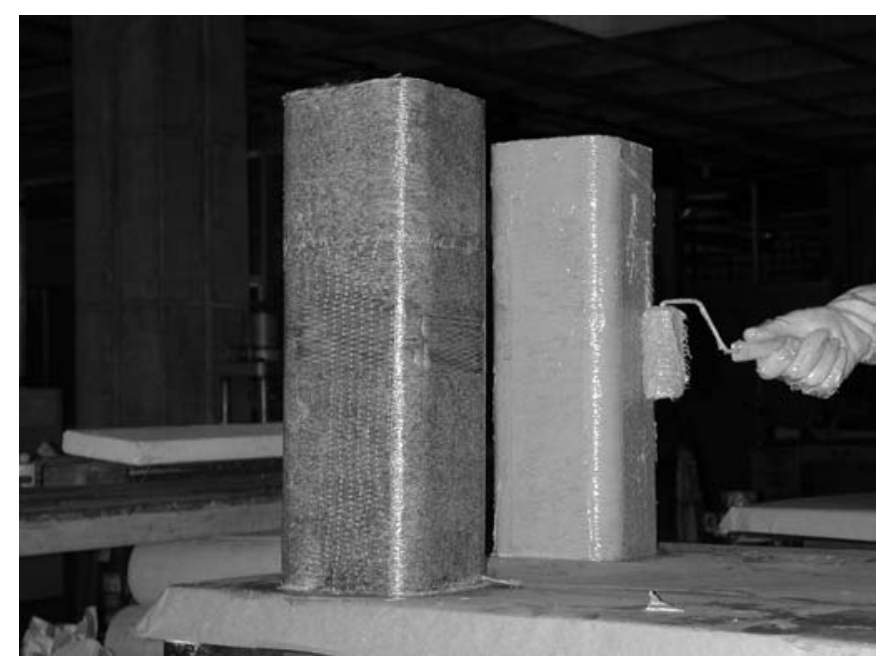

Figura 5.9 - Encamisamento com fibras de carbono

\subsection{Pilares submetidos à compressão centrada sem o sistema de rótulas}

Alguns pilares de concreto da série 5 com dimensões iguais às dos pilares dos ensaios de compressão excêntrica foram ensaiados sob compressão centrada apenas com o sistema de rótulas original da Instron. Este tipo de ensaio é o mais comumente realizado em pesquisas de pilares de concreto simples e armado. Na Figura 5.10 é apresentada uma ilustração de um dos pilares ensaiados sob compressão centrada nesta pesquisa. 


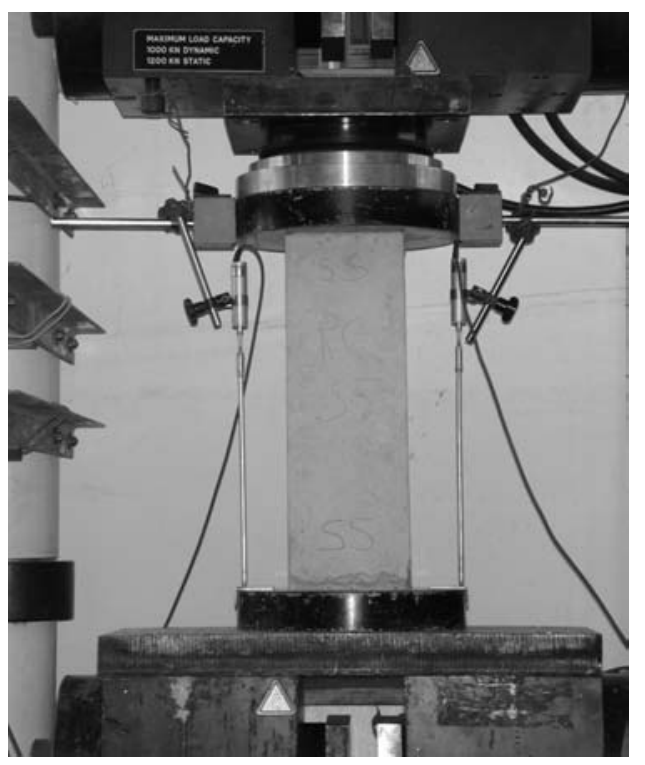

Figura 5.10 - Pilar de referência ensaiado sob compressão centrada

As condições de vinculação podem ser aproximadamente representadas na Figura 5.11 com uma condição próxima do engaste na extremidade inferior e próxima de uma ligação rotulada na parte superior.

Neste tipo de ensaio, pequenas inclinações na superfície do pilar são até aceitáveis, já que o sistema de rótulas permite certa redistribuição de tensões no concreto. Além disso, as diferenças de leituras de deslocamento em faces opostas de pilares curtos são normalmente observadas apenas no início do ensaio, quando ocorre a acomodação.

No entanto, este sistema não permite consideráveis rotações da extremidade "rotulada" durante o ensaio, de modo que esta vinculação não pode ser realmente considerada como rótula. Isto ocorre principalmente em virtude do grande raio de curvatura deste tipo de rótula, que faz com que seu centro de rotação fique bem afastado das extremidades do pilar.

Logo, para que ocorresse uma rotação na extremidade superior do pilar na Figura 5.11 durante o ensaio, seria necessário um considerável deslocamento lateral da parte móvel deste sistema de rótulas para permitir esta rotação. Isto não acontece devido ao atrito entre a parte móvel da rótula e o pilar, que cresce ainda mais com o acréscimo do carregamento. 


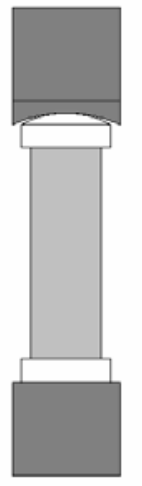

(a)

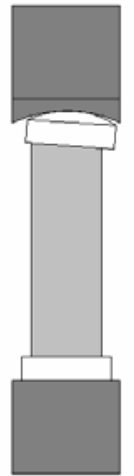

(b)

Figura 5.11 - Esquema de ensaio dos pilares com o sistema de rótula da INSTRON:

(a) pilar com superfícies das extremidades perpendiculares ao eixo longitudinal

(b) pilar com superfície da extremidade superior inclinada por defeito de acabamento

Foram assim obtidos os diagramas tensão x deformação de modelos de pilares de concreto da série 5, de seção transversal quadrada e circular, com $45 \mathrm{~cm}$ de comprimento. Os pilares de seção quadrada tinham $15 \mathrm{~cm}$ de lado. Os de seção circular tinham $15 \mathrm{~cm}$ de diâmetro. As leituras de deslocamentos axiais foram realizadas com transdutores entre os pratos da máquina de ensaio e apresentaram um considerável efeito de acomodação. Felizmente a acomodação pôde ser facilmente eliminada dos resultados do pilar de seção circular S5refC, como mostra a Figura 5.12.

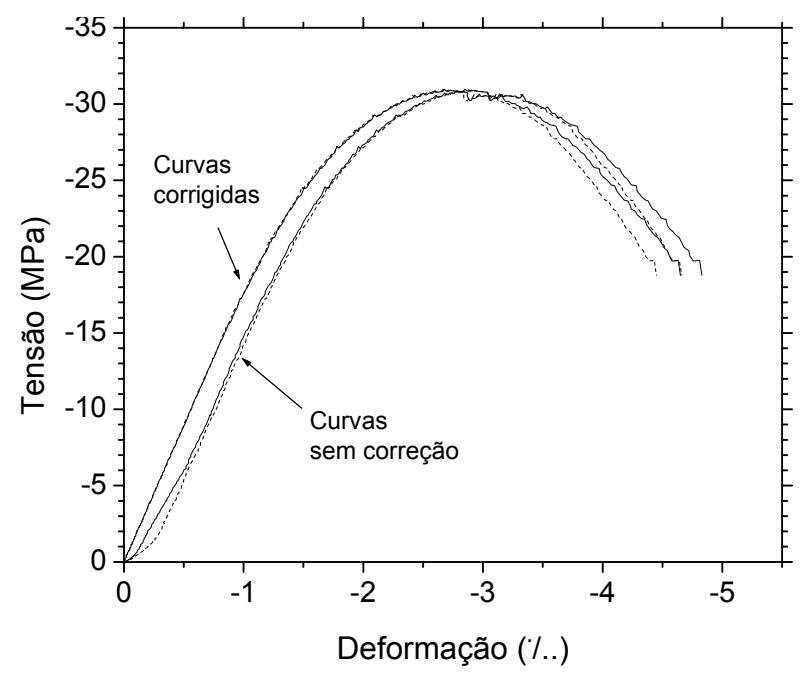

Figura 5.12 - Diagrama tensão x deformação do pilar de referência S5refC

O mesmo processo de correção foi utilizado para o pilar S5refS, de seção quadrada. Observou-se que o módulo de elasticidade, a deformação e a tensão de pico 
variaram quando as medidas foram feitas com modelos de pilares de seção circular e seção quadrada e com corpos-de-prova de 10 x $20 \mathrm{~cm}$. Além disso, no caso dos corposde-prova de 10 x $20 \mathrm{~cm}$ foram obtidas leituras diferentes utilizando extensômetros removíveis (nos $10 \mathrm{~cm}$ centrais) e transdutores entre pratos. A comparação dos resultados é feita na Figura 5.13 e na Tabela 5.10.

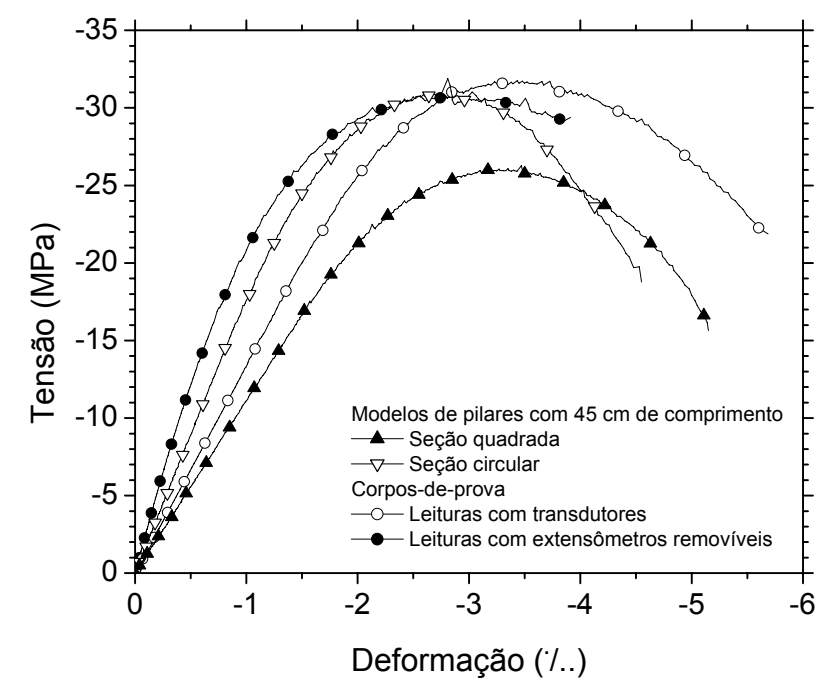

Figura 5.13 - Diagramas tensão x deformação com diferentes modelos de pilares e instrumentações

Diversos fatores afetam a deformabilidade destes modelos de pilares e corposde-prova de concreto. Estes fatores estão representados implicitamente pela forma da seção transversal, esbeltez dos modelos e material utilizado para capeamento, que no caso dos pilares foi massa plástica e nos corpos-de-prova enxofre.

Tabela 5.10 - Valores representativos dos diagramas tensão x deformação

\begin{tabular}{ccccc}
\hline Modelo & Instrumentação & $\mathrm{E}_{\mathrm{c}}(\mathrm{GPa})$ & $\mathrm{f}_{\mathrm{co}}(\mathrm{MPa})$ & $\varepsilon_{\mathrm{co}}(1 / 1000)$ \\
\hline Corpo-de-prova & Transdutores entre pratos & 13,4 & 31,6 & 3,45 \\
Corpo-de-prova & Extensômetros removíveis & 26,0 & 30,7 & 2,81 \\
Pilar de seção circular & Transdutores entre pratos & 17,9 & 30,9 & 2,76 \\
Pilar de seção quadrada & Transdutores entre pratos & 11,1 & 25,9 & 3,31 \\
\hline
\end{tabular}

Conclui-se que todos estes fatores e outros podem estar presentes nos ensaios dos pilares excêntricos com o sistema de rótulas de facas, dificultando a análise precisa da deformabilidade dos pilares. 


\subsection{Pilares submetidos à flexo-compressão}

Trinta e nove modelos de pilares, encamisados ou de referência, com diferentes números de camadas (n) de tecidos de PRFC e formas de seção transversal foram ensaiados à compressão com diferentes excentricidades. Para estes ensaios foi utilizado um sistema de rótulas de facas (unidirecional) que assegurou a liberdade de rotação nas duas extremidades dos pilares em uma das direções. Inicialmente é apresentada uma descrição do sistema de rótulas e os ensaios de verificação do comportamento do sistema de rótulas, realizados com um pilar de aço. Em seguida são apresentados os ensaios realizados com os pilares de concreto sob flexo-compressão.

\subsubsection{Metodologia de ensaio}

Os ensaios dos pilares foram realizados com controle de deslocamento em uma máquina universal de ensaios INSTRON 8506, com capacidade estática de $2500 \mathrm{kN}$. A taxa de aplicação do carregamento foi de $33,3 \mu \varepsilon / \mathrm{s}$, de modo que o tempo médio de ensaio de cada pilar foi de aproximadamente 15 minutos.

Foi utilizado um sistema de rótulas de facas ("knife bearings") possibilitando o ensaio dos pilares à flexo-compressão com diferentes excentricidades. As rótulas foram projetadas por Humberto Correia Lima Júnior, tomando como base o trabalho de KILPATRIC e RANGAN (1999). Alguns detalhes da rótula são apresentados esquematicamente na Figura 5.14. Maiores informações sobre o sistema de rótulas podem ser encontrados em LIMA JUNIOR (2003).

A rótula foi construída com chapas de aço 1020 e o núcleo com aço tipo VC 131. O núcleo foi temperado atingindo dureza de 62 na escala Rockwell, com uma resistência mínima à tração de $2090 \mathrm{MPa}$. A rótula foi projetada para uma força de 2000 $\mathrm{kN}$ e possibilita uma rotação de até $15^{\circ}$.

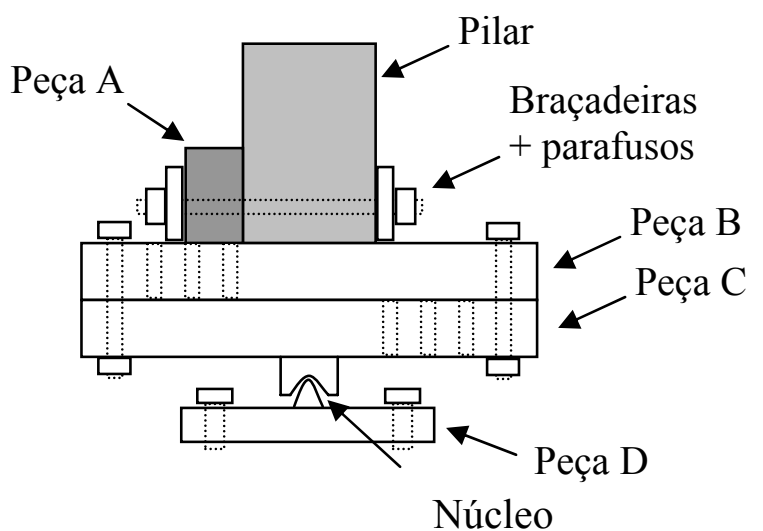

Figura 5.14 - Representação esquemática do sistema de rótulas 
Na Figura 5.14 são apresentados detalhes de fixação da rótula ao pilar. Pode-se observar que o pilar foi preso à peça $\mathrm{A}$ da rótula com o auxílio de braçadeiras de aço $\mathrm{e}$ parafusos. A peça A, por sua vez, estava soldada à peça B. Existiam quatro linhas de furos de parafusos, permitindo o deslocamento relativo entre as peças B e C de 0, 2, 4 e $6 \mathrm{~cm}$. As peças do núcleo eram soldadas às peças $\mathrm{C} \mathrm{e} \mathrm{D}$. No núcleo todo o carregamento foi transferido verticalmente, havendo liberdade de rotação. A peça D, finalmente, estava presa por parafusos à máquina de ensaio e constitui a parte fixa do sistema de rótulas. Logo, a parte móvel é constituída das peças $\mathrm{A}, \mathrm{B}$ e $\mathrm{C}$.

$\mathrm{Na}$ Figura 5.15 são apresentados detalhes do sistema de rótulas. Pode-se observar a colocação de uma peça de aço presa por um parafuso à peça $\mathrm{B}$ da rótula. Esta chapa de aço foi utilizada para a contenção lateral do pilar em caso de escorregamento lateral. De qualquer maneira, esta chapa foi fixada com folgas para não interferir sobre a liberdade de rotação do sistema.

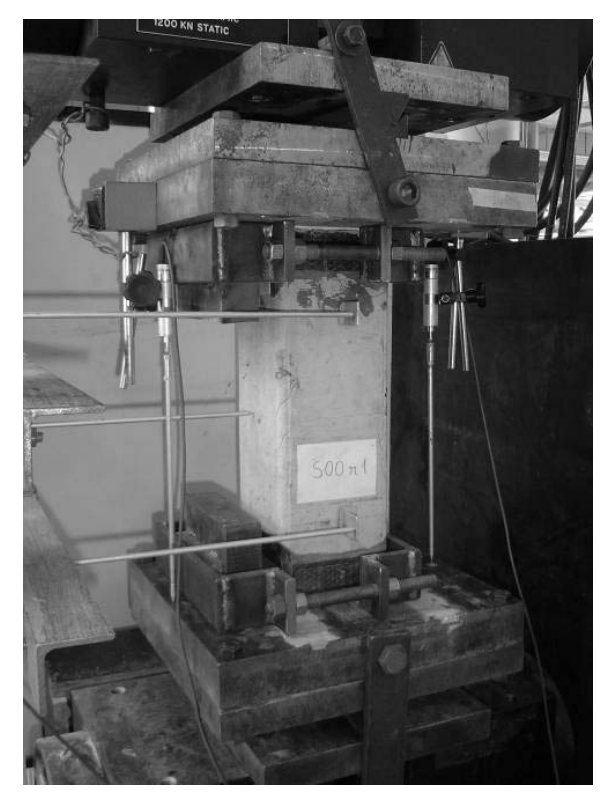

Figura 5.15 - Ilustração do esquema de ensaio

\subsubsection{Ensaios de verificação do comportamento da rótula}

Nestes ensaios, um pilar de aço de seção quadrada $(100$ x $100 \mathrm{~mm})$ com espessura de parede de 4,75 $\mathrm{mm}$ foi ensaiado à flexo-compressão utilizando o sistema de rótulas. O objetivo foi verificar se o sistema de rótulas permitia a aplicação de excentricidades pré-determinadas e se a liberdade de rotação das extremidades foi assegurada. O módulo de elasticidade obtido a partir do diagrama tensão x deformação 
axial do pilar sob compressão centrada foi de 211,4 GPa, de modo que nas presentes análises teóricas foi considerado como $210 \mathrm{GPa}$. O carregamento foi aplicado a uma taxa de deslocamento de $0,005 \mathrm{~mm} / \mathrm{s}$.

Foram utilizados transdutores de deslocamento para medir deslocamentos transversais e longitudinais conforme indica a Figura 5.16. As setas apresentadas indicam a direção positiva dos deslocamentos medidos pelos transdutores.
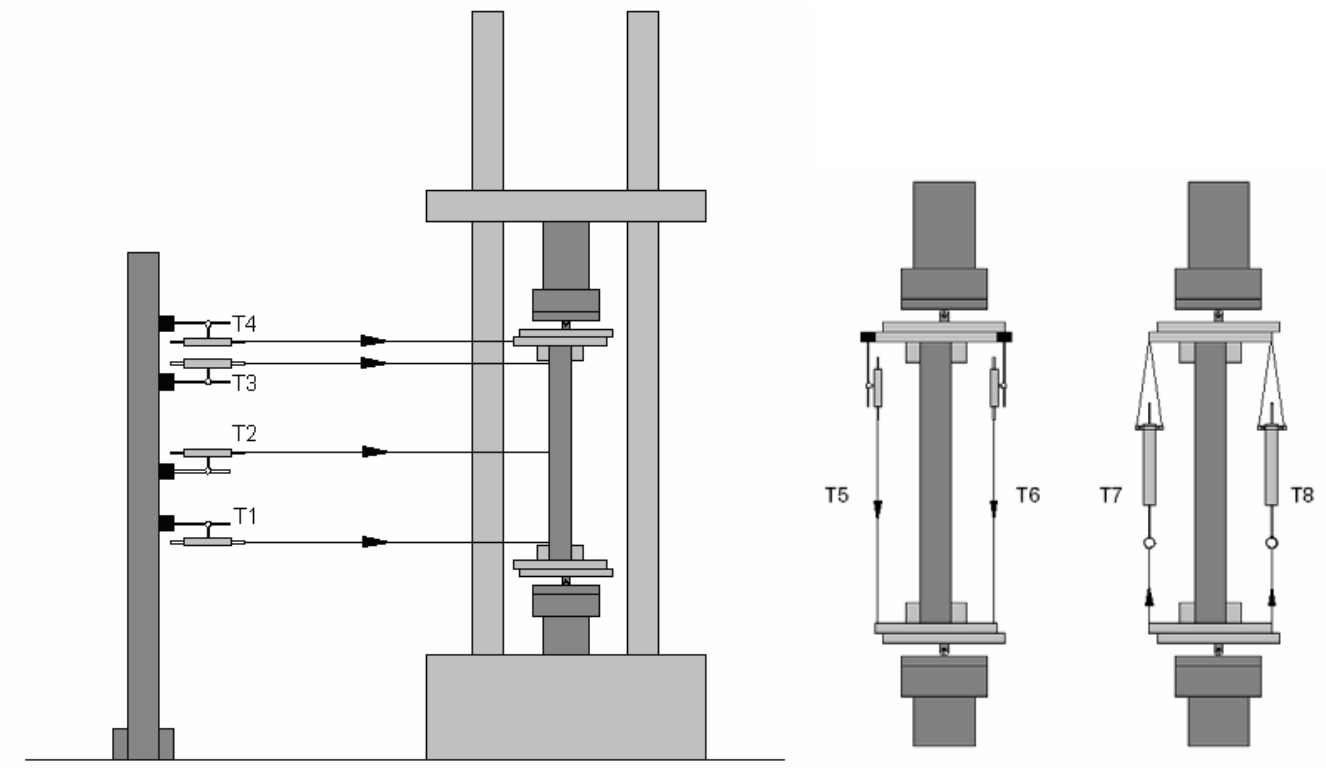

Figura 5.16 - Transdutores de deslocamento utilizados

Além disso, foram empregados extensômetros elétricos de resistência (KFG - 5 120 - C1-11) em faces opostas em relação ao eixo de rotação, como indica a Figura 5.17 .

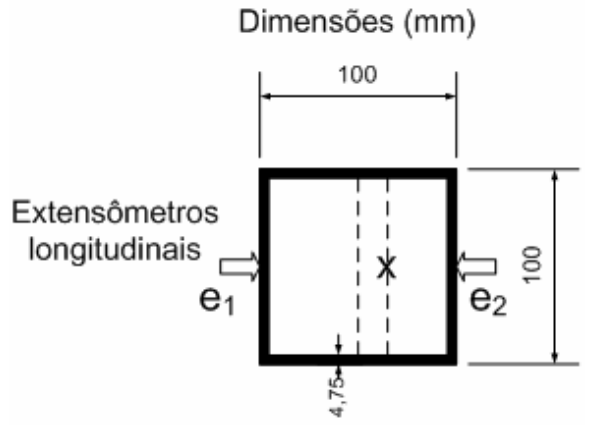

Figura 5.17 - Extensômetros elétricos na direção longitudinal

A comparação do momento externo $\left(\mathrm{M}_{\mathrm{ext}}\right)$ e momento interno $\left(\mathrm{M}_{\text {int }}\right)$ mostrou que as excentricidades nominais coincidiram satisfatoriamente com as efetivamente 
observadas no ensaio, como se pode observar na Figura 5.18. O momento externo é dado pelo produto da força atuante pela distância do ponto de aplicação da força até o centro geométrico da seção (excentricidade inicial + deslocamento lateral no meio do pilar). O momento interno foi calculado com base na relação entre momento e curvatura, sendo a curvatura avaliada a partir dos extensômetros axiais (e1 e e2). As equações (5.7) e (5.8) foram utilizadas nestas avaliações.

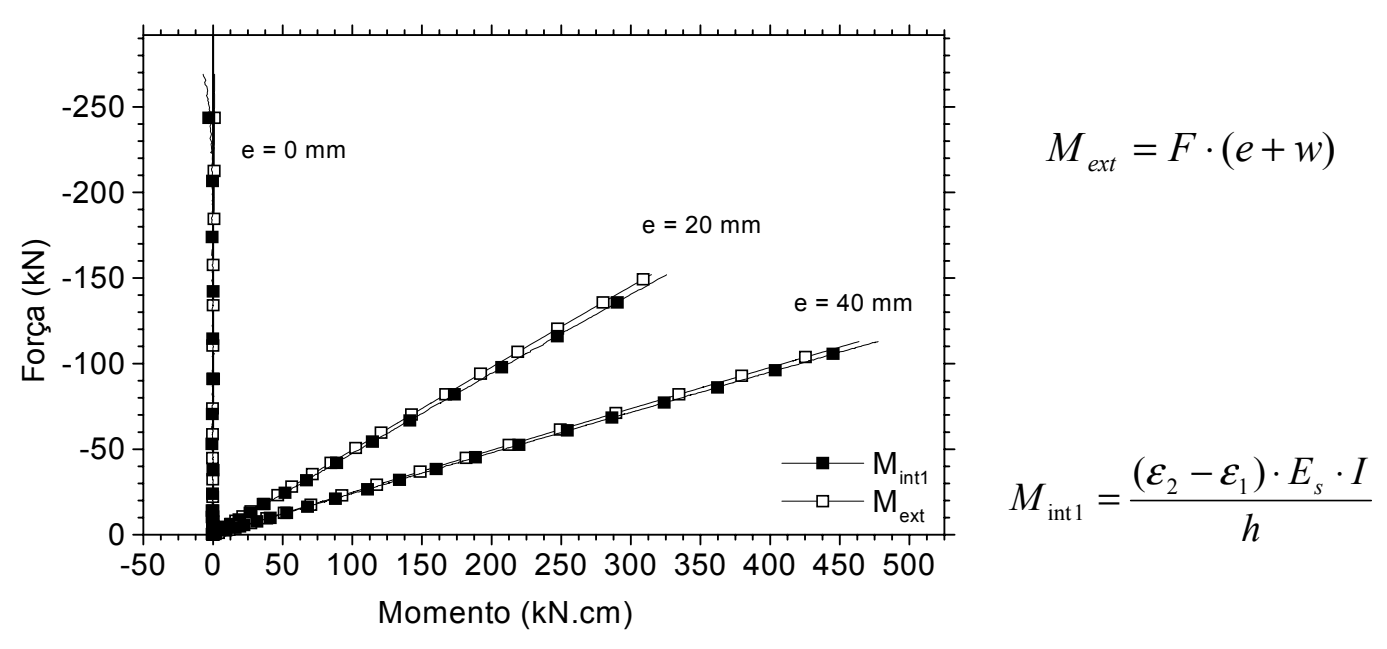

Figura 5.18 - Comparação do momento interno e externo

onde:

- $\mathrm{F}$ - força aplicada no ensaio;

- e - excentricidade nominal;

- $\mathrm{w}$ - deslocamento lateral no centro do pilar;

- $\varepsilon_{1}$ e $\varepsilon_{2}$ - deformações registradas pelos extensômetros e1 e e2;

- h altura da seção transversal (ou distância entre os extensômetros e1 e e2);

- $\mathrm{E}_{\mathrm{s}}$ - módulo de elasticidade do aço;

- I- momento de inércia.

$\mathrm{O}$ diagrama força $\mathrm{x}$ deslocamento lateral indica que no início do carregamento ocorreram acomodações do sistema de rótulas que se refletiram sobre as leituras. Estas acomodações foram mais significativas no primeiro ensaio (e $=0 \mathrm{~mm}$ ). Os ensaios foram não destrutivos e com forças que causaram apenas tensões dentro do regime elástico do aço.

Com isto, nos ensaios subseqüentes, o mesmo pilar continuou fixado ao sistema de rótulas por meio das braçadeiras e apenas as excentricidades foram alteradas, por 
meio do ajuste das peças B e C. Logo, nos demais ensaios, as acomodações foram menores por causa da eliminação das folgas existentes inicialmente.

Ocorreram também boas aproximações dos deslocamentos laterais medidos pelos transdutores $\mathrm{t} 1$ e $\mathrm{t} 2 \mathrm{com}$ os valores teóricos $\mathrm{t} 1 \mathrm{TEO}$ e $\mathrm{t} 2 \mathrm{TEO}$, respectivamente. $\mathrm{O}$ valor t2TEO foi calculado com a fórmula da secante (a partir de F e "e") e o t1TEO a partir deste valor, utilizando uma aproximação senoidal para a deformada do pilar. As leituras do transdutor t3, que deveriam ser iguais às de t1TEO, foram diferentes, indicando a presença de acomodações no apoio superior.
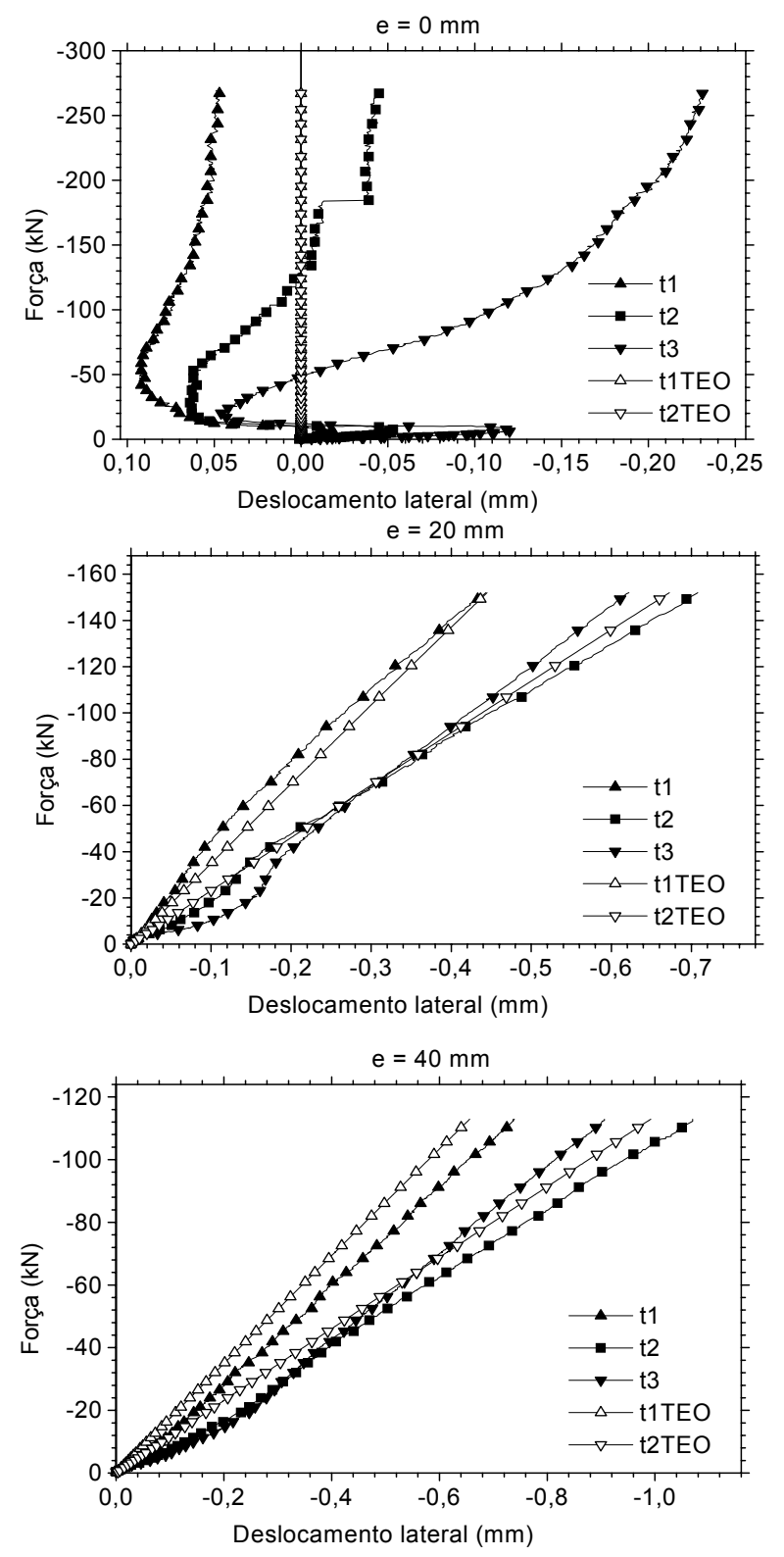

Figura 5.19 - Diagramas força x deslocamento lateral 
Como as rotações foram pequenas (menores que $0,5^{\circ}$ ) o deslocamento registrado pelo transdutor $\mathrm{t} 4$ foi considerado como acomodação de apoio. Isto é aceitável, já que o efeito de uma rotação de $0,5^{\circ}$ causaria um deslocamento lateral de apenas 0,08 mm. Acredita-se que este deslocamento lateral no início do ensaio ocorreu até que as peças do núcleo estivessem corretamente ajustadas com relação ao eixo longitudinal do pilar.

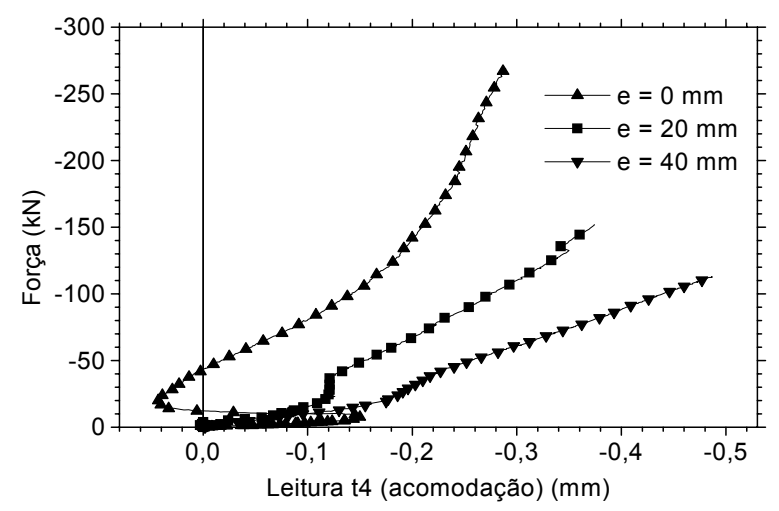

Figura 5.20 - Força $x$ deslocamento lateral registrado pelo $t 4$

Acredita-se ainda que há um acoplamento entre a rotação de apoio e o deslocamento transversal no apoio, em função das condições de contato entre as duas peças do núcleo da rótula, como ocorreu no sistema de rótulas original da máquina de ensaio. No entanto, como o raio de curvatura deste sistema de rótulas é bem menor que o original, este deslocamento lateral é bem mais reduzido. Sobretudo, como o pilar possui as rótulas nas duas extremidades é possível que o pilar se desloque lateralmente o suficiente para permitir a livre rotação dos apoios. Assim conclui-se que com este sistema de rótulas o pilar pode ser considerado efetivamente bi-rotulado. Vale a pena salientar ainda que, devido ao acoplamento entre rotações e deslocamento lateral, parte deste deslocamento lateral é necessário para ocorrer a rotação do pilar e pode estar presente nas medidas de deslocamentos laterais dos pilares. 


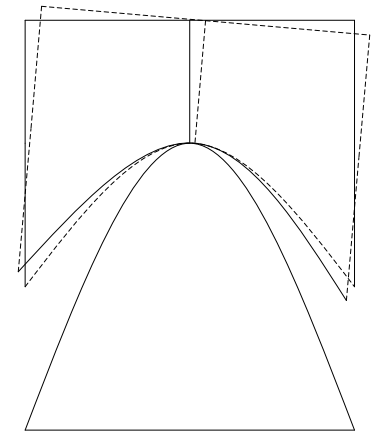

Figura 5.21 - Representação esquemática do acoplamento entre rotação e deslocamento lateral no apoio

Foram comparadas também as rotações de apoio calculadas com base em diferentes leituras dos ensaios. Pode-se observar uma boa concordância entre as rotações rot3 e rot4. Estas foram calculadas a partir dos deslocamentos axiais do pilar. A rotação rot3 utilizou os transdutores fixados com bases magnéticas enquanto a rot4 utilizou transdutores "pendurados". Esta concordância indica que o sistema de leituras com os transdutores pendurados fornece leituras confiáveis, o que os torna atrativos para medir as grandes rotações que devem acontecer no concreto confinado. No entanto, em função do grande número de ensaios a ser realizado em curto período de tempo optou-se finalmente pela utilização dos transdutores fixados com bases magnéticas pela maior facilidade de montagem.

Houve uma boa correspondência também destas rotações com as rot1 e rot2, calculadas com leituras de deslocamentos laterais dos transdutores t3 e t1 respectivamente. No entanto, as rotações rot5, calculadas com o transdutor t4 deram resultados discordantes, pois os deslocamentos laterais medidos representam mais efeitos de translação que de rotação. 

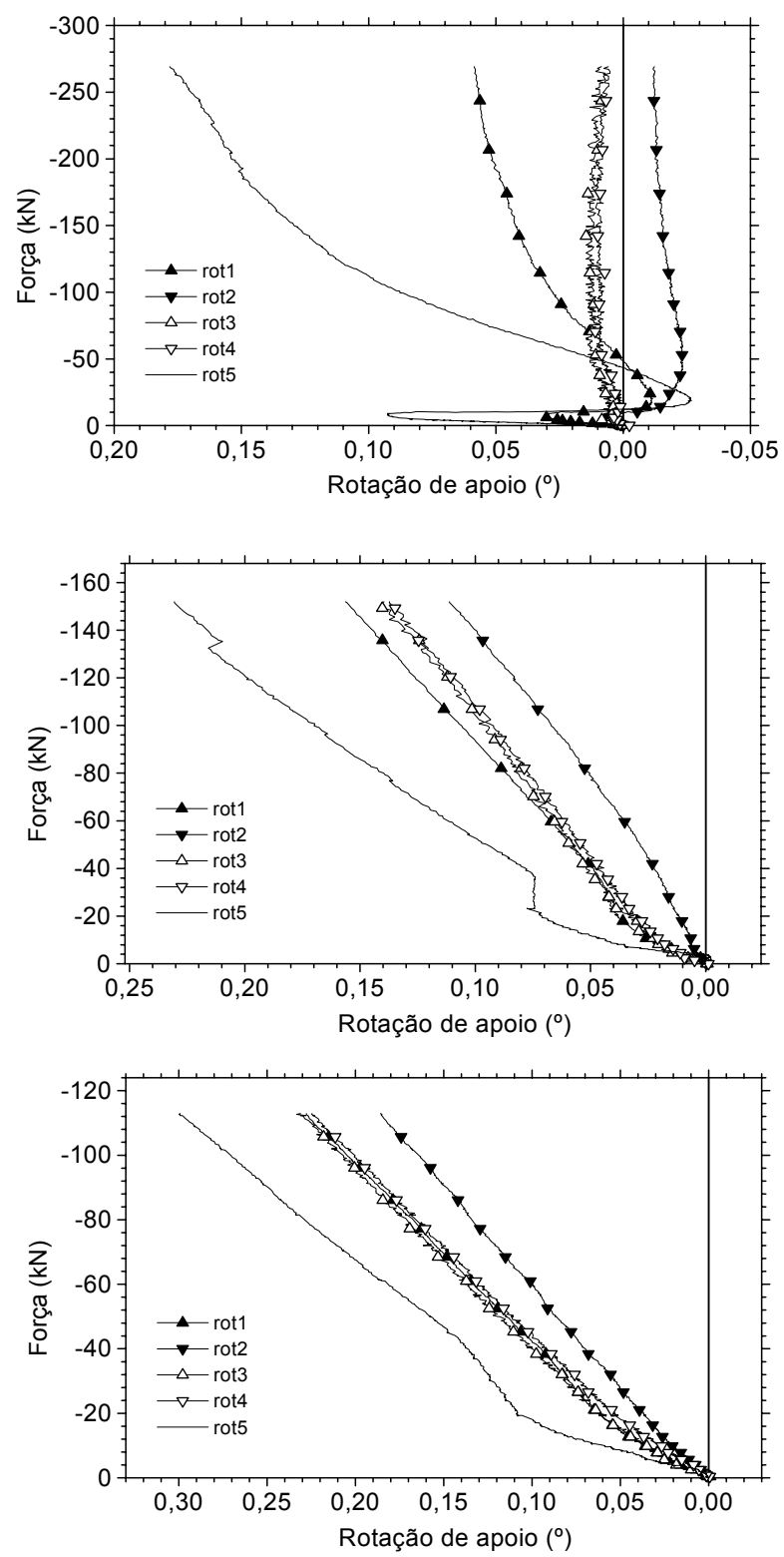

Figura 5.22 - Diagramas força x rotação de apoio

A verificação do comportamento da rótula indicou desempenho satisfatório em ensaios de flexo-compressão, encorajando sua utilização nas séries definitivas com pilares de concreto submetidos à compressão excêntrica.

\subsubsection{Descrição das séries definitivas}

Foram ensaiadas cinco séries de pilares com diferentes formas de seção transversal, excentricidades da força de compressão e número de camadas de PRFC. A nomenclatura empregada consiste de: - descrição da forma da seção transversal (primeira letra); - número de camadas de PRFC (primeiro número); - excentricidade nominal em cm (segundo número) e o último número, logo após $\mathrm{r}$, que indica o raio de 
arredondamento utilizado (quando aplicável). Esta nomenclatura, bem como a descrição dos ensaios é apresentada na Tabela 5.11.

Tabela 5.11 - Descrição das séries definitivas (séries 1 e 2)

\begin{tabular}{|c|c|c|c|c|}
\hline \multirow{2}{*}{\multicolumn{2}{|c|}{ Série $1^{*}$}} & \multicolumn{3}{|c|}{ Excentricidade nominal $(\mathrm{cm})$} \\
\hline & & 0 & 1 & 2 \\
\hline \multirow{3}{*}{$\begin{array}{c}\text { Número de } \\
\text { camadas }\end{array}$} & 0 & S00r1 & S01r1 & $\mathrm{S} 02 \mathrm{r} 1$ \\
\hline & 1 & S10r1 & $\mathrm{S} 11 \mathrm{r} 1$ & $\mathrm{~S} 12 \mathrm{r} 1$ \\
\hline & 2 & S20r1 & $\mathrm{S} 21 \mathrm{r} 1$ & $\mathrm{~S} 22 \mathrm{r} 1$ \\
\hline \multicolumn{5}{|c|}{ * seção transversal quadrada $(15 \mathrm{~cm} \times 15 \mathrm{~cm}) \mathrm{com} \mathrm{r}=1 \mathrm{~cm}$} \\
\hline
\end{tabular}

\begin{tabular}{|c|c|c|c|c|}
\hline \multirow{2}{*}{\multicolumn{2}{|c|}{ Série $2^{*}$}} & \multicolumn{3}{|c|}{ Excentricidade nominal $(\mathrm{cm})$} \\
\hline & & 0 & 1 & 2 \\
\hline \multirow{3}{*}{$\begin{array}{l}\text { Número de } \\
\text { camadas }\end{array}$} & 0 & S00r3 & S01r3 & $\mathrm{S} 02 \mathrm{r} 3$ \\
\hline & 1 & S10r3 & $\begin{array}{l}\text { S11r3-a } \\
\text { S11r3-b }\end{array}$ & - \\
\hline & 2 & $\mathrm{~S} 20 \mathrm{r} 3$ & $\mathrm{~S} 21 \mathrm{r} 3$ & $\mathrm{~S} 22 \mathrm{r} 3$ \\
\hline
\end{tabular}

\begin{tabular}{|c|c|c|c|c|}
\hline \multicolumn{2}{|c|}{ Série $3^{*}$} & & $\frac{d \mathrm{de} \text { nom }}{{ }_{\mathrm{y}}}$ & \\
\hline & & 0 & $x=3$ & $y=2$ \\
\hline Número de & 0 & R00 & R0x3 & R0y2 \\
\hline camadas & 2 & R20 & $\mathrm{R} 2 \times 3$ & $\mathrm{R} 2 \mathrm{y} 2$ \\
\hline
\end{tabular}

\begin{tabular}{|c|c|c|c|c|}
\hline \multicolumn{2}{|c|}{ Série 4* } & \multicolumn{3}{c|}{ Excentricidade nominal (cm) } \\
\cline { 3 - 5 } \multicolumn{2}{|c|}{} & 0 & 1 & 2 \\
\hline Número de & 0 & C00 & C01 & C02 \\
camadas & 2 & C20 & C21 & C22 \\
\cline { 2 - 3 } & * seção transversal circular com diâmetro de 15 cm \\
\hline
\end{tabular}

\begin{tabular}{|c|c|c|c|c|c|}
\hline \multirow{2}{*}{ Série 5* } & \multicolumn{4}{|c|}{ Excentricidade nominal $(\mathrm{cm}) ;$ raio de arredondamento $(\mathrm{cm})$} \\
\cline { 3 - 6 } & & $0 ; 1$ & $0 ; 3$ & $2 ; 1$ & $2 ; 3$ \\
\hline \multirow{2}{*}{ Número de camadas } & 0 & X00 & - & X02 & - \\
\cline { 2 - 5 } & 1 & X10r1 & X10r3 & X12r1 & X12r3 \\
\hline *seção transversal quadrada $(15 \times 15 \mathrm{~cm})$ com valor de $\mathrm{f}_{\mathrm{co}}$ diferente das demais séries \\
\hline
\end{tabular}


O comprimento dos pilares foi de $45 \mathrm{~cm}$, resultando numa relação largura / altura $=1 / 3$. Esse comprimento foi escolhido com base em dois fatores: pilares mais longos poderiam sofrer maiores efeitos de segunda ordem, dificultando a análise dos resultados; - pilares mais curtos poderiam sofrer uma influência muito grande das condições de contorno (atrito nos apoios). As únicas exceções de relação largura / altura são os pilares de seções retangulares R00, R20, R0x3 e R2x3, em que essa relação foi de $1 / 2$ para o lado maior.

Foram utilizados extensômetros elétricos de resistência do tipo uniaxial (KFG 5 - 120 - C1-11) e roseta triaxial (KFG - 5 - 120 - D17-11) da marca KYOWA colados à camisa de reforço de PRFC. Estes extensômetros foram utilizados para medir deformações axiais e laterais nos pontos da seção transversal indicados na Figura 5.23.

Seção quadrada
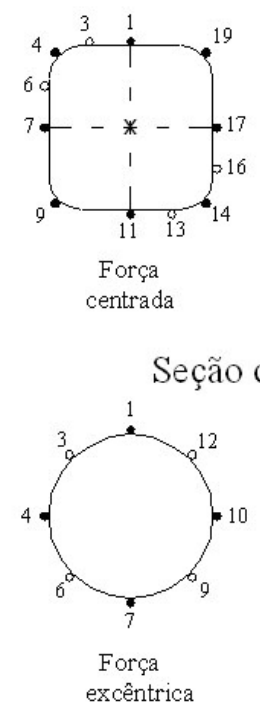

Figura 5.23 - Instrumentação com extensômetros elétricos de resistência
Seção retangular

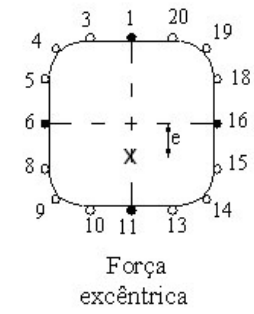

LEGENDA

- Extensômetros transversais

- Extensômetros biaxiais

(axial e transversal)

Foram empregados transdutores de deslocamento à base de extensômetros elétricos de resistência, da marca KYOWA, com curso de $10 \mathrm{~mm}$ (T1 e T3) e $20 \mathrm{~mm}$ (T2, T4 e T5) nos ensaios das séries definitivas. Os transdutores T1 e T3 foram instalados para medir os deslocamentos laterais a $10 \mathrm{~cm}$ das extremidades dos pilares, conforme Figura 5.24. O transdutor T2 foi utilizado para medir o deslocamento lateral no meio do pilar. Os transdutores T4 e T5 foram utilizados para medir os deslocamentos axiais nas faces opostas dos pilares, podendo avaliar os efeitos de compressão e flexão. 


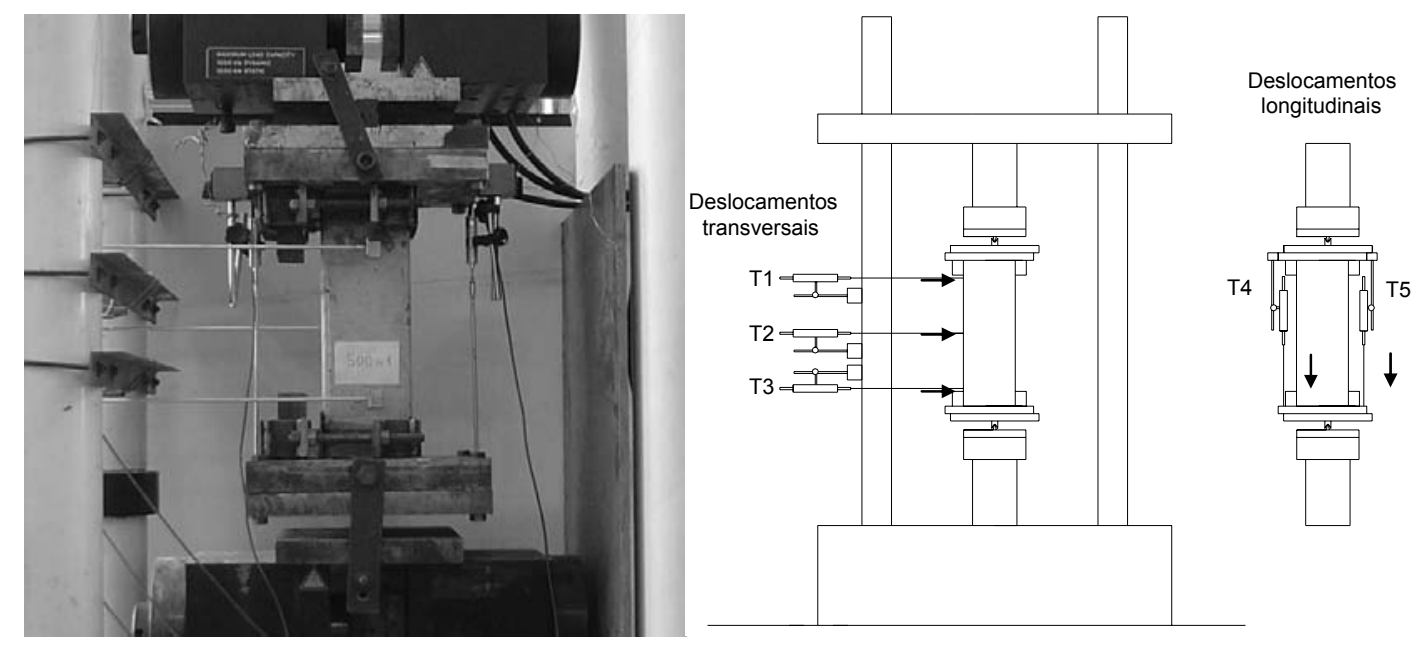

Figura 5.24 - Instrumentação com transdutores de deslocamento das séries definitivas

A força última de todos os ensaios é apresentada na Tabela 5.12. Pode-se observar que a aplicação dos tecidos de fibras de carbono trouxe acréscimos de capacidade resistente à compressão para todas as seções transversais e excentricidades nominais ensaiadas.

Tabela 5.12 - Comparativo da força última das diferentes séries

\begin{tabular}{|c|c|c|c|c|c|c|c|c|c|}
\hline Pilar & $\mathrm{n}$ & $\mathrm{e}(\mathrm{cm})$ & $\mathrm{F}_{\mathrm{u}}(\mathrm{kN})$ & $\frac{F_{u}(n)}{F_{u}(n=0)}$ & Pilar & $\mathrm{n}$ & $\mathrm{e}(\mathrm{cm})$ & $\mathrm{F}_{\mathrm{u}}(\mathrm{kN})$ & $\frac{F_{u}(n)}{F_{u}(n=0)}$ \\
\hline S00r1 & 0 & 0 & 815,4 & 1 & R00 & 0 & 0 & 1019,3 & 1 \\
\hline S10r1 & 1 & 0 & 865,9 & 1,062 & R20 & 2 & 0 & 1330,2 & 1,305 \\
\hline S20r1 & 2 & 0 & 875,5 & 1,074 & R0x3 & 0 & $x=3$ & 644,1 & 1 \\
\hline S01r1 & 0 & 1 & 706,4 & 1 & $\mathrm{R} 2 \times 3$ & 2 & $x=3$ & 1060,2 & 1,65 \\
\hline S11r1 & 1 & 1 & 779,6 & 1,104 & R0y2 & 0 & $y=2$ & 756,4 & 1 \\
\hline $\mathrm{S} 21 \mathrm{r} 1$ & 2 & 1 & 816,3 & 1,156 & $\mathrm{R} 2 \mathrm{y} 2$ & 2 & $y=2$ & 1020,0 & 1,348 \\
\hline S02r1 & 0 & 2 & 576,8 & 1 & $\mathrm{C} 00$ & 0 & 0 & 681,1 & 1 \\
\hline $\mathrm{S} 12 \mathrm{r} 1$ & 1 & 2 & 650,4 & 1,128 & $\mathrm{C} 10$ & 1 & 0 & 1000,0 & 1,468 \\
\hline $\mathrm{S} 22 \mathrm{r} 1$ & 2 & 2 & 722,0 & 1,252 & $\mathrm{C} 20$ & 2 & 0 & 1560,0 & 2,29 \\
\hline S00r3 & 0 & 0 & 730,5 & 1 & $\mathrm{C} 02$ & 0 & 2 & 469,4 & 1 \\
\hline S10r3 & 1 & 0 & 839,9 & 1,15 & $\mathrm{C} 12$ & 1 & 2 & 611,6 & 1,303 \\
\hline S20r3 & 2 & 0 & 1047,0 & 1,43 & $\mathrm{C} 22$ & 2 & 2 & 909,1 & 1,937 \\
\hline S01r3 & 0 & 1 & 573,3 & 1 & $\mathrm{X} 00$ & 0 & 0 & 561,6 & 1 \\
\hline S11r3-a & 1 & 1 & 722,4 & 1,260 & X10r1 & 1 & 0 & 632,8 & 1,127 \\
\hline S11r3-b & 1 & 1 & 742,4 & 1,295 & X10r3 & 1 & 0 & 686,3 & 1,22 \\
\hline $\mathrm{S} 21 \mathrm{r} 3$ & 2 & 1 & 928,7 & 1,62 & X02 & 0 & 2 & 367,8 & 1 \\
\hline $\mathrm{S} 02 \mathrm{r} 3$ & 0 & 2 & 552,1 & 1 & $\mathrm{X} 12 \mathrm{r} 1$ & 1 & 2 & 483,0 & 1,313 \\
\hline $\mathrm{S} 22 \mathrm{r} 3$ & 2 & 2 & 745,0 & 1,348 & $\mathrm{X} 12 \mathrm{r} 3$ & 1 & 2 & 487,3 & 1,325 \\
\hline
\end{tabular}


$\mathrm{Na}$ Tabela 5.13 são apresentadas as propriedades geométricas das seções ensaiadas e as propriedades mecânicas que foram utilizadas nas análises dos resultados dos ensaios.

Tabela 5.13 - Propriedades geométricas e mecânicas dos pilares ensaiados

\begin{tabular}{|c|c|c|c|c|c|c|c|}
\hline \multirow[t]{2}{*}{ Série } & \multirow[t]{2}{*}{ Seção } & \multirow{2}{*}{$\begin{array}{c}\text { Dimensões } \\
(\mathrm{cm})\end{array}$} & \multirow[t]{2}{*}{$\mathrm{r}(\mathrm{cm})$} & \multirow{2}{*}{$\begin{array}{c}\text { Área da } \\
\text { seção } \\
\text { transversal } \\
\quad\left(\mathrm{cm}^{2}\right)\end{array}$} & \multicolumn{2}{|r|}{${ }_{4}^{y} x$} & \multirow[b]{2}{*}{$\mathrm{I}_{\mathrm{y}}\left(\mathrm{cm}^{4}\right)$} \\
\hline & & & & & \multicolumn{2}{|c|}{$\mathrm{I}_{\mathrm{x}}\left(\mathrm{cm}^{4}\right)$} & \\
\hline 1 & Quadrada & $15 \times 15$ & 0 & 225,00 & \multicolumn{2}{|c|}{$4,219.10^{3}$} & $4,219.10^{3}$ \\
\hline 2 & & $15 \times 15$ & 1 & 224,14 & \multicolumn{2}{|c|}{$4,173 \cdot 10^{3}$} & $4,173 \cdot 10^{3}$ \\
\hline 3 & & $15 \times 15$ & 3 & 217,27 & \multicolumn{2}{|c|}{$3,856 \cdot 10^{3}$} & $3,856.10^{3}$ \\
\hline 4 & Retangular & $15 \times 22,5$ & 3 & 329,77 & \multicolumn{2}{|c|}{$5,965 \cdot 10^{3}$} & $1,337.10^{4}$ \\
\hline 5 & Circular & $\begin{array}{c}15 \\
\text { (diâmetro) }\end{array}$ & - & 176,71 & \multicolumn{2}{|c|}{$2,485 \cdot 10^{3}$} & $2,485.10^{3}$ \\
\hline & Série & $\begin{array}{l}\text { Módulo de } \\
\text { elasticidade } \\
\text { corpo-de- } \\
\text { prova (MPa) }\end{array}$ & $\begin{array}{c}\text { Módulo de } \\
\text { elasticidade } \\
\text { do } \\
\text { concreto do } \\
\text { pilar }^{4} \\
(\mathrm{MPa})\end{array}$ & $\begin{array}{l}\text { Relação } \\
\text { módulo } \\
\text { Pilar / } \\
\text { corpo-de- } \\
\text { prova }\end{array}$ & $\begin{array}{c}\text { Resistência } \\
\text { do concreto } \\
\text { do corpo-de- } \\
\text { prova } \\
(\mathrm{MPa})\end{array}$ & $\begin{array}{c}\text { Resistência } \\
\text { do concreto } \\
\text { do pilar }{ }^{4} \\
(\mathrm{MPa})\end{array}$ & $\begin{array}{c}\text { Relação } \\
\text { resistência } \\
\text { pilar/corpo-de- } \\
\text { prova }\end{array}$ \\
\hline & 1 & 28550 & 15500 & 0,543 & 42,5 & 36,4 & 0,856 \\
\hline & 2 & 28550 & 18565 & 0,650 & 42,5 & 37,1 & 0,873 \\
\hline & 3 & 28550 & 18600 & 0,651 & 42,5 & 33,6 & 0,791 \\
\hline & 4 & 28550 & 20260 & 0,710 & 42,5 & 38,5 & 0,906 \\
\hline & 5 & 26000 & 13820 & 0,532 & 31,1 & 25,1 & 0,807 \\
\hline
\end{tabular}

Pode-se observar que os fatores redutores da resistência e módulo de elasticidade em comparação com o corpo-de-prova dependem da forma seção transversal, sendo a redução maior para os pilares de seção quadrada com menores raios de arredondamento.

\subsubsection{Resultados obtidos - Série 1}

A série 1 é caracterizada por uma seção transversal quadrada $(15 \times 15 \mathrm{~cm})$ e cantos arredondados com um raio de $1 \mathrm{~cm}$. Diversas das leituras obtidas foram influenciadas por acomodações no início do ensaio, de modo que são apresentados os diagramas corrigidos (foram descontados os efeitos das acomodações).

\footnotetext{
${ }^{4}$ Resultados obtidos nos ensaios com o sistema de rótulas e excentricidade nominal nula.
} 
Na Figura 5.25 são apresentados os diagramas força $\mathrm{x}$ deslocamento axial dos pilares da série 1. O deslocamento axial apresentado é a média das leituras obtidas pelos transdutores de deslocamento axiais.

Os diagramas foram agrupados de acordo com a excentricidade aplicada, sendo assim possível observar o efeito do aumento do número de camadas do compósito sobre o diagrama tensão x deformação para cada excentricidade.

Os acréscimos de deslocamento último e a própria forma dos diagramas foram bem semelhantes para as diferentes excentricidades aplicadas, indicando um efeito de confinamento semelhante nestes ensaios. A reta pontilhada representa a curva força $\mathrm{x}$ deslocamento axial teórica para um pilar curto de material elástico linear sem considerar efeitos de segunda ordem.

Nesta série o efeito de confinamento foi relativamente baixo, devido principalmente ao pequeno valor do raio de arredondamento comparado com a largura da seção transversal. Ocorreram, assim, pequenos acréscimos de resistência e deformação última, mas uma significativa deformabilidade pós-pico até a ruptura da camisa. 

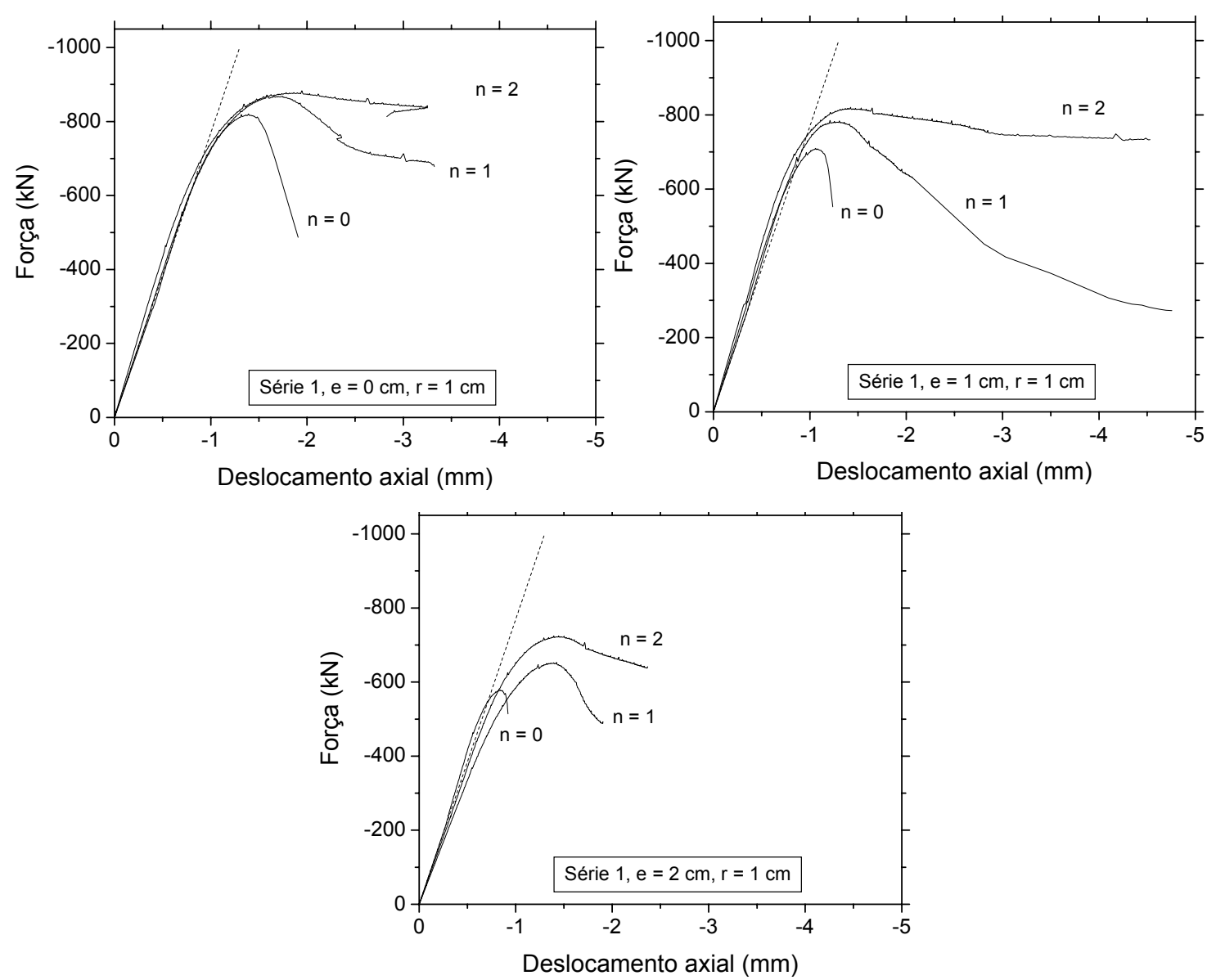

Figura 5.25 - Diagramas força $\mathrm{x}$ deslocamento axial dos pilares da série 1

A rotação dos apoios foi calculada por meio da equação:

$$
\tan (\theta)=\frac{T 4-T 5}{2 B}
$$

onde:

- T4 é o deslocamento axial medido pelo transdutor 4;

- T5 é o deslocamento axial medido pelo transdutor 5;

- B é a distância entre os eixos dos transdutores 4 e 5, de $380 \mathrm{~mm}$.

No cálculo desta rotação de apoios adotou-se por simplificação que a rotação na extremidade superior seja igual à inferior.

Na Figura 5.26 são apresentados os diagramas força $\mathrm{x}$ rotação dos apoios da série 1. Para cada diagrama, a reta apresentada em pontilhado indica a inclinação inicial do gráfico para uma excentricidade igual à nominal. Os resultados indicam que as excentricidades nominais correspondem adequadamente às efetivas para todos os ensaios. No ensaio de compressão centrada observou-se um efeito de excentricidade de provavelmente poucos milímetros, por causa de imprecisões das dimensões dos pilares e 
de posicionamento na máquina de ensaio. A utilização do PRFC possibilitou significativos aumentos de rotação do pilar até a força última e também no regime póspico de resistência, até a ruptura da camisa.

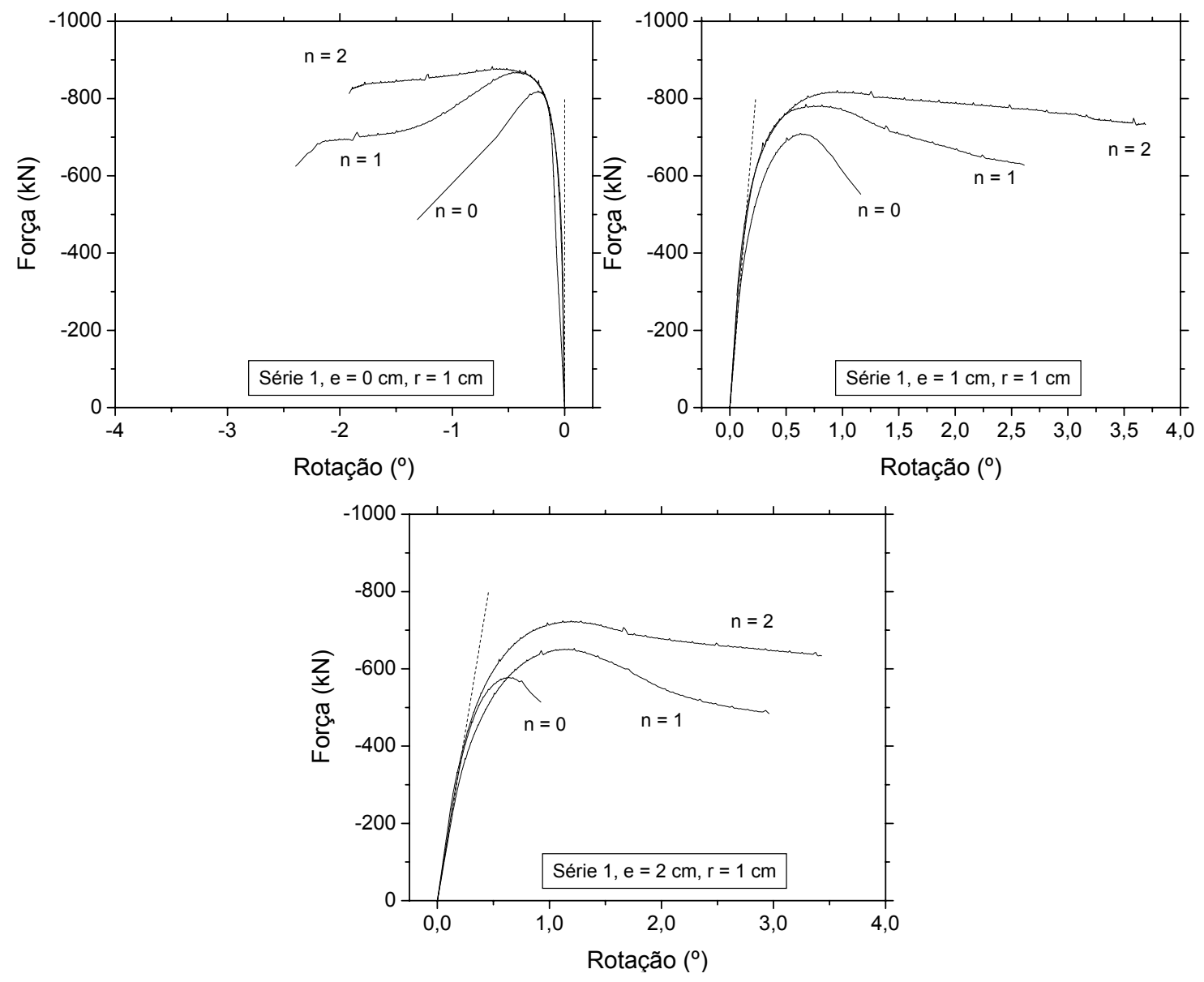

Figura 5.26 - Diagramas força x rotação de apoios dos pilares da série 1

Os diagramas força $\mathrm{x}$ deslocamento lateral dos pilares apresentaram um comportamento também condizente com a excentricidade aplicada, sendo o deslocamento lateral sempre maior com o aumento da excentricidade. As retas traçadas em pontilhado representam a inclinação inicial a ser obtida caso a excentricidade efetiva fosse exatamente igual à nominal. 

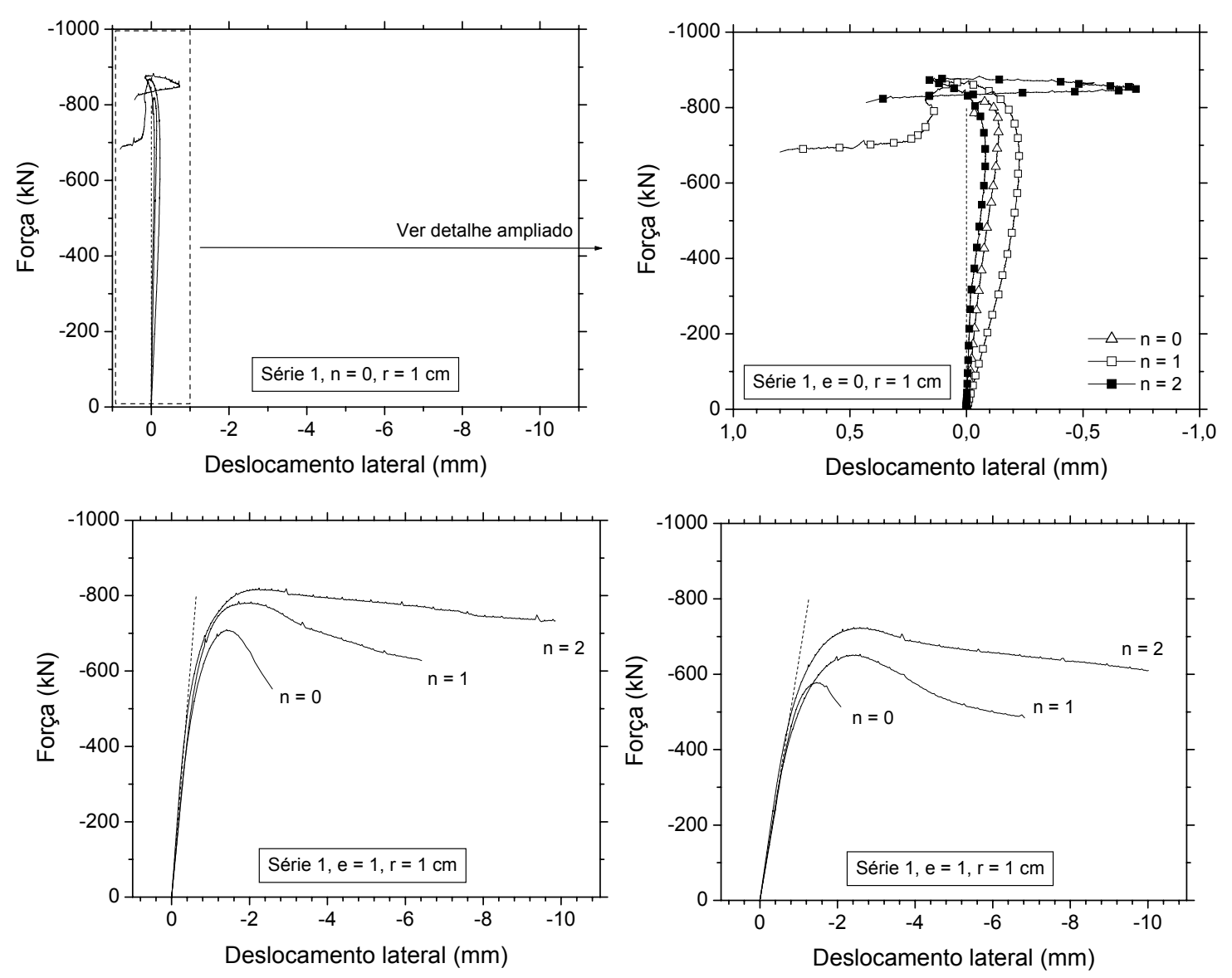

Figura 5.27 - Diagramas força $x$ deslocamento lateral

\subsubsection{Resultados obtidos - Série 2}

Na Figura 5.28 são apresentados os diagramas força $\mathrm{x}$ deslocamento axial dos pilares da série 2. Estes pilares possuem seção quadrada com lados de $15 \mathrm{~cm}$ e raio de arredondamento de $3 \mathrm{~cm}$. Pode-se observar que o pilar S01r3, mesmo com a correção, apresentou uma inclinação inicial menor em comparação aos demais.

Nesta série os diagramas foram bi-lineares com o segundo trecho ascendente ou horizontal. Isto ocorreu por que estes pilares possuem um raio de arredondamento maior que a série 1. A presença da excentricidade reduziu levemente a inclinação do segundo trecho linear. 

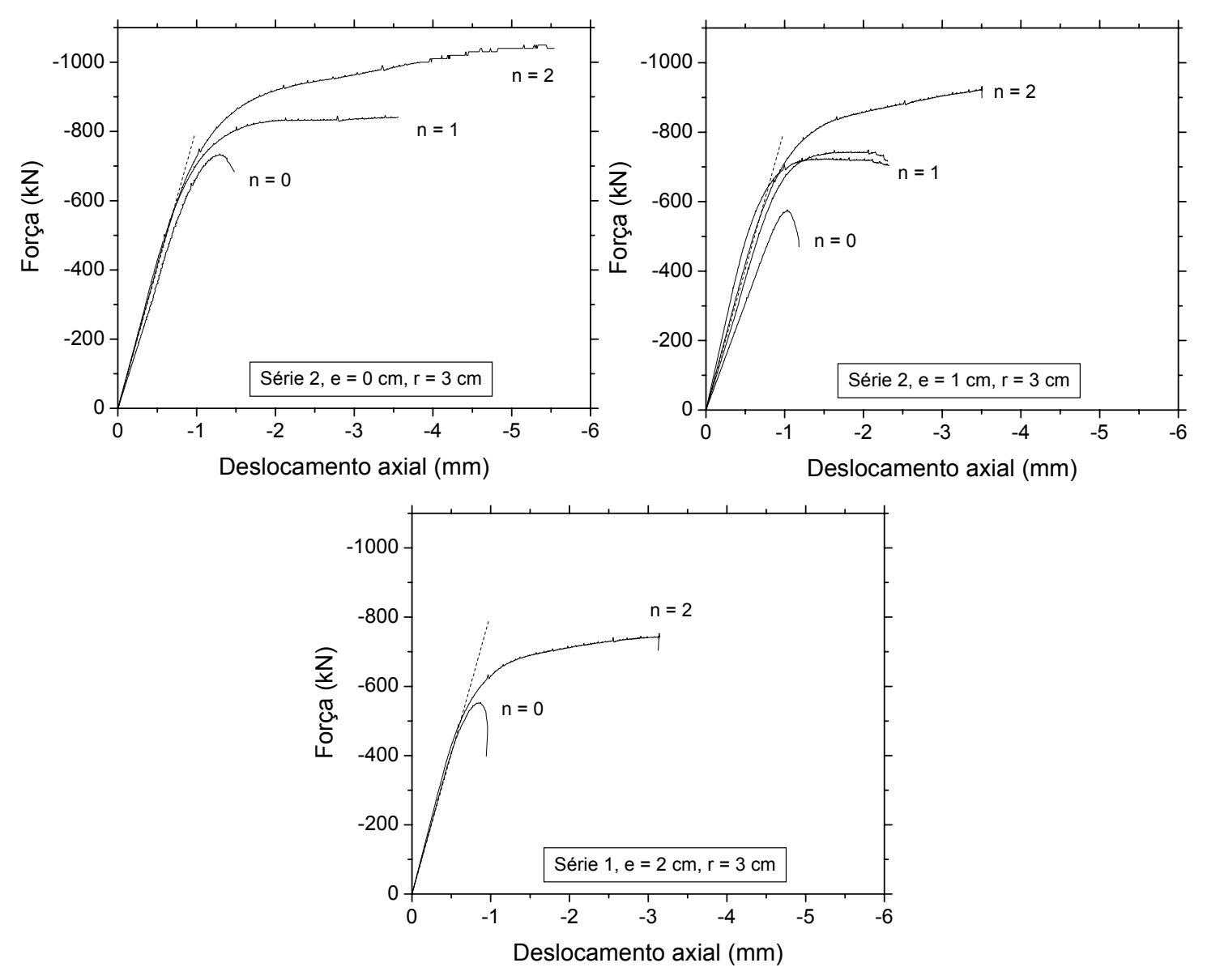

Figura 5.28 - Diagramas força $x$ deslocamento axial

Com relação aos diagramas força x rotação de apoios foi possível observar uma boa concordância dos resultados obtidos com os valores iniciais esperados para todos os ensaios. Deve-se notar que a aplicação do PRFC possibilitou grandes aumentos da rotação na ruptura dos pilares ensaiados nesta série. 

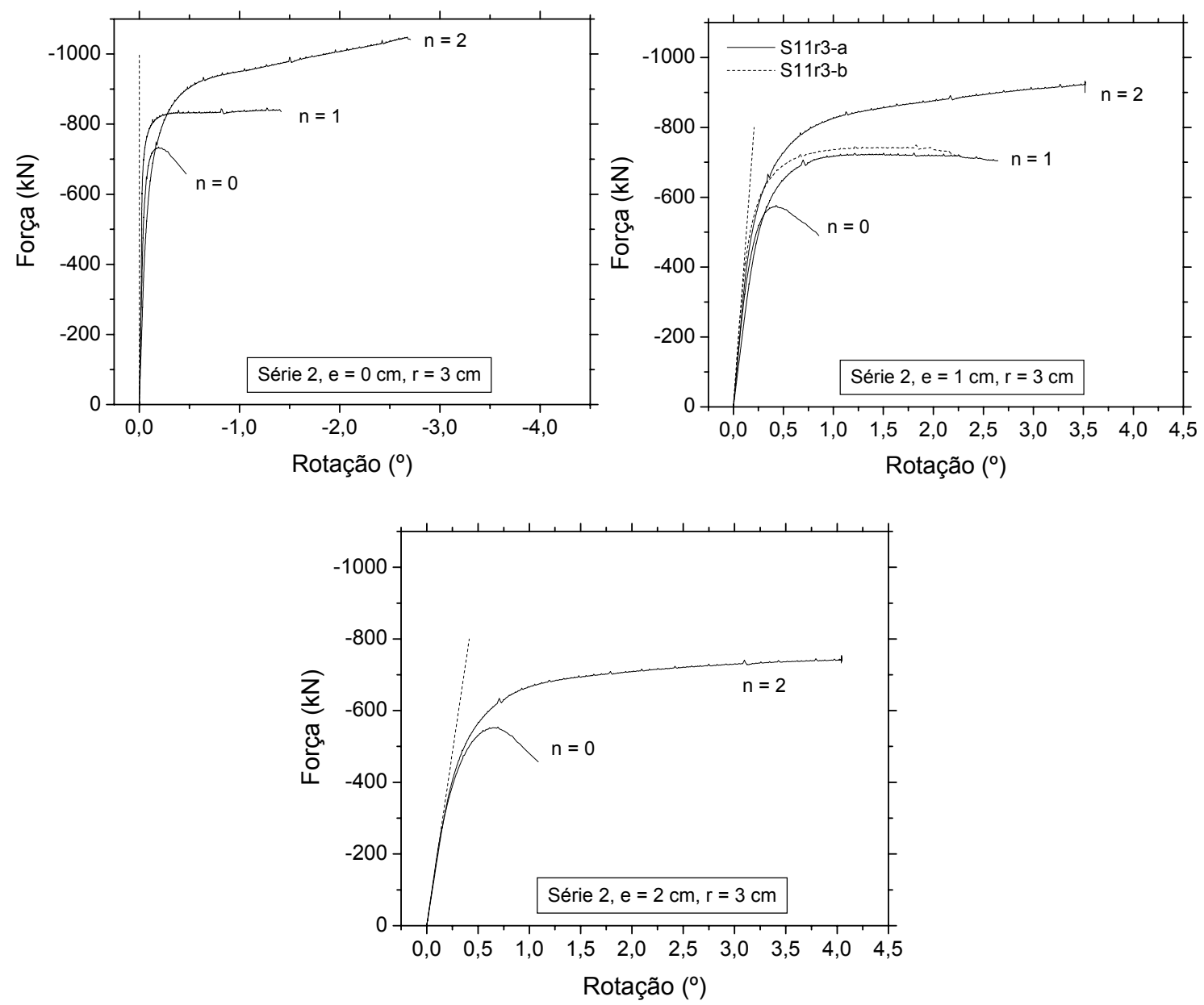

Figura 5.29 - Diagramas força $x$ rotação de apoios

Foi possível observar grandes deslocamentos laterais na ruptura dos pilares encamisados, indicando que a influência dos efeitos de segunda ordem em pilares mais longos podem ser muito importantes. 

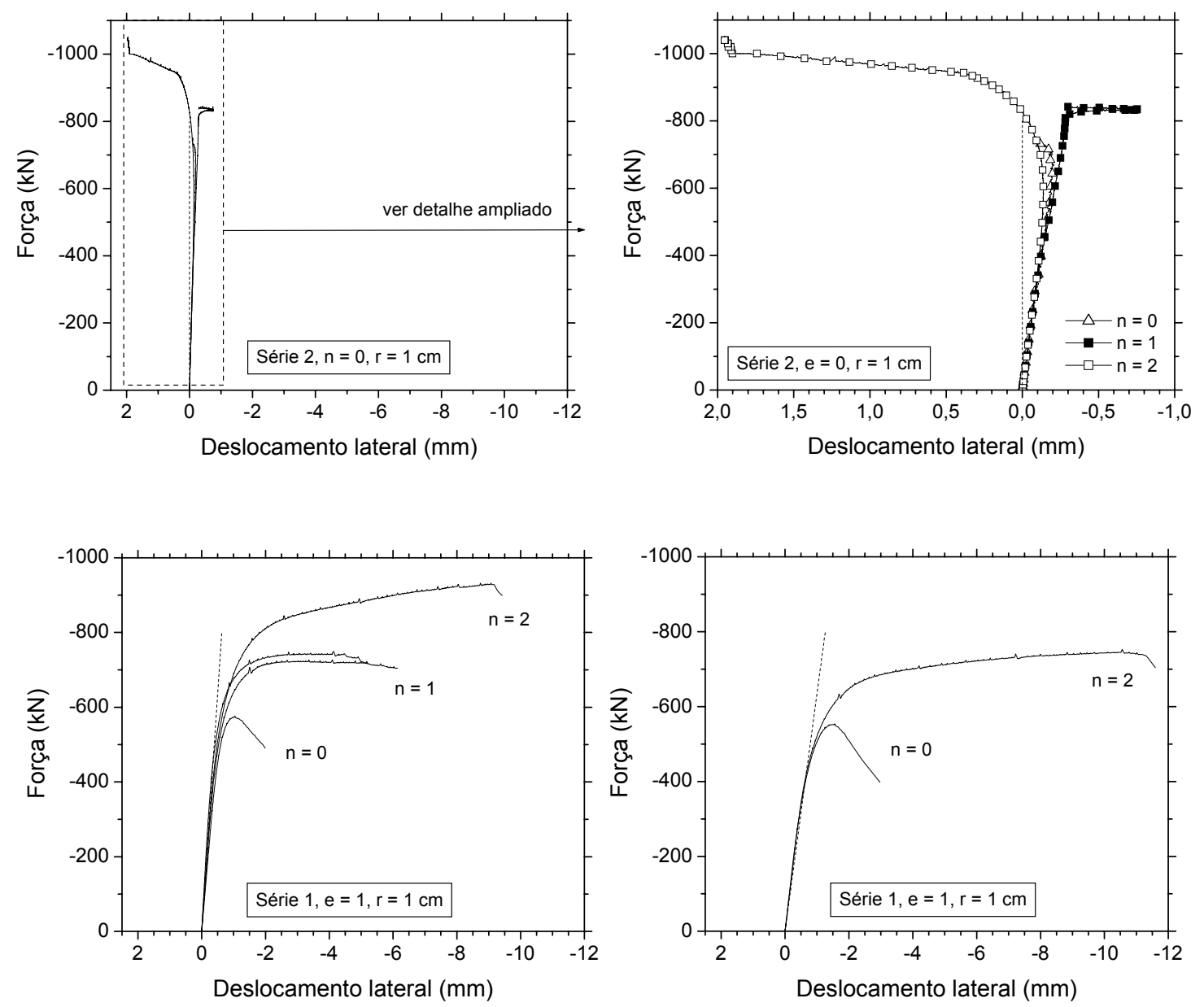

Figura 5.30 - Diagramas força $x$ deslocamento lateral 


\subsubsection{Resultados obtidos - Série 3}

Os diagramas força $\mathrm{x}$ deslocamento axial dos pilares de seção retangular (15 x $22,5 \mathrm{~cm}$ ) e raio de arredondamento de $3 \mathrm{~cm}$ são apresentados na Figura 5.31. Pode-se observar que ocorreram importantes aumentos de capacidade resistente e ductilidade nos pilares retangulares encamisados com 2 camadas de PRFC em comparação aos de referência, mesmos nos casos de compressão excêntrica.

Deve-se observar ainda que no ensaio do pilar R00 ocorreu uma fissura vertical na região central do modelo, indicando um possível fendilhamento, que reduziu a rigidez e a capacidade resistente deste pilar. Este fendilhamento pode ter ocorrido por algum problema na execução do capeamento com massa plástica na superfície do mesmo, que concentrou tensões na região central da superfície de aplicação do carregamento. $\mathrm{O}$ efeito da fissura surgida pode ser observado na queda de força que ocorre a partir dos $740 \mathrm{kN}$ no diagrama força $\mathrm{x}$ deslocamento axial. Por isto, nas análises dos resultados, a resistência à compressão do pilar de seção quadrada com $r=1$ cm (S00r1) foi utilizada no lugar do pilar R00.

Nos diagramas força $\mathrm{x}$ deslocamento axial desta série foram observados importantes ganhos iniciais de resistência, seguidos de trechos retos com inclinação praticamente horizontal ou negativa.

Na direção da maior inércia (lado de 22,5 cm) foi aplicada uma excentricidade de $e_{x}=3 \mathrm{~cm}$. Na direção da menor inércia $(15 \mathrm{~cm}$ de lado) foi aplicada uma excentricidade de $e_{y}=2 \mathrm{~cm}$. Apesar de ter sido adotada a mesma excentricidade relativa nas duas direções $(\mathrm{e} / \mathrm{h}=0,133)$, foi observado um efeito de confinamento maior na direção da maior inércia, concordando com o observado por BOSIAS et al. (2001) em ensaios com forças axiais sobrepostas a forças laterais. 

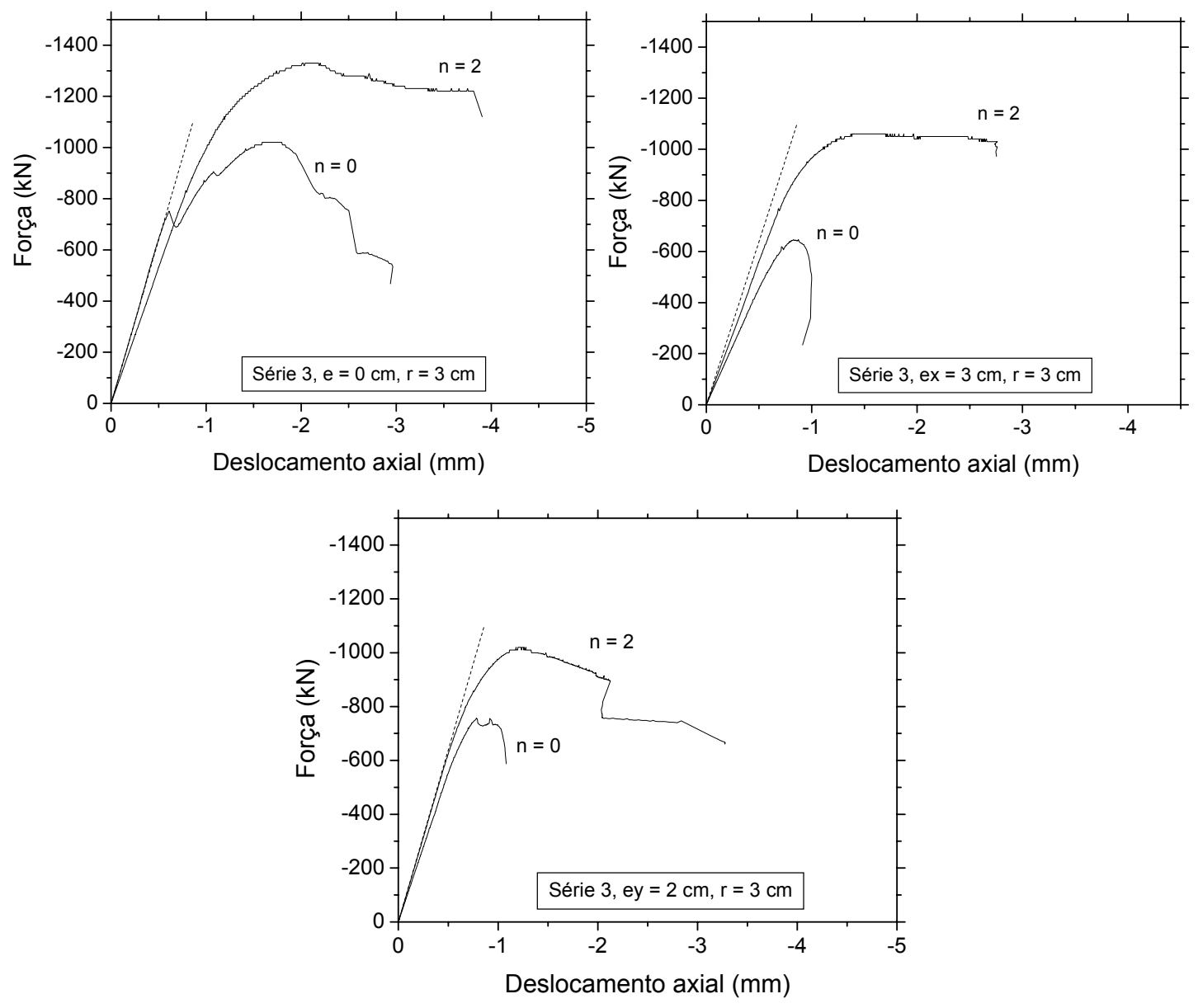

Figura 5.31 - Diagramas força $x$ deslocamento axial

As rotações últimas de apoio também foram significativamente aumentadas com a aplicação do encamisamento, como indica a Figura 5.32. Maiores ainda foram as rotações no instante da ruptura da camisa, indicando uma grande absorção de energia até a ruína do pilar. 

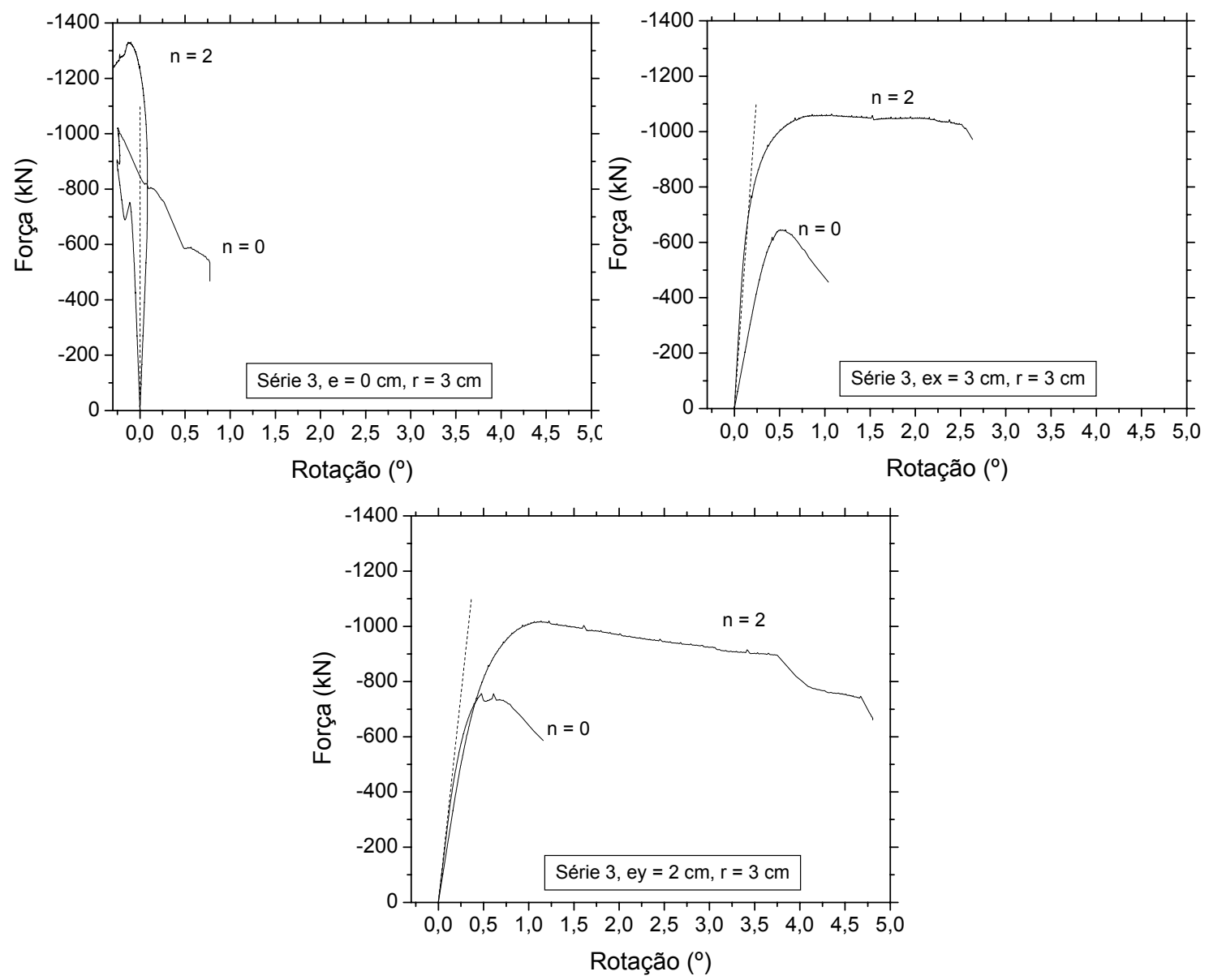

Figura 5.32 - Diagramas força x rotação de apoio - Série 3

Os deslocamentos laterais também foram bastante elevados nos pilares encamisados, como indica a Figura 5.33. 

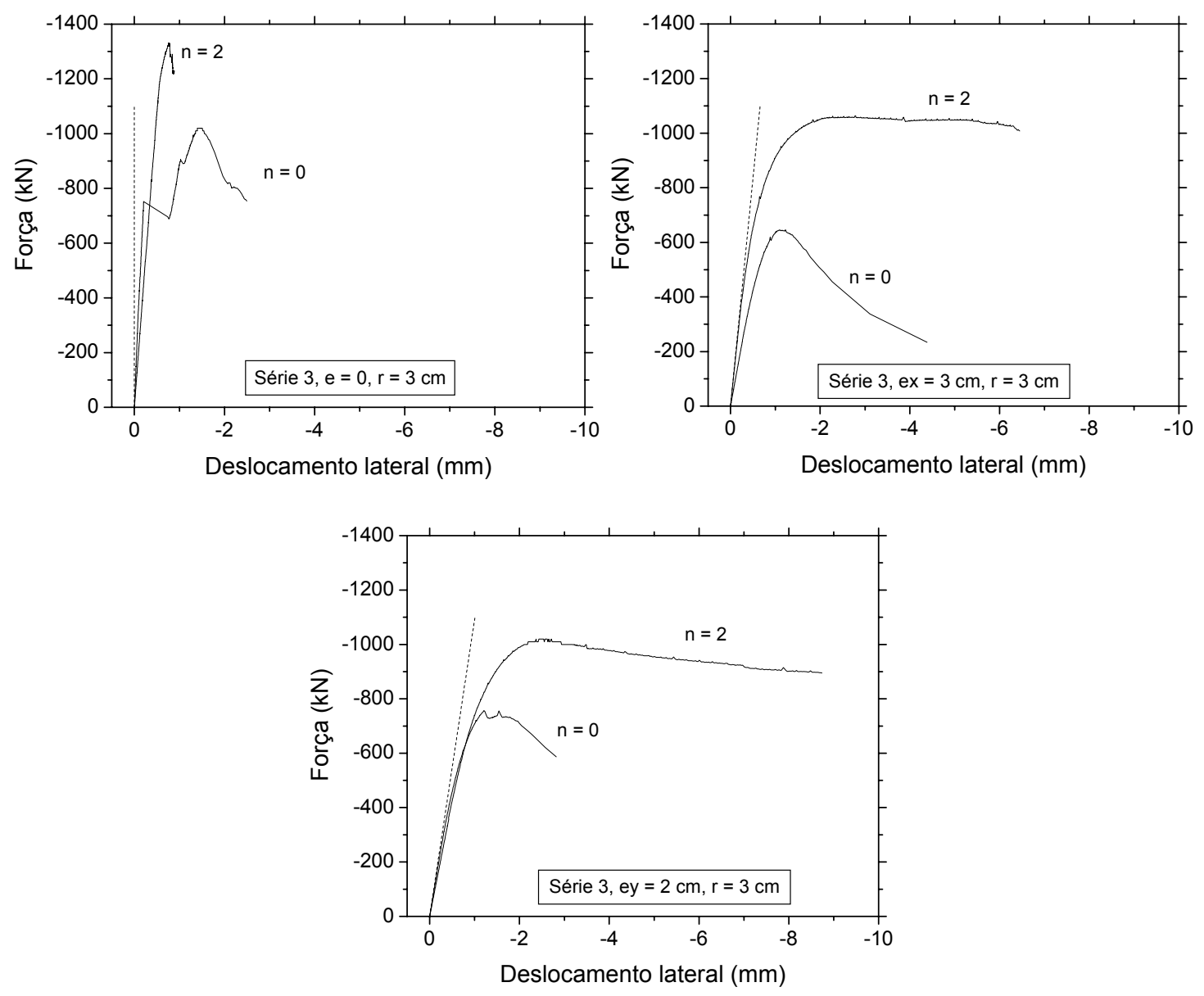

Figura 5.33 - Diagramas força $x$ deslocamento lateral (mm)

\subsubsection{Resultados obtidos - Série 4}

Os diagramas força $\mathrm{x}$ deslocamento axial dos pilares de seção circular com 15 cm de diâmetro são apresentados na Figura 5.34. Pode-se observar que, nos pilares de seção circular, com a presença da excentricidade o efeito de confinamento foi reduzido. No entanto, pode-se observar também que, mesmo no caso da excentricidade de $2 \mathrm{~cm}$, os ganhos de resistência e deformação última ainda foram significativos, e a forma do diagrama tensão $\mathrm{x}$ deformação foi semelhante.

O diagrama tensão x deformação de pilares de seção circular encamisados com PRFC é marcadamente bi-linear. No entanto, na presença de grande excentricidade, o diagrama pode apresentar uma redução gradativa da inclinação por causa do efeito de segunda ordem. 

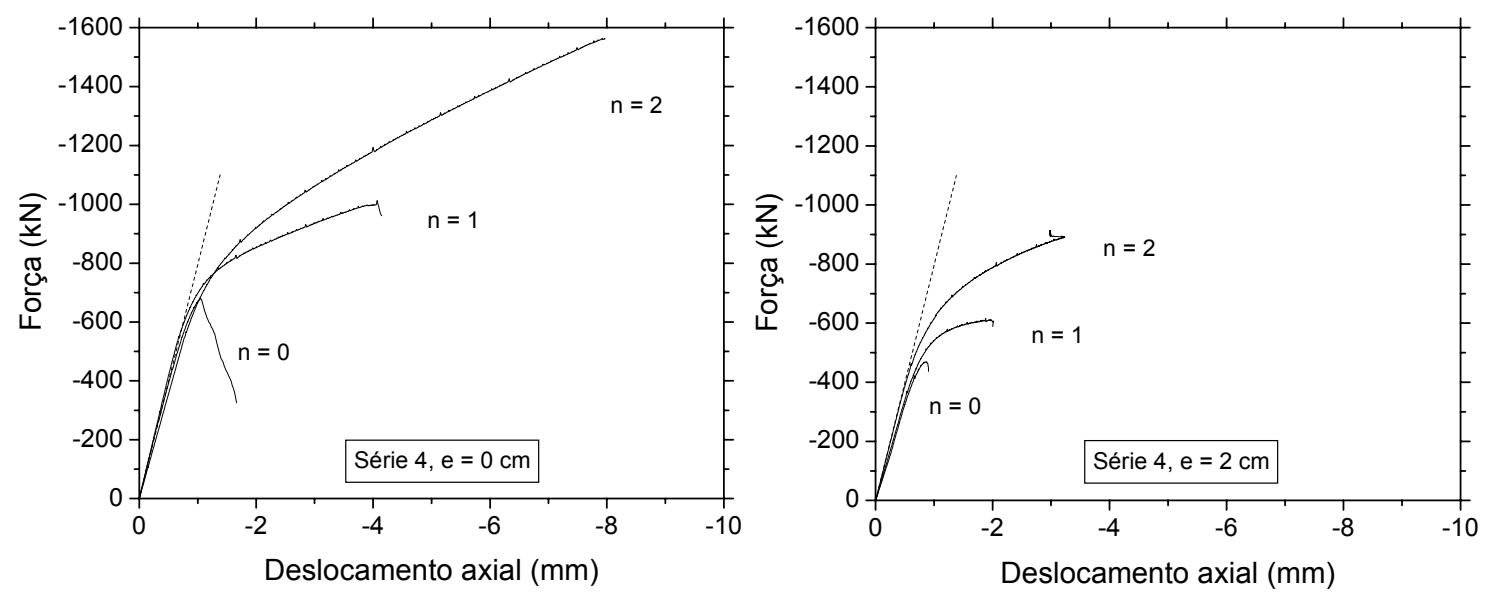

Figura 5.34 - Diagramas força $\mathrm{x}$ deslocamento axial

As rotações de apoio foram bastante elevadas, como mostra a Figura 5.35, sendo que no caso do pilar com $n=2$ não foi possível registrar as rotações precisamente até o final do ensaio, pois o curso de um dos transdutores havia terminado.
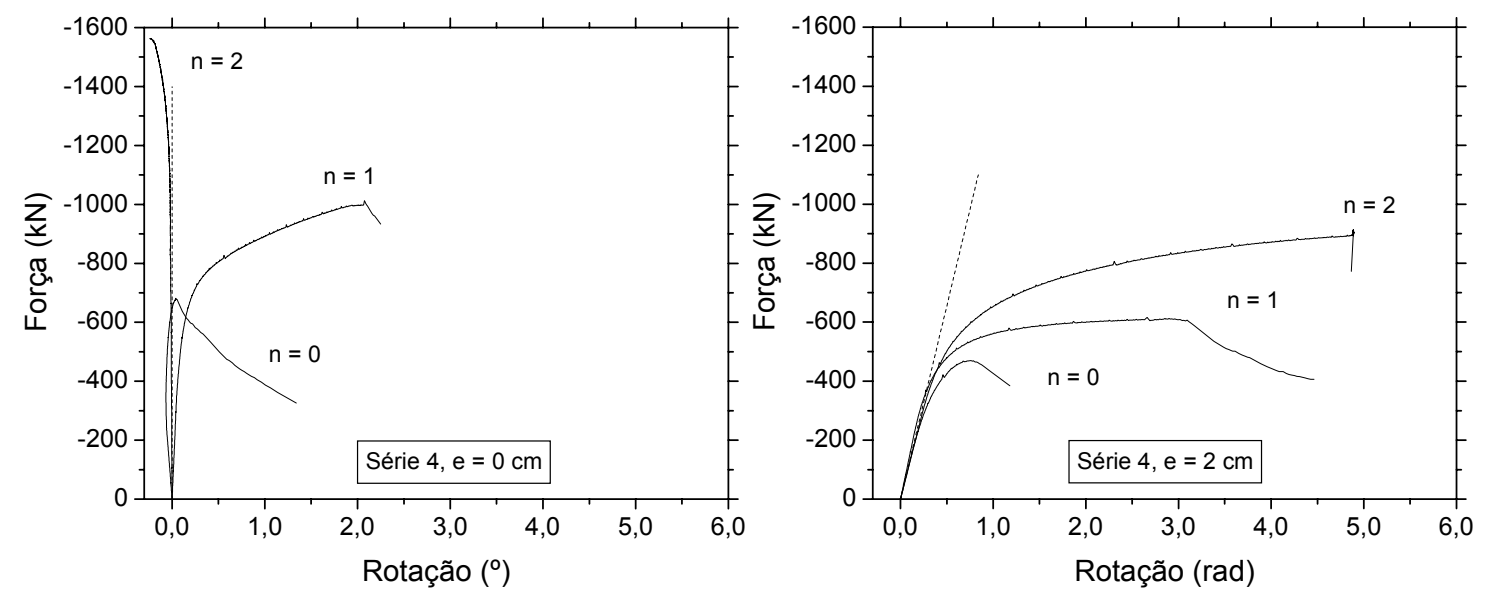

Figura 5.35 - Diagramas força $x$ rotação de apoio

Os diagramas força x deslocamento lateral são apresentados na Figura 5.36. Pode-se observar um considerável efeito de segunda ordem no pilar sob carregamento excêntrico com $n=2$. 

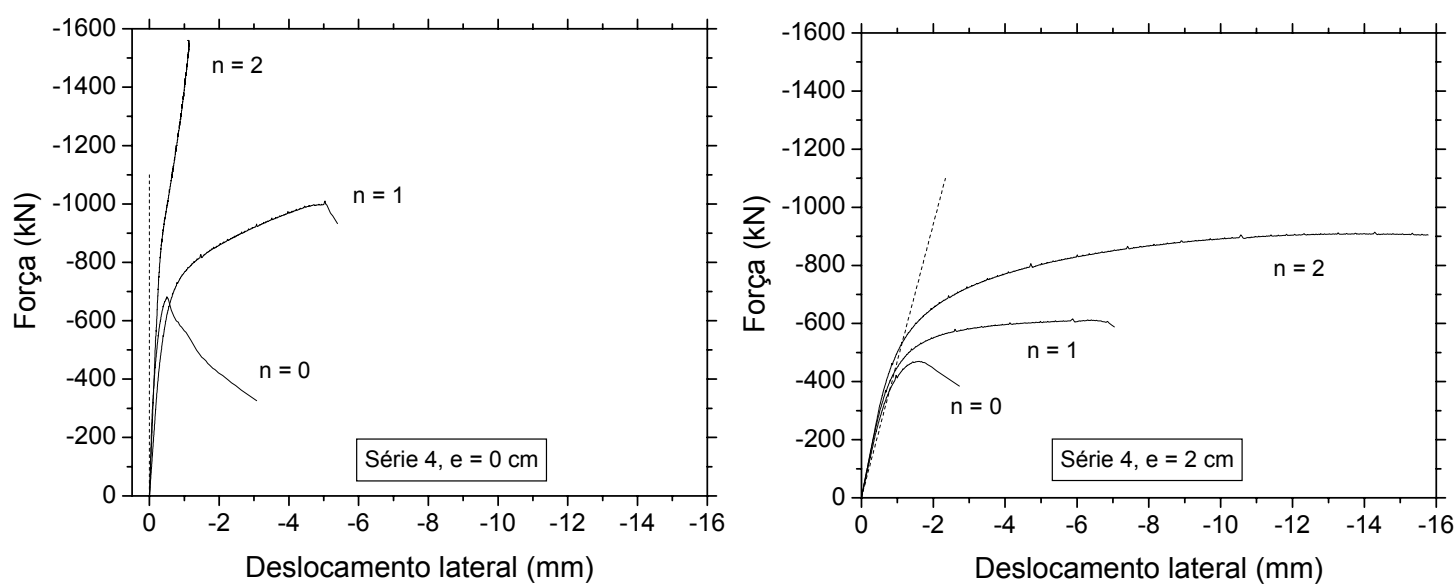

Figura 5.36 - Diagramas força $x$ deslocamento lateral

\subsubsection{Resultados obtidos - Série 5}

Os diagramas força $\mathrm{x}$ deslocamento dos pilares de seção quadrada da série 5 são apresentados na Figura 5.37. Nesta série ocorreram problemas com as leituras de um dos transdutores axiais. Logo, a média das leituras de deslocamentos axiais e a rotação calculada com estas leituras não podem ser apresentadas. Contudo, com o módulo de elasticidade do concreto, os diagramas força $\mathrm{x}$ deslocamento do pistão foram corrigidos, eliminando assim a interferência da deformabilidade da máquina de ensaio. Os diagramas corrigidos são apresentados na Figura 5.38.

Nesta série foi possível observar diretamente a diferença no diagrama tensão $\mathrm{x}$ deformação causada pelo raio de arredondamento. Para o mesmo número de camadas, os pilares com o menor raio de arredondamento $(\mathrm{r}=1 \mathrm{~cm})$ tiveram um ganho inicial de resistência maior. No entanto, com o maior raio de arredondamento $(\mathrm{r}=3 \mathrm{~cm})$, ocorreu um segundo trecho linear ascendente, fazendo com que este alcançasse e até superasse a resistência do pilar com $\mathrm{r}=1 \mathrm{~cm}$ no final do ensaio. 

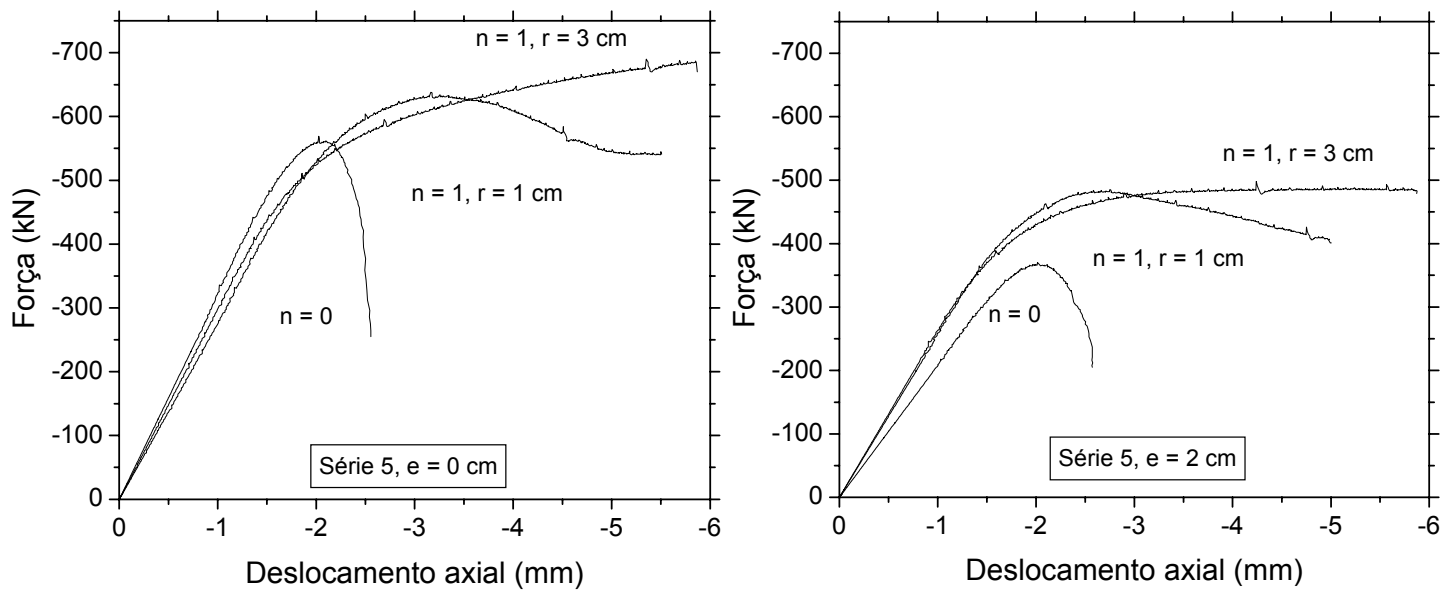

Figura 5.37 - Diagramas força x deslocamento axial (com leituras brutas de deformação do pistão)
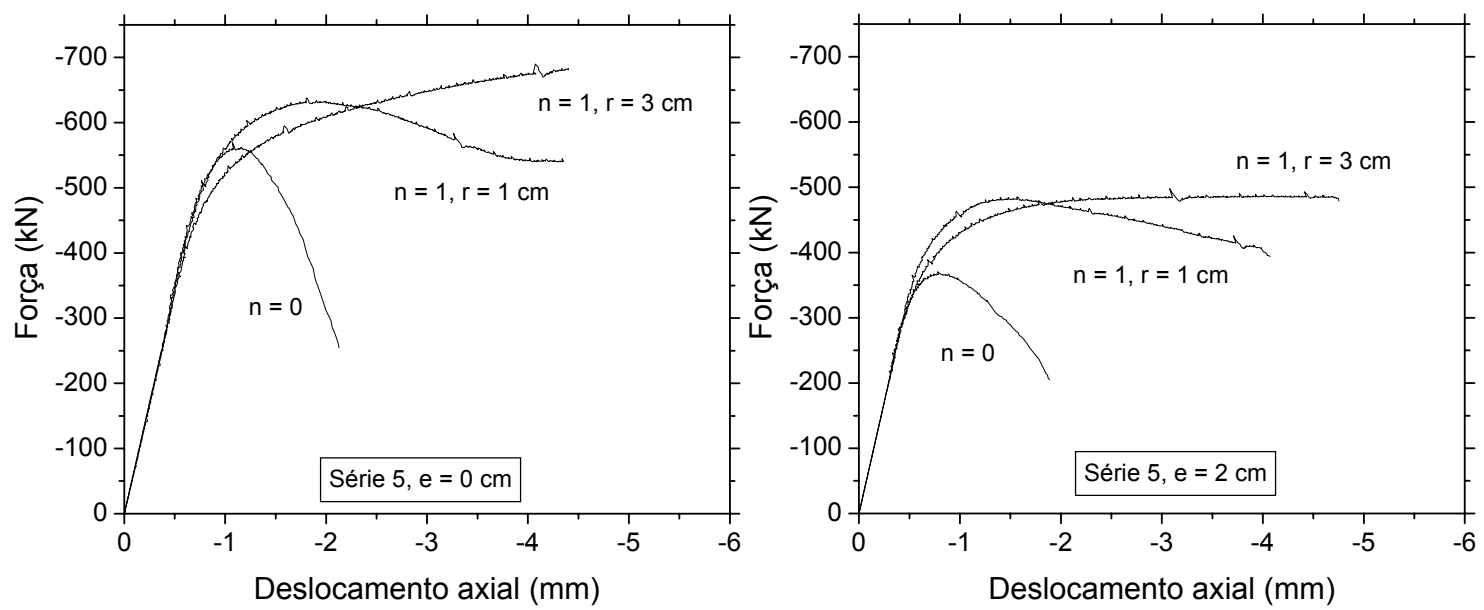

Figura 5.38 - Diagramas força $x$ deslocamento axial (com leituras de deformação do pistão corrigidas)

Nesta série também foi possível observar importantes efeitos de segunda ordem, como mostram os diagramas força x deslocamento lateral apresentados na Figura 5.39.
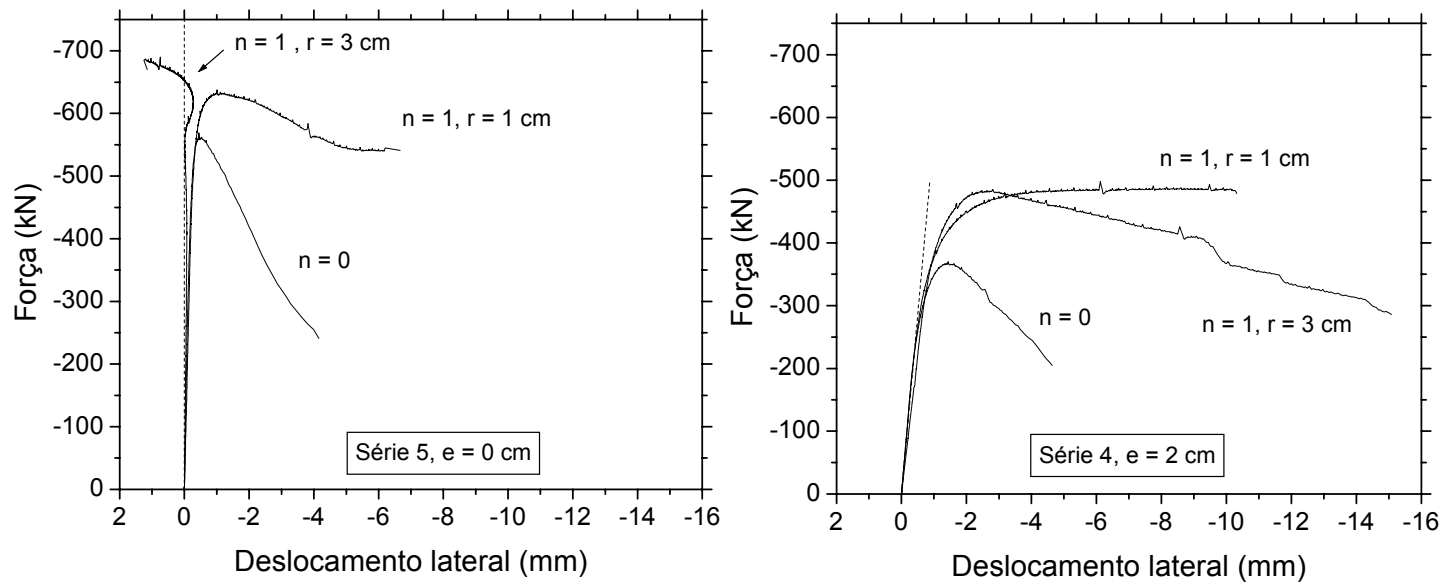

Figura 5.39 - Diagramas força x deslocamento lateral 


\subsubsection{Deformações transversais da camisa}

Foram utilizados extensômetros na direção transversal (de confinamento), no perímetro dos pilares para os diferentes casos estudados. Com isto, foi possível avaliar a distribuição de deformações externas da camisa, podendo assim auxiliar na avaliação dos efeitos de confinamento e permitir a comparação com resultados de análises numéricas. Julgou-se adequado apresentar as deformações da camisa em duas situações principais: no momento em que foi atingida a força máxima do ensaio $\left(F_{\max }\right)$ e no instante da ruptura da camisa.

Estes valores são apresentados na forma de diagramas deformação x distância percorrida ao longo do perímetro do pilar. O caminho é percorrido a partir do extensômetro 2 (na mesma posição do extensômetro 1) até o extensômetro da face oposta. O sentido anti-horário foi definido como caminho 1 e o horário como caminho 2. Os trechos hachurados nos gráficos representam os cantos dos pilares. Os diagramas dos pilares sob compressão centrada da série 1 foram montados conforme Tabela 5.14:

Tabela 5.14 - Deformação transversal x caminho percorrido - Série 1 - força centrada

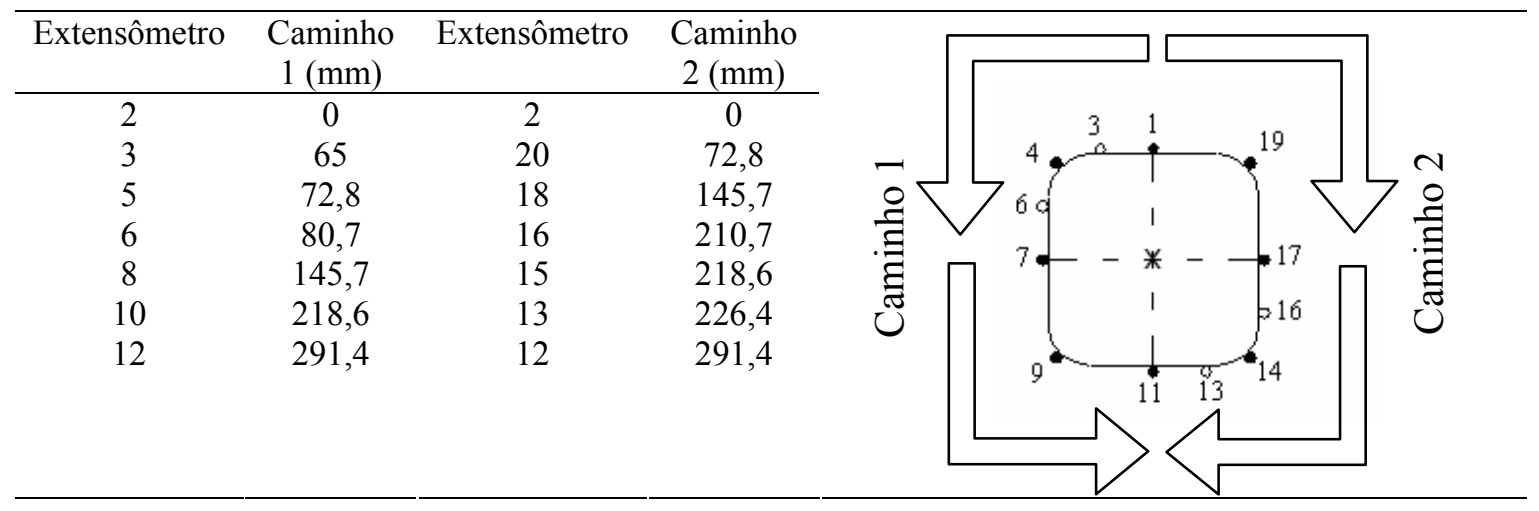

Os diagramas das deformações da camisa no instante da ruptura do pilar S10r1 indicam que ocorreu uma concentração de tensões próximo a um dos cantos, que provavelmente tenha sido responsável pela ruptura da camisa. É possível observar ainda que na ruptura do pilar ocorreu um lado com maiores tensões de compressão, por causa de um efeito de flexão. 

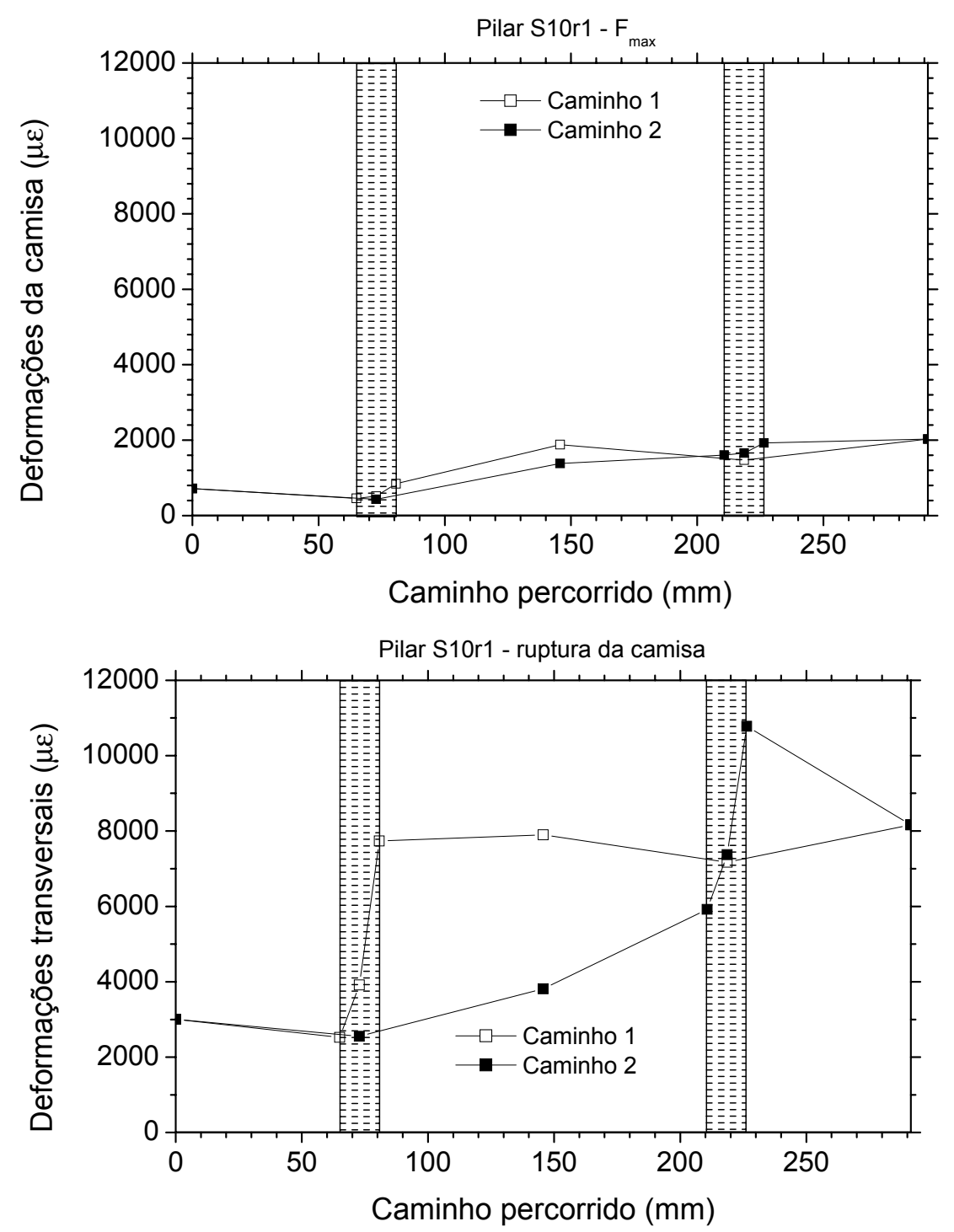

Figura 5.40 - Deformações transversais da camisa pilar S10r1

Já no pilar S20r1 o ponto crítico de deformação transversal, onde pode ter ocorrido a ruptura da camisa, estava na face lateral do lado mais comprimido. 

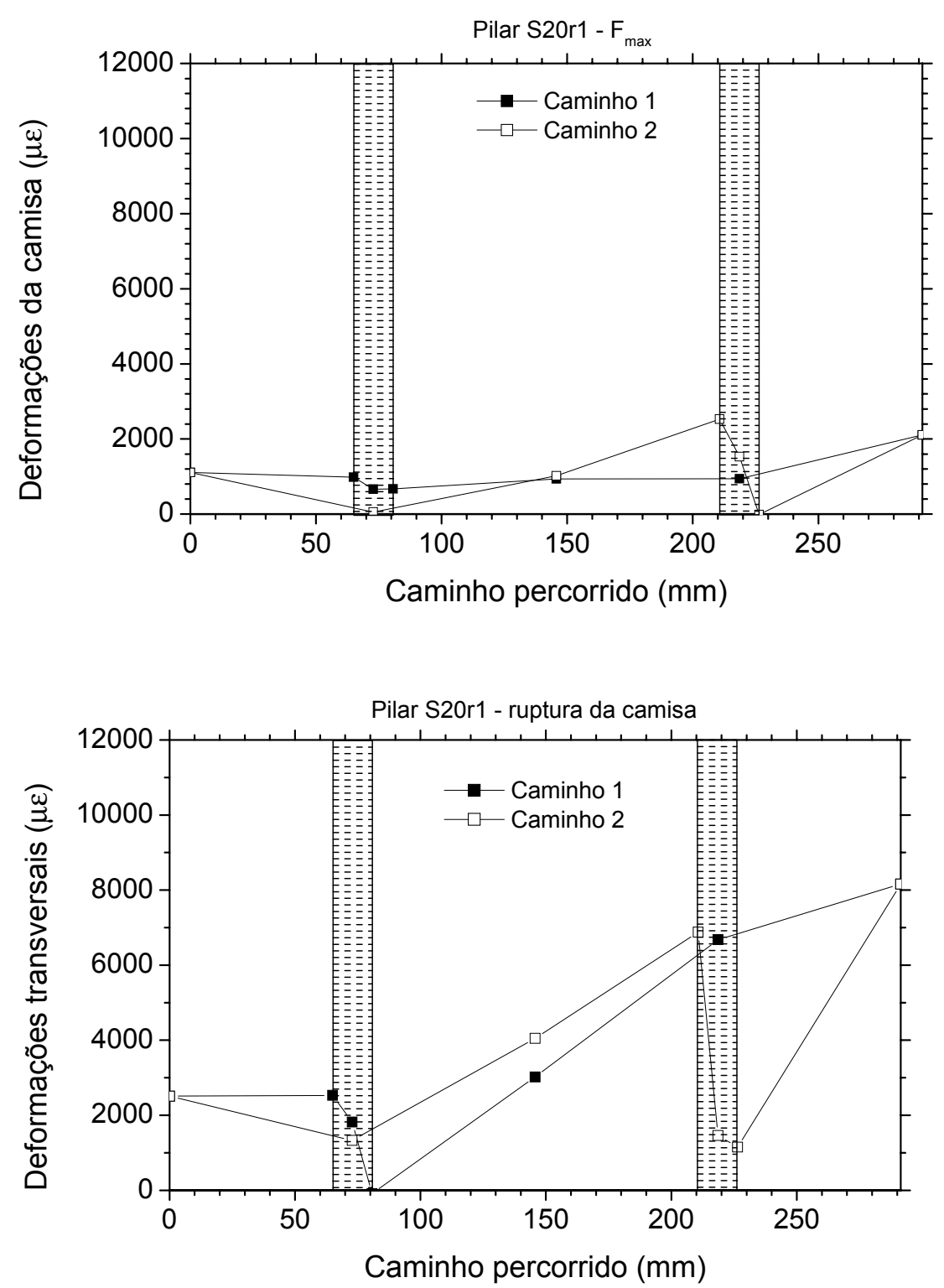

Figura 5.41 - Deformações transversais da camisa pilar S20r1

Para os pilares submetidos à ação de forças com excentricidade nominal não nula, os pontos utilizados para a confecção dos diagramas das deformações na camisa são apresentados na Tabela 5.15. 
Tabela 5.15 - Deformação transversal x caminho percorrido - Série 1 - força excêntrica

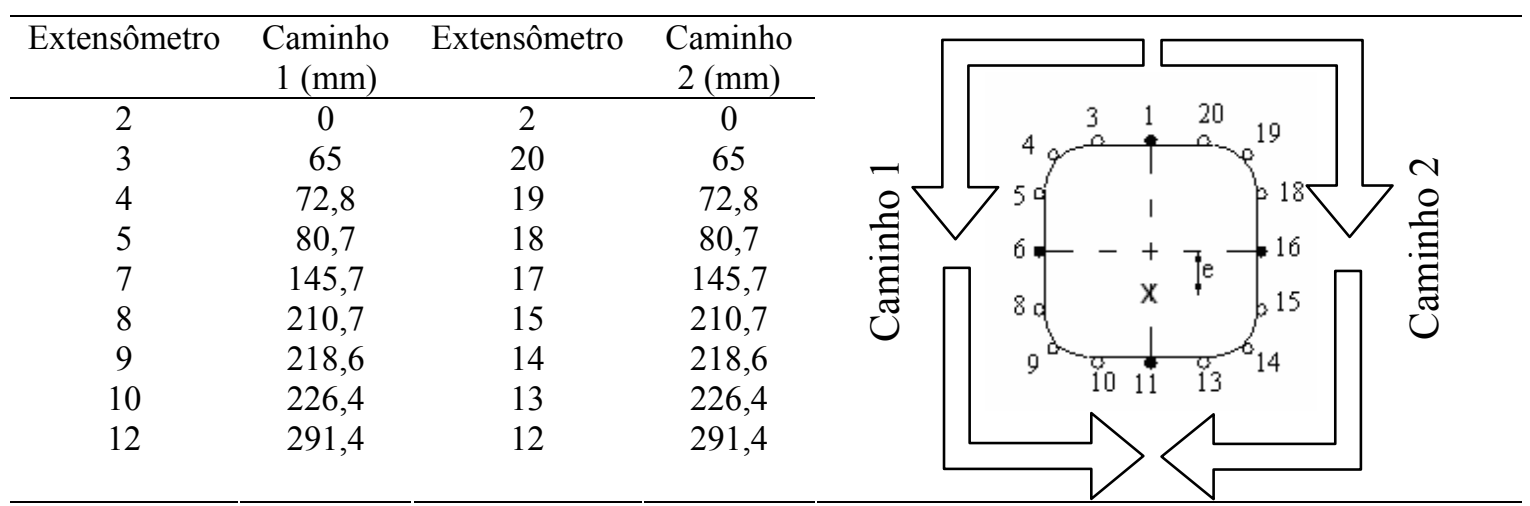

No pilar S11r1 a ruptura da camisa ocorreu provavelmente próximo do inicio dos cantos no lado mais comprimido, onde foi registrada a maior deformação transversal.
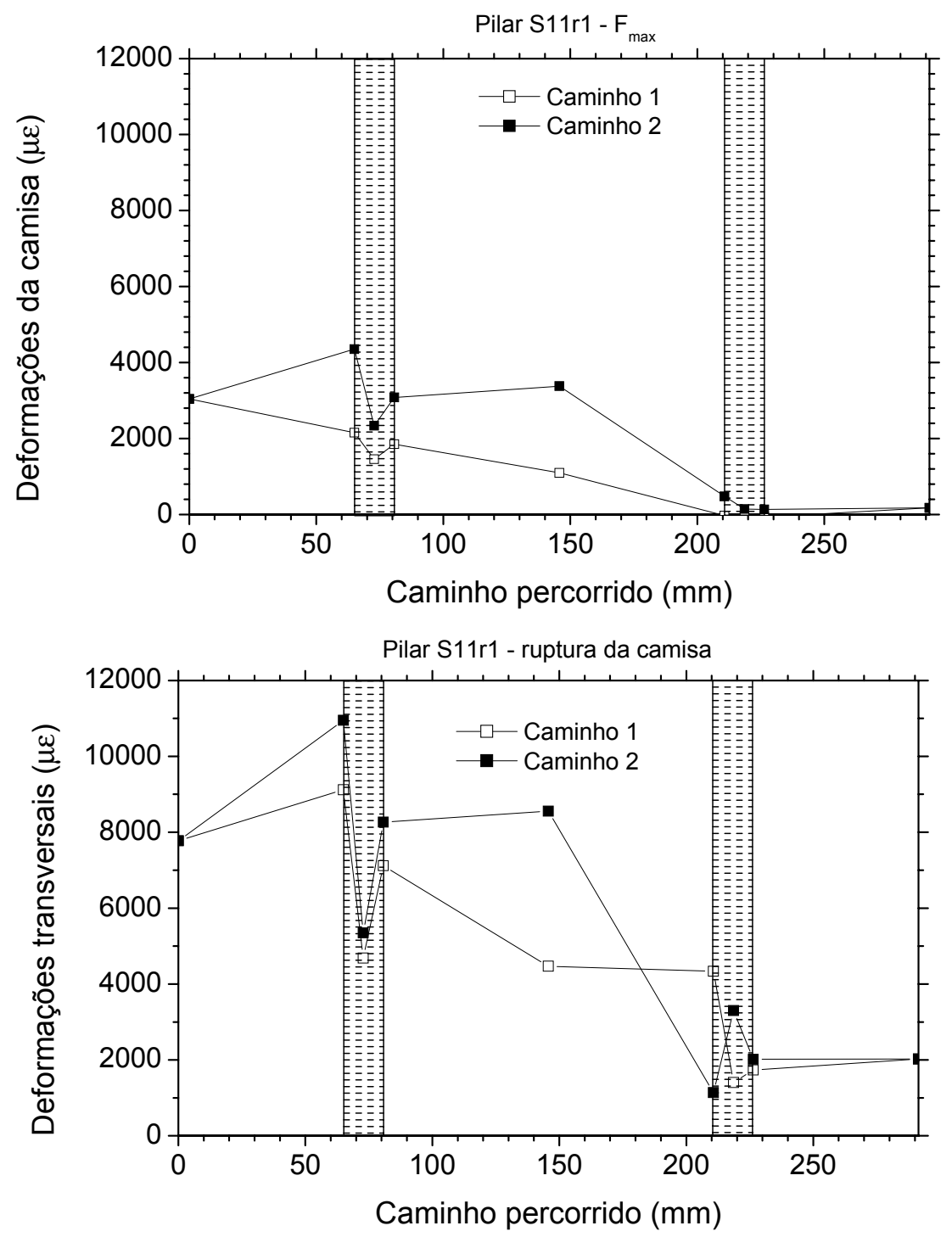

Figura 5.42 - Deformações transversais da camisa pilar S11r1 
No pilar S21r1 não foi possível determinar o ponto mais crítico das deformações da camisa, pois os valores na face mais comprimida e nos cantos próximos a esta face foram semelhantes.
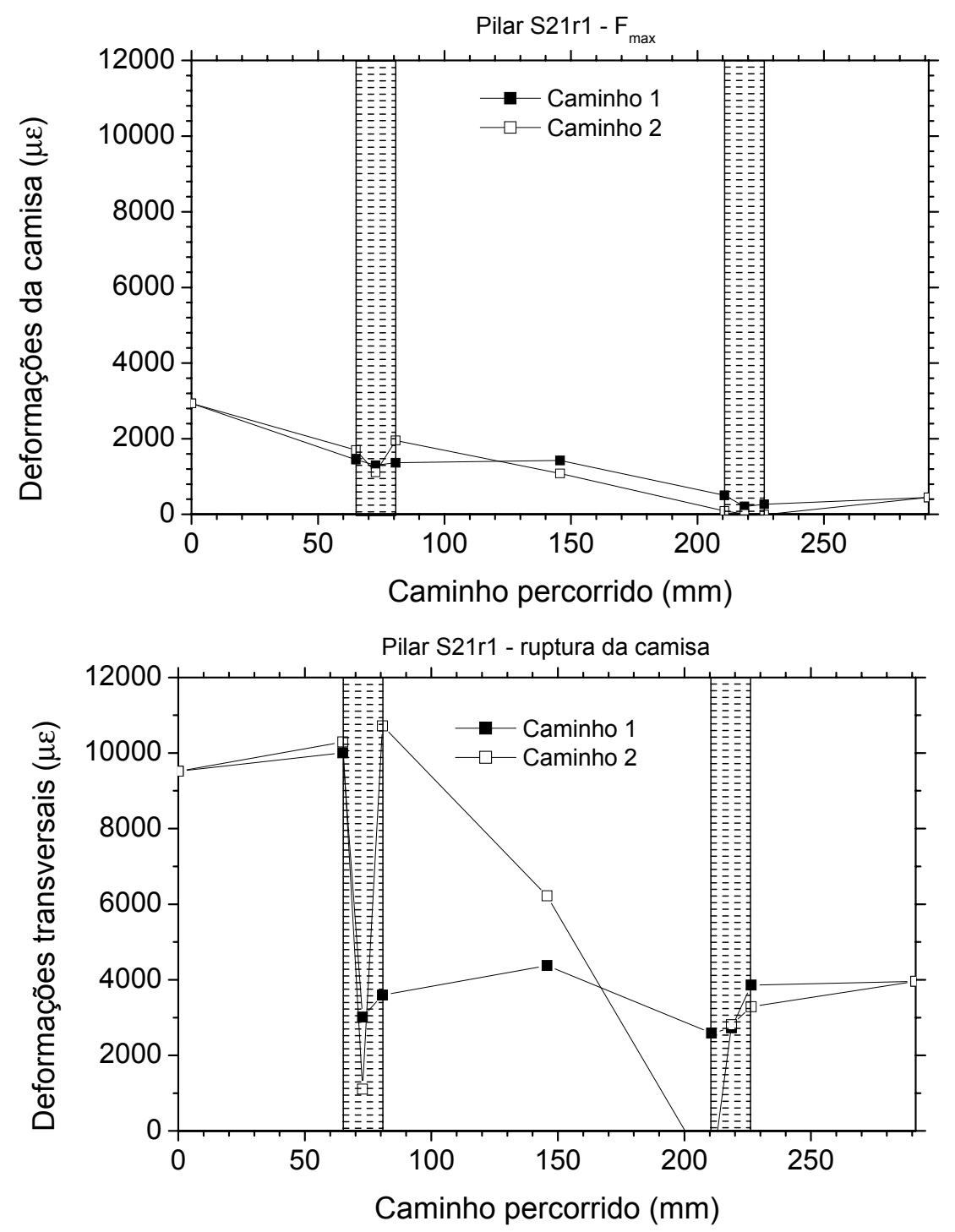

Figura 5.43 - Deformações transversais da camisa pilar S21r1

No pilar S12r1 a ruptura da camisa deve ter ocorrido bem próximo ao início dos cantos, como indicam as maiores deformações da camisa na Figura 5.44. 

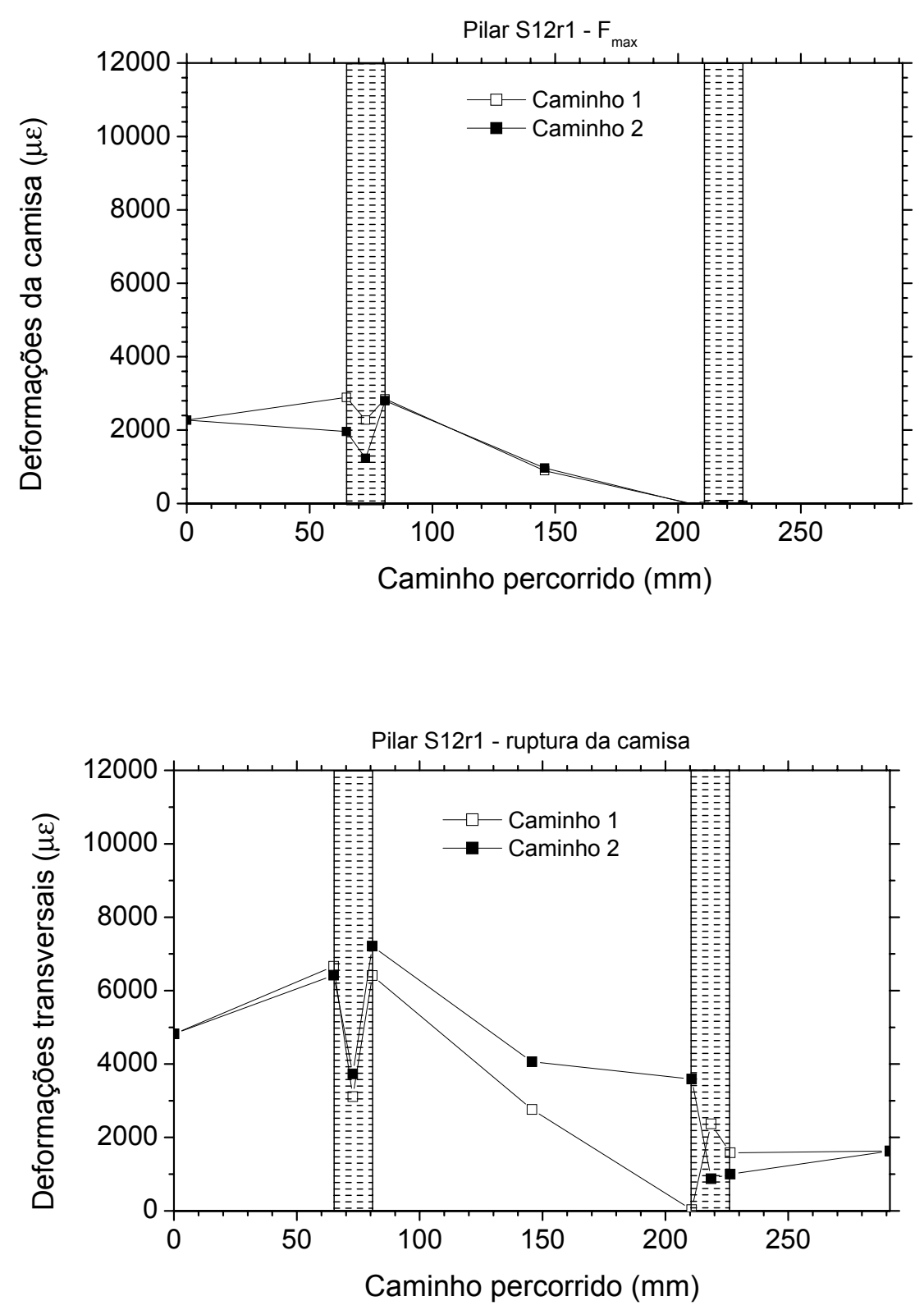

Figura 5.44 - Deformações transversais da camisa pilar S12r1 

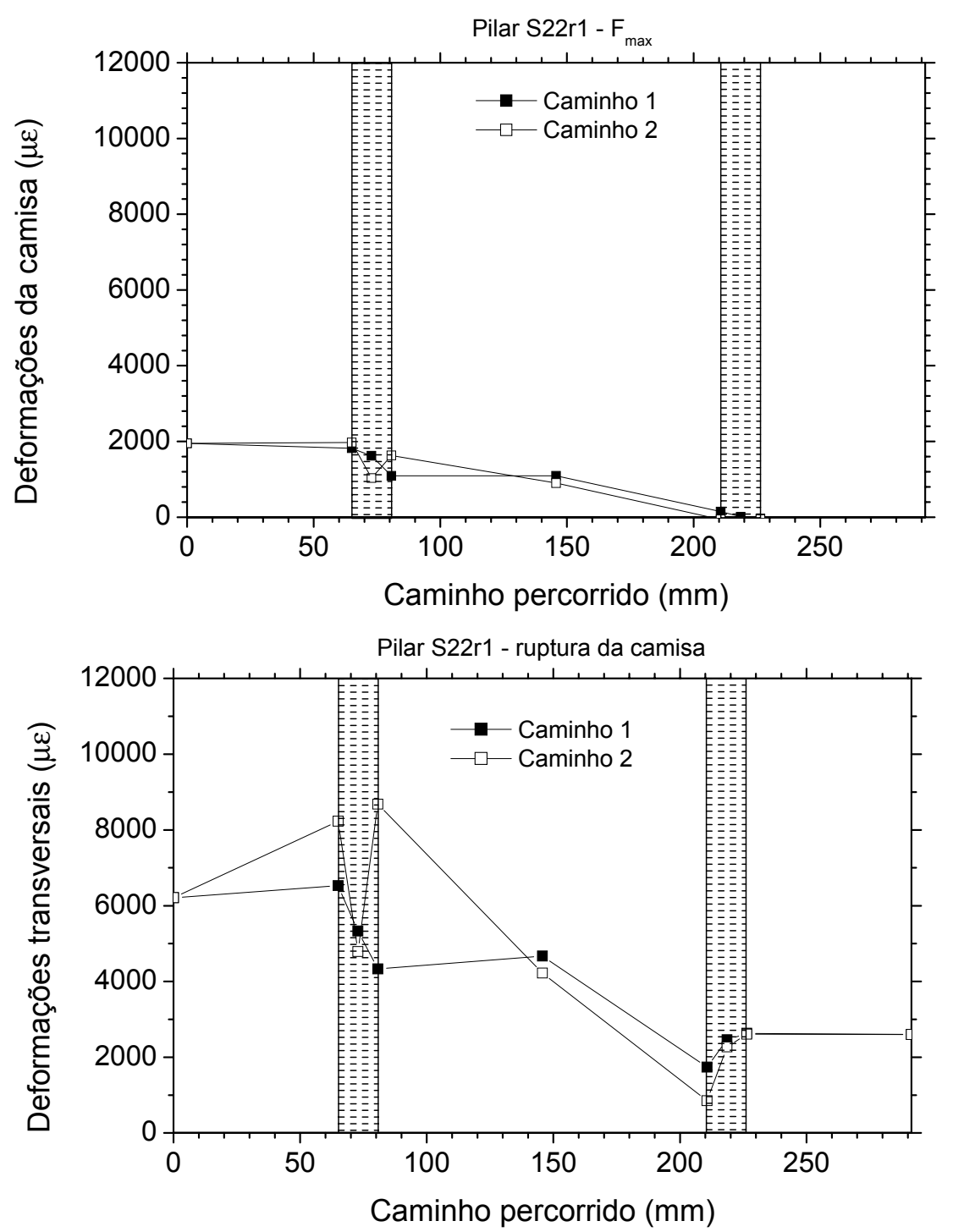

Figura 5.45 - Deformações transversais da camisa pilar S22r1

Com a análise das deformações externas da camisa na série 1 foi possível observar que com o aumento do número de camadas de PRFC as deformações no meio da face lateral mais comprimida foram maiores, sendo até possível uma alteração do local de ruptura da camisa com o aumento do número de camadas de PRFC.

Na Tabela 5.16 são apresentados os pontos utilizados para a construção dos diagramas de deformações da camisa dos pilares sob compressão centrada da série 2 . 
Tabela 5.16 - Deformação transversal x caminho percorrido - Série 2 - força centrada

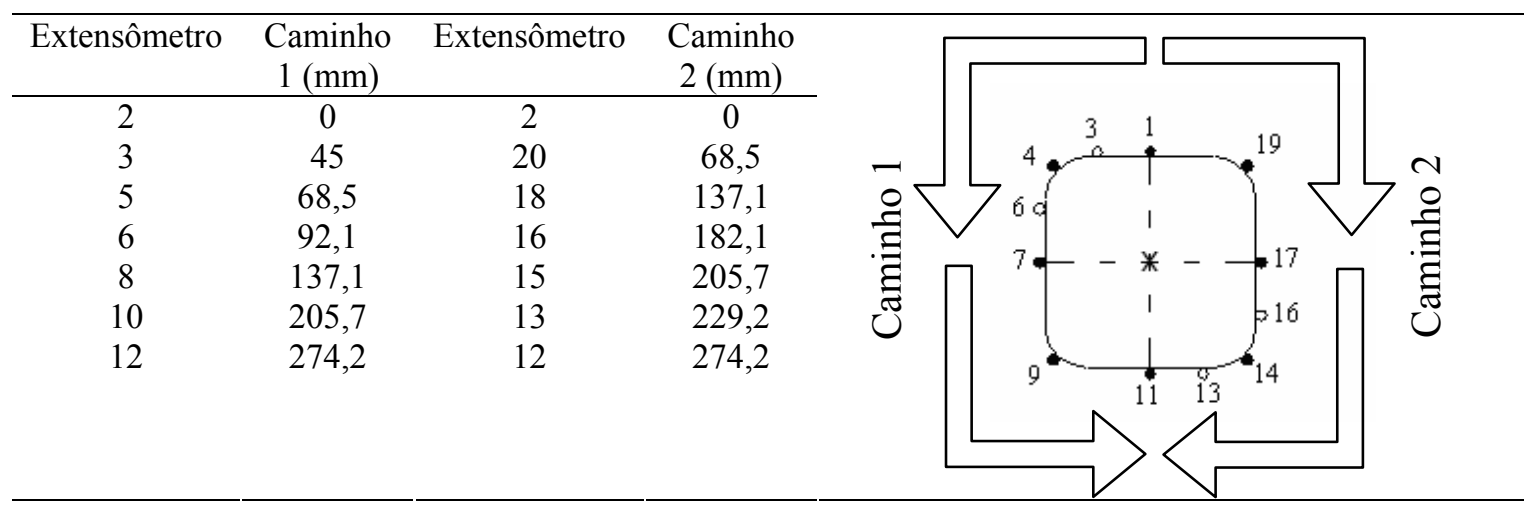

Nos pilares S10r3 e S20r3 foi possível observar que com o aumento do número de camadas de PRFC as deformações máximas da camisa passaram do início dos cantos ao meio da face lateral.

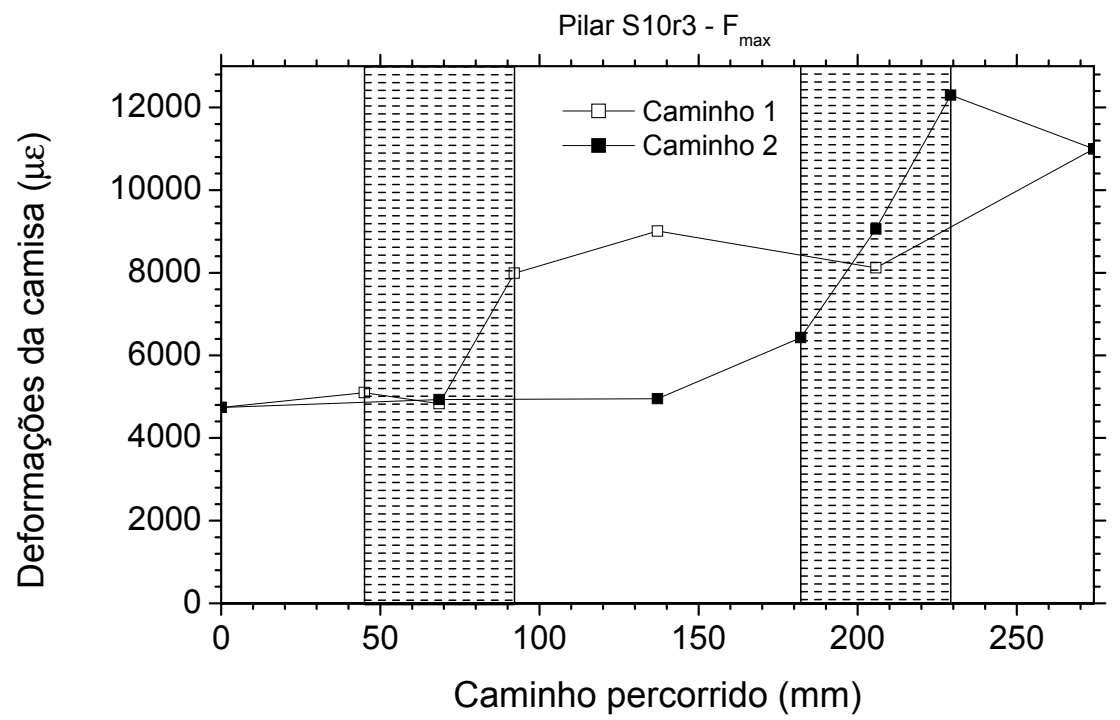

Figura 5.46 - Deformações transversais da camisa pilar S10r3 


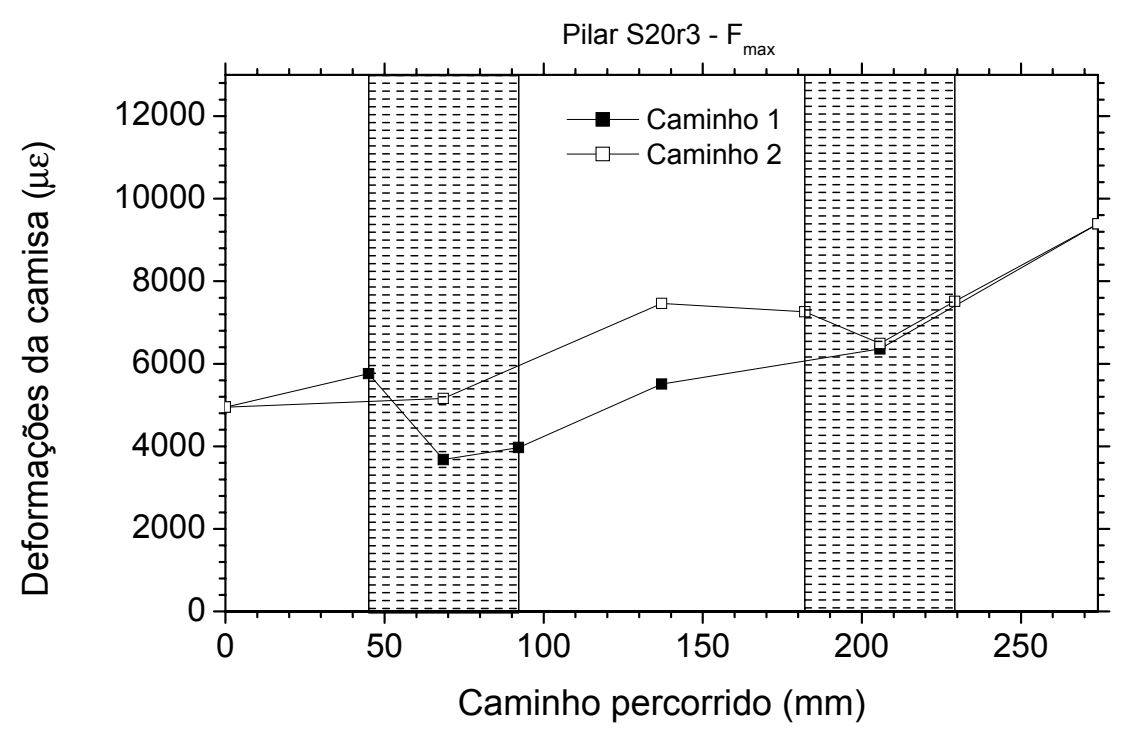

Figura 5.47 - Deformações transversais da camisa pilar S20r3

Na Tabela 5.17 são apresentados os pontos utilizados para a construção dos diagramas de deformações da camisa dos pilares sob compressão excêntrica da série 2.

Tabela 5.17 - Deformação transversal x caminho percorrido - Série 2 - força excêntrica

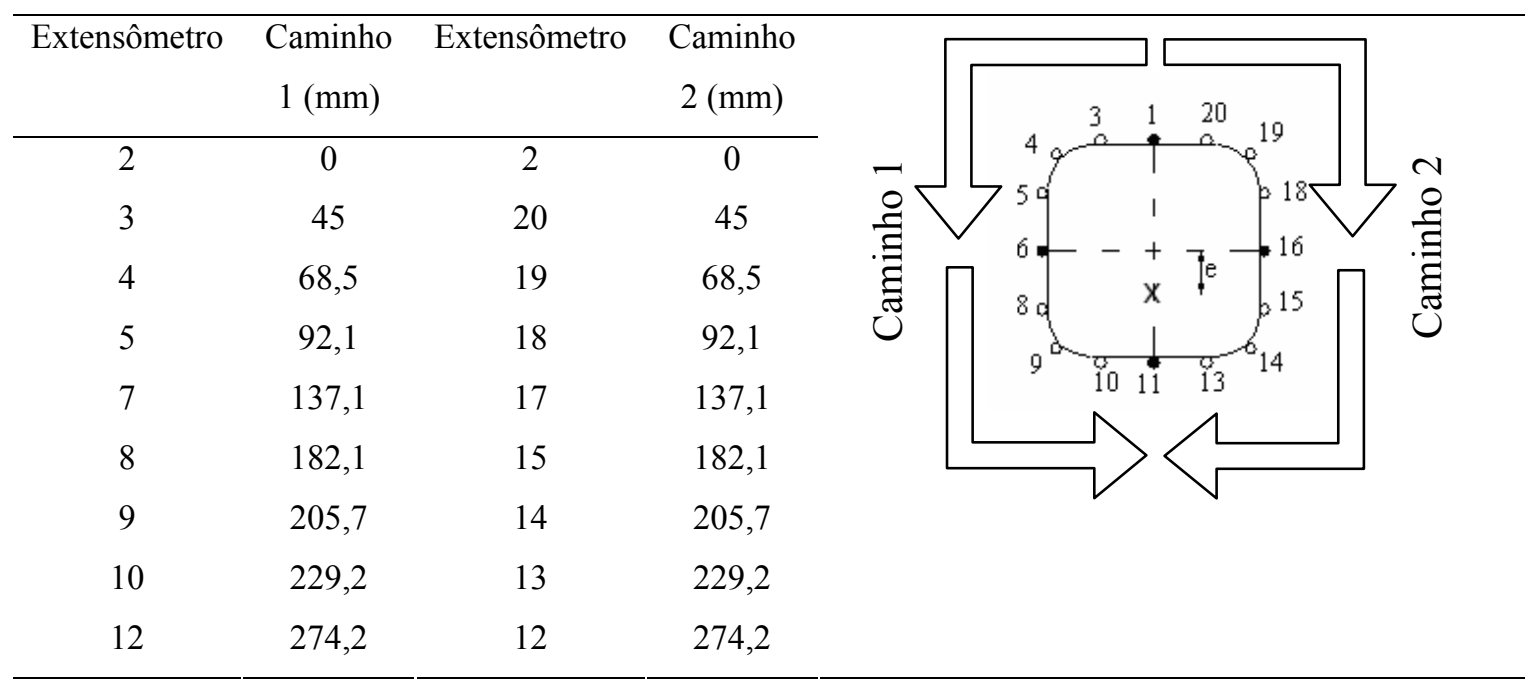

Nos pilares submetidos a forças excêntricas, as deformações no lado mais comprimido, bem próximas aos cantos, foram normalmente as maiores, no entanto, com valores levemente superiores aos do meio da face lateral. 

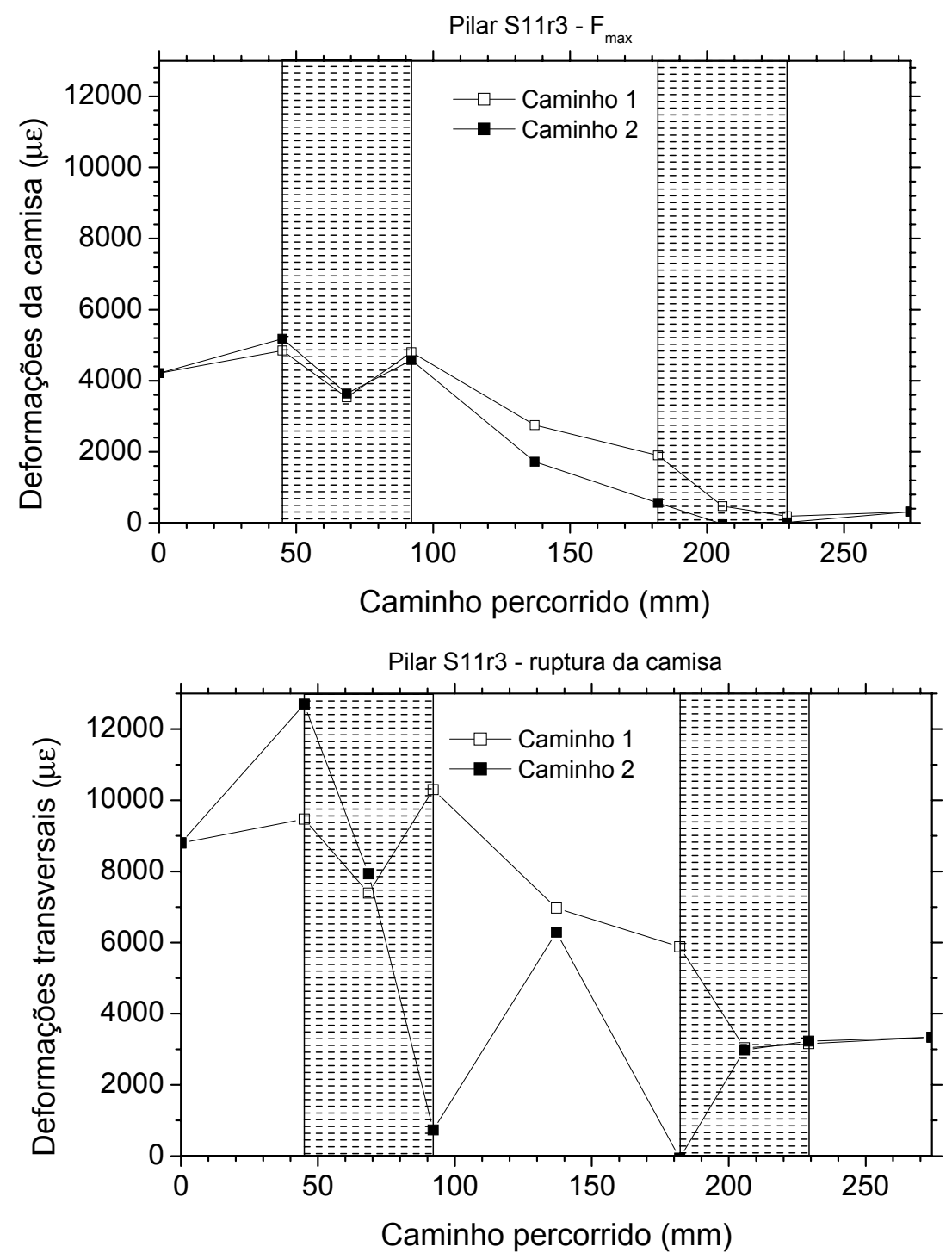

Figura 5.48 - Deformações transversais da camisa pilar S11r3 

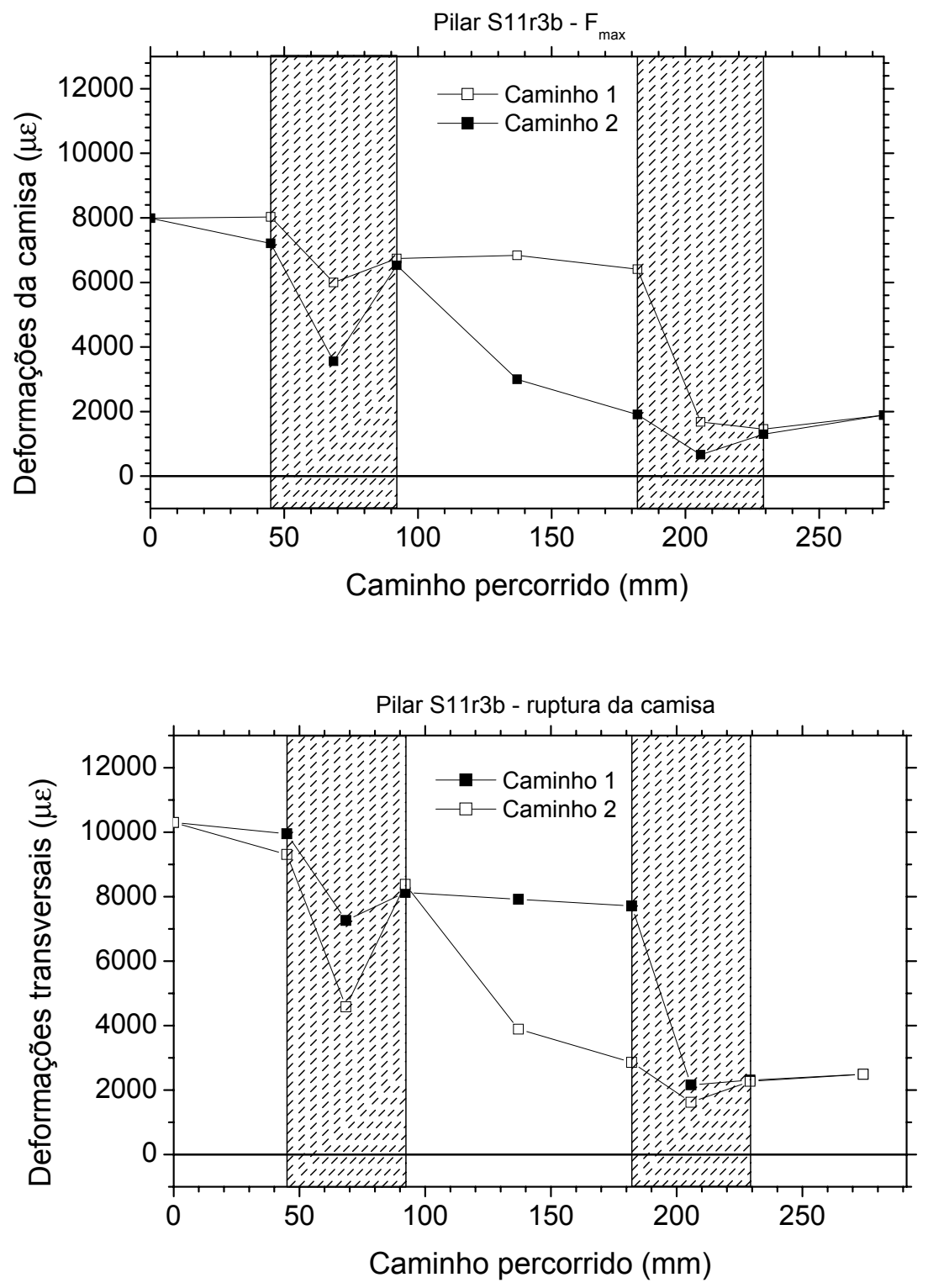

Figura 5.49 - Deformações transversais da camisa pilar S11r3b 


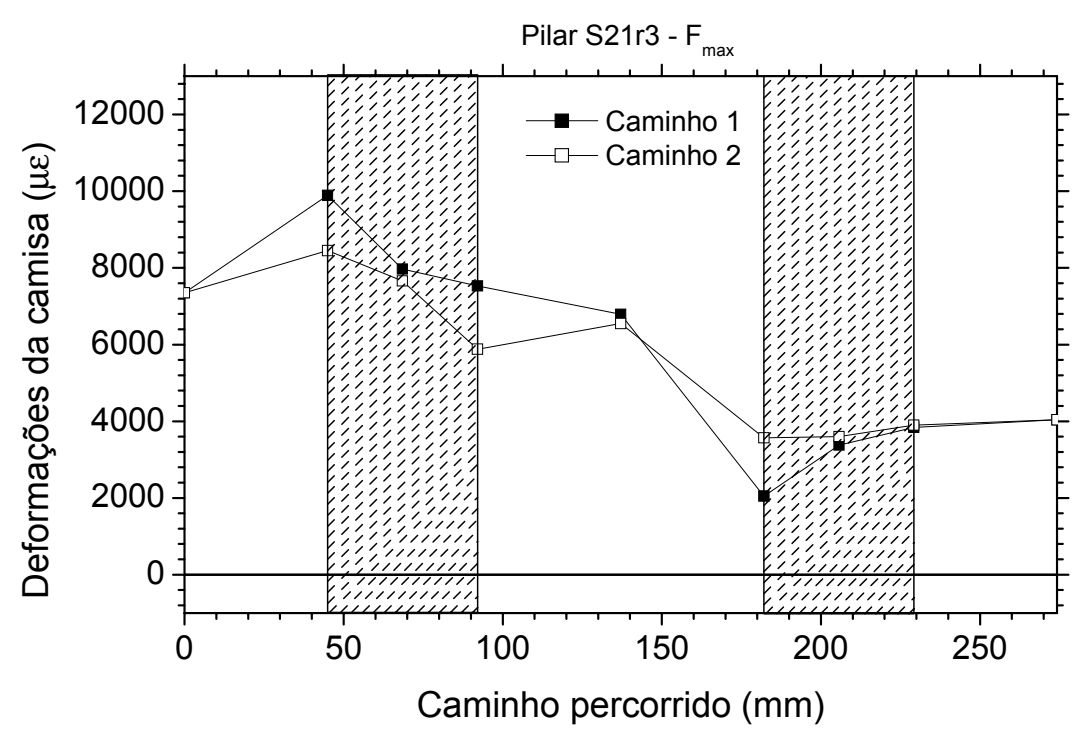

Figura 5.50 - Deformações transversais da camisa pilar S21r3

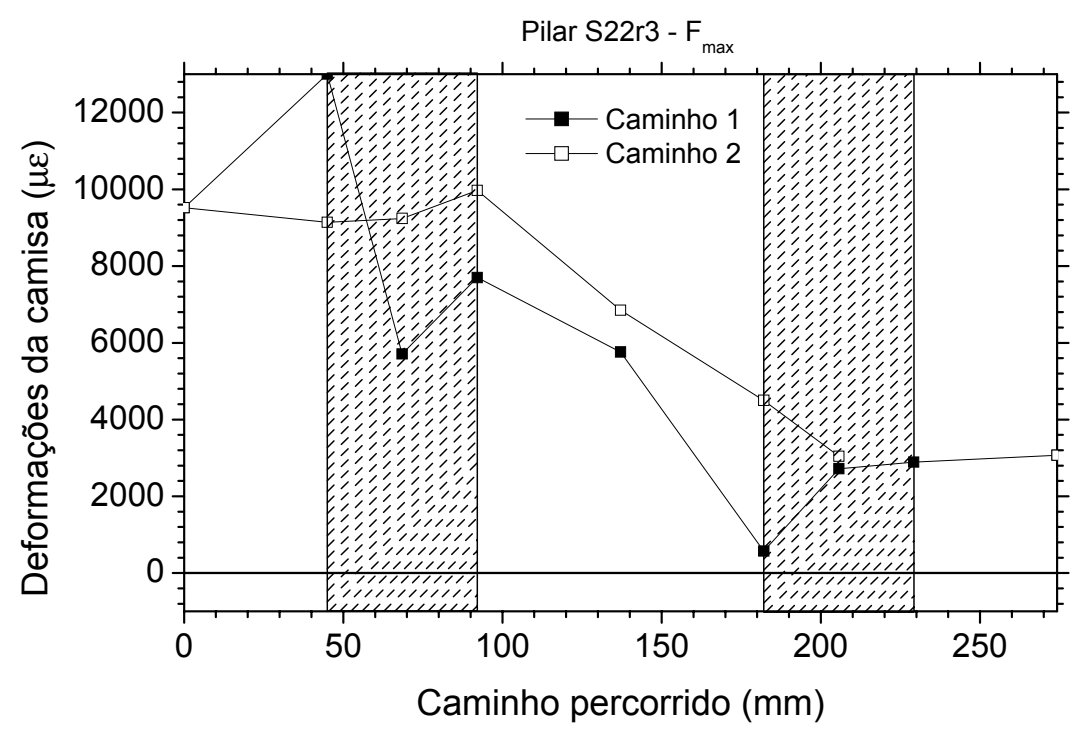

Figura 5.51 - Deformações transversais da camisa pilar S22r3

Na Tabela 5.18 são apresentados os pontos utilizados para a construção dos diagramas de deformações da camisa dos pilares R20 e R2x3 da série 3. Pode-se observar que para o pilar R20 as maiores deformações transversais da camisa ocorreram na menor face lateral. 
Tabela 5.18 - Deformação transversal x caminho percorrido - Série 3 - pilares R20 e R2x3

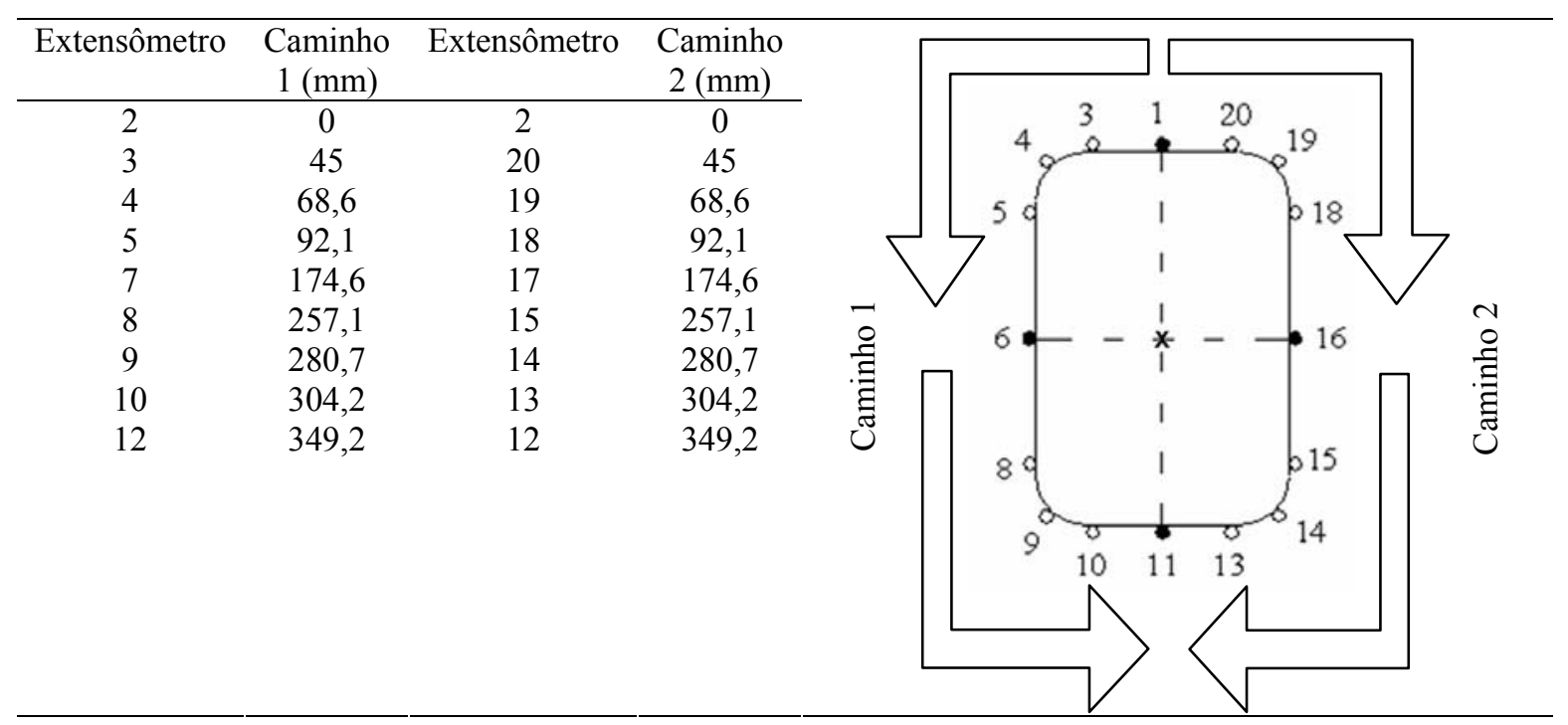
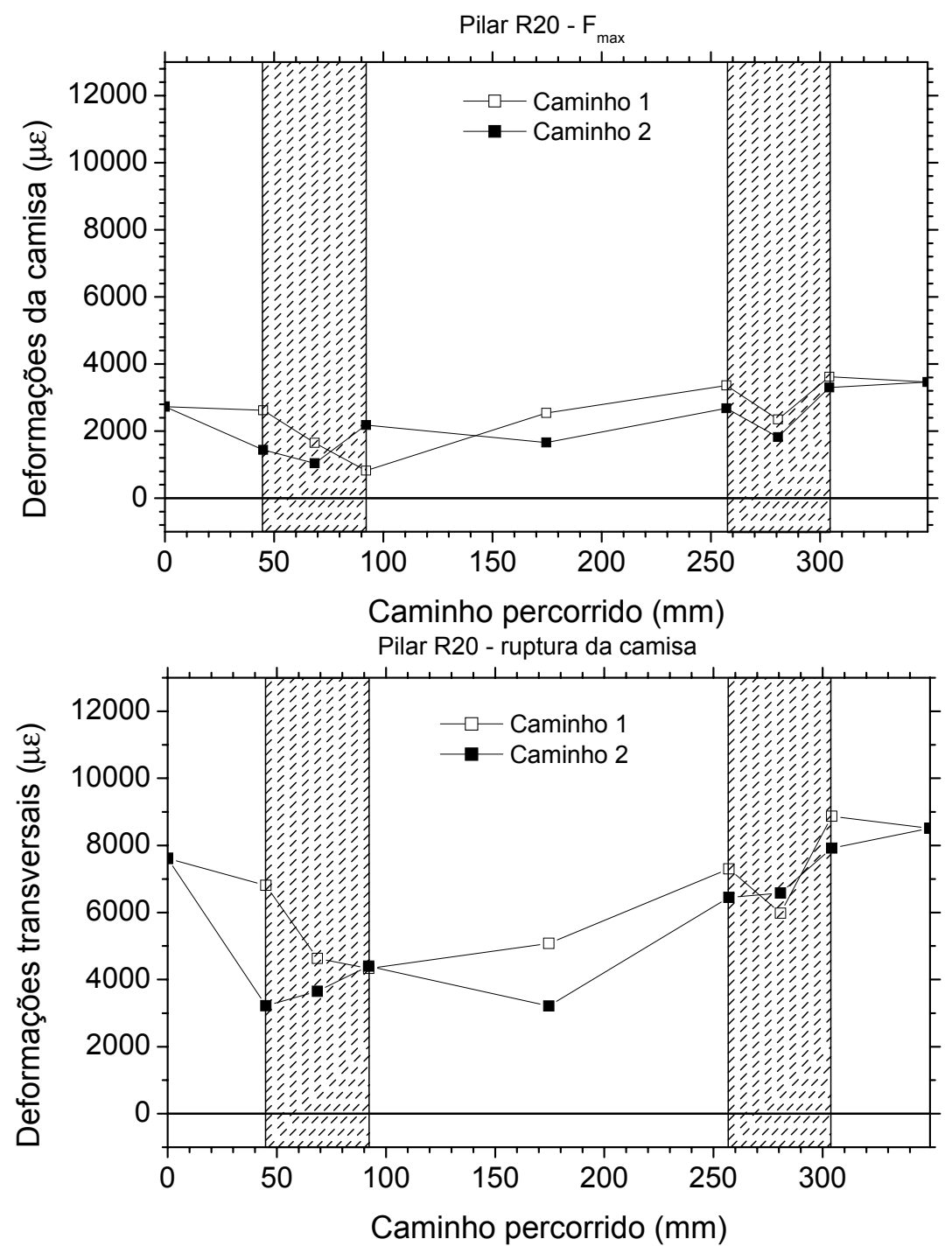

Figura 5.52 - Deformações transversais da camisa pilar R20 
No pilar R2x3 a maior deformação lateral ocorreu no início dos cantos arredondados da face lateral mais comprimida.
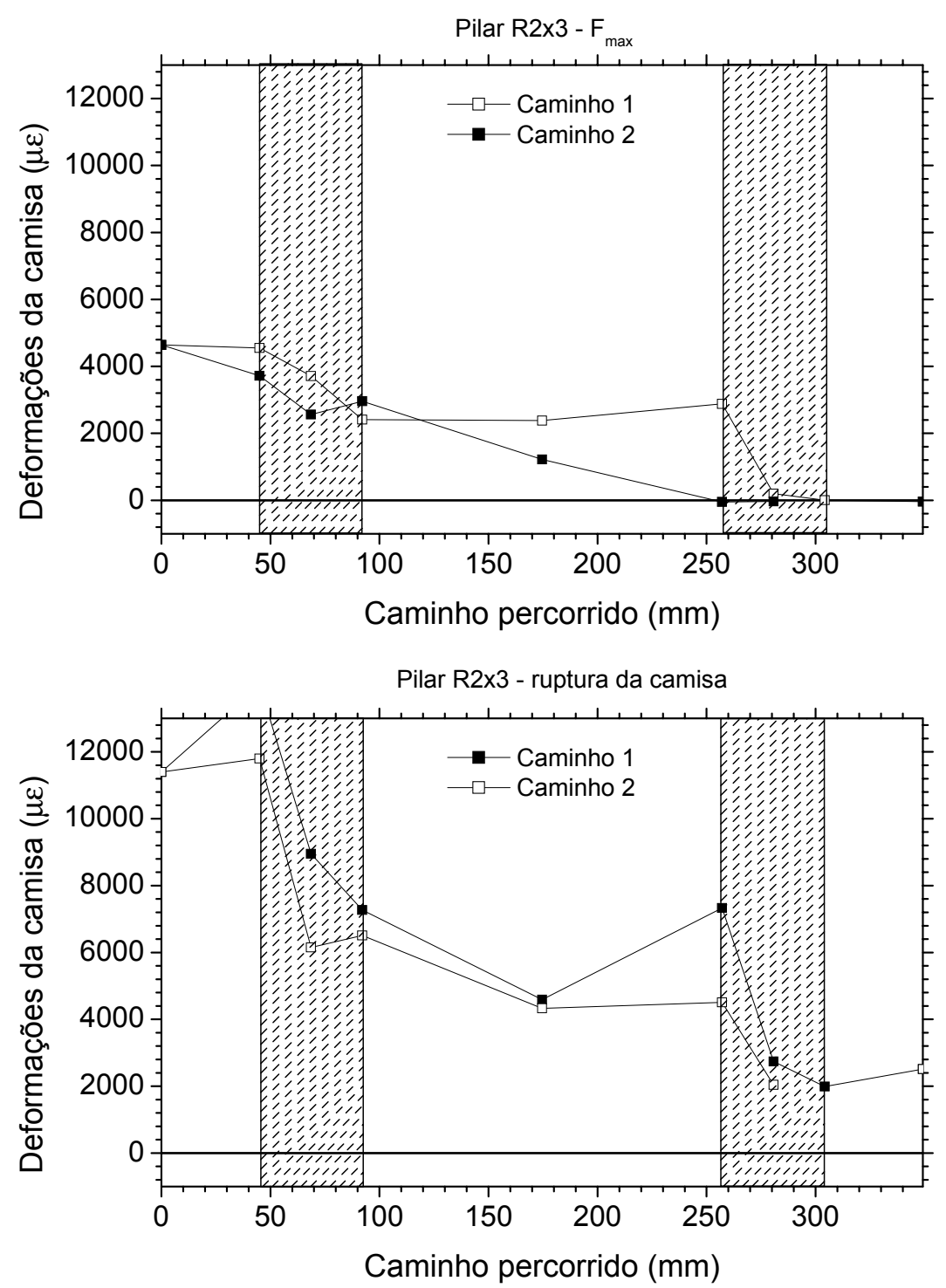

Figura 5.53 - Deformações transversais da camisa pilar R2x3

Na Tabela 5.19 são apresentados os pontos utilizados para a construção dos diagramas de deformações da camisa do pilar R2y2 da série 3. Neste pilar, observou-se claramente que as maiores deformações da camisa ocorreram logo no início dos cantos arredondados próximo à face mais comprimida. 
Tabela 5.19 - Deformação transversal x caminho percorrido - Série 3 - pilar R2y2

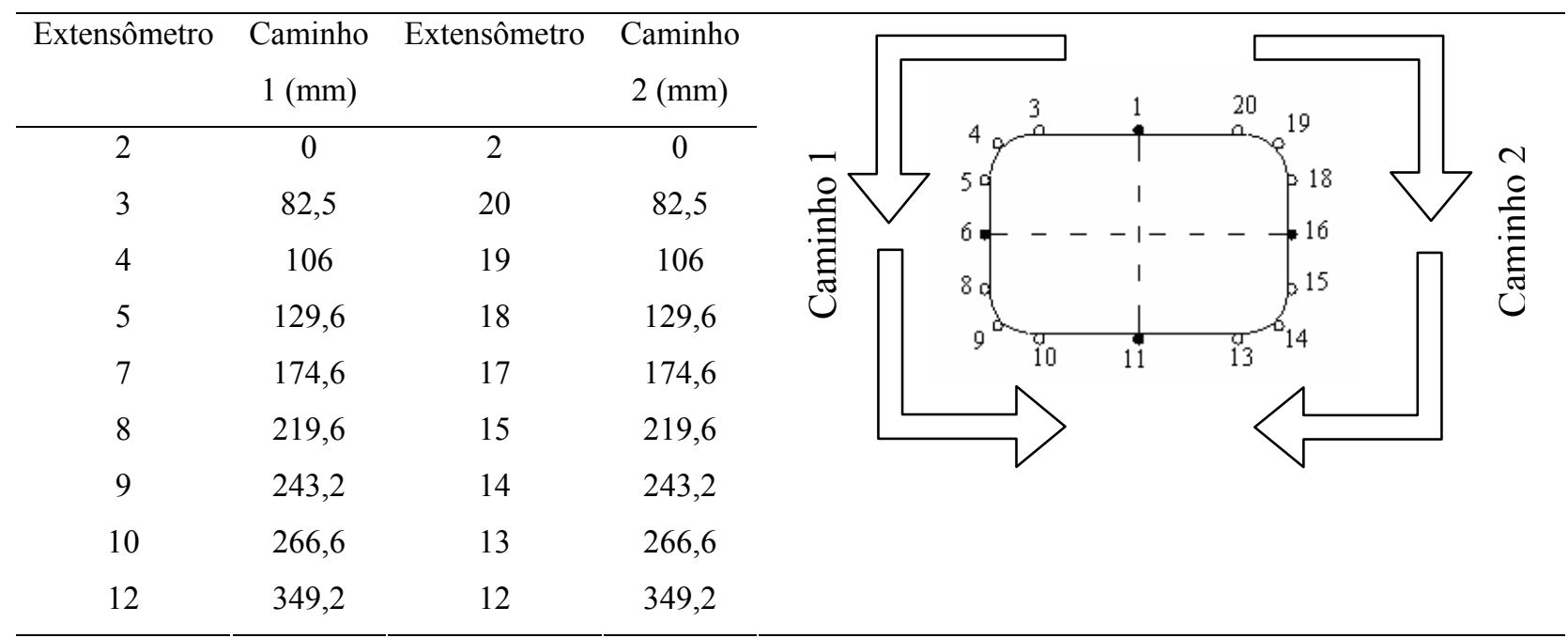
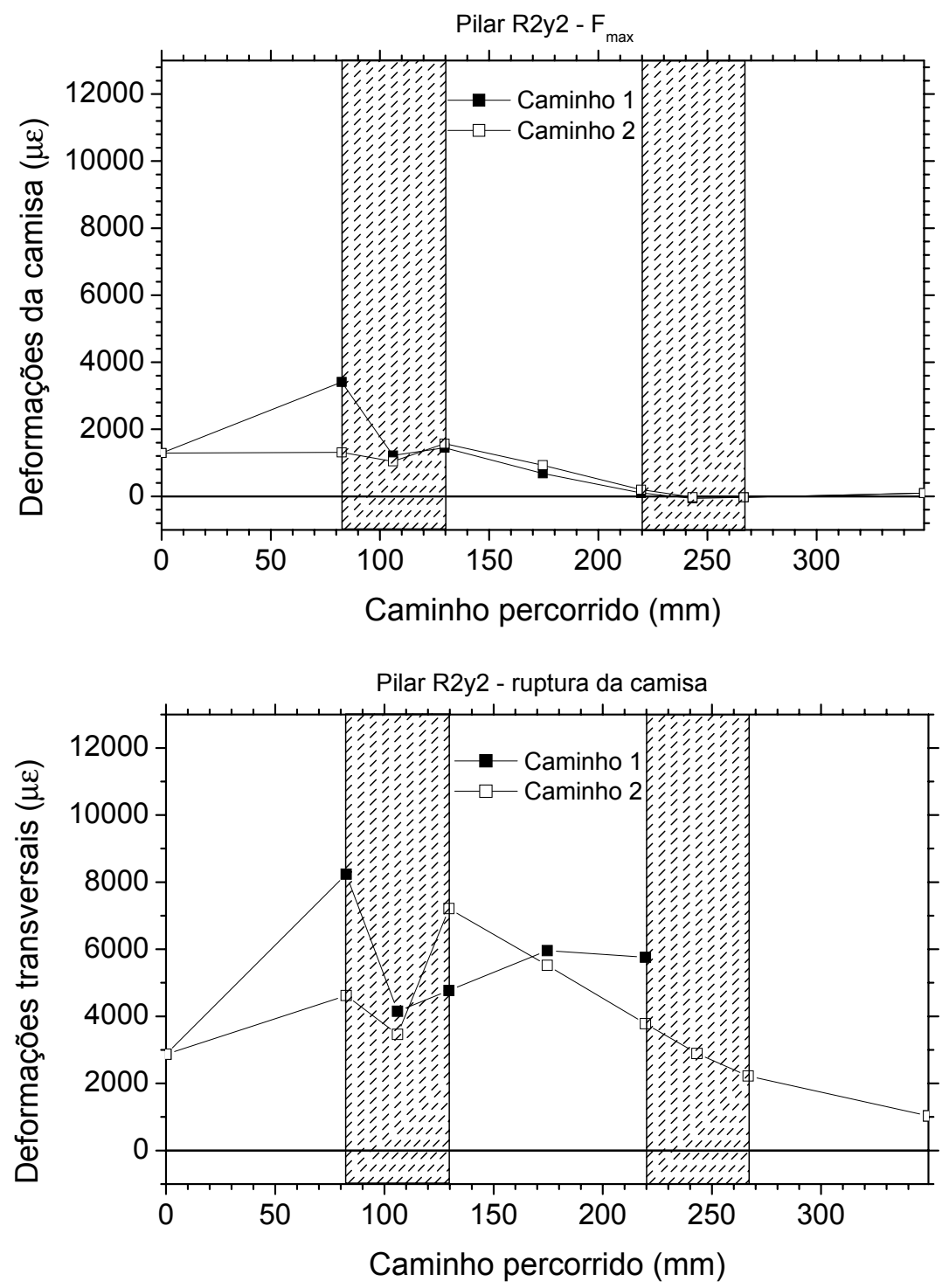

Figura 5.54 - Deformações transversais da camisa pilar R2y2 
$\mathrm{Na}$ Tabela 5.20 são apresentados os pontos utilizados para a construção dos diagramas de deformações da camisa dos pilares circulares submetidos à compressão centrada. Nos pilares $\mathrm{C} 10$ e C20 as deformações seriam constantes em todo o perímetro numa situação idealizada de compressão centrada. No entanto, como se pode observar nos diagramas, as deformações não foram uniformes na camisa por causa do efeito de flexão, provavelmente de poucos milímetros, que ocorreu.

Tabela 5.20 - Deformação transversal x caminho percorrido - Série 4 - pilares centrados

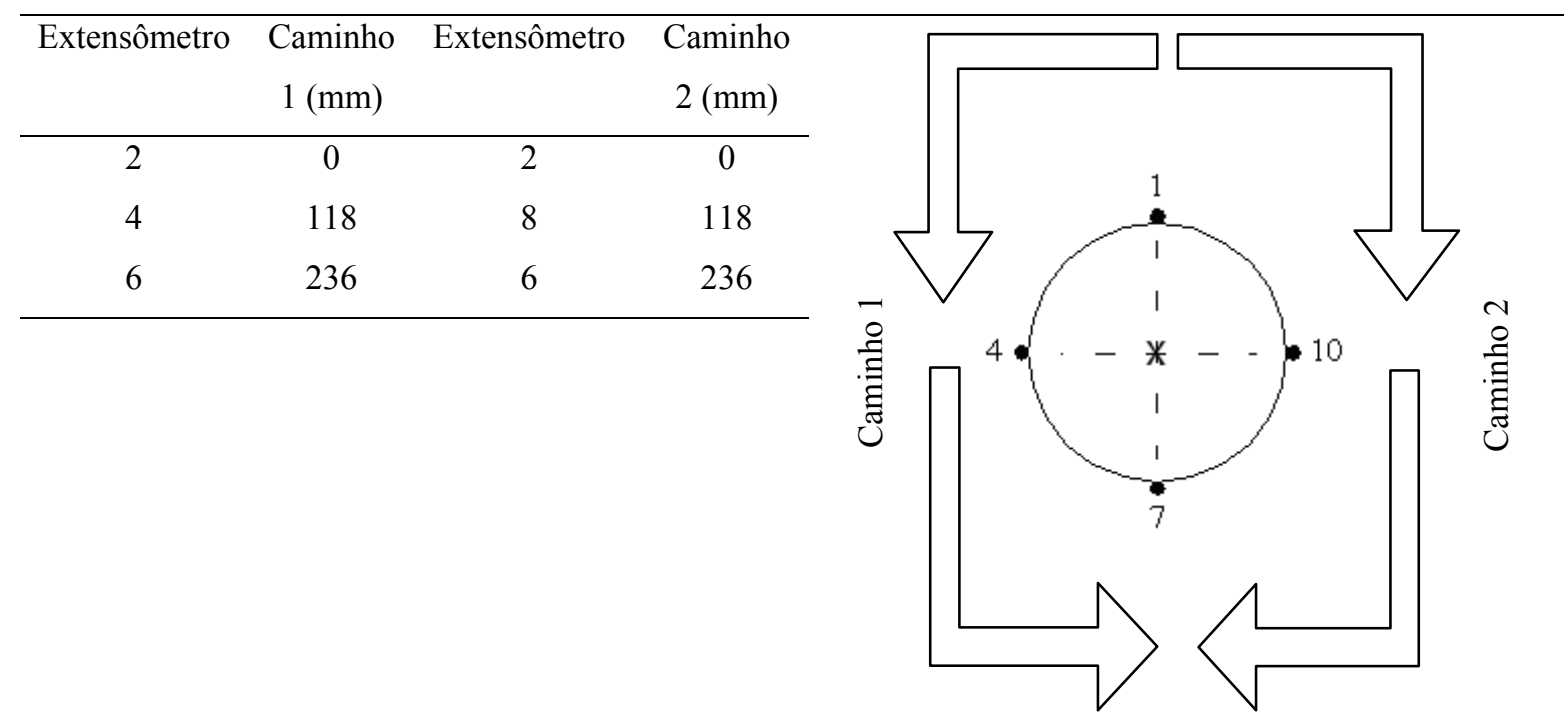

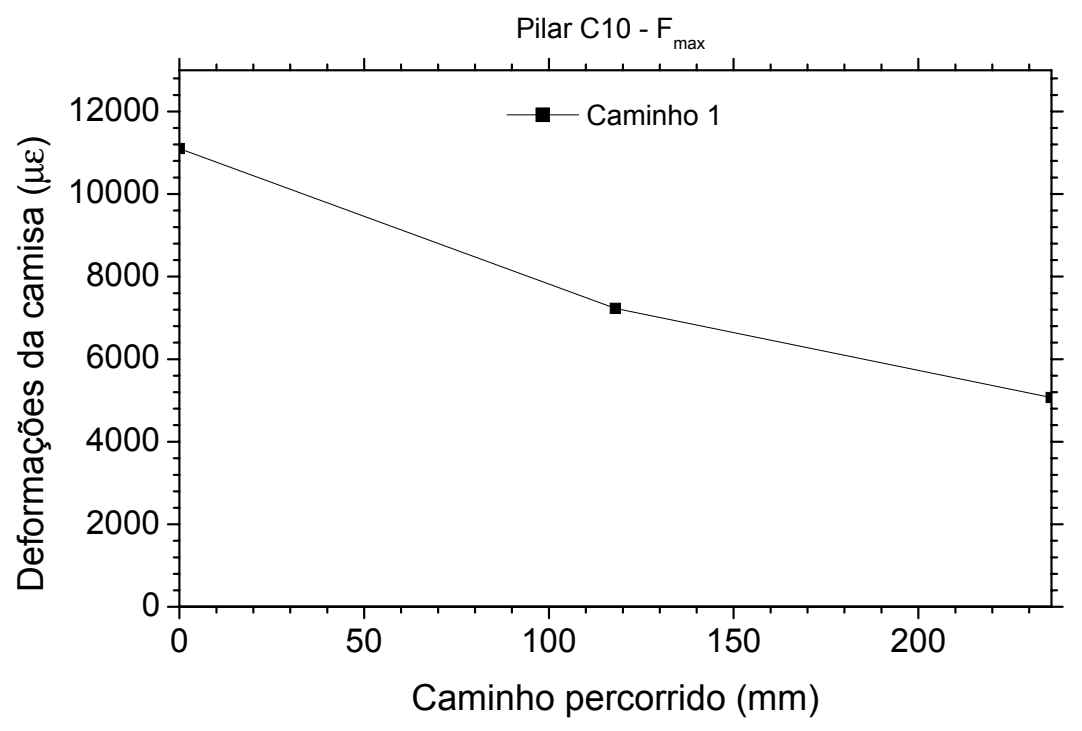

Figura 5.55 - Deformações transversais da camisa pilar C10 


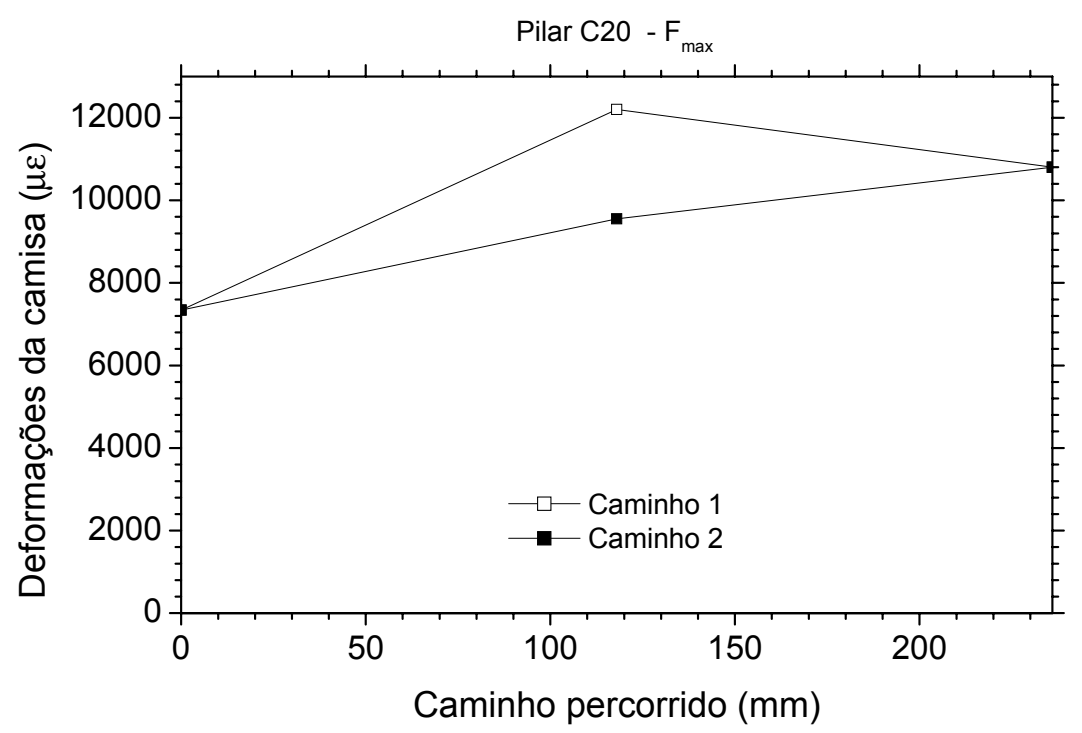

Figura 5.56 - Deformações transversais da camisa pilar C12

Na Tabela 5.21 são apresentados os pontos utilizados para a construção dos diagramas de deformações da camisa dos pilares circulares submetidos à compressão excêntrica.

Tabela 5.21 - Deformação transversal x caminho percorrido - Série 4 - pilares excêntricos

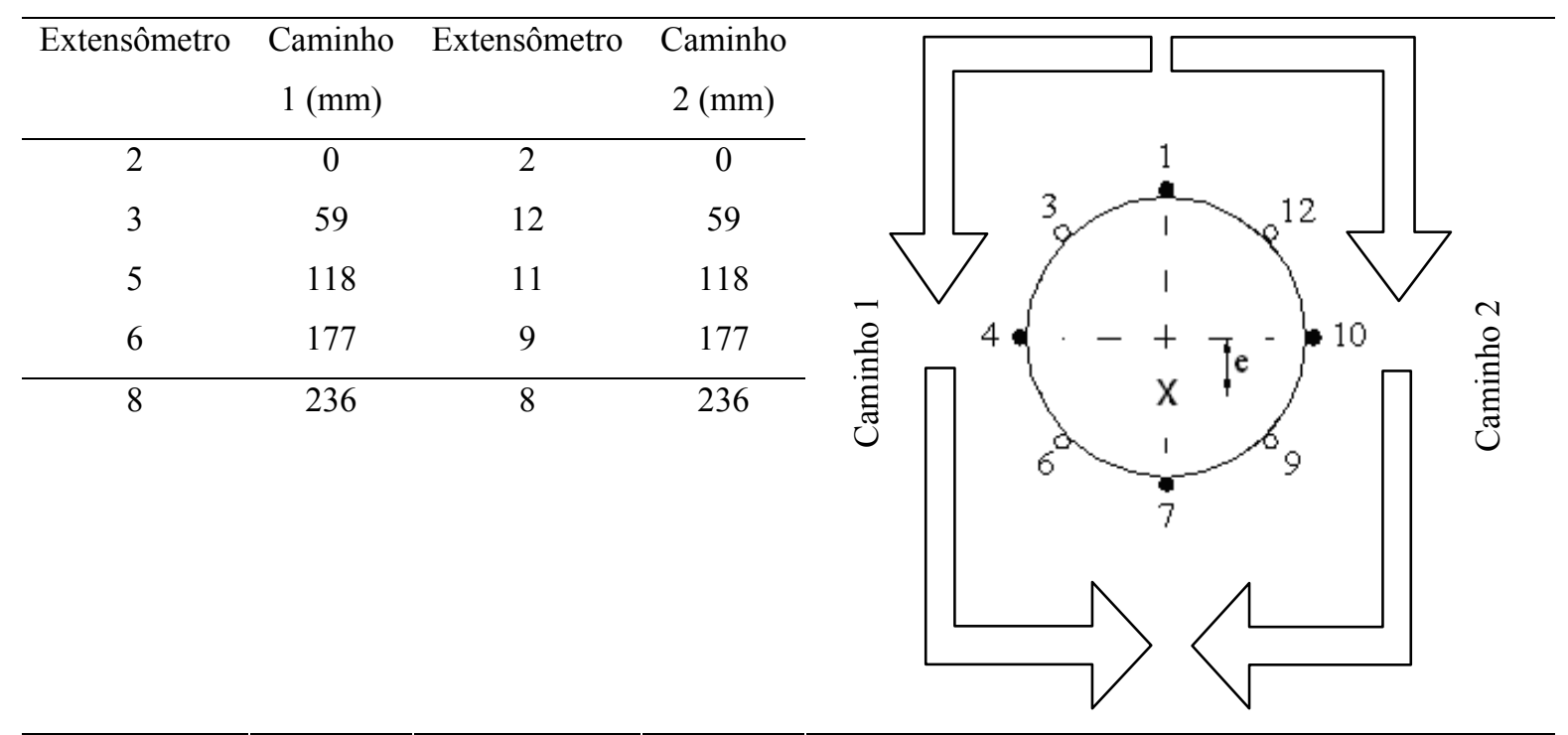


No pilar C12 as deformações transversais da camisa no lado menos comprimido foram praticamente nulas. Já no pilar C22 estas deformações não foram nulas, provavelmente porque após uma grande plastificação do concreto as tensões foram se alterando dentro da seção transversal, e o lado que estava submetido a tensões axiais praticamente nulas passou a ser solicitado.

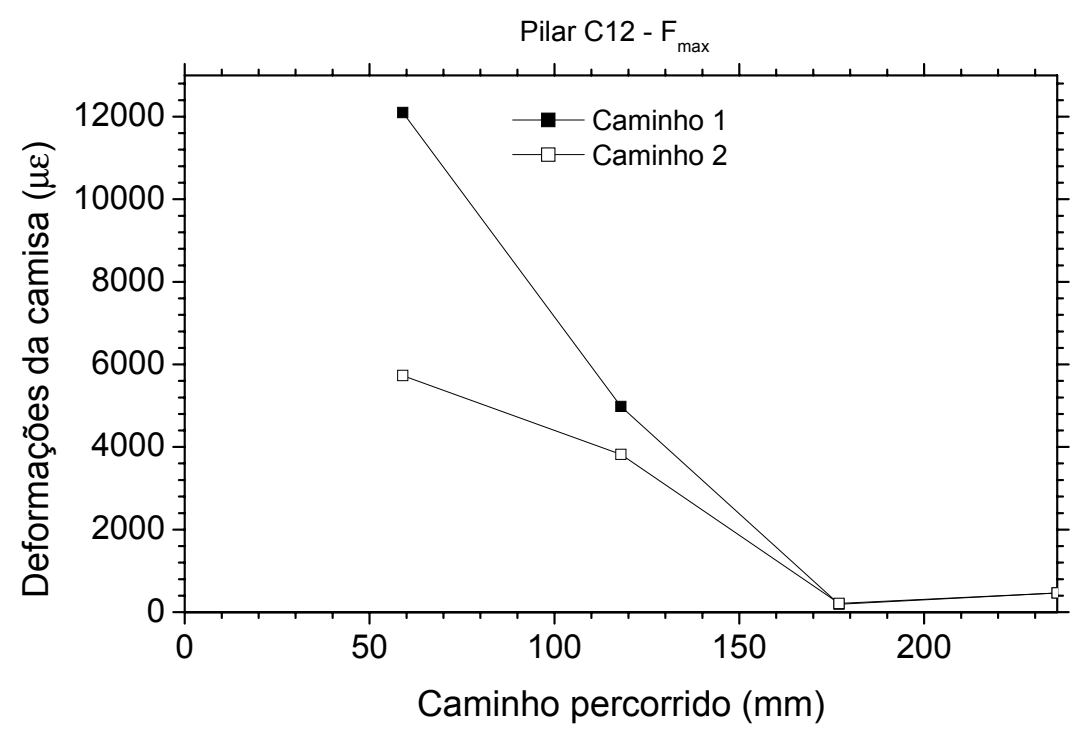

Figura 5.57 - Deformações transversais da camisa pilar C12 


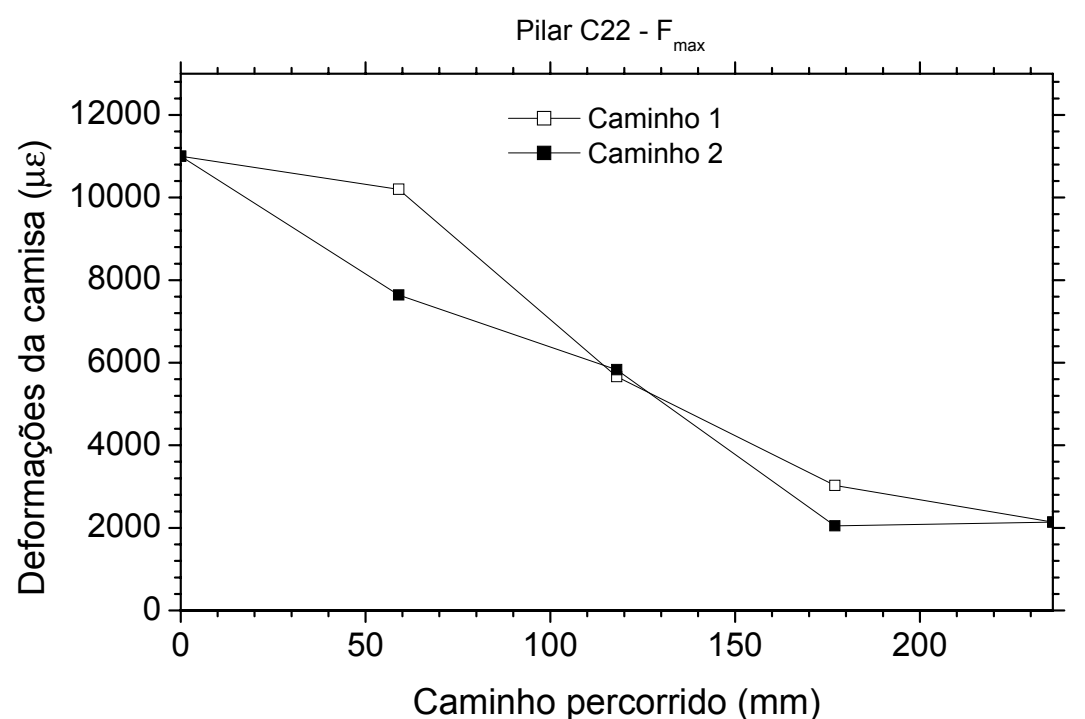

Caminho percorrido $(\mathrm{mm})$

Pilar C22 - ruptura da camisa

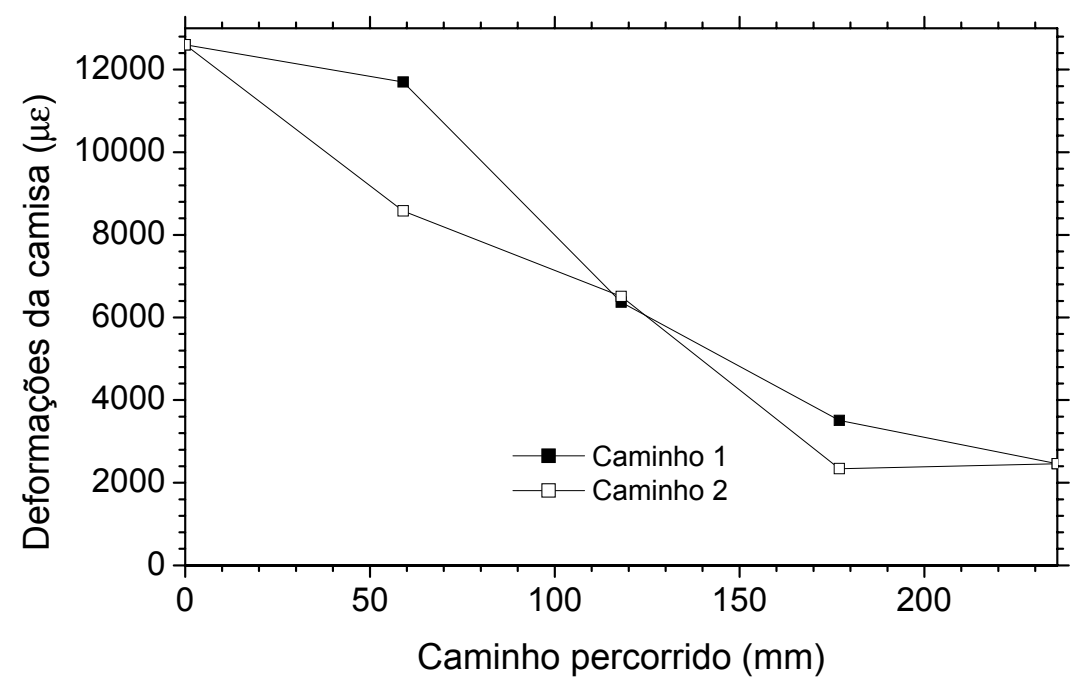

Figura 5.58 - Deformações transversais da camisa pilar C22

Na Tabela 5.22 são apresentados os pontos utilizados para a construção dos diagramas de deformações da camisa dos pilares sob compressão centrada da série 5 . Nos pilares X10r1 e X20r1 observou-se as maiores deformações da camisa nos cantos e no encontro dos cantos arredondados com as faces laterais. 
Tabela 5.22 - Deformação transversal x caminho percorrido - Série 5, $\mathrm{r}=1 \mathrm{~cm}$

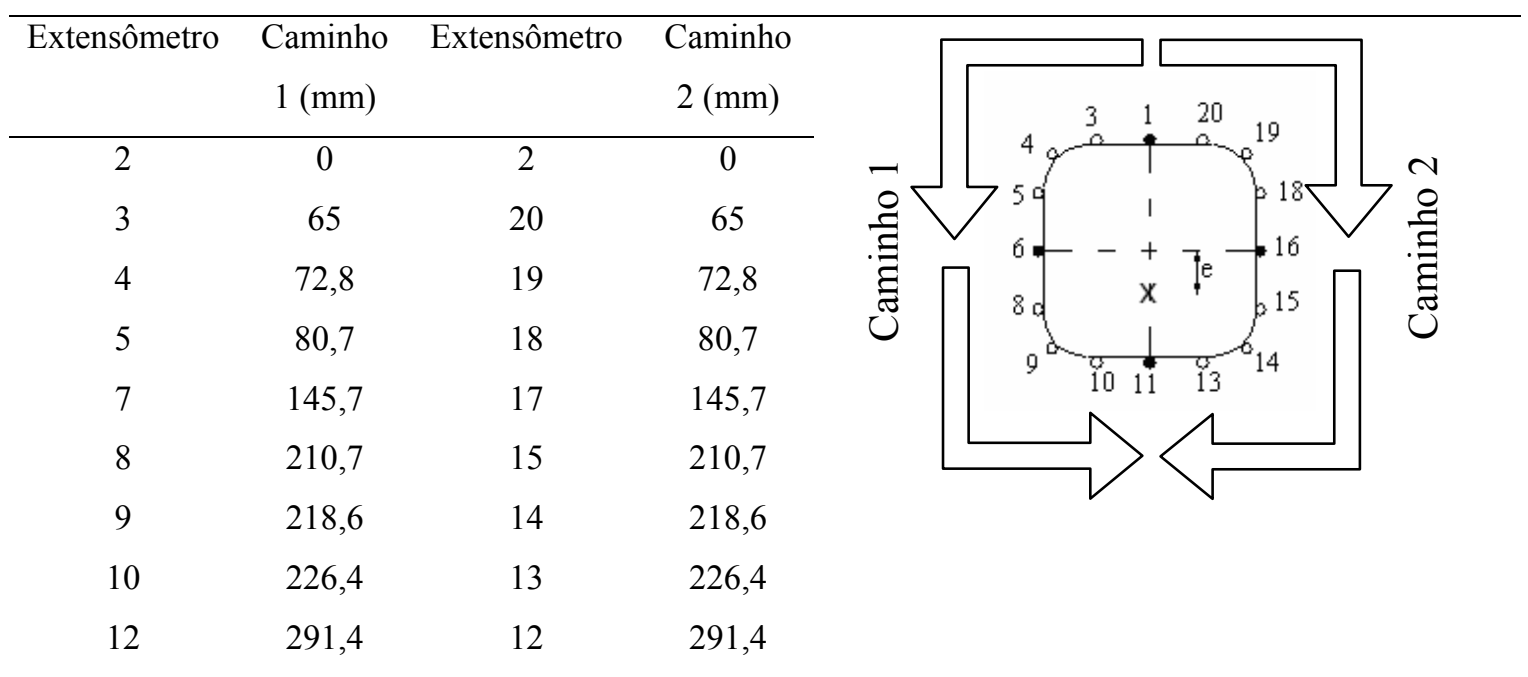
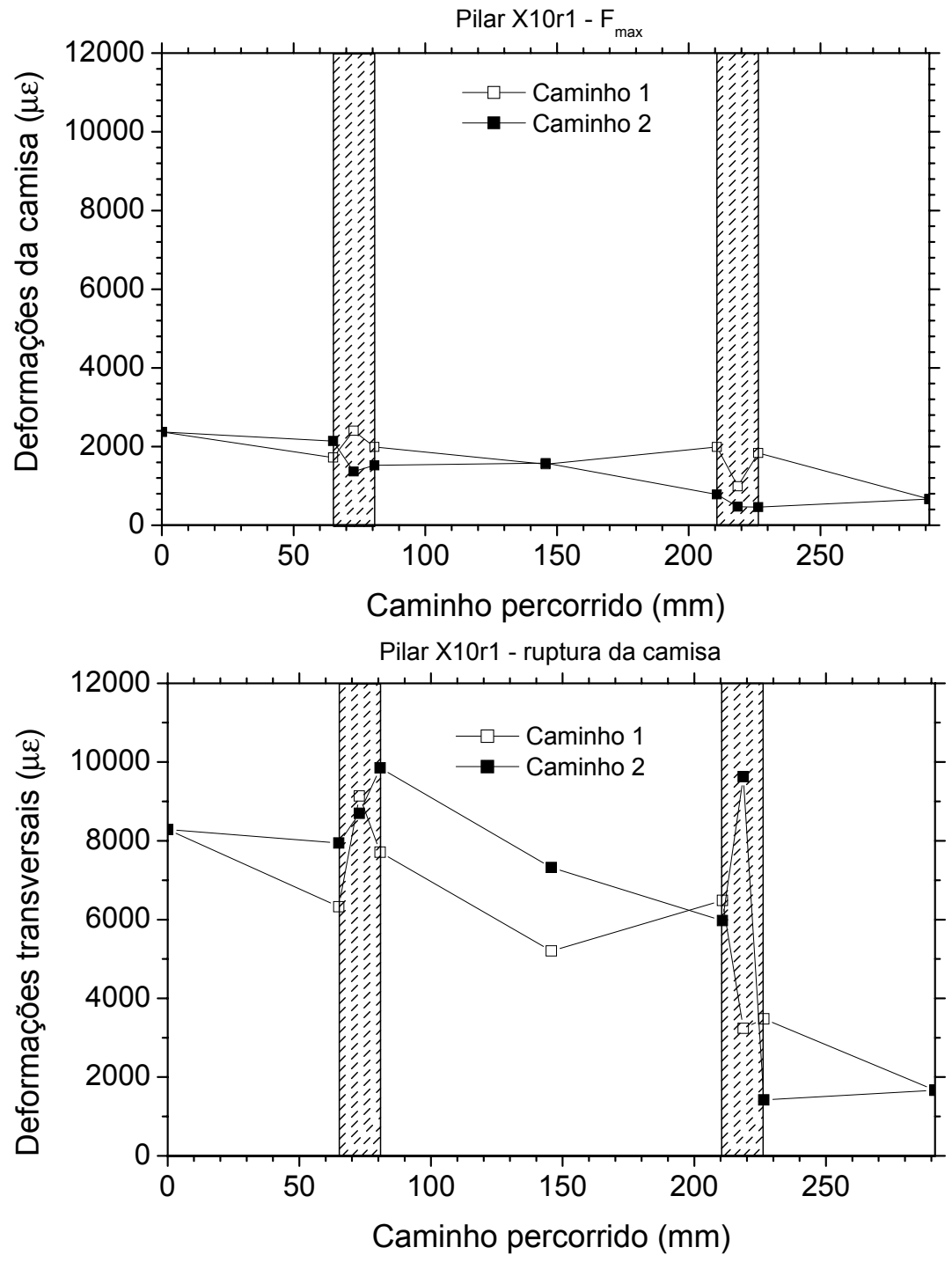

Figura 5.59 - Deformações transversais da camisa pilar X10r1 

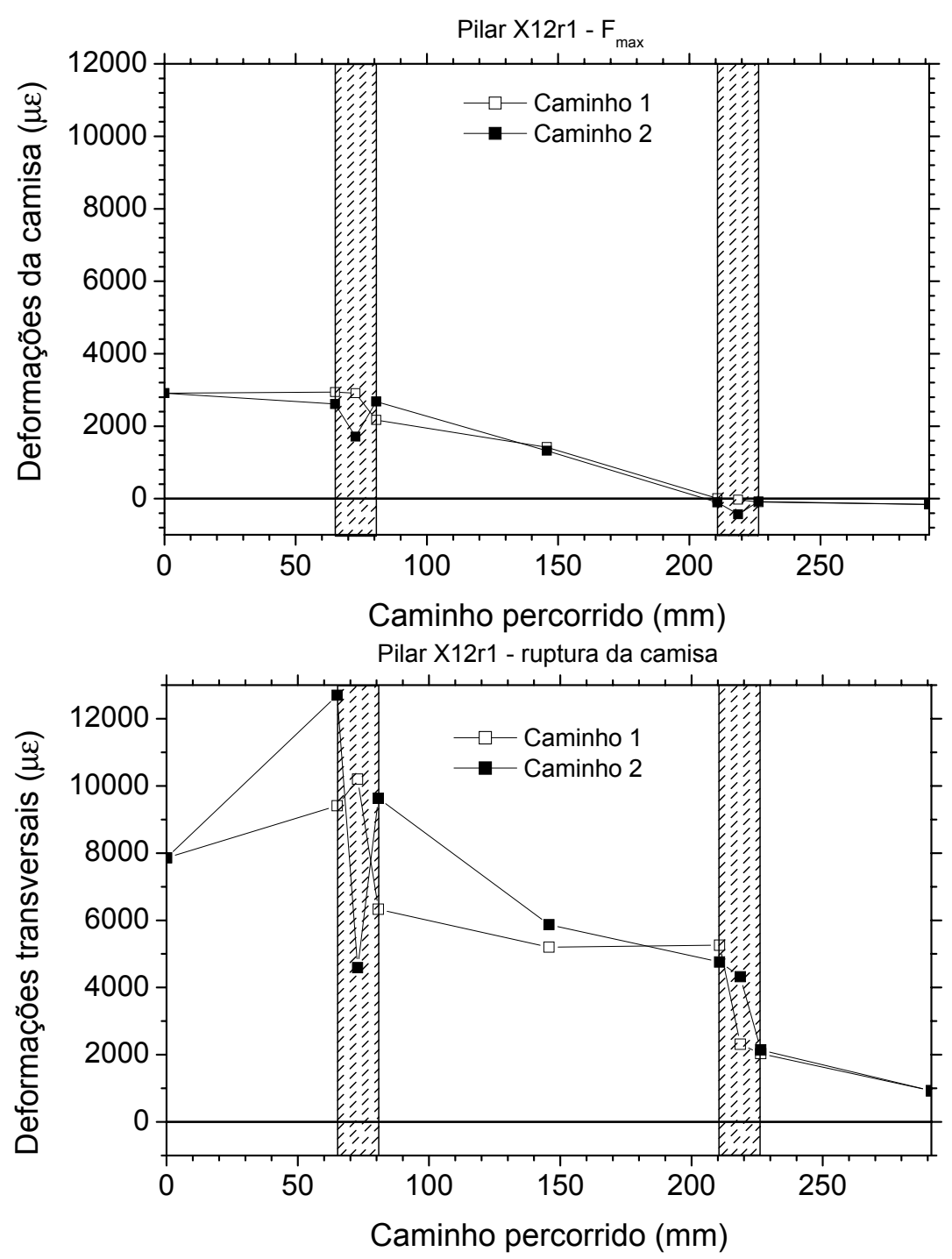

Figura 5.60 - Deformações transversais da camisa pilar X12r1

Na Tabela 5.23 são apresentados os pontos utilizados para a construção dos diagramas de deformações da camisa dos pilares sob compressão excêntrica da série 5 . Nos pilares X10r3 e X20r3 foram observadas as maiores deformações da camisa no encontro dos cantos arredondados com as faces laterais e também elevadas deformações nas faces laterais. 
Tabela 5.23 - Deformação transversal $x$ caminho percorrido - Série $5-r=3 \mathbf{c m}$

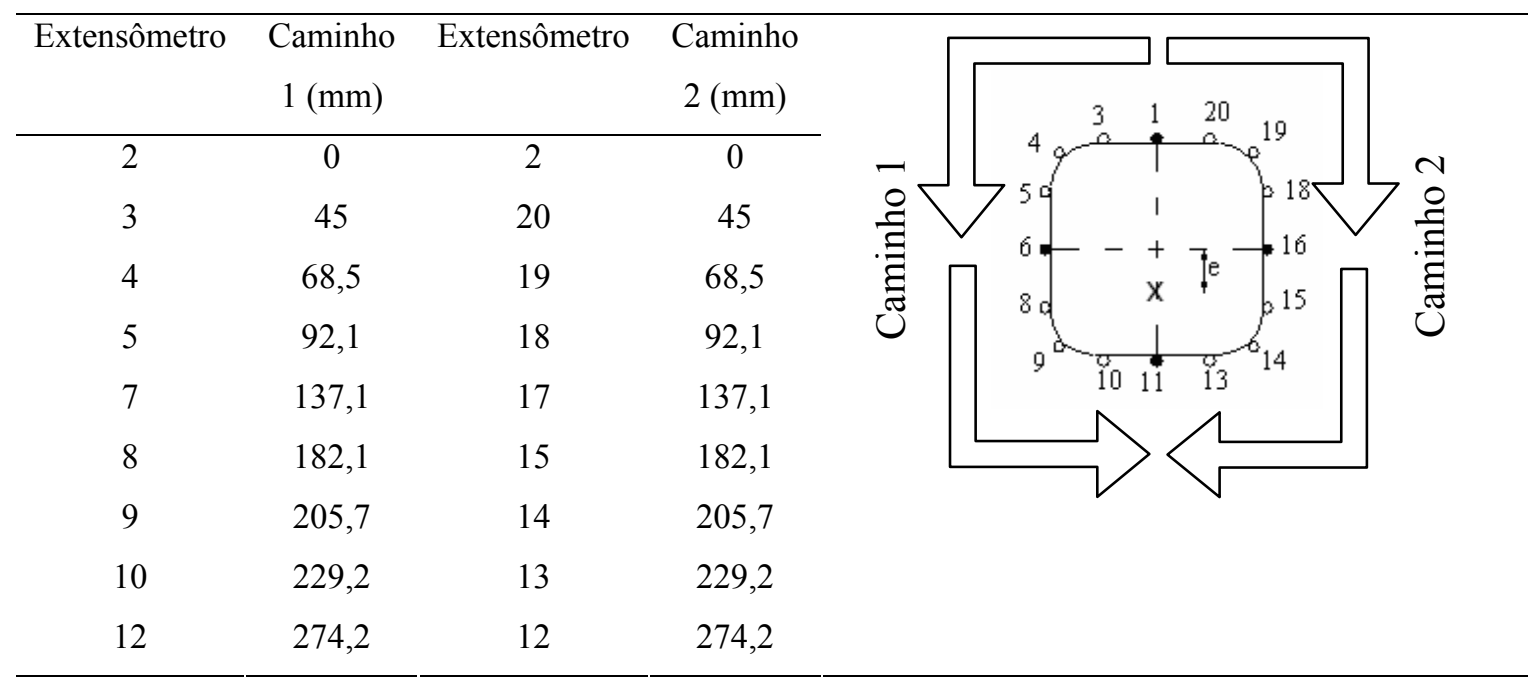

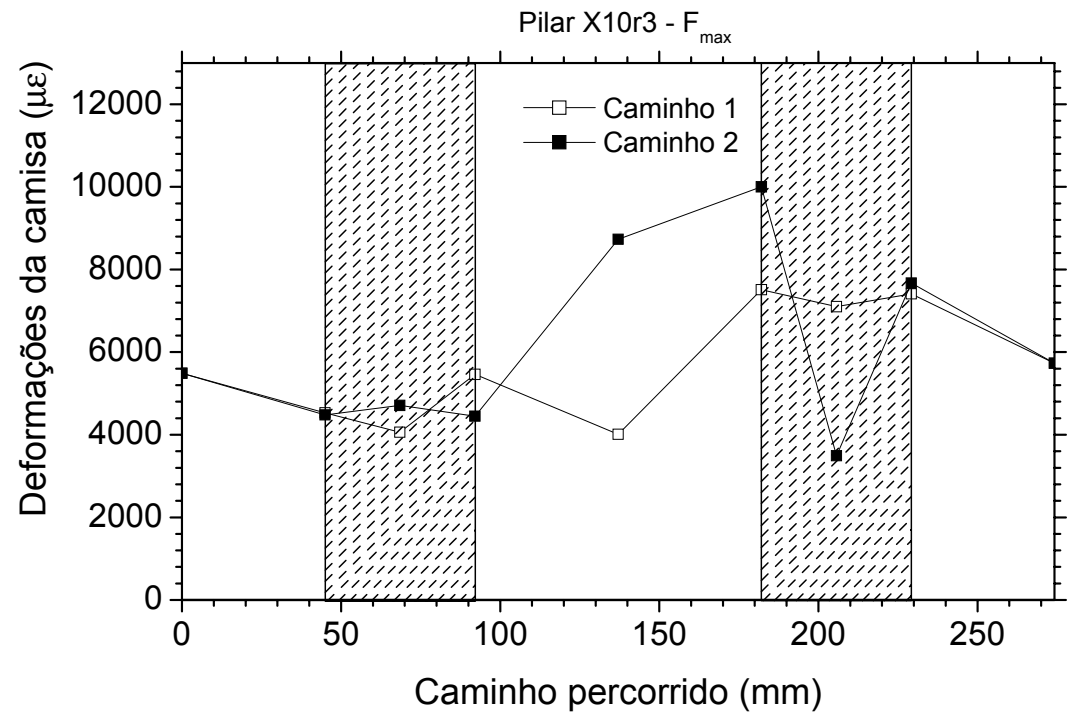

Figura 5.61 - Deformações transversais da camisa pilar X10r3 

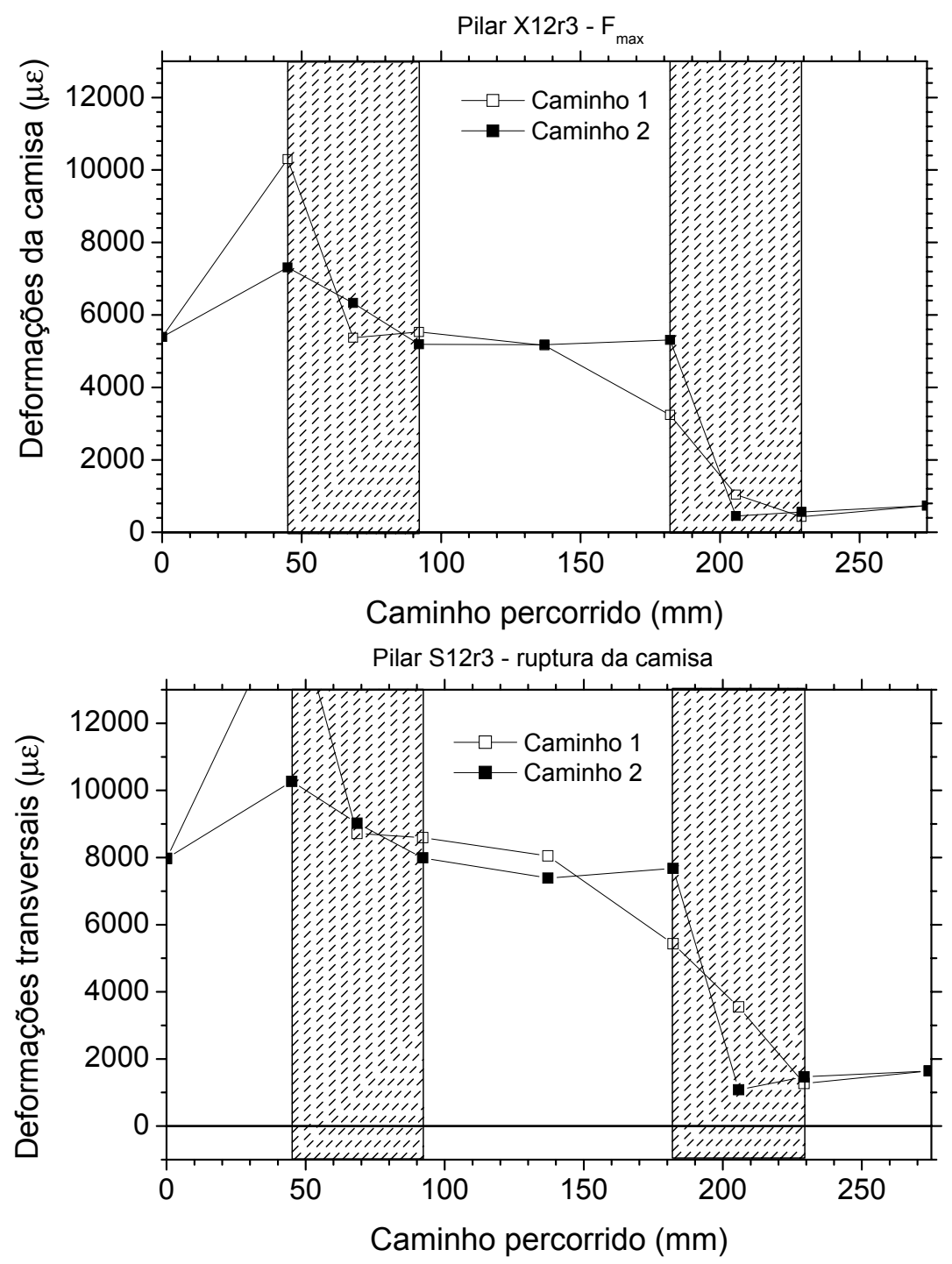

Figura 5.62 - Deformações transversais da camisa pilar X12r3

\subsubsection{Comparações de resistência axial}

A utilização do encamisamento com PRFC possibilitou aumentos de resistência à compressão axial para todos os pilares ensaiados. Foi possível observar que o ganho de resistência axial por meio do confinamento depende de diversos fatores: da forma da seção transversal, do raio de arredondamento dos cantos, da excentricidade do carregamento, da direção da excentricidade (no caso de pilares retangulares) e do número de camadas. As análises comparativas foram realizadas com base na variável $\mathrm{f}_{\mathrm{cc}} / \mathrm{f}_{\mathrm{co}}$, que representa a relação entre a resistência do pilar encamisado e a do pilar de referência $(n=0)$.

No caso dos pilares de seção quadrada com $\mathrm{r}=1 \mathrm{~cm}$, observou-se que $\mathrm{o}$ acréscimo de capacidade resistente causado pelo encamisamento foi maior no caso dos 
pilares excêntricos (sendo máximo o aumento de capacidade resistente quando a excentricidade foi igual a $2 \mathrm{~cm}$ ).

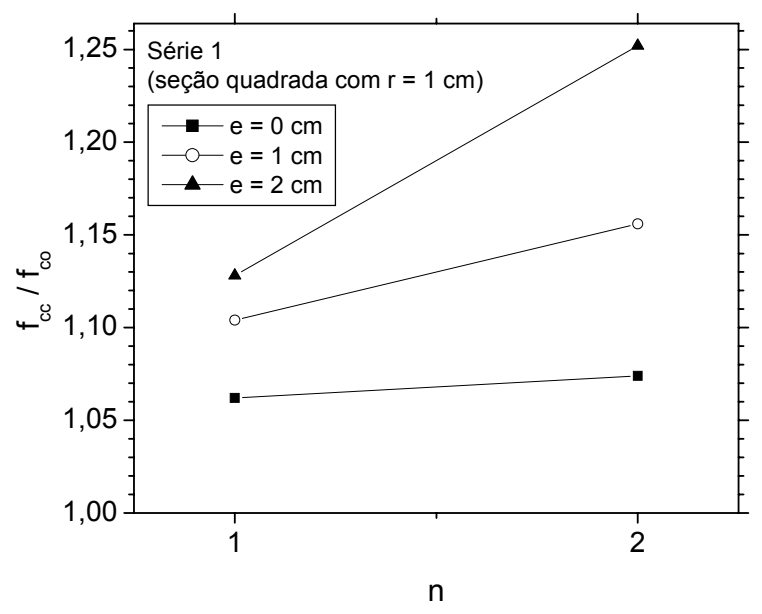

Figura 5.63 - Aumento de resistência dos pilares encamisados $(r=1 \mathrm{~cm})$

Nos pilares quadrados com $\mathrm{r}=3 \mathrm{~cm}$ observou-se o maior aumento de resistência com a excentricidade intermediária de $1 \mathrm{~cm}$.

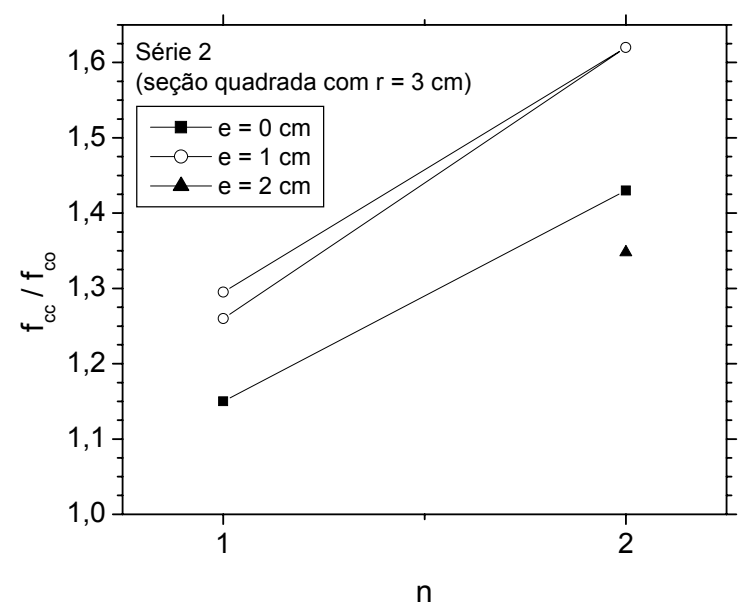

Figura 5.64 - Aumento de resistência dos pilares encamisados $(r=3 \mathrm{~cm})$

Nos pilares retangulares com $\mathrm{r}=3 \mathrm{~cm}$ foi utilizado apenas um valor de $\mathrm{n}$ não nulo $(\mathrm{n}=2)$. Na Figura 5.65 é apresentada a variação do ganho de resistência para as diferentes excentricidades. Observou-se o maior aumento de resistência com a excentricidade $e_{x}=3 \mathrm{~cm}$. Deve-se observar que, nos ensaios com força excêntrica dos pilares retangulares, a excentricidade relativa e/h (excentricidade / altura da seção na direção considerada) foi a mesma $(\mathrm{e} / \mathrm{h}=0,133)$, o que indica que para a mesma 
excentricidade relativa o ganho de resistência foi maior quando esta foi aplicada na direção da maior inércia.

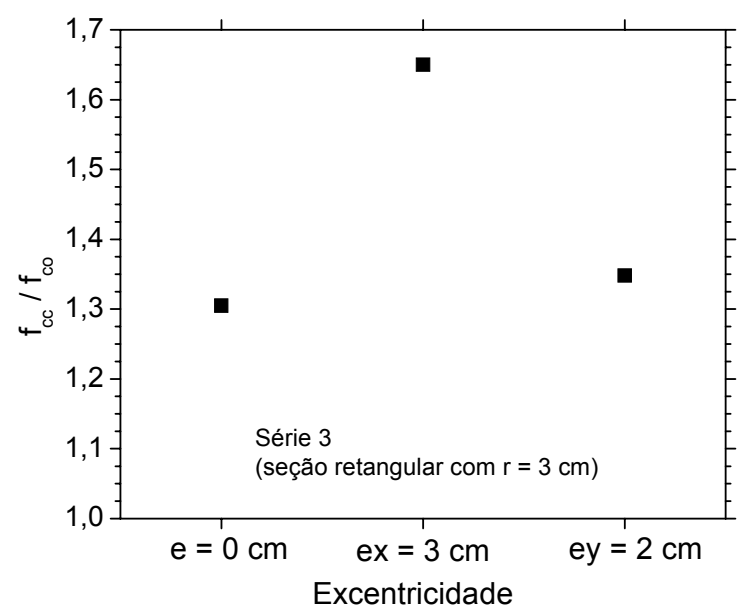

Figura 5.65 - Aumento da resistência dos pilares retangulares encamisados com $n=2$ para diferentes excentricidades

Para os pilares de seção transversal circular, como já era esperado, o ganho de resistência foi inferior com a excentricidade diferente de zero. Isto pode ser justificado pelo fato de que a compressão centrada em pilares circulares é a situação ideal de confinamento, em que a pressão lateral máxima pode ser desenvolvida, justamente por ser uniforme. Na presença do gradiente de deformações a efetividade do confinamento diminui, pois a pressão lateral deixa de ser constante.

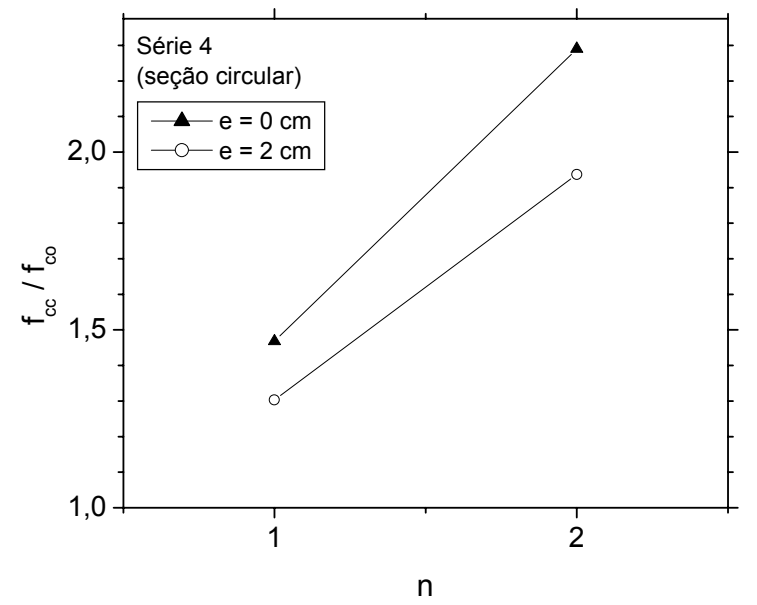

Figura 5.66 - Aumento da resistência dos pilares circulares encamisados para diferentes excentricidades 
Os ensaios da série 5 complementaram as análises anteriores indicando um comportamento semelhante. Pode-se observar que ocorreu um ganho de resistência maior para a excentricidade de $2 \mathrm{~cm}$ em ambos os casos. Deve-se observar ainda que com o raio de $1 \mathrm{~cm}$ a diferença do ganho de resistência do pilar centrado e do excêntrico é significativa. No entanto, como os pilares da série 5 foram confeccionados com uma resistência diferente dos anteriores não é possível uma comparação direta dos efeitos para o mesmo número de camadas dos pilares ensaiados nas séries anteriores, pois com o mesmo número de camadas das séries anteriores os valores de $f_{1} / f_{c o}$ são diferentes.

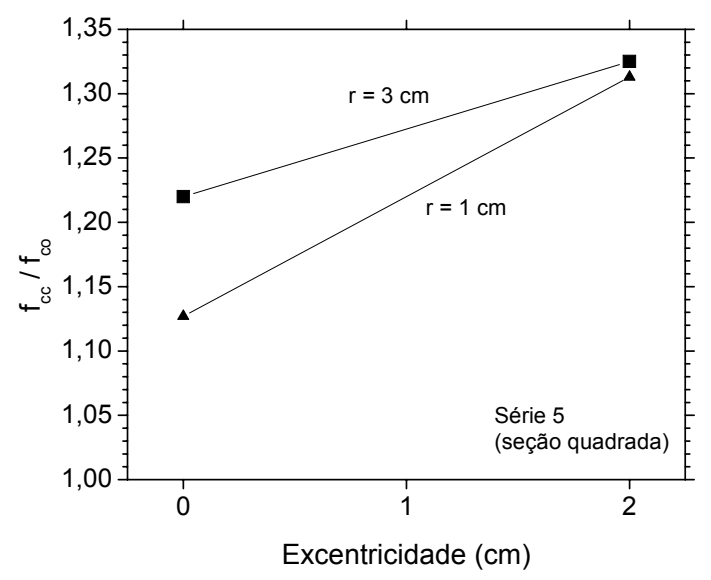

Figura 5.67 - Ganho de resistência dos pilares encamisados da série 5 para diferentes excentricidades

A comparação dos pilares das séries 1 e 2 permitiu avaliar a influência do raio de arredondamento. Para os pilares sob compressão centrada o ganho de resistência foi significativamente maior com o raio de $3 \mathrm{~cm}$.

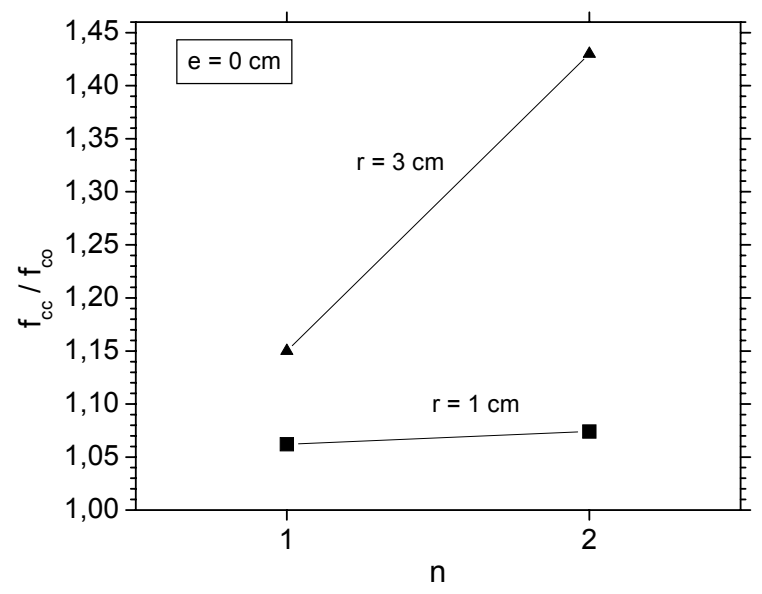

Figura 5.68 - Ganho de resistência dos pilares encamisados sob compressão centrada das séries 1 e 2 
A tendência de um maior ganho de resistência com o raio de $3 \mathrm{~cm}$ foi mantida para a excentricidade $\mathrm{e}=1 \mathrm{~cm}$.

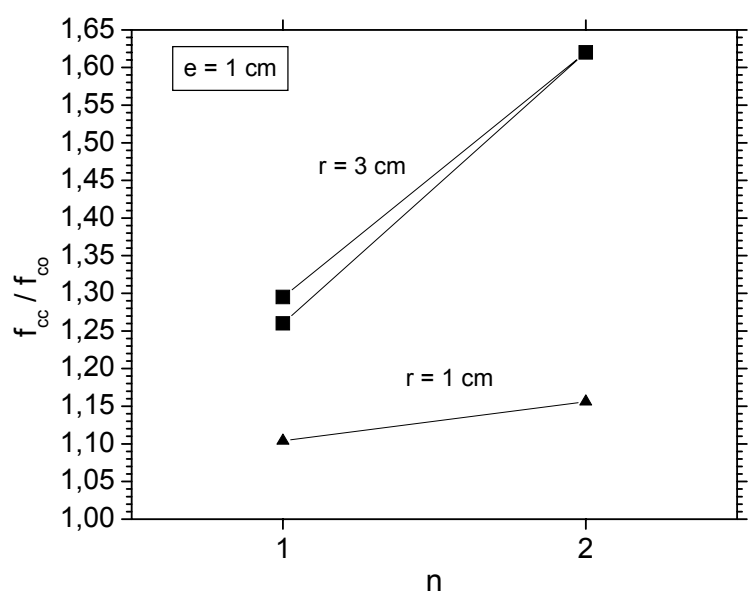

Figura 5.69 - Ganho de resistência dos pilares encamisados sob compressão centrada das séries 1 e 2

Com a excentricidade de $2 \mathrm{~cm}$ observou-se também um ganho de resistência superior com $\mathrm{r}=3 \mathrm{~cm}$, mas, no entanto, com uma diferença menor em comparação aos pilares $\mathrm{com} \mathrm{r}=1 \mathrm{~cm}$.

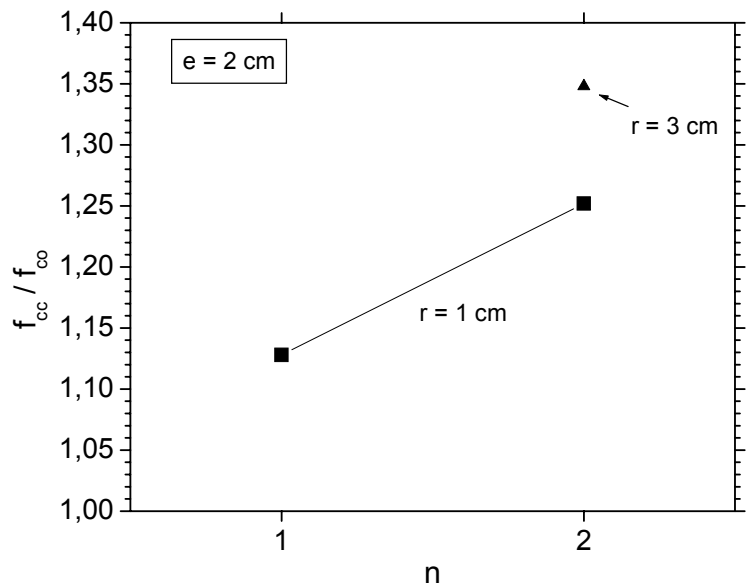

Figura 5.70 - Ganho de resistência dos pilares encamisados sob compressão centrada das séries 1 e 2

As comparações anteriores indicaram que pilares com menor raio de arredondamento parecem ter um efeito de confinamento mais efetivo sob ação de forças excêntricas. 
A avaliação do efeito da forma da seção transversal foi realizada comparando os pilares das séries 2 e 3. Pode-se observar que sob compressão centrada a resistência normalizada foi maior para o pilar de seção quadrada. Já no caso de compressão excêntrica (com e/h=0,133), observou-se o mesmo valor de resistência normalizada do pilar quadrado e do pilar retangular carregado com excentricidade na direção da menor inércia $\left(\mathrm{e}_{\mathrm{x}}=2 \mathrm{~cm}\right)$. Já para a excentricidade aplicada na direção da maior inércia, o pilar retangular apresentou uma resistência normalizada superior ao pilar quadrado.

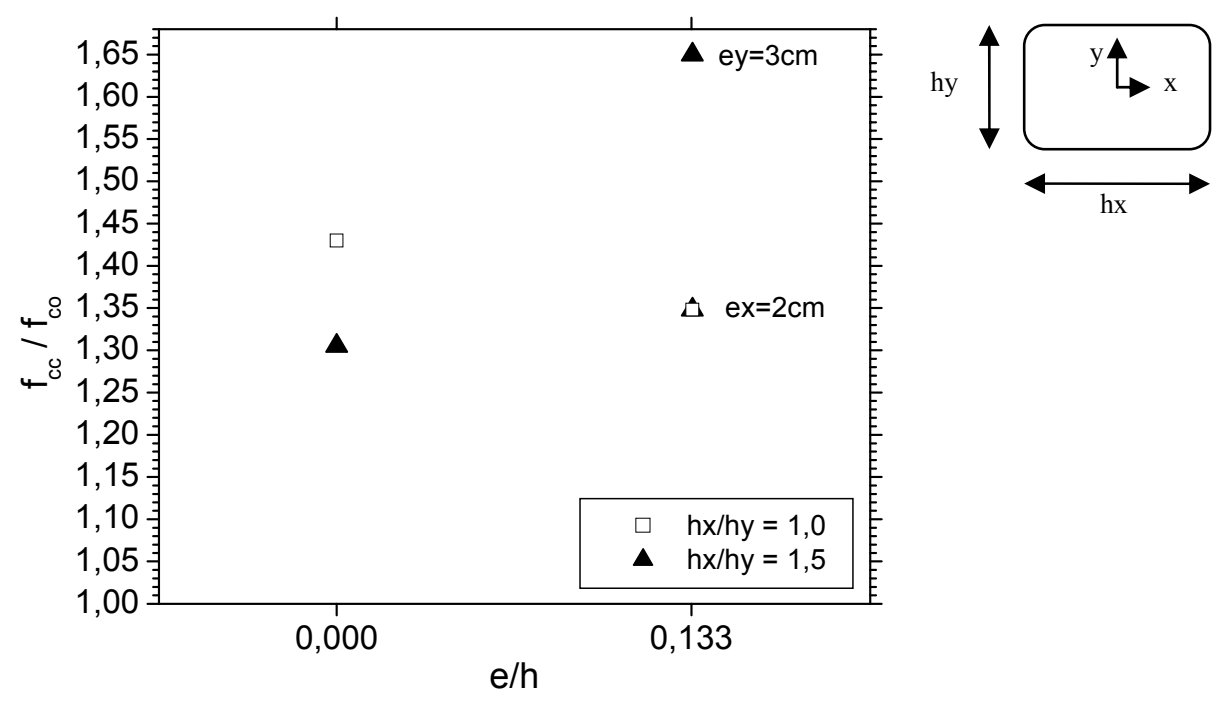

Figura 5.71 - Influência conjunta da forma da seção transversal e da excentricidade do carregamento

Considerou-se na presente análise que para pilares com confinamento não uniforme existe um coeficiente $\left(\mathrm{k}_{\mathrm{e}}\right)$ que reduz a pressão lateral efetivamente atuante no pilar confinado. Como $\mathrm{k}_{1}$ é considerada uma propriedade do material, $\mathrm{k}_{\mathrm{e}}$ pode ser determinado a partir dos resultados dos ensaios de cada pilar com:

$$
k_{e}=\frac{f_{c c}-f_{c o}}{k_{1} \cdot f_{l}}
$$

Além disso, foram eleitas as variáveis $k_{\mathrm{e} 1}, \mathrm{k}_{\mathrm{e} 2}$, e $\mathrm{k}_{\mathrm{e} 3}$ como aquelas que influenciam na efetividade do confinamento, conforme Tabela 5.24. Foi então realizada uma análise de regressão com os resultados experimentais dos pilares centrados para determinar uma equação para $\mathrm{k}_{\mathrm{e}}$ com os dados apresentados na Tabela 5.24. Como se pode observar, obteve-se uma boa representatividade dos valores experimentais de $\mathrm{k}_{\mathrm{e}}$ com o modelo gerado. 
Tabela 5.24 - Análise de regressão dos parâmetros de confinamento

\begin{tabular}{ccccccc} 
Pilar & $k_{e 1}=\frac{2 r}{h_{x}}$ & $k_{e 2}=\frac{h_{y}}{h_{x}}$ & $k_{e 3}=\frac{E_{l}}{f_{c o}}$ & $\begin{array}{c}\mathrm{k}_{\mathrm{e}} \\
\text { Regressão }\end{array}$ & $\begin{array}{c}\mathrm{k}_{\mathrm{e}} \\
\text { experimental }\end{array}$ & $\begin{array}{c}\text { Dados adicionais do } \\
\text { modelo de regressão: } \\
k_{e}=k_{e 1}{ }^{c 1} \cdot k_{e 2}{ }^{c 2} \cdot k_{e 3}{ }^{c 3}\end{array}$ \\
\hline S00r1 & 0,133 & 1,000 & 0,000 & 0,000 & 0,000 & Data: fco=42.5 \\
S10r1 & 0,133 & 1,000 & 12,890 & 0,065 & 0,088 & Model: ke \\
S20r1 & 0,133 & 1,000 & 25,779 & 0,065 & 0,061 & $\mathrm{Chi}^{\wedge} 2=0.00761$ \\
S00r3 & 0,400 & 1,000 & 0,000 & 0,000 & 0,000 & $\mathrm{R}^{\wedge} 2=0.95939$ \\
S10r3 & 0,400 & 1,000 & 12,767 & 0,291 & 0,214 & \\
S20r3 & 0,400 & 1,000 & 25,534 & 0,293 & 0,360 & $\mathrm{c} 1=1.36683 \pm 0.21627$ \\
R00 & 0,267 & 0,667 & 0,000 & 0,000 & 0,000 & $\mathrm{c} 2=-0.65481 \pm 1.19475$ \\
R20 & 0,267 & 0,667 & 17,186 & 0,219 & 0,219 & $\mathrm{c} 3=0.00727 \pm 0.02092$ \\
C00 & 1,000 & 1,000 & 0,000 & 0,000 & 0,000 & \\
C10 & 1,000 & 1,000 & 12,291 & 1,018 & 0,841 & 1,159 \\
C20 & 1,000 & 1,000 & 24,582 & 1,024 & & \\
\hline
\end{tabular}

Na Figura 5.33 são apresentados os valores de $\mathrm{k}_{\mathrm{e}}$ obtidos na análise de regressão e os valores determinados a partir dos dados experimentais.

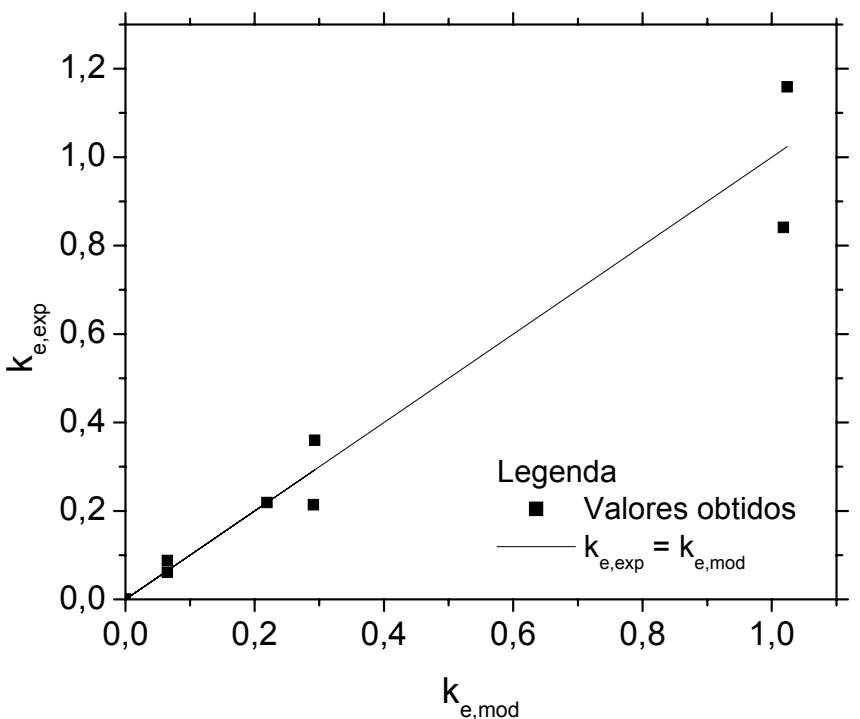

Figura 5.72 - Comparativo entre os valores experimentais e o do modelo gerado para $\mathbf{k}_{\mathrm{e}}$

Apesar do pequeno número de ensaios utilizado para a calibração foi possível observar uma boa concordância dos resultados gerados pelo modelo com os experimentais. $\mathrm{Na}$ análise anterior foram desprezados os resultados obtidos com $\mathrm{o}$ concreto da série 5, pois numa análise inicial, a sua inclusão havia prejudicado a correlação dos resultados (indicada por $\mathrm{R}^{2}$ e chi $^{2}$ ). Com a calibração acima foram calculados os valores de $\mathrm{k}_{\mathrm{e}}$ para a série 5, conforme indica a Tabela 5.25. Pode-se observar que o modelo gerado com os resultados anteriores não foi satisfatório para a 
série 5 , o que indica que a resistência do concreto tem influência sobre os parâmetros do modelo, logo deveria ser incorporada ao modelo para melhor representatividade.

Observou-se, ainda, que os coeficientes de efetividade dos pilares com concreto de menor resistência (série 5) foram maiores. Isto ocorreu por causa da influência da resistência sobre a deformabilidade, que faz com que o concreto de menor resistência apresente uma queda de resistência mais gradual e maior expansão lateral que o concreto de maior resistência.

Tabela 5.25 - Análise de regressão não linear dos parâmetros de confinamento

\begin{tabular}{cccccc}
\hline Pilar & $k_{e 1}=\frac{2 r}{h_{x}}$ & $k_{e 2}=\frac{h_{y}}{h_{x}}$ & $k_{e 3}=\frac{E_{l}}{f_{c o}}$ & $\mathrm{k}_{\mathrm{e}}$ & $\begin{array}{c}\mathrm{k}_{\mathrm{e}} \\
\text { Regressão }\end{array}$ \\
\hline experimental \\
X00 & 0,133 & 1,000 & 0,000 & 0,000 & 0,000 \\
X10r1 & 0,133 & 1,000 & 18,715 & 0,065 & 0,150 \\
X10r3 & 0,400 & 1,000 & 18,715 & 0,292 & 0,446 \\
\hline
\end{tabular}

A influência da excentricidade do carregamento foi avaliada para os pilares das séries 1 a 4, utilizando o modelo de regressão anterior para $\mathrm{k}_{\mathrm{e}}$ e acrescentando um parâmetro $\mathrm{k}_{\mathrm{e} 4}$ que considera a excentricidade relativa (e/h). Observou-se ainda que há um acoplamento do efeito da excentricidade do carregamento com a forma da seção transversal, ou seja, a influência da excentricidade do carregamento depende da forma da seção transversal considerada.

Por exemplo, analisando-se os pilares circulares encamisados conclui-se que o acréscimo máximo de capacidade resistente por encamisamento foi obtido sob compressão centrada e que qualquer mudança da posição da força de compressão levou a uma diminuição da efetividade do confinamento. Logo, em pilares de seção circular, a excentricidade do carregamento diminuiu o valor de $\mathrm{k}_{\mathrm{e}}$. Além disso, foi possível observar que, neste caso ocorreu uma redução de $F_{u \text {,excêntrico }} / F_{u \text {,centrado }}$ com o aumento do número de camadas, indicando que para pilares circulares ocorre uma redução do efeito de confinamento na presença da excentricidade. 
Tabela 5.26 - Efeito da excentricidade do carregamento

\begin{tabular}{lcccl}
\hline Pilar & $\mathrm{F}_{\mathrm{u}}(\mathrm{kN})$ & Pilar & $\mathrm{F}_{\mathrm{u}}(\mathrm{kN})$ & $\mathrm{F}_{\mathrm{u}, \text { excêntrico }} / \mathrm{F}_{\mathrm{u}, \text { centrado }}$ \\
\hline $\mathrm{C} 00$ & 681,1 & $\mathrm{C} 02$ & 469,4 & 0,689 \\
\hline $\mathrm{C} 10$ & 1000,0 & $\mathrm{C} 12$ & 611,6 & 0,612 \\
\hline $\mathrm{C} 20$ & 1560,0 & $\mathrm{C} 22$ & 909,1 & 0,583 \\
\hline
\end{tabular}

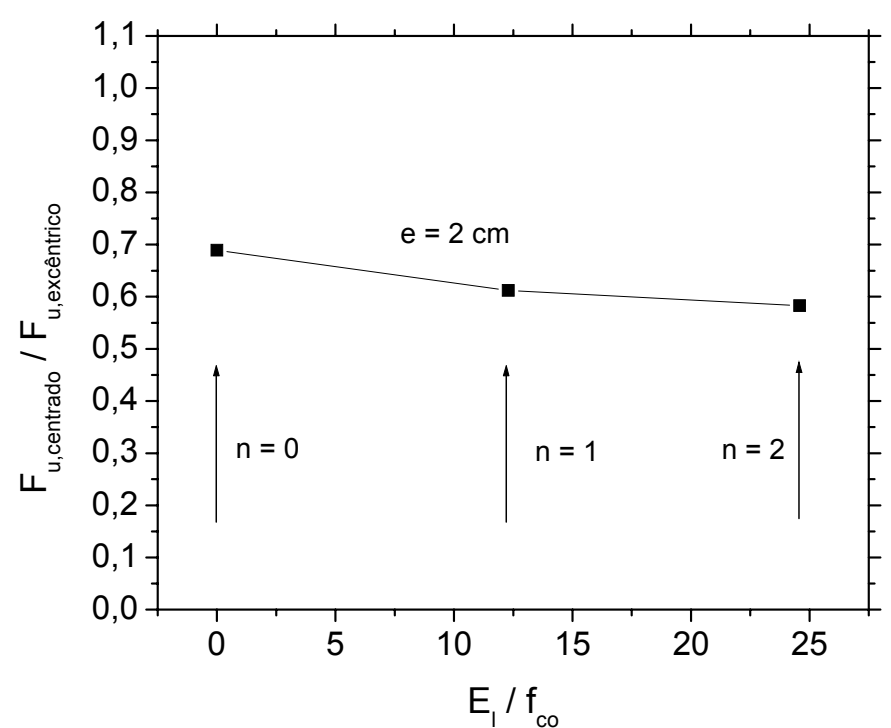

Figura 5.73 - Redução da resistência do pilar excêntrico em comparação com o centrado

Para os pilares de seção quadrada com $\mathrm{r}=1 \mathrm{~cm}$ observou-se um comportamento contrário aos circulares, em que os pilares encamisados tiveram uma redução de resistência menor na presença de excentricidades.

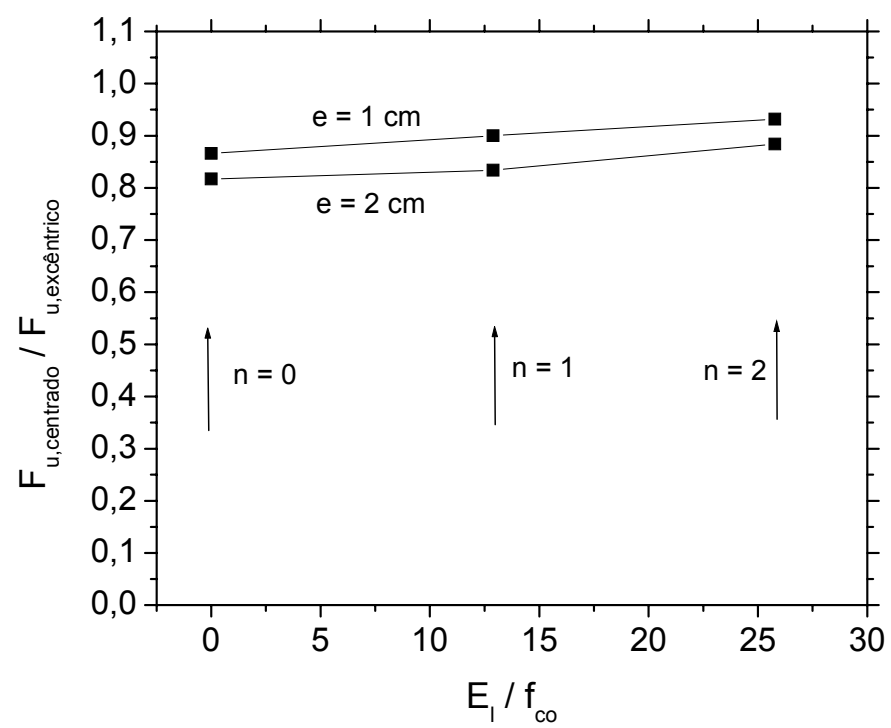

Figura 5.74 - Redução da resistência do pilar excêntrico em comparação com o centrado 
Para os pilares de seção quadrada com $\mathrm{r}=3 \mathrm{~cm}$ observou-se um comportamento intermediário entre os pilares circulares e o de seção quadrada com $\mathrm{r}=1 \mathrm{~cm}$.

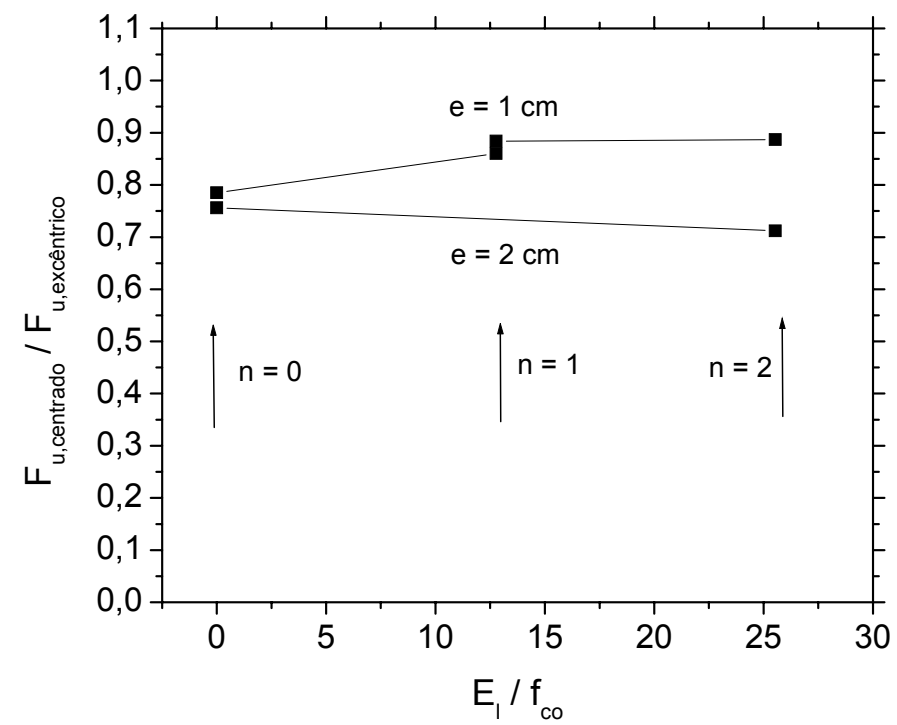

Figura 5.75 - Redução da resistência do pilar excêntrico em comparação com o centrado

Para os pilares de seção retangular com $\mathrm{r}=3 \mathrm{~cm}$ observou-se um aumento da força do pilar centrado sob excêntrico, principalmente considerando a excentricidade na direção da maior inércia.

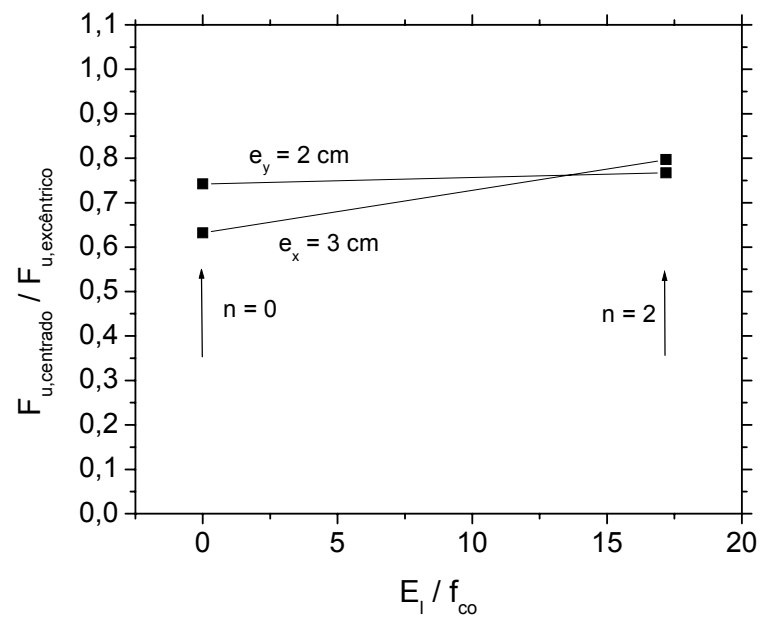

Figura 5.76 - Redução da resistência do pilar excêntrico em comparação com o centrado - Série 3

Com o objetivo de levar em consideração todos os parâmetros anteriormente mencionados, foi realizada uma análise de regressão para obter um fator redutor da 
resistência do pilar encamisado em função da excentricidade aplicada. $\mathrm{O}$ fator redutor da resistência em função da excentricidade é $\mathrm{k}_{\mathrm{e} 4}$, dado pela equação:

$$
k_{e 4}=1-2,303 \cdot\left(\frac{e_{i}}{h_{i}}\right)^{0,896} \cdot\left(\frac{2 r}{h_{x}}\right)^{0,356}
$$

onde:

- $\mathrm{e}_{\mathrm{i}}$ é a excentricidade na direção considerada;

- $\mathrm{h}_{\mathrm{i}}$ é a largura da seção na direção considerada.

Obteve-se na análise anterior uma correlação satisfatória, com $\mathrm{R}^{2}=0,921 \mathrm{e}$ $\operatorname{chi}^{2}=0,00149$. A comparação dos resultados experimentais e do modelo gerado é apresentada na Figura 5.77.

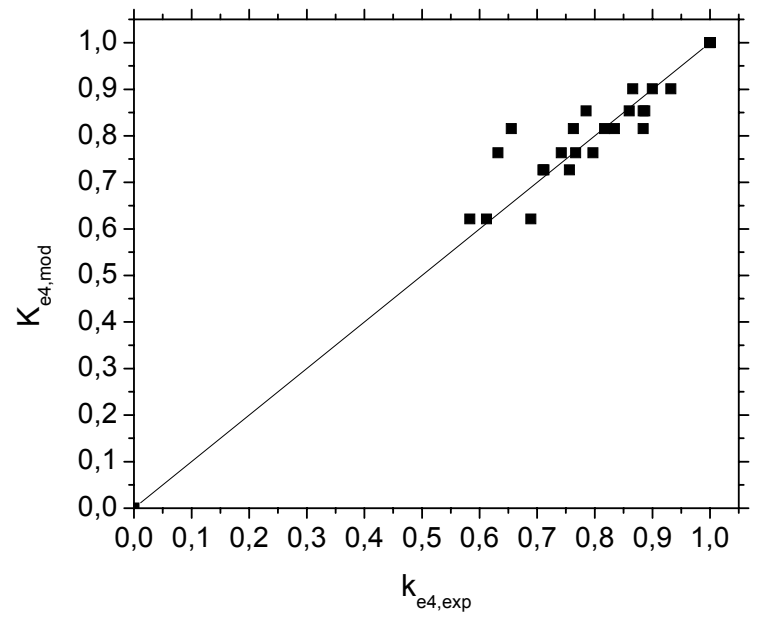

Figura 5.77 - Comparação entre $k_{e 4}$ experimental e obtido com o modelo

Com base na calibração anteriormente apresentada foi possível utilizar as equações para prever o ganho de resistência do concreto confinado e então avaliar a capacidade resistente dos pilares ensaiados. Esta análise foi realizada conforme descrição a seguir:

Inicialmente calculou-se o valor de $\mathrm{k}_{1}$, coeficiente que representa o ganho de resistência no confinamento uniforme (com base nos ensaios de corpos-de-prova desta pesquisa):

$$
k_{1}=3,933+\left(1,174-\frac{f_{l}}{f_{c o}}\right)^{6,44}
$$

Calculou-se então o coeficiente de efetividade do confinamento, dado por:

$$
k_{e}=k_{e 1} \cdot k_{e 2} \cdot k_{e 3}
$$


sendo

$$
\begin{aligned}
& k_{e 1}=\left(\frac{2 r}{h_{x}}\right)^{1,367} \\
& k_{e 2}=\left(\frac{h_{y}}{h_{x}}\right)^{-0,655} \\
& k_{e 3}=\left(\frac{E_{l}}{f_{c o}}\right)^{0,00727}
\end{aligned}
$$

O próximo passo foi calcular o fator redutor em função da excentricidade:

$$
k_{e 4}=1-2,303 \cdot\left(\frac{e_{i}}{h_{i}}\right)^{0,896} \cdot\left(\frac{2 r}{h_{x}}\right)^{0,356}
$$

Calculou-se então a pressão lateral efetiva, dada por:

$$
f_{l e}=2 E_{l} \cdot \varepsilon_{f} \cdot k_{e}
$$

A resistência do concreto confinado $\left(\mathrm{f}_{\mathrm{cc}}\right)$ pôde então ser calculada com:

$$
f_{c c}=\left(f_{c o}+k_{1} \cdot f_{l e}\right) \cdot k_{e 4}
$$

E finalmente a capacidade resistente do pilar foi estimada considerando a tensão $\mathrm{f}_{\mathrm{cc}}$ uniforme ao longo da área de concreto $\mathrm{A}_{\mathrm{c}}$. Na Tabela 5.27 são apresentados os valores utilizados para o cálculo e os resultados obtidos. 
Tabela 5.27 - Comparação do modelo de regressão gerado com os resultados experimentais

\begin{tabular}{|c|c|c|c|c|c|c|c|c|c|c|c|c|c|c|c|}
\hline Pilar & $\mathbf{n}$ & $\begin{array}{c}\mathrm{e} \\
(\mathrm{cm})\end{array}$ & $\begin{array}{c}\mathbf{r} \\
(\mathrm{cm})\end{array}$ & ei /hi & $2 / \mathbf{D}$ & $\begin{array}{l}\text { EI/ } \\
\text { fco }\end{array}$ & $\begin{array}{c}\text { fco } \\
(\mathrm{MPa})\end{array}$ & fl (MPa) & k1 & ke & ke4 & $\begin{array}{c}\text { fcc } \\
(\mathrm{MPa})\end{array}$ & Fu,mod & Fu,exp & $\begin{array}{l}\text { Fu,mod } \\
\text { / Fu,exp }\end{array}$ \\
\hline S00r1 & 0 & 0 & 1 & 0,000 & 133 & 0,000 & 3675 & 0,00 & 674 & 0,000 & 1,000 & 3675 & 8154 & 815,4 & 1,000 \\
\hline S10r1 & 1 & 0 & 1 & 0,000 & 0,133 & 12,890 & 36,75 & 5,02 & & 0,065 & 1,000 & 38,45 & 853,0 & 865,9 & 0,985 \\
\hline S20r1 & 2 & 0 & 1 & 0,000 & 0,133 & 25,779 & 36,75 & 10,04 & 4,44 & 0,065 & 1,000 & 39,66 & 879,9 & 875,5 & 1,005 \\
\hline S01r1 & 0 & 1 & 1 & 0,067 & 0,133 & 0,000 & 36,75 & 0,00 & 6,74 & 0,000 & 0,901 & 33,10 & 734,4 & 706,4 & 1,040 \\
\hline S11r1 & 1 & 1 & 1 & 0,067 & 0,133 & 12,890 & 36,75 & 5,02 & 5,20 & 0,065 & 0,901 & 34,63 & 768,3 & 779,6 & 0,985 \\
\hline $\mathrm{S} 21 \mathrm{r} 1$ & 2 & 1 & 1 & 0,067 & 0,133 & 25,779 & 36,75 & 10,04 & 4,44 & 0,065 & 0,901 & 35,72 & 792,5 & 816,3 & 0,971 \\
\hline S02r1 & 0 & 2 & 1 & 0,133 & 0,133 & 0,000 & 36,75 & 0,00 & 6,74 & 0,000 & 0,815 & 29,96 & 664,7 & 576,8 & 1,152 \\
\hline $\mathrm{S} 12 \mathrm{r} 1$ & 1 & 2 & 1 & 0,133 & 0,133 & 12,890 & 36,75 & 5,02 & 5,20 & 0,065 & 0,815 & 31,34 & 695,3 & 650,4 & 1,069 \\
\hline $\mathrm{S} 22 \mathrm{r} 1$ & 2 & 2 & 1 & 0,133 & 0,133 & 25,779 & 36,75 & 10,04 & 4,44 & 0,065 & 0,815 & 32,33 & 717,3 & 722,0 & 0,993 \\
\hline S00r3 & 0 & 0 & 3 & 0,000 & 0,400 & 0,000 & 37,11 & 0,00 & 6,74 & 0,000 & 1,000 & 37,11 & 730,0 & 730,5 & 0,999 \\
\hline S10r3 & 1 & 0 & 3 & 0,000 & 0,400 & 12,767 & 37,11 & 5,02 & 5,21 & 0,291 & 1,000 & 44,72 & 879,8 & 839,9 & 1,048 \\
\hline S20r3 & 2 & 0 & 3 & 0,000 & 0,400 & 25,534 & 37,11 & 10,04 & 4,45 & 0,293 & 1,000 & 50,19 & & 1047,0 & 0,943 \\
\hline S01r3 & 0 & 1 & 3 & 0,067 & 0,400 & 0,000 & 37,11 & 0,00 & 6,74 & 0,000 & 0,853 & 31,66 & 622,8 & 573,3 & 1,086 \\
\hline $\begin{array}{l}\text { S11r3- } \\
\text { a }\end{array}$ & 1 & 1 & 3 & 0,067 & 0,400 & 12,767 & 37,11 & 5,02 & 5,21 & 0,291 & 0,853 & 38,16 & 750,6 & 722,4 & 1,039 \\
\hline $\begin{array}{c}\text { S11r3- } \\
\text { b }\end{array}$ & 1 & 1 & 3 & 0,067 & 0,400 & 12,767 & 37,11 & 5,02 & 5,21 & 0,291 & 0,853 & 38,16 & 750,6 & 742,4 & 1,011 \\
\hline $\mathrm{S} 21 \mathrm{r} 3$ & 2 & 1 & 3 & 0,067 & 0,400 & 25,534 & 37,11 & 10,04 & 4,45 & 0,293 & 0,853 & 42,82 & 842,4 & 928,7 & 0,907 \\
\hline $\mathrm{S} 02 \mathrm{r} 3$ & 0 & 2 & 3 & 0,133 & 0,400 & 0,000 & 37,11 & 0,00 & 6,74 & 0,000 & 0,727 & 26,97 & 530,5 & 552,1 & 0,961 \\
\hline $\mathrm{S} 22 \mathrm{r} 3$ & 2 & 2 & 3 & 33 & 0,400 & 25,534 & 37,11 & 10,04 & 4,45 & & 0,727 & 36,48 & & 745,0 & 0,963 \\
\hline R00 & 0 & 0 & 3 & 0,000 & & 0,000 & 36,75 & & 0,77 & & 1,000 & 36,75 & & & 1,115 \\
\hline R20 & 2 & 0 & 3 & 0,000 & 0,267 & 17,186 & 36,75 & 6,70 & 4,88 & 0,219 & 1,000 & 43,90 & 1357,4 & 1330,2 & 1,020 \\
\hline R0x3 & 0 & $x=3$ & 3 & 0,133 & 0,267 & 0,000 & 36,75 & 0,00 & 6,74 & 0,000 & 0,763 & 28,06 & 867,7 & 644,1 & 1,347 \\
\hline $\mathrm{R} 2 \times 3$ & 2 & $x=3$ & 3 & & & 17,186 & 36,75 & & 4,88 & & 0,763 & 33,51 & & & 0,978 \\
\hline R0y2 & 0 & $y=2$ & 3 & 0,133 & 0,267 & 0,000 & 36,75 & 0,00 & 6,74 & 0,000 & 0,763 & 28,06 & 867,7 & 756,4 & 1,147 \\
\hline $\mathrm{R} 2 \mathrm{y} 2$ & 2 & $y=2$ & 3 & 0,133 & 0,267 & 17,186 & 36,75 & 6,70 & 4,88 & 0,219 & 0,763 & 33,51 & 1036,4 & 1020,0 & 1,016 \\
\hline $\mathrm{COO}$ & 0 & 0 & 7,5 & 0,000 & 1,000 & 0,000 & 38,54 & 0,00 & 6,74 & 0,000 & 1,000 & 38,54 & 681,1 & 681,1 & 1,000 \\
\hline $\mathrm{C} 10$ & 1 & 0 & 7,5 & 0,000 & 1,000 & 12,291 & 38,54 & & 5,25 & 1,018 & 1,000 & 65,39 & 1155,6 & 1000,0 & 1,156 \\
\hline $\mathrm{C} 20$ & 2 & 0 & 7,5 & 0,000 & 1,000 & 24,582 & 38,54 & 10,04 & 4,49 & 1,024 & 1,000 & 84,71 & 1496,9 & 1560,0 & 0,960 \\
\hline $\mathrm{C} 02$ & 0 & 2 & 7,5 & 0,133 & 1,000 & 0,000 & 38,54 & 0,00 & 6,74 & 0,000 & 0,621 & 23,95 & 423,2 & 469,4 & 0,902 \\
\hline $\mathrm{C} 12$ & 1 & 2 & 7,5 & 0,133 & 1,000 & 12,291 & 38,54 & 5,02 & 5,25 & 1,018 & 0,621 & 40,63 & 718,0 & 611,6 & 1,174 \\
\hline $\mathrm{C} 22$ & 2 & 2 & 7,5 & 0,133 & 1,000 & 24,582 & 38,54 & 10,04 & 4,49 & 1,024 & 0,621 & 52,64 & 930,1 & 909,1 & 1,023 \\
\hline $\mathrm{X} 00$ & 0 & 0 & 1 & 0,000 & 0,133 & 0,000 & 25,31 & 0,00 & 6,74 & 0,000 & 1,000 & 25,31 & 561,6 & 561,6 & 1,000 \\
\hline $\mathrm{X} 10 \mathrm{r} 1$ & 1 & 0 & 1 & 0,000 & 0,133 & 18,715 & 25,31 & 5,02 & 4,79 & 0,065 & 1,000 & 26,88 & 596,3 & 632,8 & 0,942 \\
\hline $\mathrm{X} 10 \mathrm{r} 3$ & 1 & 0 & 3 & 0,000 & 0,400 & 18,715 & 25,31 & 5,02 & 4,79 & 0,292 & 1,000 & 32,33 & 636,0 & 686,3 & 0,927 \\
\hline X02 & 0 & 2 & 1 & 0,133 & 0,133 & 0,000 & 25,31 & 0,00 & 6,74 & 0,000 & 0,815 & 20,64 & 457,8 & 367,8 & 1,245 \\
\hline $\mathrm{X} 12 \mathrm{r} 1$ & 1 & 2 & 1 & 0,133 & 0,133 & 18,715 & 25,31 & 5,02 & 4,79 & 0,065 & 0,815 & 21,91 & 486,1 & 483,0 & 1,006 \\
\hline $\mathrm{X} 12 \mathrm{r} 3$ & 1 & 2 & 3 & 0,133 & 0,400 & 18,715 & 25,31 & 5,02 & 4,79 & 0,292 & 0,727 & 23,49 & 462,2 & 487,3 & 0,949 \\
\hline
\end{tabular}

Na Figura 5.78 é apresentado um diagrama força obtida com o modelo de regressão x força registrada nos ensaios. É possível observar uma ótima correlação entre os resultados obtidos. 


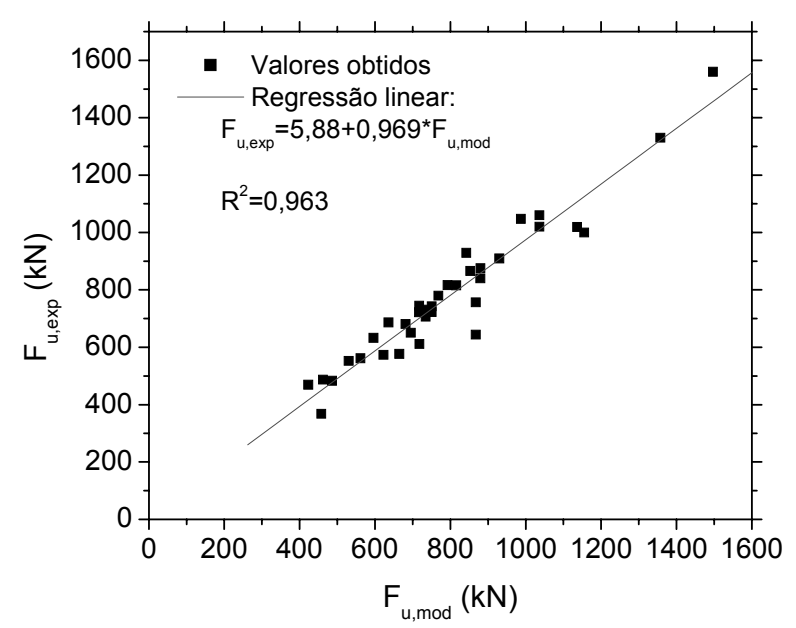

Figura 5.78 - Comparação das forças últimas obtidas com o modelo calibrado e as obtidas experimentalmente

\subsubsection{Análise da deformabilidade}

Observou-se que nos pilares ensaiados há basicamente dois tipos de diagramas tensão x deformação para o concreto confinado com PRFC, ilustrados na Figura 5.79. O diagrama tipo 1 representa um confinamento pouco efetivo (não uniforme), onde inicialmente ocorre um ganho de resistência do concreto confinado, mas logo em seguida um trecho descendente até a ruptura da camisa.

O diagrama do tipo 2 é caracterizado por um segundo trecho ascendente e representa pilares com um confinamento mais efetivo que o tipo 1. Observa-se assim que é necessário que sejam estabelecidos parâmetros para avaliar o comportamento do pilar encamisado, ou seja, se o diagrama tensão x deformação é do tipo 1 ou 2.

Comparando todos os diagramas tensão x deformação foi possível estabelecer um comportamento comum para todos os pilares encamisados com PRFC. Uma inclinação inicial igual à dos pilares não encamisados, seguida de um trecho de transição e finalmente terminando com um comportamento linear. Este comportamento foi observado em todos os casos, mesmo nos pilares com um trecho descendente após atingir o pico de resistência.

Com isto, foi possível encontrar algumas variáveis para estabelecer a forma do diagrama tensão x deformação. Estas variáveis foram o ponto inicial $\left(\varepsilon_{\mathrm{c} 1}, \mathrm{f}_{\mathrm{c} 1}\right)$ e o ponto final $\left(\varepsilon_{\mathrm{cr}}, \mathrm{f}_{\mathrm{cr}}\right)$ do segundo trecho reto, indicados na Figura 5.79. 


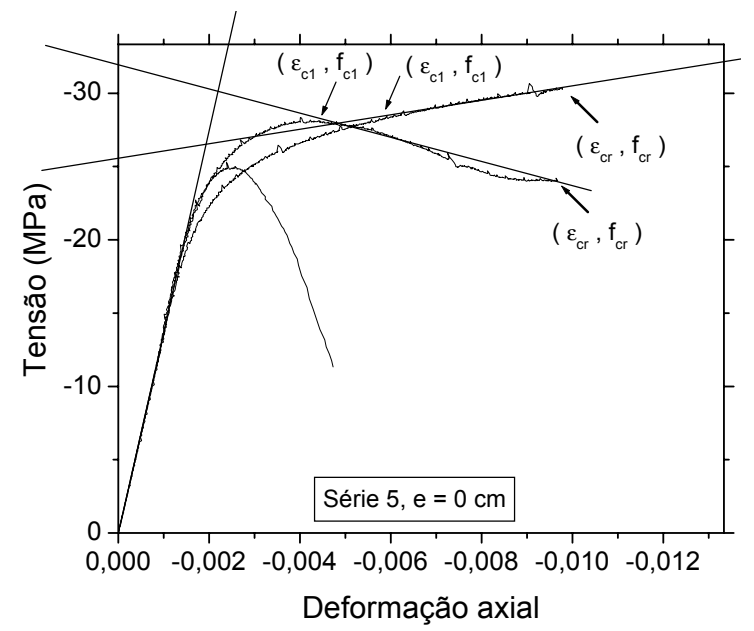

Figura 5.79 - Diagramas tensão $x$ deformação do concreto confinado

$\mathrm{Na}$ Tabela 5.28 são apresentados todos os valores de $\mathrm{f}_{\mathrm{c} 1}, \varepsilon_{\mathrm{cl}}$, $\mathrm{f}_{\mathrm{cr}}$ e $\varepsilon_{\mathrm{cr}}$ dos pilares ensaiados. Nos pilares com $n=0$ não há valores de $\varepsilon_{\text {cr }}$ e $f_{\text {cr. }}$.

Tabela 5.28 - Pontos de referência dos diagramas tensão x deformação dos pilares ensaiados

\begin{tabular}{|c|c|c|c|c|c|c|c|c|c|}
\hline Pilar & $\varepsilon_{\mathrm{c} 1}$ & $\begin{array}{c}\mathrm{f}_{\mathrm{c} 1} \\
(\mathrm{MPa})\end{array}$ & $\varepsilon_{\mathrm{cr}}$ & $\begin{array}{c}\mathrm{f}_{\mathrm{cr}} \\
(\mathrm{MPa})\end{array}$ & Pilar & $\varepsilon_{\mathrm{c} 1}$ & $\begin{array}{c}\mathrm{f}_{\mathrm{c} 1} \\
(\mathrm{MPa})\end{array}$ & $\varepsilon_{\mathrm{cr}}$ & $\begin{array}{c}\mathrm{f}_{\mathrm{cr}} \\
(\mathrm{MPa})\end{array}$ \\
\hline S00r1 & 0,00309 & 36,5 & - & - & R00 & - & - & - & - \\
\hline S10r1 & 0,00380 & 38,7 & 0,00740 & 30,6 & R20 & 0,00469 & 40,3 & 0,00847 & 37,0 \\
\hline S20r1 & 0,00407 & 39,0 & 0,00800 & 36,7 & R0x3 & 0,00191 & 19,5 & - & - \\
\hline S01r1 & 0,00240 & 31,5 & - & - & $\mathrm{R} 2 \times 3$ & 0,00342 & 32,1 & 0,00611 & 31,2 \\
\hline S11r1 & 0,00287 & 34,8 & 0,00456 & 28,2 & R0y2 & 0,00176 & 22,9 & - & - \\
\hline S21r1 & 0,00318 & 36,3 & 0,00633 & 33,6 & $\mathrm{R} 2 \mathrm{y} 2$ & 0,00271 & 30,9 & 0,00473 & 27,1 \\
\hline S02r1 & 0,00189 & 25,6 & - & - & $\mathrm{C} 00$ & 0,00231 & 38,5 & - & - \\
\hline $\mathrm{S} 12 \mathrm{r} 1$ & 0,00309 & 29,0 & 0,00422 & 21,9 & $\mathrm{C} 10$ & 0,00431 & 48,2 & 0,00907 & 57,2 \\
\hline $\mathrm{S} 22 \mathrm{r} 1$ & 0,00322 & 32,1 & 0,00524 & 28,5 & $\mathrm{C} 20$ & 0,00869 & 66,5 & 0,01778 & 90,0 \\
\hline S00r3 & 0,00287 & 33,7 & - & - & $\mathrm{C} 02$ & 0,00191 & 26,5 & - & - \\
\hline S10r3 & 0,00416 & 38,2 & 0,00791 & 38,7 & $\mathrm{C} 12$ & 0,00280 & 32,8 & 0,00449 & 34,6 \\
\hline $\mathrm{S} 20 \mathrm{r} 3$ & 0,00469 & 42,7 & 0,01209 & 48,3 & $\mathrm{C} 22$ & 0,00462 & 45,0 & 0,00782 & 51,2 \\
\hline S01r3 & 0,00229 & 26,2 & - & - & $\mathrm{X} 00$ & 0,00256 & 25,0 & - & - \\
\hline S11r3-a & 0,00289 & 33,1 & 0,00467 & 33,1 & X10r1 & 0,00422 & 28,2 & 0,00964 & 24,1 \\
\hline S11r3-b & 0,00342 & 34,1 & 0,00478 & 34,1 & X10r3 & 0,00516 & 28,8 & 0,00978 & 31,3 \\
\hline $\mathrm{S} 21 \mathrm{r} 3$ & 0,00376 & 38,7 & 0,00778 & 42,6 & $\mathrm{X} 02$ & 0,00178 & 16,3 & - & - \\
\hline $\mathrm{S} 02 \mathrm{r} 3$ & 0,00191 & 25,3 & - & - & $\mathrm{X} 12 \mathrm{r} 1$ & 0,00329 & 21,5 & 0,00884 & 18,2 \\
\hline $\mathrm{S} 22 \mathrm{r} 3$ & 0,00373 & 32,3 & 0,00698 & 34,2 & $\mathrm{X} 12 \mathrm{r} 3$ & 0,00444 & 22,0 & 0,01044 & 22,4 \\
\hline
\end{tabular}

Sendo conhecido o valor máximo de tensão axial $\left(f_{c c}\right)$, deve-se descobrir se este valor é atingido num primeiro estágio do diagrama ou no momento da ruptura da camisa. Foi então proposta uma equação para avaliar o acréscimo de resistência do concreto confinado após $\mathrm{f}_{\mathrm{c} 1}$, dada por $\Delta_{\mathrm{fc}}$. 


$$
\Delta f_{c}=1,817\left(k_{e} \frac{f_{l}}{f_{c o}}\right)^{0,584} \cdot k_{e 4}^{1,192}-0,265
$$

Se $\Delta \mathrm{f}_{\mathrm{c}}>0$ o diagrama é ascendente, e a ruptura da camisa ocorre a uma tensão axial de $f_{c r}=f_{c c}\left(f_{c r}\right.$ é a tensão de compressão no momento da ruptura da camisa). A tensão no início do trecho reto é $\mathrm{f}_{\mathrm{c} 1}$.

$$
f_{c 1}=f_{c c}-\Delta f_{c}
$$

Se $\Delta \mathrm{f}_{\mathrm{c}}<0$ o diagrama possui um máximo de $\mathrm{f}_{\mathrm{cl}}=\mathrm{f}_{\mathrm{cc}}$ e um trecho descendente até a ruptura da camisa de PRFC. Neste caso, a tensão no concreto no momento da ruptura da camisa é dada por:

$$
f_{c r}=f_{c c}+\Delta f_{c}
$$

Foi realizada uma análise de regressão de $\varepsilon_{\mathrm{cl}} / \varepsilon_{\mathrm{co}}$ com as variáveis $\mathrm{k}_{\mathrm{e}}, \mathrm{k}_{\mathrm{e} 4} \mathrm{e} \mathrm{E}_{\mathrm{l}} / \mathrm{f}_{\mathrm{co}}$. Para o cálculo de $\varepsilon_{\mathrm{cl}}$ obteve-se a seguinte equação (com $\left.\mathrm{R}^{2}=0,908\right)$ :

$$
\frac{\varepsilon_{c 1}}{\varepsilon_{c o}}=\left(1+0,0149 \cdot\left(k_{e}\right)^{0,713} \cdot\left(\frac{E_{l}}{f_{c o}}\right)^{1,484}\right) \cdot k_{e 4}^{1,177}
$$

No caso de $\varepsilon_{\mathrm{cr}} / \varepsilon_{\mathrm{co}}$, em vez de $\mathrm{E}_{1} / \mathrm{f}_{\mathrm{co}}$, foi utilizada a variável $\mathrm{f}_{1} / \mathrm{f}_{\mathrm{co}}$, que pode representar mais adequadamente a relação entre a resistência da camisa e esta variável. A deformação axial em que ocorre a ruptura da camisa pode ser estimada por meio da equação ( 5.24) (com $\left.\mathrm{R}^{2}=0,948\right)$ :

$$
\frac{\varepsilon_{c r}}{\varepsilon_{c o}}=\left(1+19,572 \cdot\left(k_{e}\right)^{0,398} \cdot\left(\frac{f_{l}}{f_{c o}}\right)^{1,055}\right) \cdot k_{e 4}^{1,798}
$$

Os diagramas simplificados podem ser obtidos por meio das equações acima, e alguns exemplos são apresentados na Figura 5.80. Nestes diagramas foram definidas três retas. A primeira reta liga o início do carregamento $(0 ; 0)$ até o ponto correspondente a uma tensão de $75 \%$ da máxima no pilar de referência $\left(0,75 . f_{c o} / E_{c} ; 0,75 . f_{c o}\right)$. A segunda reta liga o ponto $\left(0,75 . \mathrm{f}_{\mathrm{co}} / \mathrm{E}_{\mathrm{c}} ; 0,75 . \mathrm{f}_{\mathrm{co}}\right)$ até o ponto $\left(\varepsilon_{\mathrm{c} 1} ; \mathrm{f}_{\mathrm{c} 1}\right)$. A última reta liga os pontos $\left(\varepsilon_{\mathrm{c} 1} ; \mathrm{f}_{\mathrm{c} 1}\right)$ e $\left(\varepsilon_{\mathrm{cr}} ; \mathrm{f}_{\mathrm{cr}}\right)$. Outras comparações dos resultados obtidos pelo modelo para $\left(\varepsilon_{\mathrm{c} 1} ; \mathrm{f}_{\mathrm{c} 1}\right)$ e $\left(\varepsilon_{\mathrm{cr}} ; \mathrm{f}_{\mathrm{cr}}\right)$ com os valores experimentais é apresentada na Tabela 5.29. 

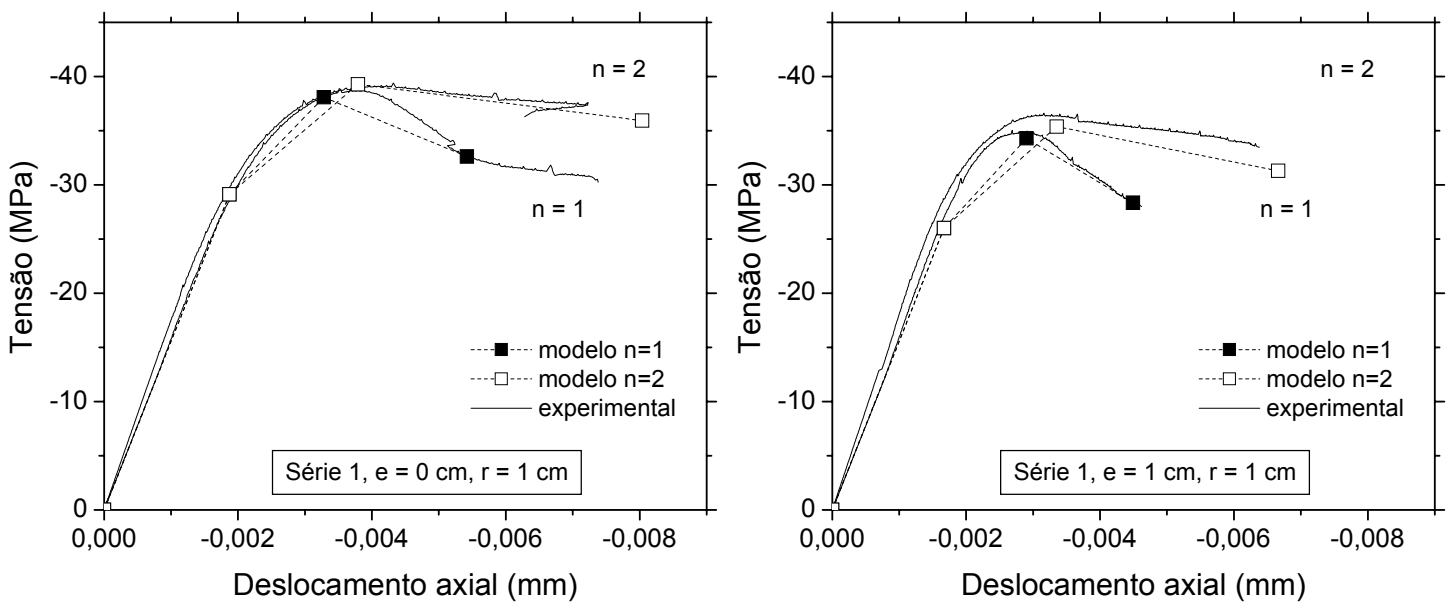

Figura 5.80 - Diagramas força $x$ deslocamento axial dos pilares da série

Tabela 5.29 - Comparação do modelo de regressão gerado com os resultados experimentais

\begin{tabular}{ccccccccc}
\hline & & & & \multicolumn{4}{c}{$\begin{array}{c}\text { Comparação } \\
\text { Modelo teórico / Experimental }\end{array}$} \\
\hline Pilar & $\mathbf{n}$ & $\mathbf{e}(\mathbf{c m})$ & $\mathbf{r} \mathbf{( c m )}$ & $\mathbf{e i} / \mathbf{h i}$ & $\boldsymbol{\varepsilon}_{\mathbf{c 1}}$ & $\mathbf{f}_{\mathbf{c 1}}$ & $\boldsymbol{\varepsilon}_{\text {cr }}$ & $\mathbf{f}_{\text {cr }}$ \\
\hline S10r1 & 1 & 0 & 1 & 0,000 & 0,864 & 0,984 & 0,732 & 1,067 \\
S20r1 & 2 & 0 & 1 & 0,000 & 0,933 & 1,006 & 1,005 & 0,980 \\
S11r1 & 1 & 1 & 1 & 0,067 & 1,012 & 0,986 & 0,986 & 1,005 \\
S21r1 & 2 & 1 & 1 & 0,067 & 1,055 & 0,974 & 1,052 & 0,931 \\
S12r1 & 1 & 2 & 1 & 0,133 & 0,835 & 1,072 & 0,889 & 1,129 \\
S22r1 & 2 & 2 & 1 & 0,133 & 0,925 & 0,997 & 1,062 & 0,958 \\
\hline S10r3 & 1 & 0 & 3 & 0,000 & 0,917 & 1,162 & 0,930 & 1,157 \\
S20r3 & 2 & 0 & 3 & 0,000 & 1,126 & 1,047 & 0,998 & 1,038 \\
S11r3-a & 1 & 1 & 3 & 0,067 & 1,095 & 1,151 & 1,185 & 1,109 \\
S11r3-b & 1 & 1 & 3 & 0,067 & 0,924 & 1,120 & 1,157 & 1,078 \\
S21r3 & 2 & 1 & 3 & 0,067 & 1,166 & 1,034 & 1,166 & 1,006 \\
S22r3 & 2 & 2 & 3 & 0,133 & 0,971 & 1,109 & 0,974 & 1,065 \\
\hline R20 & 2 & 0 & 3 & 0,000 & 0,859 & 1,068 & 0,982 & 1,174 \\
R2x3 & 2 & $\mathrm{x}=3$ & 3 & 0,133 & 0,857 & 1,033 & 0,838 & 0,988 \\
R2y2 & 2 & $y=2$ & 3 & 0,133 & 1,082 & 1,075 & 1,082 & 1,136 \\
\hline C10 & 1 & 0 & 7,5 & 0,000 & 1,131 & 1,122 & 1,091 & 1,143 \\
C20 & 2 & 0 & 7,5 & 0,000 & 0,951 & 0,940 & 0,975 & 0,940 \\
C12 & 1 & 2 & 7,5 & 0,133 & 0,994 & 1,176 & 0,936 & 1,174 \\
C22 & 2 & 2 & 7,5 & 0,133 & 1,021 & 0,987 & 0,942 & 1,027 \\
\hline & & & & & & & &
\end{tabular}

\subsubsection{Rotações e efeitos de segunda ordem}

Foi possível observar que com a utilização do encamisamento com PRFC ocorreram significativos aumentos das rotações últimas e das excentricidades de segunda ordem. Isto porque o concreto confinado é significativamente mais deformável e permite desenvolver curvaturas bastante superiores ao concreto não confinado. $\mathrm{Na}$ Tabela 5.30 são apresentadas as rotações no momento em que foi atingida a força máxima de compressão $\left(\mathrm{F}_{\max }\right)$ e no momento de ruptura da camisa $\left(\mathrm{F}_{\mathrm{r}}\right)$. São 
apresentadas ainda as excentricidades de $1^{\mathrm{a}}$ ordem $\left(\mathrm{e}_{1}\right)$, que correspondem à nominal, e as excentricidades totais $\left(\mathrm{e}_{\mathrm{tot}}\right)$, que somam o deslocamento lateral para $\mathrm{F}_{\max }$ à excentricidade nominal.

Tabela 5.30 - Rotações e deslocamentos laterais

\begin{tabular}{|c|c|c|c|c|c|c|c|c|c|}
\hline \multirow[b]{2}{*}{ Pilar } & \multirow[b]{2}{*}{$\mathbf{n}$} & \multirow[b]{2}{*}{ e (cm) } & \multirow[b]{2}{*}{$\mathbf{r}(\mathbf{c m})$} & \multicolumn{2}{|c|}{ Rotação $\left({ }^{\circ}\right)$} & \multirow{2}{*}{$\begin{array}{c}\text { Deslocamento } \\
\text { lateral }(\mathrm{mm}) \\
\mathrm{p} / \mathrm{F}_{\max }\end{array}$} & \multirow[b]{2}{*}{$\mathrm{p} / \mathrm{F}_{\mathrm{r}}$} & \multirow[b]{2}{*}{$\begin{array}{c}e_{1} \\
(\mathbf{m m})\end{array}$} & \multirow[b]{2}{*}{$\begin{array}{r}e_{\text {tot }} \\
(\mathbf{m m})\end{array}$} \\
\hline & & & & $\mathrm{p} / \mathrm{F}_{\max }$ & $\mathrm{p} / \mathrm{F}_{\mathrm{r}}$ & & & & \\
\hline S00r1 & 0 & 0 & 1 & $-0,23$ & 0,00 & $-0,06$ & & 0 & 0 \\
\hline S10r1 & 1 & 0 & 1 & $-0,41$ & $-2,12$ & 0,03 & 0,68 & 0 & 0 \\
\hline S20r1 & 2 & 0 & 1 & $-0,57$ & $-1,89$ & $-0,06$ & 0,33 & 0 & 0 \\
\hline S01r1 & 0 & 1 & 1 & 0,65 & 0,00 & $-1,42$ & & 10 & 11 \\
\hline S11r1 & 1 & 1 & 1 & 0,80 & 2,61 & $-1,98$ & $-6,40$ & 10 & 12 \\
\hline $\mathrm{S} 21 \mathrm{r} 1$ & 2 & 1 & 1 & 0,95 & 3,68 & $-2,23$ & $-9,82$ & 10 & 12 \\
\hline $\mathrm{S} 02 \mathrm{r} 1$ & 0 & 2 & 1 & 0,63 & 0,00 & $-1,46$ & & 20 & 21 \\
\hline $\mathrm{S} 12 \mathrm{r} 1$ & 1 & 2 & 1 & 1,14 & 2,95 & $-2,40$ & $-6,80$ & 20 & 22 \\
\hline $\mathrm{S} 22 \mathrm{r} 1$ & 2 & 2 & 1 & 1,20 & 3,43 & $-2,57$ & $-9,98$ & 20 & 23 \\
\hline S00r3 & 0 & 0 & 3 & $-0,20$ & 0,00 & $-0,08$ & & 0 & 0 \\
\hline S10r3 & 1 & 0 & 3 & $-1,41$ & $-1,41$ & $-0,28$ & & 0 & 0 \\
\hline S20r3 & 2 & 0 & 3 & $-2,71$ & $-2,71$ & 1,95 & 1,95 & 0 & -2 \\
\hline $\mathrm{S} 01 \mathrm{r} 3$ & 0 & 1 & 3 & 0,43 & 0,00 & $-1,05$ & & 10 & 11 \\
\hline S11r3-a & 1 & 1 & 3 & 1,23 & 2,64 & $-2,66$ & $-6,14$ & 10 & 13 \\
\hline S11r3-b & 1 & 1 & 3 & 1,29 & 2,16 & $-2,71$ & $-5,05$ & 10 & 13 \\
\hline $\mathrm{S} 21 \mathrm{r} 3$ & 2 & 1 & 3 & 3,52 & 3,52 & $-9,16$ & $-9,16$ & 10 & 19 \\
\hline $\mathrm{S} 02 \mathrm{r} 3$ & 0 & 2 & 3 & 0,66 & 0,00 & $-1,50$ & & 20 & 22 \\
\hline $\mathrm{S} 22 \mathrm{r} 3$ & 2 & 2 & 3 & 4,06 & 4,06 & $-10,57$ & $-11,33$ & 20 & 31 \\
\hline R00 & 0 & 0 & 3 & 0,00 & 0,00 & $-1,45$ & & 0 & 1 \\
\hline $\mathrm{R} 20$ & 2 & 0 & 3 & $-0,12$ & $-0,45$ & $-0,75$ & $-0,88$ & 0 & 1 \\
\hline R0x3 & 0 & $x=3$ & 3 & 0,52 & 0,00 & $-1,12$ & & $x=30$ & 31 \\
\hline $\mathrm{R} 2 \times 3$ & 2 & $x=3$ & 3 & 0,88 & 2,53 & $-2,27$ & $-6,33$ & $x=30$ & 32 \\
\hline R0y2 & 0 & $y=2$ & 3 & 0,54 & 0,00 & $-1,38$ & & $\mathrm{y}=20$ & 21 \\
\hline $\mathrm{R} 2 \mathrm{y} 2$ & 2 & $y=2$ & 3 & 1,11 & 3,76 & $-2,53$ & $-8,74$ & $\mathrm{y}=20$ & 23 \\
\hline $\mathrm{C} 00$ & 0 & 0 & 7,5 & 0,06 & 0,00 & $-0,51$ & & 0 & 1 \\
\hline $\mathrm{C} 10$ & 1 & 0 & 7,5 & 2,09 & 2,09 & $-5,05$ & $-5,05$ & 0 & 5 \\
\hline $\mathrm{C} 20$ & 2 & 0 & 7,5 & $-0,23$ & $-0,23$ & $-1,12$ & $-1,12$ & 0 & 1 \\
\hline $\mathrm{C} 02$ & 0 & 2 & 7,5 & 0,76 & 0,00 & $-1,57$ & & 20 & 22 \\
\hline $\mathrm{C} 12$ & 1 & 2 & 7,5 & 2,89 & 3,11 & $-6,40$ & $-6,87$ & 20 & 26 \\
\hline $\mathrm{C} 22$ & 2 & 2 & 7,5 & 4,90 & 4,90 & $-13,74$ & $-15,77$ & 20 & 34 \\
\hline $\mathrm{X} 00$ & 0 & 0 & 1 & & & $-0,47$ & & 0 & 0 \\
\hline $\mathrm{X} 10 \mathrm{r} 1$ & 1 & 0 & 1 & & & $-1,07$ & $-6,61$ & 0 & 1 \\
\hline X10r3 & 1 & 0 & 3 & & & 1,21 & 1,21 & 0 & -1 \\
\hline $\mathrm{X} 02$ & 0 & 2 & 1 & & & $-1,45$ & & 20 & 21 \\
\hline $\mathrm{X} 12 \mathrm{r} 1$ & 1 & 2 & 1 & & & $-2,65$ & $-9,31$ & 20 & 23 \\
\hline $\mathrm{X} 12 \mathrm{r} 3$ & 1 & 2 & 3 & & & $-10,19$ & $-10,19$ & 20 & 30 \\
\hline
\end{tabular}

As rotações de apoio aumentaram significativamente nos pilares encamisados, principalmente naqueles em que ocorreu um segundo trecho linear ascendente. Nestes 
pilares a ruptura ocorreu numa situação bem diferente da inicial, ou seja, após uma grande curvatura ser desenvolvida. Na Figura 5.82 são apresentadas as rotações no momento em que foi atingida a força máxima nos ensaios. Pode-se observar que nos pilares em que a força máxima ocorreu em $\mathrm{f}_{\mathrm{c} 1}$, as rotações foram da ordem de 1 grau. Nos pilares com o segundo trecho ascendente, a força máxima ocorreu em $\mathrm{f}_{\mathrm{cr}}$, logo as rotações neste instante foram maiores, da ordem de 3 a 5 graus.
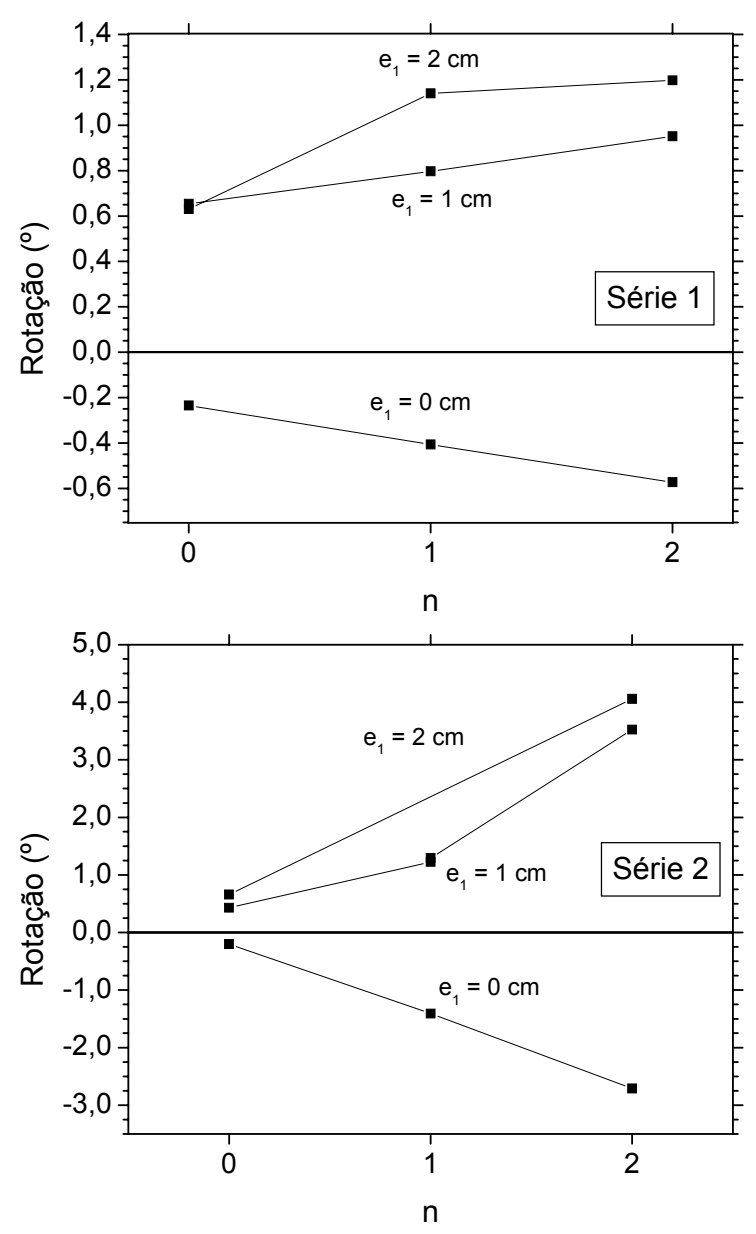

Figura 5.81 - Rotações de apoio no momento em que foi atingida a força máxima do ensaio - séries 1 e 2 

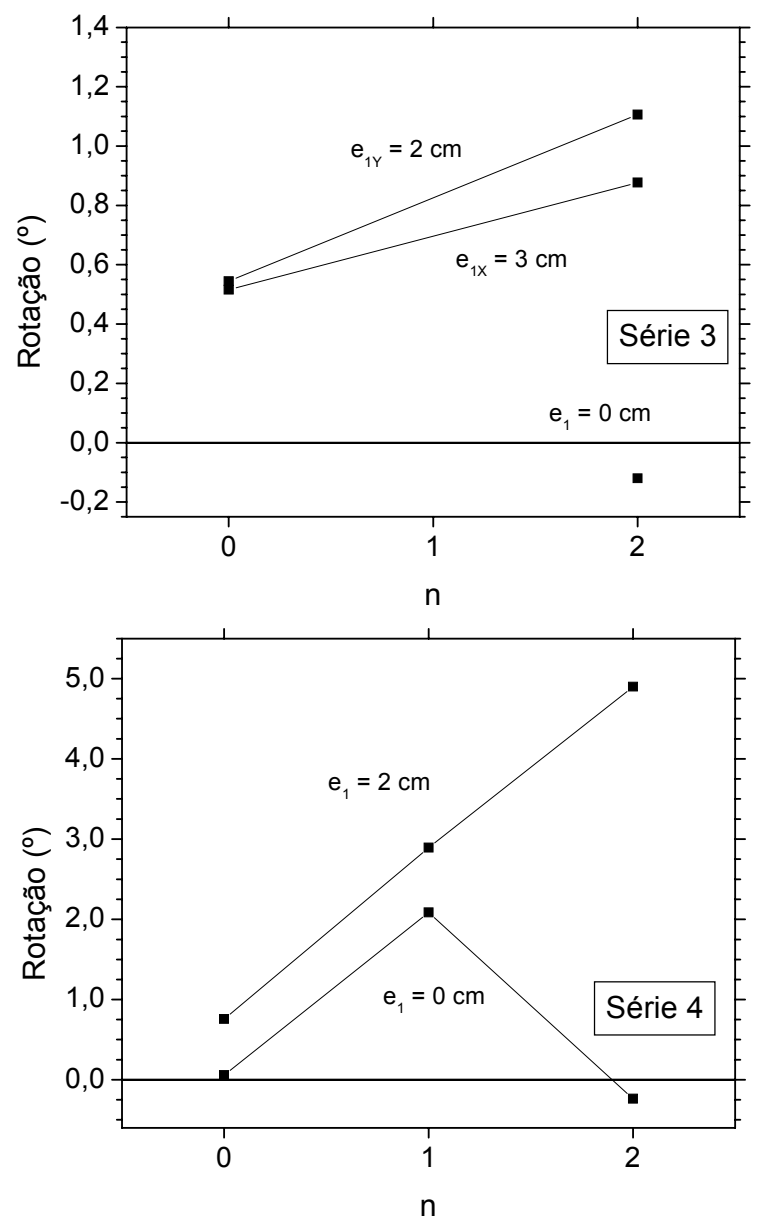

Figura 5.82 - Rotações de apoio no momento em que foi atingida a força máxima do ensaio - séries 3 e 4

Nas Figuras 5.83 e 5.84 são apresentados os diagramas com as rotações de apoio no momento da ruptura da camisa. Em todos os pilares encamisados submetidos a excentricidades nominais não nulas, ocorreram rotações acima de 2 graus. 

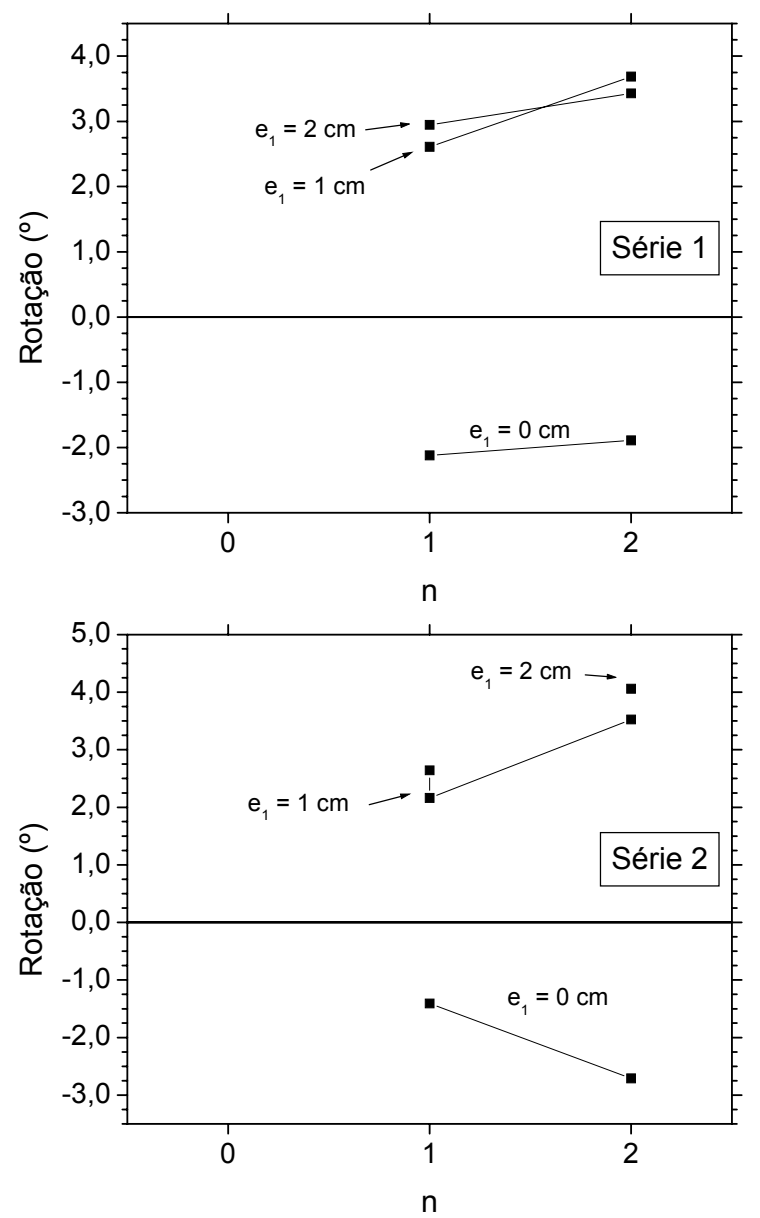

Figura 5.83 - Rotações de apoio no momento da ruptura da camisa - séries 1 e 2 

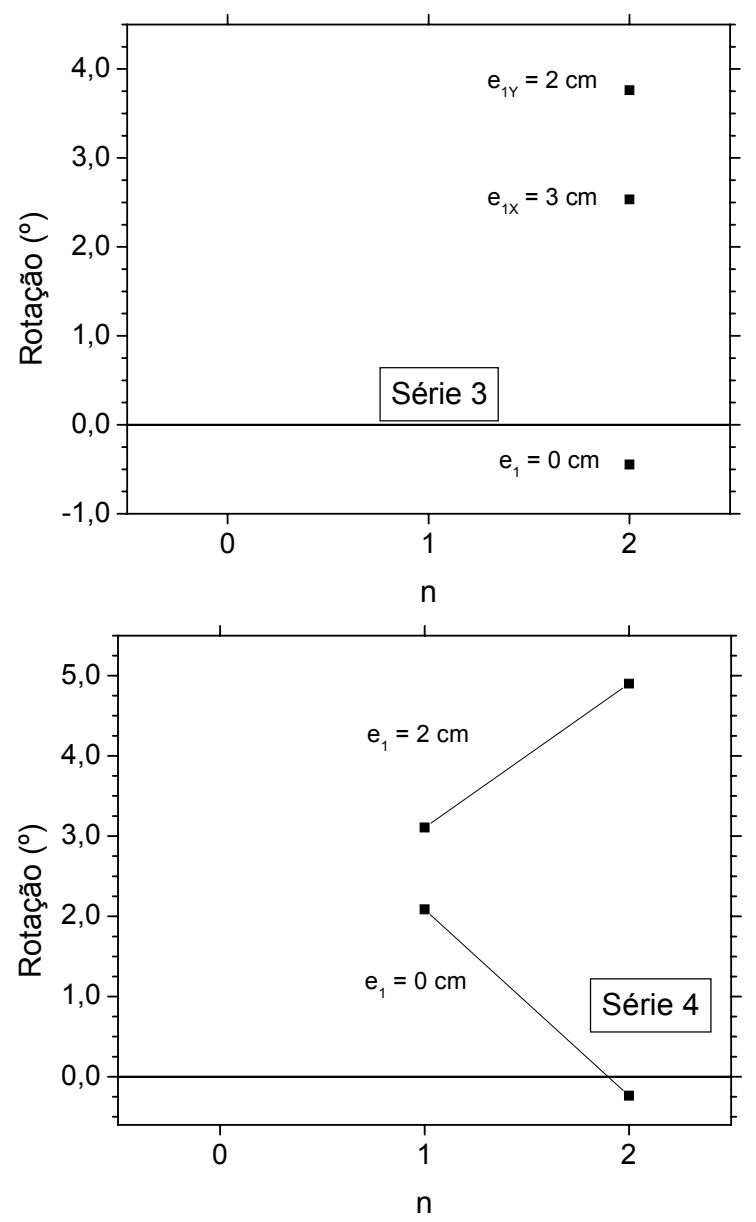

Figura 5.84 - Rotações de apoio no momento da ruptura da camisa - séries 3 e 4

Os deslocamentos laterais indicaram um comportamento semelhante às rotações, em que os pilares com o pico de resistência em $\mathrm{f}_{\mathrm{c} 1}$ tiveram uma excentricidade de segunda ordem pequena em comparação à inicial, e os pilares com o segundo trecho linear ascendente apresentaram excentricidades de segunda ordem da mesma grandeza da excentricidade de primeira ordem. Este comportamento pode ser observado na Figura 5.85 . 

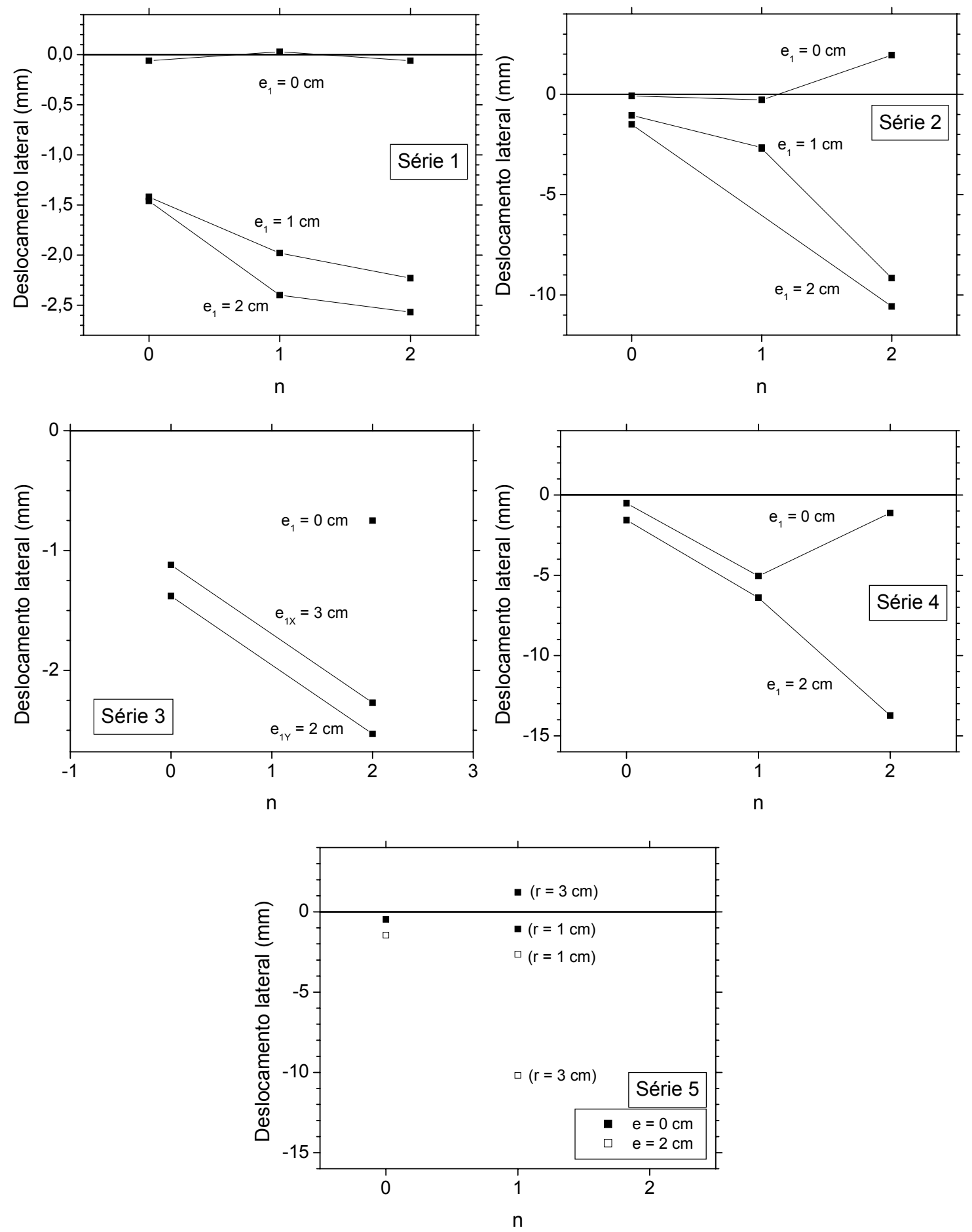

Figura 5.85 - Deslocamento lateral para $F_{\max }$

$\mathrm{Na}$ situação de ruptura da camisa, as excentricidades de segunda ordem dos pilares com o segundo trecho linear descendente foram aproximadamente entre 0,25 e 0,5 da excentricidade nominal, como indica a Figura 5.86. 

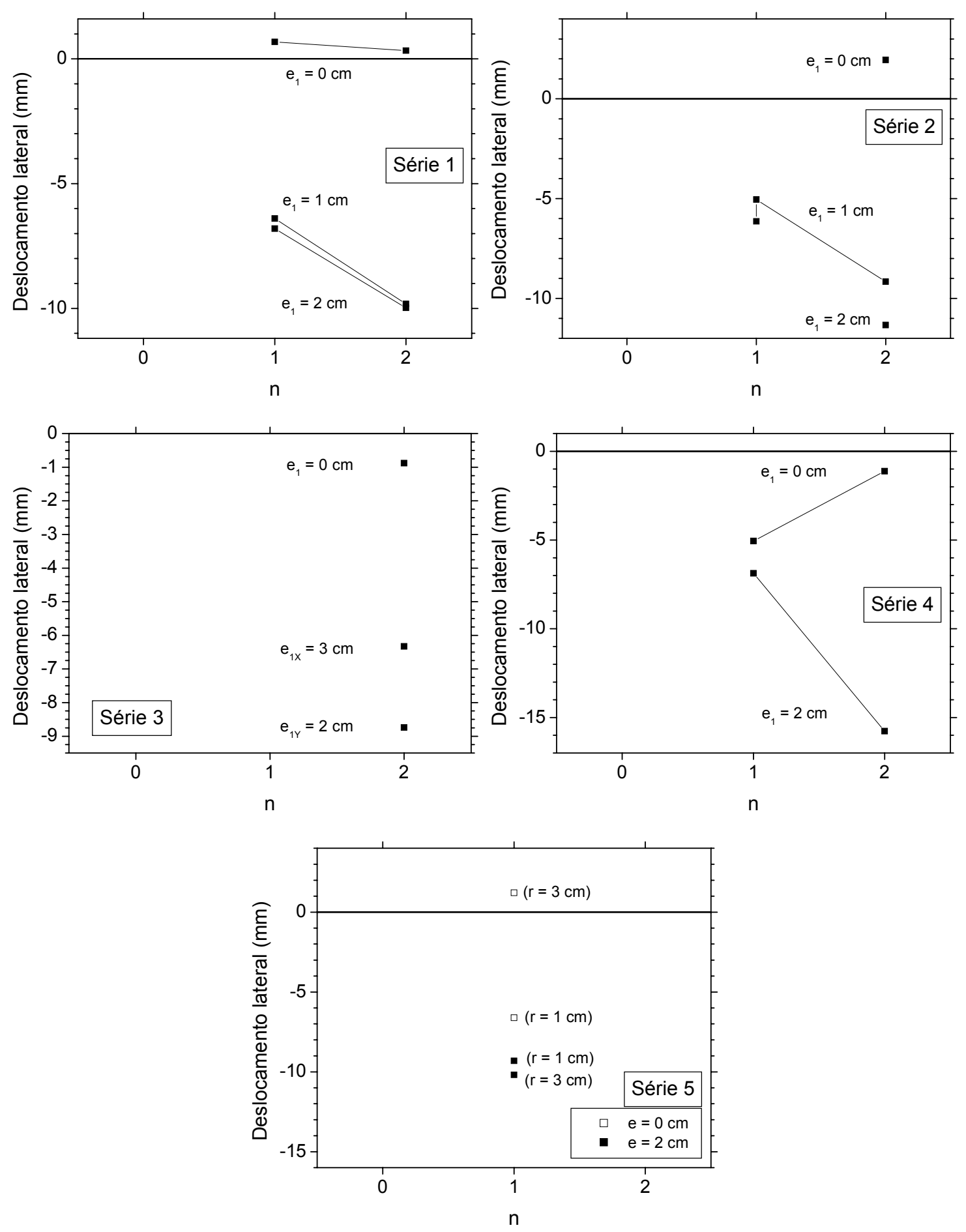

Figura 5.86 - Deslocamento lateral na ruptura da camisa

A análise apresentada anteriormente indica que os efeitos de segunda ordem têm muita importância em pilares encamisados, principalmente naqueles em que a força última será desenvolvida no final do diagrama tensão x deformação, concomitantemente com a ruptura da camisa. 


\section{Análise Numérica}

As simulações foram realizadas por meio do método dos elementos finitos utilizando o programa ABAQUS ${ }^{\circledR}$ versão 6.2.

O concreto foi modelado com elementos sólidos tridimensionais tipo C3D8R. Este elemento possui 8 nós, com três graus de liberdade por nó e integração reduzida. A camisa de PRF foi modelada com elementos de casca S4R, para os quais foram atribuídas orientações de material e propriedades elásticas orto-trópicas. Os elementos tipo S4R possuem 4 nós, 6 graus de liberdade por nó e integração reduzida. Além disso, foram utilizados os critérios de máxima resistência à tração e máxima deformação para os polímeros reforçados com fibras. Pilares encamisados de seção quadrada foram modelados com diferentes critérios para consideração do atrito no contato entre o concreto e PRF, e este atrito não mostrou grande influência sobre a resposta. Foram então utilizadas condições de total aderência entre os materiais com a opção "constraint", que possibilita melhor convergência.

As simulações foram desenvolvidas em duas etapas bem distintas: na primeira etapa, antes da execução dos ensaios definitivos e numa segunda etapa, depois dos ensaios definitivos.

$\mathrm{Na}$ primeira etapa, foi considerada a não-linearidade física, implementada inicialmente por meio dos critérios de Drucker-Prager Estendido e Mohr-Coulomb. Com o desenvolvimento das simulações numéricas observou-se a necessidade de utilizar um modelo constitutivo mais complexo para o concreto.

A segunda etapa foi realizada logo após a realização dos ensaios das séries definitivas. Esta etapa iniciou-se no estágio desenvolvido na Florida International University (FIU), sob a supervisão do Prof. Amir Mirmiran, de 07 de outubro de 2004 a 01 de fevereiro de 2005. Foi desenvolvida uma sub-rotina Umat para a utilização do modelo de GRASSL et al. (2002), apresentando resultados significativamente melhores que os obtidos na primeira etapa. 
Em ambas as etapas das simulações foi utilizado o controle automático do esquema incremental disponível no ABAQUS ${ }^{\circledR}$. Para um tempo total igual a 1 , os valores típicos utilizados foram de 0,001 a 0,01 para o incremento mínimo, de 0,01 a 0,05 para o incremento inicial e de 0,01 a 0,1 para o incremento máximo. Na primeira etapa das simulações foi obtida convergência mesmo utilizando os limites superiores apresentados acima. Já na segunda etapa das simulações, foi necessário utilizar incrementos menores e em alguns casos, como o de compressão excêntrica, mesmo com um incremento bastante pequeno (de 0,001$)$ a convergência ocorreu com dificuldade e não foi possível obter o comportamento pós-pico de resistência.

Foram utilizados os valores padrões de tolerâncias de convergência. Por exemplo, a tolerância para o resíduo de força foi de $0,5 \%$. Com este esquema de controle dos incrementos obteve-se convergência na primeira etapa das simulações com um número total de incrementos da ordem de 20 a 30 por análise. Já na segunda etapa das simulações o número de incrementos necessário por análise foi maior, sendo necessários normalmente 50 incrementos de deslocamento e em algumas simulações, como no caso dos pilares sob carregamento excêntrico o número de incrementos foi superior a 100 .

\subsection{Primeira etapa das simulações}

Iniciou-se o trabalho de simulação numérica do concreto confinado com camisa de PRF utilizando para o concreto modelos como o de Drucker-Prager e Mohr-Coulomb com elasto-plasticidade perfeita. Além disso, foi sempre necessário definir o módulo de elasticidade e o coeficiente de Poisson do concreto, que determinam as propriedades mecânicas do material no regime elástico.

\subsubsection{Critério de Mohr-Coulomb}

Este critério parte do princípio de que a resistência do material depende do ângulo de atrito interno de suas partículas $\phi$ e da coesão c. De uma maneira simplificada pode-se dizer que:

$$
[\tau]=c-\sigma \cdot \tan \phi
$$

onde $\tau$ é a tensão de cisalhamento e $\sigma$ é a tensão normal atuantes em um plano qualquer, passando por um ponto do material. Na Figura 6.1 o critério é apresentado em função de $\tau$ e $\sigma$. Qualquer estado de tensão contido entre as linhas da envoltória está no regime elástico. 


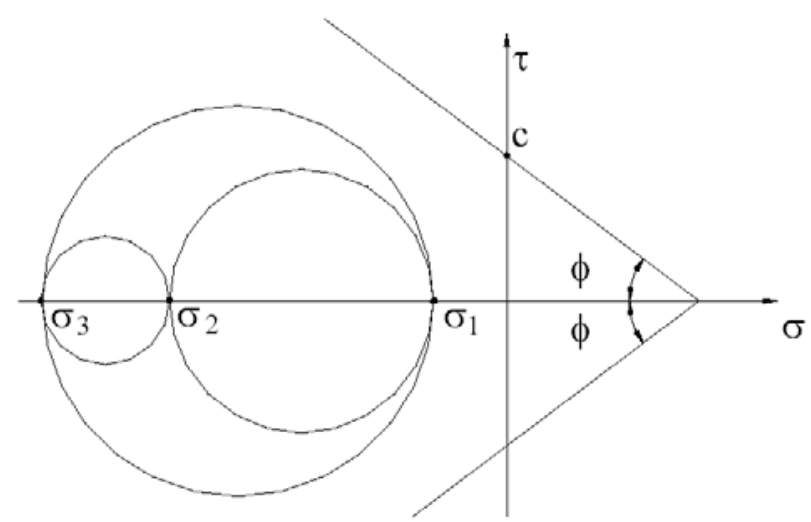

Figura 6.1 - Critério de Mohr-Coulomb

A superfície de plastificação pode ser escrita de outra maneira, que admite representação espacial:

$$
\mathrm{F}=\mathrm{R}_{\mathrm{mc}} \cdot \mathrm{q}-\mathrm{p} \cdot \tan \phi-\mathrm{c}=0
$$

onde

$$
\mathrm{R}_{\mathrm{mc}}(\theta, \phi)=\frac{1}{\sqrt{3 \cos \phi}} \sin \left(\theta+\frac{\pi}{3}\right)+\frac{1}{3} \cos \left(\theta+\frac{\pi}{3}\right) \tan \phi
$$

sendo $\theta$ o ângulo de Lode e q dada por:

$$
q=\sqrt{3 J_{2}}
$$

sendo $\mathrm{J}_{2} \mathrm{o}$ segundo invariante das tensões desviadoras e $\mathrm{p}$ a tensão hidrostática com sinal invertido. A representação espacial da superfície de plastificação é apresentada na Figura 6.2.
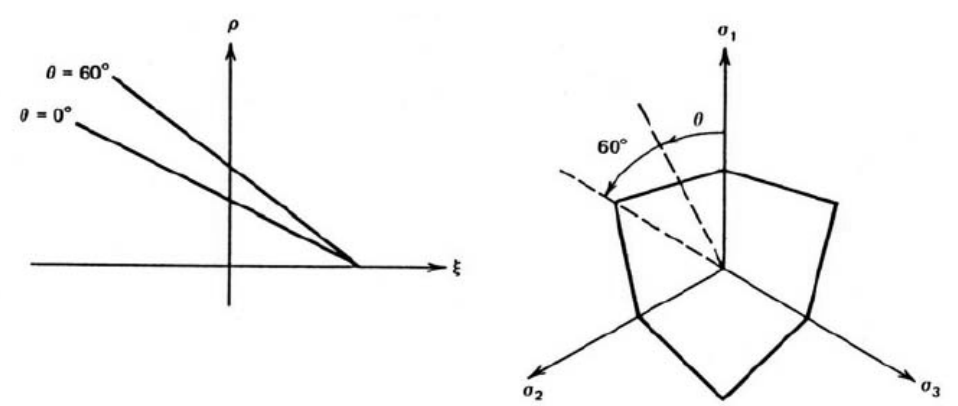

Figura 6.2 - Superfície de plastificação do critério de Mohr-Coulomb (CHEN, 1982) 
A lei de fluxo é hiperbólica nos meridianos e elíptica nas seções desviadoras, implementada segundo MENÉTREY \& WILLAM (1995). Deste modo, o fluxo é nãoassociativo e permite ainda a utilização do ângulo de dilatação. O modelo foi utilizado como elasto-plástico perfeito nestas análises.

\subsubsection{Critério de Drucker-Prager Estendido}

Este critério, utilizado no programa de elementos finitos ABAQUS ${ }^{\circledR}$, difere da sua formulação original (disponível no programa $\operatorname{ANSYS}^{\circledR}$ ) com relação à forma da função de plastificação e à lei de fluxo. A função de plastificação é dada por:

$$
F=t-p \cdot \tan \beta-d
$$

sendo $\beta$ o ângulo de atrito e d a coesão. Deve-se ressaltar que as variáveis denominadas ângulo de atrito $(\beta)$ e coesão $(d)$ neste modelo são diferentes das variáveis originais $\phi$ e c do critério de Mohr-Coulomb, pois são calculadas com base em outros invariantes de tensão.

As variáveis $\beta$ e d são responsáveis (além de $\mathrm{K}$ ) pela determinação da superfície de plastificação. O critério utilizado pode ser ajustado de maneira que seu meridiano de compressão coincida com o do critério de MOHR-COULOMB. Estas variáveis podem então ser relacionadas à coesão (c) e ângulo de atrito $(\phi)$ do critério de MOHRCOULOMB, como indica a Figura 6.3.

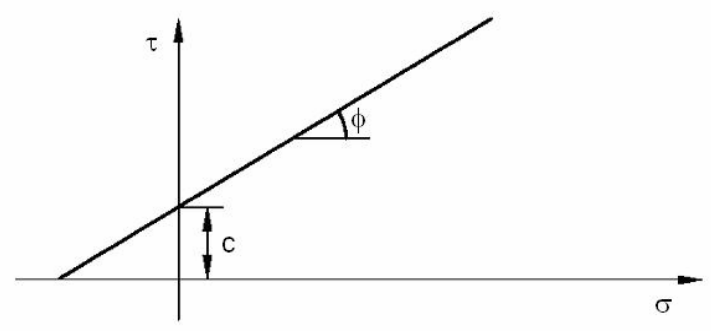

$$
\begin{aligned}
& \tan \beta=\frac{6 \operatorname{sen}(\phi)}{(3-\operatorname{sen} \phi)} \\
& d=\frac{6 \cdot c \cdot \cos \phi}{(3-\operatorname{sen} \phi)}
\end{aligned}
$$

Figura 6.3 - Envoltória do critério de MOHR-COULOMB - relação entre $\beta, \mathrm{d}, \phi$ e c

A variável t possibilita a utilização de uma seção transversal não circular, e é dada por:

$$
t=\frac{1}{2} \cdot q \cdot\left[1+\frac{1}{K}-\left(1-\frac{1}{K}\right) \cdot \cos (3 \theta)\right]
$$

A representação espacial da função de plastificação é apresentada na Figura 6.4. Utilizando a opção Drucker-Prager Linear os meridianos são lineares. No entanto, o 
parâmetro $\mathrm{K}$, utilizado pela variável $\mathrm{t}$ possibilita transformar a seção transversal circular, originalmente empregada no critério de Drucker-Prager, em uma seção transversal dependente do ângulo de Lode. Adotou-se $\mathrm{K}=0,78$, próximo do valor limite inferior para manter a convexidade da superfície, que segundo o ABAQUS ${ }^{\circledR}$ versão 6.2 é de 0,778 .

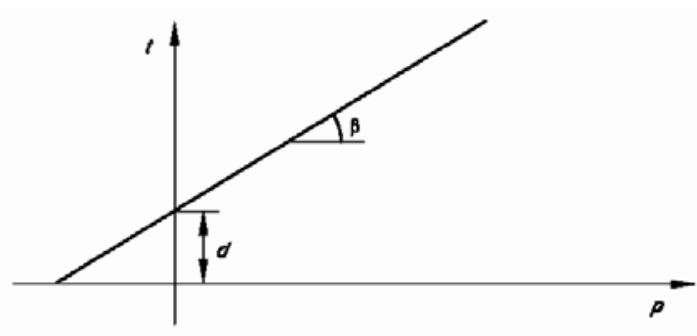

(a)

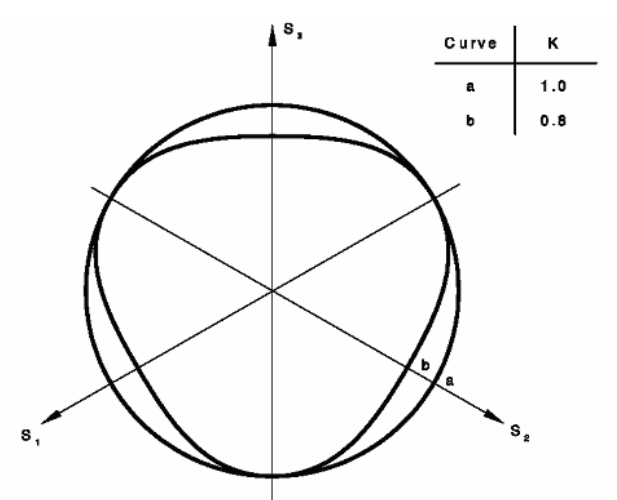

(b)

Figura 6.4 - Representação da superfície de plastificação adotada (ABAQUS ${ }^{\circledR}$ versão 6.2)

Plano meridional (b) seção transversal

A lei de fluxo é dada por:

$$
\mathrm{G}=\mathrm{t}-\mathrm{p} \cdot \tan \psi
$$

onde $\psi$ é o angulo de dilatação do material. Ao adotar-se $\psi=\beta$ o fluxo plástico é associativo. Caso contrário, o fluxo é não associativo, sendo que, no caso de $\psi=0^{\circ}$ não ocorre dilatação volumétrica do material. Quanto ao encruamento pode-se dizer que o critério utilizado foi elasto-plástico perfeito.

\subsubsection{Modelo constitutivo para a camisa de PRF}

Para a camisa foram utilizadas propriedades elásticas orto-trópicas considerando isotropia transversal. As propriedades elásticas foram adotadas representando o compósito (fibras + resina + vazios) com $0,4 \mathrm{~mm}$, conforme a Tabela 6.1.

Tabela 6.1 - Propriedades elásticas adotadas para a camisa

\begin{tabular}{ccc}
\hline Símbolo & Parâmetro & Valor adotado \\
\hline $\mathrm{E}_{1}$ & Módulo de elasticidade na direção das fibras & $71160(\mathrm{MPa})$ \\
$\mathrm{E}_{2}$ & Módulo de elasticidade na direção perpendicular às fibras & $3800(\mathrm{MPa})$ \\
$\mathrm{v}_{12}$ & Coeficiente de Poisson 1-2 & 0,25 \\
$\mathrm{G}_{12}$ & Módulo de cisalhamento na direção 1-2 & $1380(\mathrm{MPa})$ \\
$\mathrm{G}_{13}$ & Módulo de cisalhamento na direção 1-3 & $1380(\mathrm{MPa})$ \\
$\mathrm{G}_{23}$ & Módulo de cisalhamento na direção 2-3 & $1005(\mathrm{MPa})$ \\
\hline
\end{tabular}


Para avaliar a ruptura da camisa foi utilizado o critério da máxima deformação à tração na direção das fibras, de 0,0119, obtida em CARRAZEDO (2002).

\subsubsection{Estudos sobre a forma da seção transversal}

Nas simulações para verificar o efeito da forma da seção transversal sob compressão centrada, foram modeladas regiões de pequenos comprimentos dos pilares, para minimizar o trabalho computacional. Além disso, foram utilizadas condições de simetria para reduzir o tamanho dos modelos. Uma malha típica utilizada nas modelagens dos pilares quadrados é apresentada na Figura 6.5.

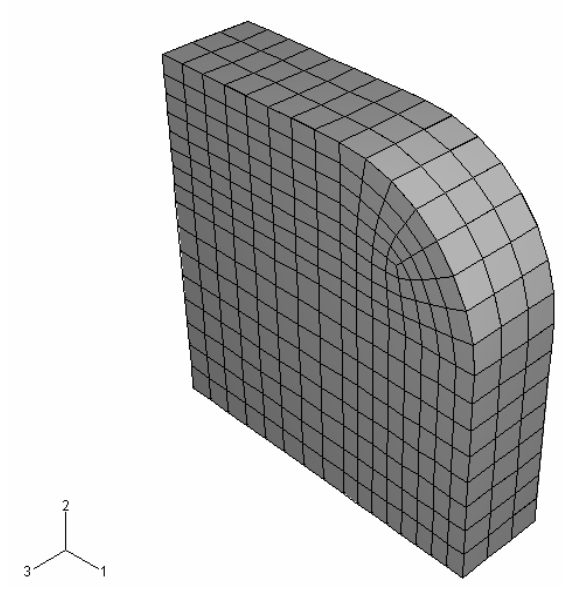

Figura 6.5 - Malhas típicas utilizadas

Os pilares de seção transversal circular foram utilizados para a calibração inicial dos parâmetros do critério de plastificação, pois neste caso a distribuição de tensões e deformações é uniforme, facilitando a comparação com resultados experimentais. A partir da calibração feita com os pilares circulares procurou-se avaliar as outras formas de seção transversal.

Inicialmente foi realizada uma comparação entre os critérios de Mohr-Coulomb e Drucker-Prager na modelagem de corpo-de-prova confinado com PRF. Utilizando um ângulo de dilatação de $0^{\circ}$ os resultados obtidos com os dois modelos foram idênticos. Isto pode ser atribuído à coincidência das superfícies de plastificação e grande semelhança das leis de fluxo. Com isto optou-se por utilizar o critério de DruckerPrager para avaliação da influência da forma da seção transversal.

Foram modelados então pilares de seção transversal circular ensaiados por CARRAZEDO (2002). O ângulo de atrito $(\phi)$ e a coesão (c) do material foram obtidos a partir dos resultados experimentais como indica a Figura 6.6 e as expressões anexas: 


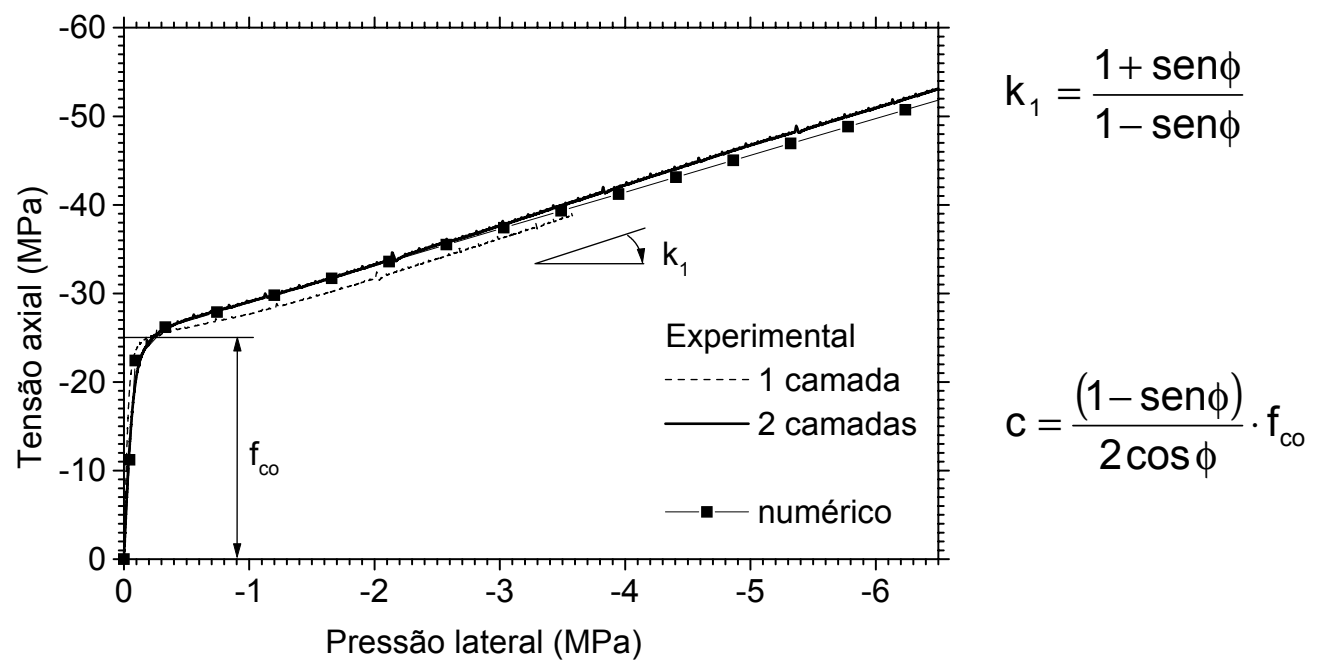

Figura 6.6 - Relação pressão lateral x tensão axial

A variável $\mathrm{k}_{1}$ representa o ganho de resistência pelo efeito de confinamento em relação à pressão lateral. Como se pôde notar $\mathrm{k}_{1}$ foi calculado como a inclinação do diagrama tensão axial x pressão lateral no regime plástico. Outra maneira de se obter $\mathrm{k}_{1}$ a partir dos resultados experimentais é por meio da equação:

$$
\mathrm{k}_{1}=\frac{\mathrm{f}_{\mathrm{cc}}-\mathrm{f}_{\mathrm{co}}}{\mathrm{f}_{\mathrm{l}}}
$$

A coesão foi calculada adotando para $f_{c o} o$ valor de tensão axial referente ao limite elástico. Com base no exposto, adotou-se os valores de 56,98 e 12,08 $\mathrm{MPa}$ para $\beta$ e d, respectivamente. Deve-se acrescentar que foi escolhida a opção "DRUCKERPRAGER HARDENING - type SHEAR”, na qual é utilizada a variável d.

O ângulo de dilatação do material mostrou-se uma variável de calibração menos precisa. Esta variável é relacionada apenas às leis de fluxo, no entanto, ela determina as relações entre tensões axiais e laterais, e, portanto, a deformabilidade volumétrica. Apesar de recomendações de MIRMIRAN et al. (2000) para a utilização de um valor nulo para esta variável, obteve-se melhor correlação entre os resultados experimentais e numéricos dos pilares circulares utilizando um ângulo de dilatação de $1 / 4 \beta$, ou seja, de $14,24^{\circ}$. Com os parâmetros utilizados obteve-se os diagramas força $\mathrm{x}$ deslocamento apresentados na Figura 6.7.

A capacidade resistente dos pilares ensaiados foi limitada pela ruptura à tração da camisa na direção das fibras. Logo, o critério de parada utilizado nas simulações foi a 
ruptura da camisa de PRF. Foi atribuída uma deformação limite de tração de 11,9 \%o, igual ao valor médio de ruptura das leituras experimentais dos extensômetros colados à camisa nos pilares circulares. Como se pode observar na Figura 6.7 os resultados dos pilares circulares em termos de capacidade resistente foram satisfatórios com estas considerações. No entanto, em relação à deformabilidade, apenas o modelo com duas camadas de PRFC obteve resultados precisos. Estes pilares possuíam seção transversal de $190 \mathrm{~mm}$ de diâmetro, comprimento de $570 \mathrm{~mm}$ e bases de leitura dos deslocamentos de $210 \mathrm{~mm}$.

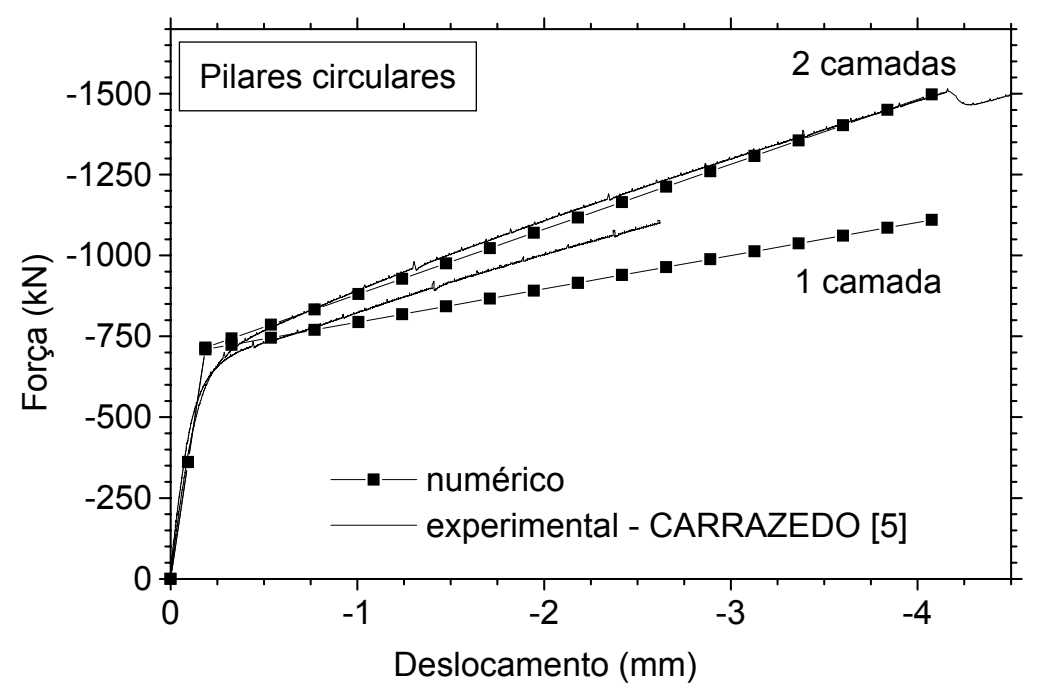

Figura 6.7 - Diagramas força $x$ deslocamento dos pilares circulares

Uma análise semelhante foi realizada com os ensaios de corpos-de-prova de AIRE UNTIVEROS (2002). Adotou-se os parâmetros $\beta=53,56^{\circ}, \mathrm{d}=23,03 \mathrm{MPa}$ e $\psi=$ $13,39^{\circ}$. Do mesmo modo, as deformações de ruptura da camisa limitaram o ganho de resistência do concreto confinado. Os valores adotados para a deformação de ruptura à tração da camisa foram semelhantes aos experimentais, como se pode verificar na Figura 6.8.

Foi possível observar nas simulações com pilares circulares que o critério empregado para o concreto obteve bons resultados na previsão da resistência à compressão, no entanto, o mesmo não ocorreu em relação à deformabilidade. Os modelos numéricos superestimaram a deformação última do concreto confinado nos casos em que a rigidez da camisa era baixa e, por outro lado, subestimaram a deformação última do concreto confinado nos modelos com camisas mais rígidas. 


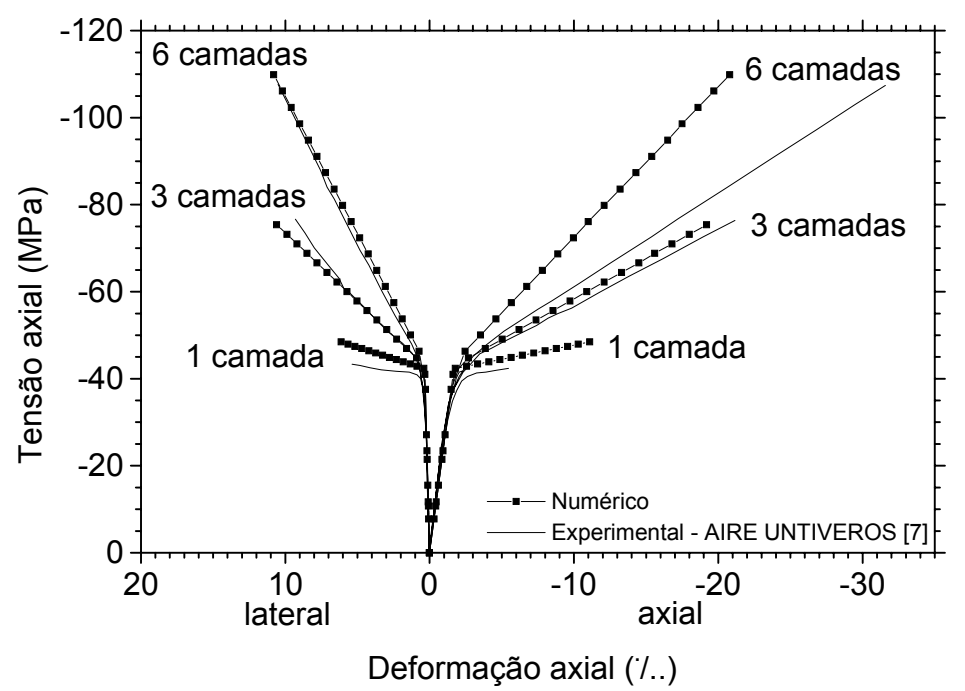

Figura 6.8 - Simulação de corpos-de-prova circulares encamisados com PRF

\subsubsection{Pilares quadrados}

Foram simulados os pilares quadrados ensaiados por CARRAZEDO (2002), para comparação entre resultados numéricos e experimentais. Os pilares possuíam dimensões e instrumentação indicadas na Figura 6.9.

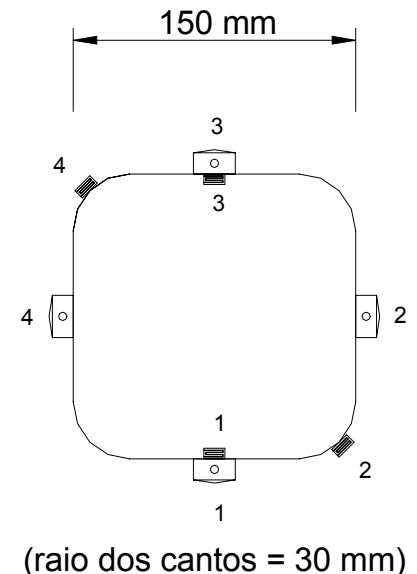

Figura 6.9 - Pilares de seção transversal quadrada

Nestas simulações foram utilizados parâmetros semelhantes aos calibrados para os pilares circulares. Houve apenas uma redução na coesão do material, já que a resistência à compressão axial dos pilares de seção quadrada foi um pouco inferior à dos de seção circular. Na Figura 6.10 são apresentados os diagramas força x deslocamento dos pilares quadrados obtidos com os parâmetros $\beta=56,98^{\circ}, \mathrm{d}=11,476 \mathrm{MPa}$ e $\psi=14,24^{\circ}$. O deslocamento foi medido numa base de leitura de $210 \mathrm{~mm}$. 
Neste caso, os modelos numéricos superestimaram tanto o ganho de resistência como o de deformação última do concreto confinado, como indica a Figura 6.10. A diferença em relação à deformabilidade já era esperada, em função dos resultados obtidos com pilares circulares. Já a diferença em relação à capacidade resistente foi atribuída a algumas limitações na aplicação do critério de plastificação do concreto, comentadas no decorrer deste trabalho.

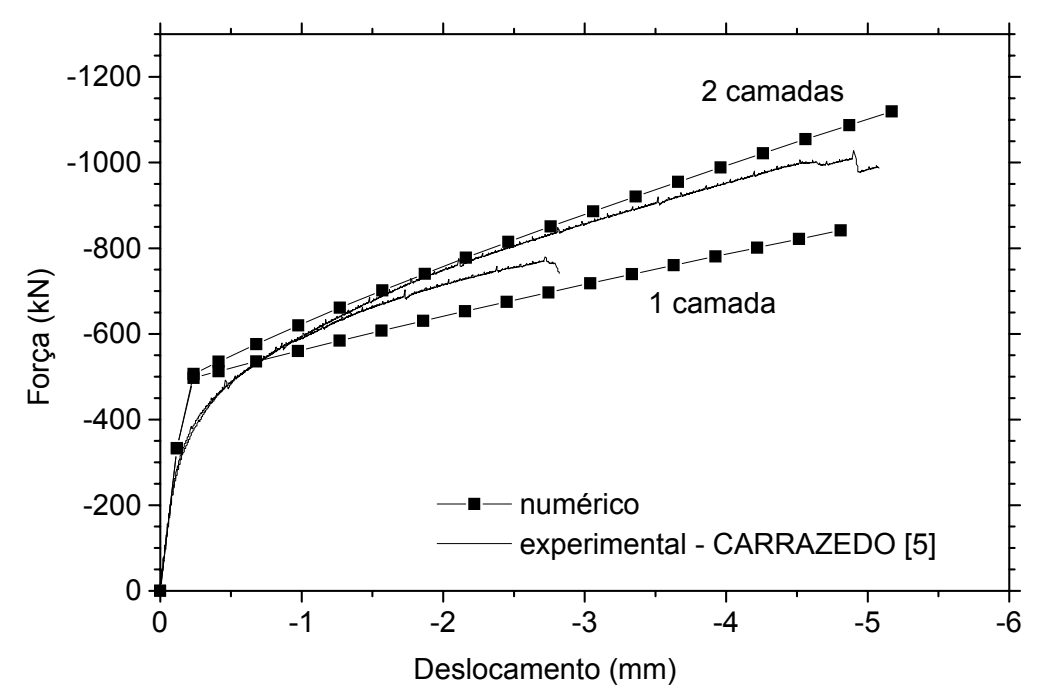

Figura 6.10 - Diagramas força $x$ deslocamento dos pilares de seção quadrada

No ensaio do pilar Q2 foram aplicados extensômetros nas faces externas da camisa, que permitiram obter as deformações da camisa na face exterior em dois pontos distintos: no meio da face lateral e no canto (como indicado na Figura 6.9). Como se pôde observar no ensaio, as leituras das deformações nos cantos foram inferiores às leituras registradas no meio das faces laterais (conforme indicam as leituras experimentais da Figura 6.11). Porém, no modelo numérico praticamente não houve distinção das deformações laterais da camisa nos cantos e nas faces. 


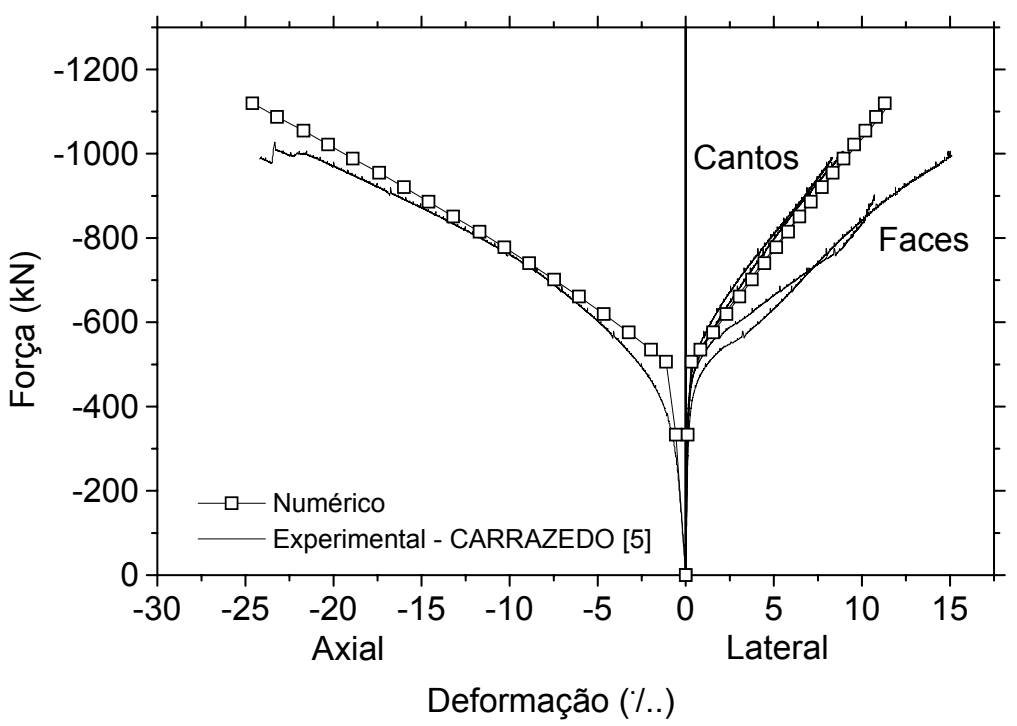

Figura 6.11 - Deformações na face externa da camisa de PRFC

Estas diferenças nas deformações laterais da camisa indicam uma deficiência do modelo numérico em representar a deformabilidade lateral do concreto de maneira adequada. Esta deficiência pôde ser mais bem compreendida com as simulações dos pilares de seção quadrada ensaiados por ROCHETTE \& LABOSSIÈRE (2000). A seção transversal possuía praticamente as mesmas dimensões, no entanto, o raio de arredondamento dos cantos era superior $(38 \mathrm{~mm})$. O modelo numérico novamente superestimou ganhos de resistência e deformação última, como indica a Figura 6.12.

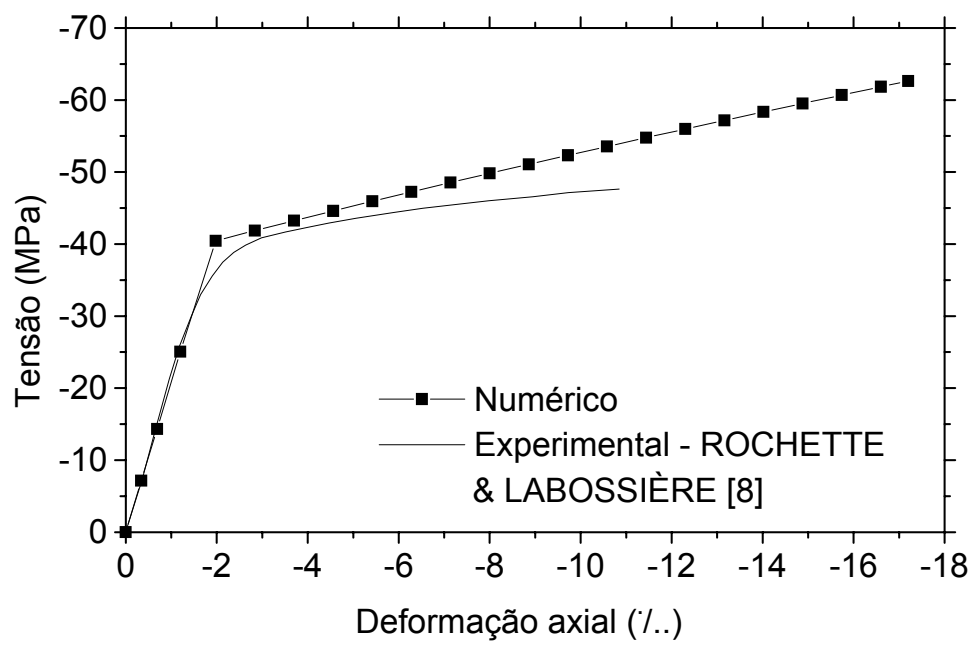

Figura 6.12 - Diagramas tensão x deformação

Neste ensaio os autores utilizaram instrumentação que permitiu medir os deslocamentos transversais da camisa no meio das faces laterais e também nos cantos (conforme indica a Figura 6.13). Um aspecto interessante observado nos ensaios de 
ROCHETTE \& LABOSSIÈRE (2000) foi a deformabilidade transversal da face lateral consideravelmente maior em relação ao canto do pilar. Este comportamento pode ser atribuído ao baixo grau de restrição lateral oferecido pela camisa nestes trechos retos e a uma maior micro-fissuração do concreto nestas regiões, menos confinadas.

Acredita-se que o modelo numérico, apesar de considerar adequadamente a rigidez da camisa, não conseguiu representar a maior deformabilidade lateral que o concreto apresenta nas regiões pouco confinadas. Com isto, ocorreram diferenças no comportamento observado experimentalmente e numericamente, como indica a Figura 6.13. Chama-se a atenção aqui, não à diferença de capacidade resistente entre modelo numérico e experimental, mas sim à limitação do modelo numérico em representar as diferenças de deformabilidade entre cantos e faces observadas nos ensaios.

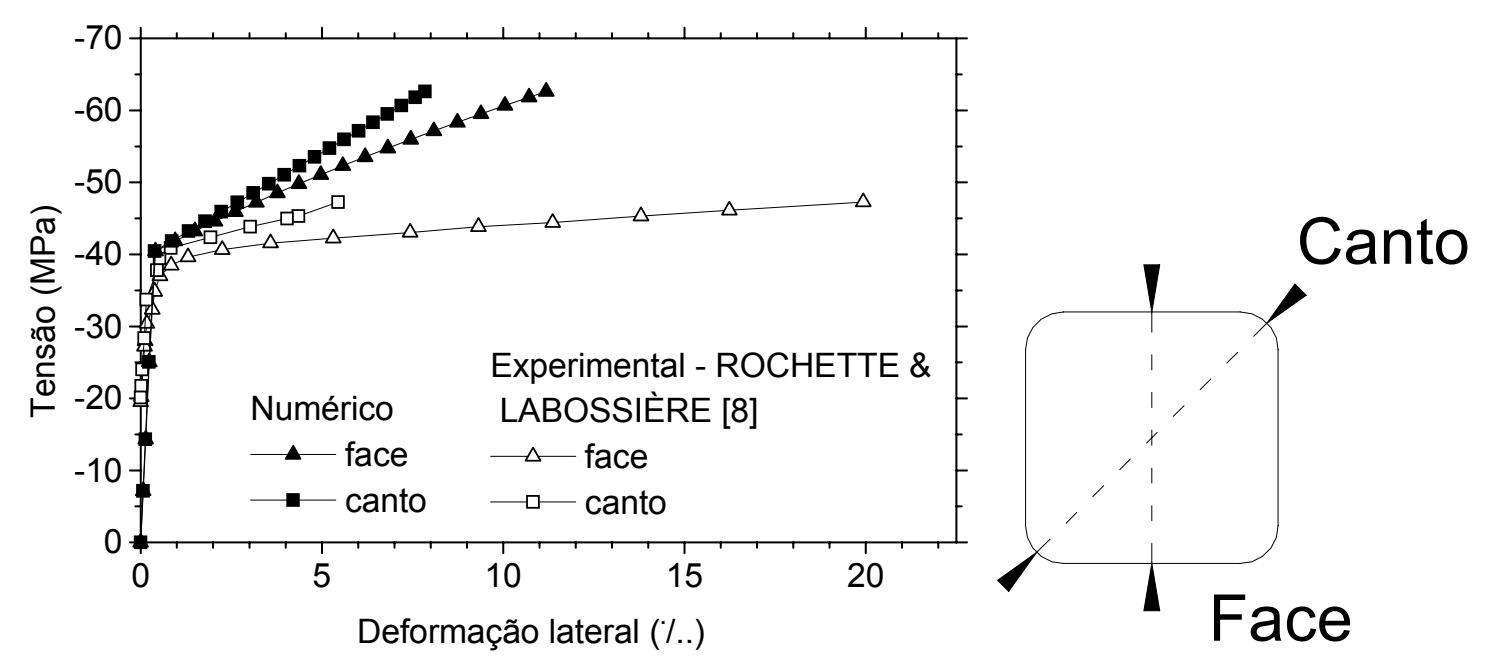

Figura 6.13 - Deformações transversais do pilar S38 C3

ROCHETTE \& LABOSSIÈRE (2000) utilizaram ainda extensômetros colados bem próximo aos cantos arredondados. Com relação a este aspecto, a análise numérica forneceu resultados um pouco acima dos experimentais, como indica a Figura 6.14. 


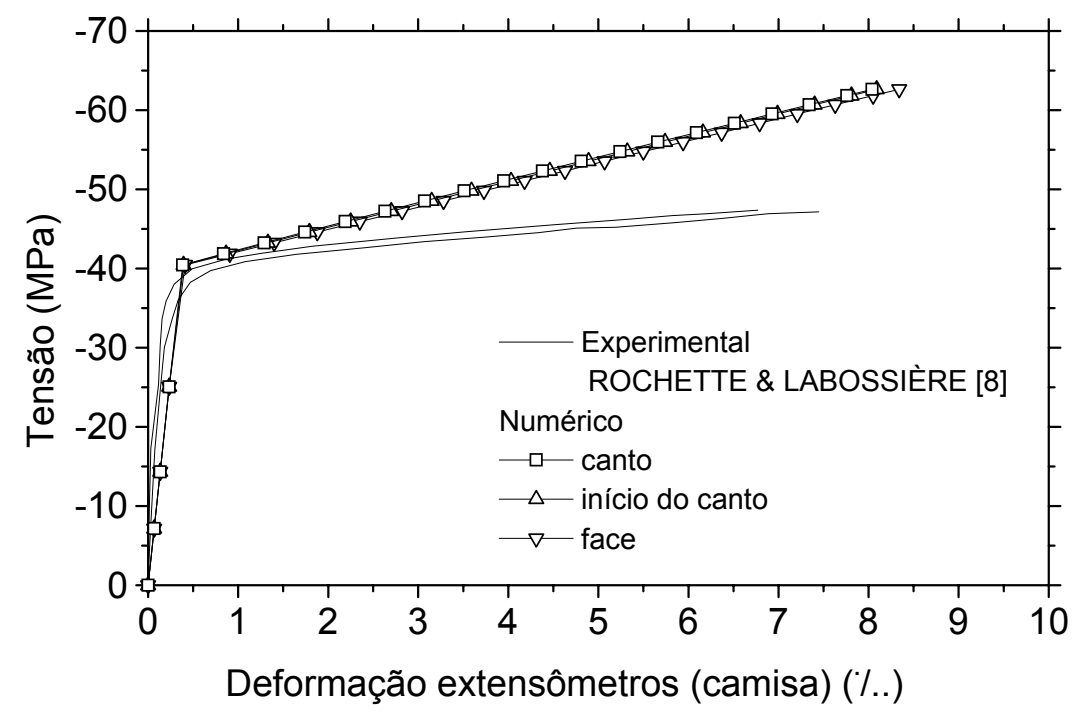

Figura 6.14 - Deformações dos extensômetros colados à camisa

Tendo em vista a distinta deformabilidade lateral dos modelos numéricos e experimentais foi realizada uma modelagem do pilar Q2 utilizando propriedades distintas para o material nas regiões indicadas em cores diferentes na Figura 6.3, para simular o comportamento distinto nas regiões menos confinadas. O concreto das regiões claras tinha propriedades normais $\left(\beta=56,98^{\circ}, \mathrm{d}=11,476 \mathrm{MPa}\right.$ e $\left.\psi=14,24^{\circ}\right)$, enquanto o das regiões escuras foi modificado para $\left(\beta=\psi=37,67^{\circ}\right.$ e $\left.d=18,41 \mathrm{MPa}\right)$. Nesta modelagem ilustrativa o concreto das regiões escuras possuía o mesmo limite de plastificação porém um ganho de resistência em função do efeito de confinamento muito reduzido $\left(\beta=37,67^{\circ}\right)$ associado a uma alta deformabilidade lateral $\left(\psi=37,67^{\circ}\right)$.

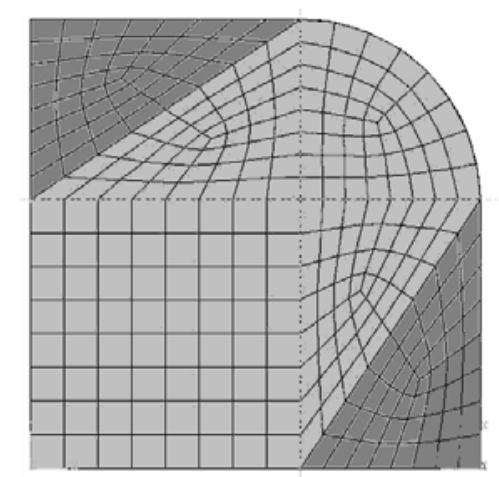

Figura 6.15 - Modelagem ilustrativa

Comparando a simulação ilustrativa à realizada anteriormente observou-se um comportamento força $\mathrm{x}$ deslocamento muito semelhante, porém a capacidade resistente do modelo ilustrativo mostrou-se reduzida. 


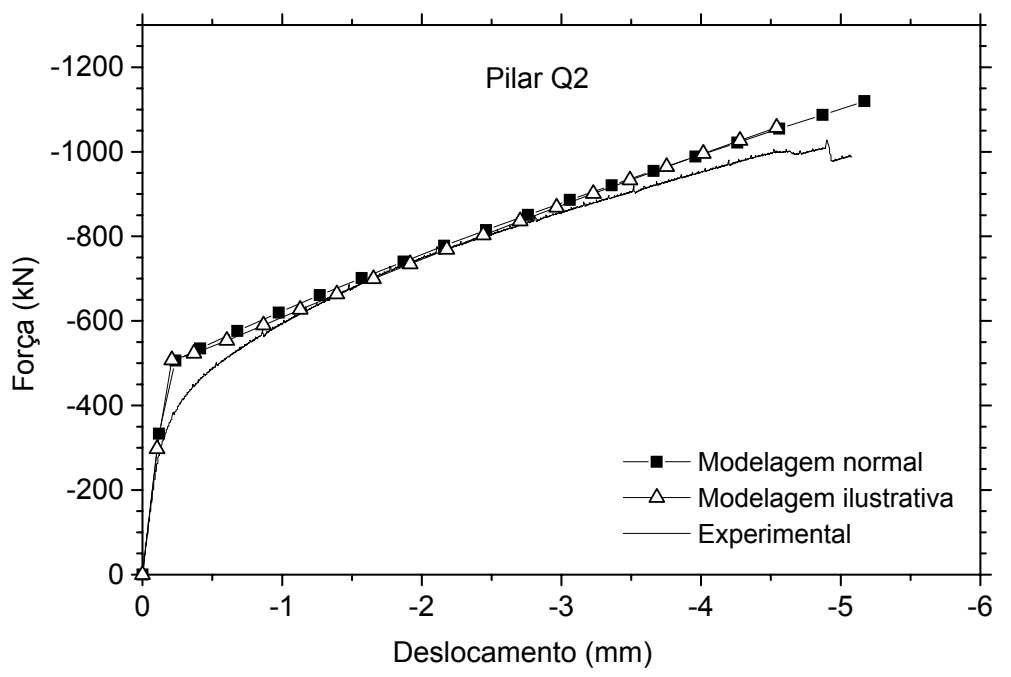

Figura 6.16 - Diagramas força $x$ deslocamento - modelagem normal $x$ ilustrativa

Outra comparação foi realizada com as deformações de extensômetros da camisa, que como se havia comentado, não haviam sido bem representadas pelo modelo numérico normal. Na modelagem ilustrativa ocorreu uma certa distinção entre leituras nos cantos e nas faces lateral, o que representa melhor o comportamento experimental.

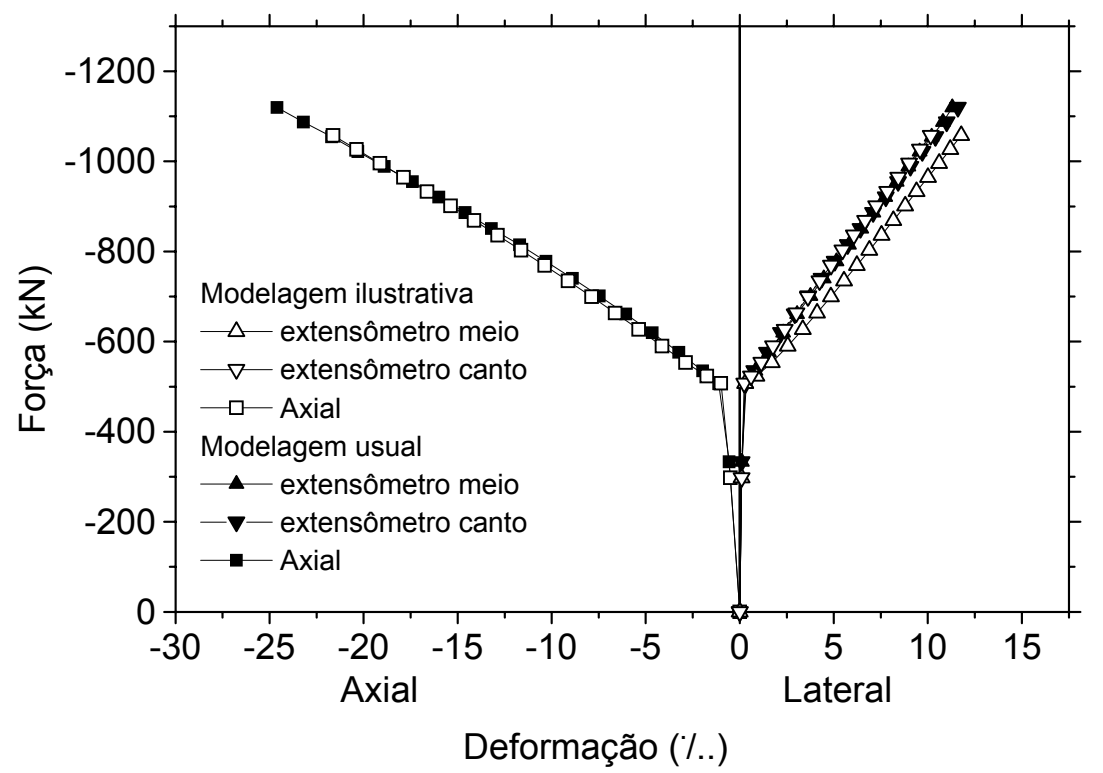

Figura 6.17 - Deformabilidade dos modelos numéricos

Além disso, a comparação de deformações transversais nos cantos e no meio das faces laterais mostrou melhorias no modelo ilustrativo (ver Figura 6.18). 


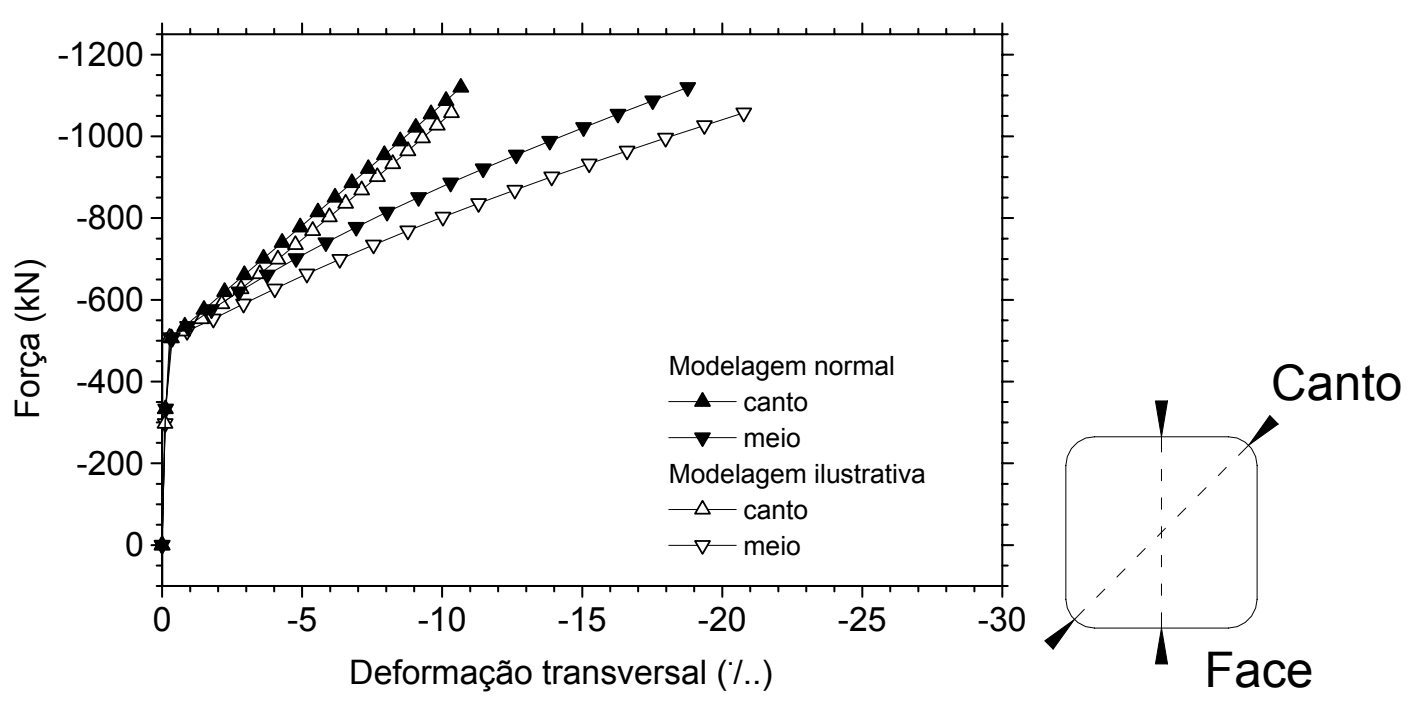

Figura 6.18 - Diferenças nas deformações transversais

Atribui-se este comportamento diferenciado nas duas modelagens em função do critério de Drucker-Prager não representar adequadamente o comportamento do concreto nas regiões parcialmente confinadas, em que os estados de tensão são bem diferentes de uma compressão uniforme, já que uma das tensões é nula.

Logo, o objetivo desta modelagem ilustrativa foi apenas demonstrar que utilizando um modelo constitutivo para o concreto que represente melhor o estado biaxial de compressão ou outros estados gerais pode-se obter resultados mais precisos.

\subsubsection{Extrapolação das análises}

Mesmo considerando as limitações do modelo numérico até então utilizado (com o critério de Drucker-Prager Estendido), foi possível realizar algumas análises para verificar o comportamento de pilares quadrados com diferentes raios de arredondamento dos cantos. A primeira avaliação realizada foi a respeito da influência do raio de arredondamento sobre as deformações na camisa. Esta análise foi motivada pelo fato de terem sido observadas diferentes formas de ruptura da camisa em função deste raio. No trabalho de SHEHATA et al. (2001), por exemplo, que possui dimensões semelhantes às utilizadas por CARRAZEDO (2002), porém com um raio de arredondamento de 1 $\mathrm{cm}$, foi relatada a ruptura nos cantos, enquanto nos ensaios de CARRAZEDO (2002) a ruptura ocorreu no meio da face lateral.

A comparação das deformações da camisa na eminência da ruptura foi efetuada para pilares com 1, 3 e 3,8 cm, com base nos resultados das simulações numéricas aqui realizadas. Na Figura 6.19 são apresentadas as deformações da camisa na face interna e 
externa, o valor médio e o limite de deformação de ruptura (linha superior na figura). Com o raio de $1 \mathrm{~cm}$ observa-se claramente um ponto critico de deformações de tração na face interna da camisa nos cantos. Nesta simulação, com um raio de $1 \mathrm{~cm}$ a ruptura ocorreria nos cantos, como ocorreu nos ensaios de SHEHATA et al. (2001).

Com os raios de arredondamento maiores (3 e 3,8 cm), ocorreu uma certa uniformização das deformações nas diferentes regiões da camisa em relação ao caso anterior $(1 \mathrm{~cm})$, sendo levemente maiores as deformações próximas ao início dos cantos. No entanto, deve-se lembrar que a limitação do modelo constitutivo empregado para o concreto de não representar adequadamente a sua deformabilidade lateral nas regiões pouco confinadas das proximidades da face lateral, pode ter levado o modelo numérico a subestimar as deformações da camisa nesta região.
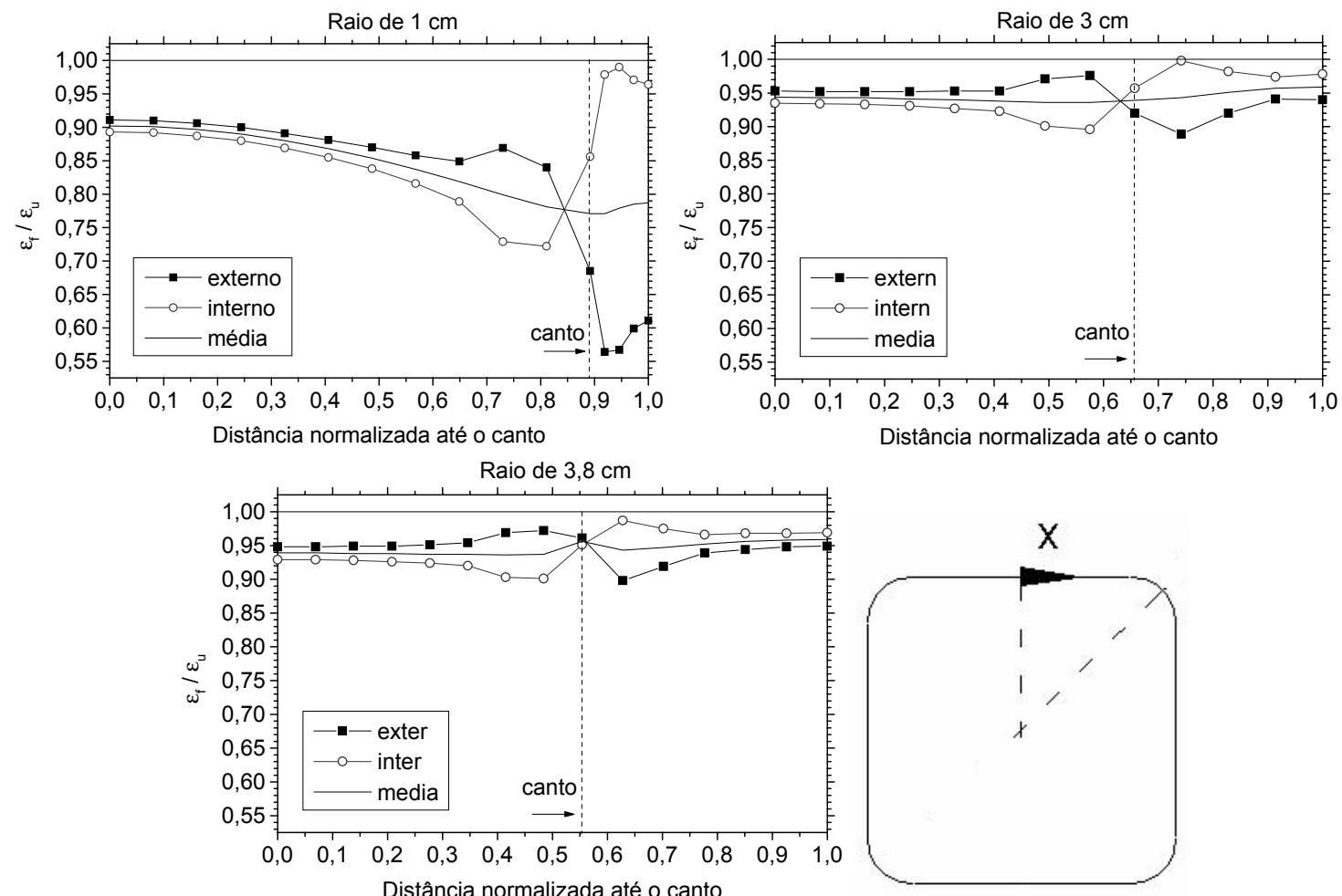

Figura 6.19 - Distribuição das deformações na camisa

Com base no exposto, pode-se imaginar a influência do efeito de flexão da camisa sobre seu modo de ruptura. Existe, aparentemente, uma tendência da camisa se expandir tentando se aproximar de uma configuração final circular (ver Figura 6.20). Este efeito de flexão da camisa tende a provocar um aumento das deformações externas registradas por extensômetros localizados nos pontos 1 e 2 e reduzir as leituras das deformações de extensômetros nos pontos 3 e 4 . 
Além disso, como ocorreu nos ensaios de CARRAZEDO (2002) e SHEHATA et al. (2001), estas regiões podem tornar-se regiões críticas, onde ocorre a ruptura da camisa. Por exemplo, nos ensaios de CARRAZEDO (2002) a ruptura ocorreu provavelmente nas proximidades do ponto 2 (no trecho reto da camisa próximo do início do canto arredondado), onde seriam medidas as maiores deformações com extensômetros colados na camisa.

No entanto, ensaios realizados por outros autores apresentaram rupturas localizadas nos cantos (pontos 3 e 4). Neste caso, a tendência da abertura do raio de arredondamento pode ter provocado maiores deformações de tração no lado interno da camisa nestes pontos, o que causou a ruptura.

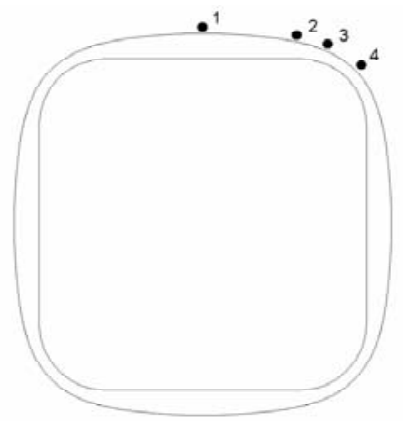

Figura 6.20 - Deformações da camisa

Na Figura 6.21 são apresentadas as tensões de compressão axial (em MPa) dentro da seção transversal para pilares com raios de $3 \mathrm{~cm}$ de arredondamento nos cantos. Como se pode observar, as maiores tensões de compressão se concentram nos cantos, onde ocorrem elevadas pressões de confinamento, que também são apresentadas na figura.
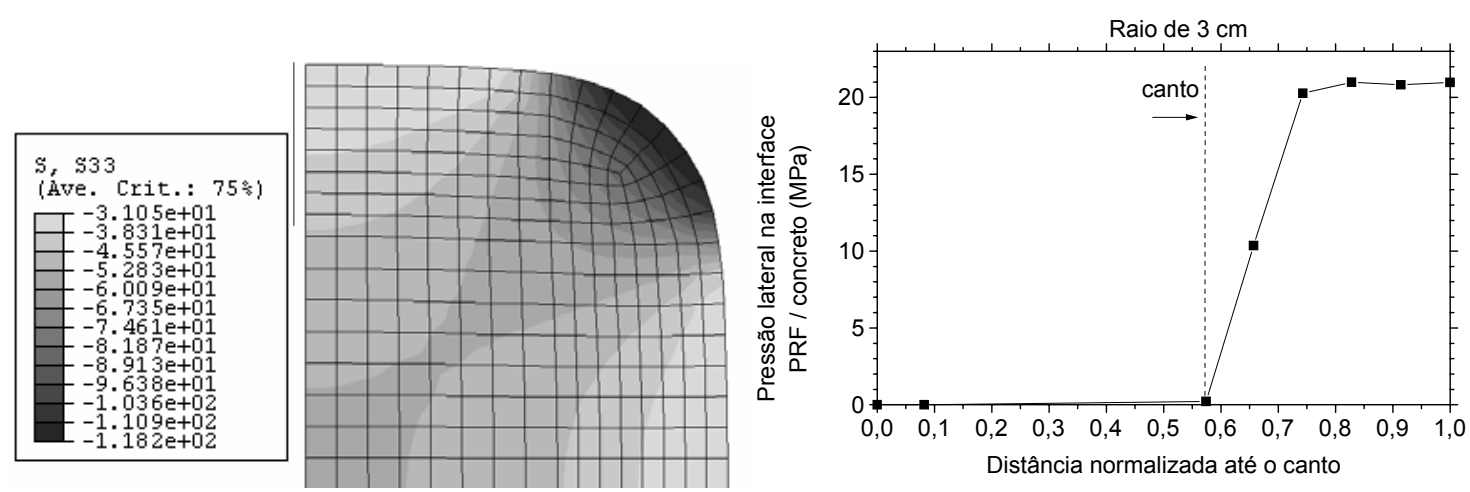

Figura 6.21 - Tensões axiais e pressões laterais no pilar com $3 \mathrm{~cm}$ de raio de arredondamento 
Na Figura 6.22 são apresentadas as tensões de compressão para pilares com raio de $1 \mathrm{~cm}$ de arredondamento nos cantos. Neste caso a concentração de tensões de compressão nos cantos é ainda maior, e a pressão lateral chegou a valores da ordem de $55 \mathrm{MPa}$.
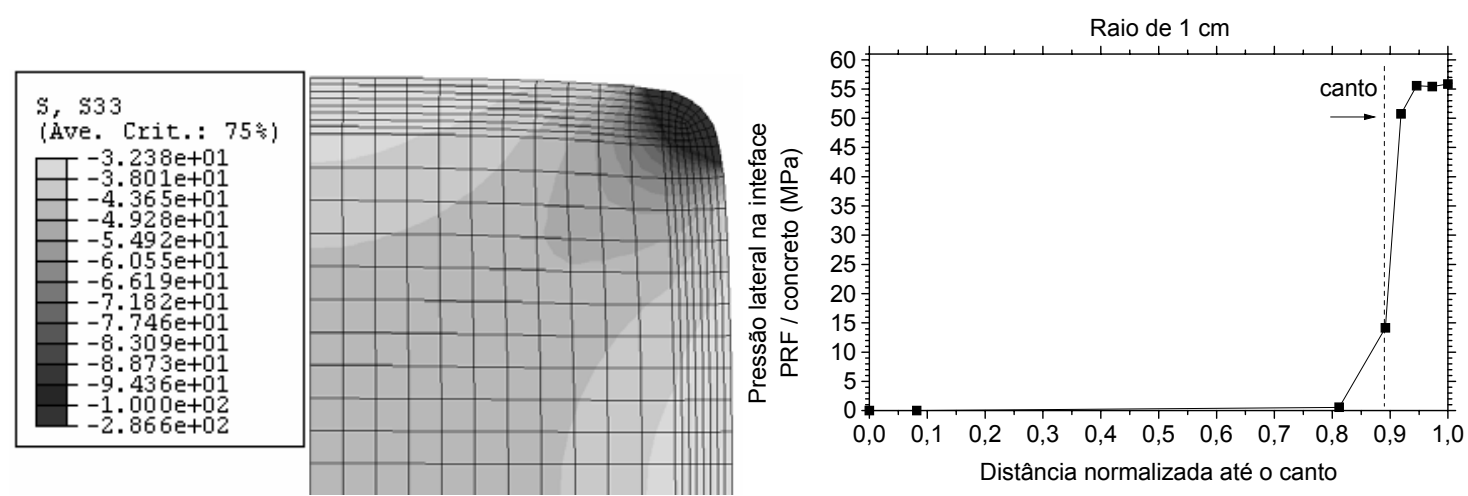

Figura 6.22 - Tensões axiais e pressões laterais no pilar com $1 \mathrm{~cm}$ de raio de arredondamento

Estas análises mostraram que o efeito de confinamento em pilares de seção quadrada depende significativamente do raio de arredondamento (r) empregado. As pressões laterais que se desenvolvem nos cantos podem ser estimadas utilizando a expressão:

$$
f_{1}=\frac{2 \cdot t_{f} \cdot E_{f} \cdot \varepsilon_{f}}{2 r}
$$

onde:

- $t_{\mathrm{f}}$ é a espessura da camisa;

- $\mathrm{E}_{\mathrm{f}}$ é o módulo de elasticidade do PRF;

- $\varepsilon_{\mathrm{f}}$ é a deformação de tração do PRF.

Utilizando esta expressão com a deformação média da camisa nos cantos obteve-se os valores de 21,45 MPa e 53,5 MPa, muito próximos dos observados nas Figuras 4.17 e 4.18. Logo, estas análises sugerem que nos pilares quadrados com cantos arredondados o efeito de confinamento se desenvolve a partir dos cantos arredondados.

Quanto menor o raio de arredondamento maior é a pressão concentrada nos cantos. No entanto, o que determina o ganho de resistência do elemento é a distribuição destas pressões no interior do concreto.

Na Figura 6.23 são apresentadas as tensões no concreto ao longo da linha que une o centro do pilar até a face lateral. Pode-se observar que as tensões de compressão são ligeiramente maiores no pilar com raio de arredondamento de $3 \mathrm{~cm}$. 
As tensões de compressão axial diminuem significativamente em direção à face destes pilares, região onde o efeito de confinamento é mais reduzido. Observa-se ainda que próximo à face lateral a componente de tensão radial $\left(\sigma_{22}\right)$ é praticamente nula, e se caracteriza um estado biaxial de tensões de compressão. Conseqüentemente, a resposta do critério de plastificação utilizado para o concreto não apresentou bons resultados nestas regiões, já que o mesmo não foi calibrado para tal situação.
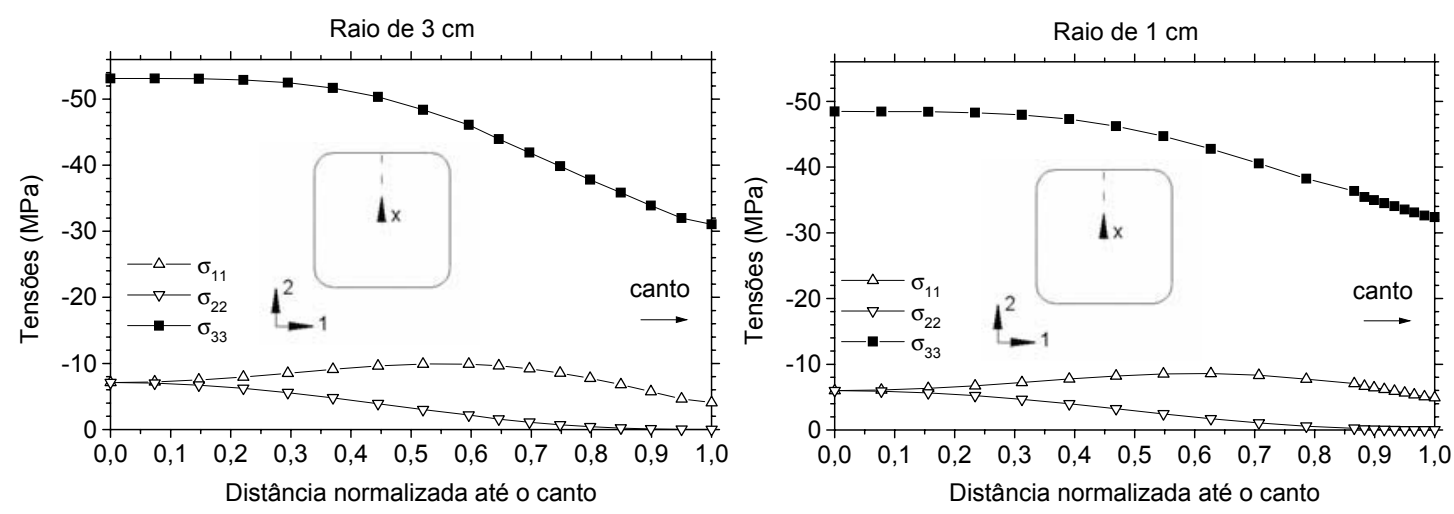

Figura 6.23 - Distribuição de tensões no concreto centro - face

Na Figura 6.24 são apresentadas as tensões no concreto no caminho que une o centro do pilar à diagonal. Neste caso, observou-se que as tensões de compressão axial crescem significativamente em direção à diagonal, onde se desenvolve um efeito de confinamento com altíssimas pressões laterais.
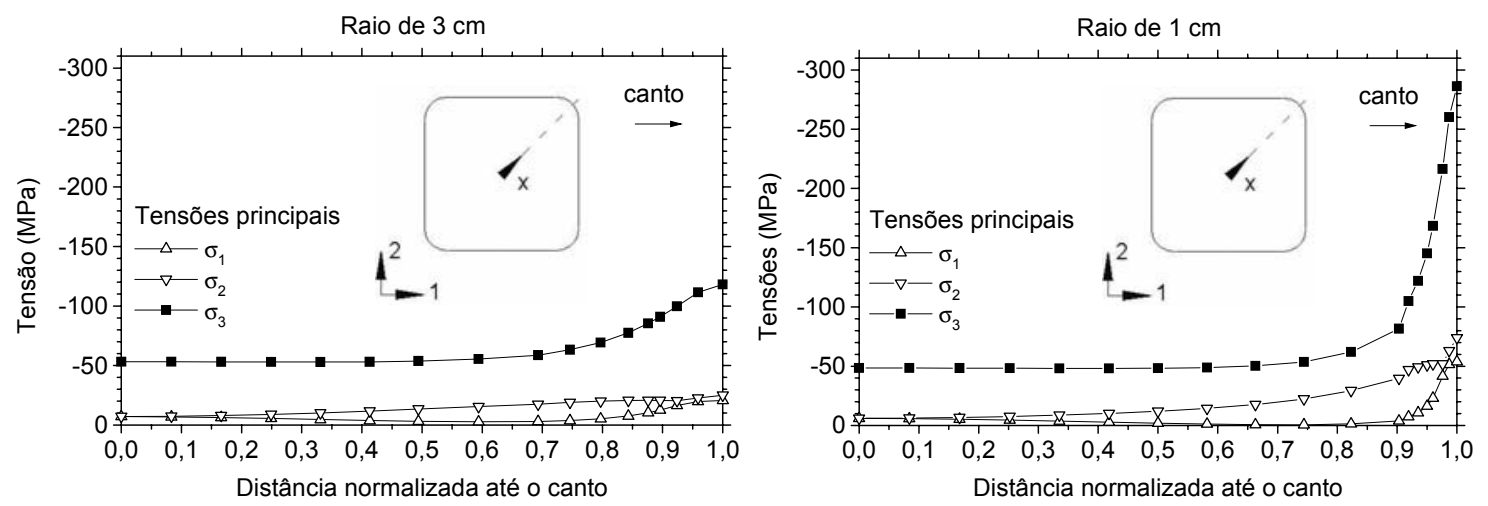

Figura 6.24 - Distribuição de tensões no concreto centro - diagonal

\subsubsection{Simulação dos ensaios piloto}

Foram simulados os ensaios piloto sob flexo-compressão. Nestas modelagens foi possível utilizar apenas dois planos de simetria, (em relação aos planos cujas normais 
são as direções 1 e 3, conforme Figura 6.25). Além disso, de forma diferente do caso de compressão centrada, foi necessário representar $1 \frac{1}{4}$ do pilar no modelo numérico.

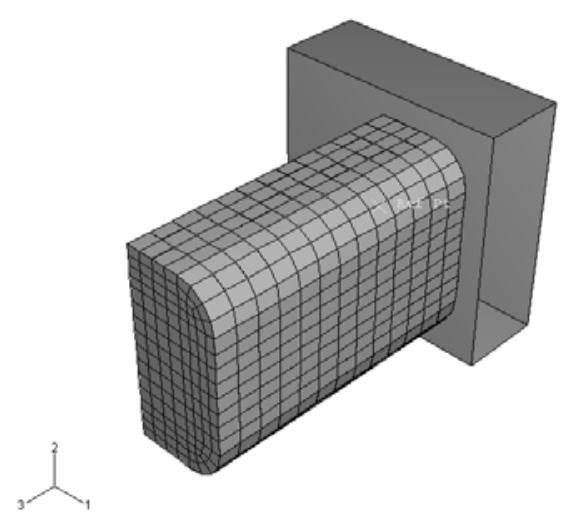

Figura 6.25 - Representação do modelo empregado para a flexo-compressão

Para aplicação do carregamento foi utilizada uma superfície analítica rígida (Figura 6.25), que possibilita a representação da placa metálica da rótula como infinitamente rígida. A vantagem da utilização deste procedimento é que, como não é necessária a criação de novos elementos, o número de graus liberdade não é aumentado, o que melhora a rapidez da solução. Além disso, segundo o manual do ABAQUS ${ }^{\circledR}$ versão 6.2, estas superfícies melhoram a convergência em problemas de contato desta natureza. No entanto, deve-se ter atenção, pois as condições de contorno só podem ser aplicadas no ponto de referência da superfície rígida, sendo que o movimento da superfície como um todo funciona como o de um corpo-rígido. Deste modo, o ponto de referência deve representar o centro de rotação da rótula.

\subsubsection{Calibração dos parâmetros}

A calibração dos parâmetros do critério de MOHR-COULOMB para simulação dos pilares excêntricos foi feita com base nos resultados de ensaios de corpos-de-prova de concreto encamisados com PRFC, que fizeram parte dos ensaios piloto. Como se pode observar na Figura 6.26 os resultados experimentais e numéricos foram bem próximos com os parâmetros adotados. O módulo de elasticidade do concreto foi um pouco exagerado nos modelos numéricos. Isto ocorreu porque foi adotado a partir das leituras dos extensômetros removíveis enquanto as medidas de deformação axial experimentais apresentadas na figura são originárias de leituras de transdutores de deslocamento entre os pratos da máquina de ensaio. 


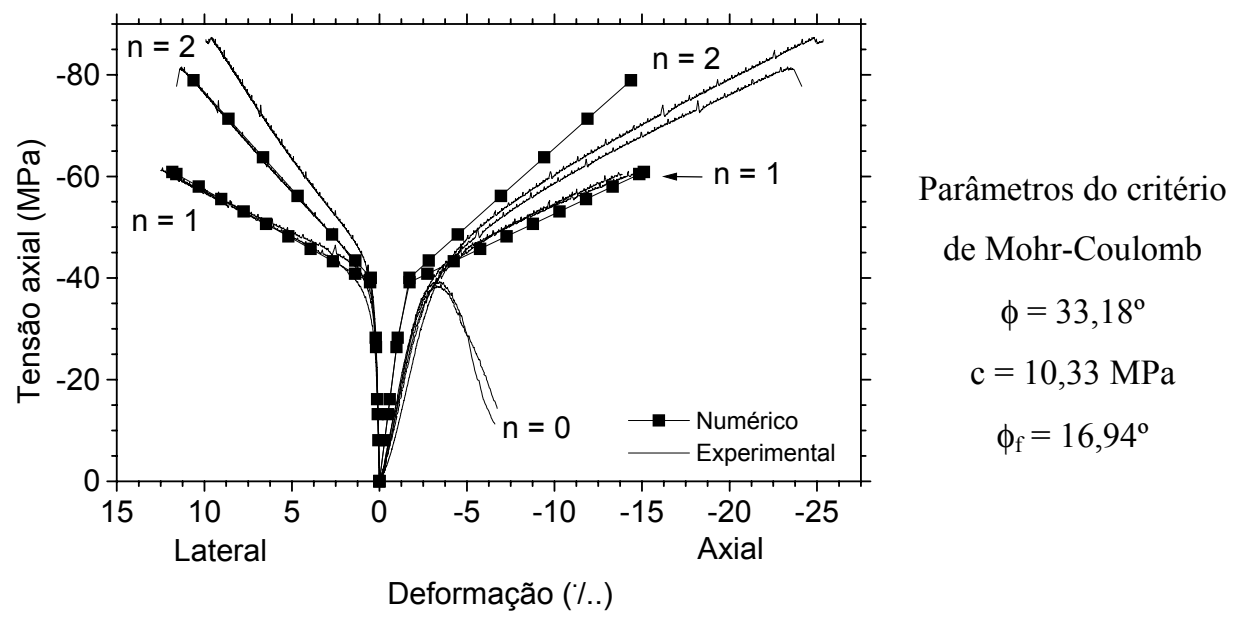

Figura 6.26 - Representação do modelo empregado para a flexo-compressão

Estes parâmetros foram então utilizados para modelagem dos pilares carregados excentricamente. Na Figura 6.27 são apresentados os diagramas força x deslocamento axial médio (C.G.) dos pilares $\mathrm{C} 4$ e $\mathrm{C} 18$, comparando resultados numéricos e experimentais.

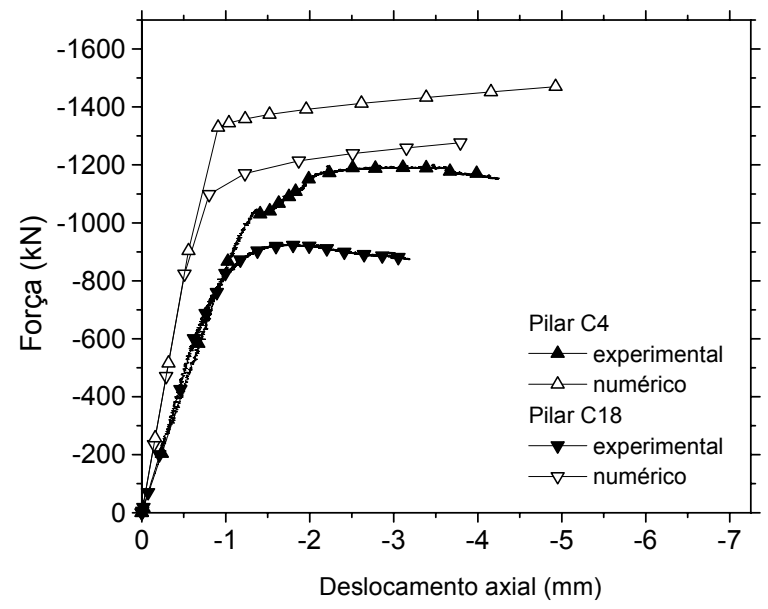

Figura 6.27 - Representação do modelo empregado para a flexo-compressão

Como se pôde observar, os modelos numéricos calibrados com resultados de corpo-de-prova forneceram resultados muito exagerados de ganho de resistência e rigidez inicial. Segundo NIELSEN (1999) a resistência do concreto observada no ensaio de uma estrutura é normalmente bem diferente da resistência medida em corpos-deprova padronizados. Segundo o autor, a principal causa desta redução é a fissuração e recomenda a utilização de fatores redutores da resistência à compressão. Normalmente, para o concreto fissurado pode ser utilizado o mesmo ângulo de atrito que o do concreto 
não fissurado, logo a redução da resistência à compressão é proporcional à coesão (NIELSEN, 1999).

Nos pilares ensaiados em CARRAZEDO (2002) já haviam sido observadas diferenças entre a resistência à compressão dos corpos-de-prova cilíndricos de 10 x 20 cm com os pilares de seção circular com 19 x $57 \mathrm{~cm}$. Os pilares apresentaram uma resistência à compressão de $76 \%$ da obtida com os corpos-de-prova. Na falta de outros parâmetros, foi utilizado este fator redutor da resistência à compressão do concreto nas simulações numéricas dos ensaios piloto. Quanto ao módulo de elasticidade, CARRAZEDO (2002) obteve valores praticamente iguais (28500 MPa) nos ensaios de corpos-de-prova e pilares já citados, devendo-se observar que as medidas em ambos os casos foram feitas apenas na região central do pilar, excluindo assim a influência das extremidades.

Porém, como já foi observado nos corpos-de-prova dos ensaios piloto, a medida de deformações na região central da amostra ou no comprimento total resultou em valores bem distintos para o módulo de elasticidade, da ordem de 27 e $17 \mathrm{GPa}$, respectivamente. A influência do capeamento com enxofre ou de outras deformações não identificadas pode ser representada no modelo em série apresentado na Figura 6.28. Seja, por exemplo, um corpo-de-prova constituído de dois materiais com módulos de elasticidade $E_{1}$ e $E_{2}$, em regiões de comprimento $L_{1}$ e $L_{2}$, respectivamente, carregado axialmente. Como ambos os materiais estão submetidos ao mesmo carregamento, o módulo de elasticidade equivalente é dado pela equação:

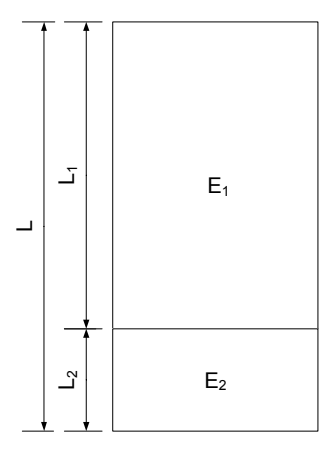

$$
E_{\text {eq }}=\frac{L \cdot E_{1} \cdot E_{2}}{L_{1} \cdot E_{2}+L_{2} \cdot E_{1}}
$$

Figura 6.28 - Modelo de dois materiais em série

Como as leituras de deslocamentos axiais dos pilares nos ensaios piloto foram realizadas no comprimento total a influência destes fatores esta implícita nas medidas. Logo, utilizando as propriedades elásticas do concreto obtidas dos ensaios de 
caracterização os modelos numéricos acabaram se comportando de maneira mais rígida, principalmente no início do carregamento.

Na Figura 6.29 são apresentados os diagramas força x deslocamento axial médio (C.G.) dos pilares, comparando resultados numéricos e experimentais. Nestas simulações a coesão foi reduzida para $\mathrm{c}=7,96 \mathrm{MPa}$, porém não foram feitas alterações no módulo de elasticidade do concreto.

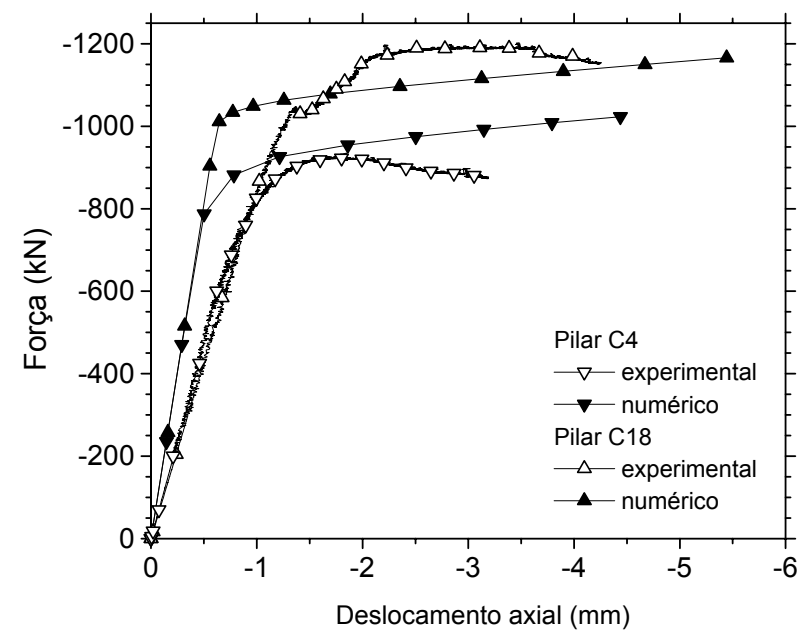

Parâmetros do critério de Mohr-Coulomb

$$
\begin{gathered}
\phi=33,18^{\circ} \\
\mathrm{c}=7,96 \mathrm{MPa} \\
\phi_{\mathrm{f}}=16,94^{\circ}
\end{gathered}
$$

Figura 6.29 - Diagramas força $\mathrm{x}$ deslocamento axial

\subsubsection{Comparação resultados numéricos $\mathrm{x}$ experimentais}

$\mathrm{Na}$ Figura 6.30 são comparados os diagramas força $\mathrm{x}$ rotação de apoio experimentais e numéricos, mostrando uma boa correlação.
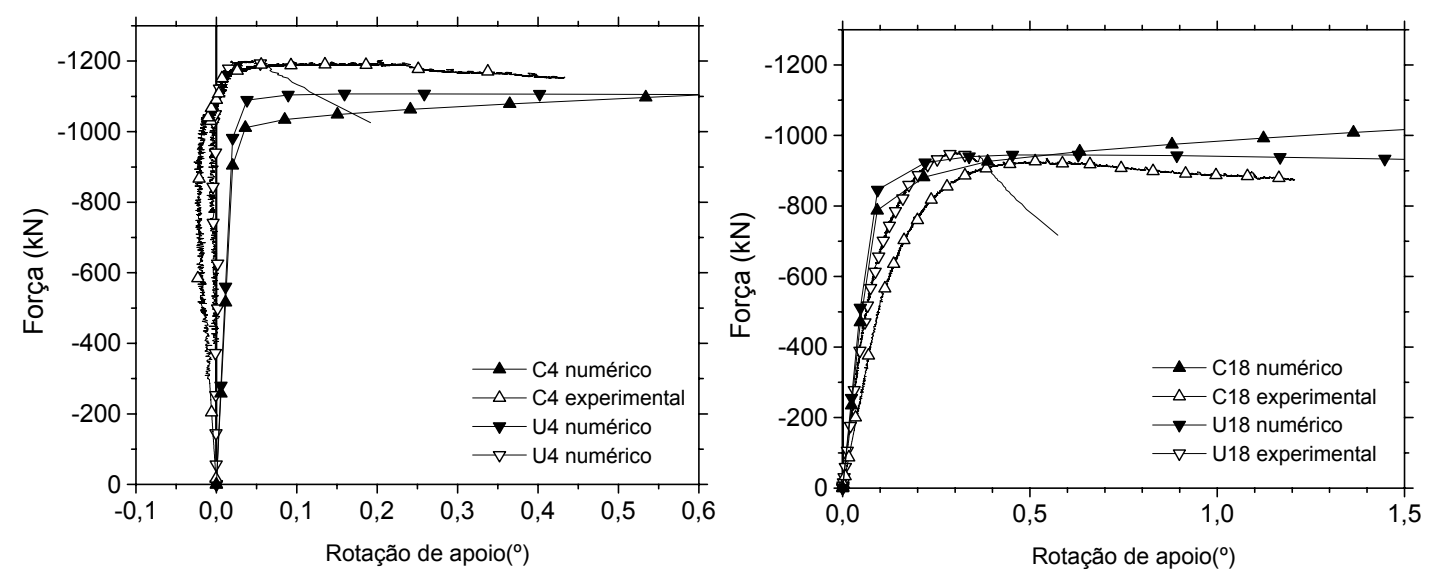

Figura 6.30 - Diagramas força $x$ rotação experimentais e numéricos 
Na Figura 6.31 são apresentados os diagramas força $\mathrm{x}$ deslocamento no meio do pilar. Pode-se observar também uma boa aproximação de resultados numéricos e experimentais, principalmente no caso dos pilares encamisados.
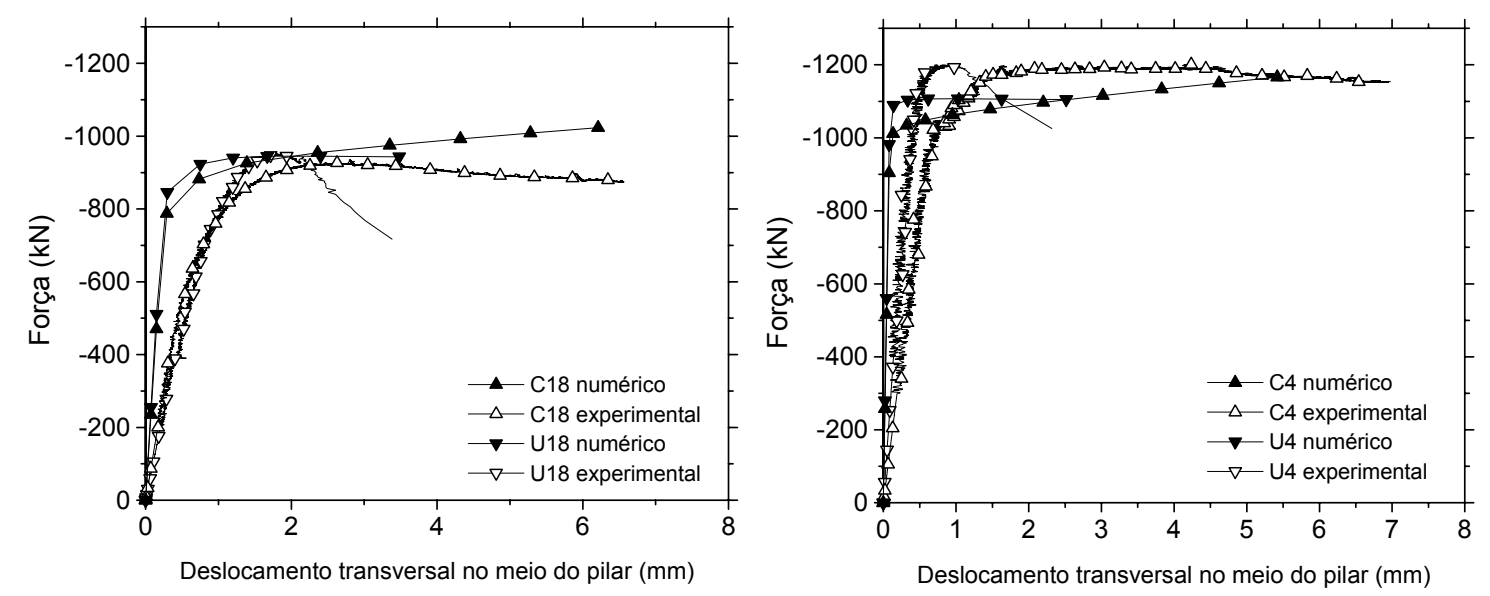

Figura 6.31 - Diagramas força $\mathrm{x}$ deslocamento transversal

Outra comparação foi realizada com as deformações externas da camisa registradas pelos extensômetros transversais e as obtidas nos modelos numéricos. Podese observar uma boa concordância entre resultados experimentais e numéricos.
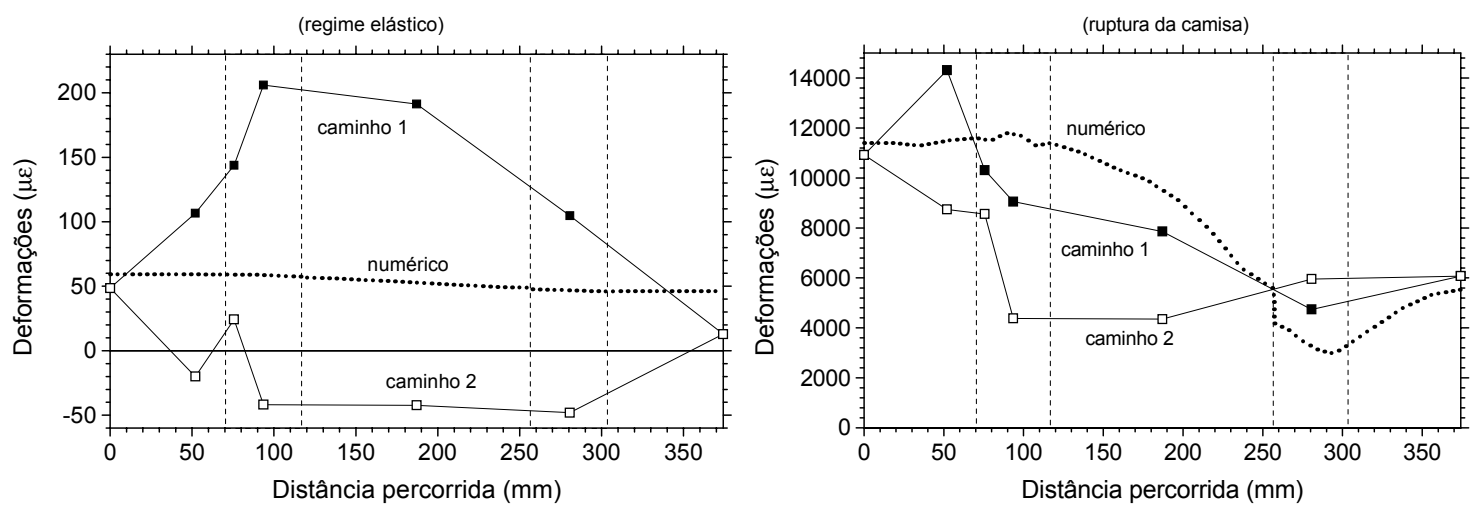

Figura 6.32 - Comparação deformações externas da camisa - numérico x experimental - Pilar C4 

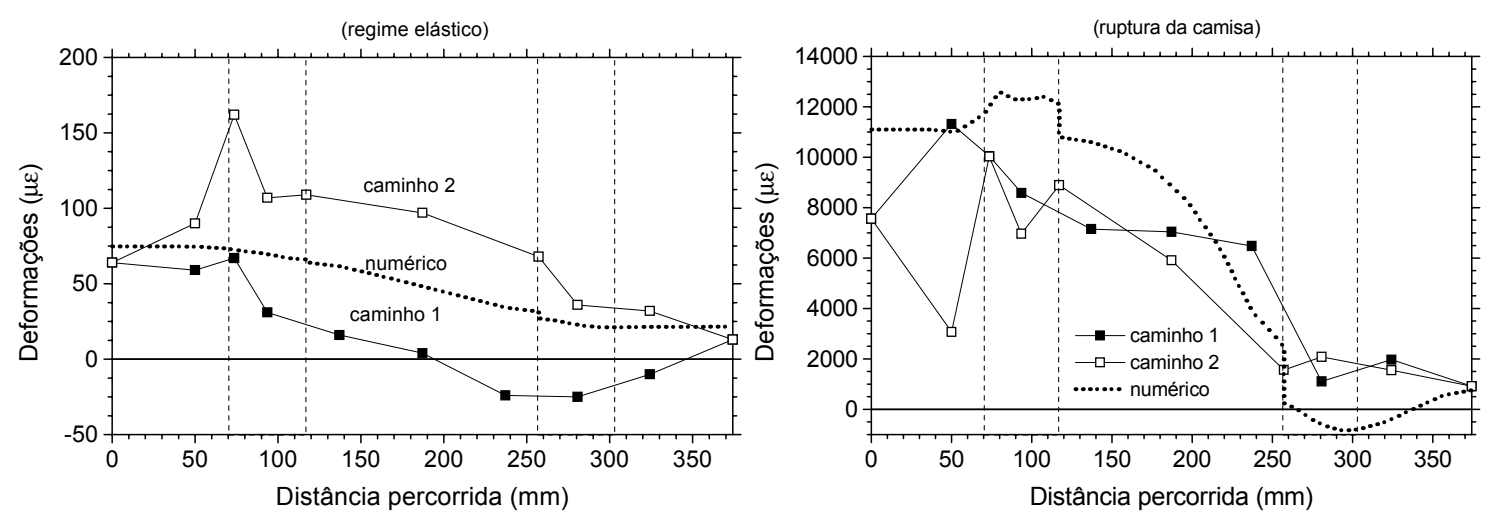

Figura 6.33 - Comparação deformações externas da camisa - numérico x experimental - Pilar C18

\subsubsection{Resultados das simulações}

Na Figura 6.34 são apresentadas as tensões principais transversais na seção central dos pilares. Estas são representadas por vetores que indicam a direção e o valor das tensões com sua magnitude. Pode-se observar que as pressões de confinamento são geradas principalmente a partir dos cantos arredondados.

Na Figura 6.35 são apresentados diagramas de cores com as tensões principais atuantes no concreto. Pode-se observar que os efeitos de confinamento são gerados a partir dos cantos arredondados, mesmo no caso de pilares sob carregamento excêntrico.

Pilar C4

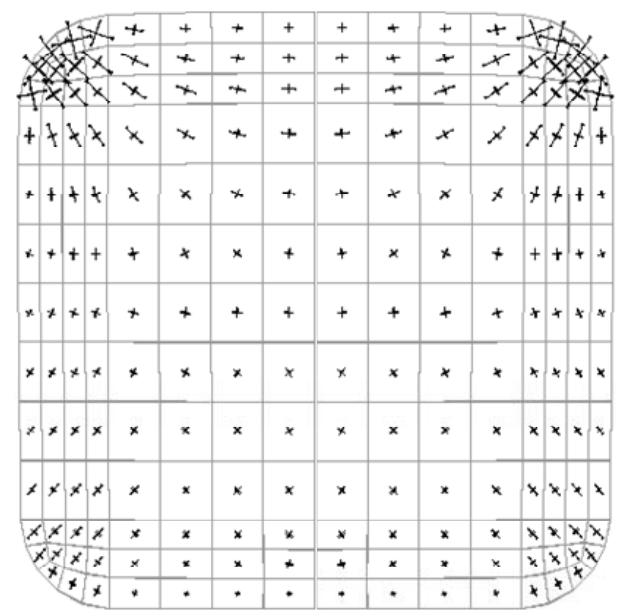

Pilar C18

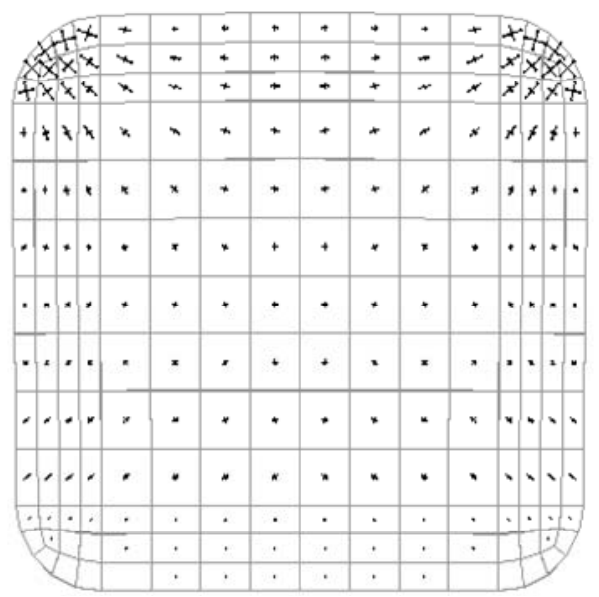

Figura 6.34 - Tensões principais no concreto confinado 

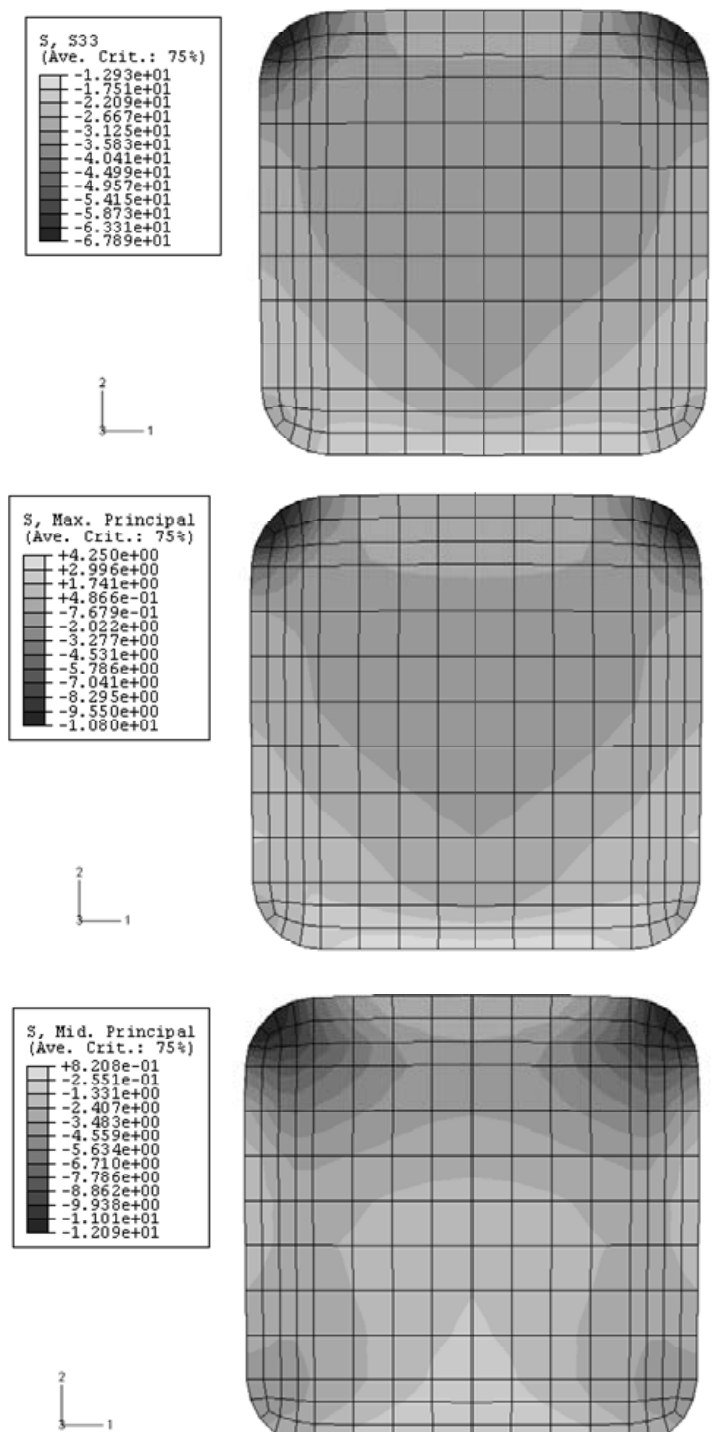
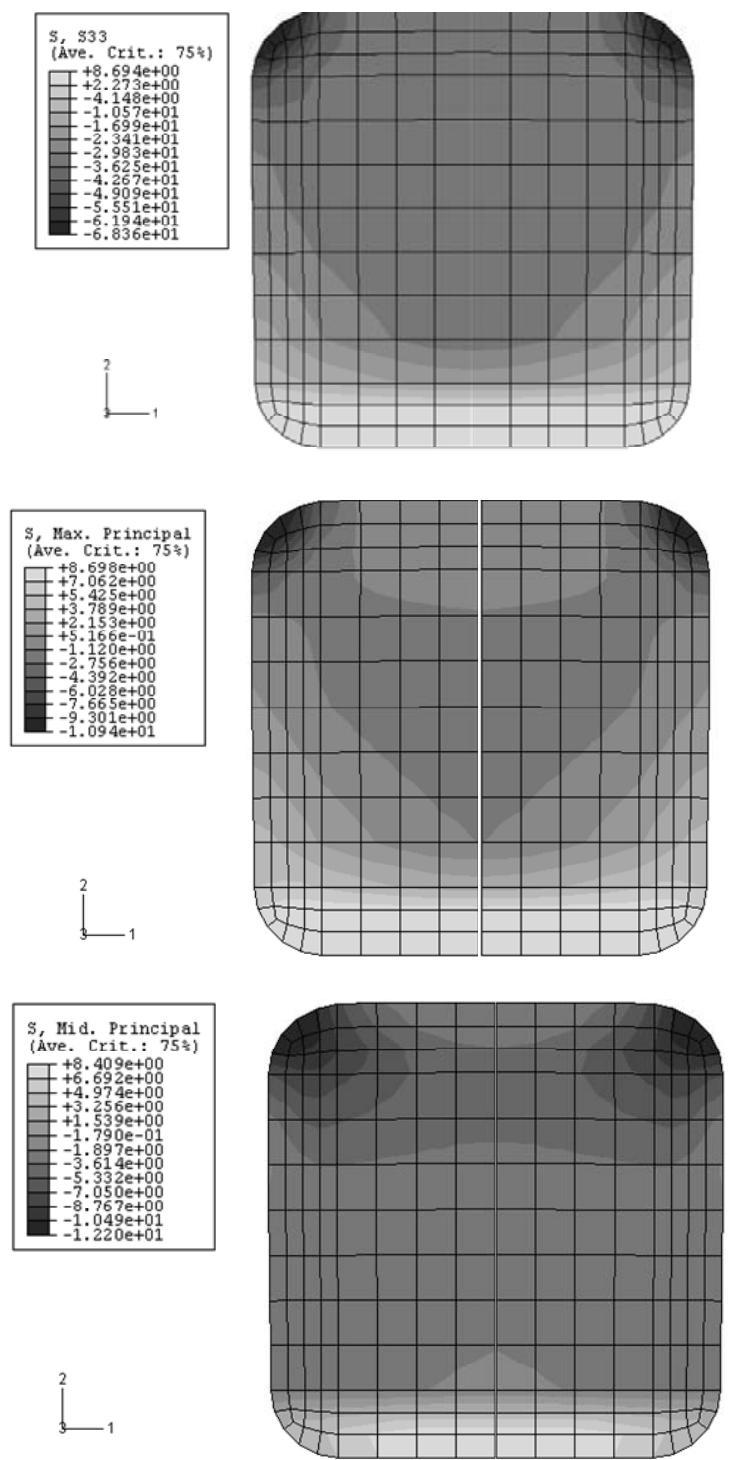

Figura 6.35 - Distribuição de tensões no concreto

\subsubsection{Limitações das análises da primeira etapa}

As simulações com pilares de seção circular forneceram bons resultados em temos de ganho de resistência, já que haviam dados experimentais adequados para uma boa calibração. Observou-se que para obter uma boa correlação de capacidade resistente entre resultados numéricos e experimentais foi necessário conhecer a resistência à tração da camisa na direção das fibras e o coeficiente $k_{1}$, que relaciona o ganho de resistência axial à pressão lateral aplicada. Estas propriedades foram obtidas a partir de ensaios.

No entanto, em relação à deformabilidade, pode-se dizer que o critério de plastificação utilizado para $\mathrm{o}$ concreto não representou adequadamente $\mathrm{o}$ 
comportamento do concreto confinado para todas as intensidades de pressão lateral. No caso de pilares com camisas pouco rígidas as simulações forneceram resultados exagerados de ganho de deformação última, enquanto para camisas rígidas (de maior espessura) os resultados subestimaram o ganho de deformação última.

Nas simulações com pilares quadrados ocorreram estimativas exageradas do ganho de resistência e de deformação última do concreto confinado. Observou-se que este erro se deve, em grande parte, a uma imprecisão dos modelos numéricos em representar o comportamento do concreto nas regiões pouco confinadas. Estas regiões ocorreram próximo às faces laterais dos pilares, onde a camisa é retilínea e oferece uma restrição lateral muito pequena. Nestas regiões ocorrem estados de tensão de compressão biaxial, já que uma das componentes de tensão é nula. Conseqüentemente, como o critério não foi calibrado de modo a representar o ganho de resistência e a deformabilidade do concreto em estados biaxiais, o comportamento numérico foi divergente do experimental.

Outra limitação do modelo empregado foi $\mathrm{o}$ fato deste apresentar comportamento elasto-plástico perfeito. Observou-se que, em situações de nível elevado de confinamento com PRF, com pressões laterais aproximadamente uniformes, isto não representa uma imprecisão. Porém, nos casos em que as pressões laterais são muito baixas ou o confinamento é pouco efetivo, o modelo não representa adequadamente as regiões pouco confinadas.

\subsection{Segunda etapa das simulações}

Nesta etapa da pesquisa foi desenvolvida uma sub-rotina UMAT no programa de elementos finitos ABAQUS $^{\circledR}$ versão 6.2 para representar o modelo constitutivo de GRASSL et al. (2002). Foram feitas algumas contribuições para complementar o modelo e então este foi utilizado em análises paramétricas do concreto confinado com PRFC. O código da sub-rotina foi desenvolvido em FORTRAN e é apresentado no apêndice I.

\subsubsection{Modelo de Grassl et al. (2002)}

A função de plastificação é dada por:

$$
f=(\sqrt{1,5} \rho)^{2}+q_{h}(k) \cdot m\left[\frac{\rho}{\sqrt{6}} \cdot r(\theta, e)+\frac{\xi}{\sqrt{3}}\right]-q_{h}(k) \cdot q_{s}(k) \leq 0
$$

onde: 


$$
m=3 \frac{f_{c}^{2}-f_{t}^{2}}{f_{c} f_{t}} \frac{e}{e+1}
$$

e:

- $\mathrm{f}_{\mathrm{c}}=$ resistência à compressão do concreto;

- $\mathrm{f}_{\mathrm{t}}=$ resistência à tração do concreto;

- $\mathrm{e}=$ excentricidade da função de plastificação na seção desviadora.

Como a relação entre a resistência à compressão e tração pode ser considerada da ordem de 10 para o concreto de resistência usual, a excentricidade pode ser calculada como:

$$
e=0,125\left(\frac{f_{b c}}{f_{c}}\right)+0,375
$$

$\mathrm{Na}$ falta de dados experimentais, a relação entre a resistência no estado de compressão biaxial igual e a resistência à compressão uniaxial $\left(f_{b c} / f_{c}\right)$ pode ser estimada como 1,16, o que implica em e $=0,52$.

A dependência em relação ao ângulo de Lode é dada por:

$$
r(\theta, e)=\frac{4\left(1-e^{2}\right) \cos ^{2} \theta+(2 e-1)^{2}}{2\left(1-e^{2}\right) \cos \theta+(2 e-1)\left[4\left(1-e^{2}\right) \cos ^{2} \theta+5 e^{2}-4 e\right]^{1 / 2}}
$$

onde:

- $\quad \theta$ = ângulo de Lode;

- $\rho=$ tensão desviadora;

- $\xi=$ tensão hidrostática.

O potencial plástico é dado por:

$$
g=-A\left(\frac{\rho}{\sqrt{q(k)}}\right)^{2}-B \frac{\rho}{\sqrt{q(k)}}+\frac{\xi}{\sqrt{q(k)}}=0
$$

O parâmetro de encruamento é a deformação plástica volumétrica (k). A função de encruamento é dividida em duas partes: ascendente e descendente. No trecho ascendente $\mathrm{q}_{\mathrm{s}}=1$, ao passo que, no trecho descendente $\mathrm{q}_{\mathrm{h}}=1$ :

$$
q(k)=q_{h}(k) \cdot q_{s}(k)
$$




\subsubsection{Contribuições ao modelo}

A primeira contribuição ao modelo de GRASSL et al. (2002) foi a elaboração de uma nova função de encruamento. Esta função de encruamento, por sua vez, foi dividida em duas funções, uma para o trecho ascendente e outra para o descendente.

A função de encruamento para o trecho ascendente é dada por uma equação racional da seguinte forma:

$$
q_{h}(k)=\sigma_{c r}+\frac{\left[1-\sigma_{c r}\right] \cdot r \cdot k}{r-1+k^{r}} ; \quad q_{s}(k)=1
$$

onde:

- $\sigma_{\mathrm{cr}}=$ é denominado tensão crítica. Para compressão uniaxial este parâmetro vale o quadrado da tensão axial normalizada $\left(\sigma_{c} / f_{c}\right)$ que define o fim do regime elástico;

- $\mathrm{k}=$ parâmetro de encruamento normalizado $\left(\varepsilon_{\mathrm{pv}} / \varepsilon_{\mathrm{pvo}}\right)$;

- $\varepsilon_{\mathrm{pv}}=$ deformação plástica volumétrica;

- $\varepsilon_{\mathrm{pvo}}=$ deformação plástica volumétrica referente à tensão de pico do concreto sob compressão uniaxial;

- $r=\frac{E_{1}}{E_{1}-E_{2}}$

- $\mathrm{E}_{1}=$ inclinação inicial da curva q x k;

- $E_{2}=1-\sigma_{c r}$;

Para o trecho descendente também foi utilizada uma equação racional:

$$
q_{h}(k)=1 ; \quad q_{s}(k)=\frac{C_{1}(k-1)^{2}+C_{2}(k-1)+C_{3}}{(k-1)^{2}+C_{2}(k-1)+C_{3}}
$$

onde $\mathrm{C}_{1}, \mathrm{C}_{2}$ e $\mathrm{C}_{3}$ são as constantes a ser definidas com base nos resultados de ensaios.

As constantes foram calibradas para representar o comportamento do concreto sob compressão uniaxial, apresentando uma boa correspondência com a curva experimental, como indica a Figura 6.36. 


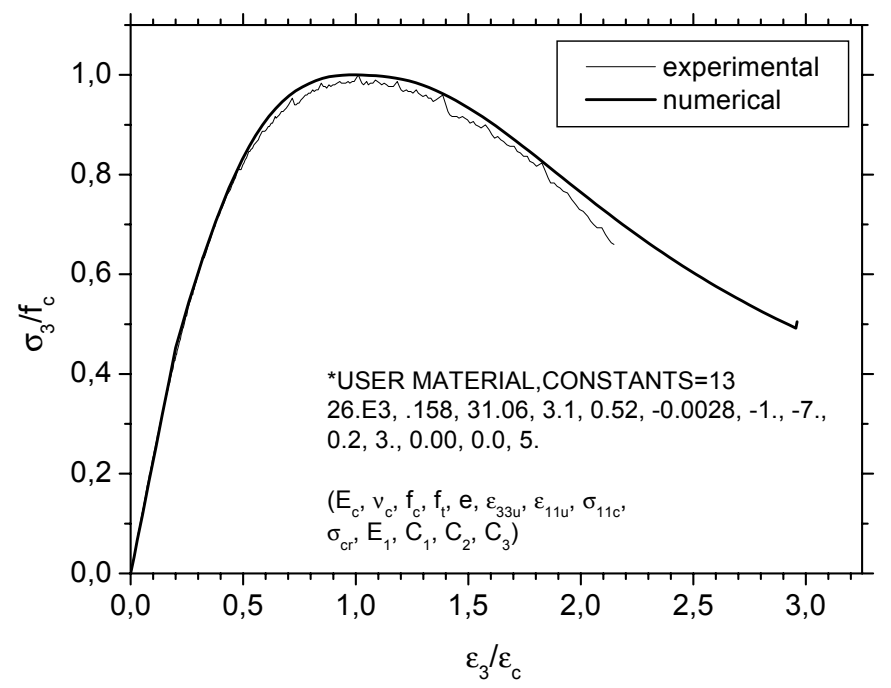

Figura 6.36 - Comparação entre resultados experimentais e numéricos no caso de compressão uniaxial

\subsubsection{Escolha dos parâmetros da sub-rotina}

Para definição completa do comportamento do material é necessária a entrada de 13 parâmetros, sendo estes:

- $\quad \mathrm{E}_{\mathrm{c}}=$ módulo de elasticidade do concreto;

- $\quad v_{\mathrm{c}}=$ coeficiente de Poisson do concreto;

- $\mathrm{f}_{\mathrm{c}}=$ resistência à compressão uniaxial do concreto (valor positivo);

- $\mathrm{f}_{\mathrm{t}}=$ resistência à tração do concreto;

- $\mathrm{e}=$ excentricidade da função de plastificação;

- $\varepsilon_{\mathrm{c}}=$ deformação axial de pico do concreto sob compressão uniaxial;

- option $1=\left\{\begin{array}{l}\text { deformação lateral de pico sob compressão uniaxial } \\ -1: \text { para adotar deformação volumétrica nula de pico }\end{array} ;\right.$

- $\sigma_{11}=$ pressão lateral para um estado de confinamento uniforme;

- $\sigma_{\mathrm{cr}}=$ é a tensão crítica;

- $\mathrm{E}_{1}=$ inclinação inicial da curva $\mathrm{q} \times \mathrm{k}$;

- $\mathrm{C}_{1}, \mathrm{C}_{2}, \mathrm{C}_{3}=$ parâmetros da curva da função de encruamento.

É necessário definir as tensões e deformações de pico em um ensaio de confinamento com pressão lateral uniforme. $\mathrm{Na}$ sub-rotina, é necessária apenas a escolha da pressão lateral, sendo as demais variáveis automaticamente calculadas. A própria função de plastificação foi utilizada para calcular a tensão axial de pico para a 
pressão lateral escolhida. A deformação axial de pico foi calculada utilizando a equação de CANDAPPA et al. (2001), dada pela equação da (6.23):

$$
\frac{\varepsilon_{c c}}{\varepsilon_{c c}}=1+20 \cdot \frac{f_{l}}{f_{c o}}
$$

\subsubsection{Validação da sub-rotina}

Antes da comparação entre resultados numéricos e experimentais julgou-se necessária a comparação entre os resultados numéricos obtidos com a presente subrotina e os apresentados por GRASSL et al. (2002) na sua implementação original. Na Figura 6.37 são apresentados os resultados das simulações de ensaios de compressão uniaxial (à esquerda) e confinamento ativo (à direita). Pode-se observar uma boa concordância entre os resultados apresentados, considerando ainda que existe uma diferença na função de encruamento aqui proposta e as curvas inicialmente adotadas por GRASSL et al. (2002). Nas presentes simulações foram considerados: $f_{c}=47,4 \mathrm{MPa}, \mathrm{f}_{\mathrm{t}}$ $=4,74 \mathrm{MPa}, \mathrm{e}=0,52, \mathrm{E}_{\mathrm{c}}=30 \mathrm{GPa}, \mathrm{v}=0,15, \varepsilon_{33 \mathrm{u}}=-2,13 \times 10^{-3}, \varepsilon_{11 \mathrm{u}}=1,065 \times 10^{-3}, \mathrm{f}_{\mathrm{l}}=-8,6$ $\mathrm{MPa}, \sigma_{33 \mathrm{c}}=-88,7 \mathrm{MPa}$ e $\varepsilon_{33 \mathrm{c}}=-17,6 \times 10^{-3}$.
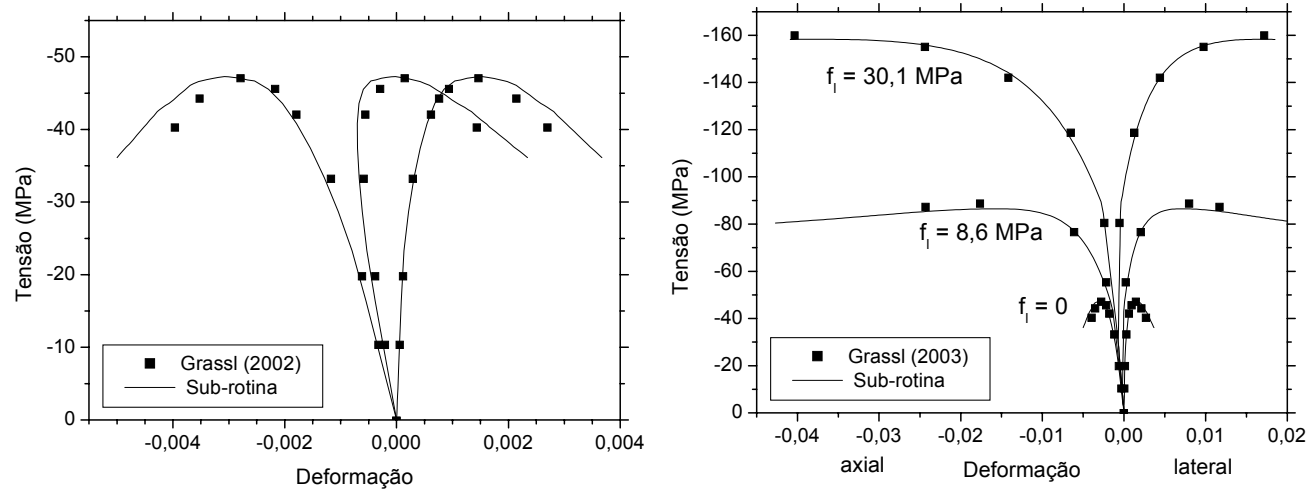

Figura 6.37 - Comparação entre resultados obtidos com a sub-rotina e os apresentados por GRASSL et al. (2002)

\subsubsection{Comparação com resultados experimentais}

Foi simulado numericamente o ensaio de compressão uniaxial do concreto de AIRE UNTIVEROS (2002). Este foi escolhido por apresentar uma boa descrição dos procedimentos de ensaio e as curvas tensão x deformação axial e lateral até boa parte do trecho pós-pico. Foram utilizados: $\mathrm{f}_{\mathrm{c}}=41,46 \mathrm{MPa}, \mathrm{f}_{\mathrm{t}}=4,15 \mathrm{MPa}, \mathrm{e}=0,52, \mathrm{E}_{\mathrm{c}}=26 \mathrm{GPa}$, 
$v=0,158, \varepsilon_{33 \mathrm{u}}=-2,2 \times 10^{-3}, \varepsilon_{11 \mathrm{u}}=6,75 \times 10^{-4}, \mathrm{f}_{\mathrm{l}}=-7 \mathrm{MPa}, \sigma_{33 \mathrm{c}}=-70,1 \mathrm{MPa}$ e $\varepsilon_{33 \mathrm{c}}=-$ $12,32 \times 10^{-3}$.

Os parâmetros da função de encruamento foram inicialmente escolhidos de maneira a representar de maneira mais próxima possível a curva q x $\mathrm{k}$ experimental (ver Figura 6.38-a). No entanto, com estes parâmetros, a representação da deformação axial foi muito imprecisa no trecho descendente (curva a da Figura 6.38-b). Obteve-se uma melhor representação da deformação axial com a curva b, ajustada para otimizar o desempenho com relação à deformação axial.

Com isto pode-se concluir que não é possível a escolha de parâmetros para a função de encruamento que satisfaçam a ambos os comportamentos: axial e lateral no regime pós-pico. A relação entre as deformações axiais e laterais não é adequada para o regime pós-pico, logo esta limitação se deve ao potencial plástico empregado neste modelo.

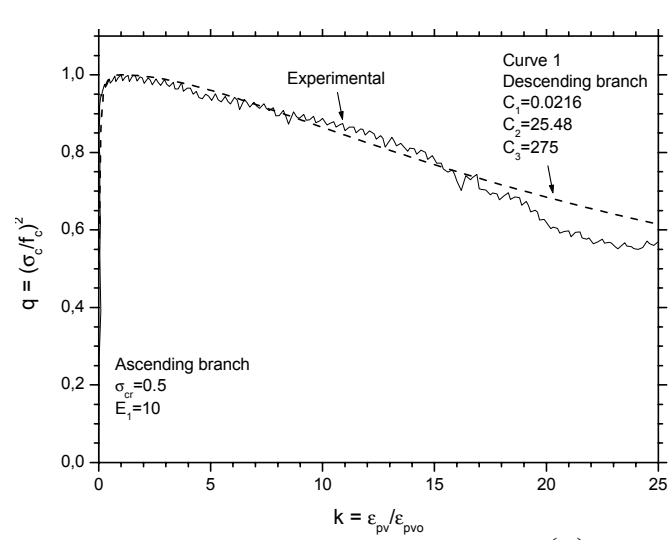

(a)

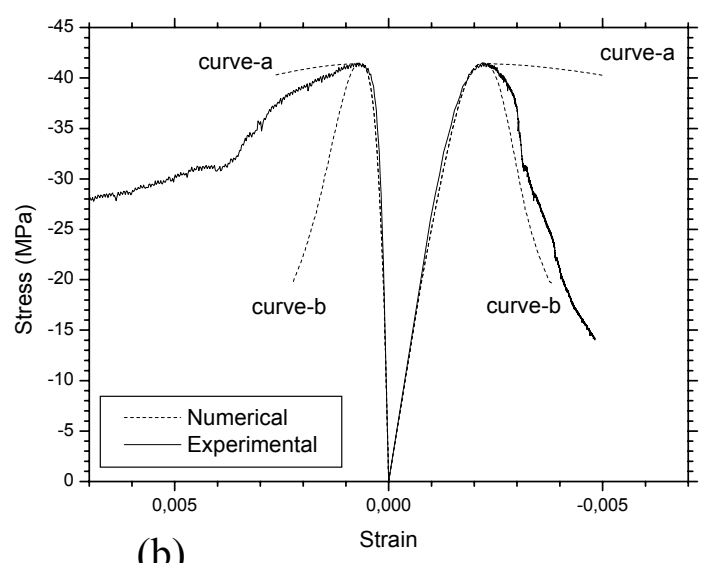

(b)

Curve a: $\sigma_{\mathrm{cr}}=0.2 ; \mathrm{E}_{1}=3 ; \mathrm{C}_{1}=0.022 ; \mathrm{C}_{2}=25.5 ; \mathrm{C}_{3}=275$

Curve b: $\sigma_{\mathrm{cr}}=0.2 ; \mathrm{E}_{1}=3 ; \mathrm{C}_{1}=0 ; \mathrm{C}_{2}=0 ; \mathrm{C}_{3}=5$

Figura 6.38 - Comparação com os resultados experimentais de AIRE UNTIVEROS (2002)

para o caso de compressão uniaxial

A principal diferença entre os resultados numéricos e experimentais pode ser explicada por meio da taxa de dilatação lateral. O modelo numérico previu um comportamento em que esta variável se estabilizava no valor de 0,73. Mas o comportamento experimental se mostra bem distinto após uma deformação axial de 0,002. Ou seja, após atingida a tensão de pico, a taxa de dilatação experimental aumentou significativamente, enquanto a numérica permaneceu praticamente constante. 
Esta expansão significativa está associada à grande fissuração do concreto que se desenvolve e não pode ser prevista adequadamente pelo presente modelo.

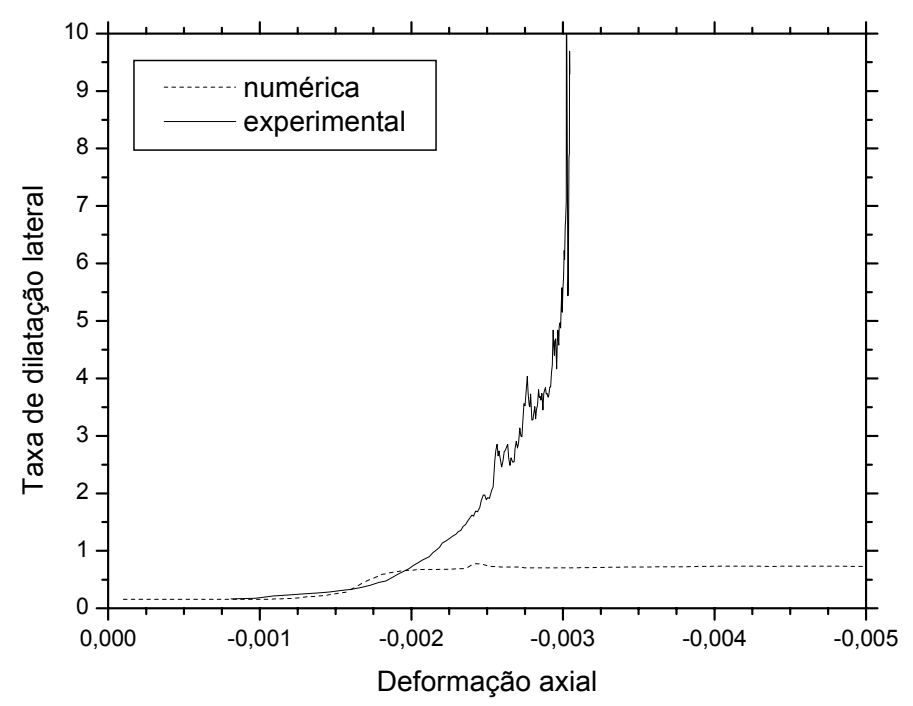

Figura 6.39 - Taxa de dilatação lateral numérica x experimental

Mesmo com estas limitações na direção lateral durante o regime pós-pico, o modelo pode representar adequadamente a resposta axial para o confinamento ativo e o comportamento axial e lateral no confinamento passivo com PRF, como discutido a seguir.

Foram simulados os ensaios de corpos-de-prova de concreto encamisados com PRFC da presente pesquisa. Estes corpos-de-prova possuíam dimensões de 15 x $30 \mathrm{~cm}$ (diâmetro x altura). Na Figura 6.40 são apresentados os diagramas tensão x deformação axial e lateral. Pode-se observar uma boa correspondência entre os valores experimentais e numéricos. Deve-se observar ainda que os resultados experimentais de deformação axial foram obtidos a partir de leituras com transdutores entre pratos da máquina de ensaio, o que alterou a rigidez inicial, por causa das acomodações. 


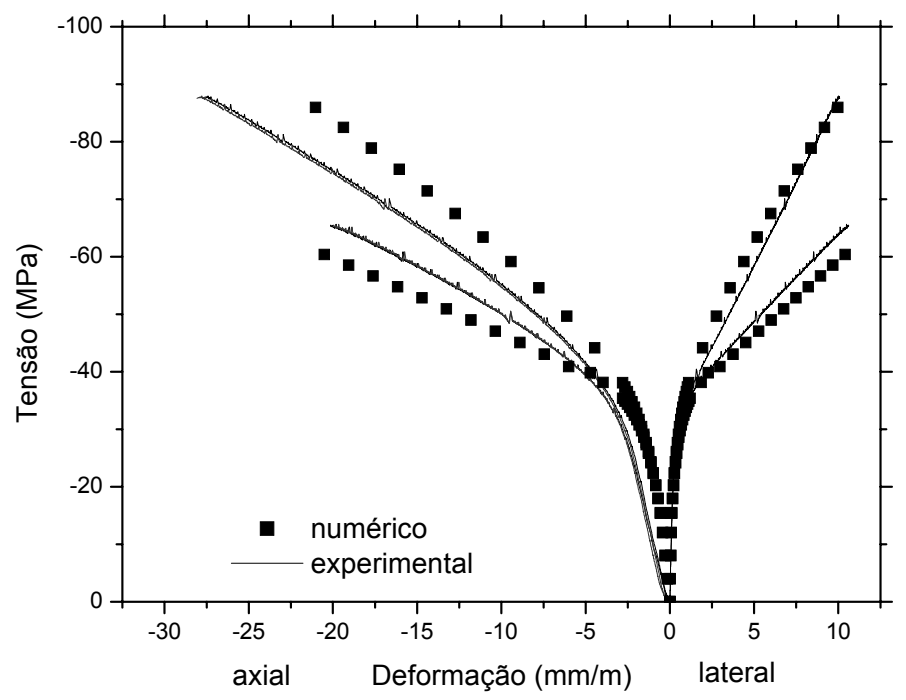

Figura 6.40 - Comparação entre resultados numéricos e experimentais para corpos de prova confinados com PRFC

\subsubsection{Escolha dos parâmetros do potencial plástico}

GRASSL et al. (2002) assumiu a validade da hipótese de PANTAZOUPOULOU (1995) de que a deformação volumétrica próxima à ruína do concreto sob compressão uniaxial é nula. Com isto, o cálculo dos parâmetros $\mathrm{A}$ e $\mathrm{B}$ do potencial plástico foi sugerido com base nesta hipótese.

No entanto, observações de ensaios de diversos autores mostram que a deformação volumétrica na ruptura não é necessariamente nula, como indica a Figura 6.41. Pode-se observar que as deformações volumétricas na ruptura variaram entre $1 / 1000$ e 1/1000. Esta variação pode ser atribuída a diferentes propriedades dos concretos utilizados, forma e tamanho dos corpos-de-prova e instrumentação utilizada nestes experimentos. 


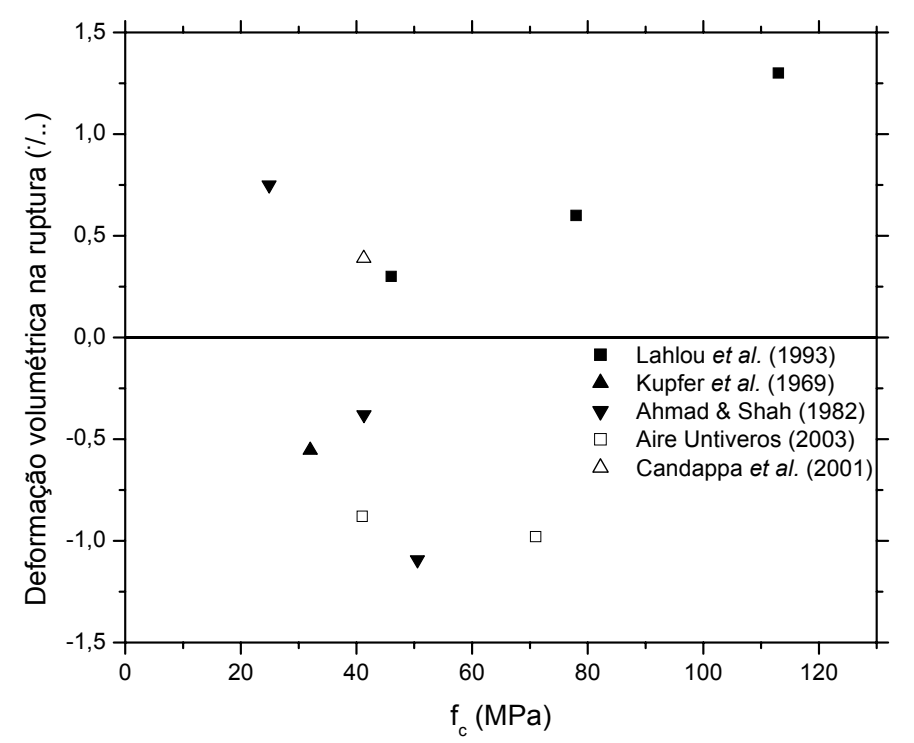

Figura 6.41 - Deformação volumétrica na eminência da ruptura do concreto

Para verificar a influência da deformação volumétrica na eminência da ruptura do concreto sobre os resultados das simulações, foram realizadas simulações com três valores distintos para a deformação volumétrica de pico: -0,001, 0 e 0,001. Foram adotados ainda $\mathrm{f}_{\mathrm{c}}=41,46 \mathrm{MPa}, \mathrm{f}_{\mathrm{t}}=4,15 \mathrm{MPa}, \mathrm{e}=0,52, \mathrm{E}_{\mathrm{c}}=26 \mathrm{GPa}, v=0,158, \varepsilon_{33 \mathrm{u}}=$ $2,2 \times 10^{-3}, \varepsilon_{11 \mathrm{u}}=6,75 \times 10^{-4}, \mathrm{f}_{1}=-7 \mathrm{MPa}, \sigma_{33 \mathrm{c}}=-70,1 \mathrm{MPa}$ e $\varepsilon_{33 \mathrm{c}}=-12,32 \times 10^{-3}$.

Pode-se observar na Figura 6.42 que é possível escolher os parâmetros do potencial plástico de maneira a manter a deformação axial de pico e alterar somente a deformação lateral de pico. Com isto apenas o comportamento quanto às deformações lateral e volumétrica é alterado.

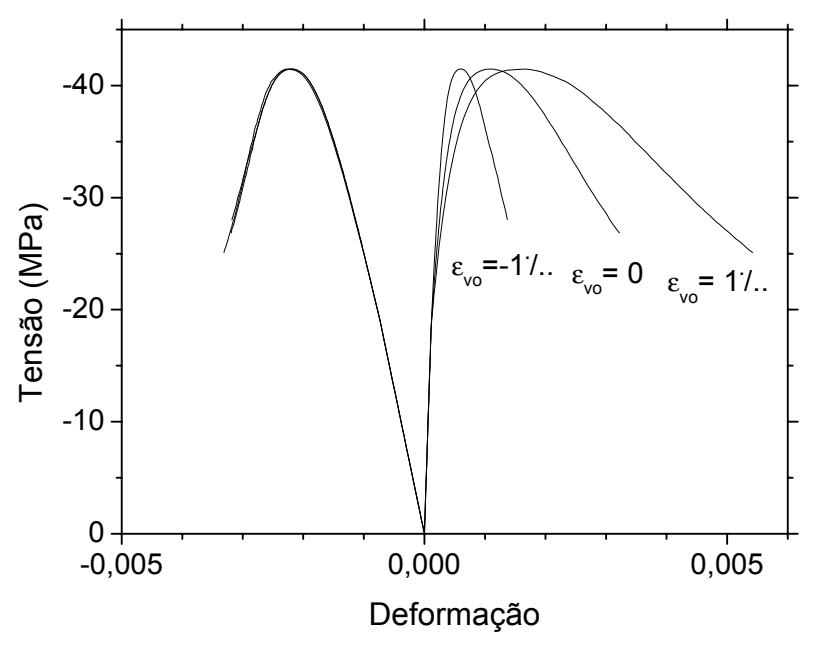

Figura 6.42 - Influência da deformação volumétrica de pico 
Foi possível observar que, neste caso, com uma deformação volumétrica de pico de 1/1000 os resultados teóricos e experimentais foram mais próximos do que os obtidos anteriormente. Logo, é possível a utilização deste modelo assumindo, ao invés de uma deformação volumétrica de pico nula, um valor que otimize a resposta axial e lateral.

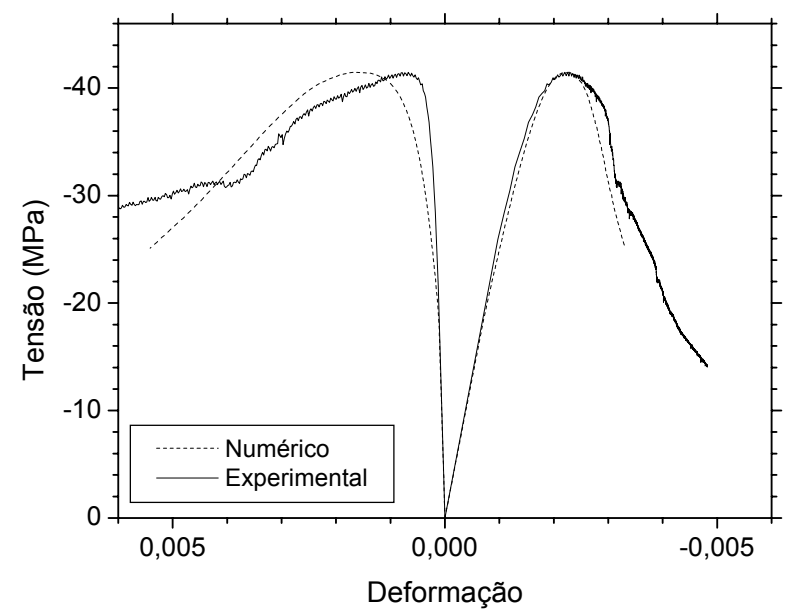

Figura 6.43 - Comparação entre resultados numéricos e experimentais considerando uma expansão volumétrica de pico

Foi possível observar ainda que, nas simulações de pilares encamisados com PRFC, a utilização de $\varepsilon_{\mathrm{vo}}$ maior ou menor que zero não altera significativamente os resultados nos pilares bem confinados, sendo esta diferença mais sensível para situações de baixo confinamento. Foi considerada uma camisa com espessura de camada de 0,117 $\mathrm{mm}, \mathrm{E}_{\mathrm{f}}=204,3 \mathrm{GPa}$ e com uma deformação de ruptura arbitrada em 1\%.

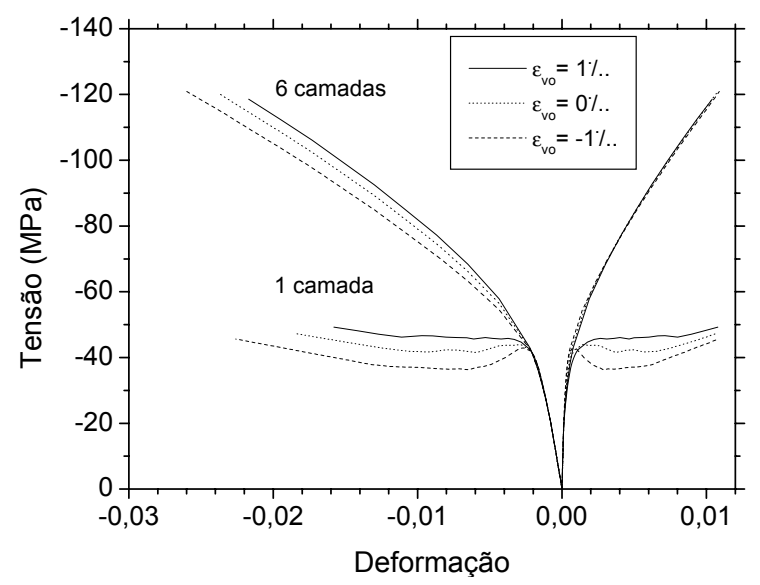

Figura 6.44 - Influência da escolha do parâmetro $\varepsilon_{\mathrm{vo}}$ 


\subsection{Análises paramétricas}

Considerando a boa representatividade do modelo numérico desenvolvido na sub-rotina com relação ao comportamento experimental, foram desenvolvidas análises paramétricas para complementar os resultados obtidos na análise experimental e avaliar ainda alguns aspectos adicionais ainda não avaliados experimentalmente como a influência da protensão das fibras.

\subsubsection{Influência da protensão das fibras}

Foi realizada uma análise verificando a viabilidade do uso da protensão das fibras para melhorar o efeito de confinamento. A protensão das fibras foi simulada atribuindo um coeficiente de dilatação térmica para as fibras e então aplicando uma variação de temperatura negativa. Com isto as fibras se contraíram comprimindo o concreto. Após esta fase de protensão superpôs-se um carregamento de compressão axial, simulando o ensaio do pilar. O estudo foi realizado com pilares de seção circular $\operatorname{com} \mathrm{f}_{\mathrm{c}}=42 \mathrm{MPa}$ e $\varepsilon_{\mathrm{c}}=0,00239$.

O índice de protensão foi definido como a porcentagem da deformação última $\left(\varepsilon_{\mathrm{fu}}\right)$ aplicada. Foi atribuído às fibras $\varepsilon_{\mathrm{fu}}=10.5 \mathrm{~mm} / \mathrm{m}$, resultando numa tensão de ruptura de $2142 \mathrm{MPa}$. Na Tabela 6.2 e na Figura 6.45 são apresentados o ganho de resistência axial $\mathrm{f}_{\mathrm{cc}} / \mathrm{f}_{\mathrm{co}}$ e o aumento de ductilidade, representado por meio de $\varepsilon_{\mathrm{cc}} / \varepsilon_{\mathrm{co}}$.

Tabela 6.2 - Influência da protensão das fibras em pilares de seção circular encamisados com PRFC

\begin{tabular}{ccccc}
\hline Tipo & $\mathbf{n}$ & Protensão & $\mathbf{f}_{\mathbf{c c}} / \mathbf{f}_{\mathbf{c o}}$ & $\boldsymbol{\varepsilon}_{\mathbf{c c}} / \boldsymbol{\varepsilon}_{\mathbf{c o}}$ \\
\hline PRFC & 1 & $0 \%$ & 1,20 & 6,24 \\
PRFC & 1 & $20 \%$ & 1,30 & 5,64 \\
PRFC & 1 & $40 \%$ & 1,39 & 4,49 \\
PRFC & 1 & $60 \%$ & 1,42 & 3,34 \\
PRFC & 1 & $80 \%$ & 1,34 & 1,95 \\
\hline
\end{tabular}

\begin{tabular}{ccccc}
\hline Tipo & $\mathbf{n}$ & Protensão & $\mathbf{f}_{\mathbf{c c}} / \mathbf{f}_{\mathbf{c o}}$ & $\boldsymbol{\varepsilon}_{\mathbf{c c}} / \boldsymbol{\varepsilon}_{\mathbf{c o}}$ \\
\hline PRFC & 3 & $0 \%$ & 2,03 & 8,22 \\
PRFC & 3 & $20 \%$ & 2,09 & 7,04 \\
PRFC & 3 & $40 \%$ & 2,08 & 5,54 \\
PRFC & 3 & $60 \%$ & 2,01 & 4,05 \\
PRFC & 3 & $80 \%$ & 1,71 & 2,28 \\
\hline
\end{tabular}

\begin{tabular}{ccccc}
\hline Tipo & $\mathbf{n}$ & Protensão & $\mathbf{f}_{\mathbf{c c}} / \mathbf{f}_{\mathbf{c o}}$ & $\boldsymbol{\varepsilon}_{\mathbf{c c}} / \boldsymbol{\varepsilon}_{\mathbf{c o}}$ \\
\hline PRFC & 6 & $0 \%$ & 2,87 & 9,12 \\
PRFC & 6 & $20 \%$ & 2,89 & 7,95 \\
PRFC & 6 & $40 \%$ & 2,83 & 6,29 \\
PRFC & 6 & $60 \%$ & 2,58 & 4,31 \\
PRFC & 6 & $80 \%$ & 2,23 & 2,66 \\
\hline
\end{tabular}



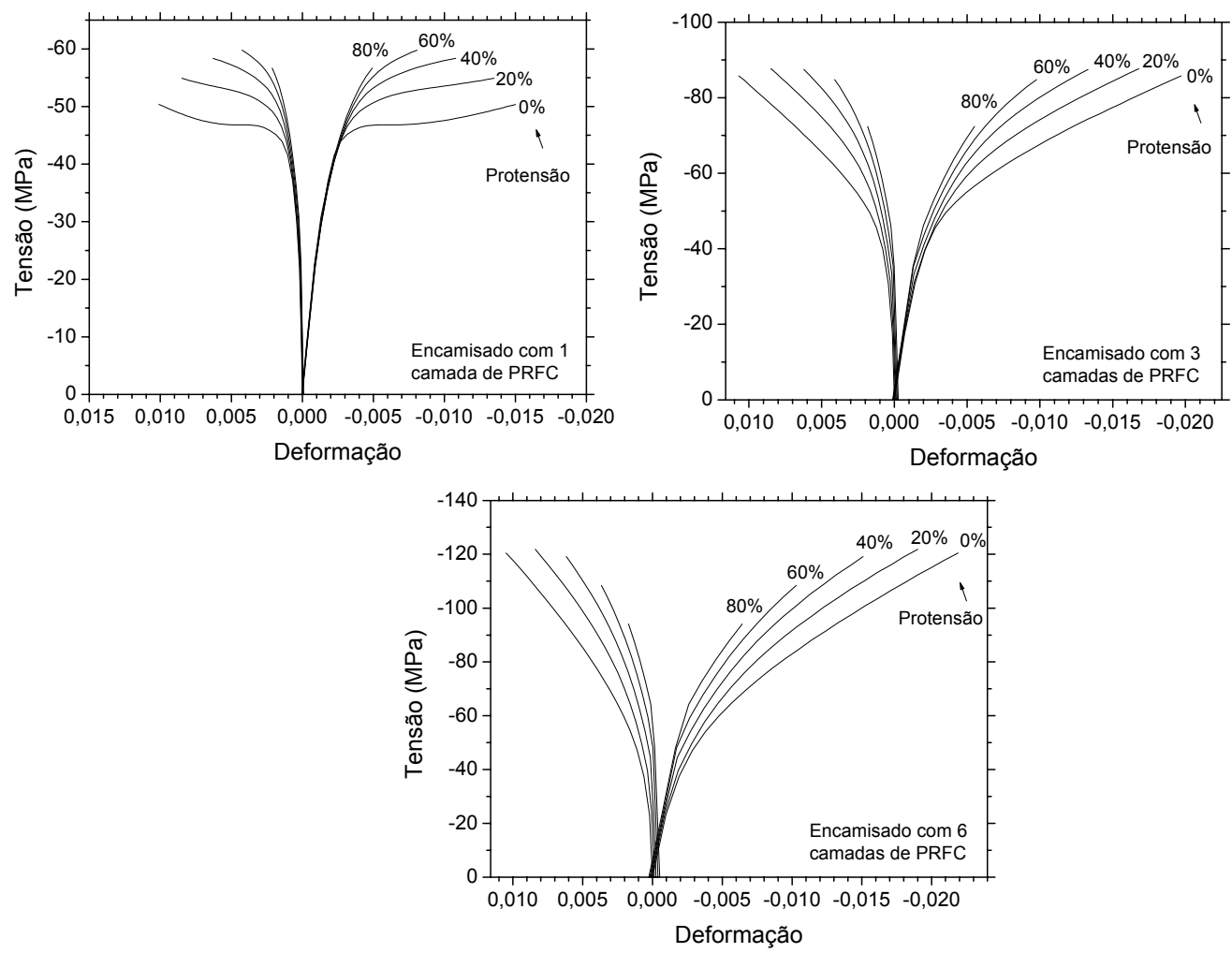

Figura 6.45 - Efeito da protensão das fibras em pilares encamisados com PRFC

Pode-se observar que aumentando a porcentagem de protensão ocorreu uma redução da ductilidade do pilar, representada por meio da variável $\varepsilon_{\mathrm{cc}} / \varepsilon_{\mathrm{co}}$. Logo, quando o objetivo do encamisamento é aumentar a ductilidade do pilar, a protensão deve ser evitada.

No entanto, a protensão proporcionou aumentos de resistência, principalmente em pilares com baixo índice de confinamento. Por exemplo, no pilar com 1 camada de fibras de carbono, a utilização da protensão trouxe aumentos de resistência significativos até um índice de protensão de 60\%. Isto significa que neste caso, com 1 camada de fibras de carbono pode ser interessante utilizar as fibras com uma protensão de 20 a 40\%, pois assim o ganho de resistência seria maior do que sem protensão, proporcionando ainda aumento de ductilidade considerável. Com $80 \%$ de protensão, no entanto, os pilares com 1 camada sofreram ruptura prematura, não aproveitando totalmente a resistência da camisa para promover o confinamento.

Já no caso de confinamento moderado $(n=3)$ e elevado $(n=6)$, aparentemente não houve vantagens na utilização da protensão, pois não ocorreram aumentos significativos de resistência com a protensão e a ductilidade diminuiu. Novamente, observou-se rupturas prematuras da camisa com a protensão de $80 \%$. 
Uma vantagem da protensão é antecipar o ganho de resistência do concreto confinado, sendo isto adequado para estruturas cujos pilares não podem sofrer grandes deformações em serviço.

Outro aspecto a ser considerado, quando da utilização da protensão, é a possibilidade de ruptura sob ação de carga de longa duração. Sabe-se que determinados tipos de fibras possuem resistência reduzida sob ações de longa duração, principalmente a fibra de vidro. A protensão faz com que uma maior parcela de carga seja mantida ao longo do tempo, tornando o pilar encamisado mais suscetível a problemas desta natureza.

\subsubsection{Influência do tipo de fibras utilizado}

Este estudo foi realizado com um concreto de propriedades fixas e diferentes tipos de fibras, conforme Tabela 6.3. Considerou-se uma espessura constante dos tecidos de $0,13 \mathrm{~mm}$ e então foram realizadas as simulações de corpos-de-prova cilíndricos de concreto de 15 x $30 \mathrm{~cm}$ (diâmetro x altura) com número de camadas igual a 1, 3 e 6. Assim foi possível avaliar os efeitos de confinamento com uma pressão lateral baixa, moderada e elevada, para cada tipo de fibras. Ao concreto foi atribuída uma resistência de $42 \mathrm{MPa}$ e uma deformação de pico de $2,3 \mathrm{~mm} / \mathrm{m}$.

Tabela 6.3 - Tipos de fibras utilizadas nas análises

\begin{tabular}{ccccccc}
\hline Fibra & & $\begin{array}{c}\mathrm{E}_{\mathrm{f}} \\
\mathrm{GPa}\end{array}$ & $\begin{array}{c}\varepsilon_{\mathrm{fu}} \\
\mathrm{mm} / \mathrm{m}\end{array}$ & $\begin{array}{c}\varepsilon_{\mathrm{fu}, \mathrm{d}} \\
\mathrm{mm} / \mathrm{m}\end{array}$ & $\begin{array}{c}\sigma_{\mathrm{f}} \\
\mathrm{MPa}\end{array}$ & $\begin{array}{c}\sigma_{\mathrm{f}, \mathrm{d}} \\
\mathrm{MPa}\end{array}$ \\
\hline Carbono & $\mathrm{HS}$ & 220 & 15 & 12 & 3300 & 2640 \\
& UHS & 220 & 22 & 17,6 & 4840 & 3872 \\
& $\mathrm{HM}$ & 400 & 6,25 & 5 & 2500 & 2000 \\
Vidro & UHM & 600 & 3,66 & 2,928 & 2196 & 1756,8 \\
& $\mathrm{E}$ & 70 & 30 & 24 & 2100 & 1680 \\
Aramida & $\mathrm{S}$ & 90 & 50 & 40 & 4500 & 3600 \\
& $\mathrm{LM}$ & 70 & 50 & 40 & 3500 & 2800 \\
& $\mathrm{HM}$ & 120 & 30 & 24 & 3600 & 2880 \\
\hline
\end{tabular}

Os resultados obtidos, como a resistência do concreto confinado $\left(f_{c c}\right)$ e a deformação de pico do mesmo $\left(\varepsilon_{\mathrm{cc}}\right)$ são apresentados na Tabela 6.4. Além disso, são apresentados o ganho relativo de resistência $\left(\mathrm{f}_{\mathrm{cc}} / \mathrm{f}_{\mathrm{co}}\right)$ e o de deformação última $\left(\varepsilon_{\mathrm{cc}} / \varepsilon_{\mathrm{co}}\right)$. Considerou-se a ruptura como o momento em que a camisa atingiu a deformação convencional de ruptura $\varepsilon_{\mathrm{fu}, \mathrm{d}}$, obtida multiplicando-se a deformação última das fibras por 0,8 (coeficiente de redução médio considerado nestas simualações). 
Tabela 6.4 - Valores obtidos nas simulações numéricas do tipo de fibras

\begin{tabular}{|c|c|c|c|c|c|c|c|}
\hline Fibra & & $\mathrm{n}$ & $\mathrm{f}_{\mathrm{cc}}(\mathrm{MPa})$ & $\varepsilon_{\mathrm{cc}}(\%)$ & $\varepsilon_{\mathrm{fu}, \mathrm{d}}(\%)$ & $\mathrm{f}_{\mathrm{cc}} / \mathrm{f}_{\mathrm{co}}$ & $\varepsilon_{\mathrm{cc}} / \varepsilon_{\mathrm{co}}$ \\
\hline \multirow[t]{3}{*}{ Carbono } & $\mathrm{HS}$ & 1 & $-56,6$ & $-18,8$ & 12 & 1,35 & 8,17 \\
\hline & $\mathrm{HS}$ & 3 & $-98,4$ & $-22,8$ & 12 & 2,34 & 9,91 \\
\hline & HS & 6 & $-141,4$ & $-25,5$ & 12 & 3,37 & 11,09 \\
\hline \multirow[t]{3}{*}{ Carbono } & UHS & 1 & $-65,1$ & $-28,9$ & 17,6 & 1,55 & 12,57 \\
\hline & UHS & 3 & $-119,9$ & $-34,8$ & 17,6 & 2,85 & 15,13 \\
\hline & UHS & 6 & $-177,2$ & $-38,1$ & 17,6 & 4,22 & 16,57 \\
\hline \multirow[t]{3}{*}{ Carbono } & $\mathrm{HM}$ & 1 & $-59,8$ & $-8,7$ & 5 & 1,42 & 3,78 \\
\hline & $\mathrm{HM}$ & 3 & $-90,3$ & $-11,1$ & 5 & 2,15 & 4,83 \\
\hline & $\mathrm{HM}$ & 6 & $-125,8$ & $-13,3$ & 5 & 3,00 & 5,78 \\
\hline \multirow[t]{3}{*}{ Carbono } & UHM & 1 & $-59,1$ & $-5,8$ & 2,9 & 1,41 & 2,52 \\
\hline & UHM & 3 & $-82,5$ & $-7,3$ & 2,9 & 1,96 & 3,17 \\
\hline & UHM & 6 & $-115,6$ & $-9,2$ & 2,9 & 2,75 & 4,00 \\
\hline \multirow[t]{3}{*}{ Vidro } & $E$ & 1 & $-41,5$ & $-37,1$ & 24 & 0,99 & 16,13 \\
\hline & $E$ & 3 & -72 & $-41,0$ & 24 & 1,71 & 17,83 \\
\hline & $E$ & 6 & -102 & $-45,3$ & 24 & 2,43 & 19,70 \\
\hline \multirow[t]{3}{*}{ Vidro } & $S$ & 1 & $-58,4$ & $-68,8$ & 40 & 1,39 & 29,91 \\
\hline & $S$ & 3 & $-105,4$ & $-72,2$ & 40 & 2,51 & 31,39 \\
\hline & S & 6 & $-162,5$ & $-78,0$ & 40 & 3,87 & 33,91 \\
\hline \multirow[t]{3}{*}{ Aramida } & LM & 1 & $-50,8$ & $-68,2$ & 40 & 1,21 & 29,65 \\
\hline & LM & 3 & -96 & $-74,0$ & 40 & 2,29 & 32,17 \\
\hline & LM & 6 & $-139,4$ & $-78,8$ & 40 & 3,32 & 34,26 \\
\hline \multirow[t]{3}{*}{ Aramida } & $\mathrm{HM}$ & 1 & $-54,6$ & $-38,4$ & 24 & 1,30 & 16,70 \\
\hline & $\mathrm{HM}$ & 3 & $-97,4$ & $-44,1$ & 24 & 2,32 & 19,17 \\
\hline & $\mathrm{HM}$ & 6 & $-148,2$ & $-49,1$ & 24 & 3,53 & 21,35 \\
\hline
\end{tabular}

$\mathrm{Na}$ Figura 6.46 são apresentados os diagramas tensão $\mathrm{x}$ deformação axial de todos os pilares simulados nesta análise paramétrica. Pode-se observar que a forma dos diagramas tensão x deformação teve uma grande influência do tipo de fibras utilizado. Para dado número de camadas de PRF, a resistência final dependeu basicamente do valor da resistência à tração do PRF, enquanto a deformação última foi alterada significativamente pelo módulo de elasticidade do PRF e também pela sua deformação última. 

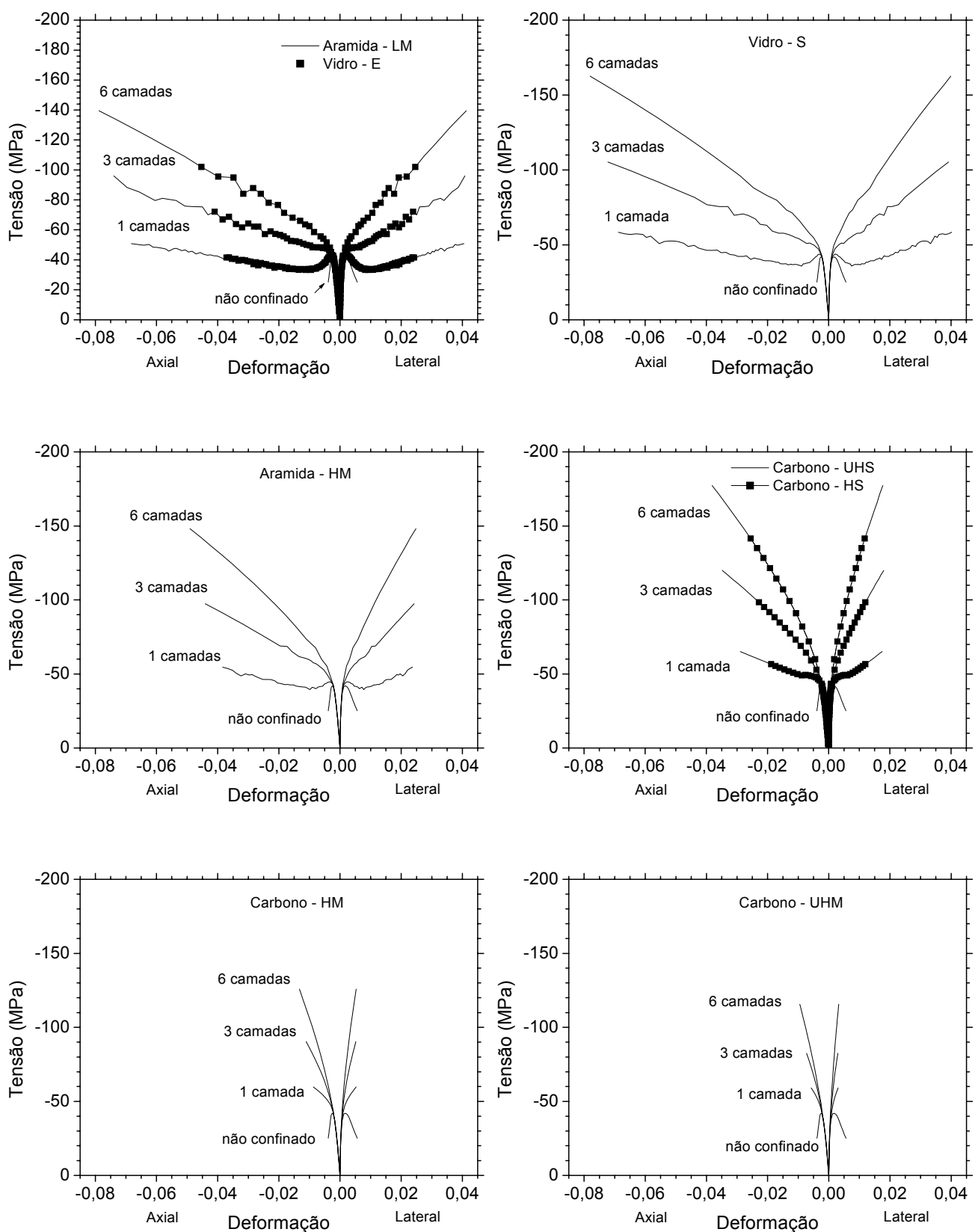

Figura 6.46 - Comparação do tipo de fibras utilizado sobre cilindros de concreto encamisados com PRF

\subsubsection{Calibração dos parâmetros para confinamento não uniforme}

Antes de iniciar os estudos paramétricos de confinamento não uniforme foi necessário calibrar as variáveis do modelo numérico. Foram assim simulados numericamente os ensaios de pilares de seção quadrada realizados por CARRAZEDO (2002). Estes pilares possuíam $15 \mathrm{~cm}$ de lado, com $3 \mathrm{~cm}$ de raio de arredondamento dos cantos. A resistência à compressão do concreto era de 23,57 $\mathrm{MPa}$, o módulo de elasticidade, a deformação última e a espessura das fibras por camada eram de 218,95 
GPa, 0,0119 e 0,13 mm, respectivamente. O pilar simulado foi o Q2, que possuía duas camadas de fibras de carbono. $\mathrm{O}$ melhor ajuste para representar o diagrama tensão $\mathrm{x}$ deformação axial e lateral experimental do concreto sob compressão uniaxial foi obtido com os parâmetros de "softening" de $\mathrm{C}_{1}=0, \mathrm{C}_{2}=0$ e $\mathrm{C}_{3}=50$, como indica a Figura 6.47.

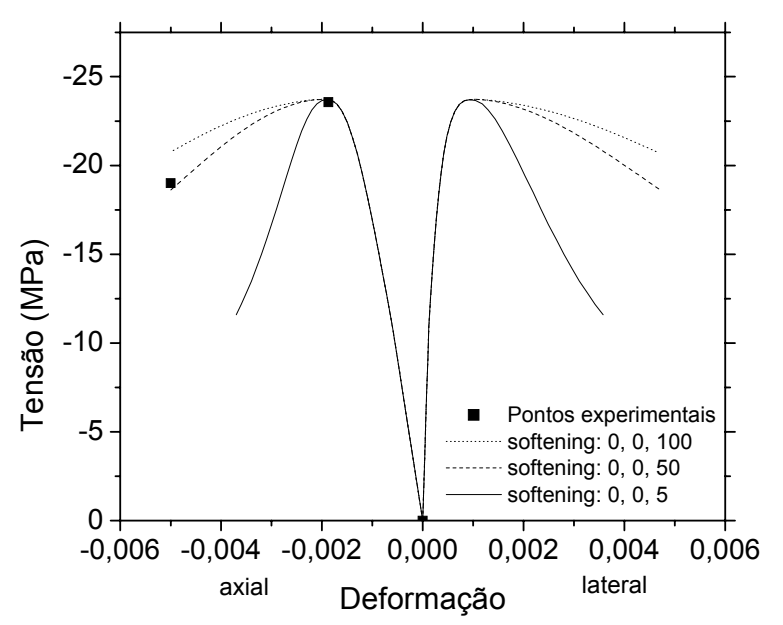

Figura 6.47 - Diagramas tensão x deformação

Nestas simulações observou-se que a modificação do diagrama tensão $\mathrm{x}$ deformação axial do concreto no trecho descendente tem uma importante influência no confinamento não uniforme, que ocorre no caso de pilares de seção quadrada. Isto ocorre porque algumas regiões destes pilares desenvolvem um diagrama tensão $\mathrm{x}$ deformação axial próximo do observado no ensaio de compressão uniaxial, enquanto em outras regiões o diagrama tensão $\mathrm{x}$ deformação é semelhante ao dos pilares circulares encamisados com PRF (bi-linear com um segundo trecho ascendente).

Definida a inclinação do trecho descendente uniaxial foi necessário definir a expansão lateral de pico. Para a escolha desta variável foram estipulados três valores, sendo um deles tal que a deformação volumétrica de pico seja nula (hipótese de PATAZOUPOULOU, 1995) e outros dois representando expansão volumétrica no pico de resistência. Na Figura 6.48 são apresentados os diagramas tensão x deformação do concreto com os diferentes valores de deformação lateral de pico. 


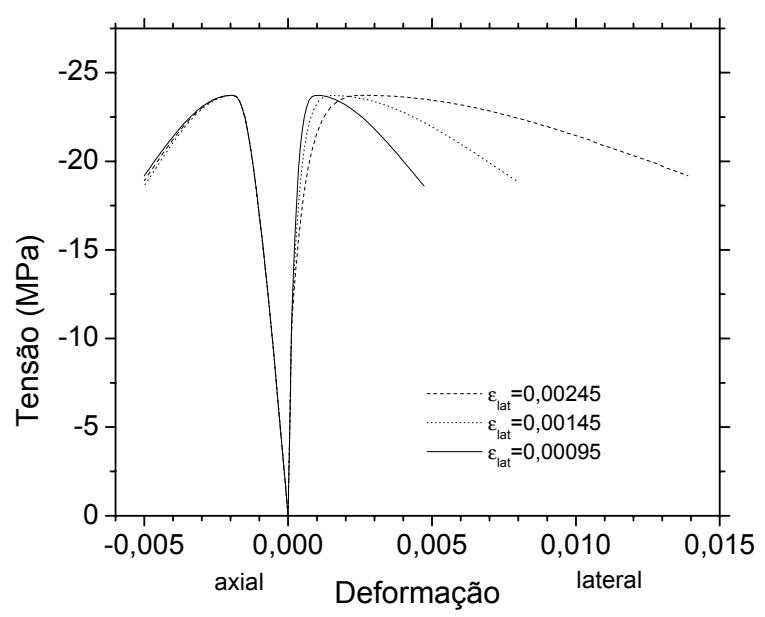

Figura 6.48 - Influência da deformação lateral de pico sobre

o diagrama tensão $x$ deformação uniaxial do concreto

Na Figura 6.49 são apresentados os diagramas força $\mathrm{x}$ deslocamento axial dos pilares ensaiados por CARRAZEDO (2002) e os resultados das simulações com os diferentes valores de deformação lateral de pico. Pode-se observar que aumentando a deformação lateral de pico do concreto não confinado, a força última do pilar encamisado cresceu levemente.

Mais visível, porém, foi a modificação da deformação lateral da camisa ao longo do perímetro do pilar. Com uma maior expansão lateral de pico, ocorreu uma maior diferenciação das leituras dos cantos e do meio da face lateral da camisa. A mudança das deformações no perímetro da camisa está associada à mudança dos parâmetros do potencial plástico, responsáveis pela geração das deformações plásticas.

Pode-se observar uma boa correspondência entre os resultados numéricos e experimentais, indicando que o modelo pode ser utilizado para as análises paramétricas do confinamento em pilares centrados, desde que a calibração dos parâmetros seja feita de maneira adequada. 

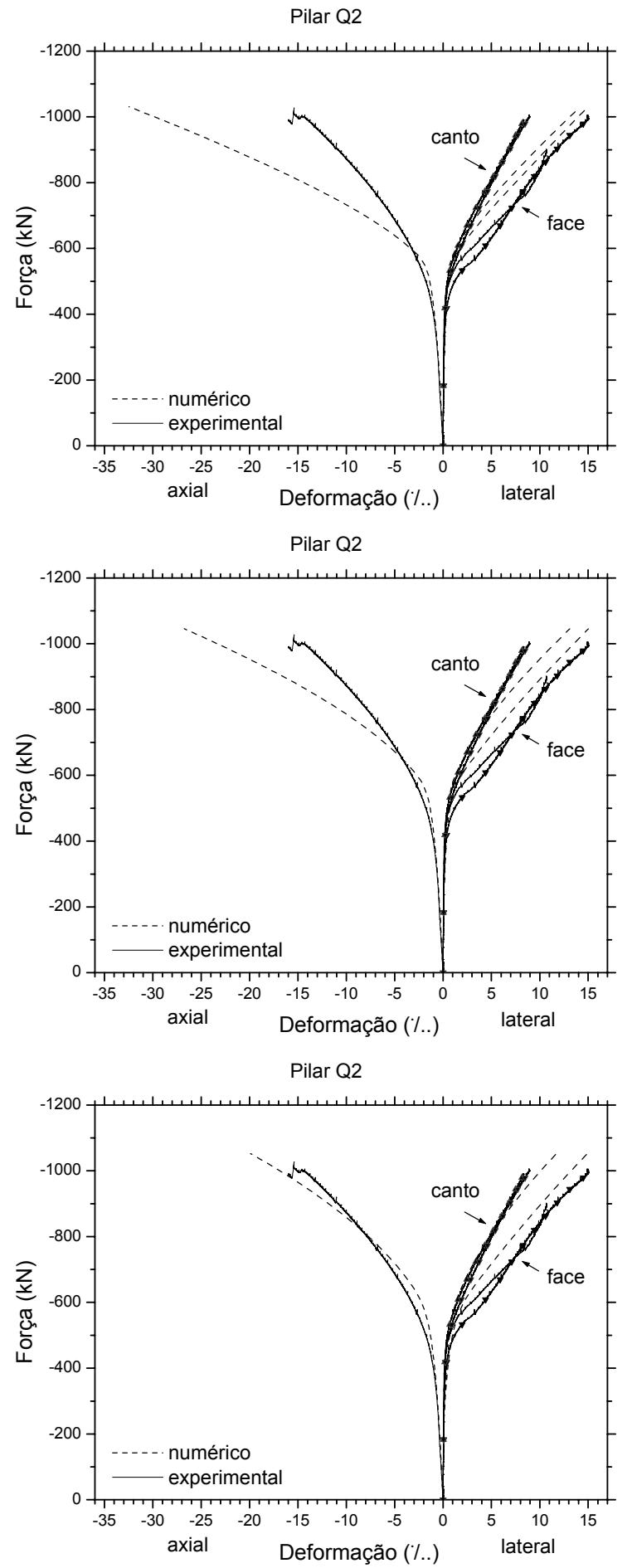

Figura 6.49 - Comparação dos diagramas força x deformações axiais e laterais

O mesmo procedimento de calibração foi então realizado para representar os pilares com excentricidade nominal nula da presente pesquisa. Inicialmente foi feita a calibração dos parâmetros $\mathrm{C}_{1}, \mathrm{C}_{2}$ e $\mathrm{C}_{3}$, por meio do diagrama tensão x deformação do concreto não confinado. Foram utilizados $\mathrm{f}_{\mathrm{c}}=36,35 \mathrm{MPa}, \mathrm{E}_{\mathrm{c}}=18230 \mathrm{MPa}$ e $\varepsilon_{\mathrm{c}}=-$ 0,003. Nesta calibração foi considerada uma expansão volumétrica de pico nula. Com a 
calibração observou-se que os parâmetros de "softening" de 0,0,2 foram os mais adequados aos resultados experimentais. Uma vez definidos os parâmetros, os mesmos valores foram utilizados em todas as análises.

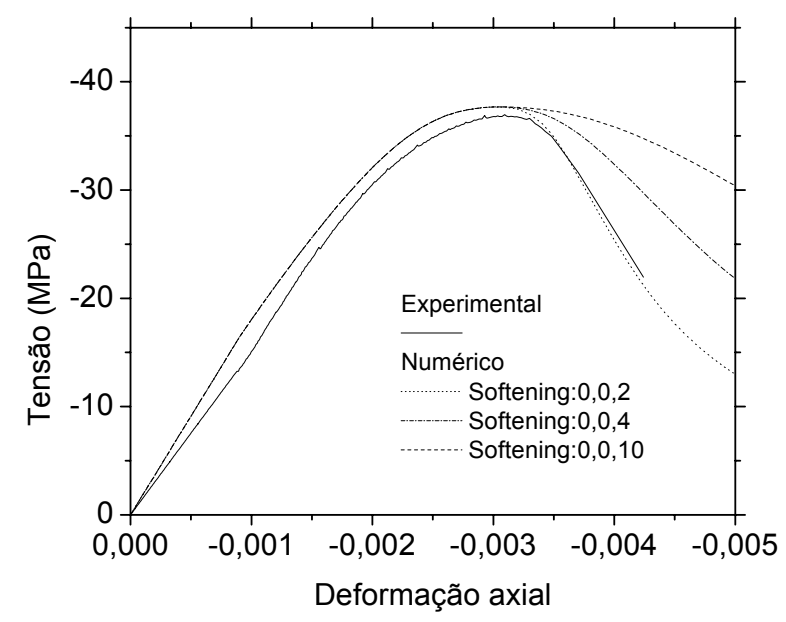

Figura 6.50 - Diagrama tensão x deformação axial

Então foi determinada a deformação lateral de pico, com base em comparações com os ensaios dos pilares S20r1 e S20r3. Observou-se que utilizando uma deformação lateral de pico correspondente a uma deformação volumétrica nula, foi possível obter uma melhor correlação com os resultados experimentais. Os valores finais dos parâmetros da sub-rotina, bem como dados adicionais sobre a camisa de PRFC utilizados nas análises numéricas dos itens 6.3.4 a 6.3.7 são apresentados na Tabela 6.5.

Tabela 6.5 - Propriedades dos materiais utilizadas nas análises dos itens 6.3.4 a 6.3.7

\begin{tabular}{|c|c|}
\hline \multicolumn{2}{|l|}{ Propriedades da camisa de PRFC } \\
\hline $\begin{array}{l}\text { Módulo de elasticidade na } \\
\text { direção das fibras }\end{array}$ & $71 \mathrm{Gpa}$ \\
\hline Espessura por camada de PRFC & $0,5 \mathrm{~mm}$ \\
\hline Deformação de ruptura do PRFC & 0,0106 \\
\hline \multicolumn{2}{|c|}{$\begin{array}{l}\text { Propriedades do concreto } \\
\text { (parâmetros de entrada da sub-rotina } \\
\text { conforme descrição no item } 6.2 .3 \text { ) }\end{array}$} \\
\hline \multicolumn{2}{|c|}{ *USER MATERIAL,CONSTANTS=13 } \\
\hline \multicolumn{2}{|c|}{$18230 ., 2,36.35,2.65,0.52,-0.003,-1 .,-9$. } \\
\hline $0.2,3 ., 0.00,0 ., 2$. & \\
\hline
\end{tabular}


$\mathrm{Na}$ Figura 6.51 são apresentados os diagramas força $\mathrm{x}$ deslocamento experimentais e numéricos. Para os pilares com carregamento excêntrico, inicialmente foi testado um mecanismo de estabilização da solução. No entanto o mecanismo de estabilização induziu certa intensidade de confinamento, interferindo sobre os resultados. Então a solução para os pilares com forças excêntricas só foi possível utilizando um grande número de iterações e, ainda assim, ocorrendo problemas de convergência muito superiores aos pilares sob compressão centrada. Ainda assim, a solução até o pico de força no diagrama força $\mathrm{x}$ deslocamento só foi obtida para alguns destes pilares.

Na Figura 6.51 são apresentados diagramas força x deslocamento de alguns dos pilares utilizados para calibração dos parâmetros da análise paramétrica. Foram comparados os resultados dos ensaios de pilares com excentricidade nominal nula, apresentando resultados satisfatórios.

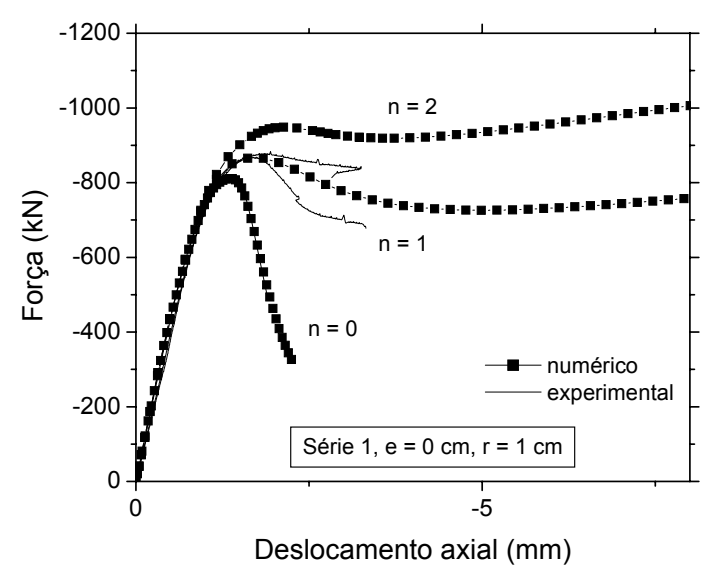

Figura 6.51 - Comparação de resultados numéricos x experimentais

\subsubsection{Análise paramétrica da influência do raio de arredondamento}

Tendo em vista a boa comparação de resultados numéricos e experimentais expressada no item anterior, o modelo numérico, calibrado com os mesmos parâmetros, foi utilizado para realizar um estudo paramétrico da influência da forma da seção transversal. Os estudos da forma da seção transversal foram realizados de maneira a determinar a influência de parâmetros pré-determinados, como a relação (2r/D) dos pilares. Foram utilizados valores iguais aos das simulações numéricas, para comparação, e acrescentados valores superiores e inferiores, permitindo assim complementar a análise paramétrica ( conforme Tabela 6.6). 
Tabela 6.6 - Pilares sob compressão centrada

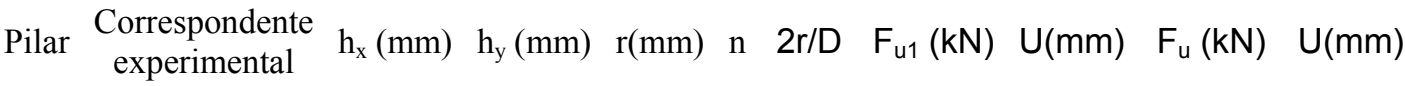

\begin{tabular}{llclccccccc}
\hline P1 & & 150 & 150 & 50 & 1 & 0,667 & $-848,44$ & $-2,08$ & $-999,90$ & $-8,53$ \\
P2 & S10r3 & 150 & 150 & 30 & 1 & 0,400 & $-871,65$ & $-1,76$ & $-904,06$ & $-8,53$ \\
P3 & S10r1 & 150 & 150 & 10 & 1 & 0,133 & $-884,53$ & $-1,72$ & $-816,26$ & $-8,97$ \\
P4 & & 150 & 150 & 5 & 1 & 0,067 & $-884,73$ & $-1,64$ & $-796,64$ & $-9,36$ \\
P5 & & 150 & 150 & 50 & 2 & 0,667 & & & $-1418,28$ & $-9,32$ \\
P6 & S20r3 & 150 & 150 & 30 & 2 & 0,400 & & & $-1274,71$ & $-9,79$ \\
P7 & S20r1 & 150 & 150 & 10 & 2 & 0,133 & $-950,09$ & $-2,11$ & $-1102,78$ & $-11,41$ \\
P8 & & 150 & 150 & 5 & 2 & 0,067 & $-946,34$ & $-2,01$ & $-926,27$ & $-7,47$ \\
P9 & & 150 & 150 & 50 & 4 & 0,667 & & & $-2051,22$ & $-10,42$ \\
P10 & & 150 & 150 & 30 & 4 & 0,400 & & & $-1817,69$ & $-11,37$ \\
P11 & & 150 & 150 & 10 & 4 & 0,133 & & & $-1355,48$ & $-11,92$ \\
P12 & & 150 & 150 & 5 & 4 & 0,067 & & & $-1124,75$ & $-5,02$ \\
P13 & C10 & 150 & 150 & 75 & 1 & 1,000 & & & $-1062,33$ & $-9,19$ \\
P14 & C20 & 150 & 150 & 75 & 2 & 1,000 & & & $-1534,49$ & $-10,14$ \\
P15 & & 150 & 150 & 75 & 4 & 1,000 & & & $-222,46$ & $-11,25$ \\
\hline
\end{tabular}

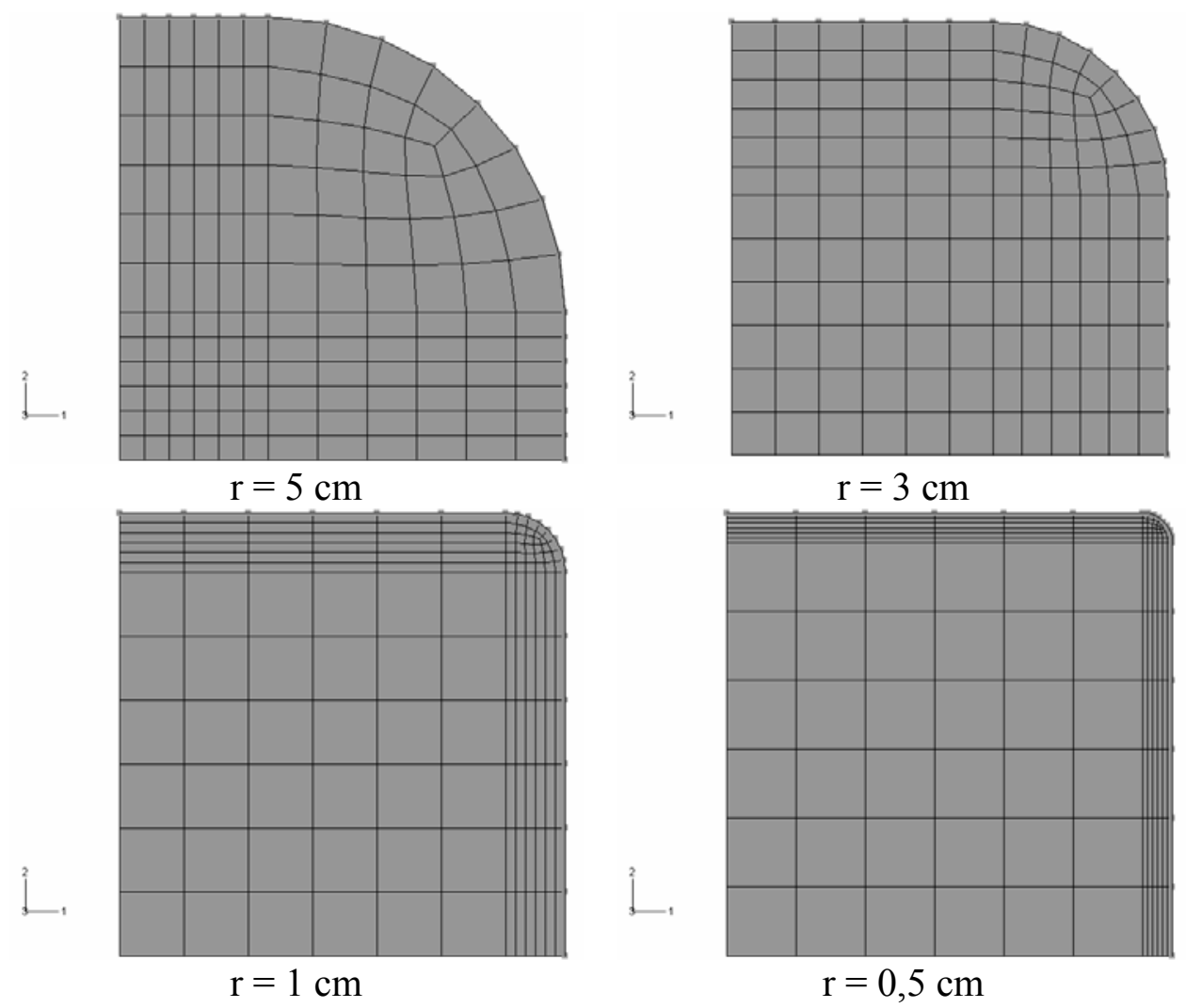

Figura 6.52 - Malhas utilizadas nas análises do efeito do raio de arredondamento

Os resultados numéricos se mostraram próximos dos experimentais, como indica a Figura 6.54. 
As malhas destas análises paramétricas foram geradas utilizando um arquivo de entrada paramétrico. Com este arquivo, a forma da seção transversal foi descrita em função de algumas variáveis, como a largura do pilar nas duas direções e seu raio de arredondamento.

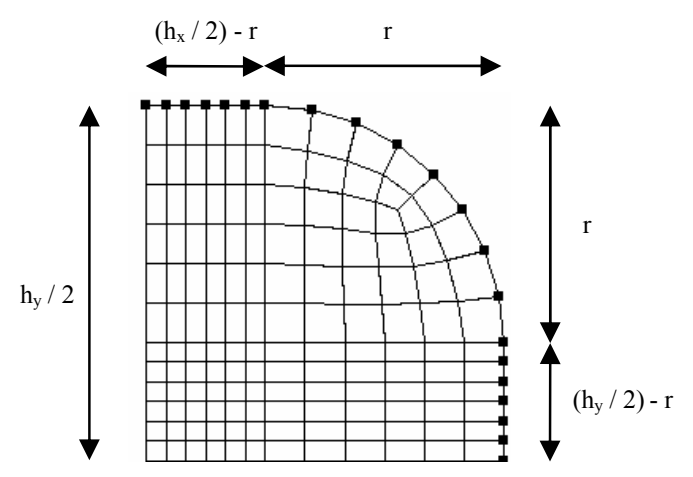

Figura 6.53 - Características do modelo parametrizado para análise da forma da seção transversal
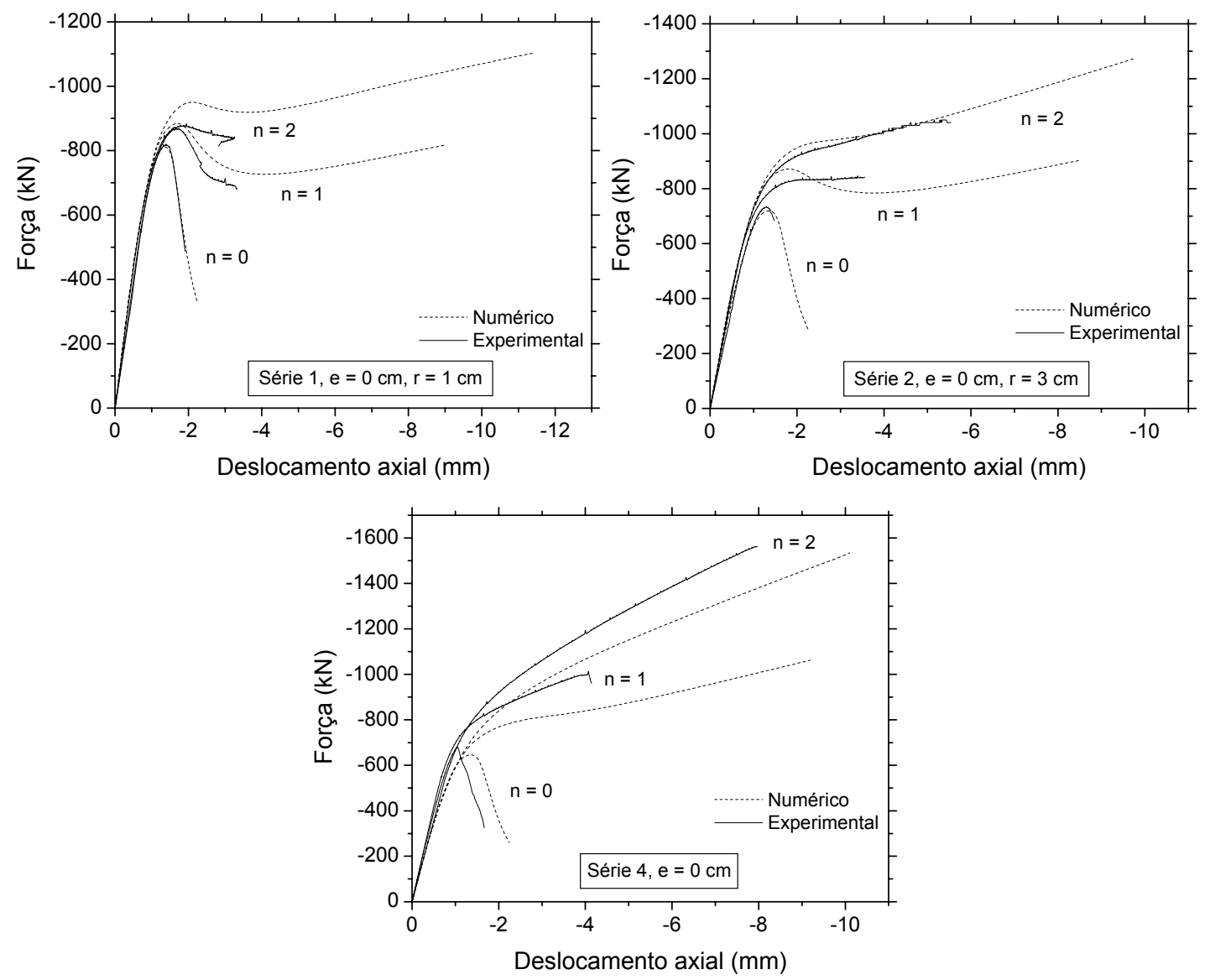

Figura 6.54 - Comparação resultados numéricos x experimentais 
Foi possível verificar a influência do raio de arredondamento para diferentes números de camadas de PRFC. Em todas as situações analisadas a variável (2r/D) teve importância significativa sobre o diagrama tensão x deformação do concreto confinado, como mostram os diagramas da Figura 6.55.

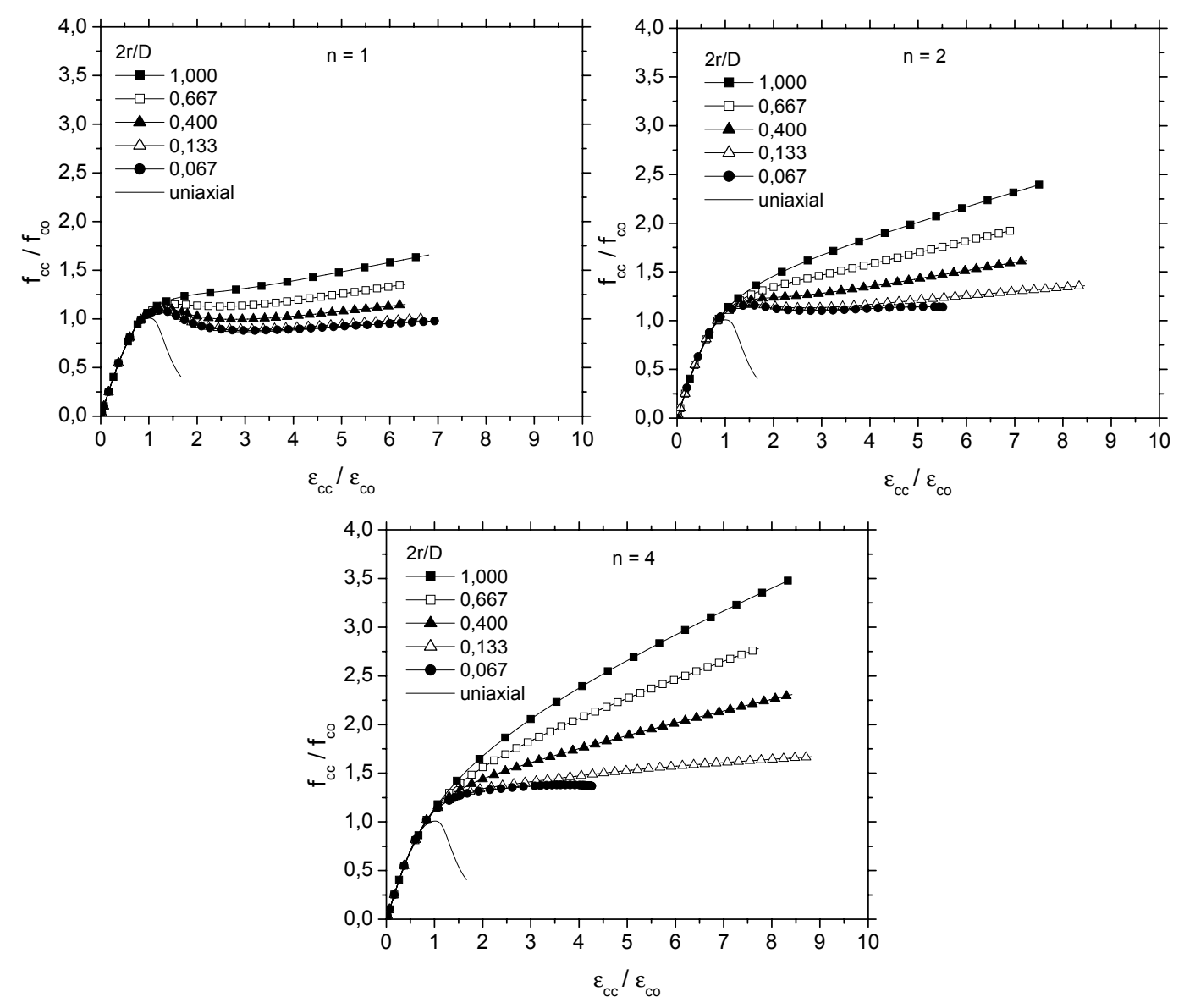

Figura 6.55 - Influência de 2r/D e n sobre o diagrama tensão x deformação do concreto confinado

Observou-se que nos diagramas tensão x deformação de determinados pilares ocorreu um pico inicial de resistência seguido de um trecho descendente. Os valores das tensões normalizadas do pico inicial de resistência $\left(\mathrm{f}_{\mathrm{c} 1} / \mathrm{f}_{\mathrm{co}}\right)$ destes pilares são indicados na Figura 6.56. 

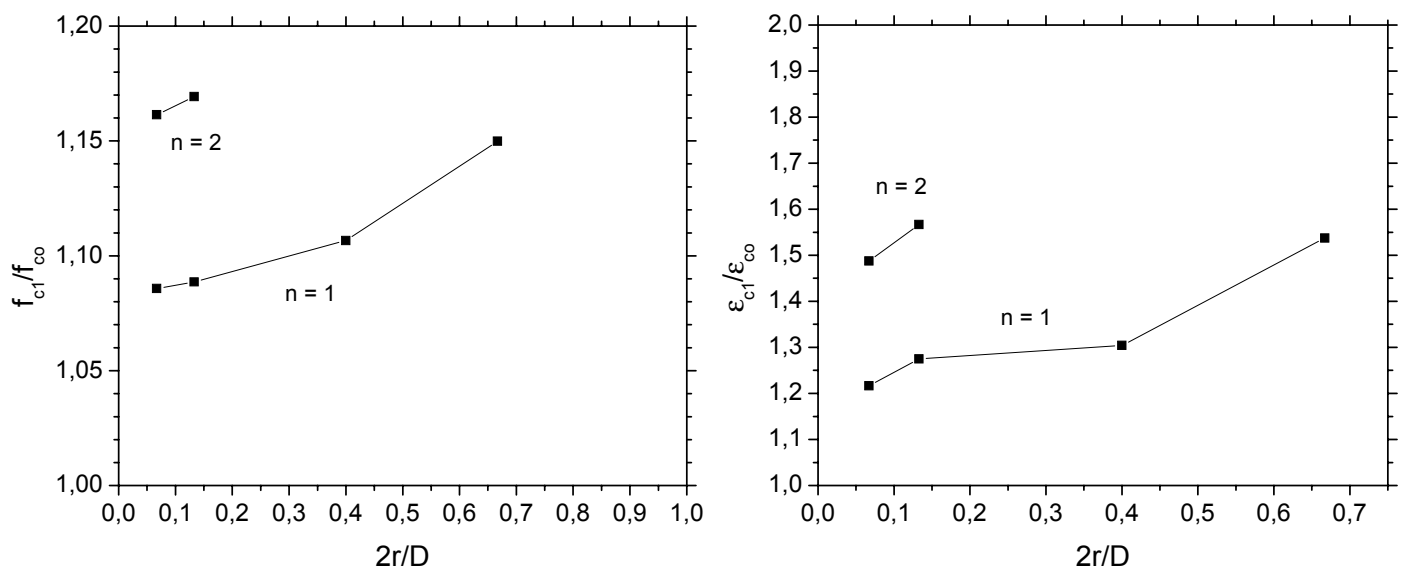

Figura 6.56 - Valores de referência do pico inicial dos pilares com baixo confinamento

$\mathrm{Na}$ Figura 6.57 pode-se observar a curva $\mathrm{k}_{1} \mathrm{x}$ pressão lateral. $\mathrm{O}$ modelo numérico, apesar de superestimar o ganho de resistência pelo confinamento em algumas situações, representa satisfatoriamente a envoltória do concreto, em que o valor de $\mathrm{k}_{1}$ diminui com o aumento de $f_{1} / f_{c o}$.

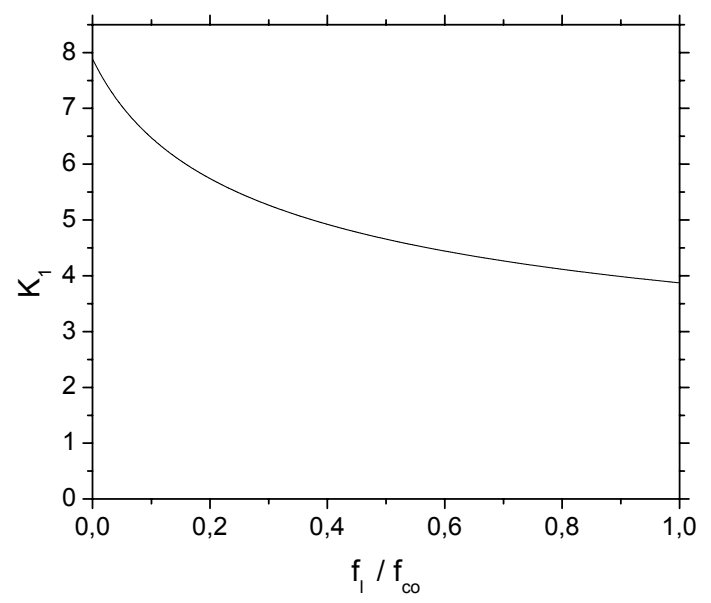

Figura 6.57 - Relação entre $k_{1}$ e $\mathbf{f}_{\mathbf{l}} / \mathbf{f}_{\mathrm{co}}$

Baseado na envoltória acima foi possível calcular $\mathrm{k}_{1}$ para as pressões laterais idealizadas $\left(f_{1}\right)$ dos pilares com o número de camadas de 1 a 4 . Na Tabela 6.7 são apresentados os valores de $2 \mathrm{r} / \mathrm{D}$ e $\mathrm{k}_{\mathrm{e}}=\left(\mathrm{f}_{\mathrm{cc}}-\mathrm{f}_{\mathrm{co}}\right) /\left(\mathrm{k}_{1} \cdot \mathrm{f}_{\mathrm{l}}\right)$ : 
Tabela 6.7 - Pilares sob compressão centrada

\begin{tabular}{ccccccc}
\hline Pilar & $\mathrm{r}(\mathrm{mm})$ & $\mathrm{n}$ & $\mathrm{f}_{\mathrm{l}}(\mathrm{MPa})$ & $\mathrm{f}_{\mathrm{cc}} / \mathrm{f}_{\mathrm{co}}$ & $2 \mathrm{r} / \mathrm{D}$ & $\mathrm{k}_{\mathrm{e}}=\left(\mathrm{f}_{\mathrm{cc}}-\mathrm{f}_{\mathrm{co}}\right) /\left(\mathrm{k}_{1} \cdot \mathrm{f}_{\mathrm{l}}\right)$ \\
\hline P1 & 50 & 1 & 6,156 & 1,355 & 0,667 & 0,417 \\
P2 & 30 & 1 & 6,156 & 1,148 & 0,400 & 0,174 \\
P3 & 10 & 1 & 6,156 & 1,005 & 0,133 & 0,005 \\
P4 & 5 & 1 & 6,156 & 0,978 & 0,067 & $-0,026$ \\
P5 & 50 & 2 & 5,37 & 1,922 & 0,667 & 0,620 \\
P6 & 30 & 2 & 5,37 & 1,618 & 0,400 & 0,416 \\
P7 & 10 & 2 & 5,37 & 1,357 & 0,133 & 0,240 \\
P8 & 5 & 2 & 5,37 & 1,137 & 0,067 & 0,092 \\
P9 & 50 & 4 & 4,54 & 2,780 & 0,667 & 0,708 \\
P10 & 30 & 4 & 4,54 & 2,308 & 0,400 & 0,520 \\
P11 & 10 & 4 & 4,54 & 1,668 & 0,133 & 0,266 \\
P12 & 5 & 4 & 4,54 & 1,380 & 0,067 & 0,151 \\
P13 & 75 & 1 & 6,156 & 1,658 & 1,000 & 0,773 \\
P14 & 75 & 2 & 5,37 & 2,395 & 1,000 & 0,939 \\
P15 & 75 & 4 & 4,54 & 3,477 & 1,000 & 0,986 \\
\hline \multicolumn{6}{c}{}
\end{tabular}

Observou-se uma forte relação entre as variáveis $\mathrm{k}_{\mathrm{e}}$ e $2 \mathrm{r} / \mathrm{D}$, como indica a Figura 6.58 .

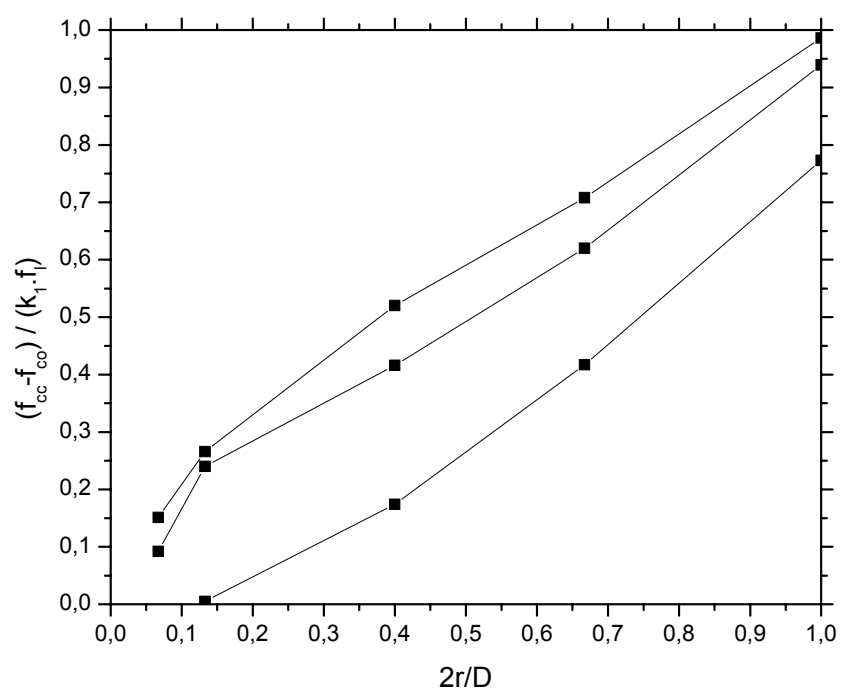

Figura 6.58 - Comparação do efeito de 2r/D sobre $k_{e}$

Pode-se observar que, independentemente do número de camadas utilizado, o ganho de resistência do concreto confinado está diretamente relacionado à variável $2 \mathrm{r} / \mathrm{D}$, que é um coeficiente de forma. 


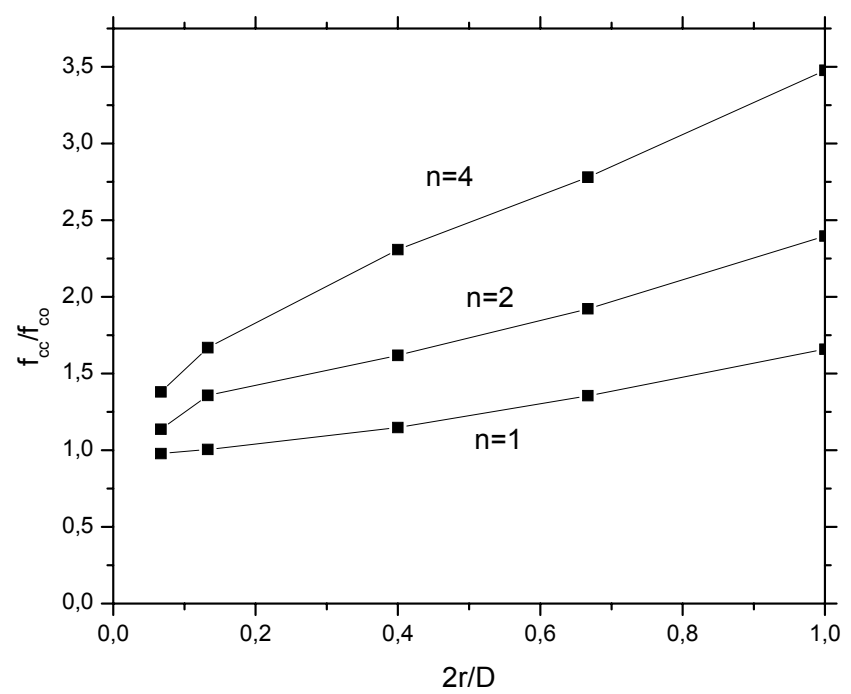

Figura 6.59 - Ganho de resistência $\left(f_{c c} / f_{c o}\right) \times 2 r / D$

Pode-se observar ainda que a pressão lateral efetiva, dada pela multiplicação deste coeficiente de forma pela pressão lateral calculada com o lado da seção transversal (h), é diretamente relacionada ao ganho de resistência. Em cada caso $\mathrm{f}_{1}$ é a pressão lateral calculada como no caso dos pilares de seção circular, pela equação:

$$
f_{l}=\frac{2 t}{h} \cdot E_{f} \cdot \varepsilon_{f}
$$

$\mathrm{Na}$ Figura 6.60 são apresentadas as resistências obtidas em função de $\mathrm{k}_{\mathrm{e}}=2 \mathrm{r} / \mathrm{D}$. Pode-se observar que houve uma boa correlação entre a variável 2r/D e a interpolação linear utilizada.

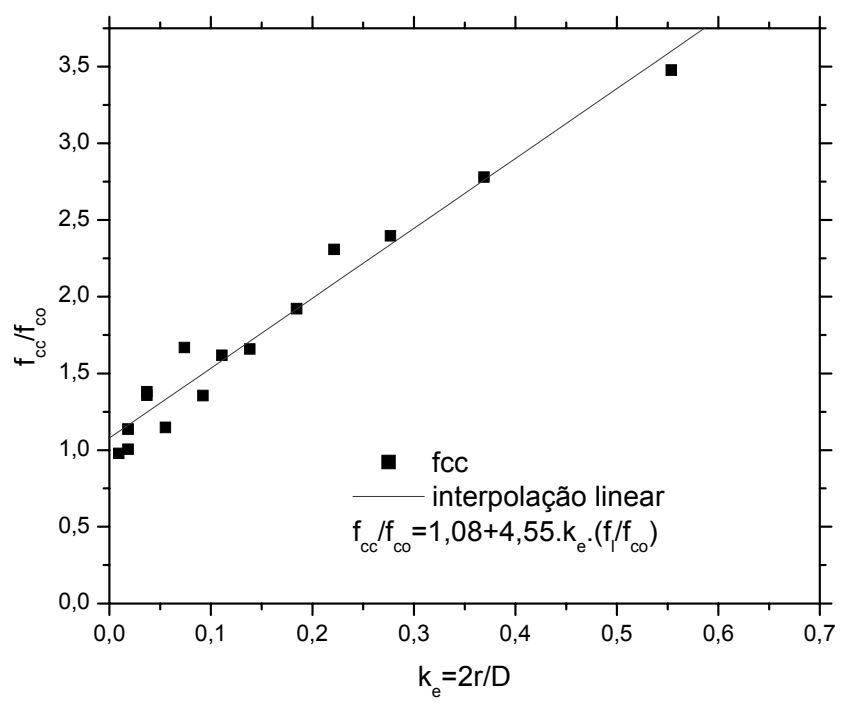

Figura 6.60 - Relação entre $\mathbf{f}_{\mathrm{cc}} / \mathbf{f}_{\mathrm{co}}$ e $\mathbf{f}_{\mathrm{l}} \cdot \mathbf{k}_{\mathrm{e}}$ 


\subsubsection{Análise da influência da relação entre lados}

A análise da influência da relação entre lados foi realizada em duas etapas. $\mathrm{Na}$ primeira etapa foram escolhidos valores de $2 \mathrm{r} / \mathrm{h}_{\mathrm{x}}$ (sendo $\mathrm{h}_{\mathrm{x}} \mathrm{o}$ maior lado), da relação $\mathrm{h}_{\mathrm{x}} /$ $\mathrm{h}_{\mathrm{y}}$ e de $\mathrm{n}$ então combinados numa análise paramétrica.

Foram considerados como resistência à compressão do concreto $36,35 \mathrm{MPa}$ e módulo de elasticidade de $18230 \mathrm{MPa}$. Como deformação de ruptura da camisa de PRFC foi adotado o valor de 0,0106 .

Tabela 6.8 - Pilares sob compressão centrada

\begin{tabular}{|c|c|c|c|c|c|c|c|}
\hline Pilar & $\begin{array}{c}\text { Correspondente } \\
\text { experimental }\end{array}$ & $\mathrm{h}_{\mathrm{x}}(\mathrm{mm})$ & $\mathrm{h}_{\mathrm{y}}(\mathrm{mm})$ & $\mathrm{h}_{\mathrm{x}} / \mathrm{h}_{\mathrm{y}}$ & $\mathrm{r}(\mathrm{cm})$ & $\mathrm{n}$ & $2 r / D$ \\
\hline Pr1 & & 150 & 150 & 1 & 2,0 & 1 & 0,267 \\
\hline $\operatorname{Pr} 2$ & S10r3 & 150 & 150 & 1 & 3,0 & 1 & 0,267 \\
\hline $\operatorname{Pr} 3$ & & 150 & 150 & 1 & 2,0 & 2 & 0,267 \\
\hline Pr4 & S20r3 & 150 & 150 & 1 & 3,0 & 2 & 0,4 \\
\hline $\operatorname{Pr} 5$ & & 150 & 150 & 1 & 2,0 & 4 & 0,4 \\
\hline Pr6 & & 150 & 150 & 1 & 3,0 & 4 & 0,4 \\
\hline $\operatorname{Pr} 7$ & & 225 & 150 & 1,5 & 3,0 & 1 & 0,267 \\
\hline Pr8 & & 225 & 150 & 1,5 & 4,5 & 1 & 0,267 \\
\hline Pr9 & $\mathrm{R} 20$ & 225 & 150 & 1,5 & 3,0 & 2 & 0,267 \\
\hline $\operatorname{Pr} 10$ & & 225 & 150 & 1,5 & 4,5 & 2 & 0,4 \\
\hline Pr11 & & 225 & 150 & 1,5 & 3,0 & 4 & 0,4 \\
\hline $\operatorname{Pr} 12$ & & 225 & 150 & 1,5 & 4,5 & 4 & 0,4 \\
\hline Pr13 & & 300 & 150 & 2 & 4,0 & 1 & 0,267 \\
\hline $\operatorname{Pr} 14$ & & 300 & 150 & 2 & 6,0 & 1 & 0,267 \\
\hline $\operatorname{Pr} 15$ & & 300 & 150 & 2 & 4,0 & 2 & 0,267 \\
\hline Pr16 & & 300 & 150 & 2 & 6,0 & 2 & 0,4 \\
\hline Pr17 & & 300 & 150 & 2 & 4,0 & 4 & 0,4 \\
\hline $\operatorname{Pr} 18$ & & 300 & 150 & 2 & 6,0 & 4 & 0,4 \\
\hline
\end{tabular}

Pode-se observar na Figura 6.61 que a relação hx / hy teve pouca influência na resistência e deformação última do concreto confinado, desde que fixa a relação $2 \mathrm{r} / \mathrm{h}_{\mathrm{x}}$. Esta tendência fica ainda mais clara ao se analisar a Figura 6.62. 

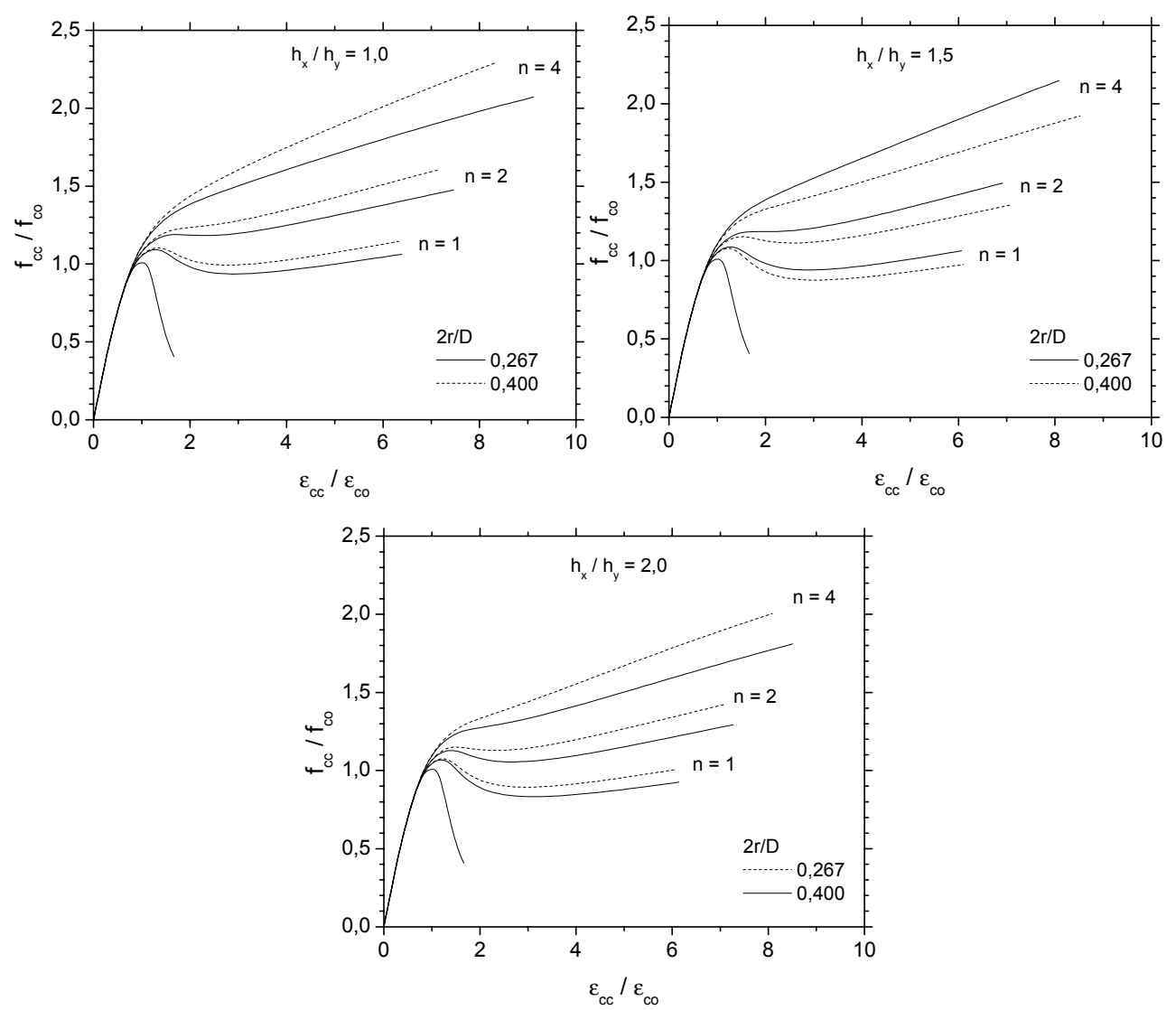

Figura 6.61 - Influência de $h_{x} / h_{y}$ com valores fixos de $2 r / h_{x}$

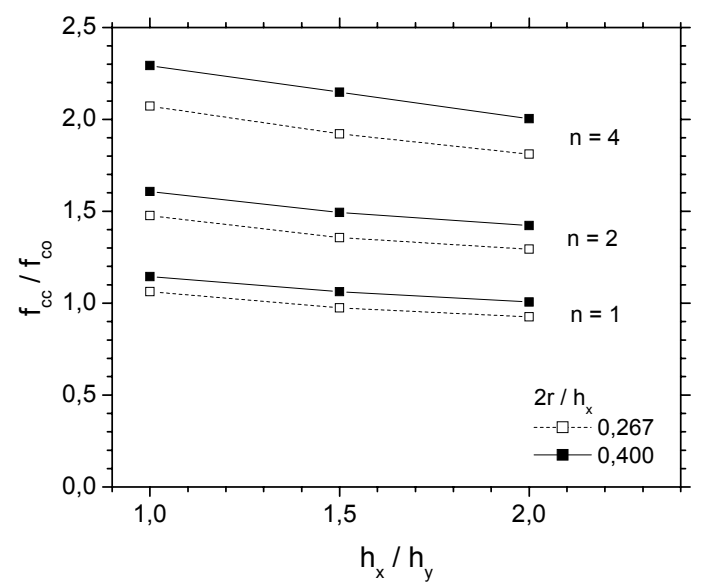

Figura 6.62 - Influência de $h_{x} / h_{y}$ com valores fixos de $2 r / h_{x}$ sobre a tensão e a deformação axial últimas

Na Figura 6.63 são apresentadas as malhas utilizadas nestas análises numéricas. Pode-se observar que algumas das seções simuladas são de difícil implementação prática, pelo fato do raio de arredondamento ser muito grande. 


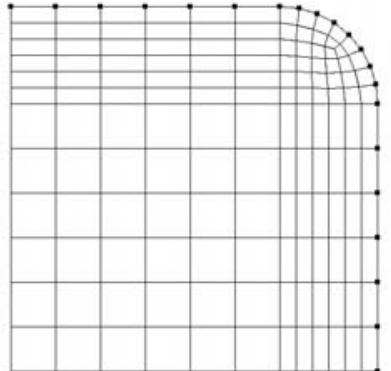

$2 \mathrm{r} / \mathrm{h}_{\mathrm{x}}=0,267$

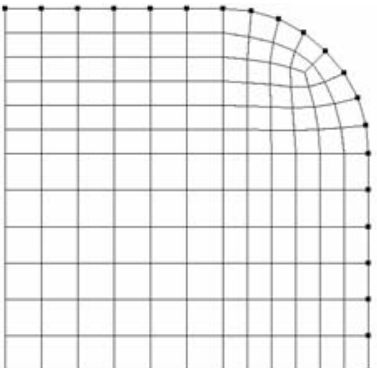

$2 \mathrm{r} / \mathrm{h}_{\mathrm{x}}=0,400$

$\mathrm{h}_{\mathrm{x}} / \mathrm{h}_{\mathrm{y}}=1$

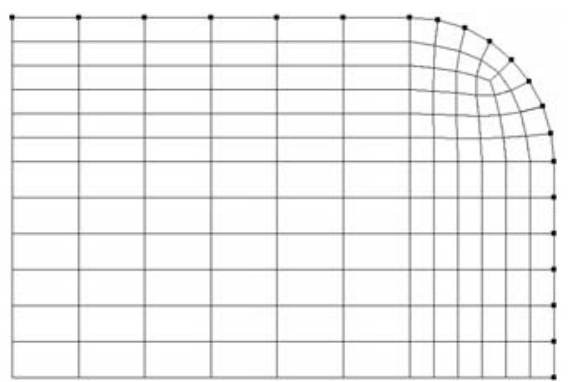

$2 \mathrm{r} / \mathrm{h}_{\mathrm{x}}=0,267$

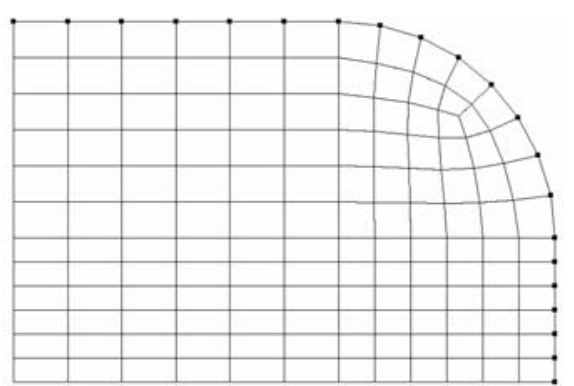

$$
2 \mathrm{r} / \mathrm{h}_{\mathrm{x}}=0,400
$$

$\mathrm{h}_{\mathrm{x}} / \mathrm{h}_{\mathrm{y}}=1,5$
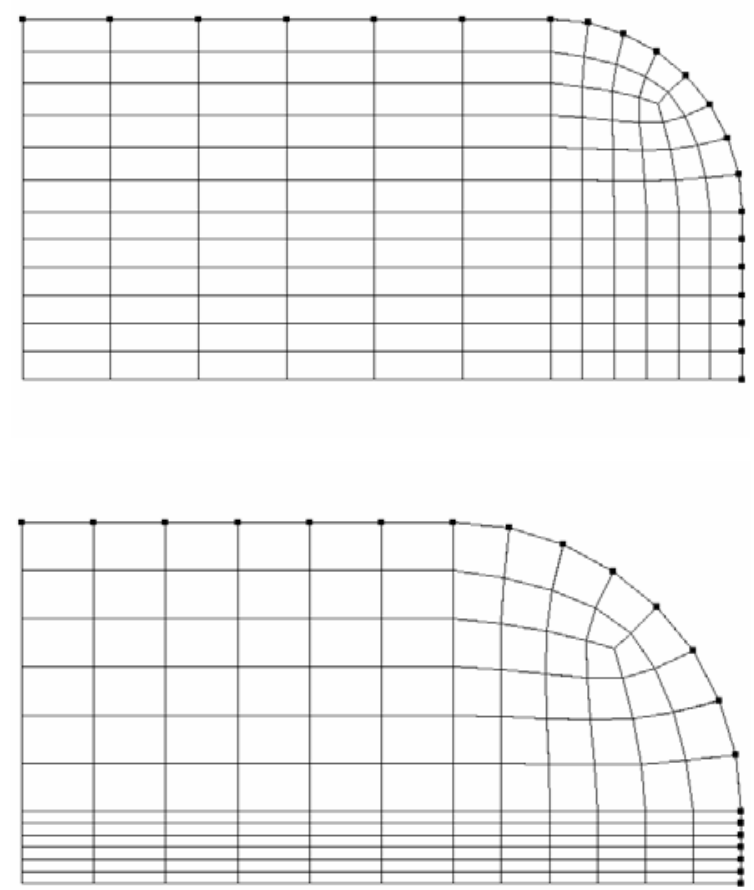

$2 \mathrm{r} / \mathrm{h}_{\mathrm{x}}=0,267$

$2 \mathrm{r} / \mathrm{h}_{\mathrm{x}}=0,400$

$\mathrm{h}_{\mathrm{x}} / \mathrm{h}_{\mathrm{y}}=2,0$

Figura 6.63 - Malhas utilizadas na primeira etapa do estudo da influência da forma da seção transversal 
Obviamente, algumas das seções transversais consideradas na primeira parte da análise não são viáveis para aplicação, pois os raios de arredondamento resultantes para manter constante a relação $2 \mathrm{r} / \mathrm{h}_{\mathrm{x}}$ são de difícil execução. Isto motivou uma segunda etapa do estudo da forma da seção transversal $\left(h_{x} / h_{y}\right)$, porém mantendo o raio de arredondamento fixo em valores possíveis de aplicação prática, como 1 ou $3 \mathrm{~cm}$. Na segunda etapa foram fixados alguns valores de $r$, de $n$ e da relação $h_{x} / h_{y}$, conforme Tabela 6.9. Os resultados desta segunda análise são complementados pelos já obtidos na análise do efeito de $r$, onde foram simulados pilares de seção quadrada com os respectivos raios de arredondamento.

Tabela 6.9 - Análise complementar do efeito da relação entre lados

\begin{tabular}{ccccccc} 
Pilar & $\mathrm{h}_{\mathrm{x}}(\mathrm{mm})$ & $\mathrm{h}_{\mathrm{y}}(\mathrm{mm})$ & $\mathrm{h}_{\mathrm{x}} / \mathrm{h}_{\mathrm{y}}$ & $\mathrm{r}(\mathrm{mm})$ & $\mathrm{n}$ & $2 \mathrm{r} / \mathrm{h}_{\mathrm{x}}$ \\
\hline Pra1 & 225 & 150 & 1,5 & 10 & 1 & 0,089 \\
\hline Pra2 & 225 & 150 & 1,5 & 30 & 1 & 0,267 \\
\hline Pra3 & 225 & 150 & 1,5 & 10 & 2 & 0,089 \\
\hline Pra4 & 225 & 150 & 1,5 & 30 & 2 & 0,267 \\
\hline Pra5 & 225 & 150 & 1,5 & 10 & 4 & 0,089 \\
\hline Pra6 & 225 & 150 & 1,5 & 30 & 4 & 0,267 \\
\hline Pra7 & 300 & 150 & 2 & 10 & 1 & 0,067 \\
\hline Pra8 & 300 & 150 & 2 & 30 & 1 & 0,200 \\
\hline Pra9 & 300 & 150 & 2 & 10 & 2 & 0,067 \\
\hline Pra10 & 300 & 150 & 2 & 30 & 2 & 0,200 \\
\hline Pra11 & 300 & 150 & 2 & 10 & 4 & 0,067 \\
\hline Pra12 & 300 & 150 & 2 & 30 & 4 & 0,200 \\
\hline
\end{tabular}

Pode-se observar na Figura 6.64 e na Figura 6.65 que, com o aumento de $h_{x} / h_{y}$, se for mantido constante o valor de $\mathrm{r}$, ocorre uma significativa queda da resistência do concreto confinado, principalmente considerando camisas de maior espessura (4 camadas). 

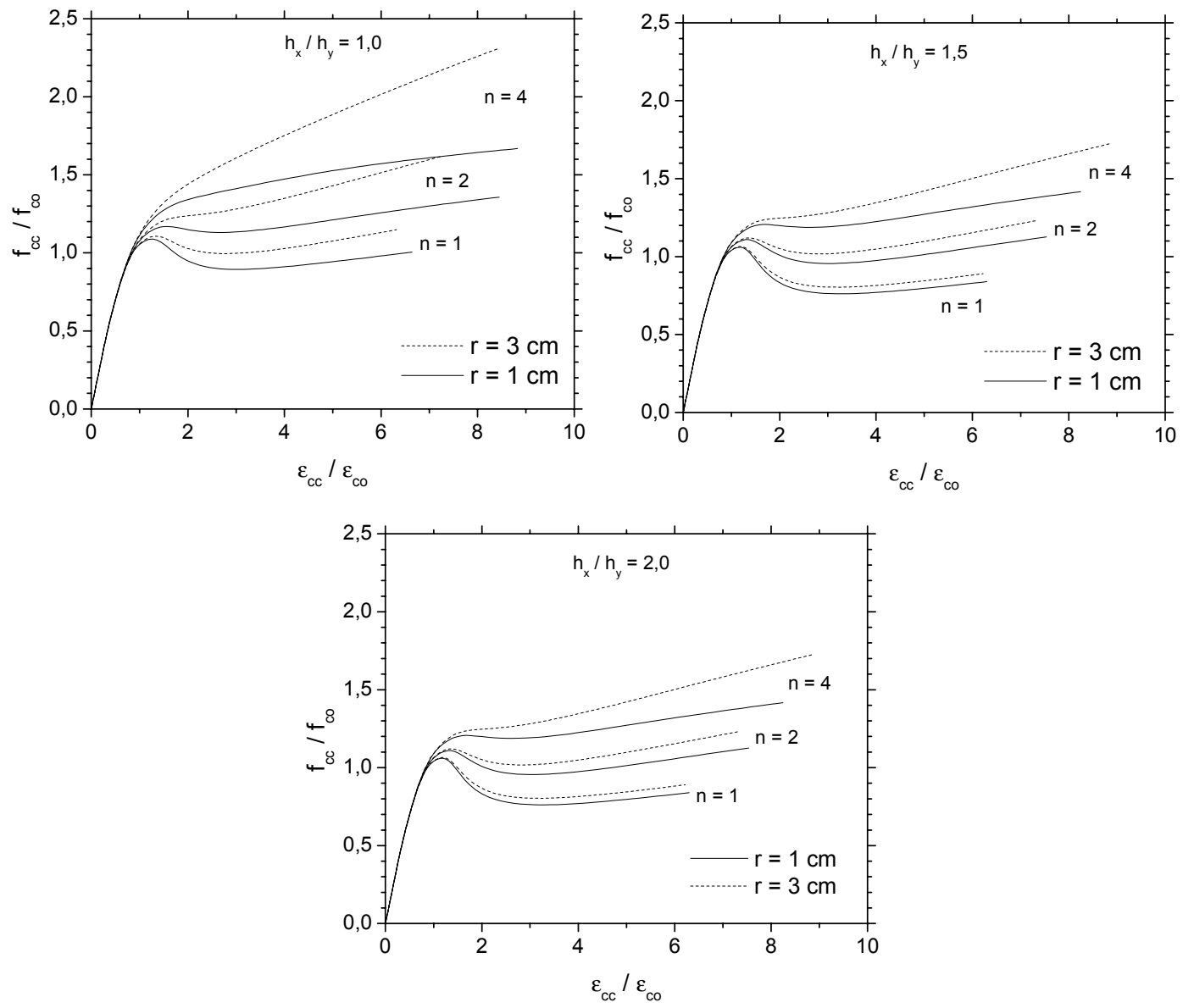

Figura 6.64 - Influencia do aumento de $h_{x} / h_{y}$

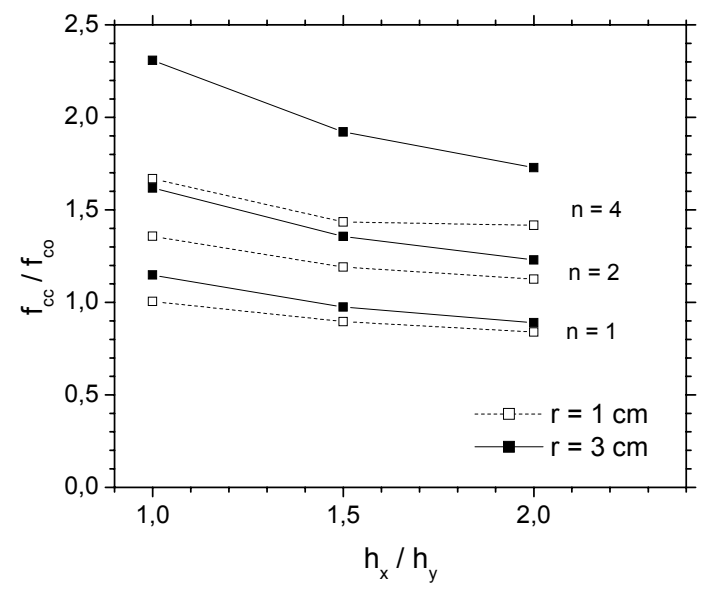

Figura 6.65 - Influencia do aumento de $h_{x} / h_{y}$ 


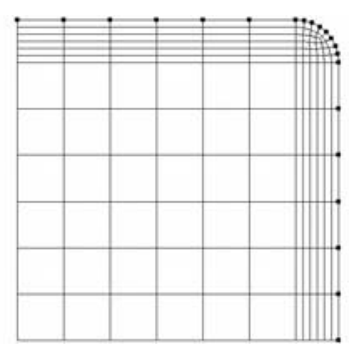

$\mathrm{r}=1 \mathrm{~cm}$

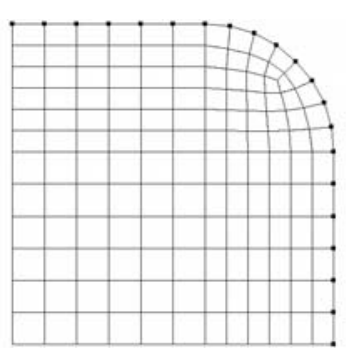

$\mathrm{r}=3 \mathrm{~cm}$

$\mathrm{h}_{\mathrm{x}} / \mathrm{h}_{\mathrm{y}}=1$

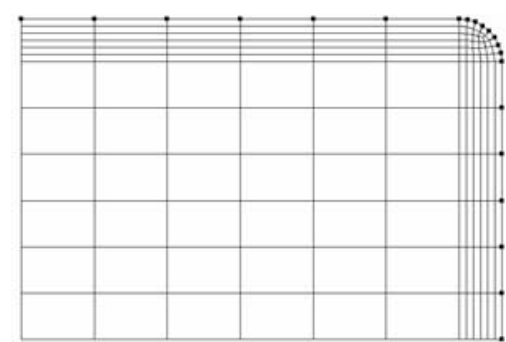

$\mathrm{r}=1 \mathrm{~cm}$

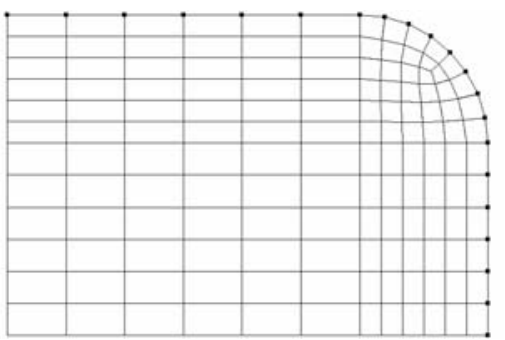

$\mathrm{r}=3 \mathrm{~cm}$

$\mathrm{h}_{\mathrm{x}} / \mathrm{h}_{\mathrm{y}}=1,5$

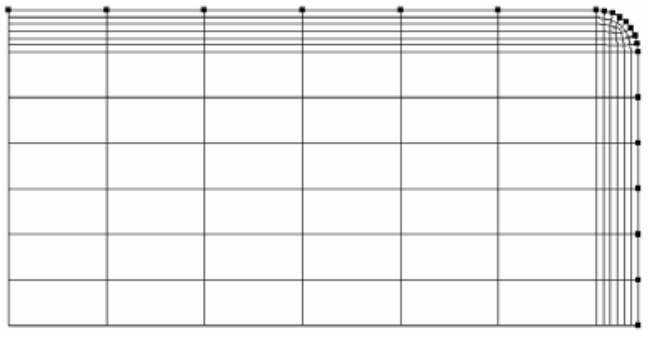

$\mathrm{r}=1 \mathrm{~cm}$

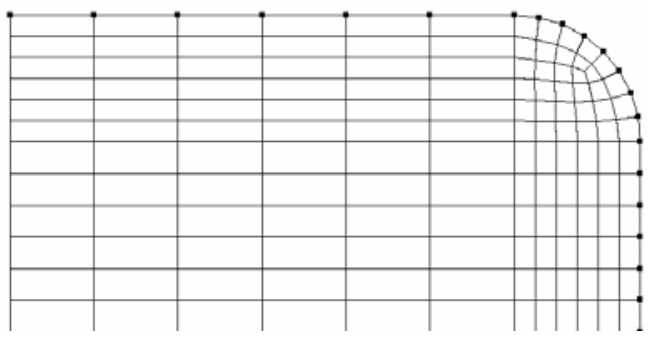

$\mathrm{r}=3 \mathrm{~cm}$

$$
\mathrm{h}_{\mathrm{x}} / \mathrm{h}_{\mathrm{y}}=2
$$

Figura 6.66 - Malhas utilizadas nas análises da forma da seção - parte 2

Na Figura 6.67 é apresentado o diagrama força x deslocamento experimental do pilar retangular R20 e o correspondente numérico. Pode-se observar uma boa representatividade do modelo numérico. 


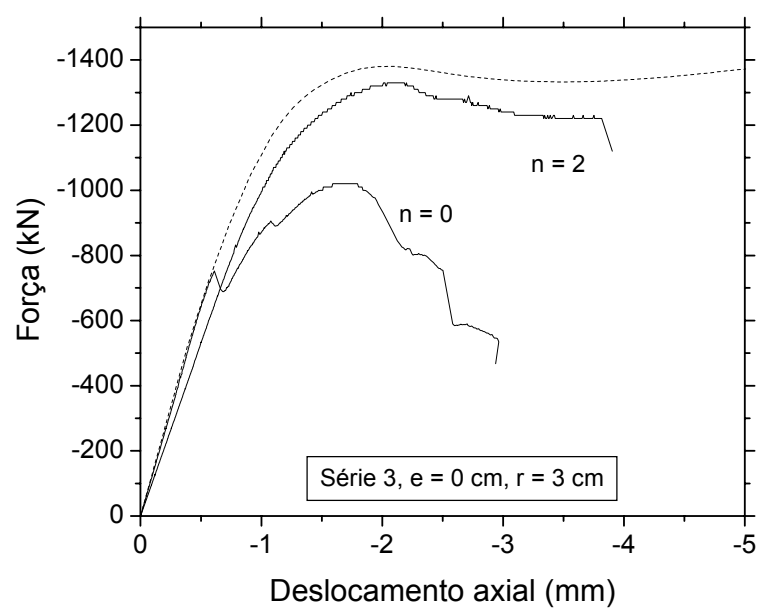

Figura 6.67 - Comparação dos resultados numéricos e experimentais para os pilares retangulares

\subsubsection{Influência da excentricidade da força de compressão}

As análises de pilares curtos sob confinamento não uniforme com camisa de PRF foram realizadas por meio da modelagem com o MEF utilizando o modelo constitutivo de GRASSL et al. (2002). Optou-se por analisar apenas os efeitos de primeira ordem, logo a modelagem foi realizada com apenas uma camada de elementos na direção axial, sendo dispensada maior atenção à definição da área da seção transversal do pilar. Foram modelados pilares de seção quadrada e retangular com diferentes raios de arredondamento dos cantos e diferentes espessuras de camisa de PRF. Esta análise foi útil para a avaliação dos efeitos de confinamento com qualquer tipo de PRF, pois como já observado no capítulo anterior, a pressão lateral máxima depende da máxima tensão de tração do compósito, enquanto a deformabilidade do pilar depende, além desta variável, da rigidez transversal da camisa e das propriedades do concreto.

A análise paramétrica foi realizada com um arquivo de entrada com forma parametrizada segundo a Figura 6.68. Deste modo, as variáveis de entrada na análise paramétrica foram $h_{x}, h_{y}, r, n$ e "e", sendo estas variáveis respectivamente: a largura do pilar na direção x, a largura do pilar na direção y, o raio de arredondamento dos cantos, o número de camadas do compósito e a excentricidade do carregamento. 


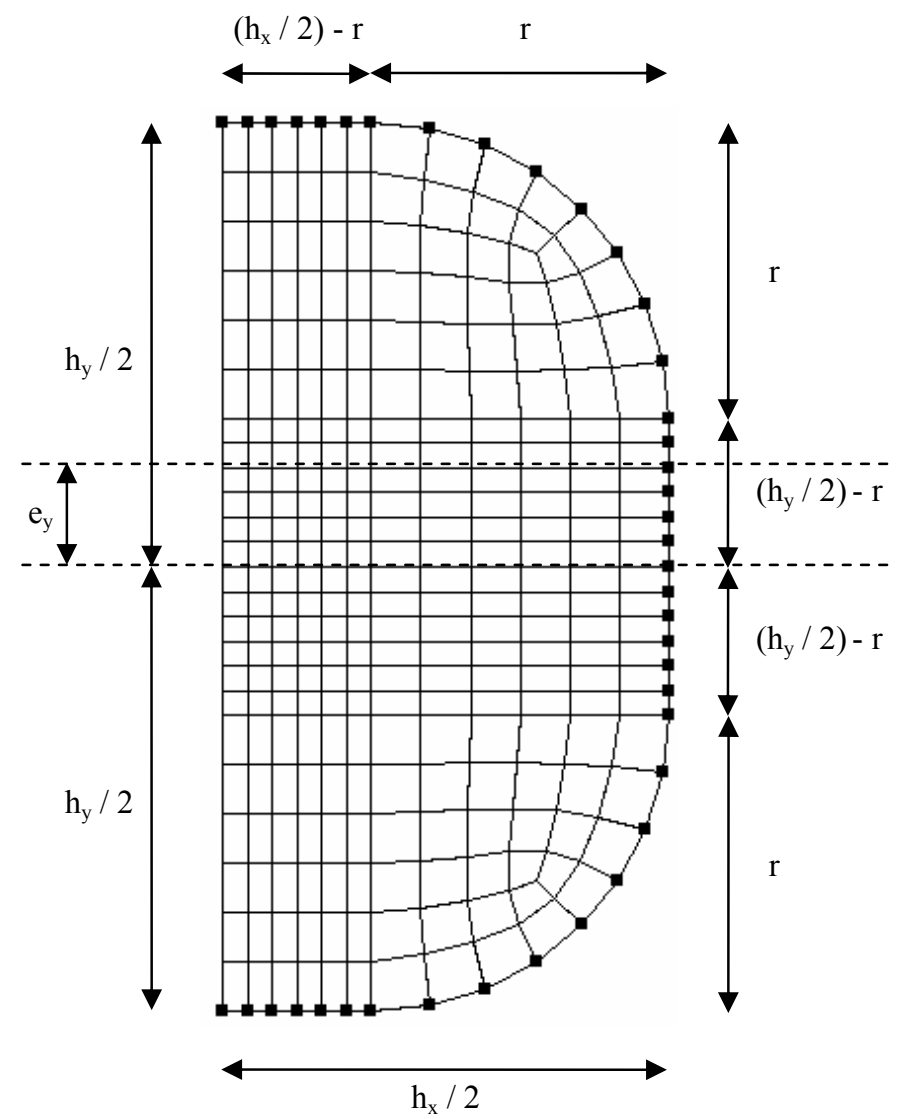

Figura 6.68 - Características do modelo parametrizado para análise da forma da seção transversal

\subsubsection{Verificação da validade das condições de contorno das simulações de compressão excêntrica}

As simulações de compressão excêntrica foram realizadas com a utilização de um nó mestre no qual foi aplicado o carregamento e um acoplamento cinemático de todos os nós do mesmo plano desta seção transversal. Desta maneira foi possível variar a excentricidade, apenas variando a posição deste nó mestre. O carregamento aplicado foi, na verdade, um deslocamento na direção axial (3) com valor não nulo e um valor nulo de deslocamento na direção 2. Desta maneira representou-se uma situação mais fiel possível em relação ao ensaio de compressão excêntrica, desprezando os efeitos de segunda ordem.

Foram acoplados os deslocamentos na direção 3 (ver Figura 6.69) e as rotações em torno do eixo 1. Isto significa que estes graus de liberdade (para todos os nós da face superior do modelo) ficaram acoplados ao movimento de corpo rígido do nó mestre. Os demais graus de liberdade destes nós ficaram livres. 
Além disso, foram aplicadas duas condições de simetria, com relação ao plano 2-3 (XSYM) e com relação ao plano 1-2 (ZSYM).

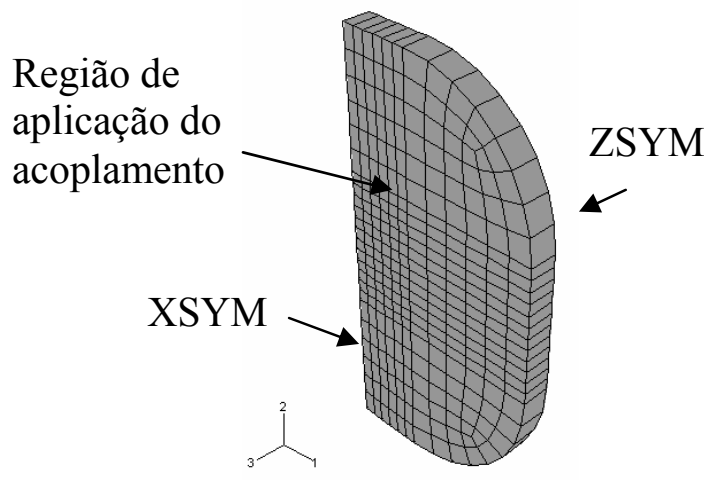

Figura 6.69 - Representação do modelo geométrico da analise com o MEF

Para verificar a adequação do modelo numérico foi simulado um pilar quadrado $(15 \times 15 \mathrm{~cm})$ de canto arredondado com raio de $5 \mathrm{~cm}$. Ao concreto foi atribuído comportamento elástico linear com $\mathrm{E}_{\mathrm{c}}=25000 \mathrm{MPa}$ e $v_{\mathrm{c}}=0,2$. Neste caso verificou-se válida a equação (6.25), apresentando diferenças entre resultados teóricos e numéricos inferiores a $1 \%$.

$$
\sigma_{3}=\frac{P \cdot e_{y} \cdot y}{I}+\frac{P}{A}
$$

onde:

- P é o esforço axial aplicado;

- $\mathrm{e}=1 \mathrm{~cm}$ é a excentricidade aplicada;

- y é a posição com relação ao centro de gravidade da seção transversal;

- $\mathrm{I}=3,326 \cdot 10^{3} \mathrm{~cm}^{4}$ é o momento de inércia;

- $\mathrm{A}=156,42 \mathrm{~cm}^{2}$ é a área da seção transversal;

Foi feita uma comparação da tensão axial $\left(\sigma_{3}\right)$ obtida com os resultados teóricos e numéricos ao longo da linha que liga o centro de gravidade da seção até a borda mais comprimida. Como se pode observar na Tabela 6.10 , os valores de $\sigma_{3}$ calculados e numéricos foram praticamente coincidentes, indicando que a simulação representa adequadamente a flexo-compressão em pilares curtos com material de comportamento elástico-linear. 
Tabela 6.10 - Comparação dos resultados do modelo numérico e valores teóricos

\begin{tabular}{cccc}
\hline $\mathrm{y}(\mathrm{cm})$ & $\begin{array}{c}\sigma_{3}(\mathrm{MPa}) \\
\text { Numérico }\end{array}$ & $\begin{array}{c}\sigma_{3}(\mathrm{MPa}) \\
\text { Teórico }\end{array}$ & $\begin{array}{c}\text { Comparação } \\
\text { numérico/teórico }\end{array}$ \\
\hline 0,00 & $-94,22$ & $-93,98$ & 1,002 \\
0,42 & $-96,63$ & $-96,38$ & 1,003 \\
0,83 & $-99,04$ & $-98,78$ & 1,003 \\
1,25 & $-101,45$ & $-101,17$ & 1,003 \\
1,67 & $-103,86$ & $-103,57$ & 1,003 \\
2,08 & $-106,27$ & $-105,97$ & 1,003 \\
2,50 & $-109,28$ & $-108,36$ & 1,008 \\
3,33 & $-113,50$ & $-113,16$ & 1,003 \\
4,17 & $-118,32$ & $-117,95$ & 1,003 \\
5,00 & $-123,14$ & $-122,74$ & 1,003 \\
5,83 & $-127,95$ & $-127,53$ & 1,003 \\
6,67 & $-132,77$ & $-132,33$ & 1,003 \\
7,50 & $-135,18$ & $-137,12$ & 0,986 \\
\hline
\end{tabular}

Durante as analises numéricas de flexo-compressão considerando material elástico-linear não ocorreram problemas de convergência, obtendo-se solução para todos problemas estudados. No entanto, ocorreram problemas de convergência quando o modelo constitutivo não linear foi utilizado.

Foi então realizado um teste utilizando elementos de segunda ordem (com 20 nós), que possuem melhor comportamento na flexão. Não ocorreram melhoras significativas, o que levou então a crer que os problemas de convergência se devem à grande não linearidade do modelo constitutivo da sub-rotina.

\subsubsection{Modelagem do concreto confinado sob compressão excêntrica}

Procurou-se simular os pilares em condições semelhantes às dos pilares ensaiados no programa experimental. No entanto, como ocorreram problemas significativos de convergência, poucos resultados foram obtidos, limitando assim as análises a poucos casos. Os modelos simulados numericamente são apresentados na Tabela 6.11 . 
Tabela 6.11 - Simulações da excentricidade do carregamento

\begin{tabular}{llrrrrr}
\hline Pilar & Seção & $\mathrm{hx}(\mathrm{cm})$ & $\mathrm{hy}(\mathrm{cm})$ & $\mathrm{r}(\mathrm{cm})$ & $\mathrm{n}$ & $\mathrm{e}$ \\
\hline P1 & quadrada & 15 & 15 & 1 & 1 & 1 \\
P2 & quadrada & 15 & 15 & 1 & 1 & 1 \\
P3 & quadrada & 15 & 15 & 3 & 2 & 1 \\
P4 & quadrada & 15 & 15 & 3 & 2 & 1 \\
P5 & retangular & 15 & 22,5 & 3 & 2 & 1 \\
P6 & retangular & 22,5 & 15 & 3 & 2 & 1 \\
P7 & circular & 15 & 15 & 7,5 & 1 & 1 \\
P8 & circular & 15 & 15 & 7,5 & 2 & 1 \\
\hline
\end{tabular}

Na Figura 6.70 são apresentados os diagramas numérico e experimental dos pilares de seção transversal quadrada simulados com carregamento excêntrico. Pode-se observar uma boa concordância dos resultados numéricos com os experimentais. No pilar S21r3 não foi possível atingir a força máxima do ensaio nas simulações, já que o modelo numérico deixou de convergir.
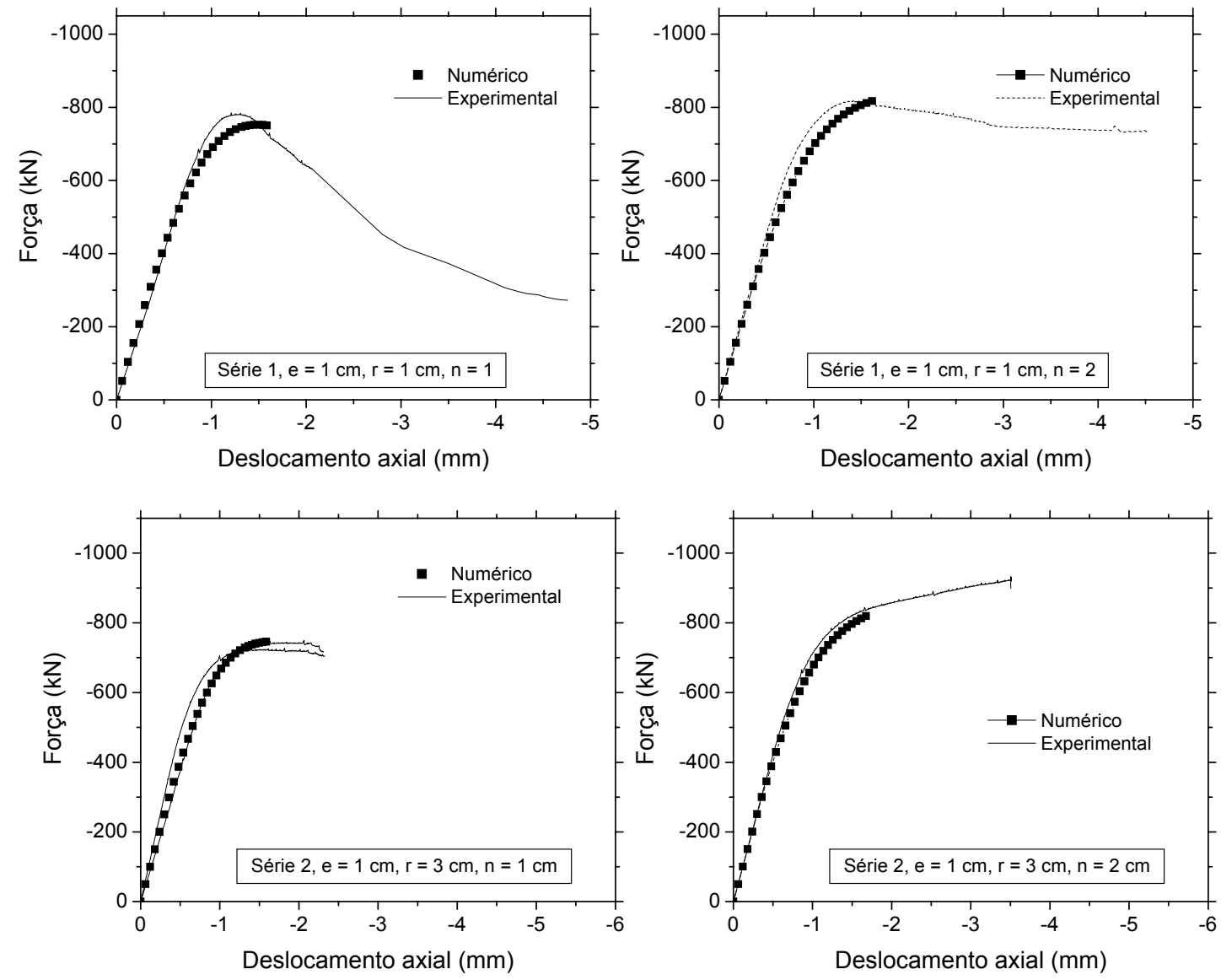

Figura 6.70 - Comparação dos resultados numéricos e experimentais dos pilares de seção quadrada sob carregamento excêntrico 
Na Figura 6.71 são apresentados os diagramas dos pilares de seção transversal retangular. Neste caso, não foi possível atingir a força máxima do ensaio em ambas as simulações.
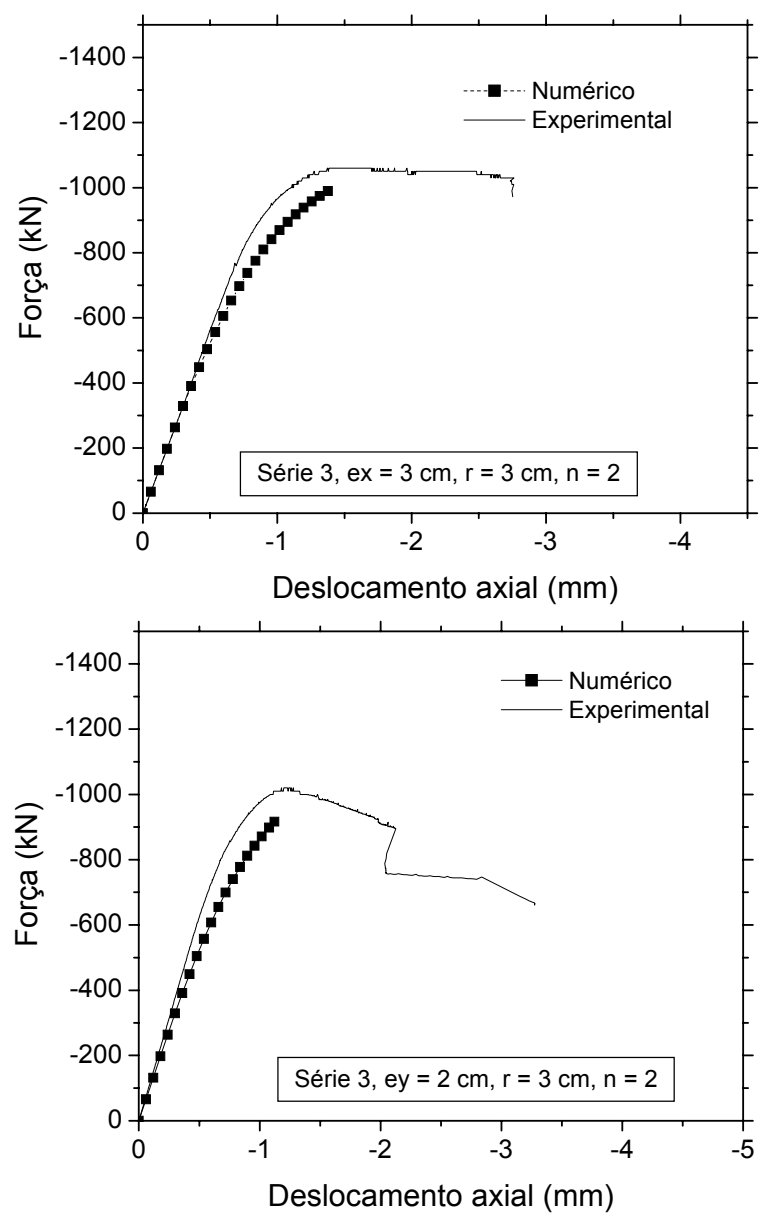

Figura 6.71 - Comparação dos resultados numéricos e experimentais dos pilares de seção retangular sob carregamento excêntrico

Nos pilares de seção circular, como mostra a Figura 6.72, também não foi possível chegar ao pico de resistência nas simulações com excentricidade não nula. 

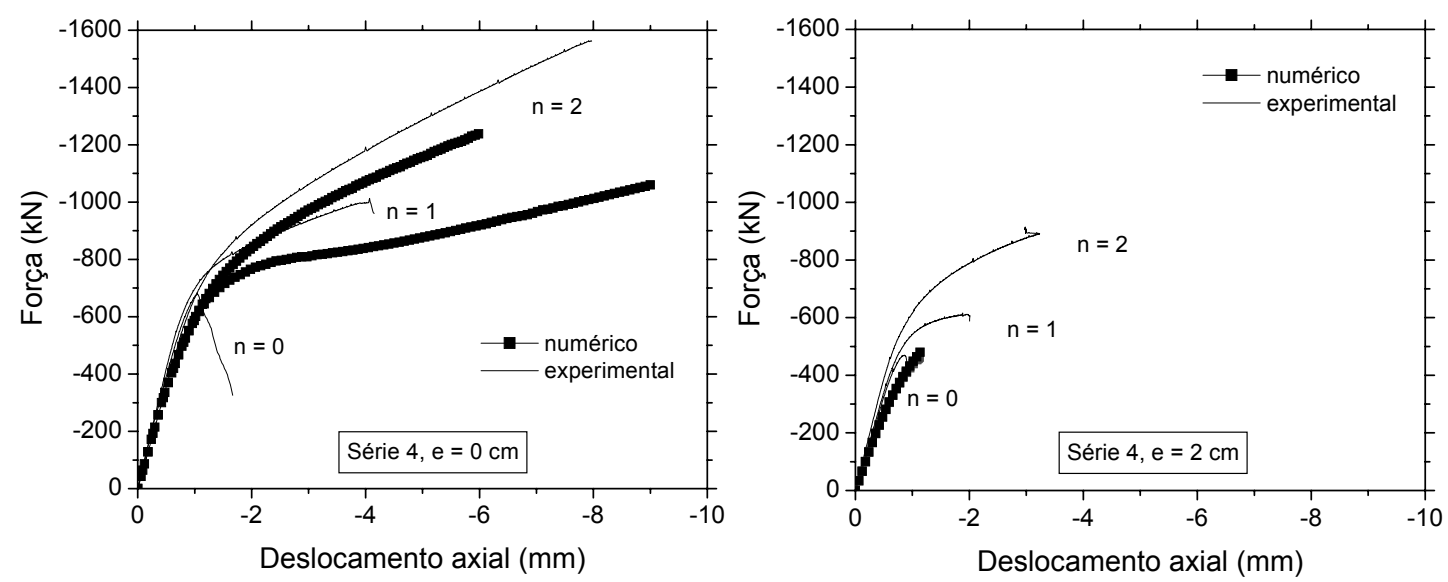

Figura 6.72 - Comparação dos resultados numéricos e experimentais dos pilares de seção circular sob carregamento centrado e excêntrico

\subsubsection{Estudo das tensões principais}

Neste item são apresentados os diagramas representando as tensões principais do concreto confinado, com o objetivo de melhor explicar os aspectos envolvidos nas diversas situações estudadas.

\subsubsection{Influência do raio de arredondamento}

Para avaliação da influência do raio de arredondamento dos cantos são apresentadas as tensões principais para os pilares de seção quadrada, na situação em que foi atingida a ruptura da camisa.

As figuras a seguir ilustram que quanto menor o raio de arredondamento dos cantos maior é a pressão lateral máxima gerada e consequentemente é maior a tensão axial nos cantos. No entanto, com a redução do raio de arredondamento as tensões nas regiões do núcleo central apresentaram valores inferiores. Este comportamento foi observado para todos os números de camadas de PRF simulados.

Devido a estas grandes pressões laterais desenvolvidas nos cantos, inicialmente os pilares com pequenos raios de arredondamento apresentam uma resposta mais rígida no diagrama tensão $\mathrm{x}$ deformação axial. É correto até afirmar que estes pilares apresentam uma resistência maior no início do carregamento. Porém, como as outras regiões são muito pouco confinadas, estas vão perdendo a resistência gradativamente e a rigidez do pilar vai diminuindo chegando possivelmente a uma inclinação negativa do diagrama tensão $\mathrm{x}$ deformação. 


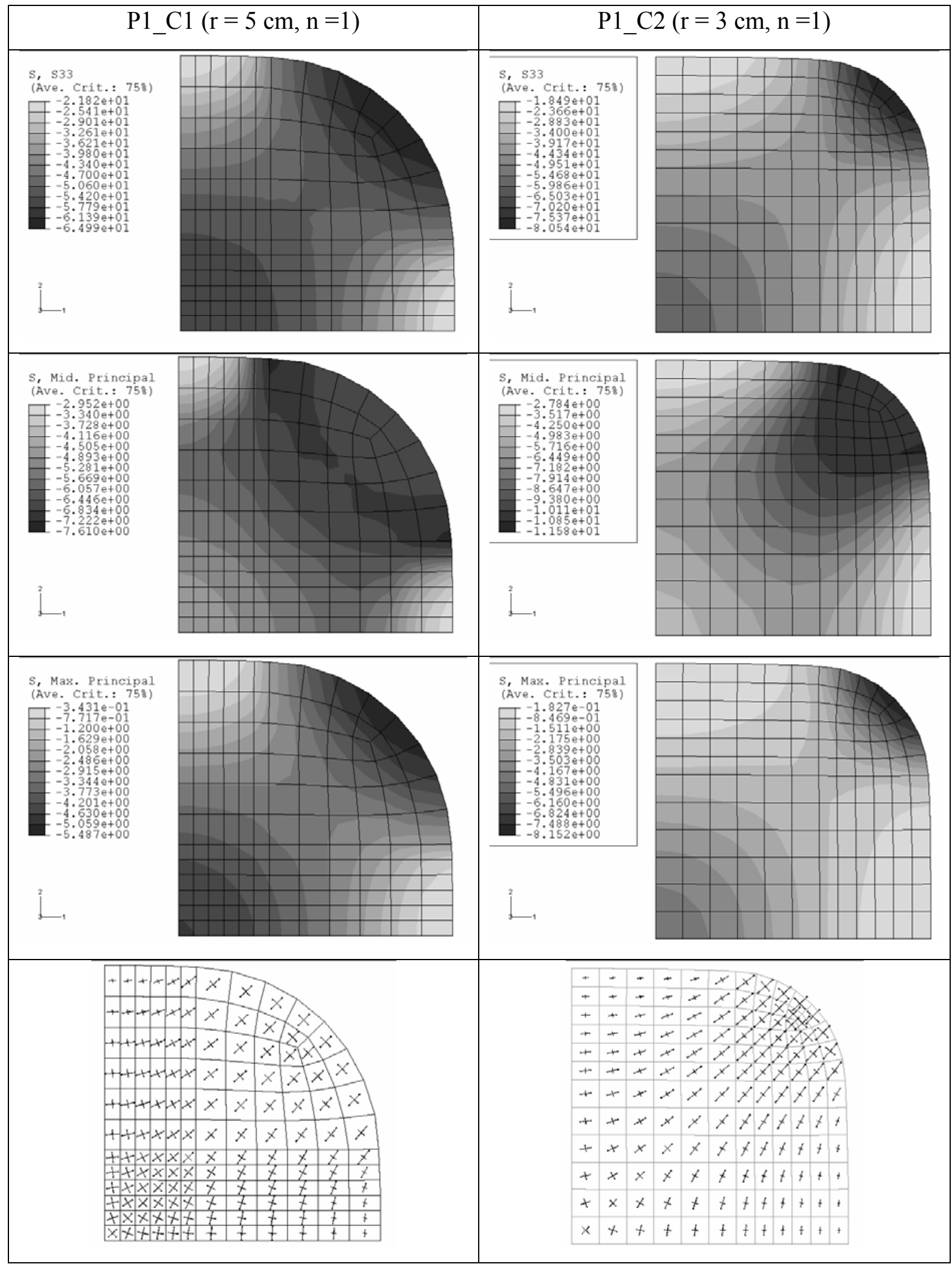

Figura 6.73 - Tensões principais nos pilares de seção quadrada 


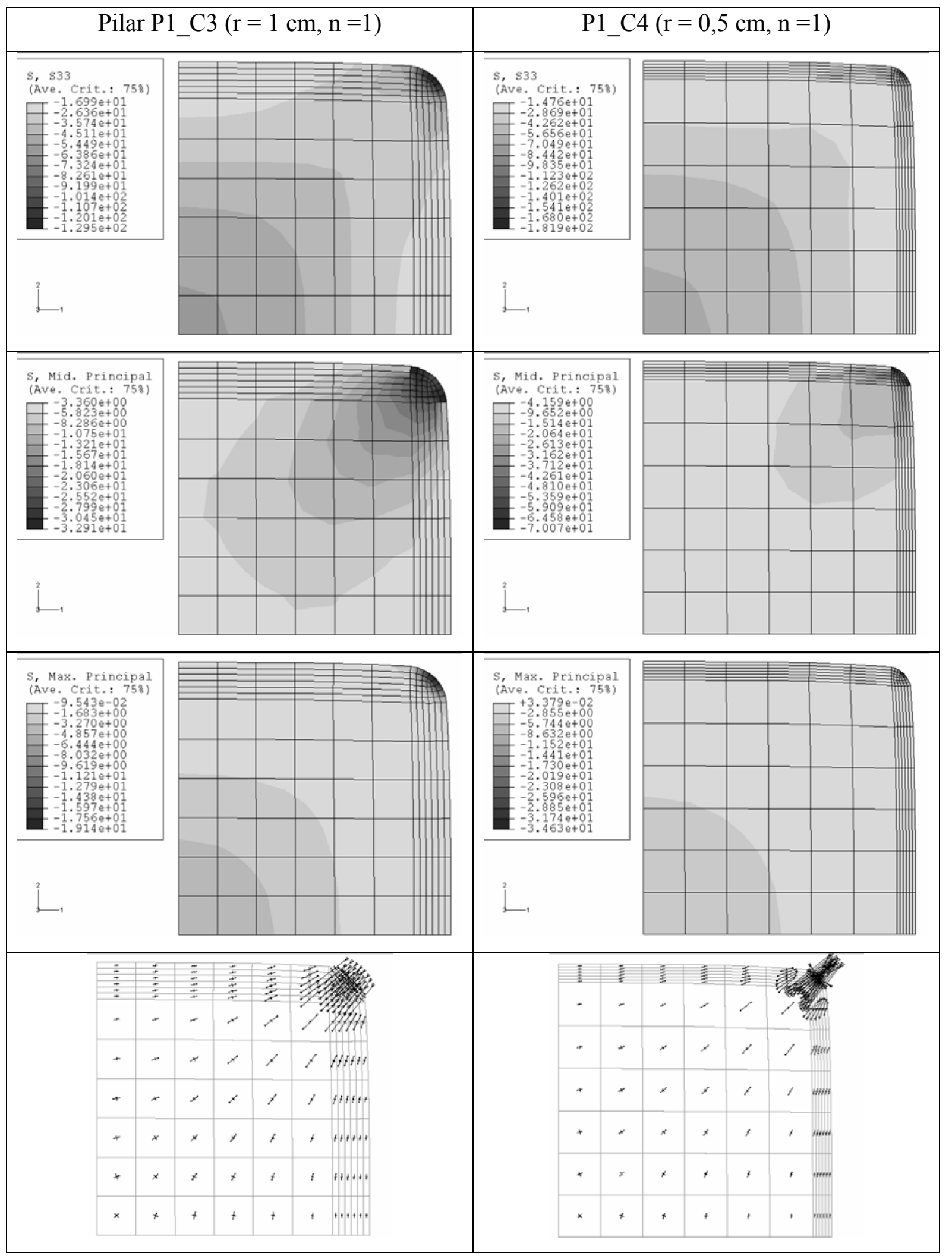

Figura 6.74 - Tensões principais nos pilares de seção quadrada 


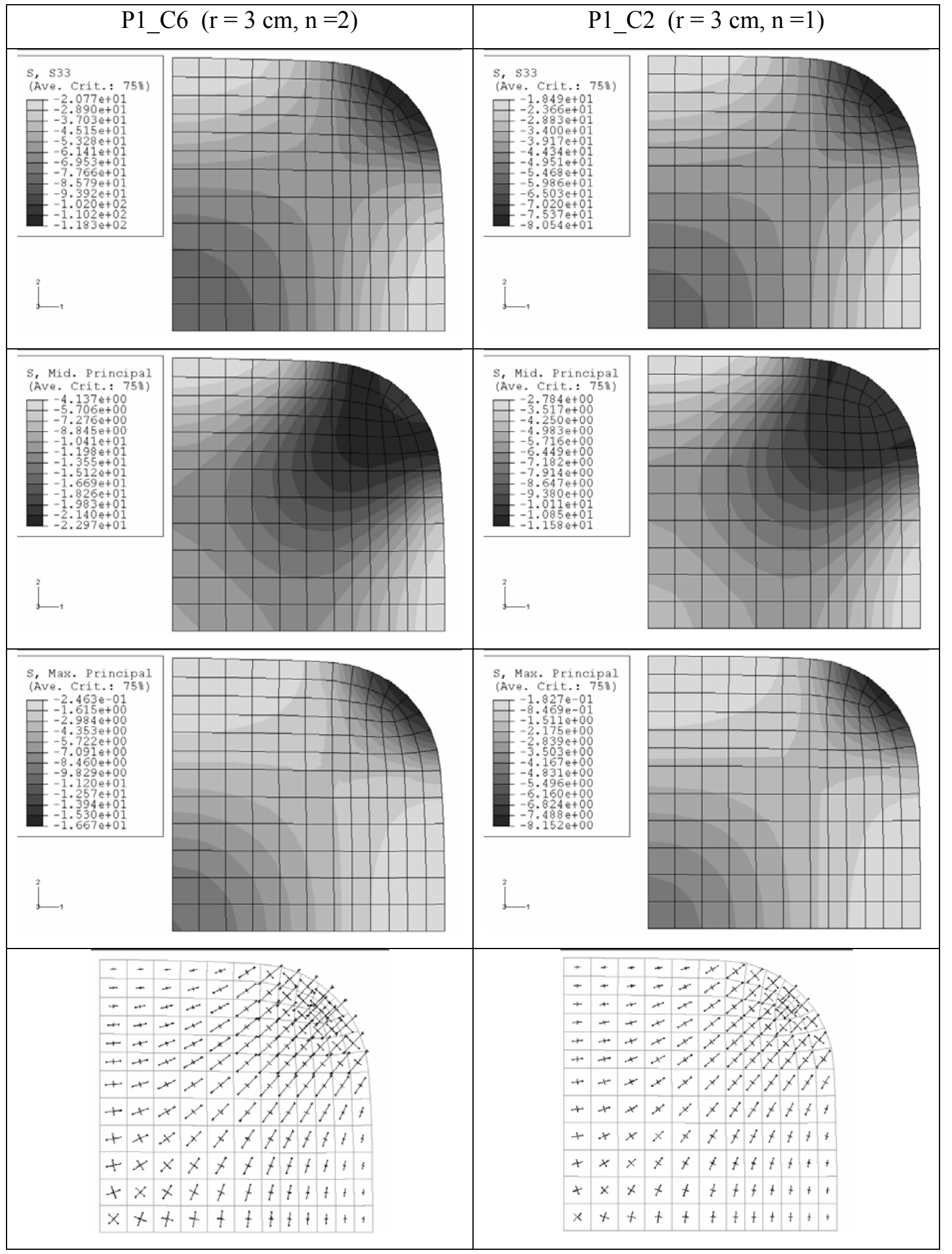

Figura 6.75 - Tensões principais nos pilares de seção quadrada 


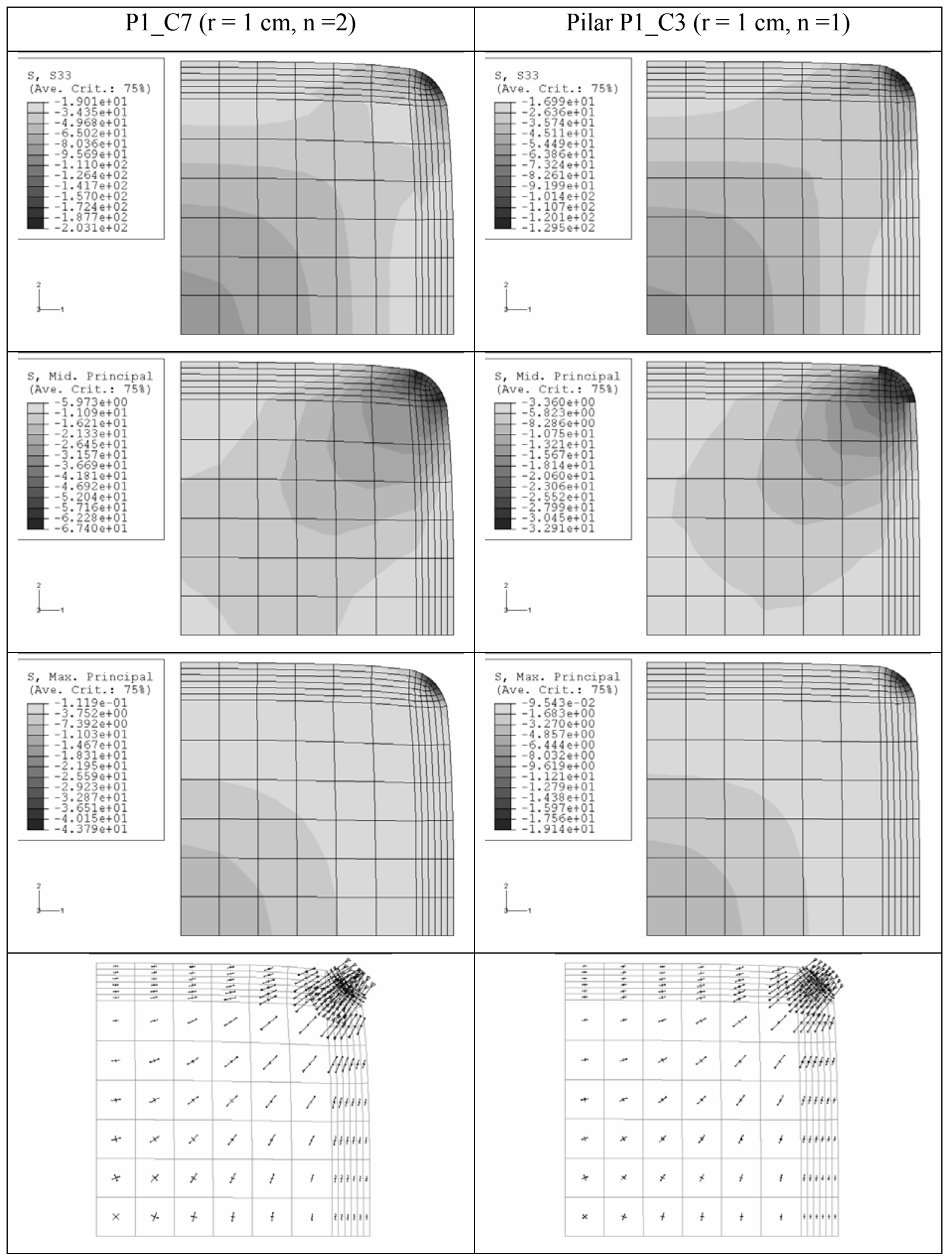

Figura 6.76 - Tensões principais nos pilares de seção quadrada 


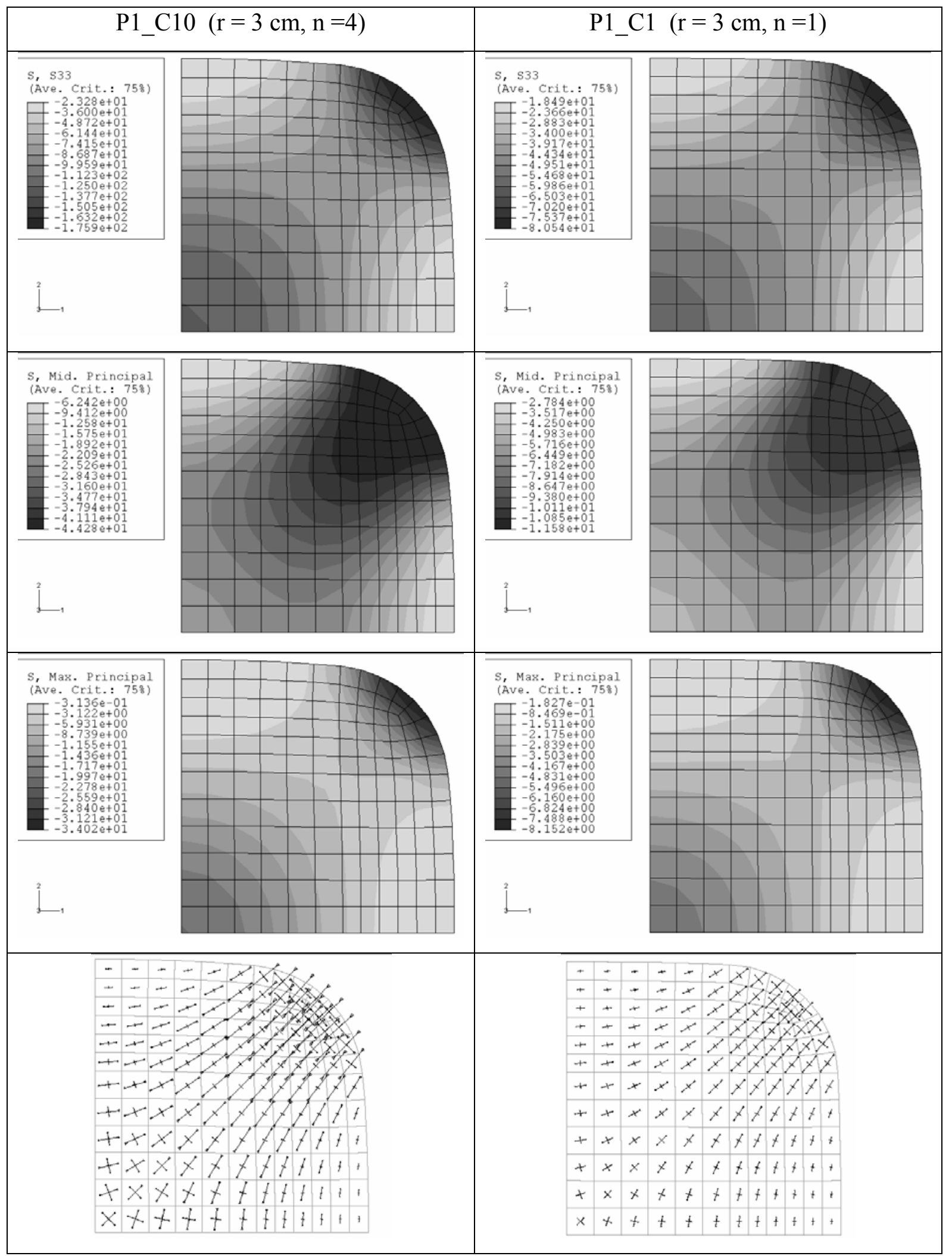

Figura 6.77 - Tensões principais nos pilares de seção quadrada 


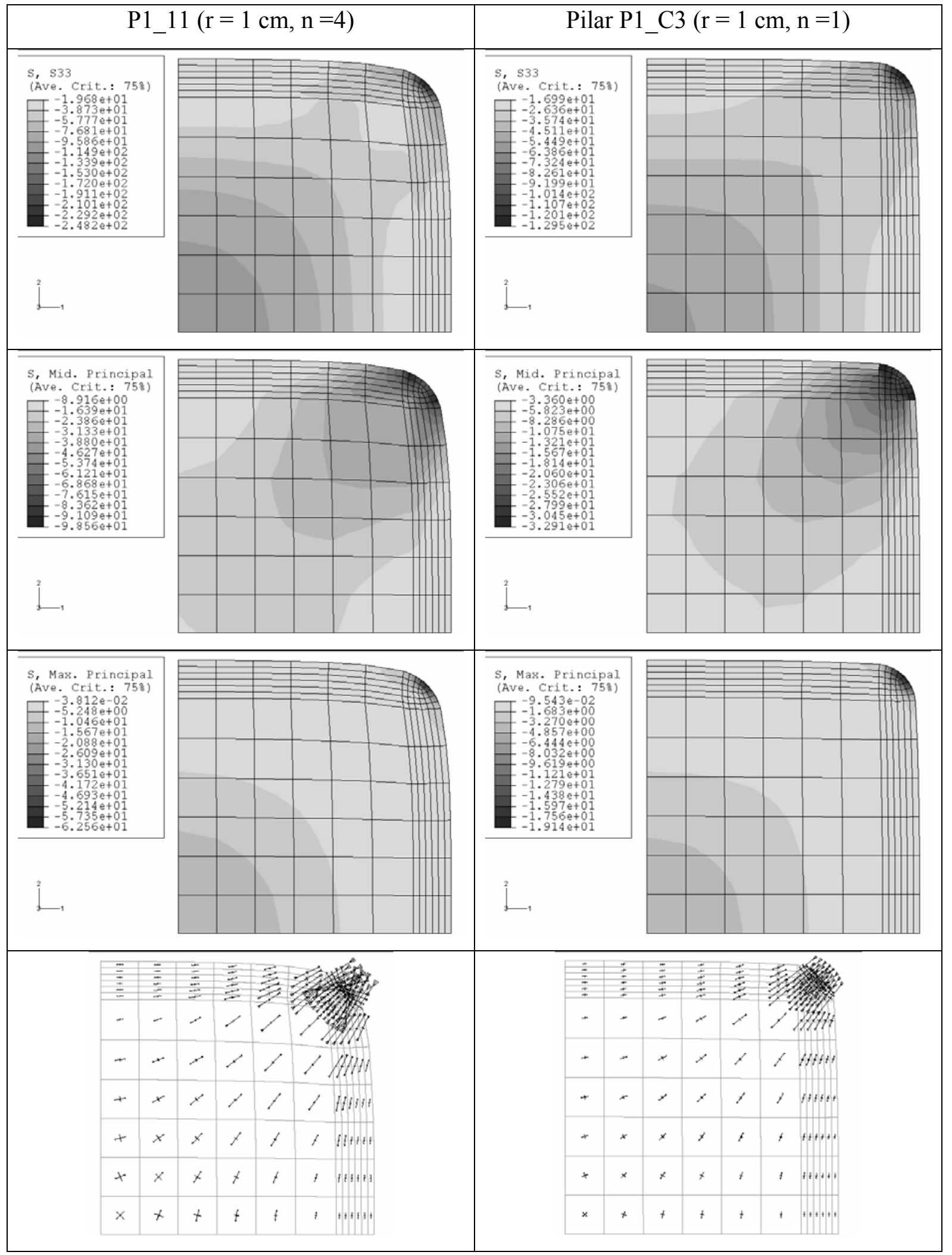

Figura 6.78 - Tensões principais nos pilares de seção quadrada 


\subsubsection{Influência da relação entre lados}

Para avaliação da influência da relação entre lados, são apresentadas as tensões principais considerando as duas formas de analisar o problema: mantendo a relação $2 \mathrm{r} / \mathrm{hx}$ fixa e mantendo o raio de arredondamento fixo $(3 \mathrm{~cm})$. Ambas as situações foram analisadas com $n=2$, na situação em que foi atingida a ruptura da camisa. $\mathrm{Na}$ análise da influência de hx/hy mantendo fixo $2 \mathrm{r} / \mathrm{hx}$ obteve-se os seguintes resultados:

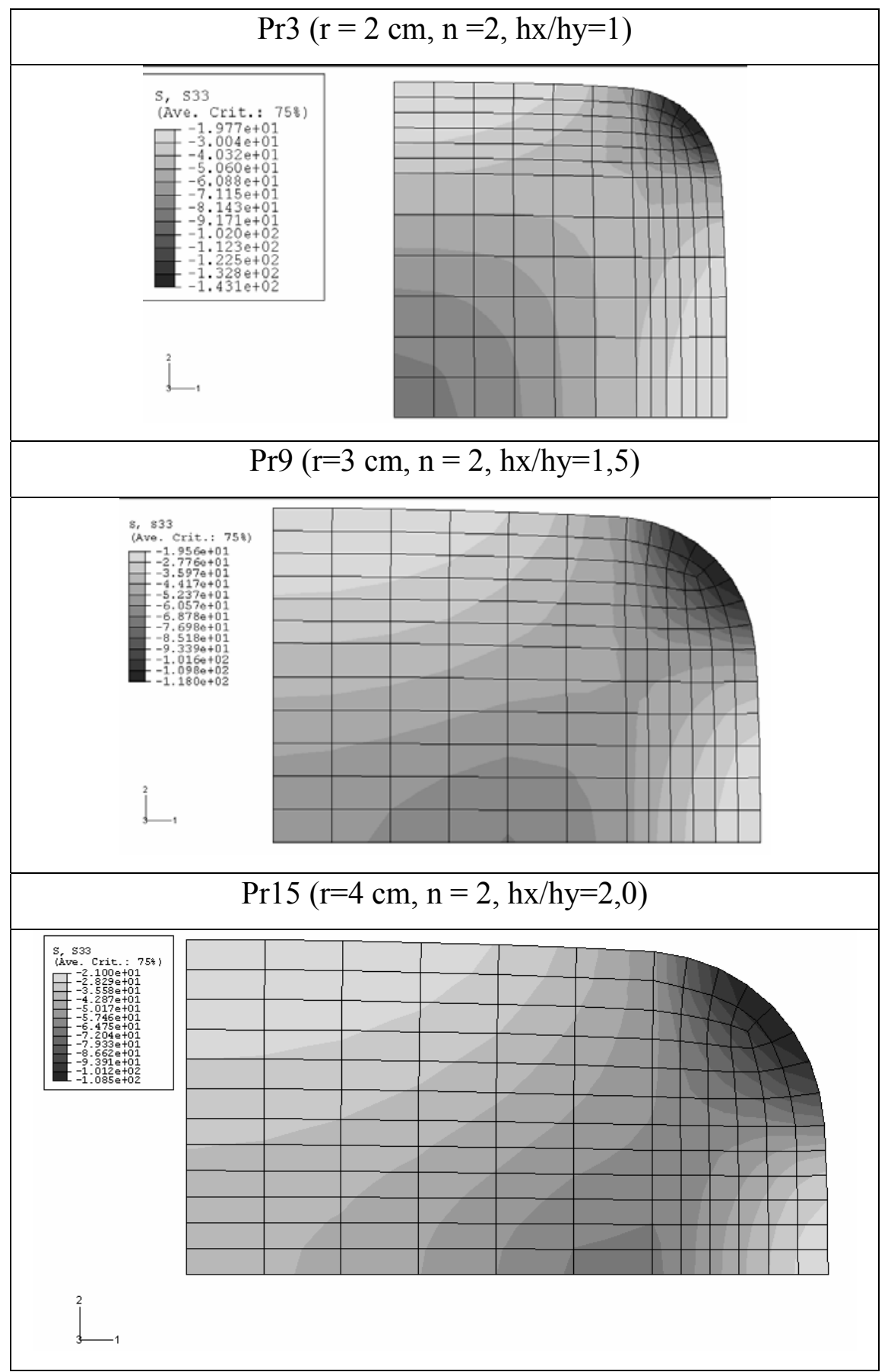

Figura 6.79 - Distribuição das tensões de compressão nos pilares de seção retangular $\operatorname{com} 2 \mathrm{r} / \mathrm{hx}=0,267$ 
Quando a relação $2 \mathrm{r} / \mathrm{h}_{\mathrm{x}}$ é mantida fixa em pilares de seção retangular, observouse que as regiões mais confinadas mudam de localização com o aumento de $h_{x} / h_{y}$. No entanto, se notou que não ocorreu uma mudança significativa do nível de confinamento desenvolvido.

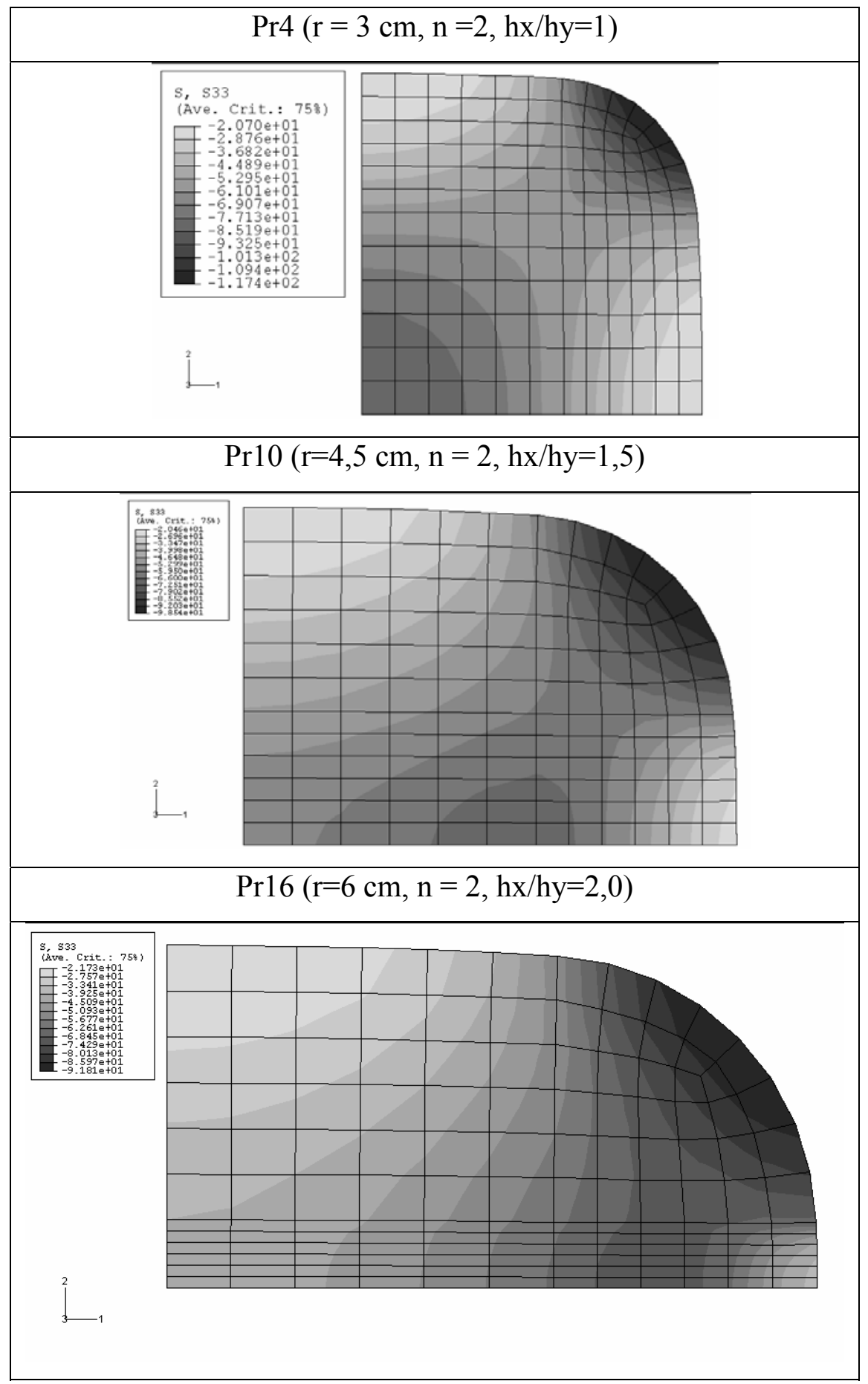

Figura 6.80 - Distribuição das tensões de compressão nos pilares de seção retangular $\operatorname{com} 2 \mathrm{r} / \mathrm{hx}=0,267$ 
Considerando que em muitos casos utilizar raios de arredondamento dos cantos acima de $3 \mathrm{~cm}$ é inviável, foi realizada uma análise da influência da relação hx/hy mantendo o raio de arredondamento constante.

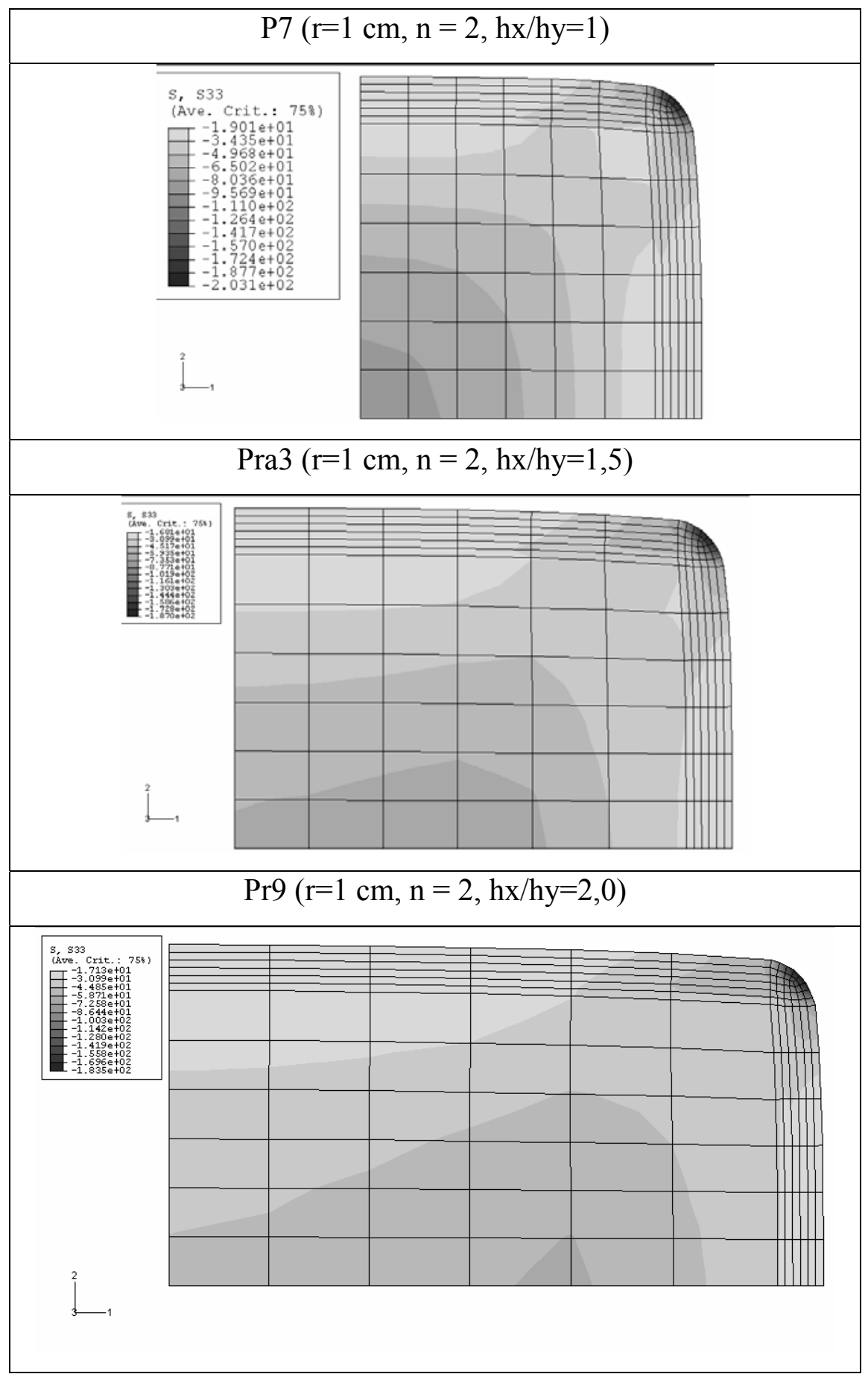

Figura 6.81 - Distribuição das tensões de compressão nos pilares de seção retangular $\operatorname{com} 2 \mathrm{r} / \mathrm{hx}=0,267$

Nos pilares de seção retangular observou-se que mantendo constante o raio de arredondamento ocorreram importantes reduções do efeito de confinamento ao 
aumentar a relação $h_{x} / h_{y}$. Estas se devem mais à redução de $2 r / h_{x}$ do que do próprio valor de $h_{\mathrm{x}} / h_{\mathrm{y}}$.

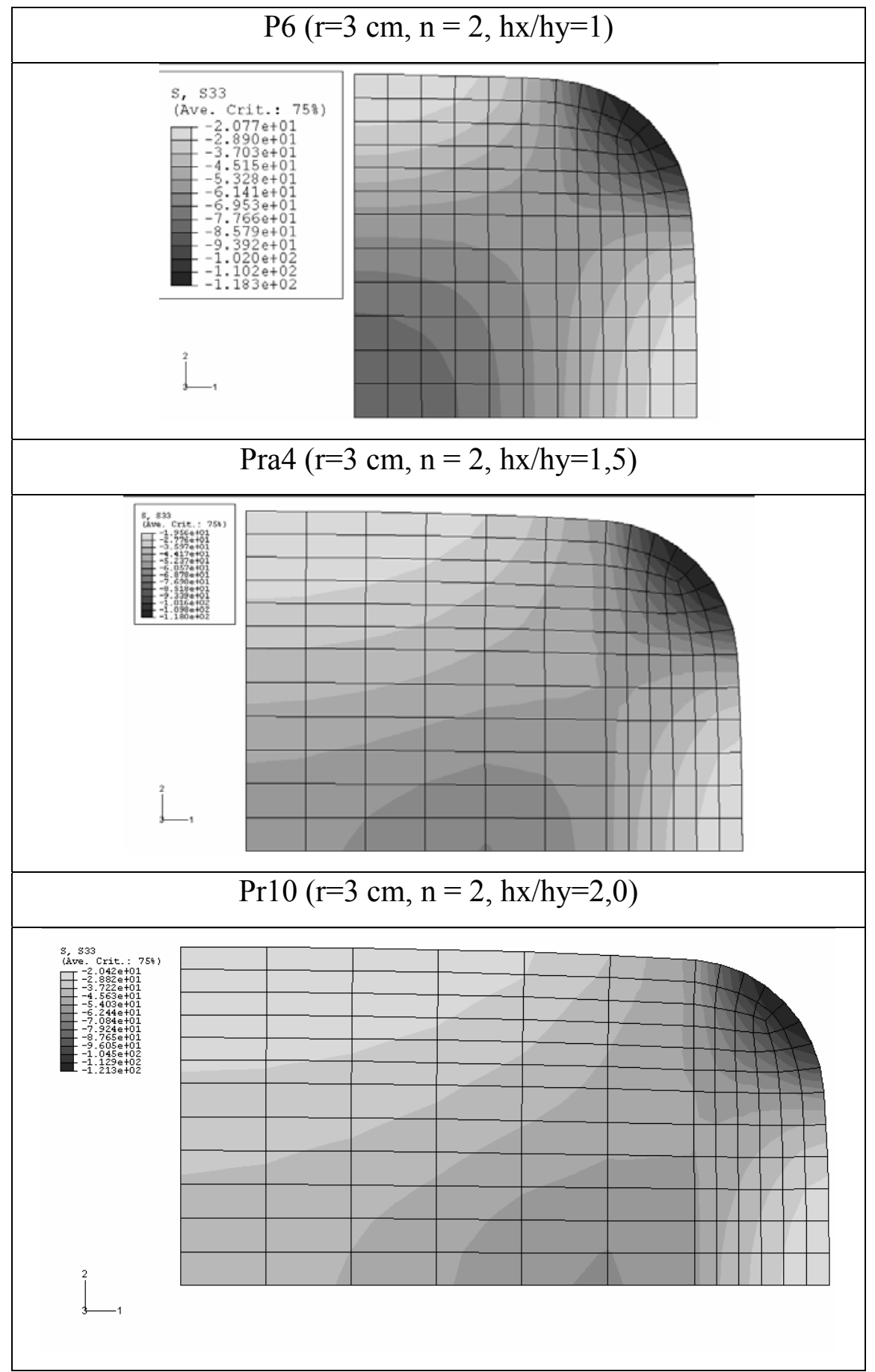

Figura 6.82 - Distribuição das tensões de compressão nos pilares de seção retangular

$\operatorname{com} 2 \mathrm{r} / \mathrm{hx}=0,267$

\subsubsection{Influência da excentricidade do carregamento}

Para avaliação do efeito da excentricidade, são apresentadas as tensões nos pilares de seção quadrada, retangular e circular. Nos pilares de seção quadrada são 
apresentadas as tensões com 1 e 2 camadas para os raios de arredondamento de 1 e 3 $\mathrm{cm}$.

\begin{tabular}{|c|c|c|c|}
\hline \multicolumn{2}{|c|}{$\operatorname{Pe} 1(\mathrm{r}=1 \mathrm{~cm}, \mathrm{n}=1, \mathrm{e}=1 \mathrm{~cm})$} & \multicolumn{2}{|c|}{$\operatorname{Pe} 3(\mathrm{r}=1 \mathrm{~cm}, \mathrm{n}=2, \mathrm{e}=1 \mathrm{~cm})$} \\
\hline 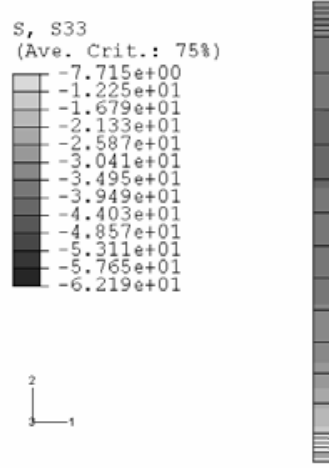 & 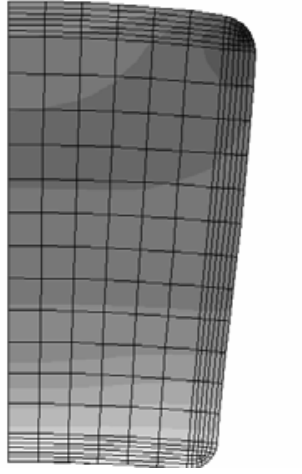 & 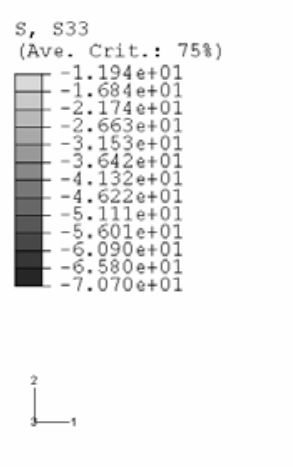 & 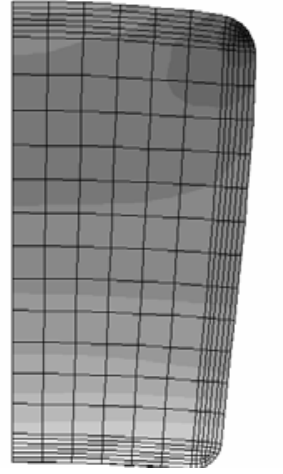 \\
\hline 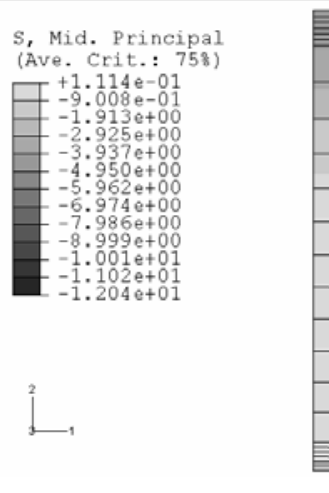 & 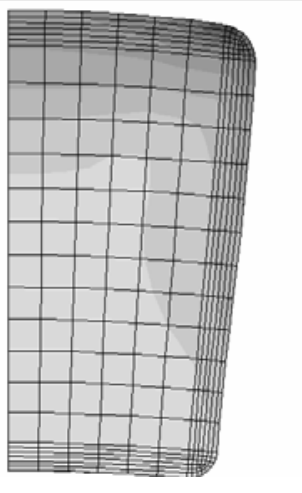 & 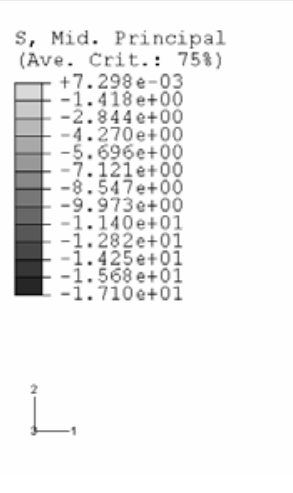 & 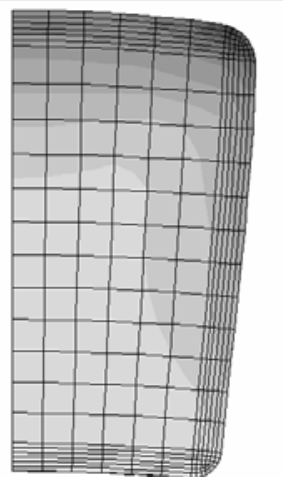 \\
\hline 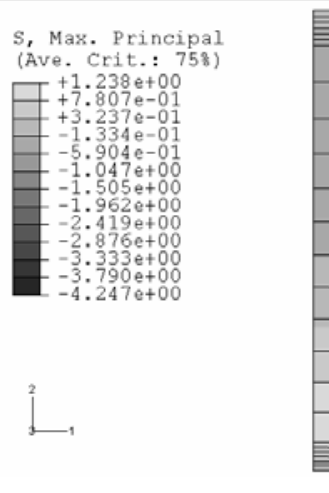 & $\begin{array}{l} \\
\end{array}$ & 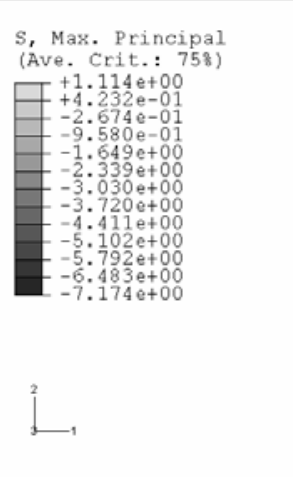 & 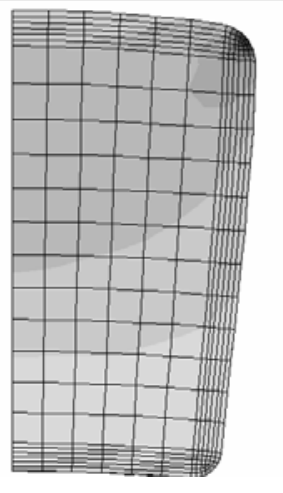 \\
\hline $\begin{array}{l}\text { s, Max. Principal } \\
\text { s, Midd. Principal } \\
\text { s, Min. Principal }\end{array}$ & 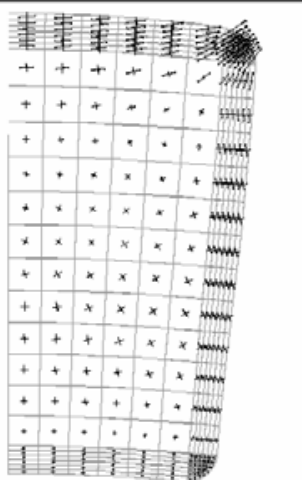 & 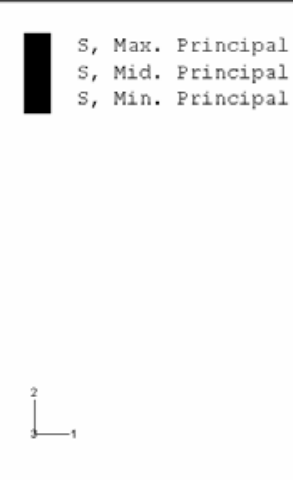 & 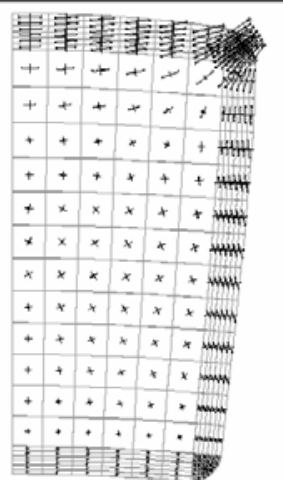 \\
\hline
\end{tabular}

Figura 6.83 - Tensões principais nos pilares de seção quadrada com $r=1 \mathrm{~cm}$ e e $=1 \mathrm{~cm}$ 


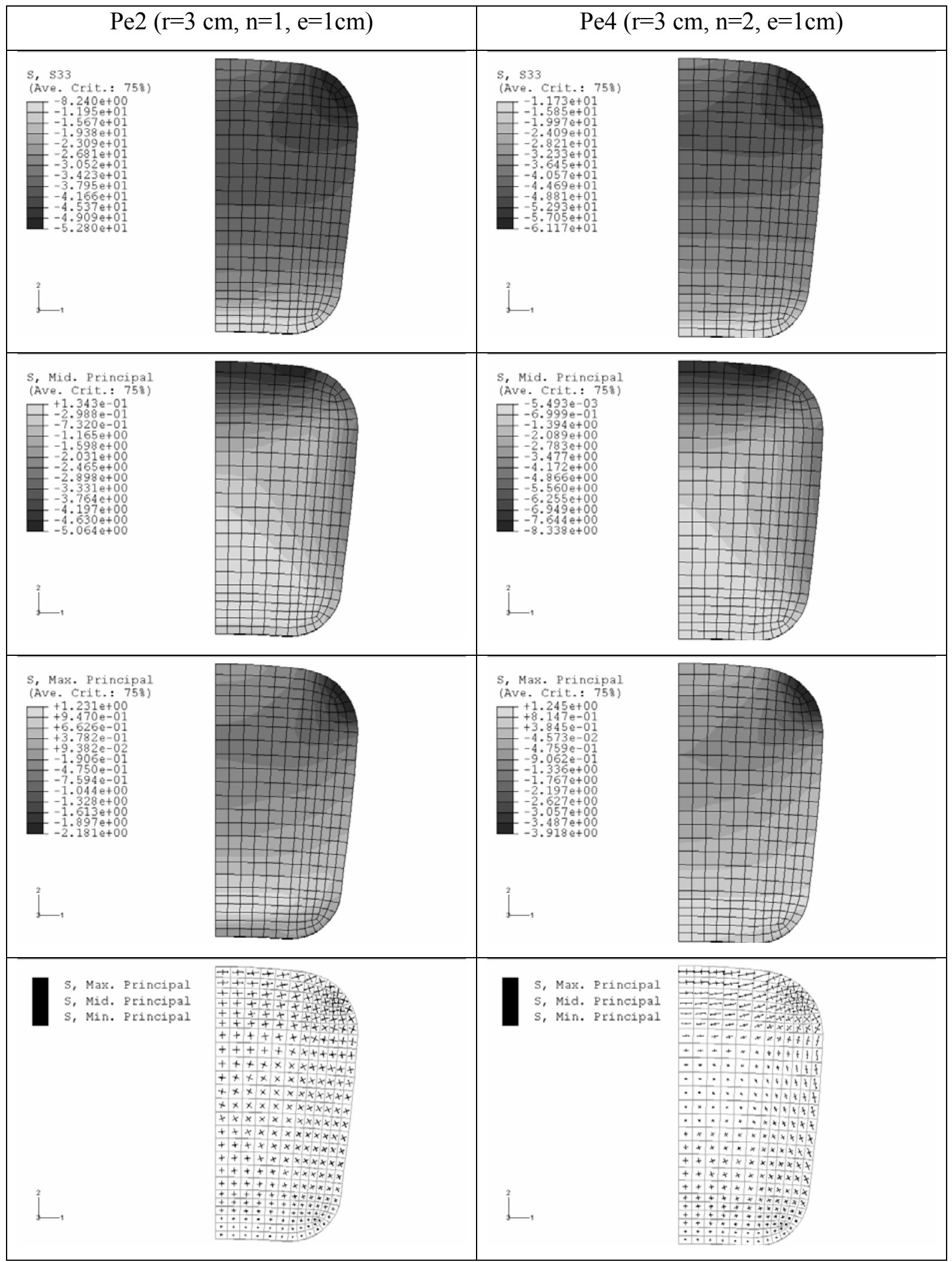

Figura 6.84 - Tensões principais nos pilares de seção quadrada com $r=3 \mathrm{~cm}$ e e $=1 \mathrm{~cm}$

As tensões principais nos pilares de seção transversal retangular são apresentadas na Figura 6.85 e na Figura 6.86. 


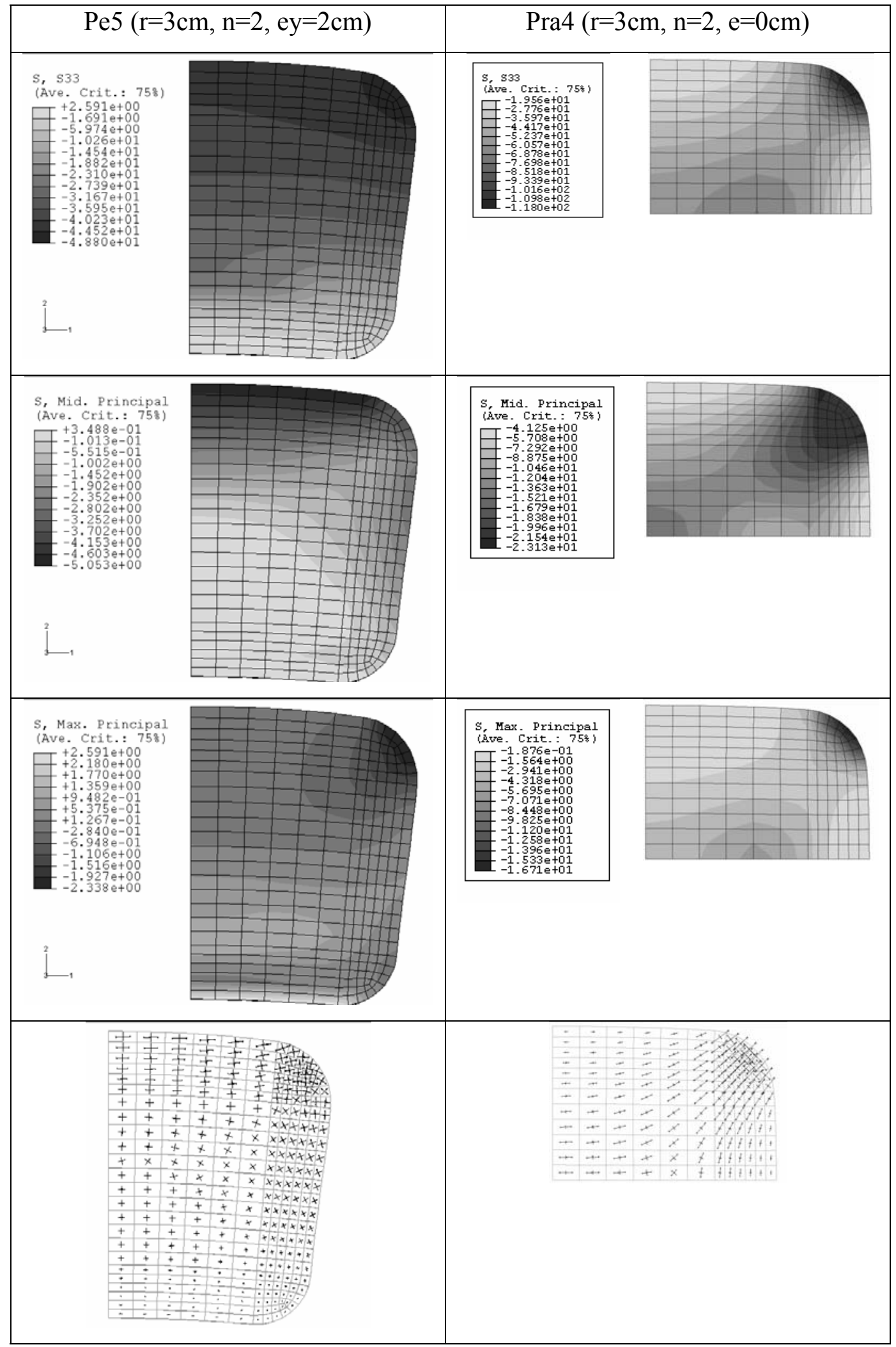

Figura 6.85 - Tensões principais nos pilares de seção quadrada $\operatorname{com} r=3 \mathrm{~cm}$ e e $=1 \mathrm{~cm}$ 


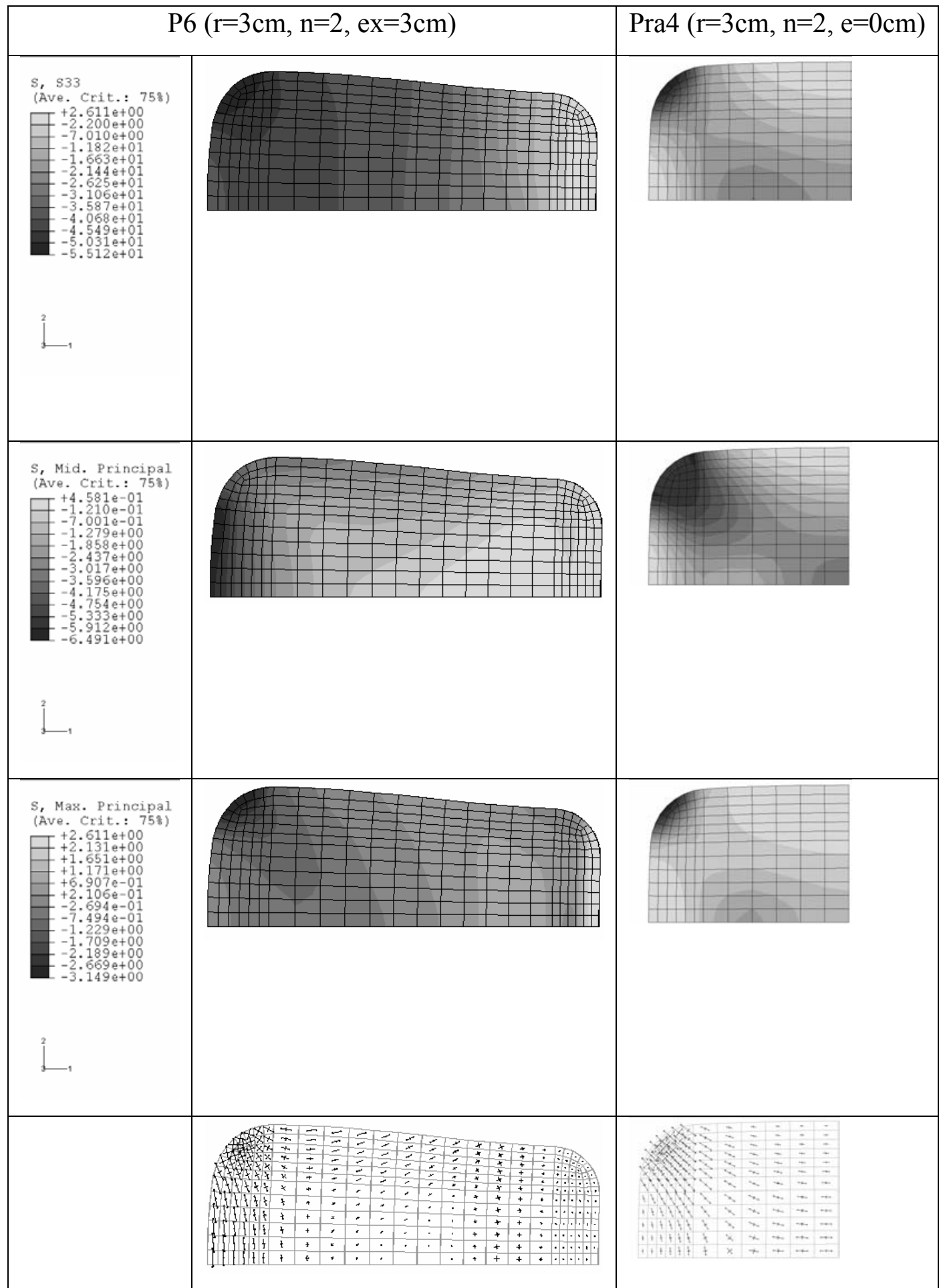

Figura 6.86 - Tensões principais nos pilares de seção quadrada com $r=3 \mathrm{~cm}$ e e $=1 \mathrm{~cm}$

Foram ainda simulados pilares de seção transversal circular encamisados com PRFC. Estes pilares possuíam 1 e 2 camadas de PRFC e foram submetidos a uma força com excentricidade de 1 e $2 \mathrm{~cm}$. 


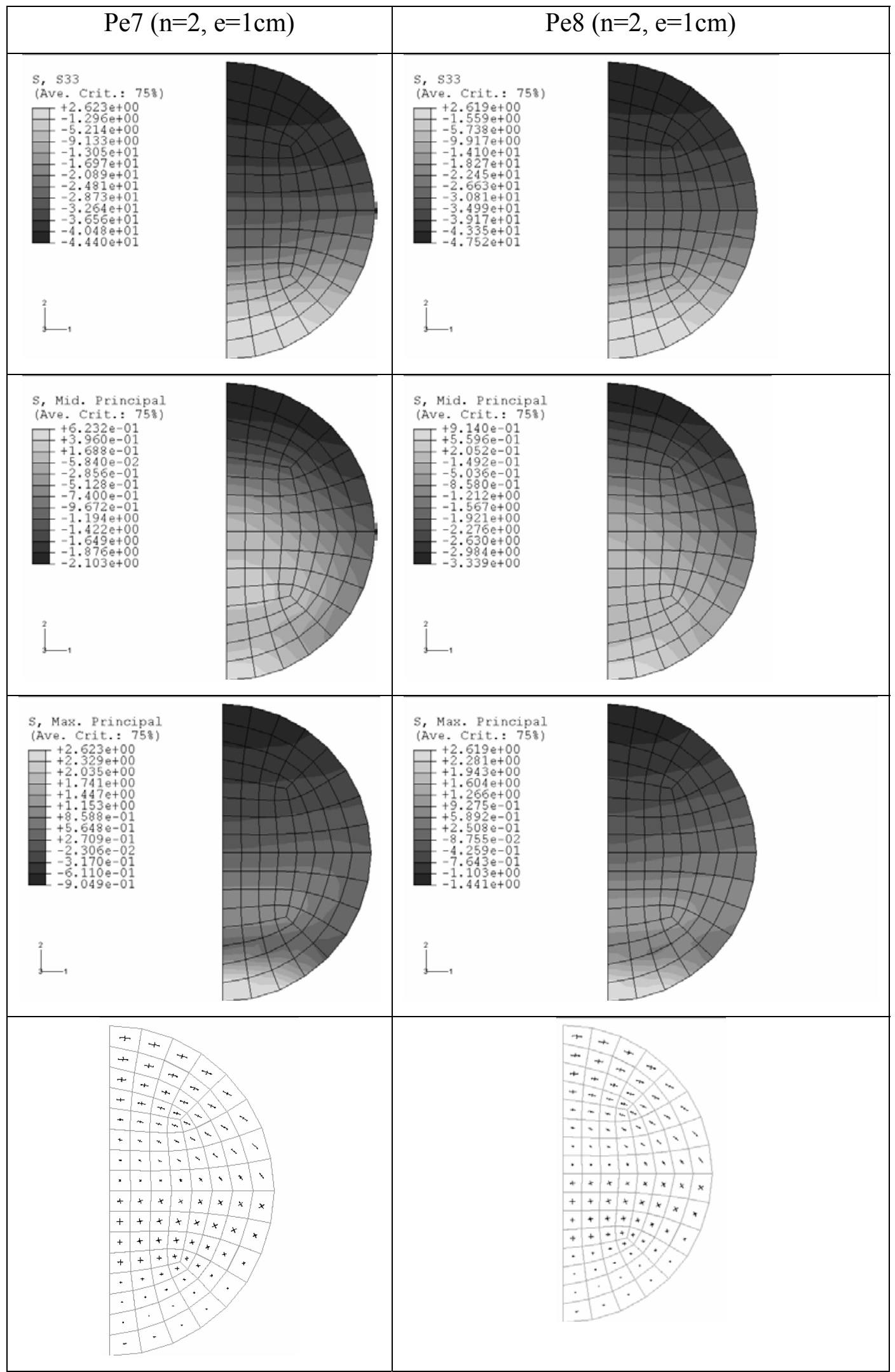

Figura 6.87 - Tensões principais nos pilares de seção quadrada com $r=3 \mathrm{~cm}$ e e $=1 \mathrm{~cm}$ 


\subsubsection{Deformações transversais da camisa}

Neste item são apresentadas as deformações da camisa obtidas com os modelos numéricos para algumas das situações estudadas.

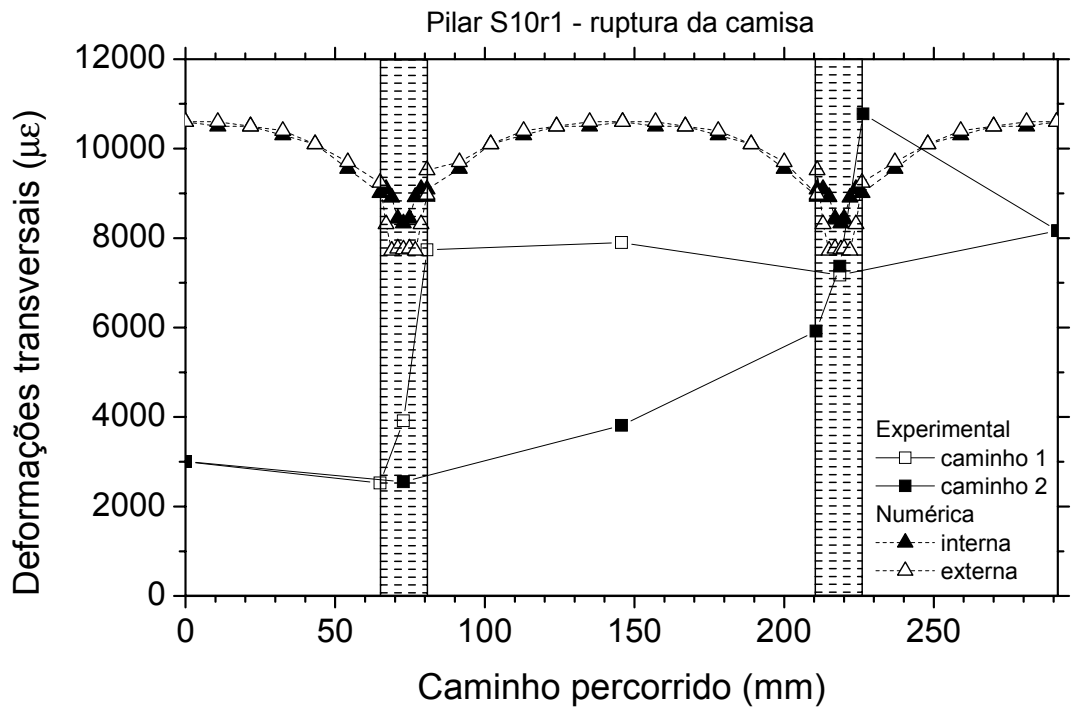

Figura 6.88 - Deformações transversais da camisa pilar S10r1

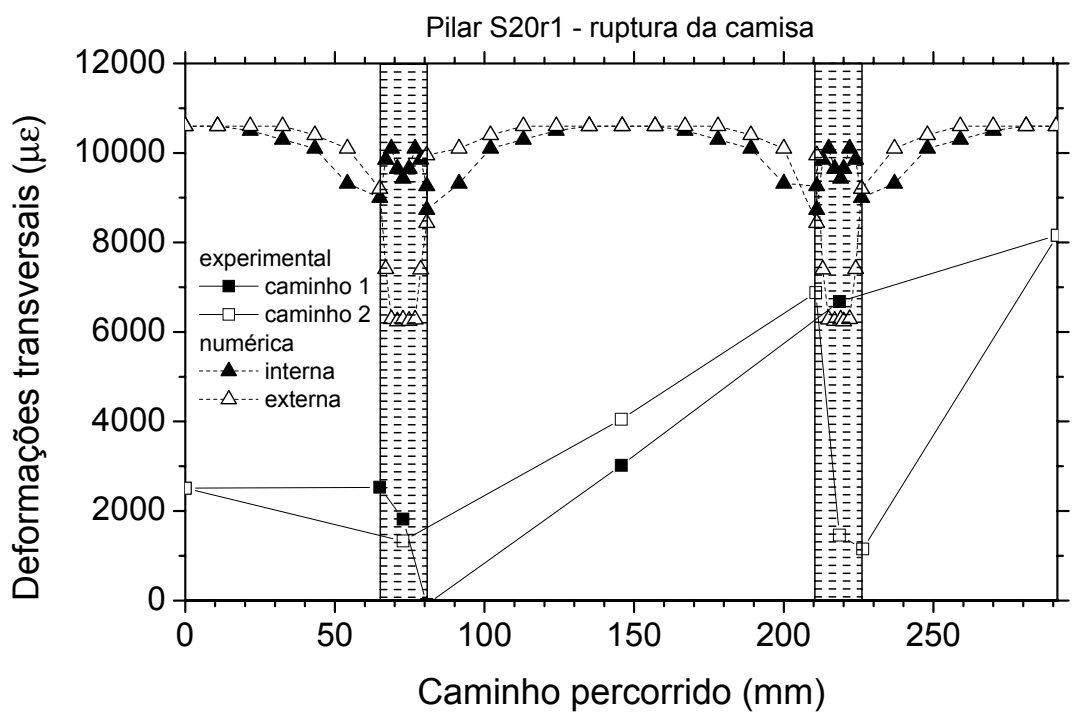

Figura 6.89 - Deformações transversais da camisa pilar S20r1 


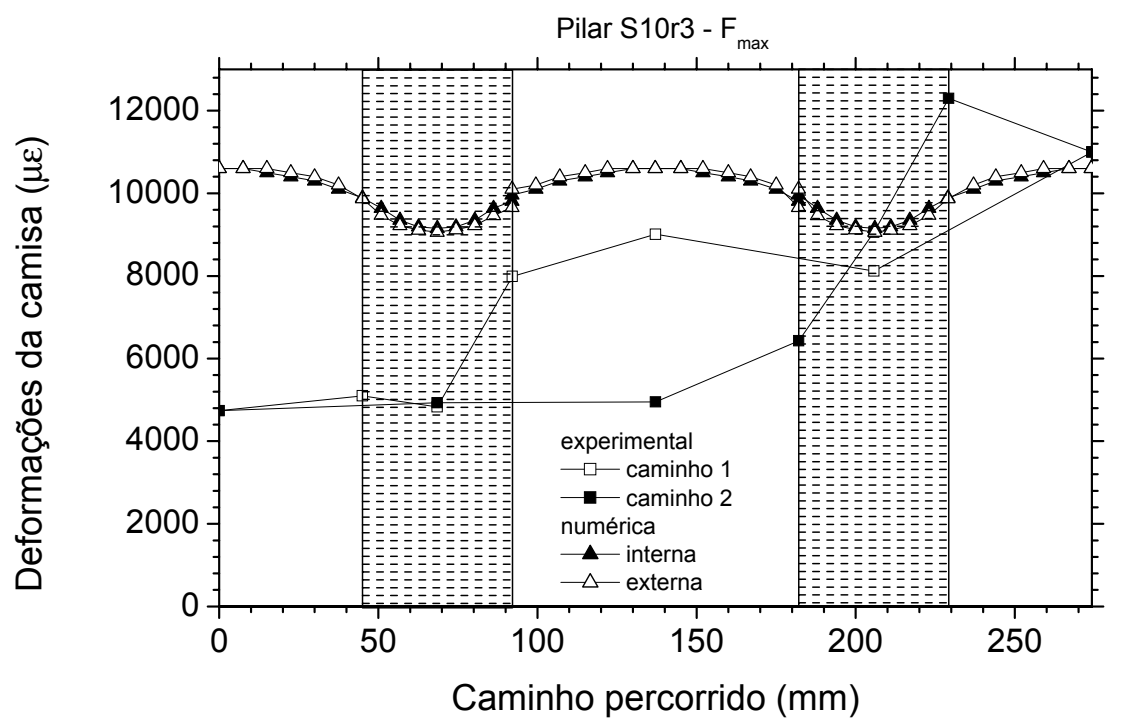

Figura 6.90 - Deformações transversais da camisa pilar S10r3

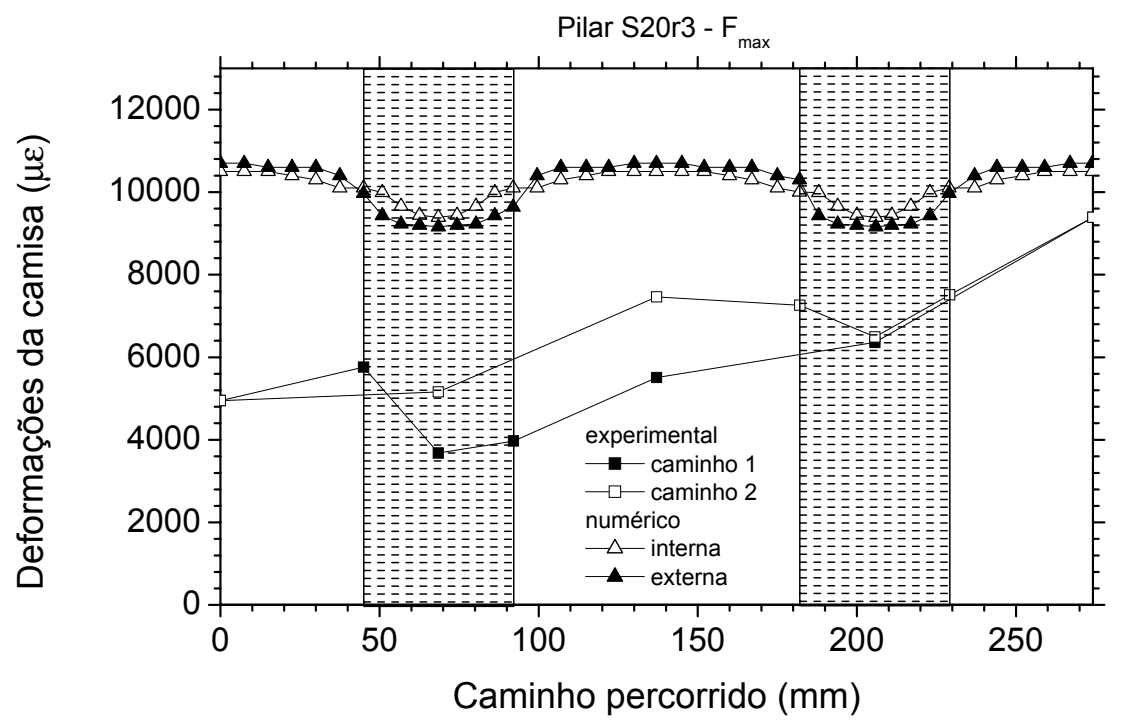

Figura 6.91 - Deformações transversais da camisa pilar S20r3 


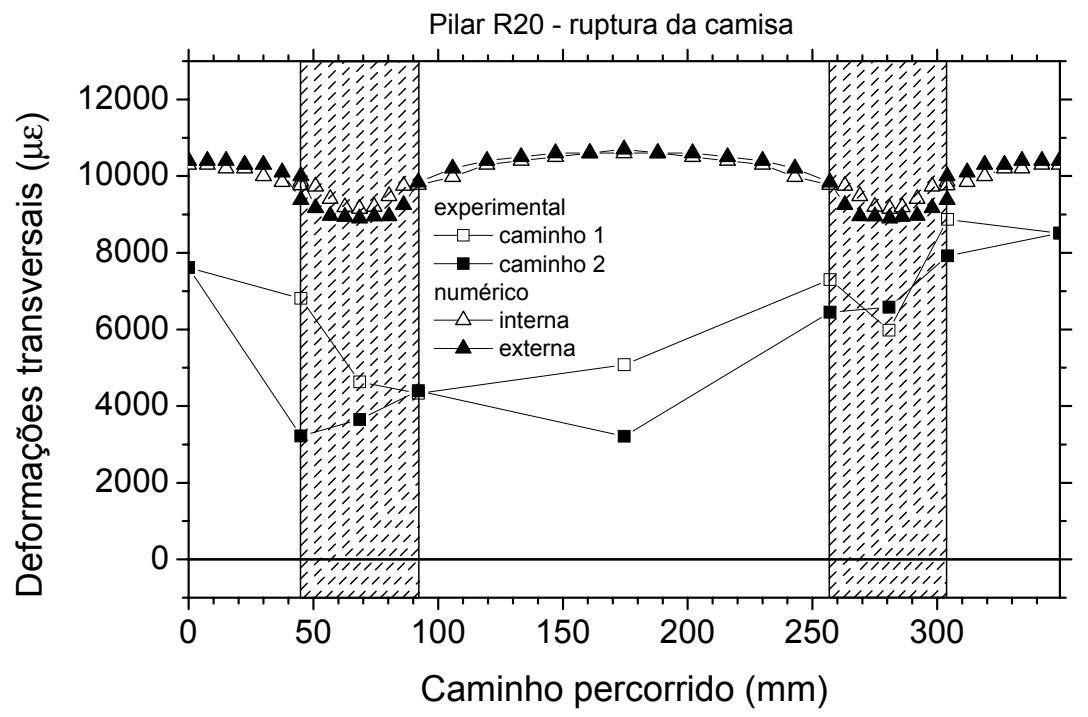

Figura 6.92 - Deformações transversais da camisa pilar R20

Para os pilares de seção transversal quadrada e retangular submetidos à compressão excêntrica são apresentadas as deformações da camisa experimentais no momento em que foi atingida a força máxima no ensaio e os últimos resultados obtidos na análise numérica.

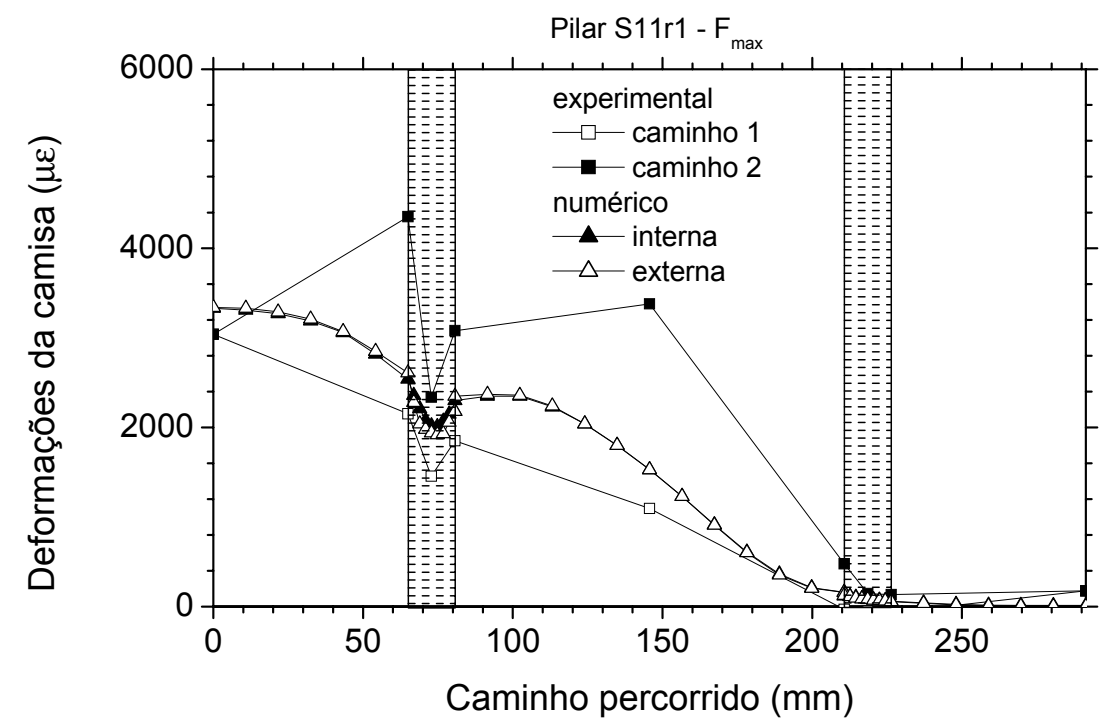

Figura 6.93 - Deformações na camisa: valores numéricos x experimentais 


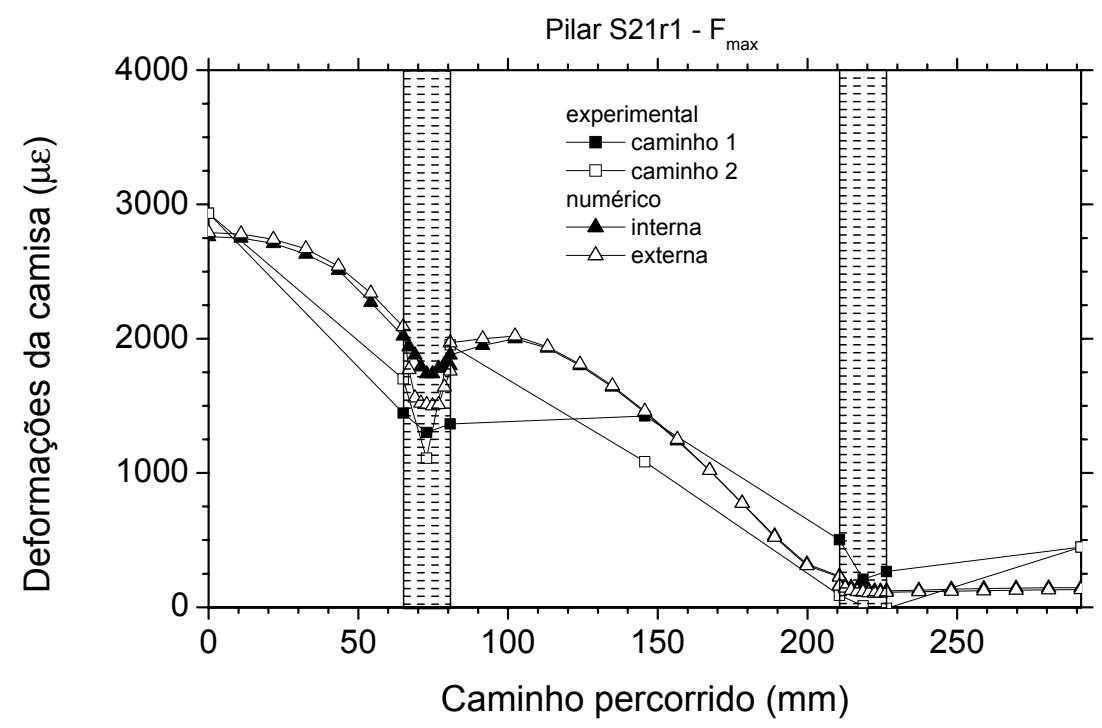

Figura 6.94 - Deformações na camisa: valores numéricos x experimentais

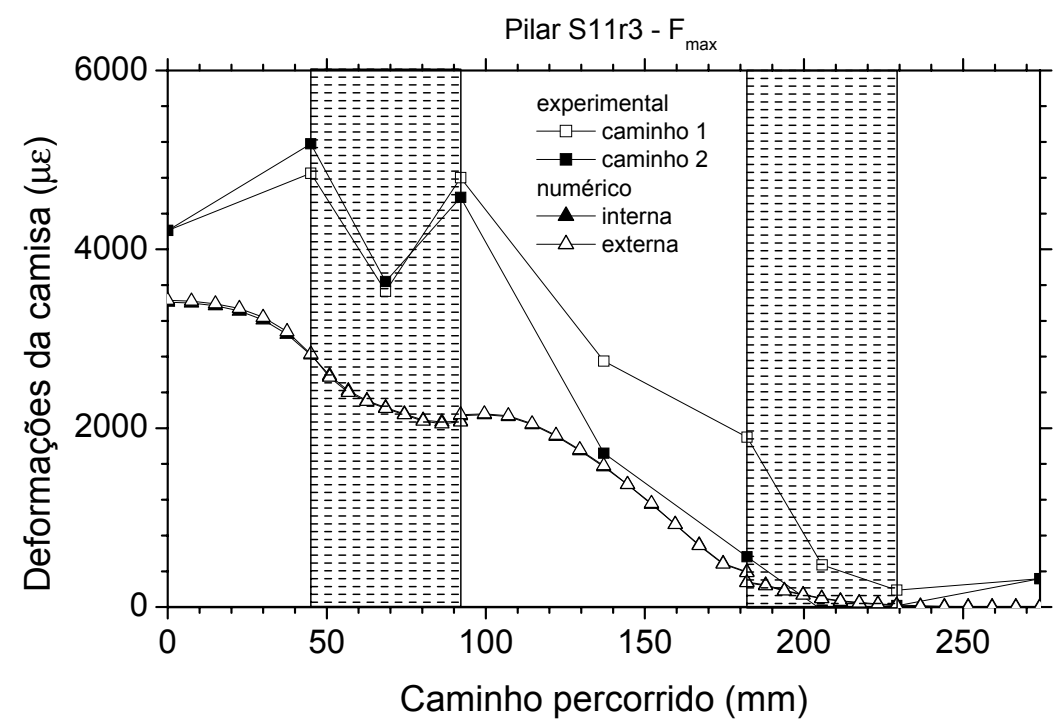

Figura 6.95 - Deformações na camisa: valores numéricos x experimentais

Para o pilar S21r3, como o modelo deixou de convergir antes do final da análise, a comparação das deformações na camisa foi realizada para valores experimentais com a força do ensaio igual à numérica. 


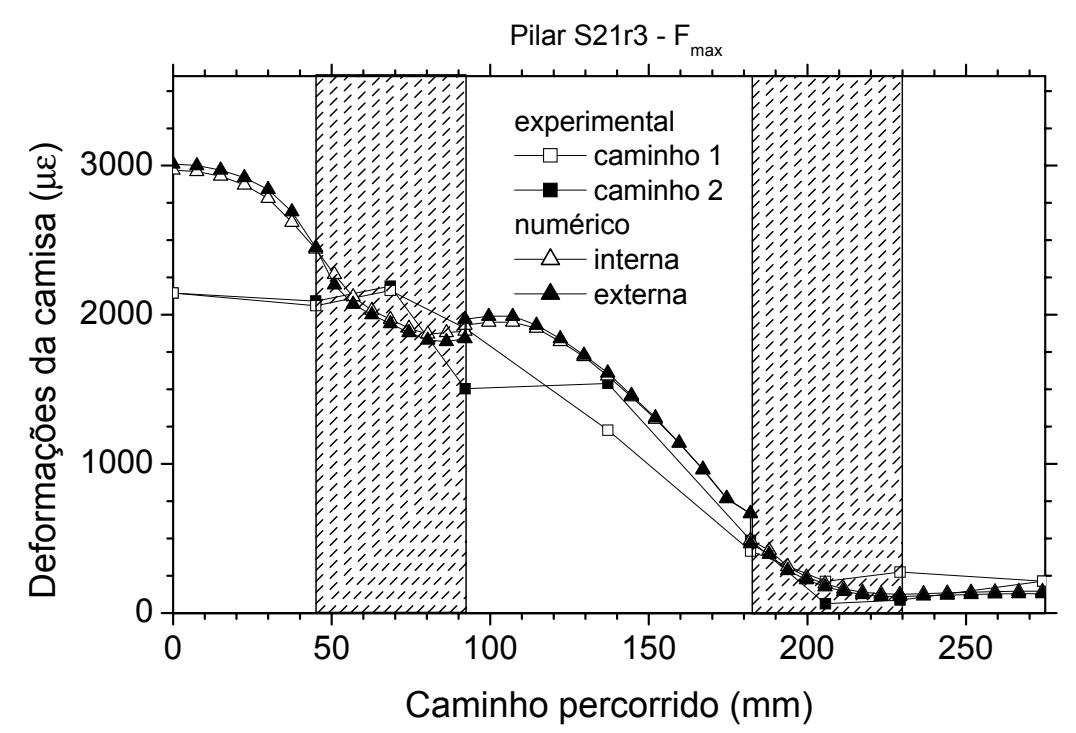

Figura 6.96 - Deformações na camisa: valores numéricos x experimentais

Para os pilares de seção retangular submetidos a carregamentos com excentricidade foram comparadas as deformações da camisa para a força máxima do ensaio (Fmax), por estar mais próxima da força em que pararam de convergir as simulações.

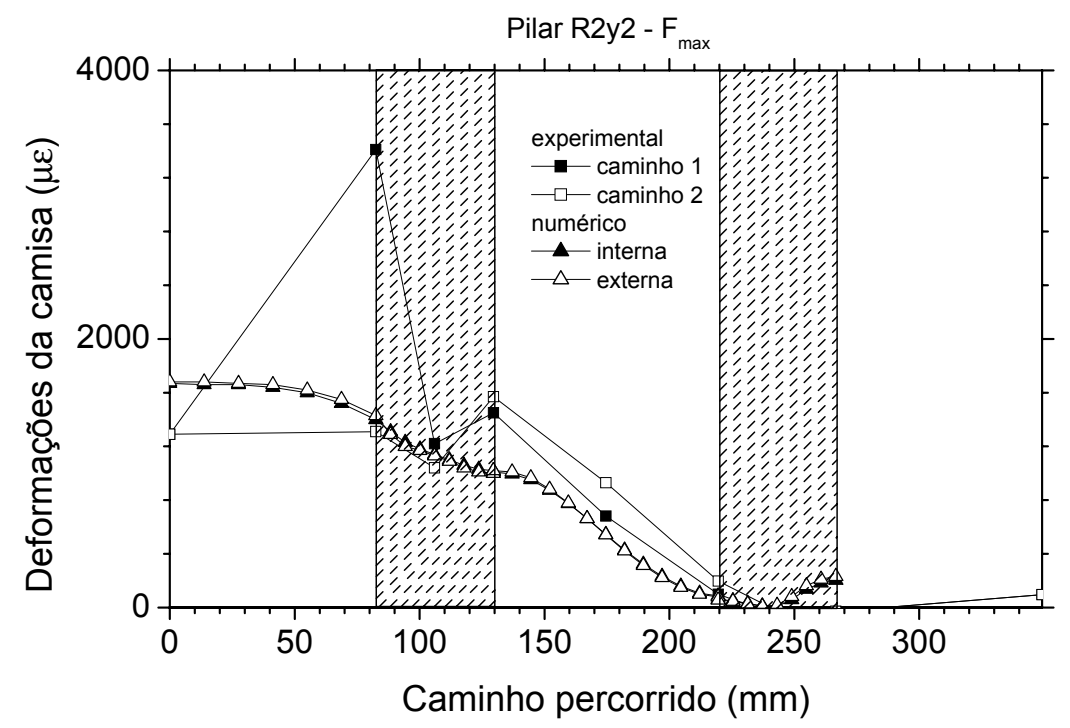

Figura 6.97 - Deformações transversais da camisa pilar R2y2 


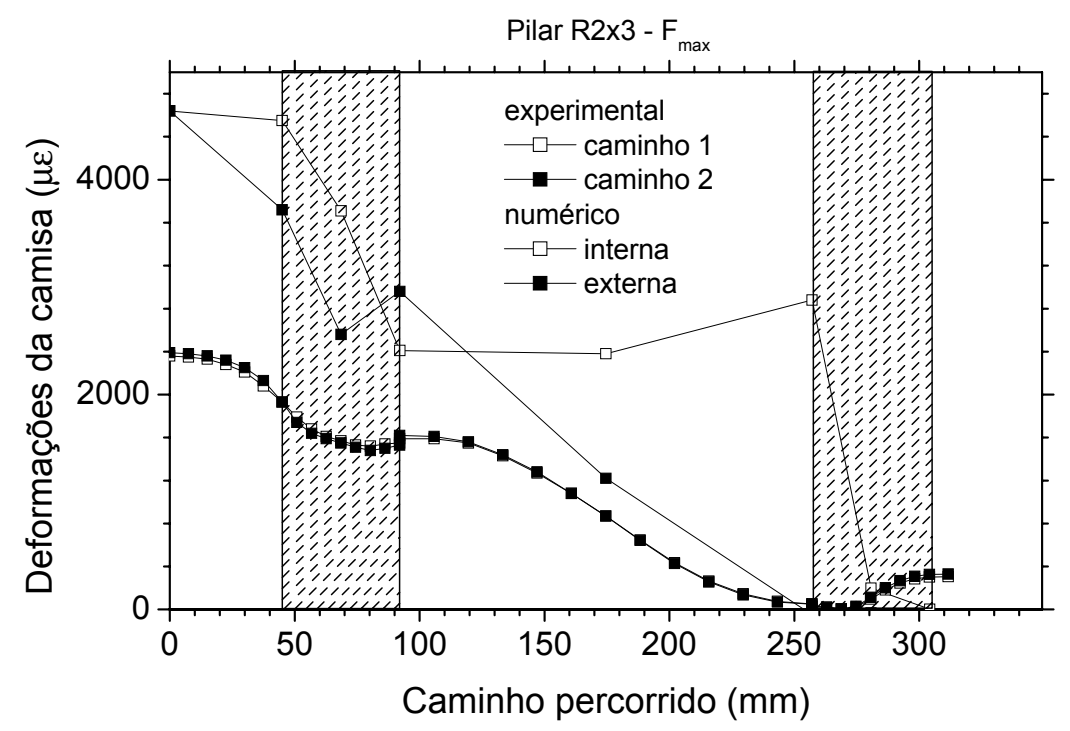

Figura 6.98 - Deformações transversais da camisa pilar R2x3

Os pilares de seção circular também tiveram problemas de convergência na solução, logo são apresentadas as deformações da camisa para uma força igual àquela em que a simulação deixou de convergir.

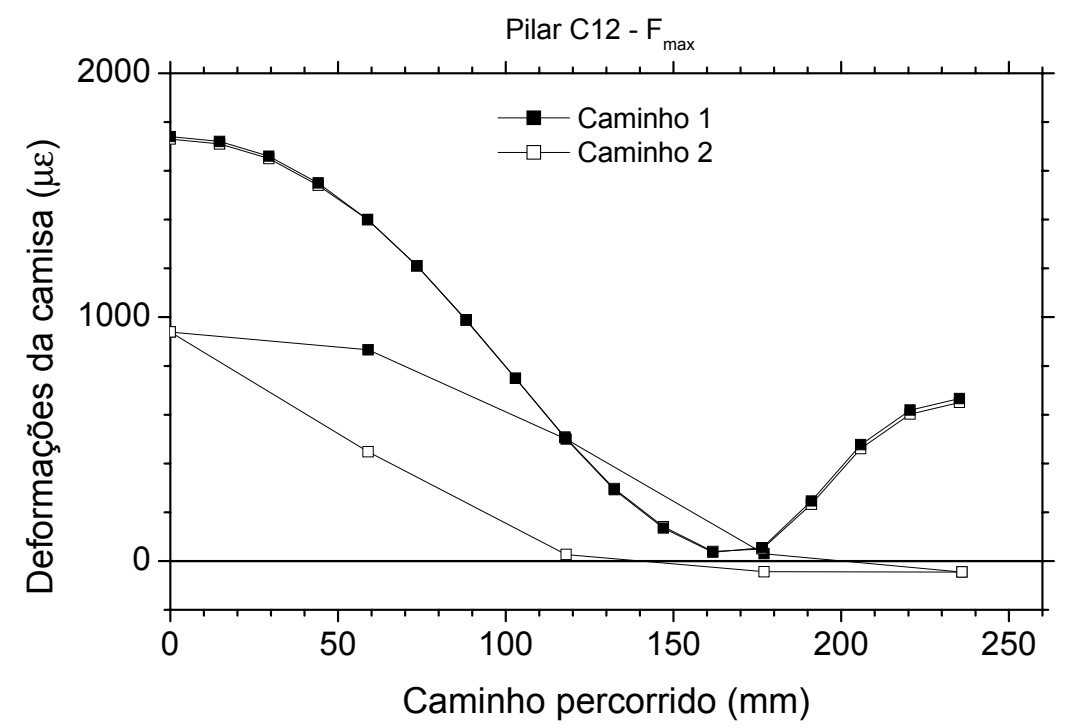

Figura 6.99 - Deformações transversais da camisa pilar C22 


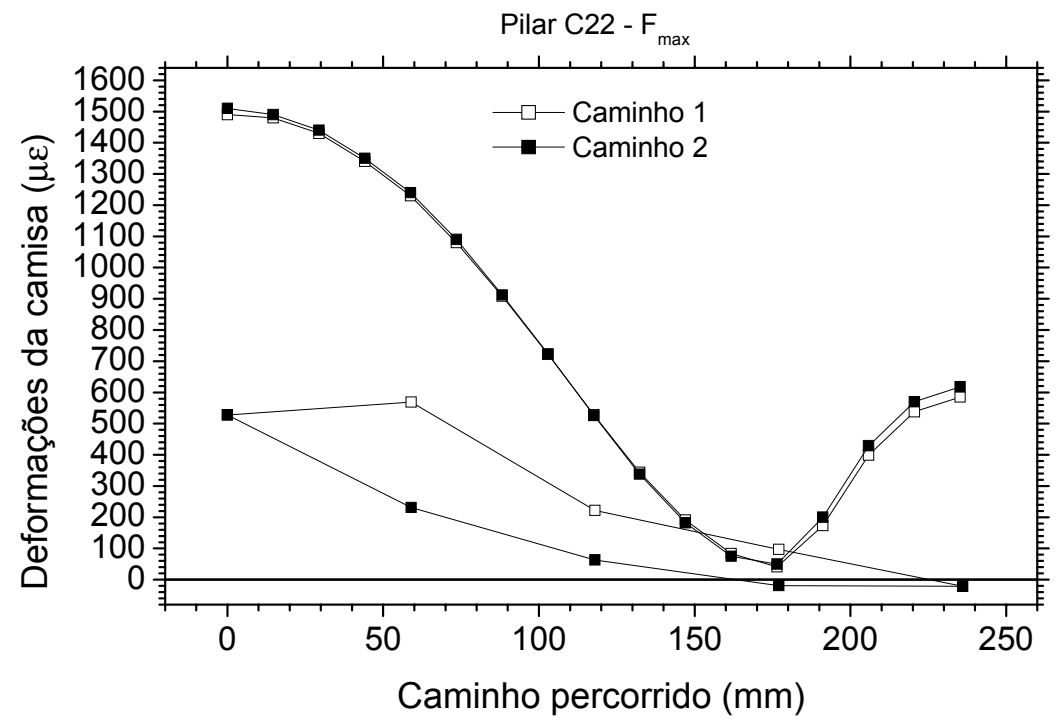

Figura 6.100 - Deformações transversais da camisa pilar C22 


\section{Análise dos efeitos de confinamento}

Neste capítulo pretende-se apresentar mais algumas contribuições deste trabalho para a avaliação dos efeitos de confinamento. Não foi proposto um modelo teórico completo, mas ao menos foram propostas idéias para a avaliação do efeito de confinamento por encamisamento com PRF em pilares de seção circular. Na segunda etapa são propostas formulações para considerar a influência da forma da seção transversal no caso de pilares sob compressão centrada. $\mathrm{Na}$ última etapa são apresentadas recomendações para avaliação do efeito de confinamento em pilares submetidos a esforços de flexo-compressão.

\subsection{Pilares de seção circular encamisados com PRF}

Pilares submetidos a confinamento uniforme são o problema de confinamento mais simples e ocorrem em pilares circulares encamisados com PRF.

\subsubsection{Pressão lateral}

A pressão lateral máxima aplicada pela camisa de PRF pode ser calculada por meio da expressão:

$$
f_{l}=\frac{2 \cdot n \cdot t_{f} \cdot E_{f}}{D} \cdot \varepsilon_{f, w}
$$

onde:

- n é o número de camadas;

- $t_{\mathrm{f}}$ é a espessura da camada de PRF;

- $\mathrm{E}_{\mathrm{f}}$ é o módulo de elasticidade do PRF na direção transversal (de confinamento);

- D é o diâmetro do pilar;

- $\varepsilon_{\mathrm{f}, \mathrm{w}}$ é a deformação lateral última registrada em ensaios de corpos-de-prova ou pilares circulares encamisados com o PRF. Nesta pesquisa observou-se uma deformação lateral última de 0,0105 . 
Quando esta informação não estiver disponível durante a avaliação pode-se estimá-la a partir da deformação última do ensaio de caracterização (tração) de amostras de PRF, utilizando um coeficiente redutor adequado $\mathrm{k}_{\mathrm{f}}$. Nesta pesquisa a deformação última à tração no ensaio de caracterização da ASTM D3039 (1995) foi de 0,013. Já nos ensaios de pilares normalmente observou-se deformações últimas entre 0,0105 e 0,012. Logo o fator redutor a favor da segurança foi de 0,81 .

Na pesquisa de CARRAZEDO (2002) obteve-se a deformação última de 0,0125 no ensaio de tração segundo a ASTM D3039 (1995), enquanto nos pilares circulares observou-se uma deformação última de 0,0119. Neste caso obteve-se um fator redutor de 0,95 .

\subsubsection{Diagrama tensão $x$ deformação}

Nas simulações realizadas e nos resultados de ensaios disponíveis de pilares de seção circular, observou-se que dependendo da rigidez da camisa e da resistência do concreto não confinado, podem ocorrer diagramas tensão $\mathrm{x}$ deformação dos três tipos apresentados na Figura 7.1.

O diagrama do tipo A ocorre para situações de moderado confinamento e concreto de resistência normal. É um diagrama do tipo bi-linear, em que o comportamento do diagrama tensão $\mathrm{x}$ deformação segue o do concreto confinado até $\mathrm{f}_{\mathrm{co}}$ e depois um trecho linear cuja inclinação depende da rigidez da camisa e propriedades do concreto.

O diagrama do tipo B está mais presente nas situações de confinamento com camisas de grande espessura e concreto de alta resistência e é caracterizado pelo ganho de resistência inicial que é praticamente um prolongamento do diagrama tensão $\mathrm{x}$ deformação do concreto não confinado até certo valor de tensão acima de $\mathrm{f}_{\mathrm{co}}$.

Já o diagrama do tipo $\mathrm{C}$ ocorre tanto para o concreto de alta como de resistência usual, para camisas de pequena rigidez lateral. É caracterizado por uma redução da tensão logo após determinado valor máximo ser atingido, podendo depois ser recuperada caso a inclinação estabilize em um valor positivo. 


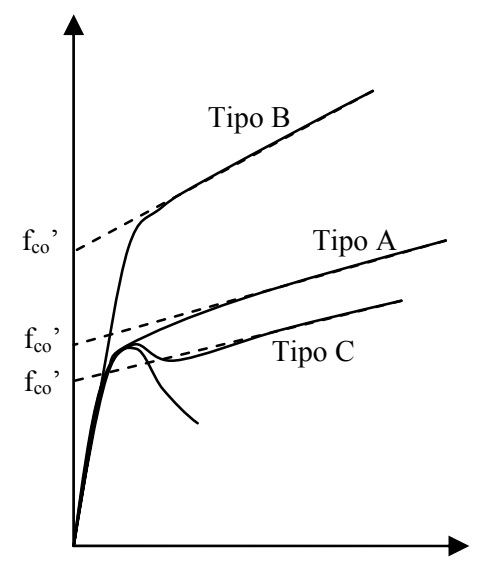

Figura 7.1 - Características do diagrama tensão x deformação do concreto confinado com PRFC

\subsubsection{Ganho de resistência do concreto confinado}

O ganho de resistência do concreto confinado normalmente pode ser expresso por uma equação do tipo:

$$
f_{c c}=f_{c o}+k_{1} \cdot f_{l}
$$

Diversos autores mostraram que $\mathrm{k}_{1}$ não possui um valor constante e que depende de $f_{1} / f_{\text {co }}$. Obteve-se a equação (7.3) para $k_{1}$ em função de $f_{1} / f_{\text {co }}$ por meio de análise de regressão com os dados experimentais de AIRE UNTIVEROS (2002), CARRAZEDO (2002), de LORENZIS \& TEPFERS (2001) e alguns resultados da presente pesquisa. Foram utilizados apenas resultados de ensaios em que foi registrada a deformação de ruptura da camisa de PRF. A comparação da curva proposta com os dados experimentais é feita na Figura 7.2.

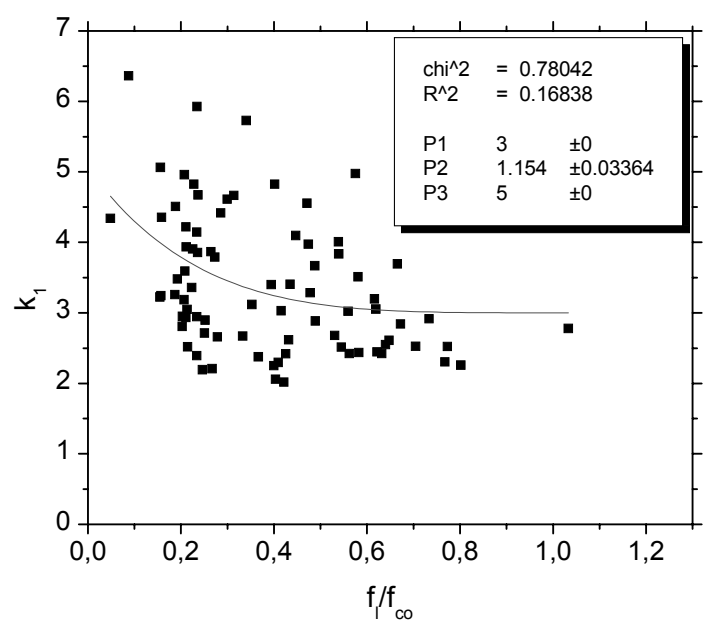

Figura 7.2 - Análise de regressão para $\mathbf{k}_{1}$ 


$$
k_{1}=3+\left[1,15-\frac{f_{l}}{f_{c o}}\right]^{5} \text { válida até } \mathrm{f}_{1} / \mathrm{f}_{\mathrm{co}}=1,5
$$

\subsubsection{Ganho de resistência inicial do concreto confinado}

Nas simulações numéricas, observou-se que a partir de uma deformação axial de 0,01 a inclinação do diagrama tensão x deformação se estabilizava. Com isto, definiu-se a tensão axial referente a esta deformação como ganho inicial de resistência $\left(f_{c 1}\right)$.

Observou-se, nas simulações numéricas, que o que controla o ganho inicial de resistência do concreto confinado com PRF é a rigidez lateral da camisa $\left(E_{1} / f_{c o}\right)$ e não o valor da pressão lateral final $\mathrm{f}_{\mathrm{l}}$. Foi então realizada uma análise de regressão com os resultados numéricos, obtendo-se a equação (7.4), que é comparada com os resultados numéricos na Figura 7.3.

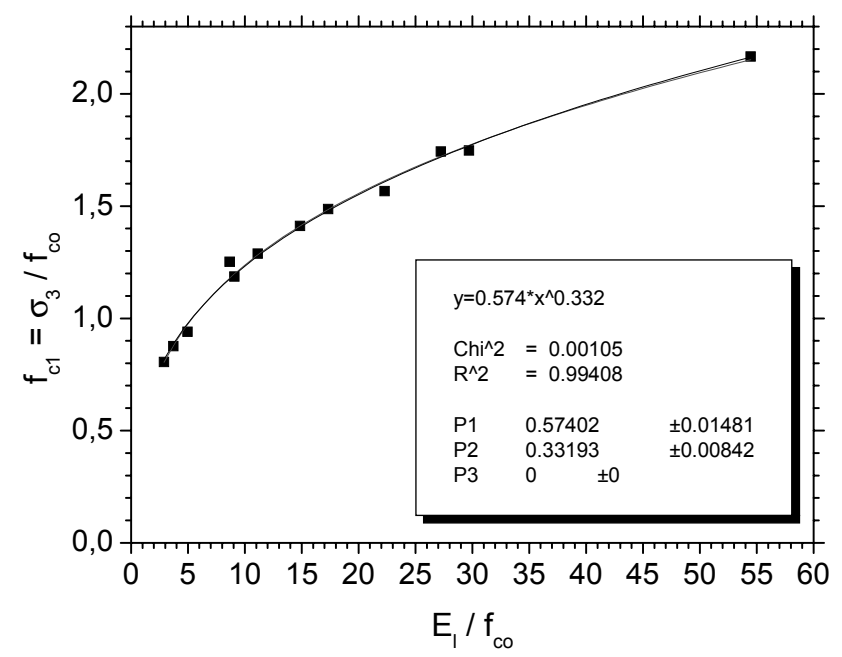

Figura 7.3 - Relação entre o ganho inicial de resistência e a rigidez lateral da camisa

Com base na análise de regressão observou-se que para valores de $E_{1} / f_{c o}$ abaixo de 5,3 ocorreram valores de resistência inicial menores ou iguais a $\mathrm{f}_{\mathrm{co}}$. Neste caso, o diagrama tensão $\mathrm{x}$ deformação foi do tipo $\mathrm{C}$.

Logo, o diagrama tensão $\mathrm{x}$ deformação pode ser representado por três trechos distintos. O primeiro trecho segue o comportamento do concreto confinado até aproximadamente $90 \%$ de $\mathrm{f}_{\mathrm{co}}$. A partir deste ponto seguiu uma transição até a deformação axial $\varepsilon_{\mathrm{c} 1}$. A partir da transição, a inclinação do diagrama tensão $\mathrm{x}$ deformação axial foi praticamente constante, dada por $\mathrm{E}_{\mathrm{cc}}$.

O valor do ganho inicial de resistência foi expresso por: 


$$
f_{c 1}=0,574 \cdot\left(\frac{E_{l}}{f_{c o}}\right)^{0,332}
$$

\subsubsection{Inclinação do trecho de confinamento}

A determinação da inclinação do trecho confinado foi deduzida a partir da formulação em taxas. Utilizando a formulação em taxas pode-se demonstrar que, no caso de confinamento com pressão lateral uniforme é válida a seguinte relação tensão $\mathrm{x}$ deformação para o trecho confinado:

$$
\dot{\sigma}_{3}=2 \cdot D_{31} \cdot \dot{\varepsilon}_{1}+D_{33} \cdot \dot{\varepsilon}_{3}
$$

Onde $\dot{\sigma}_{i}$ representa a taxa de variação da componente de tensão i, $\dot{\varepsilon}_{i}$ representa a taxa de variação da componente de deformação i e $\mathrm{D}_{\mathrm{ij}}$ representa a componente do tensor de quarta ordem elasto-plástico.

Pode-se demonstrar ainda que, no caso de confinamento com PRF, é válida a relação:

$$
\dot{\sigma}_{1}=-E_{l} \cdot \dot{\varepsilon}_{1}
$$

Onde $\mathrm{E}_{1}$ é o módulo lateral ou de confinamento.

Com isto resulta:

$$
\dot{\sigma}_{3}=-\frac{2 \cdot D_{31} \cdot \dot{\sigma}_{1}}{E_{l}}+D_{33} \cdot \dot{\varepsilon}_{3}
$$

Sabe-se também que existe uma relação direta entre $\sigma_{1}$ e $\sigma_{3}$ obtida a partir de (7.2):

$$
\sigma_{3}=f_{c o}+k_{1} \cdot \sigma_{1}
$$

Isto implica que, em taxas:

$$
\dot{\sigma}_{3}=k_{1} \cdot \dot{\sigma}_{1}
$$

Logo, resulta que:

$$
\dot{\sigma}_{3}=-\frac{2 \cdot D_{31} \cdot \dot{\sigma}_{3}}{E_{l} \cdot k_{1}}+D_{33} \cdot \dot{\varepsilon}_{3}
$$

E, finalmente: 


$$
\dot{\sigma}_{3}=\frac{D_{33}}{1+\frac{2 \cdot D_{31}}{E_{l} \cdot k_{1}}} \cdot \dot{\varepsilon}_{3}
$$

Logo, a inclinação do trecho confinado, trecho em que a inclinação do diagrama tensão x deformação se estabiliza, é dada por:

$$
E_{c c}=\frac{\Delta \sigma_{3}}{\Delta \varepsilon_{3}}=\frac{D_{33}}{1+\frac{2 \cdot D_{31}}{E_{l} \cdot k_{1}}}
$$

Assim, obteve-se uma equação para determinar a inclinação do trecho confinado que depende de apenas dois parâmetros $D_{31}$ e $D_{33}$. Estes parâmetros podem ser considerados propriedades do concreto, como se pretende mostrar aqui, e podem ser determinados para determinado concreto a partir de dois ensaios de cilindros de concreto encamisados.

O primeiro teste foi realizado com os resultados das simulações numéricas. A vantagem desta comparação, é que nas simulações numéricas o concreto tinha propriedades constantes, de modo que os valores determinados a partir de dois resultados deve representar adequadamente $\mathrm{E}_{\mathrm{cc}}$ para os demais. A determinação de $\mathrm{D}_{31} \mathrm{e}$ $\mathrm{D}_{33}$ foi feita a partir dos dados dos pilares "carbono HS" e "vidro S", ambos com $\mathrm{n}=6$. Logo, foram utilizados os valores de $\mathrm{E}_{\mathrm{cc}}, \mathrm{k}_{1}$ (estimado com (7.3)) e $\mathrm{E}_{1}$ destes pilares, resultando no seguinte sistema de equações lineares:

$$
\left\{\begin{array}{l}
-0,967 D_{31}+D_{33}=3252 \\
-1,048 D_{31}+D_{33}=1422
\end{array}\right.
$$

Obteve-se assim $\mathrm{D}_{31}=22663$ e $\mathrm{D}_{33}=25167$, que foram utilizados para estimar a inclinação da trecho confinado de todos os pilares, cuja comparação com os resultados numéricos é feita na Tabela 7.1. Pode-se observar que a comparação entre a inclinação dada pela equação e a numérica foi muito boa para todos os pilares, exceto aqueles com fibras de carbono de alto módulo. No entanto, isto pode ser explicado, pois nestes pilares a inclinação final ainda não tinha sido atingida ao final da simulação, pois os pilares tiveram uma deformação última de apenas $-1 \%$. Não foram comparados os resultados com fibras de ultra alto módulo, mas acredita-se também que o erro seria um pouco maior neste caso, pois nesta situação de confinamento não há deslocamento axial suficiente para a estabilização da inclinação no confinamento. 
Tabela 7.1 - Determinação da inclinação do trecho de confinamento

\begin{tabular}{lccrrrrr}
\hline Fibra & & $\mathrm{n}$ & $\mathrm{E}_{1}(\mathrm{MPa})$ & $\mathrm{K}_{1}$ & $\begin{array}{r}\mathrm{E}_{\mathrm{cc}}(\mathrm{MPa}) \\
\text { numérico }\end{array}$ & $\begin{array}{c}\mathrm{E}_{\mathrm{cc}}(\mathrm{MPa}) \\
(7.12)\end{array}$ & $\begin{array}{c}\text { Equação } \\
\text { numérico }\end{array}$ \\
\hline Carbono & $\mathrm{HS}$ & 1 & 381 & 3,9 & 773 & 863 & 1,12 \\
& $\mathrm{HS}$ & 3 & 1144 & 3,3 & 1969 & 1977 & 1,00 \\
& $\mathrm{HS}$ & 6 & 2288 & 2,7 & 3252 & 3339 & 1,03 \\
\hline Carbono & $\mathrm{HM}$ & 1 & 693 & 4,3 & 1915 & 1582 & 0,83 \\
& $\mathrm{HM}$ & 3 & 2080 & 3,4 & 4403 & 3567 & 0,81 \\
& $\mathrm{HM}$ & 6 & 4160 & 3,6 & 6370 & 5603 & 0,88 \\
\hline Vidro & $\mathrm{E}$ & 1 & 121 & 5,1 & 284 & 298 & 1,05 \\
& $\mathrm{E}$ & 3 & 364 & 3,4 & 626 & 734 & 1,17 \\
& $\mathrm{E}$ & 6 & 728 & 3,0 & 1120 & 1235 & 1,10 \\
\hline Vidro & $\mathrm{S}$ & 1 & 156 & 4,5 & 367 & 342 & 0,93 \\
& $\mathrm{~S}$ & 3 & 468 & 3,4 & 825 & 798 & 0,97 \\
& $\mathrm{~S}$ & 6 & 936 & 3,0 & 1422 & 1469 & 1,03 \\
\hline Aramida & $\mathrm{HM}$ & 1 & 208 & 4,1 & 532 & 472 & 0,89 \\
& $\mathrm{HM}$ & 3 & 624 & 3,4 & 1117 & 1098 & 0,98 \\
& $\mathrm{HM}$ & 6 & 1248 & 2,8 & 1913 & 1930 & 1,01 \\
\hline
\end{tabular}

\subsubsection{Deformação última do concreto confinado}

A deformação última do concreto confinado foi então calculada com:

$$
\varepsilon_{c c}=\frac{f_{c c}-f_{c o}{ }^{\prime}}{E_{c c}}
$$

$\mathrm{O}$ valor de $\mathrm{f}_{\mathrm{co}}$ ', $\mathrm{o}$ intercepto no eixo das tensões da reta do trecho de inclinação constante, foi dado por:

$$
f_{c o}{ }^{\prime}=f_{c 1}-E_{c c} \cdot \varepsilon_{c 1}
$$

onde $\mathrm{E}_{\mathrm{cc}}$ é a inclinação do diagrama tensão x deformação no segundo trecho linear.

Foi realizado um teste do modelo teórico para comparação com os resultados numéricos, sendo os resultados apresentados na Tabela 7.2. A comparação dos resultados teóricos e numéricos foi satisfatória. Isto estimulou a comparação com alguns resultados experimentais.

Tabela 7.2 - Valores obtidos nas simulações com diferentes tipos de fibras para confinamento

\begin{tabular}{ccccccccc}
\hline \multicolumn{1}{c}{ Fibra } & & & & & & \multicolumn{3}{c}{ Teórico / numérico } \\
\hline Carbono & $\mathrm{n}$ & $\mathrm{f}_{\mathrm{cc}}(\mathrm{MPa})$ & $\varepsilon_{\mathrm{cc}}(\%)$ & $\mathrm{f}_{\mathrm{cc}}(\mathrm{MPa})$ & $\varepsilon_{\mathrm{cc}}(\%)$ & $\mathrm{f}_{\mathrm{cc}}$ & $\varepsilon_{\mathrm{cc}}$ \\
& $\mathrm{HS}$ & $-56,6$ & $-18,8$ & $-60,8$ & $-22,4$ & 1,07 & 1,19 \\
& $\mathrm{HS}$ & 6 & $-141,4$ & $-25,5$ & $-140,7$ & $-24,9$ & 1,00 & 0,98 \\
\hline Carbono & UHS & 1 & $-65,1$ & $-28,9$ & $-68,6$ & $-32,8$ & 1,05 & 1,13 \\
& UHS & 3 & $-119,9$ & $-34,8$ & $-116,9$ & $-34,2$ & 0,97 & 0,98 \\
& UHS & 6 & $-177,2$ & $-38,1$ & $-178,6$ & $-36,5$ & 1,01 & 0,96 \\
\hline Carbono & HM & 1 & $-59,8$ & $-8,7$ & $-60,5$ & $-9,6$ & 1,01 & 1,10
\end{tabular}




\begin{tabular}{ccccccccc} 
& HM & 3 & $-90,3$ & $-11,1$ & $-89,8$ & $-10,5$ & 0,99 & 0,95 \\
& HM & 6 & $-125,8$ & $-13,3$ & $-119,7$ & $-11,6$ & 0,95 & 0,87 \\
\hline Carbono & UHM & 1 & $-59,1$ & $-5,8$ & $-60,1$ & $-5,8$ & 1,02 & 0,99 \\
& UHM & 3 & $-82,5$ & $-7,3$ & $-83,1$ & $-6,6$ & 1,01 & 0,90 \\
& UHM & 6 & $-115,6$ & $-9,2$ & $-107,8$ & $-7,5$ & 0,93 & 0,82 \\
\hline Vidro & E & 1 & $-41,5$ & $-37,1$ & $-44,3$ & $-43,7$ & 1,07 & 1,18 \\
& E & 3 & -72 & $-41,0$ & $-74,7$ & $-44,5$ & 1,04 & 1,09 \\
& E & 6 & -102 & $-45,3$ & $-105,9$ & $-45,5$ & 1,04 & 1,00 \\
\hline Vidro & S & 1 & $-58,4$ & $-68,8$ & $-58,9$ & $-73,0$ & 1,01 & 1,06 \\
& S & 3 & $-105,4$ & $-72,2$ & $-105,1$ & $-74,4$ & 1,00 & 1,03 \\
& S & 6 & $-162,5$ & $-78,0$ & $-165,2$ & $-76,5$ & 1,02 & 0,98 \\
\hline Aramida & LM & 1 & $-50,8$ & $-68,2$ & $-51,8$ & $-72,8$ & 1,02 & 1,07 \\
& LM & 3 & -96 & $-74,0$ & $-91,4$ & $-74,0$ & 0,95 & 1,00 \\
& LM & 6 & $-139,4$ & $-78,8$ & $-138,5$ & $-75,5$ & 0,99 & 0,96 \\
\hline Aramida & HM & 1 & $-54,6$ & $-38,4$ & $-57,1$ & $-44,1$ & 1,05 & 1,15 \\
& HM & 3 & $-97,4$ & $-44,1$ & $-97,7$ & $-45,2$ & 1,00 & 1,02 \\
& HM & 6 & $-148,2$ & $-49,1$ & $-145,4$ & $-46,8$ & 0,98 & 0,95 \\
\hline
\end{tabular}
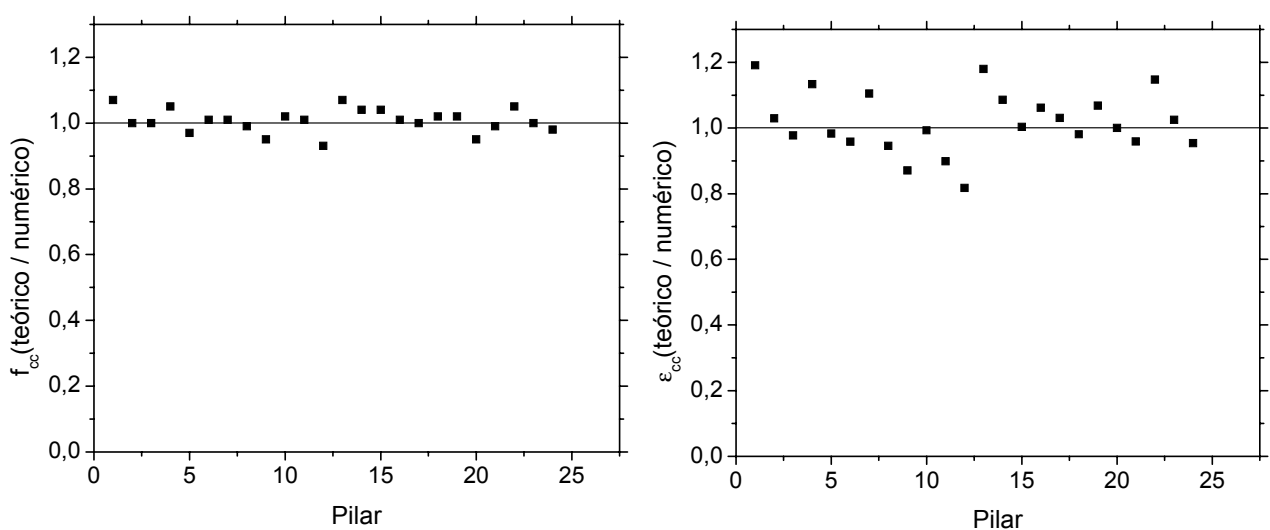

Figura 7.4 - Comparação entre o modelo teórico e os resultados numéricos

Para verificar a validade das equações para pilares de seção circular encamisados com PRF foram utilizados os dados de AIRE UNTIVEROS (2002). Estes dados são os resultados de ensaios de corpos-de-prova de concreto de 15 x $30 \mathrm{~cm}$ (diâmetro x altura) encamisados com PRF. Os parâmetros $D_{31}$ e $D_{33}$ foram calculados separadamente para o concreto $\mathrm{H} 30$ e $\mathrm{H} 70$, concretos de diferentes resistências à compressão. Na Tabela 7.3 são apresentados os valores utilizados para o cálculo de $\mathrm{D}_{33}$ e $\mathrm{D}_{31}$. 
Tabela 7.3 - Cálculo dos parâmetros $D_{31}$ e $D_{33}$ para os dados experimentais de AIRE UNTIVEROS (2002)

\begin{tabular}{cccccccc}
\hline Concreto & Fibras & $n$ & $\begin{array}{c}\mathrm{E}_{\mathrm{l}} \\
(\mathrm{MPa})\end{array}$ & $\mathrm{k}_{1}$ & $\mathrm{E}_{\mathrm{cc}}$ & $\mathrm{D}_{31}$ & $\mathrm{D}_{33}$ \\
H30 & vidro & 3 & 492 & 4,00 & 1370 & 1134 & 2949 \\
H30 & carbono & 6 & 1912 & 3,14 & 2140 & 1134 & 2949 \\
H70 & vidro & 9 & 1476 & 3,74 & 3300 & 9365 & 14495 \\
H70 & carbono & 6 & 1912 & 3,48 & 3800 & 9365 & 14495 \\
\hline
\end{tabular}

Para verificar o comportamento do trecho de transição foi realizada uma análise de regressão com base nos ensaios de AIRE UNTIVEROS (2002). Adotou-se $\varepsilon_{\mathrm{c} 1}=$ 0,005 e então foram registradas as tensões axiais referentes a esta deformação para os diversos ensaios. Os dados são apresentados na Tabela 7.4.

Tabela 7.4- Comparação entre resultados teóricos e experimentais de AIRE UNTIVEROS (2002)

\begin{tabular}{|c|c|c|c|c|c|c|c|c|c|c|}
\hline Concreto & Fibras & $\begin{array}{c}\mathrm{f}_{\mathrm{co}} \\
\mathrm{MPa}\end{array}$ & $\mathrm{n}$ & $\begin{array}{c}\mathrm{t}_{\mathrm{f}} \\
\mathrm{mm}\end{array}$ & $\begin{array}{c}\text { Ef } \\
\mathrm{GPa}\end{array}$ & $\begin{array}{l}\varepsilon_{\mathrm{fu}, \mathrm{d}} \\
(\%)\end{array}$ & $\begin{array}{c}\mathrm{E}_{\mathrm{I}} \\
\mathrm{MPa}\end{array}$ & $\mathrm{E}_{\mathrm{l}} / \mathrm{f}_{\mathrm{co}}$ & $\begin{array}{c}\mathrm{f}_{\mathrm{c} 1} \\
\mathrm{MPa}\end{array}$ & $\mathrm{f}_{\mathrm{c} 1} / \mathrm{f}_{\mathrm{co}}$ \\
\hline $\mathrm{H} 30$ & vidro & 42 & 1 & 0,149 & 82,55 & 0,88 & 164 & 4 & 38,0 & 0,90 \\
\hline $\mathrm{H} 30$ & vidro & 42 & 3 & 0,149 & 82,55 & 12,8 & 492 & 12 & 44,1 & 1,05 \\
\hline $\mathrm{H} 30$ & vidro & 42 & 6 & 0,149 & 82,55 & 11,3 & 984 & 23 & 48,6 & 1,16 \\
\hline $\mathrm{H} 30$ & arbono & 42 & 1 & 0,117 & 204,3 & 8,8 & 319 & 8 & 42,0 & 1,00 \\
\hline $\mathrm{H} 30$ & carbono & 42 & 3 & 0,117 & 204,3 & 9,3 & 956 & 23 & 48,3 & 1,15 \\
\hline $\mathrm{H} 30$ & carbono & 42 & 6 & 0,117 & 204,3 & 10,5 & 1912 & 46 & 50,3 & 1,20 \\
\hline $\mathrm{H} 70$ & vidro & 69 & 1 & 0,149 & 82,55 & 1,1 & 164 & 2 & 60,0 & 0,87 \\
\hline $\mathrm{H} 70$ & vidro & 69 & 3 & 0,149 & 82,55 & 2 & 492 & 7 & 79,0 & 1,14 \\
\hline $\mathrm{H} 70$ & vidro & 69 & 6 & 0,149 & 82,55 & 8,9 & 984 & 14 & 99,0 & 1,43 \\
\hline $\mathrm{H} 70$ & vidro & 69 & 9 & 0,149 & 82,55 & 9,7 & 1476 & 21 & 109,0 & 1,58 \\
\hline $\mathrm{H} 70$ & vidro & 69 & 12 & 0,149 & 82,55 & 11 & 1968 & 29 & 117,0 & 1,70 \\
\hline $\mathrm{H} 70$ & carbono & 69 & 1 & 0,117 & 204,3 & 0,9 & 319 & 5 & 87,0 & 1,26 \\
\hline $\mathrm{H} 70$ & carbono & 69 & 3 & 0,117 & 204,3 & 8,2 & 956 & 14 & 92,5 & 1,34 \\
\hline $\mathrm{H} 70$ & carbono & 69 & 6 & 0,117 & 204,3 & 10,3 & 1912 & 28 & 110,0 & 1,59 \\
\hline $\mathrm{H} 70$ & carbono & 69 & 9 & 0,117 & 204,3 & 11,4 & 2868 & 42 & 119,5 & 1,73 \\
\hline $\mathrm{H} 70$ & carbono & 69 & 12 & 0,117 & 204,3 & 8,5 & 3824 & 55 & 131,0 & 1,90 \\
\hline
\end{tabular}

A análise de regressão foi realizada para os dois concretos (H30 e H70) em separado, tendo em vista o comportamento diferenciado de ambos. Obteve-se $\mathrm{P}_{1}=$ 0,783 e $\mathrm{P}_{2}=0,117$ para o concreto $\mathrm{H} 30$, enquanto para o concreto $\mathrm{H} 70$ obteve-se $\mathrm{P}_{1}=$ 0,799 e $P_{2}=0,214$. Sugere-se que estes parâmetros sejam então interpolados para concretos de resistência entre 30 e $70 \mathrm{MPa}$. 


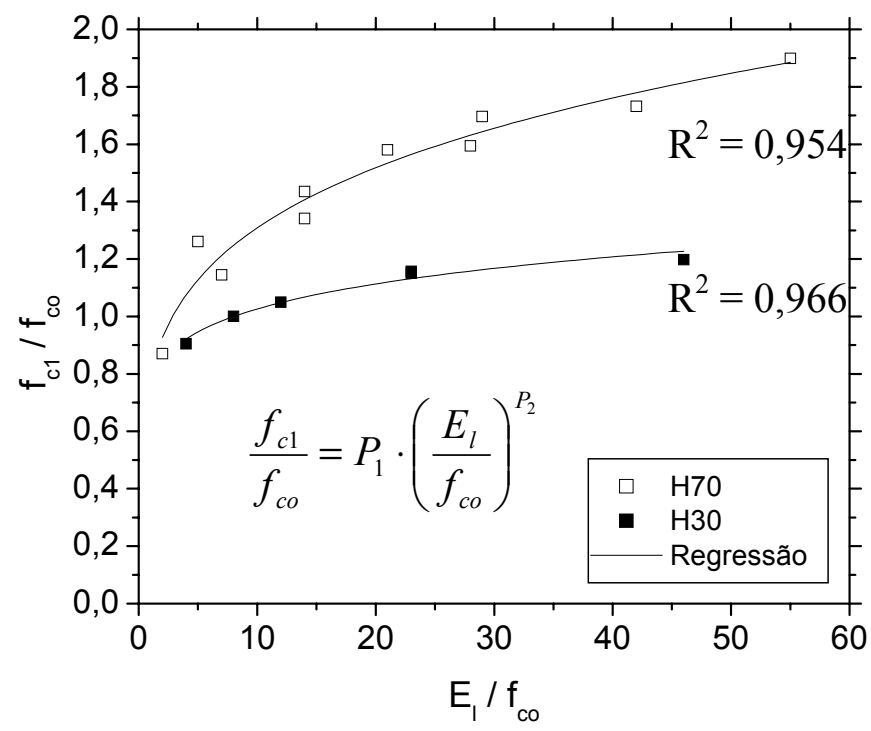

Figura 7.5 - Análise de regressão para determinação do trecho de transição

Pode-se observar uma boa correlação entre resultados numéricos e experimentais para $\varepsilon_{c c}$ e $f_{c c}$. Os piores resultados foram obtidos para as situações de baixo índice de confinamento, onde o diagrama tensão x deformação não é bi-linear (tipo C) ou possui um trecho descendente no diagrama tensão x deformação.

Tabela 7.5- Comparação entre resultados teóricos e experimentais de AIRE UNTIVEROS (2002)

\begin{tabular}{|c|c|c|c|c|c|c|c|c|c|c|c|c|}
\hline \multirow[t]{2}{*}{ Concreto } & \multirow[t]{2}{*}{ Fibras } & \multirow{2}{*}{$\begin{array}{c}\mathrm{f}_{\mathrm{co}} \\
\mathrm{MPa}\end{array}$} & \multirow[t]{2}{*}{$n$} & \multirow{2}{*}{$\begin{array}{c}\mathrm{t}_{\mathrm{f}} \\
\mathrm{mm}\end{array}$} & \multirow{2}{*}{$\begin{array}{c}\mathrm{Ef} \\
\mathrm{GPa}\end{array}$} & \multirow{2}{*}{$\begin{array}{l}\varepsilon_{\mathrm{fu}, \mathrm{d}} \\
(\%)\end{array}$} & \multicolumn{2}{|c|}{ Experimental } & \multicolumn{2}{|c|}{ Teórico } & \multicolumn{2}{|c|}{ Teórico/experimental } \\
\hline & & & & & & & $\begin{array}{c}\mathrm{f}_{\mathrm{cc}} \\
(\mathrm{MPa})\end{array}$ & $\begin{array}{c}\varepsilon_{\mathrm{cc}} \\
(\%)\end{array}$ & $\begin{array}{c}\mathrm{f}_{\mathrm{cc}} \\
(\mathrm{MPa})\end{array}$ & $\begin{array}{c}\varepsilon_{\mathrm{cc}} \\
(\%)\end{array}$ & $\frac{f_{\text {cc,teo }}}{f_{\text {cc,exp }}}$ & $\frac{\underline{\varepsilon}_{\mathrm{cc, \text {teo }}}}{\varepsilon_{\mathrm{cc}, \exp }}$ \\
\hline $\mathrm{H} 30$ & vidro & 42 & 1 & 0,149 & 82,55 & 0,88 & 41 & 2,5 & 35,4 & 0,9 & 0,82 & 0,66 \\
\hline $\mathrm{H} 30$ & vidro & 42 & 3 & 0,149 & 82,55 & 12,8 & 61 & 17,1 & 62,2 & 18,4 & 1,14 & 1,43 \\
\hline $\mathrm{H} 30$ & vidro & 42 & 6 & 0,149 & 82,55 & 11,3 & 85 & 20,2 & 78,0 & 22,1 & 1,06 & 1,10 \\
\hline $\mathrm{H} 30$ & carbono & 42 & 1 & 0,117 & 204,3 & 8,8 & 46 & 9,2 & 48,6 & 11,0 & 1,14 & 1,81 \\
\hline $\mathrm{H} 30$ & carbono & 42 & 3 & 0,117 & 204,3 & 9,3 & 77 & 21,2 & 71,5 & 18,4 & 1,08 & 0,86 \\
\hline $\mathrm{H} 30$ & carbono & 42 & 6 & 0,117 & 204,3 & 10,5 & 108 & 31,6 & 103,7 & 29,4 & 1,10 & 0,68 \\
\hline $\mathrm{H} 70$ & vidro & 69 & 1 & 0,149 & 82,55 & 1,1 & 79 & 2,4 & 64,2 & 1,5 & 2 & 36 \\
\hline $\mathrm{H} 70$ & vidro & 69 & 3 & 0,149 & 82,55 & 2 & 83 & 2,6 & 80,5 & 2,9 & & 49 \\
\hline $\mathrm{H} 70$ & vidro & 69 & 6 & 0,149 & 82,55 & 8,9 & 107 & 6,2 & 120,6 & 14,0 & & 36 \\
\hline $\mathrm{H} 70$ & vidro & 69 & 9 & 0,149 & 82,55 & 9,7 & 140 & 14,1 & 143,3 & 16,2 & & 0 \\
\hline $\mathrm{H} 70$ & vidro & 69 & 12 & 0,149 & 82,55 & 11 & 170 & 14,7 & 167,6 & 19,3 & & 55 \\
\hline $\mathrm{H} 70$ & & 69 & 1 & 0,117 & 204,3 & 0,9 & 9 & 2,7 & 72,3 & 1,3 & 2 & 0,64 \\
\hline $\mathrm{H} 70$ & carbo & 69 & 3 & 0,117 & 204,3 & 8,2 & 98 & 7,8 & 116,9 & 12,9 & 1,10 & 2,09 \\
\hline $\mathrm{H} 70$ & carbono & 69 & 6 & 0,117 & 204,3 & 10,3 & 156 & 16,3 & 161,8 & 18,0 & 0,99 & 1,31 \\
\hline $\mathrm{H} 70$ & carbono & 69 & 9 & 0,117 & 204,3 & 11,4 & 199 & 22,8 & 201,6 & 21,8 & 0,98 & 1,08 \\
\hline $\mathrm{H} 70$ & carbono & 69 & 12 & 0,117 & 204,3 & 8,5 & 217 & 23,9 & 204,1 & 18,0 & 0,91 & 0,80 \\
\hline
\end{tabular}




\subsection{Pilares submetidos a confinamento com pressão não uniforme}

Segundo MIRMIRAN et al. (1998), para avaliar o ganho de resistência do concreto confinado com PRF deve-se avaliar se o valor da variável MCR ( é maior ou igual a 15\%. Se MCR é menor que $15 \%$ não ocorre ganho significativo de resistência e pode-se contar apenas com o aumento de ductilidade do pilar. Caso MCR $>15 \%$ ocorre ganho de resistência.

$$
M C R=\frac{2 r}{D} \cdot \frac{f_{l}}{f_{c o}}
$$

Na presente pesquisa foi possível observar que o fator 2r/D é realmente um dos principais fatores redutores da efetividade do confinamento em pilares de seção transversal diferente da circular e deve ser considerado na avaliação do efeito de confinamento.

\subsubsection{Avaliação da capacidade resistente}

O ganho de resistência de pilares de concreto confinado com PRFC em pilares de seção transversal diferente da circular pode ser estimado por meio de uma relação do tipo:

$$
f_{c c}=f_{c o}+k_{1} \cdot f_{l e}
$$

onde:

- $\mathrm{f}_{\mathrm{cc}}$ é a resistência do concreto confinado;

- $\mathrm{f}_{\mathrm{co}}$ é a resistência do concreto não confinado;

- $\mathrm{k}_{1}$ é o coeficiente de confinamento;

- $\mathrm{f}_{\mathrm{le}}$ é a pressão lateral efetiva;

A pressão lateral efetiva, por sua vez, é dada por:

$$
f_{l e}=k_{e} \cdot f_{l}
$$

onde $\mathrm{f}_{1}$ é a pressão lateral calculada como se o pilar tivesse uma seção circular, dada por:

$$
f_{l}=\frac{2 t}{h_{x}} E_{f} \cdot \varepsilon_{f u}
$$

Sendo que:

- $\mathrm{h}_{\mathrm{x}}$ é a maior dimensão do pilar. 
Foram realizadas análises de regressão para determinar a relação entre $\mathrm{k}_{\mathrm{e}} \mathrm{e}$ a variável (2r/D), utilizando os resultados experimentais e numéricos. Ambas análises indicaram que a variável 2r/D é o coeficiente de efetividade que reduz a pressão lateral em pilares de seção transversal quadrada.
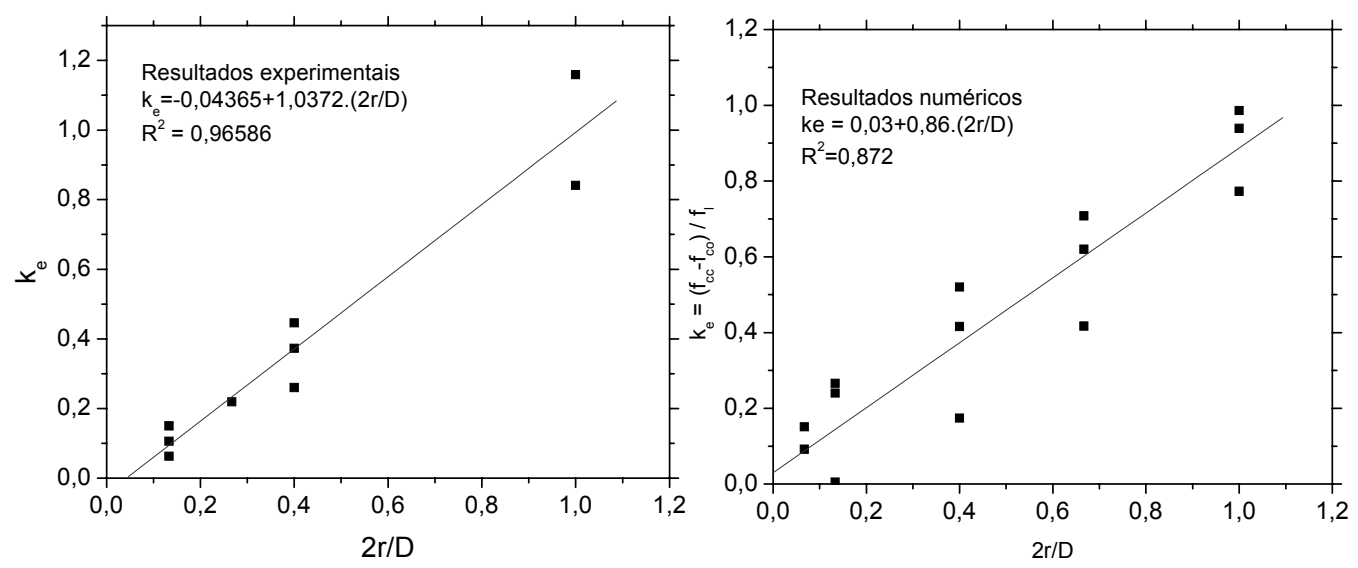

Figura 7.6 - Relação entre $k_{\mathrm{e}} \mathrm{e}(2 \mathrm{r} / \mathrm{D})$

Logo, pode-se propor a relação para pilares de seção quadrada:

$$
k_{e}=\frac{2 r}{D}
$$

Com base nos resultados experimentais foi realizada uma análise de regressão que propôs a inclusão de mais alguns fatores dentro do coeficiente de efetividade que reduz a pressão lateral, estes coeficientes foram:

$$
\begin{aligned}
& k_{e 1}=\left(\frac{2 r}{h_{x}}\right)^{1,367} \\
& k_{e 2}=\left(\frac{h_{y}}{h_{x}}\right)^{-0,655} \\
& k_{e 3}=\left(\frac{E_{l}}{f_{c o}}\right)^{0,00727}
\end{aligned}
$$

Calculou-se então o coeficiente de efetividade do confinamento com:

$$
k_{e}=k_{e 1} \cdot k_{e 2} \cdot k_{e 3}
$$

A análise da influência da forma da seção transversal foi então realizada numericamente, podendo assim ampliar os parâmetros e estudar conjuntamente a influência da relação $h_{y} / h_{x}$, julgada de importância nos pilares de seção retangular. Esta análise indicou que a redução da efetividade do confinamento pelo fator $h_{x} / h_{y}$ não é 
primordial até uma relação $h_{x} / h_{y}=2$, desde que seja considerado corretamente o valor de $2 \mathrm{r} / \mathrm{h}_{\mathrm{x}}$ para reduzir a efetividade do confinamento.

$\mathrm{O}$ coeficiente $\mathrm{E}_{1} / \mathrm{f}_{\mathrm{co}}$ procura incluir a influência da rigidez da camisa. Supõe que quanto mais rígida a camisa menor a redução da efetividade. Porém sua influência é pequena sobre o fator redutor final.

$\mathrm{O}$ efeito da excentricidade de carregamento foi incluído com um fator redutor da resistência do concreto confinado dado pela seguinte equação:

$$
k_{e 4}=1-2,303 \cdot\left(\frac{e_{i}}{h_{i}}\right)^{0,896} \cdot\left(\frac{2 r}{h_{x}}\right)^{0,356}
$$

A excentricidade relativa $\left(\mathrm{e}_{\mathrm{i}} / \mathrm{h}_{\mathrm{i}}\right)$, obviamente reduz a resistência final do pilar e por isto foi incluída no fator redutor.

A variável $2 r / h_{x}$ também se mostrou importante, pois se notou que pilares de seção circular tinham uma redução maior de resistência que pilares de seção quadrada sob a ação de forças com excentricidade. Além disso, quanto menor a relação $2 \mathrm{r} / \mathrm{h}_{\mathrm{x}}$ menor foi a redução devido à excentricidade.

A resistência do concreto confinado $\left(f_{c c}\right)$ pôde então ser calculada com:

$$
f_{c c}=\left(f_{c o}+k_{1} \cdot f_{l e}\right) \cdot k_{e 4}
$$

A deformabilidade dos pilares de seção quadrada e retangular sob ação de força excêntrica também foi estudada com base na análise experimental, sendo apresentada no item 5.3.11. 


\section{Conclusões}

Como foi possível elaborar conclusões com relação a diversos aspectos estas são apresentadas separadamente para cada item analisado.

\subsection{Considerações finais}

Ao optar pelo encamisamento com PRF no reforço de pilares, deve-se observar que existem duas possibilidades para o aumento de resistência e deformação última:

- Utilizar as fibras para prover confinamento, tema abordado por esta pesquisa, que permite ao concreto alcançar aumentos de resistência e deformação última consideráveis, dependendo de diversos aspectos enumerados a seguir;

- a utilização de fibras na direção longitudinal, que contribuem resistindo diretamente aos esforços axiais de compressão e flexão. Neste caso é altamente recomendado que as fibras na direção longitudinal sejam envolvidas por uma camada de fibras de carbono na direção transversal, evitando assim a sua flambagem.

Principalmente no caso de seções bastante alongadas acredita-se que a melhor opção seja o projeto do encamisamento aproveitando as duas contribuições acima citadas.

\subsection{Ganho de resistência}

Em todos os ensaios realizados o encamisamento com PRF possibilitou aumentos de resistência axial dos pilares. Estes aumentos foram de 6,2\% a 129\%, dependendo do número de camadas, da forma da seção transversal e da excentricidade do carregamento.

$\mathrm{O}$ coeficiente $\mathrm{k}_{1}$ que determina o ganho de resistência do concreto confinado em função da pressão lateral é variável com $\mathrm{f}_{\mathrm{l}} / \mathrm{f}_{\mathrm{co}}$, de modo que recomenda-se a utilização de uma envoltória de ruptura para $\mathrm{k}_{1}$ baseada em ensaios de pilares de concreto 
encamisado com PRF em que tenha sido registrada a deformação lateral de ruptura, podendo assim ter avaliado corretamente a pressão lateral.

No caso de pilares de seção transversal diferente da circular deve ser considerado um coeficiente de efetividade $\mathrm{k}_{\mathrm{e}}$ para reduzir a pressão lateral, obtendo-se assim uma pressão lateral efetiva que pode ser utilizada no projeto destes pilares. Observou-se que a variável $k_{e}$ é influenciada principalmente pela relação $2 r / h_{x}$, onde $h_{x}$ é o maior lado da seção transversal. $\mathrm{O}$ aumento da relação entre lados $h_{\mathrm{x}} / \mathrm{h}_{\mathrm{y}}$ (lado maior/lado menor) afetou muito pouco a efetividade do confinamento, de modo que mesmo com uma relação entre lados $h_{x} / h_{y}=1,5$ obteve-se importantes efeitos de confinamento. As análises numéricas realizadas indicaram que nos pilares retangulares o principal redutor da efetividade foi $2 \mathrm{r} / \mathrm{h}_{\mathrm{x}}$ e não $\mathrm{h}_{\mathrm{x}} / \mathrm{h}_{\mathrm{y}}$.

Nos pilares com um concreto de menor resistência observaram-se maiores coeficientes de efetividade em seções não circulares. Isto ocorreu porque as regiões pouco confinadas apresentaram uma queda de resistência mais gradual e também porque a expansão lateral do concreto de resistência usual é maior.

A influência da excentricidade da força de compressão foi diferente para seções transversais diferentes. Nas seções transversais circulares ocorreu uma redução do ganho de resistência na presença da excentricidade do carregamento.

Nos pilares de seção transversal quadrada ocorreram maiores ganhos de resistência na presença da excentricidade. Principalmente no caso dos pilares com $r=1$ $\mathrm{cm}$, a translação da região comprimida para próximo dos cantos beneficiou $o$ desempenho destes pilares. Isto porque sob carregamento centrado, as regiões no núcleo central apresentam pequenos acréscimos de resistência pelo confinamento. Com o deslocamento da região comprimida para uma região mais próxima dos cantos foram desenvolvidas maiores tensões axiais por causa do confinamento.

Nos pilares de seção retangular observou-se um comportamento semelhante aos pilares de seção quadrada quando a excentricidade foi aplicada na direção da menor inércia. No entanto, quando a excentricidade foi aplicada na direção da maior inércia o ganho de resistência foi bastante superior com relação ao centrado. Isto é justificado pelo fato de na compressão centrada as tensões axiais no pilar de seção retangular serem pequenas na sua região central (em comparação com os cantos). Com a excentricidade foram deslocadas as regiões comprimidas para próximo dos cantos e o efeito de confinamento tornou-se ainda mais benéfico. Esta conclusão é ainda mais interessante 
ao se imaginar que grande parte dos pilares existentes é retangular e possuem uma excentricidade na direção da maior inércia.

\subsection{Ruptura da camisa de PRF}

A ruptura da camisa de PRF ocorreu principalmente na região reta da face lateral nos pilares de seção quadrada ou retangular, bem próximo do início do raio de arredondamento. No raio de arredondamento propriamente dito, as deformações no lado externo da camisa foram inferiores às observadas nas demais regiões. Isto ocorreu por causa da flexão que ocorre na tendência de abertura deste canto com a expansão lateral do concreto.

As deformações de ruptura da camisa registradas pelos extensômetros ficaram normalmente entre 0,010 e 0,012. Eventualmente foram registradas algumas deformações de ruptura de 0,008. Este valores foram sempre inferiores aos 0,013 obtidos nos ensaios de caracterização.

\subsection{Forma do diagrama tensão $x$ deformação do concreto confinado}

Observou-se que a rigidez lateral adimensional da camisa $\left(E_{1} / f_{c o}\right)$ é a principal variável para definir a forma do diagrama tensão x deformação do concreto confinado em pilares de seção transversal circular. Camisas bastante rígidas possibilitam um certo prolongamento do trecho inicial do diagrama tensão deformação, principalmente quando é utilizado concreto de alta resistência.

Por outro lado, se camisas pouco rígidas são utilizadas ocorre uma queda da tensão axial logo após um pico inicial. Dependendo da deformação última da camisa, esta queda pode ser recuperada posteriormente, caso a rigidez tangente se estabilize com um valor positivo. Isto explica a grande diferença dos diagramas tensão $\mathrm{x}$ deformação do concreto confinado com PRF e concreto confinado com aço. Nas camisas de aço, a rigidez inicial é muito maior, o que permite ganhos imediatos de resistência axial. No entanto, quando o aço atinge o escoamento a rigidez cai drasticamente e a partir daí o concreto passa a apresentar apenas ganho de ductilidade.

Nos pilares ensaiados nesta pesquisa foram observados diagramas tensão $\mathrm{x}$ deformação bi-lineares, sendo que nos bem confinados ocorreu um segundo trecho ascendente e nos com baixo índice de confinamento ocorreu um segundo trecho descendente. A inclinação do segundo trecho linear se deveu principalmente à rigidez 
lateral efetiva da camisa, na qual deve ser considerada a redução da efetividade com o fator $2 \mathrm{r} / \mathrm{h}_{\mathrm{x}}$.

\subsection{Influência do tipo de fibras}

Quanto ao tipo de fibras utilizado, deve-se lembrar que as de maior módulo de elasticidade (carbono) possibilitam ganhos de resistência sem a necessidade de que sejam desenvolvidas grandes deformações axiais até a ruptura. No caso das fibras de alto módulo e ultra-alto módulo, as simulações numéricas mostraram que a rigidez axial do elemento confinado é bastante elevada. No entanto, caso o objetivo seja aumentar a deformabilidade do pilar devem ser utilizadas as fibras de vidro ou aramida, que possuem uma deformação de ruptura bastante elevada. Já resistência final do concreto confinado em pilares de seção circular depende basicamente da pressão lateral desenvolvida, logo é influenciada apenas pela resistência à tração do PRF.

\subsection{Influência da protensão}

A influência da protensão das fibras também foi estudada numericamente, e observou-se que a protensão pode ser benéfica, principalmente no caso de camisas pouco rígidas, em que pode trazer significativos acréscimos de resistência do concreto confinado. A protensão possibilita que a resistência do concreto confinado seja atingida a menores deformações axiais. Deste modo, com a protensão das fibras ocorre uma redução da ductilidade do pilar. Deve ser ainda considerado o fato de que com a protensão uma parcela maior de carga de longa duração solicita a camisa, e que as fibras utilizadas nos PRF possuem menor resistência à tração quando submetidas a esforços de longa duração, principalmente as fibras de vidro.

\subsection{Efeito das armaduras pré-existentes}

Quanto à presença de armaduras pré-existentes para confinamento, pode-se dizer que estas não reduzem o desempenho do confinamento com PRF (ver CARRAZEDO, 2002). Observou-se inclusive que os efeitos de confinamento da armadura transversal pré-existente e da camisa de PRF podem ser superpostos na avaliação da resistência do elemento confinado. Quanto à deformabilidade nestas situações, pode-se dizer que se existe uma armadura transversal significativa no pilar original, esta já é suficiente para fornecer ao concreto um aumento de deformação última. Neste caso, a utilização do PRF não possibilitará aumento significativo de deformação última. Deve-se apenas lembrar que caso o pilar original possua uma quantidade significativa de armadura 
transversal pode ocorrer uma redução da deformação última da camisa de PRF. CARRAZEDO (2002) observou uma redução de 0,0119 para 0,0106, ou seja, uma redução de $11 \%$ comparando pilares encamisados sem nenhuma armadura transversal interna e pilares encamisado com uma armadura transversal interna com taxa volumétrica de $2 \%$.

\subsection{Desempenho dos ensaios de flexo-compressão}

O desempenho do sistema de rótulas desta pesquisa foi satisfatório, possibilitando a aplicação das excentricidades e assegurando a liberdade de rotação nas extremidades. No entanto, observou-se certa dificuldade em realizar ensaios de compressão centrada nos pilares de concreto com este sistema de rótulas, contrariamente aos ensaios realizados previamente com pilares de aço. Acredita-se que isto se deve principalmente à variação das dimensões dos pilares de concreto por falta de uniformidade das fôrmas e falta de homogeneidade do material, que provocou respostas diferentes de rigidez em regiões diferentes dos pilares, fazendo que os resultados dos pilares indicassem a presença de pequenas excentricidades.

\subsection{Desenvolvimento da sub-rotina}

Foi desenvolvida uma sub-rotina Umat para representar o modelo de plasticidade não associativa de GRASSL et al. (2002), ao qual foram acrescentadas algumas equações que não haviam sido definidas previamente pelos autores.

Os resultados obtidos com a sub-rotina foram muito próximos dos experimentais, tanto para o concreto sob compressão uniaxial como em diferentes formas de confinamento, indicando que esta ferramenta pode ser muito importante para a avaliação do efeito de confinamento em pesquisas futuras.

\subsection{Recomendações para pesquisas futuras}

Neste trabalho avaliou-se a influência da excentricidade do carregamento em conjunto com a forma da seção transversal. No entanto, foram consideradas apenas pequenas excentricidades. Acredita-se que seja interessante o estudo do comportamento de pilares encamisados com PRF submetidos a maiores excentricidades. Recomenda-se ainda que sejam utilizadas fibras tanto no sentido transversal como longitudinal.

Como a sub-rotina implementada nesta pesquisa possibilitou obter resultados bastante próximos dos experimentais, acredita-se que seja interessante utilizá-la em 
análises paramétricas mais completas sobre o efeito de confinamento com diferentes materiais e formas de seção transversal.

Recomenda-se a implementação de alguma modificação na sub-rotina para melhorar sua convergência em problemas que envolvam flexão.

$\mathrm{O}$ modelo constitutivo implementado na sub-rotina apresentou um comportamento bastante realista para tensões predominantemente de compressão. Acredita-se que o acoplamento de um modelo de mecânica da fratura para representar $o$ comportamento sob tensões de tração possa melhorar ainda mais o desempenho da subrotina e permitir avaliações de vigas e outros elementos de concreto armado.

Neste trabalho observou-se que os efeitos de segunda ordem no concreto confinado podem ser muito importantes, de modo que se recomenda que pesquisas futuras sejam realizadas para avaliar o efeito da excentricidade do carregamento em pilares longos.

Nos ensaios realizados nesta pesquisa não foram utilizadas armaduras internas. Logo, seria interessante que em pesquisas futuras sobre confinamento do concreto com PRF na flexo-compressão, fossem utilizadas armaduras longitudinais e transversais nos pilares ensaiados. 


\section{Referências Bibliográficas}

ABAQUS $^{\circledR}$ versão 6.2 - Manual on-line.

ASSOCIAÇÃO BRASILEIRA DE NORMAS TÉCNICAS (2003). NBR 6118: Projeto de estruturas de concreto. Rio de Janeiro.

AIRE UNTIVEROS, C. A., Estúdio experimental del comportamiento del hormigón confinado submetido à compressión. Tese de Doutorado - Universidade Politécnica da Catalunha, Barcelona, 2002.

AMERICAN SOCIETY FOR TESTING AND MATERIALS (1992). ASTM D 2290 Standard Test Method for Apparent Hoop Tensile Strength of Plastic or Reinforced Plastic Pipe by Split Disk Method.

AMERICAN SOCIETY FOR TESTING AND MATERIALS (1995). ASTM D 3039/ D 3039M - Standard test method for tensile properties of polymer matrix composite materials. Philadelphia.

ANSARI, F.; LI, Q. (1998). High-Strength Concrete Subjected to Triaxial Compression. ACI Structural Journal, Vol. 95, n. 6, November/December 1998, pp. 747-755.

BAZANT, Z. P.; TSUBAKI, T. (1980). Total strain theory and path-dependence of concrete, Journal of the Engineering Mechanics Division, ASCE, v. 106, No. EM6, pp. 1151-1172.

BOUSIAS, S.; TRIANTAFILLOU, T.; FARDIS, M.; SPATHIS, L.; OREGAN, B. (2002). Experimental Behaviour of Deficient Rectangular Columns with Externally Bonded FRPs. In: The first fib congress, 2002, Osaka.

CAMPIONE, G.; MIRAGLIA, N. (2003). Strength and strain capacities of concrete compression members reinforced with FRP. Cement \& Concrete Composites, V. 25 , 2003, 31-41.

CANDAPPA, D. C.; SANJAYAN, J. G.; SETUNGE, S. (2001). Complete Triaxial Stress-Strain Curves of High-Strength Concrete. Journal of Materials in Civil Engineering, Vol. 13, n. 3, May/June, 2001, pp. 209-215.

CARRAZEDO, R. (2002). Mecanismos De Confinamento e Suas Implicações no Reforço de Pilares de Concreto por Encamisamento com Compósito de Fibras de 
Carbono. Dissertação (Mestrado), Escola de Engenharia de São Carlos, Universidade de São Paulo, São Carlos, 2002.

CHAALLAL, O.; SHAHAWY, M. (2000). Performance of Fiber-Reinforced PolymerWrapped Reinforced Concrete Column under Combined Axial-Flexural Loading. ACI Structural Journal, v. 97, n. 4, August, 659-668.

CHEN, W.F. (1982). Constitutive equations for engineering materials. John Wiley \& Sons.

COLE, C.; BELARBI, A. (2001). Confinement Characteristics of Rectangular FRPJacketed RC Columns, Proceedings of the Fifth International Symposium on Fiber Reinforced Polymer for Reinforced Concrete Structures (FRPRCS-5), Cambridge, UK, July 16-18, 2001, pp. 823-832.

CUSSON, D.; PAULTRÈ, P. (1995). Stress-strain model for confined high- strength concrete. Journal of Structural Engineering, v.121, n.3, p. 468-476, March, 1995.

DE LORENZIS, L. ; TEPFERS, R. (2001). A comparative study on confinement of concrete cylinders with frp composites. Göteborg, Sweden, Chalmers University of Technology. 73p. Publication 01:04, Work n.46, http://www.bm.chalmers.se/bm9707/Division/Dindex.htm.

FARDIS, M. N.; AND KHALILI, H. (1981) Concrete encased in fiberglass-reinforcedplastic. Journal of the American Concrete Institute. Proceedings, v. 78, No. 6. November- December 1981, pp. 440-446.

FÉDÉRATION INTERNATIONALE DU BÉTON (1999). FIB - Structural concrete: textbook on behaviour, design and performance. Bulletin 1, v.1, p.35-37, p.206-212. FÉDERATION INTERNATIONALE DU BETÓN (2001). FIB - Externally bonded FRP reinforcement for RC structures. Bulletin 14, July, 2001.

GETTU, R. (2002). Utilização de polímeros reforçados com fibras para reparo e reforço. /Palestra proferida no Departamento de Engenharia de Estruturas da EESC/USP em outubro de 2002/.

GIBSON, R.F. (1994). Priciples of composite material mechanics. McGraw-Hill. 
GRASSL, P.; LUNDGREN, K.; GYLLTOFT, K. (2002). Concrete in compression: a plasticity theory with a novel hardening law. International Journal of Solids and Structures. v. 39, p. 5205-5223.

HARRIES, K. A.; KHAREL, G. (2003). Experimental investigation of the behavior of variably confined concrete. Cement and Concrete Research, v. 33, 2003, p. 873-880.

HOWIE, I.; CASTRO, P.F.; KARBHARI, V.M. (1996). Um estudo experimental sobre reforço de colunas de concreto com manta compósita. Revista IBRACON, v.4, n.12, p.13-18, abril.

HYER, R. (1998). Stress Analysis of Fiber-Reinforced Composite Materials. Mc. Graw Hill.

IMRAN, I.; PANTAZOPOULOU, S. J. (1996) Experimental study of plain concrete under triaxial stress, ACI Materials Journal, v. 93, No.6, pp. 589-601.

KARBHARI, V. M.; GAO, Y. (1997). Composite Jacketed Concrete under Uniaxial Compression - Verification of Simple Design Equations. Journal of Materials in Civil Engineering. V. 9, n. 4, November, 1997, 185-193.

KILPATRIC, A. E.; RANGAN, B. V. (1999). Tests on High Strength Concrete - Filled Steel Tubular Columns. ACI Structural Journal, Vol. 96, March/April 1999, pp. 268274.

KURT, C. E. (1978). Concrete filled structural plastic columns, Journal of the Structural Division ASCE, v. 104, No. ST1, pp. 55-63.

LIMA JÚNIOR, H. C. (2003). Avaliação da ductilidade de pilares de concreto armado, submetidos à flexo-compressão reta com e sem adição de fibras metálicas. Tese (Doutorado), Escola de Engenharia de São Carlos, Universidade de São Paulo, São Carlos, 2003.

MAALEJ, M.; TANWONGSVAL, S.; PARAMASIVAM, P. (2003). Modelling of rectangular RC columns strengthened with FRP. Cement \& Concrete Composites, v. 25, 2003, 263-276.

MANDER, J.B.; PRIETSLEY, M.J.N ; PARK, R.J.T. (1988). Theoretical stress strain model for confined concrete. Journal of Structural Engineering, v.114, p.1804-1827. 
MENÉTREY P.; WILLAM K. J. (1995). Triaxial failure criterion for concrete and its generalization. ACI Structural Journal, Vol. 92, No. 3, May-June 1995, pp. 311-318.

MIRMIRAN, A. ; ZAGERS, K. ; YUAN, W. (2000). Nonlinear finite element modeling of concrete confined by fiber composites. Finite Elements in Analysis and Design, v. 35, p.79-96.

MIRMIRAN, A., SHAHAWY, M., SAMAAN, M., EL ECHARY, H., MASTRAPA, J.C., AND PICO, O. (1998). Effect of Column Parameters on FRP-Confined Concrete. Journal of Composites for Construction, ASCE, v. 2, n. 4, 175-185.

MIRMIRAN, A.; SHAHAWY, M. (1997). Behavior of Concrete Columns Confined by Fiber Composites. Journal of Structural Engineering, ASCE, v. 123, No. 5, May 1997. pp. 583-590.

MIRMIRAN, A.; SHAHAWY, M. (1997)-b. Dilation Characteristics of Confined Concrete. Mechanics of Cohesive-Frictional, v. 2, p. 237-249.

MIRMIRAN, A.; SHAHAWY, M.; BEITLEMAN, T. (2001). Slenderness Limit For Hybrid FRP-Concrete Columns. Journal of Composites for Construction, ASCE, 5(1), 26-34.

MIRMIRAN, A.; SHAHAWY, M.; EL KHOURY, C.; NAGUIB, W. (2000). Large Beam-Column Tests on Concrete-Filled Composite Tubes. ACI Structural Journal, $A C I$, v. 97, n. 2, 268-276.

MIYAUCHI, K. ; NISHIBAYASHI, S. ; INOUE, S. (1997). Estimation of strengthening effects with carbon fiber sheet for concrete column. In: INTERNATIONAL SYMPOSIUM, 3., Tokyo, Japan, October. Proc. Tokyo, Japan Concrete Institute. v.1, p.217-225.

NIELSEN, M. P. (1998). Limit analysis and concrete plasticity. 2. ed., CRC Press, Boca Raton, 936 pp.

PANTAZOPOULOU S. J. (1995). Role of Expansion on Mechanical Behavior of Concrete. Journal of Structural Engineering, ASCE, v. 121, No. 12, December 1995. pp. 1795-1805.

PARVIN, A.; WANG, W. (2001). Behavior of FRP Jacketed Concrete Columns under Eccentric Loading. Journal of Composites for Construction, v. 5, n. 3, August, 2001, $146-152$. 
PESSIKI, S.; HARRIES, K. A.; KESTNER, J.; SAUSE, R.; RICLES, J. M. (2001). The axial behavior of concrete confined with fiber reinforced composite jackets, ASCE J. Compos. Constr. v. 5, n. 4, 2001, p. 237-245.

RICHART, F. E.; BRADTZAEG, A.;BROWN, R. L. (1929). The failure of plain and spirally reinforced concrete in compression. Bull. No. 190, University of Illinois, Engineering Experimental Station, Urbana, III., 74

RICHART, F.E., BRANDTZAEG, A., AND BROWN, R.L. (1928). A study of the failure of concrete under combined compressive stresses, University of Illinois, Urbana. Engineering Experiment Station Bulletin No. 185.

RILEM TC 148-SSC: Strain Softening of Concrete - Test Methods for Compressive Softening. Materials and Structures, v. 33, July, 2000, pp 347-351.

ROCHETTE, P.; LABOSSIÈRE, P. (2000). Axial Testing of Rectangular Column Models Confined With Composites. Journal of Composites for Construction, ASCE, v. 4 , n. 3, 129-136.

SAAFI, M.; TOUTANJI, H. A.; LI, Z. (1999) Behavior of Concrete Columns Confined with Fiber Reinforced Polymer Tubes. ACI Materials Journal, v. 96, No. 4, July August 1999. pp. 500-509.

SAMAAN, M. ; MIRMIRAN, A. ; SHAHAWY, M. (1998). Model of concrete confined by fiber composites. Journal of Structural Engineering, v.124, p.1025-1031.

SANTOS, L. M. (1987). Estado Limite Último de Instabilidade. Escola Politécnica da Universidade de São Paulo, 112 pp., 1987.

SETUNGE, S.; ATTARD, M. M.; DARVALL, P. L. P. (1993). Ultimate Strength of Confined Very High Strength Concretes. ACI Structural Journal, Vol. 90, n. 6, November/December 1993, pp. 632-640.

SHAHAWY, M., MIRMIRAN, A., AND BEITELMANN, T. (2000). Tests and modeling of carbon-wrapped concrete columns. Composites Part B, v. 31, 471-480.

SHEHATA, I.A.E.M.; CARNEIRO, L.A.V.; SHEHATA, L.C.D. (2001). Strength of short concrete columns confined with CFRP sheets. Materials and Structures, v. 35.

SPOELSTRA, M. R.; MONTI, G. (1999). FRP-Confined Concrete Model. Journal of Composites for Construction, ASCE, v. 3, No. 3, August 1999. pp. 143-150. 
TAN (2002). Strength Enhancement of Rectangular Reinforced Concrete Columns using Fiber-Reinforced Polymer. Journal of Composites for Construction, ASCE, v. 6, No. 3, August 2002, pp. 175-183.

TENG, J. G.; LAN, L. (2003). Compressive Behavior of Carbon Fiber Reinforced Polymer-Confined Concrete in Elliptical Columns. Journal of Structural Engineering, ASCE, v. 128, No. 12, December 2003, pp. 1535-1543.

THÉRIAULT, M.; NEALE, K. W. (2000). Design equations for axially loaded reinforced concrete columns strengthened with fibre reinforced polymer wraps. Canadian Journal of Civil Engineering. V. 27, 2000, 1011-1020.

TOUTANJI, H. (1999). Stress-Strain Characteristics of Concrete Columns Externally Confined with Advanced Fiber Composite Sheets. ACI Materials Journal, v. 96, No. 3, MAY-JUNE 1999. PP.397-404.

WANATABE, K.; NAKAMURA, H.; HONDA, Y.; TOYOSHIMA, M.; ISO, M.; FUJIMAKI, T.; KANETO, M.; SHIRAI, N. (1997). Confinement Effect of FRP Sheet on Strength and Ductility of Concrete Cylinders under Uniaxial Compression. In: INTERNATIONAL SYMPOSIUM, 3., Tokyo, Japan, October. Proc. Tokyo, Japan Concrete Institute. v.1, p.233-240.

YANG, X.; NANNI, A.; CHEN, G. (2001). Effect of Corner Radius on Performance of Externally Bonded FRP Reinforcement. In: Non-Metallic Reinforcement for Concrete Structures - FRPRCS-5, Cambridge, July, 16-18, 2001, pp. 197-204. 


\section{APÊNDICE I - Sub-rotina Umat implementada}

(conforme algoritmo de GRASSL et al. $(2002)^{5}$ e equações adicionais descritas no item 6.2.2 desta tese)

5 GRASSL, P.; LUNDGREN, K.; GYLLTOFT, K. (2002). Concrete in compression: a plasticity theory with a novel hardening law. International Journal of Solids and Structures. v. 39, p. 5205-5223. 


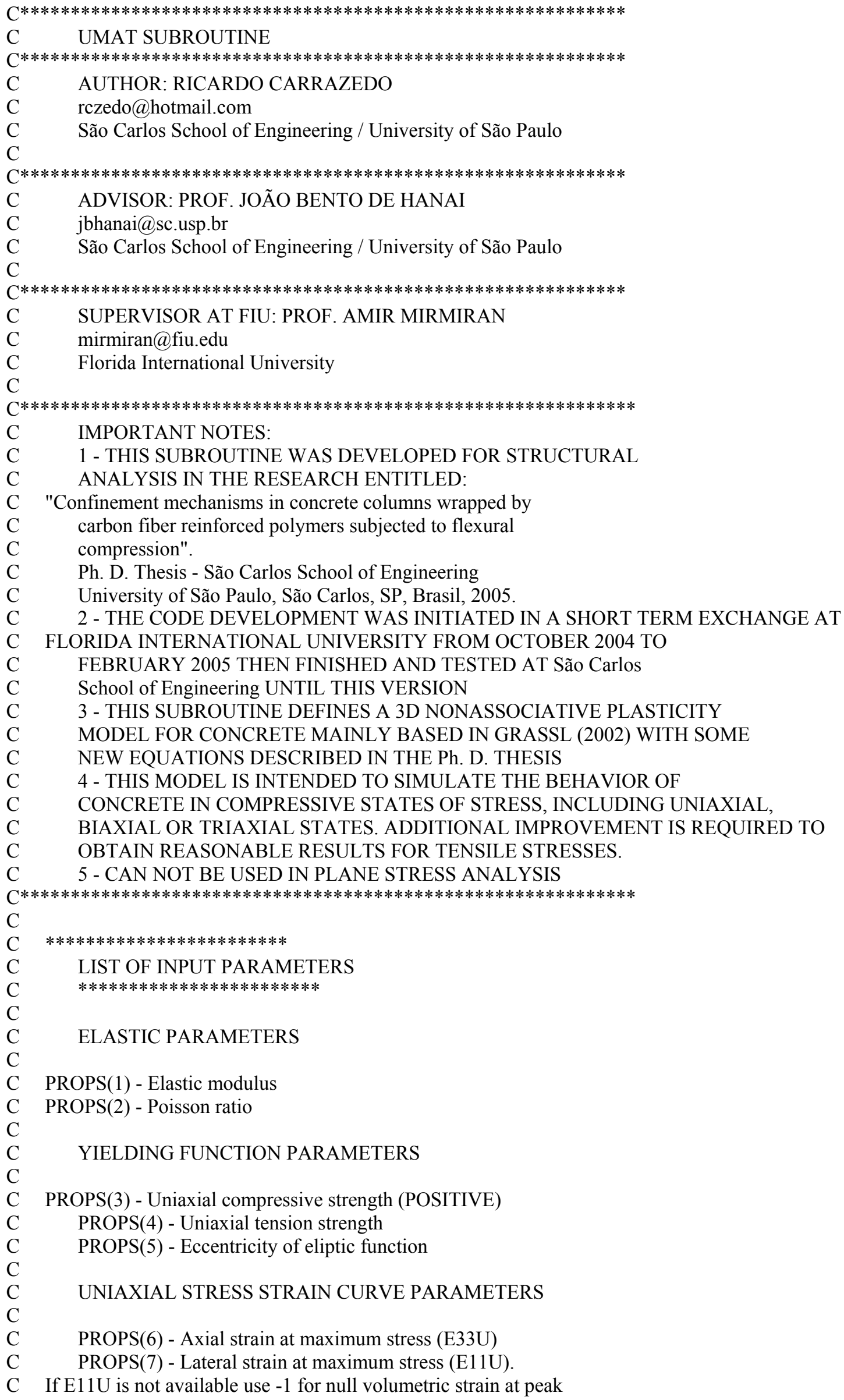


$\mathrm{C}$

$\mathrm{C}$

$\mathrm{C}$

$\mathrm{C}$

$\mathrm{C}$

$\mathrm{C}$

C PROPS(9) - "Critic stress" (initial value of $\mathrm{q}\left(\mathrm{k}^{\prime}\right)$

C PROPS(10) - E1 = INITIAL SLOPE

$\mathrm{C} \quad$ PROPS(11)- $\mathrm{C} 1$ = PARAMETER FOR DESCENDING BRANCH

C PROPS(12)- C2 = PARAMETER FOR DESCENDING BRANCH

$\mathrm{C} \quad$ PROPS(13)- $\mathrm{C} 3$ = PARAMETER FOR DESCENDING BRANCH

$\mathrm{C} * * * * * * * * * * * * * * * * * * * * * * * * * * * * * * * * * * * * * * * * * * * * * * * * * * * * * * * * * * * * * *$

$\mathrm{C}$

$\mathrm{C}$

SUBROUTINE UMAT(STRESS,STATEV,DDSDDE,SSE,SPD,SCD, 1 RPL,DDSDDT,DRPLDE,DRPLDT,STRAN,DSTRAN,

2 TIME,DTIME,TEMP,DTEMP,PREDEF,DPRED,MATERL,NDI,NSHR,NTENS, 3 NSTATV,PROPS,NPROPS,COORDS,DROT,PNEWDT,CELENT, 4 DFGRD0,DFGRD1,NOEL,NPT,KSLAY,KSPT,KSTEP,KINC)

INCLUDE 'ABA PARAM.INC'

CHARACTER *80 MATERL REAL*8 STRESS(NTENS),STATEV(NSTATV), 1 DDSDDE(NTENS,NTENS),DDSDDT(NTENS),DRPLDE(NTENS), 2 STRAN(NTENS),DSTRAN(NTENS),TIME(2),PREDEF(1),DPRED(1), 3 PROPS(NPROPS),COORDS(3),DROT(3,3),SDEV(NTENS),STRESS1(6), 4 DFGRD0(3,3),DFGRD1(3,3),SECFLOW(NTENS,NTENS),ABSRESI 5 EQ1,EQ2,EQ3,EQ4,EQ5,EQ6,EQ7,EQ8,EQ9,COS3TETA,P,DLAMBDA1, 6INV1,INV2,INV3,JOTA2,JOTA3,KSI,RO,MODSTRAN,M,EQ1B,INVE(6,

76), $\operatorname{CONF}(6,6), \operatorname{IDENT}(6,6), \mathrm{Q}(6,6), \operatorname{MATRIXR}(6,6), \operatorname{TRSTRESS}(6)$, 8DIVLAMBDA,RHS(6),ABSRHS,NUMER,DENOMI,NUMERATOR(6),AUXILIAR(6), 9PARENT(6,6),STABLE(2,7),KA,HARD,QT,QH,QS,TANGE,TANGEH,TANGES, 1GRADFK,EELAS(6),EPLAS(6),FLOW(NTENS),FSIGMA(6),KA1,YFUNCANT,

2CMINUS(6,6),RESI(6),QMINUS(6,6),DLAMBINT,CORSTRESS(6),

3OLDSTRESS(6),VERYFUNC,RIGID,VEC(6),FINIC,FACTOR,ZERO,DSIJ, 4DNORM(6,6),SIGMACR,E1,PFAC,EPCR,KINI,CONTROL,E33UP,E11UP,E33CP,

5E11CP,PSI1,PSI2,RO1,RO2,INCDEF(6),DDSDDEMINUS(6,6),DSTRESS(6), 6SIGM,SIG1,SIG3,KISI,JOT2,ROT,EFE,DEFEDSIG,DS33C

PARAMETER $(\mathrm{ONE}=1.0 \mathrm{D} 0, \mathrm{TWO}=2.0 \mathrm{D} 0, \mathrm{THREE}=3.0 \mathrm{D} 0, \mathrm{FOUR}=4.0 \mathrm{D} 0$, $1 \mathrm{FIVE}=5.0 \mathrm{D} 0, \mathrm{SIX}=6.0 \mathrm{D} 0)$

INTEGER CEWTON

DATA NEWTON,TOLER/30,1.D-10/

$\mathrm{C}$

IF (NDI.NE.3) THEN

WRITE $(6,101)$

101 FORMAT(//,30X,***ERROR - THIS UMAT MAY ONLY BE USED FOR ',

1 'ELEMENTS WITH THREE DIRECT STRESS COMPONENTS') ENDIF

$\mathrm{C}$

C ELASTIC PROPERTIES

C

EMOD $=$ PROPS $(1)$

$\mathrm{ENU}=\mathrm{PROPS}(2)$

IF(ENU.GT.0.4999.AND.ENU.LT.0.5001) ENU =0.499

EBULK3 $=\mathrm{EMOD} /(\mathrm{ONE}-\mathrm{TWO} * \mathrm{ENU})$

$\mathrm{EG} 2=\mathrm{EMOD} /(\mathrm{ONE}+\mathrm{ENU})$ 


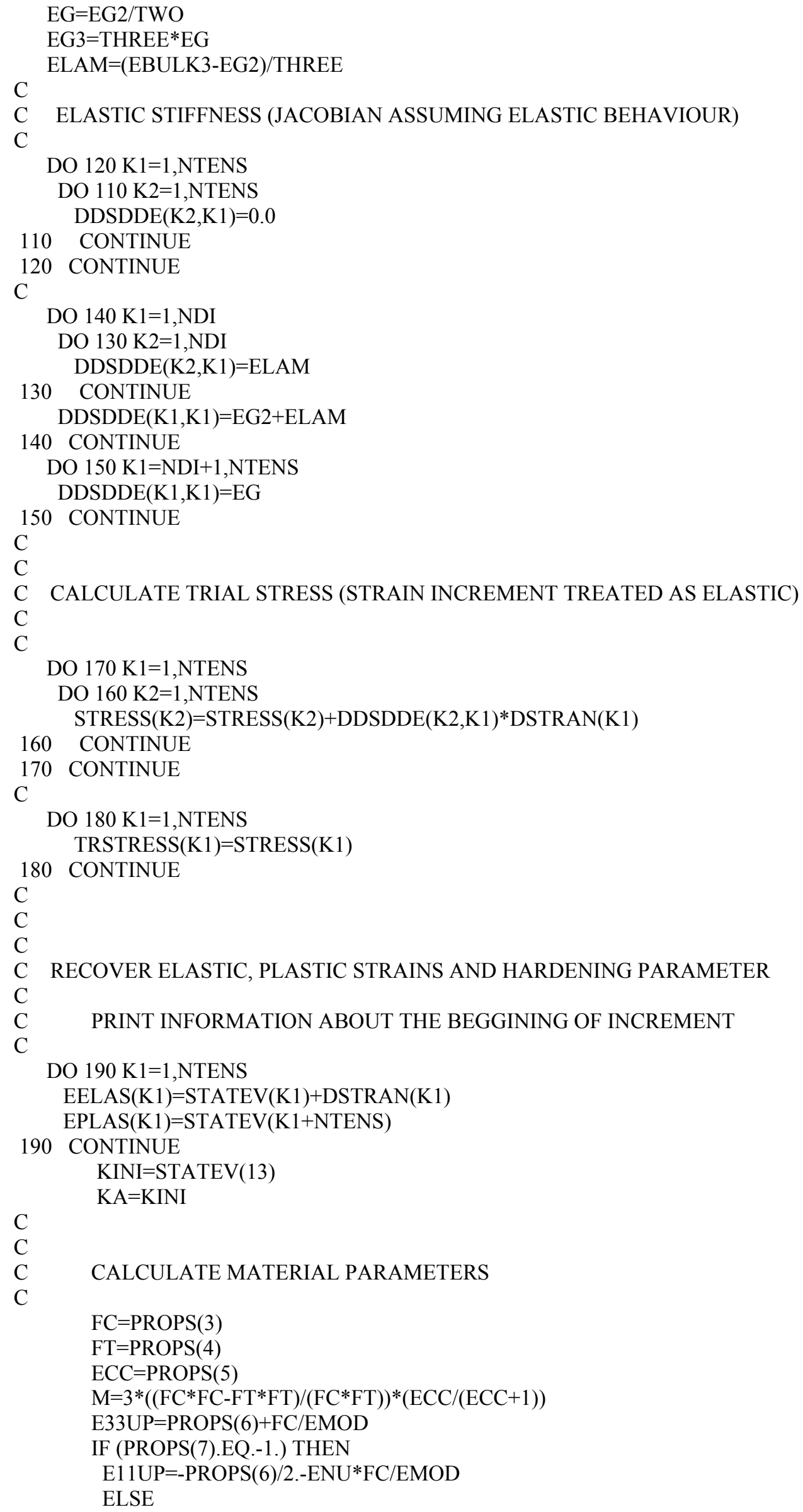




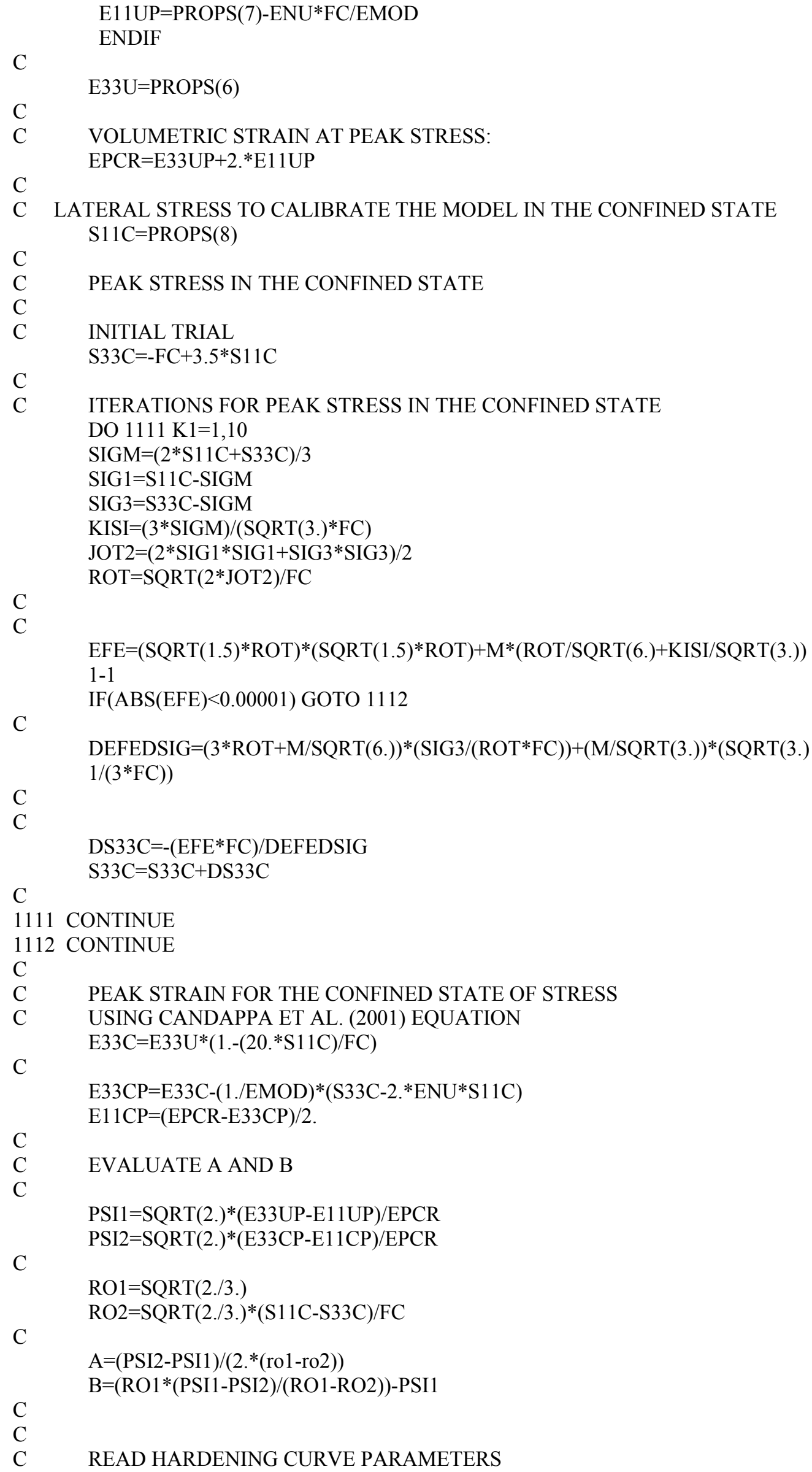




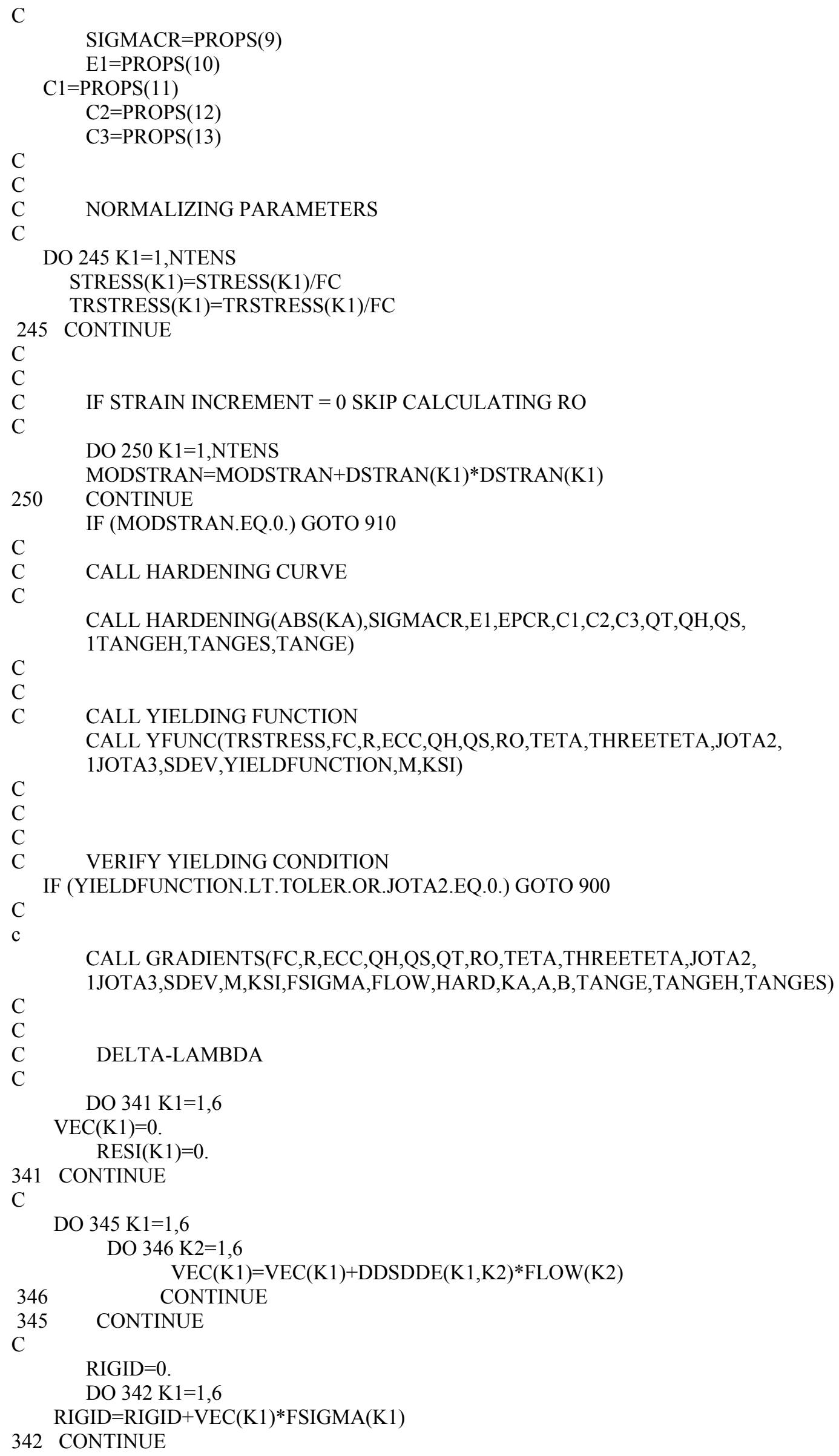


$\mathrm{C}$

$\mathrm{C}$

$\mathrm{C}$

C CORRECT STRESS

$\mathrm{C}$

CALL CORRECTION(FC,QH,QS,QT,YIELDFUNCTION,FSIGMA,FLOW,DDSDDE,HARD, 1KA,DLAMBDA,RIGID,STRESS,TRSTRESS,KINI)

c

$\mathrm{C}$

$\mathrm{C}$

c

$\mathrm{C}$

C

C

$\mathrm{c}$

$\mathrm{C}$

C

C

$\mathrm{c}$

C CALL YIELDING FUNCTION

CALL YFUNC(STRESS,FC,R,ECC,QH,QS,RO,TETA,THREETETA,JOTA2, 1JOTA3,SDEV,YIELDFUNCTION,M,KSI)

$\mathrm{C}$

$\mathrm{C}$

DO $378 \mathrm{~K} 1=1,6$

$\operatorname{VEC}(\mathrm{K} 1)=0$.

378 CONTINUE

$\mathrm{C}$

DO $379 \mathrm{~K} 1=1,6$

DO $380 \mathrm{~K} 2=1,6$

380

379

C

c

C

c

C PLASTIC FLOW SECOND DERIVATIVES

DO $387 \mathrm{~K} 1=1$,NDI

DO $392 \mathrm{~K} 2=1$,NDI

IF (K1.EQ.K2) THEN

$\mathrm{DSIJ}=2 . / 3$

$\operatorname{SECFLOW}(\mathrm{K} 1, \mathrm{~K} 2)=-2 . * \mathrm{~A} * \operatorname{SDEV}(\mathrm{K} 2) * \operatorname{SDEV}(\mathrm{K} 1) /(\mathrm{QT} * \mathrm{RO} * \mathrm{RO})+(-2 * \mathrm{~A} *$

$2\left(\mathrm{RO}^{*}(\mathrm{RO}) * * 2\right)$ ) CONTINUE

DO $381 \mathrm{~K} 1=1,6$

RESI $(\mathrm{K} 1)=\mathrm{STRESS}(\mathrm{K} 1)-\mathrm{TRSTRESS}(\mathrm{K} 1)+\mathrm{DLAMBDA} * \operatorname{VEC}(\mathrm{K} 1)$

CONTINUE

ELSE

$\operatorname{DSIJ}=-1 . / 3$.

$\operatorname{SECFLOW}(\mathrm{K} 1, \mathrm{~K} 2)=-2 .{ }^{*} \mathrm{~A} * \mathrm{SDEV}(\mathrm{K} 2) * \operatorname{SDEV}(\mathrm{K} 1) /(\mathrm{QT} * \mathrm{RO} * \mathrm{RO})+(-2 * \mathrm{~A} *$

$\left.2\left(\mathrm{RO} *(\mathrm{RO})^{* * 2}\right)\right)$

ENDIF 


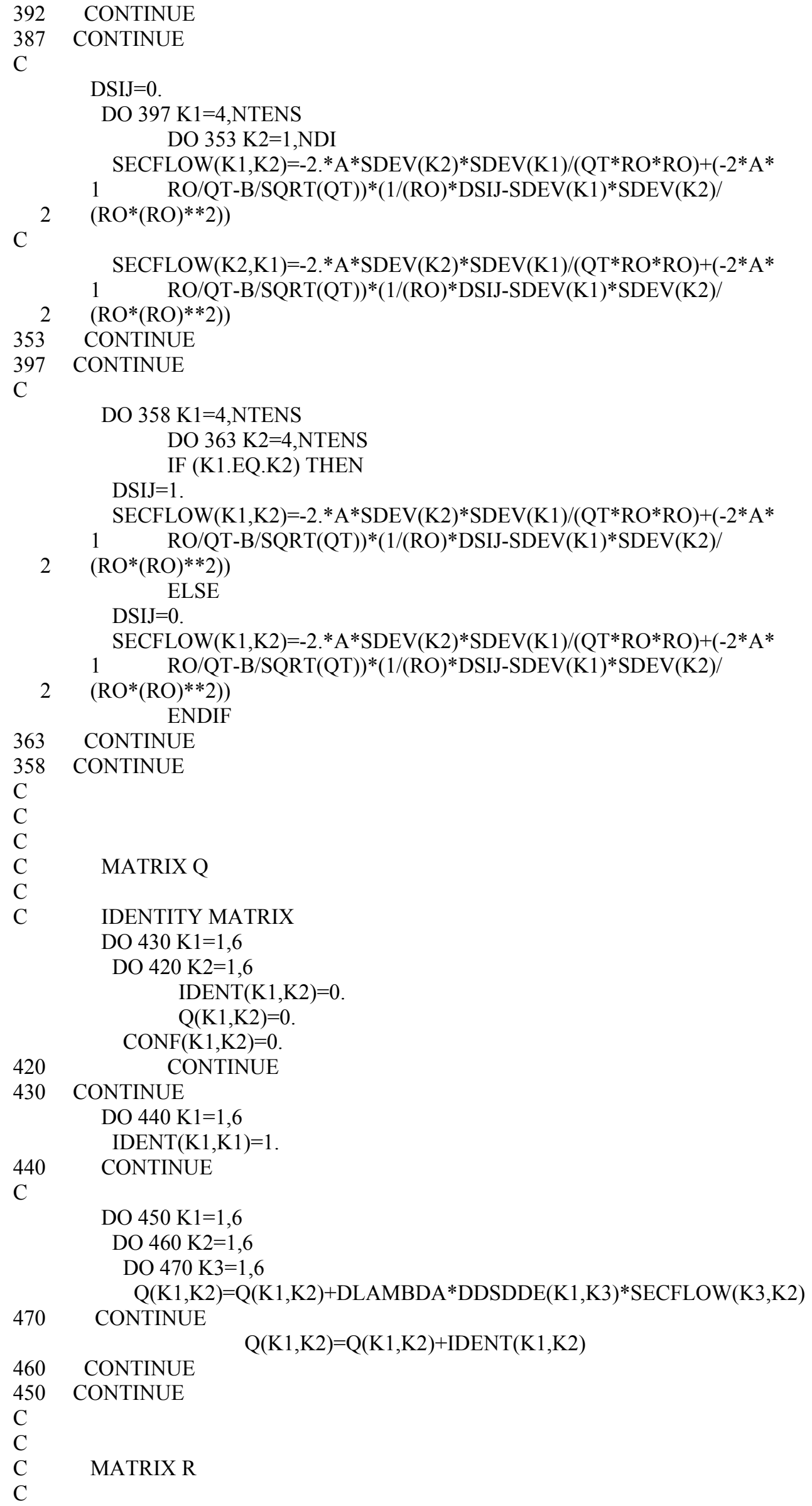




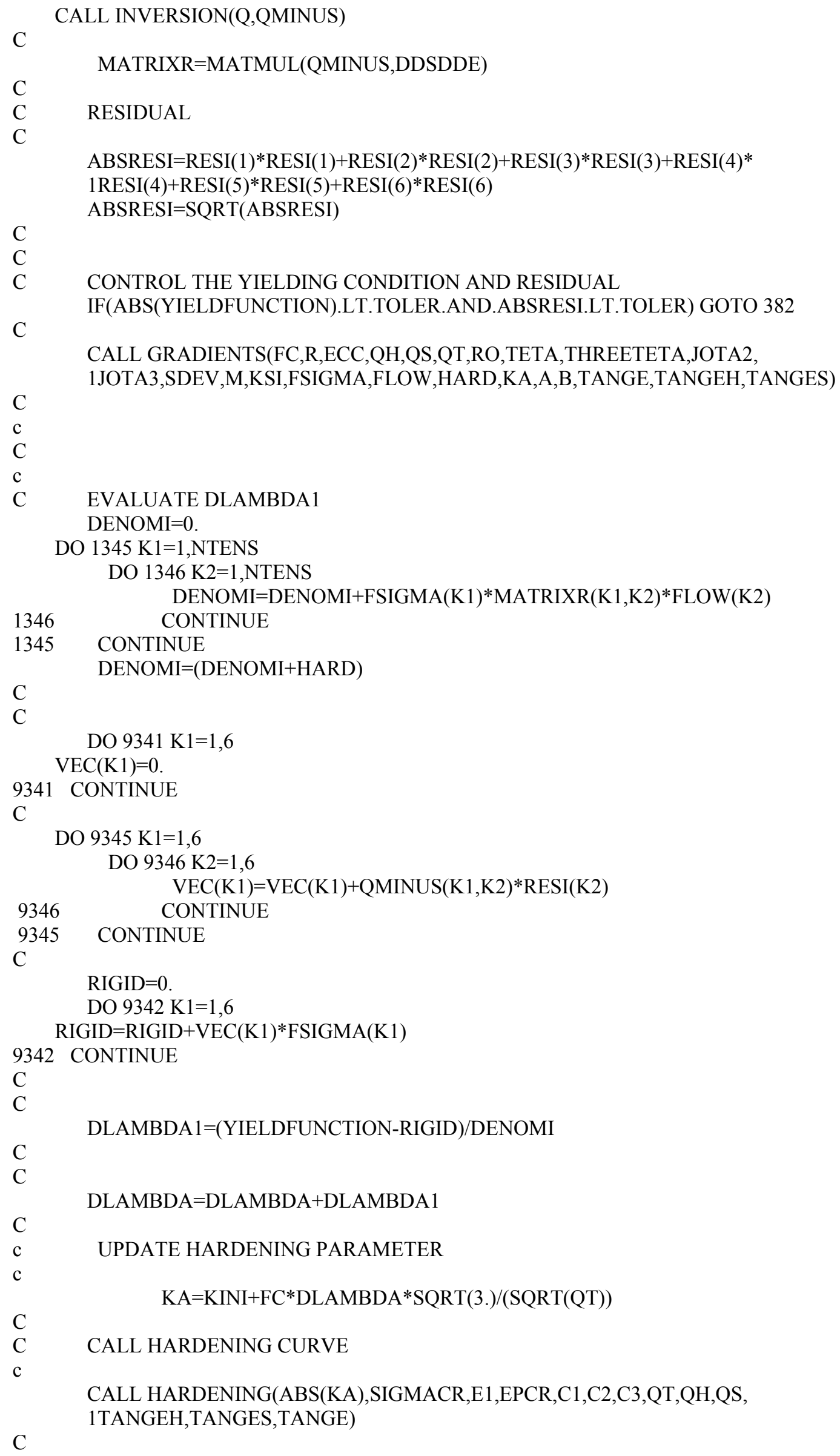




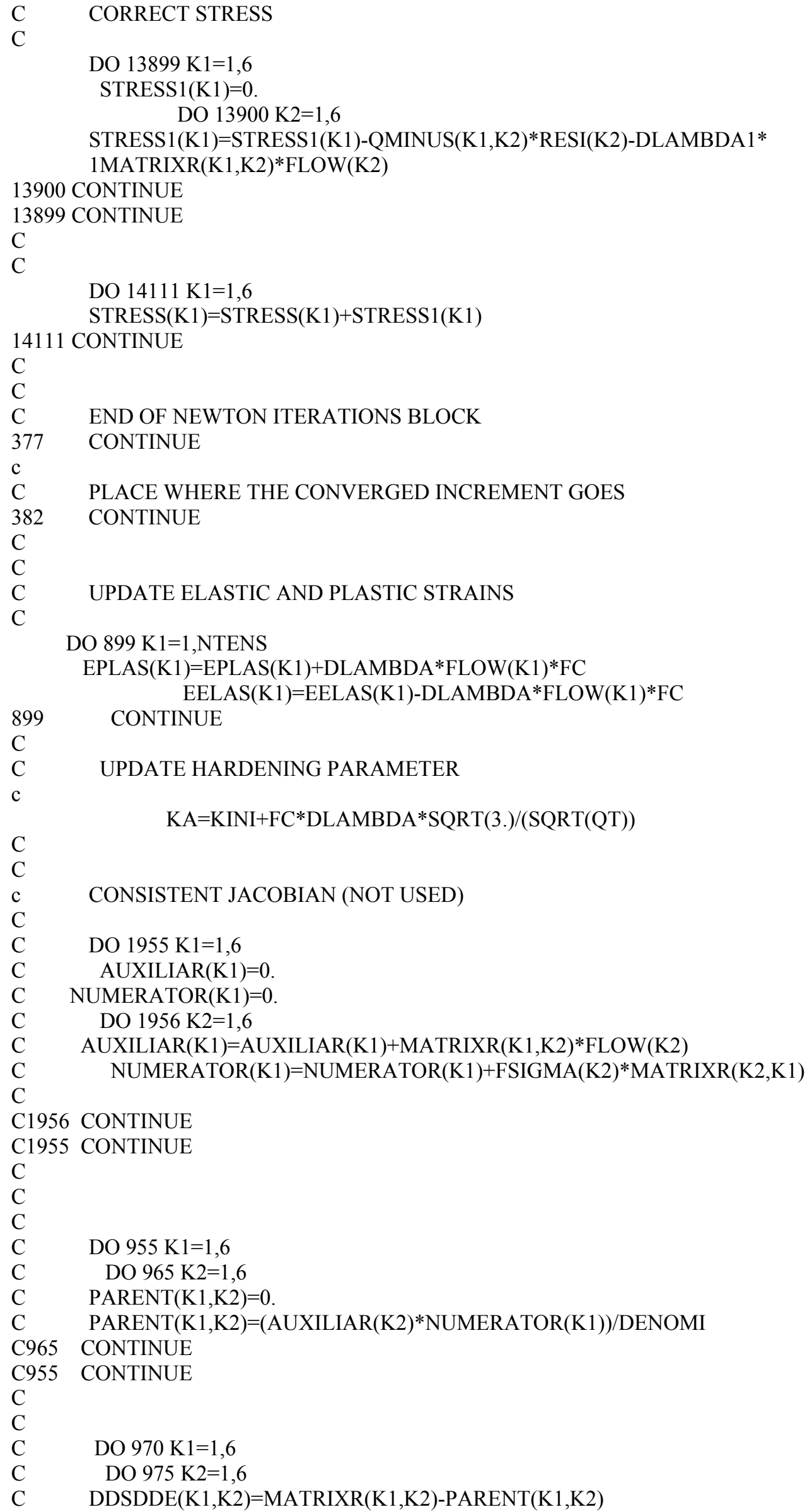




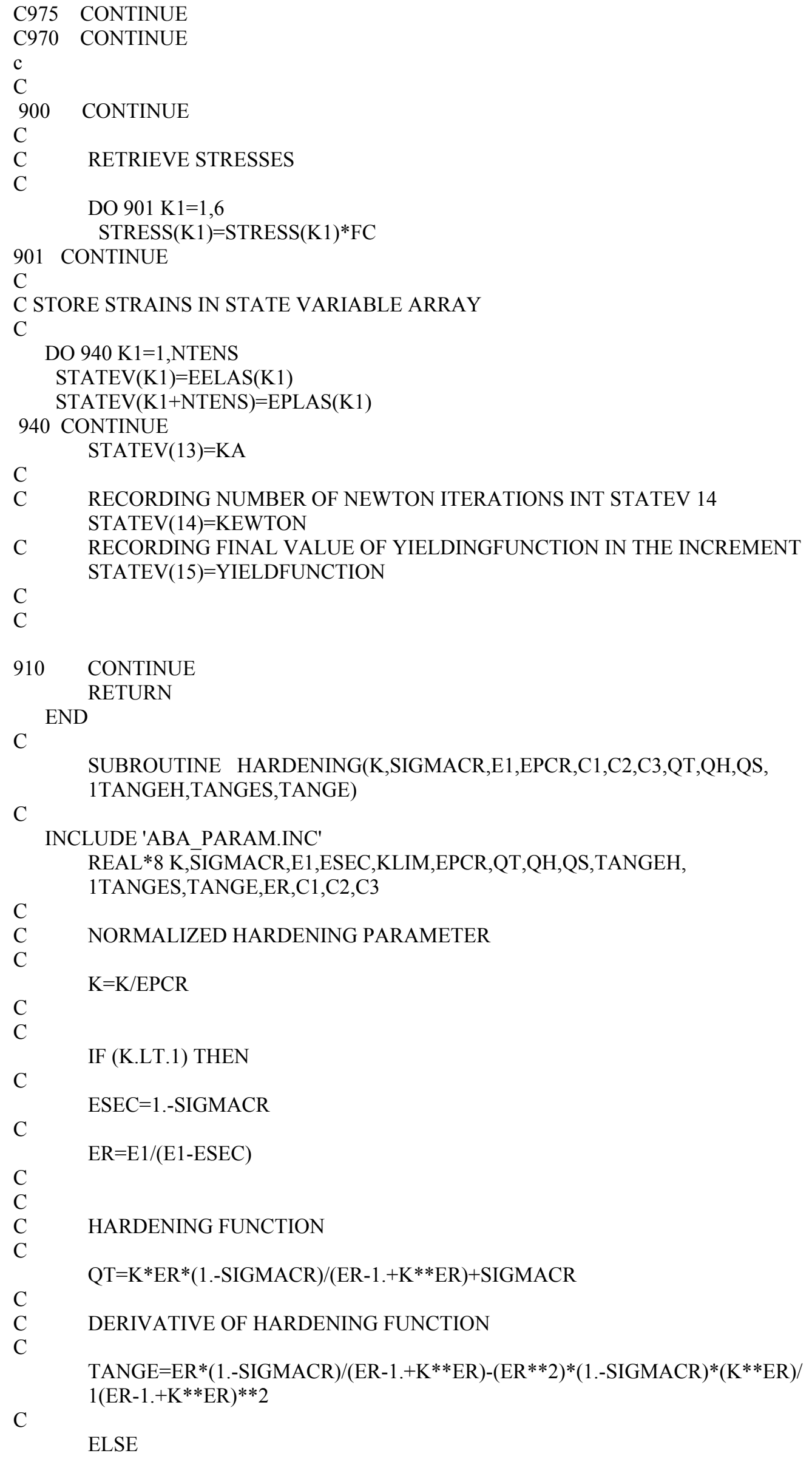

C

C HARDENING FUNCTION

$\mathrm{C}$

$\mathrm{QT}=\mathrm{K} * \mathrm{ER} *(1 .-\mathrm{SIGMACR}) /(\mathrm{ER}-1 .+\mathrm{K} * * \mathrm{ER})+\mathrm{SIGMACR}$

$\mathrm{C}$

C DERIVATIVE OF HARDENING FUNCTION

$\mathrm{C}$

TANGE $=\mathrm{ER} *(1 .-\mathrm{SIGMACR}) /(\mathrm{ER}-1 .+\mathrm{K} * * \mathrm{ER})-(\mathrm{ER} * * 2) *(1 .-\mathrm{SIGMACR}) *(\mathrm{~K} * * \mathrm{ER}) /$

$\mathrm{C}$ 1(ER-1.+K**ER)**2

ELSE 


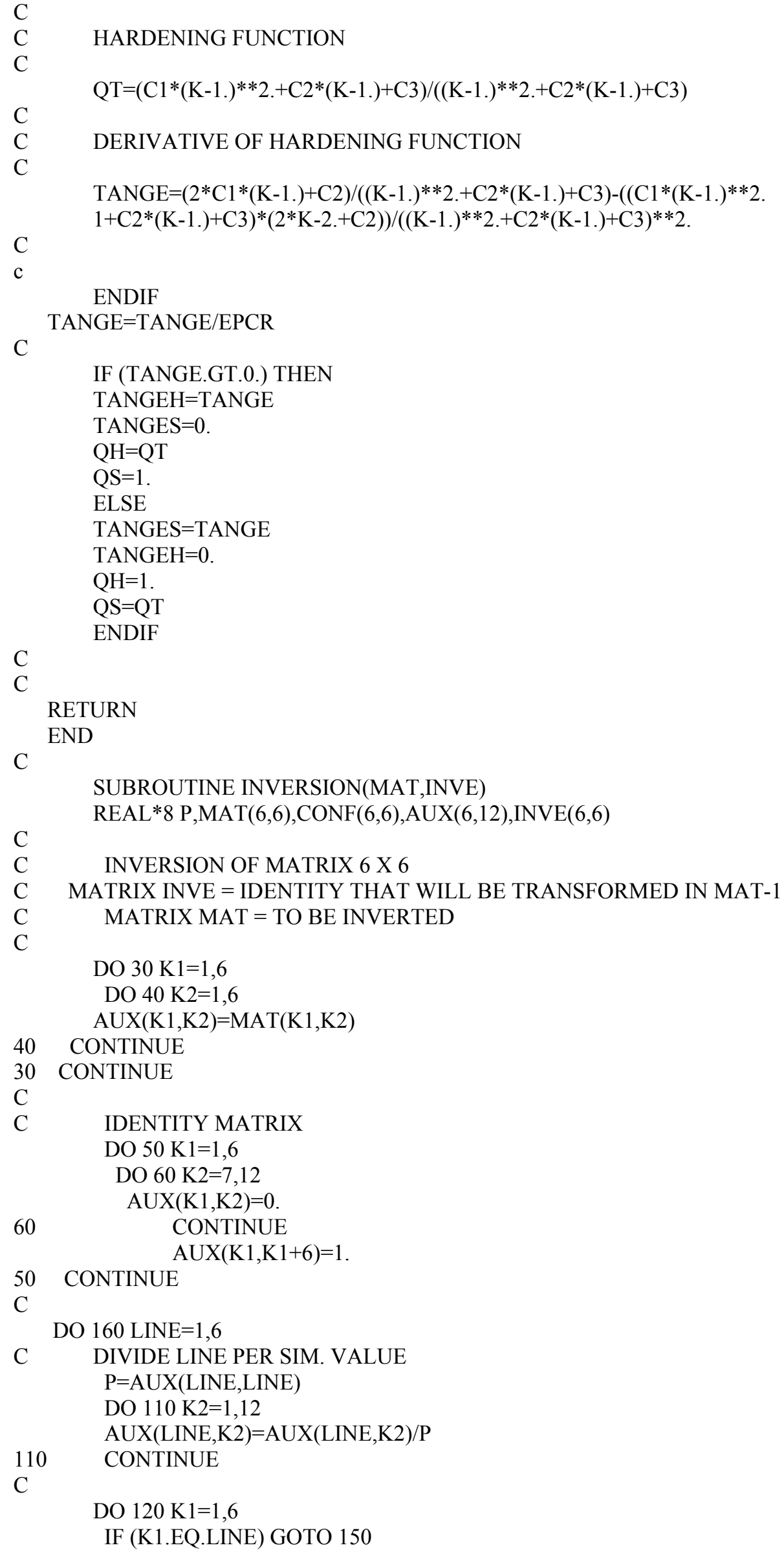




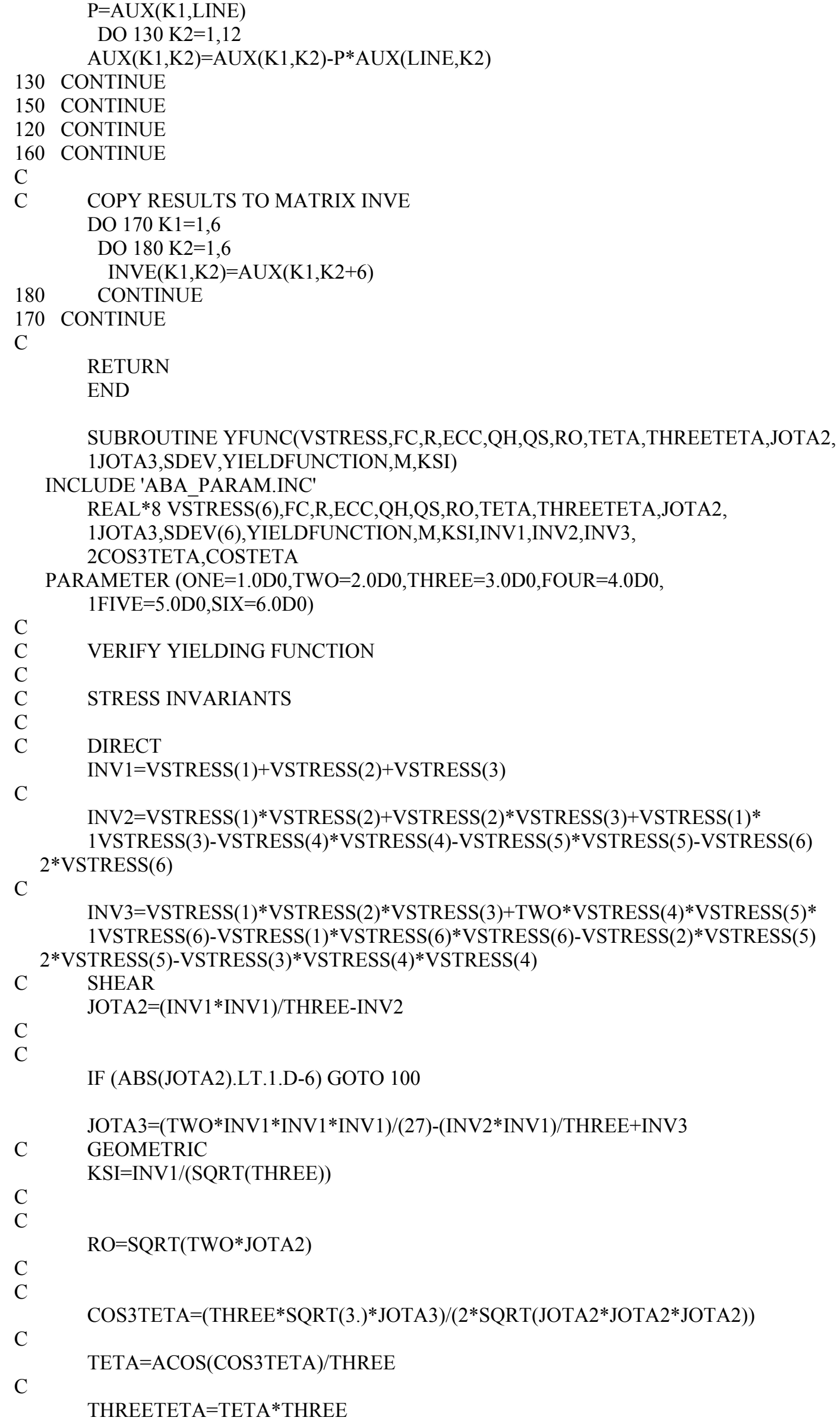


C

C ELIPTIC FUNCTION (R)

$\mathrm{R}=($ FOUR $*(\mathrm{ONE}-\mathrm{ECC} * \mathrm{ECC}) * \mathrm{COSTETA} *$ COSTETA $+(\mathrm{TWO} * \mathrm{ECC}-\mathrm{ONE}) * *$ TWO $) /$ 1(TWO*(ONE-ECC**TWO $) *$ COSTETA $+($ TWO*ECC-ONE)*(FOUR*(ONE-ECC $* *$ TWO $)$ $\mathrm{C}$

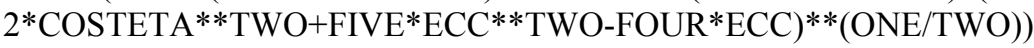

C DEVIATORIC VSTRESSES

DO $841 \mathrm{~K} 1=1,3$

841 CONTINUE

$\operatorname{SDEV}(\mathrm{K} 1)=\operatorname{VSTRESS}(\mathrm{K} 1)-\mathrm{INV} 1 / \mathrm{THREE}$

DO $842 \mathrm{~K} 1=4,6$

842 CONTINUE

$\operatorname{SDEV}(\mathrm{K} 1)=\operatorname{VSTRESS}(\mathrm{K} 1)$

$\mathrm{C}$

C YIELDING CONDITION

YIELDFUNCTION $=(\mathrm{SQRT}(\mathrm{THREE} / \mathrm{TWO}) * \mathrm{RO}) * * \mathrm{TWO}+\mathrm{QH} * \mathrm{M} *((\mathrm{RO} / \mathrm{SQRT}(\mathrm{SIX})) * \mathrm{R}+\mathrm{KSI}$ 1/SQRT(THREE))-QH*QS

$\mathrm{C}$

C

100 CONTINUE

C

RETURN

END

$\mathrm{C}$

$\mathrm{C}$

SUBROUTINE GRADIENTS(FC,R,ECC,QH,QS,QT,RO,TETA,THREETETA,JOTA2, 1JOTA3,SDEV,M,KSI,FSIGMA,FLOW,HARD,KA,A,B,TANGE,TANGEH,TANGES)

INCLUDE 'ABA PARAM.INC'

REAL*8 EQ1,EQ2,EQ3,EQ4,EQ5,EQ6,EQ7,EQ8,EQ9,FSIGMA(6),GRADFK,FC,R, 1ECC,QH,QS,QT,RO,TETA,THREETETA,JOTA2,JOTA3,SDEV(6),YIELDFUNCTION, 2M,KSI,VEC(6),HARD,FLOW(6),A,B,TANGE,TANGEH,TANGES

PARAMETER $(\mathrm{ONE}=1.0 \mathrm{D} 0, \mathrm{TWO}=2.0 \mathrm{D} 0, \mathrm{THREE}=3.0 \mathrm{D} 0, \mathrm{FOUR}=4.0 \mathrm{D} 0$, $1 \mathrm{FIVE}=5.0 \mathrm{D} 0, \mathrm{SIX}=6.0 \mathrm{D} 0$ )

$\mathrm{C}$

C YIELDING FUNCTION GRADIENT

C

$\mathrm{C}$

C

C

$$
\text { Fsigma }=\text { eq } 1 * \text { eq } 2+\text { eq } 3 * \text { eq } 4+\text { eq } 5 * \text { eq } 6 * \text { eq } 7
$$

DO $320 \mathrm{~K} 1=1,6$

IF (K1.LT.3+1) THEN

$\mathrm{K} 2=1$

ELSE

$\mathrm{K} 2=0$

ENDIF

C

C $\quad \mathrm{EQ} 1=\mathrm{DF} / \mathrm{DRO}$

C

$\mathrm{EQ} 1=3 * \mathrm{RO}+\mathrm{M} * \mathrm{QH} * \mathrm{R} / \mathrm{SQRT}(6$.

C $\quad \mathrm{EQ} 2=$ DRO/DSIGMA

C $\mathrm{EQ} 2=\operatorname{SDEV}(\mathrm{K} 1) /(\mathrm{RO})$

$\mathrm{C} \quad \mathrm{EQ} 3=\mathrm{DF} / \mathrm{DKSI}$

C $\mathrm{EQ} 3=\mathrm{QH} * \mathrm{M} / \mathrm{SQRT}(3$.

C $\quad$ EQ4 = DKSI/DSIGMA

C EQ4=K2*SQRT(THREE)/(THREE) 


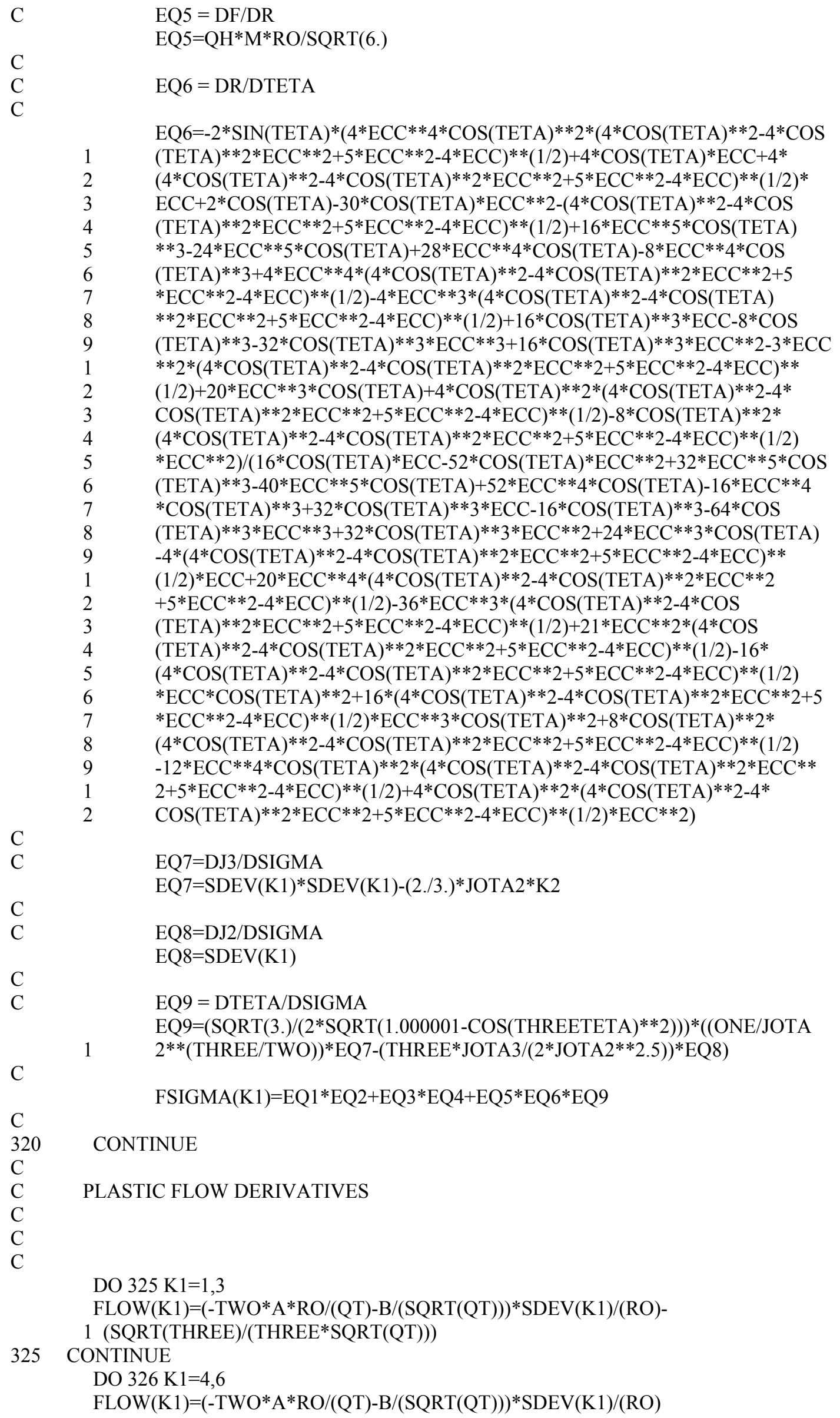

$\mathrm{C}$

C

C

$\mathrm{C}$

DO $325 \mathrm{~K} 1=1,3$

$\mathrm{FLOW}(\mathrm{K} 1)=(-\mathrm{TWO} * \mathrm{~A} * \mathrm{RO} /(\mathrm{QT})-\mathrm{B} /(\mathrm{SQRT}(\mathrm{QT}))) * \operatorname{SDEV}(\mathrm{K} 1) /(\mathrm{RO})-$ 1 (SQRT(THREE)/(THREE*SQRT(QT)))

CONTINUE

DO $326 \mathrm{~K} 1=4,6$

$\mathrm{FLOW}(\mathrm{K} 1)=(-\mathrm{TWO} * \mathrm{~A} * \mathrm{RO} /(\mathrm{QT})-\mathrm{B} /(\mathrm{SQRT}(\mathrm{QT}))) * \operatorname{SDEV}(\mathrm{K} 1) /(\mathrm{RO})$ 


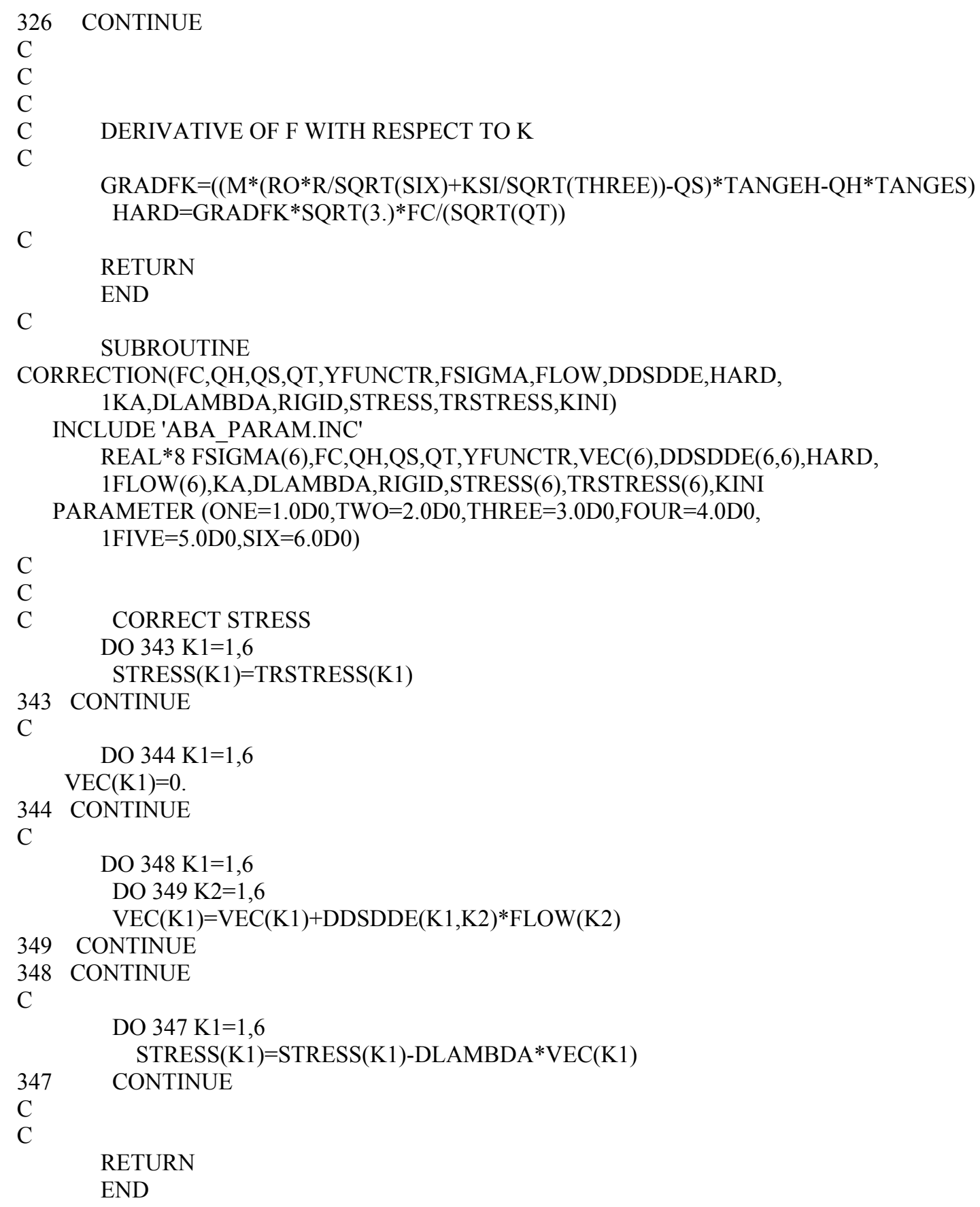

